UNIVERSIDADE DE SÃO PAULO

FACULDADE DE EDUCAÇÃO

RicARDO AVELAR SOTOMAIOR KARAM

ESTRUTURAÇ̃̃o MATEMÁTICA DO PENSAMENTO FÍSICO NO ENSINO:

UMA FERRAMENTA TEÓRICA PARA ANALISAR ABORDAGENS DIDÁTICAS

SÃo PAULO

2012 

RicARDO AVELAR SOTOMAIOR KARAM

\section{ESTRUTURAÇ̃̃o MATEMÁTICA DO PENSAMENTO FÍSICO NO ENSINO: \\ UMA FERRAMENTA TEÓRICA PARA ANALISAR ABORDAGENS DIDÁTICAS}

Tese de Doutorado apresentada à Faculdade de Educação da Universidade de São Paulo para obtenção do título de Doutor em Educação.

Área de Concentração: Ensino de Ciências e Matemática Orientador: Prof. Dr. Maurício Pietrocola

SÃo PAULO

2012 
Autorizo a reprodução e divulgação total ou parcial deste trabalho, por qualquer meio convencional ou eletrônico, para fins de estudo e pesquisa, desde que citada a fonte.

Catalogação na Publicação

Serviço de Biblioteca e Documentação

Faculdade de Educação da Universidade de São Paulo

\footnotetext{
$378.3053 \quad$ Karam, Ricardo Avelar Sotomaior

K18e Estruturação matemática do pensamento físico no ensino: uma ferramenta teórica para analisar abordagens didáticas / Ricardo Avelar Sotomaior Karam; orientação Maurício Pietrocola. São Paulo: s.n., 2012.

275 p. ils.; tabs.; anexos

Tese (Doutorado - Programa de Pós-Graduação em Educação. Área de Concentração: Ensino de Ciências e Matemática) - - Faculdade de Educação da Universidade de São Paulo.
}

1. Epistemologia 2. Física 3. Matemática 4. Didática 5. Ensino superior I. Pietrocola, Maurício, orient. 
Ricardo Avelar Sotomaior Karam

Estruturação matemática do pensamento físico no ensino:

Uma ferramenta teórica para analisar abordagens didáticas

Tese de Doutorado apresentada à Faculdade de Educação da Universidade de São Paulo para obtenção do título de Doutor em Educação.

Área de Concentração: Ensino de Ciências e Matemática

Aprovada em

Banca Examinadora

Prof. Dr. Maurício Pietrocola (FEUSP)

Orientador - Membro Titular

Prof. Dr. Olival Freire Junior (UFBA)

Membro Titular

Profa. Dra. Sonia Krapas Teixeira (UFF)

Membro Titular

Profa. Dra. Ileana Greca (Universidad de Burgos)

Membro Suplente

Prof. Dr. Alberto Villani (IFUSP)

Membro Suplente
Prof. Dr. Michel Paty (Université Paris 7)

Membro Titular

Profa. Dra. Cibelle Celestino Silva (IFSC-USP)

Membro Titular

Prof. Dr. Elio Carlos Ricardo (FEUSP)

Membro Suplente

Prof. Dr. Frederico Firmo de Souza Cruz (UFSC)

Membro Suplente

Prof. Dr. Nelson Fiedler-Ferrara (IFUSP)

Membro Suplente 

Para Natalia

Por seu amor incondicional

"A felicidade só existe se compartilhada" 



\section{AgRADECIMENTOS}

Muitos foram os responsáveis pelo sucesso dessa longa caminhada de quatro anos. Deixando de lado a redação acadêmica, dou-me o direito de agradecê-los da maneira mais sincera e carinhosa que conseguir me expressar.

Primeiramente gostaria de agradecer ao meu orientador e amigo Maurício Pietrocola, o qual soube conduzir de maneira primordial nossa relação "orientador-orientando" durante esses quatro anos. Agradeço pela confiança em mim depositada ao me incentivar a alçar voos cada vez mais altos, por me proporcionar as condições necessárias para o desenvolvimento da pesquisa, pelas intensas conversas sobre as relações entre física e matemática, bem como por sua inigualável disposição para as orientações "extra-acadêmicas".

Tive o privilégio de poder contar com dois orientadores nessa jornada. Dessa forma, julgo importante frisar que a professora Gesche Pospiech teve um papel fundamental para o desenvolvimento de minha pesquisa. Peço licença para agradecê-la em seu idioma, cujo aprendizado de minha parte deve-se muito à sua paciência e esforço. Liebe Doktormutter Frau Pospiech, ohne Sie hätte ich es nicht schaffen können. Ich danke Ihnen sehr für alles, dass Sie für mich gemacht haben und hoffe, dass wir in die Zukunft noch viel zusammen arbeiten können.

Agradeço a todos os amigos que me acolheram em minha chegada a São Paulo. À minha grande amiga e parceira Thaís Forato (por me receber como um membro de sua família, por seu jeito sempre alegre e carinhoso, pelas frutíferas parcerias e pela criteriosa revisão do Capítulo 1), ao Ivã Gurgel (por me abrigar várias vezes no Centro de Estudos Avançados do LAPEF e me deixar sua ampla biblioteca à disposição), à Lúcia Sasseron (pelas hospedagens, por sua prestatividade e pelo café mineiro sempre pronto para embalar a prosa), ao Guilherme Brockington (por me hospedar várias vezes e pelas conversas instigantes até altas horas), ao Maxwell (pelas horas de estudo de relatividade e esclarecimentos sobre suas equações), à Ivani Lawall (também pelas hospedagens e pela atenção sempre especial), à Vipa (por sua alegria contagiante e pelas hospedagens) ao Elio Ricardo (por suas estórias dignas de deixar o Barão de Münchhausen com inveja e pelas produtivas conversas sobre matemática e física) e de maneira geral a todos os amigos integrantes da família lapefiana. O estimulante ambiente que encontrei no LAPEF compensou todo o esforço e horas despendidas em ônibus nos exaustivos movimentos pendulares entre Floripa e São Paulo. Tenho muito orgulho de ter feito parte desse grupo!

Da mesma forma, gostaria de agradecer o carinho de todos os amigos que fiz em minha estadia na Universidade de Dresden, o qual foi fundamental para minha adaptação quase imediata às diversas novidades inerentes a esse tipo de experiência. Herzlichen Dank an alle: Liebe Silvia (die beste Sekretärin aller Zeiten), David (Mr. Fruit: ein lieber Freund und der Informatik-Expert), Göran (der, der alle mögliche Experimente kennt), Kerstin (Danke für die täglichen Kaffees und für die tollen Lieder!), Mathias (ein humorvoller Mensch), Manu (die, die mehr als 30 Termine am Tag hat), Jessie (eine super Lehrerin und eine liebe Freundin, die mir wegen meines Deutsches viele Komplimente gemacht hat, auch wenn ich kaum ein Wort konnte), Ulrike (Danke für die Diskussionen über die Didaktik der Mathematik und auch für die guten Reisetipps). Wegen euch allen habe ich mich an der TU Dresden wie Zuhause gefühlt. Ich vermisse sehr den pünktlichen Frühstück immer um 10:00, das leckere Essen aus der Mensa Siedepunkt und unsere Arbeitsgruppetreffen. Insbesondere, möchte ich mich bei meinem großartigen Freund und besten Partner Olaf Uhden ganz herzlich bedanken. Alles was du für mich getan hast, werde ich nie vergessen. Deine Freundschaft und Partnerschaft habe ich sicherlich für das ganze Leben. 
Agradeço a um dos principais responsáveis por minha ida à Alemanha, o Prof. Dietmar Höttecke: Lieber Dietmar, vielen Dank für die empfehlenswerte Mail, die du gleich nach unserem Gespräch an Frau Pospiech geschickt hast! Du bist ,schuldig“ für meinen Aufenthalt in Dresden! Agradeço também à Profa. Cibelle Celestino Silva por ter possibilitado a vinda do Dietmar para o Brasil.

Tive o prazer e a honra de poder debater sobre o tema de minha pesquisa com alguns dos maiores experts no assunto. Agradeço ao Prof. Michel Paty pela gentil disponibilidade em conversar comigo sobre seus trabalhos em diversas ocasiões, ao Prof. Manoel Robilotta pelos inúmeros encontros para discutirmos a relação entre física e matemática e por seu grande exemplo, tanto como professor quanto como pessoa, e ao Prof. Edward Redish, por toda sua atenção durante minha visita à Universidade de Maryland (Dear Joe, thanks a lot for the opportunity of presenting my work to your group, for the fruitful discussions and for the kind attention you gave me during my stay in Maryland. I would also like to thank everyone from the PERG-Maryland, especially Eric and Brian for sharing their research interests with me and for their helpful suggestions in the final version of our Sci\&Ed paper).

Agradeço aos professores Elio Carlos Ricardo e Sonia Krapas Teixeira que participaram do exame de qualificação e deram importantes contribuições à pesquisa.

Um agradecimento especial aos ilustres integrantes da Akademie Olympia! Obrigado pela amizade, pelo auxílio na validação das categorias e pelas sempre produtivas discussões sobre a enigmática relação entre física e matemática. Pedro (pela dedicação e disponibilidade para a filmagem de todas as aulas deste estudo), Jorge (pelas discussões acaloradas e pelos auxílios tecnológicos), Fabiana (por representar tão bem a ala feminina da Akademie e pela revisão dos capítulos 2 e 3), Alex (pela revisão do Capítulo 4 e pelas alegrias partilhadas no concurso em Joinville). Conto com vocês para darmos continuidade aos estudos que nossos antecessores Albert, Conrad e Maurice iniciaram em Berna!

Muito obrigado também à minha amiga e colega Debora Coimbra (pela criteriosa revisão dos capítulos 5 e 6 e por me fazer refletir sobre o dilema "ser versus ter") e à minha mãe acadêmica, Ana Maria Liblik, pelo constante incentivo e pela revisão do Capítulo 2.

A incrível eficiência dos funcionários responsáveis pelos procedimentos administrativos da USP faz com que tudo fique muito mais fácil. Um agradecimento especial ao Marcelo, Antonio e Moisés pelo apoio nos momentos que antecederam a entrega da tese.

Agradeço à minha família pelo apoio incondicional durante esses quatro anos, pela educação que recebi e pela estável estrutura que ela sempre me ofereceu. À minha mãe por seu irrestrito amor materno que coloca as necessidades do filho acima de tudo, ao meu pai por seu incentivo, seu orgulho paterno e pelos valores ensinados, ao Mario por sua amizade, pelas conversas e conselhos, à minha irmã pelo carinho e pelos momentos compartilhados no velho continente. Agradeço também à minha tia Elsie por me receber como um filho em sua casa nos meses finais da tese.

Sou imensamente grato à minha esposa Natalia por seu amor, companheirismo, paciência, por sua força durante os momentos que estive ausente e por sua coragem ao tomar decisões cruciais que permitiram que vivêssemos esse sonho juntos. Agradeço também pela preciosa ajuda com as transcrições das aulas e entrevistas.

Por fim (but not least!), agradeço às agências de fomento pelo auxílio financeiro que possibilitou o desenvolvimento desta pesquisa: DAAD (pela bolsa de quatro meses para o curso de alemão), CAPES (pelos 12 meses de bolsa-sanduíche na Alemanha) e FAPESP (pelos 12 meses de bolsa para concluir a tese após o retorno ao Brasil). 

[...] a análise matemática é tão extensa quanto a própria natureza, ela define todas as relações sensoriais, mede tempos, espaços, forças, temperaturas; esta difícil ciência se forma lentamente, mas conserva todos os princípios adquiridos; ela se amplia e se fortalece constantemente em meio a tantas mudanças e erros da mente humana. Seu principal atributo é a clareza; ela não se presta a significar noções confusas. Ela reúne os mais diversos fenômenos e descobre as analogias secretas que os unem. Se a matéria nos escapa como a do ar e da luz, por sua extrema tenuidade, se os corpos são colocados longe de nós na imensidão do espaço, se o homem quer conhecer o espetáculo dos céus em épocas separadas por muitos séculos, se as ações da gravidade e do calor são exercidas no interior de um globo sólido em profundidades inacessíveis, a análise matemática nos permite compreender todas as leis destes fenômenos. Ela os torna presente e mensuráveis, e parece ser uma faculdade da razão humana destinada a compensar a brevidade da vida e a imperfeição dos sentidos. (FOURIER, 1822, p. xiv-xv, grifo nosso).

\begin{abstract}
Você precisa entender o que o símbolo representa. Essa é a coisa mais importante. $O$ jogo da física é esse. É jogar símbolos na natureza, tirar os símbolos e extrair a natureza de volta.
\end{abstract}

(Aula 9-57:40-58:00)

Uma fonte de problemas para o ensino [de física] tem como ponto central o formalismo matemático que dá sustentação lógica a uma teoria física. De um lado, é preciso encher esse formalismo de significado, de realidade, com todas as dificuldades práticas e filosóficas que isso acarreta. Por outro lado, é comum que, fascinados pela lógica, façamos um esforço para linearizar a forma e o conteúdo da física, suprimindo as contradições que marcaram o seu desenvolvimento. Surge então uma ciência falsamente ascética, sem disputas, sem descontinuidades. Ao se basear na supressão dos sentimentos, ela parece apoiar a repressão dos mesmos. Essa física excessivamente lógica, cristalina e límpida é precisamente falsa: ao identificarmos o processo ao produto, estamos afastando dela os estudantes. A apologia da lógica torna a ciência sobre-humana aos olhos dos estudantes, superior às possibilidades dos mortais. (ROBILOTTA, 1988, p. 17, grifo nosso).

[...] esse negócio de você ensinar as coisas formais, pra mim tem um cheiro de uma violência; de um ritual eclesiástico que você é obrigado a acreditar.

(Entrevista com o professor) 



\section{RESUMO}

A física é uma ciência altamente matematizada, tendo seus conceitos e métodos profundamente influenciados pelo pensamento matemático. Apesar disso, em contextos de ensino, o papel da matemática na física tende a se resumir ao de uma ferramenta para a descrição e operacionalização de grandezas, fazendo com que os estudantes não percebam o caráter estruturante do formalismo matemático para a constituição teórica da física. Assim, é fundamental dedicar um esforço sistemático de pesquisa para investigar estratégias que visem a apropriação dessa maneira matemática de conceber o mundo físico pelos estudantes. Apesar da existência de um número razoável de pesquisas que identificam as principais dificuldades enfrentadas pelos estudantes para a compreensão do significado de equações e utilização da matemática para a resolução de problemas de física, esse tema tem sido pouco investigado sob a ótica do ensino. Dessa forma, este trabalho objetiva contribuir para tal esforço por meio da realização de um estudo de caso em aulas de relatividade e eletromagnetismo, ministradas por um professor experiente e diferenciado em nível superior. A análise das aulas com auxílio do software videograph, juntamente com estudos históricos e epistemológicos, nos conduz à proposição de uma ferramenta teórica composta por oito categorias de análise, a qual se destina a descrever e avaliar abordagens didáticas em relação à ênfase em múltiplos aspectos da imbricada inter-relação entre física e matemática em contextos de ensino. Essa ferramenta é utilizada na análise de 19 episódios de ensino extraídos da gravação do curso de eletromagnetismo ministrado pelo professor do estudo de caso. Sua abordagem focada na estruturação matemática de conceitos físicos, na interpretação física de expressões matemáticas, no incentivo constante à metacognição, entre outros aspectos, nos permite apontar critérios associados à qualidade didática das aulas analisadas, os quais são posteriormente justificados pelo próprio professor em entrevistas semiestruturadas. Dentre as perspectivas deste trabalho, estão a possibilidade de utilizar a ferramenta de análise para realizar estudos comparativos entre aulas ministradas por diferentes professores sobre o mesmo tema, avaliar concepções diversas sobre o papel da matemática presentes em materiais didáticos, bem como a utilização de tais análises como recurso didático-pedagógico para a formação de professores de física e matemática.

Palavras-chave: Relação entre física e matemática no ensino; Estudo de caso; Ensino de eletromagnetismo; Estruturação matemática no ensino de física; Análise de abordagens didáticas. 


\begin{abstract}
Physics is a highly mathematized science, so that its concepts and methods are profoundly influenced by the mathematical thinking. Nevertheless, in the context of physics education, mathematics tends to be seen as a mere tool to describe and operate physical quantities, preventing students from understanding the structural role of the mathematical formalism for the development of physical theories. Thus, it is essential to devote a systematic research effort to investigate how to enable students to reason mathematically about the physical world. Despite the existence of several studies that identify the main difficulties faced by students to understand the meaning of physics equations and to use mathematics to solve physics problems, this topic has not been sufficiently investigated from the perspective of instruction. Aiming at contributing to this effort, this work conducts a case study in relativity and electromagnetism lectures, which were taught by an experienced and distinguished professor. The analysis of these lectures with the software videograph, along with historical and epistemological studies, led us to proposing a theoretical framework with eight categories, which is intended to describe and evaluate teaching approaches regarding the emphasis on the multiple aspects of the relationship between physics and mathematics. This framework is used in the analysis of 19 teaching episodes extracted from the recordings of the electromagnetism course given by the case study professor. His approach focused on constructing mathematical representations of physical concepts, physically interpreting mathematical expressions, encouraging metacognition, among others. This allowed us to identify several criteria related to the didactical quality of the lectures analyzed. These criteria are later justified by the professor in semi-structured interviews. The use of this analytical tool to conduct comparative studies between different lecturers/teachers, to evaluate different conceptions about the role of mathematics in physics textbooks and as a didactic resource for teacher education, are some of the future perspectives of this research.
\end{abstract}

Keywords: Relation between physics and mathematics in education; Case study; Teaching of electromagnetism; Structural role of mathematics in physics education; Didactical analysis. 


\section{SUMÁRIO}

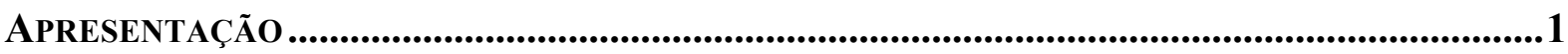

1 - ABORDAGEM EPISTEMOLÓGICA DE RELAÇÕES ENTRE FÍSICA E MATEMÁTICA ..................7

1.1 UMA PROFÍCUA RELAÇÃO DE INTERDEPENDÊNCIA..........................................................

1.2 ASPECTOS DO CARÁTER HISTÓRICO DA MATEMATIZAÇÃO DA FÍSICA ...............................16

1.3 PosicionAmENTOS FILOSÓFICOS E A “REVOLUÇÃO METODOLÓGICA” DO SÉCULO XX ....25

1.4 SÍNTESE DA ABORDAGEM EPISTEMOLÓGICA E IMPLICAÇÕES PARA O ENSINO ....................33

2 - RELAÇÕES ENTRE FÍSICA E MATEMÁTICA NO ENSINO ..................................................37

2.1 ANÁLISE CRÍTICA DE TRABALHOS PRESENTES NA LITERATURA......................................37

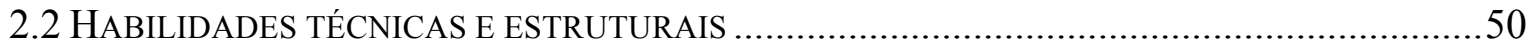

2.3 A NECESSIDADE DE UM MODELO ALTERNATIVO PARA A FÍSICA …..................................59

3 - ASPECTOS METODOLÓGICOS DO DESENVOLVIMENTO DA PESQUISA................................68

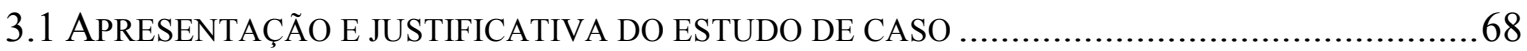

3.2 ESTUDO PILOTO: AULAS DE RELATIVIDADE RESTRITA.................................................. 73

3.3 ESTUDO DEFINITIVO: CURSO DE ELETROMAGNETISMO - ANÁLISE COM O VIDEOGRAPH.. 82

4 - CATEgorias de ANÁliSE ..................................................................................................86

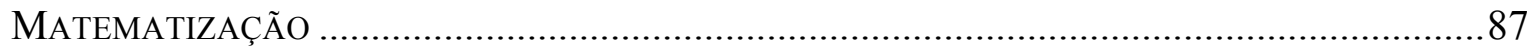

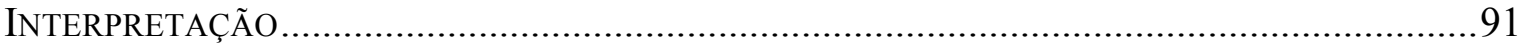

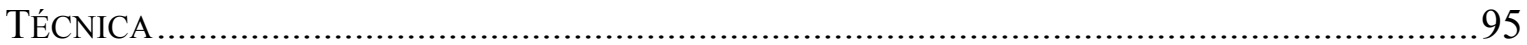

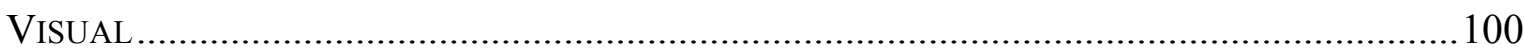

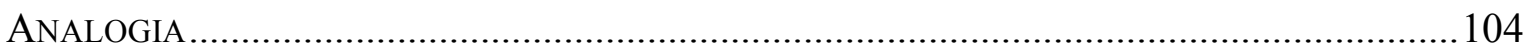

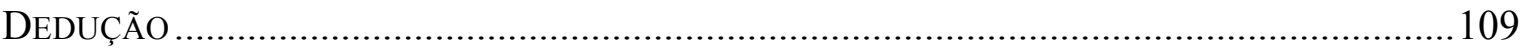

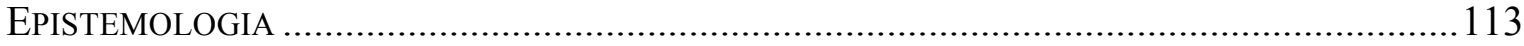

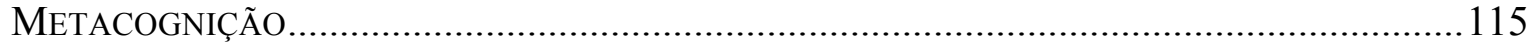

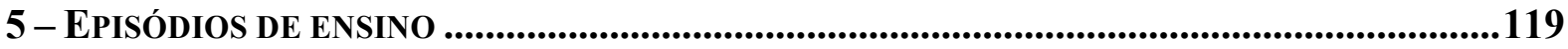

6 - REFLETINDO SOBRE A PRÁTICA: A ENTREVISTA COM O PROFESSOR .............................187

7 - CONCLUSÕES E DESDOBRAMENTOS DA PESQUISA............................................................205

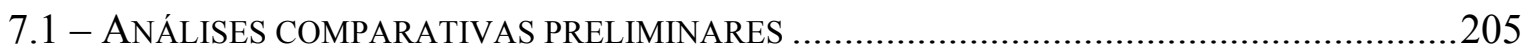

7.1.1 - COMPARAÇÃO ENTRE DUAS AULAS SOBRE FLUXO ..........................................205

7.1.2 - IDENTIFICANDO SEMELHANÇAS NO LIVRO DE FEYNMAN .................................210

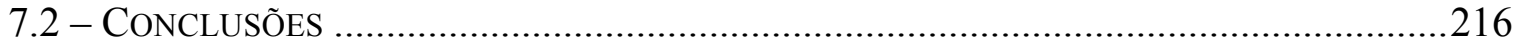

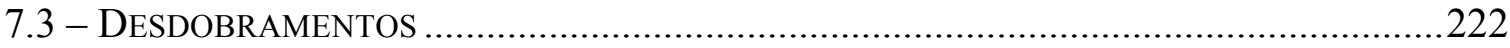

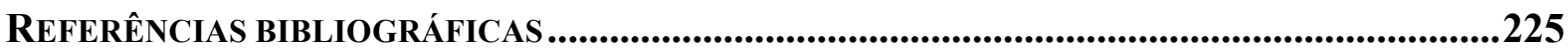

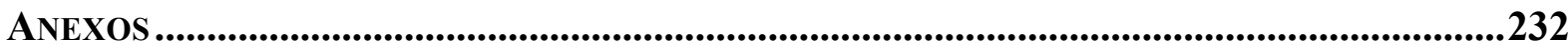





\section{APRESEnTAÇÃo}

[...] é impossivel explicar honestamente a beleza das leis da natureza de uma forma que as pessoas possam realmente sentir, sem que se tenha um profundo conhecimento de matemática. (FEYNMAN, 1985, p. 35)

A complexa relação entre física e matemática é um tema fascinante e talvez a principal razão para o poder das ciências físicas. Mas quais são as implicações dessa relação para o ensino de física? Se a real compreensão das leis da natureza depende de um significativo domínio do raciocínio matemático, não deveria ser esta uma das principais habilidades a serem desenvolvidas no ensino de ciências (física em particular)? Sem dúvida, a pesquisa em ensino de física das últimas décadas forneceu importantes elementos para aprimorar o entendimento conceitual e fenomenológico dos estudantes. Entretanto, pouco se tem avançado no sentido de amenizar a "dicotomia conceitual-formal" em favor de uma compreensão conceitual da física auxiliada pelo formalismo matemático. Hestenes (2003, p. 104) chama atenção para esse fato quando menciona que "o desafio é considerar seriamente o papel da matemática como um importante tema para a pesquisa em ensino de física".

Diversos estudos históricos e epistemológicos ${ }^{1}$ evidenciam que física e matemática estão profundamente relacionadas. De fato, a descrição de processos físicos por meios matemáticos é uma das principais características da física. Se analisado mais precisamente, o papel da matemática na física tem vários aspectos: ela serve como uma ferramenta (perspectiva pragmática), como uma linguagem (função comunicativa), além de propiciar uma estrutura lógico-dedutiva (função estrutural).

Após dez anos de experiência lecionando matemática e física para alunos de ensino médio e superior, tenho me deparado com inúmeras dificuldades para fazer com que os estudantes aprendam a utilizar matemática para pensar os fenômenos do mundo físico. Objetivando amenizar tais dificuldades, como professor de matemática procuro mencionar fenômenos físicos para motivar meus alunos para a aprendizagem de conceitos matemáticos dando um significado mais concreto a estes. Por outro lado, como professor de física, sinto frequentemente a necessidade de abordar temas essenciais de matemática para que os alunos possam operar com equações, gráficos, vetores e compreender a função dessas estruturas matemáticas para a modelagem dos fenômenos físicos. Ao lecionar a cadeira de Cálculo em nível superior, constatei que os conceitos centrais como limite, derivada e integral fazem

\footnotetext{
${ }^{1}$ POINCARÉ, 1995; FEYNMAN, 1985; STEINER, 1998; WIGNER, 1960; ZAHAR, 1980; BOCHNER, 1981; GINGRAS, 2001; PATY, 2003; BONIOLO et al., 2005, entre muitos outros.
} 
mais sentido para os estudantes quando contextualizados a partir de situações físicas. $\mathrm{O}$ conceito de derivada pode ser generalizado tendo como ponto de partida a ideia de velocidade instantânea; a integral pode ser entendida como a soma de "infinitos deslocamentos infinitesimais"; as soluções de uma equação diferencial ganham sentido quando se analisa um sistema massa-mola ou um circuito RLC. Existem outros inúmeros exemplos.

Os desafios enfrentados nessa interface foram fonte de inspiração para esta pesquisa. De fato, devido a um complexo conjunto de razões, a falta de compreensão da relação de dependência mútua entre matemática e física é um problema extremamente relevante para ensino de ciências (física), apesar de não ter sido enfrentado de maneira sistemática. É bastante comum encontrarmos estudantes, e muitas vezes também professores, que consideram que a matemática é uma mera ferramenta para a física, sem perceber seu poderoso valor como instrumento de pensamento. Em diversas situações envolvendo a resolução de problemas, a tarefa básica do estudante é procurar a "fórmula correta" e aplicála cegamente para encontrar soluções numéricas. Quando questionados sobre os motivos pelos quais uma determinada fórmula tem aquela forma específica, ou solicitados a explicar o seu significado com suas próprias palavras, os alunos (e frequentemente também seus professores!) raramente conseguem responder satisfatoriamente.

Apesar de já ter sido suficientemente demonstrado que a ausência de algumas habilidades matemáticas básicas é um fator considerável para o fracasso dos alunos nos cursos de física (HUDSON; MCINTIRE, 1977), algumas pesquisas já apontam para o fato de que o domínio dessas habilidades não garante o sucesso nos mesmos (HUDSON; LIBERMAN, 1982). Essa falta de correlação entre o domínio de recursos matemáticos e o sucesso em cursos de física pode ser entendida se reconhecermos que o pensamento matemático necessário em física é, de alguma forma, diferente daquele utilizado pelos matemáticos, possuindo inclusive uma "diferente semiótica” como defende Redish (2005).

Nesse sentido, para investigar tal diferença propomos uma distinção entre habilidades técnicas e estruturais ${ }^{2}$ (KARAM, 2007; KARAM; PIETROCOLA, 2009a; PIETROCOLA,

\footnotetext{
${ }^{2}$ Há uma tênue diferença entre estrutural e estruturante. O termo estrutural refere-se ao caráter intrinsecamente matemático de teorias físicas, ou seja, a palavra estrutural faz menção ao corpo teórico da física como um produto. Por outro lado, o termo estruturante faz alusão ao processo de estruturação matemática de conceitos físicos, principalmente em relação à aprendizagem da maneira matemática de ver o mundo por parte dos alunos. $\mathrm{Na}$ verdade, esses são aspectos inseparáveis, pois não existe produto sem processo e vice-versa. Assim, em muitos momentos no decorrer da tese usaremos um termo quase como "sinônimo" do outro. Talvez isso seja um reflexo de nossa limitação humana de representar ideias com precisão por meio de palavras.
} 
2010; UHDEN et al. ${ }^{3}, 2011$ ) quando se pretende analisar o uso que estudantes (e professores) fazem de matemática na física e a compreensão da relação de interdependência entre elas. A primeira categoria - habilidades técnicas - refere-se ao campo mais "interno" da matemática e está relacionada ao domínio instrumental de algoritmos, regras, fórmulas, gráficos, equações, etc. Muitos professores de física vinculam o insucesso de seus estudantes à falta dessas habilidades técnicas sem perceberem que um mero domínio instrumental não é suficiente.

Essa postura reflete uma concepção ingênua da relação entre matemática e física uma vez que atribui à primeira um papel de mera ferramenta para a segunda (PIETROCOLA, 2002). Assim, além das habilidades técnicas, consideramos outra categoria intitulada habilidades estruturais, a qual está relacionada com a compreensão do caráter matemático da estruturação teórica da física.

Apesar do consenso em relação à insuficiência das habilidades técnicas, a noção de matemática como essencial para a estruturação teórica da física precisa ser mais bem definida e explorada. Além disso, é preciso investigar como esse aspecto pode ser abordado em contextos de ensino. Dessa forma, adotamos tanto uma abordagem histórico-epistemológica tendo como base casos históricos e posicionamentos filosóficos relativos ao tema - como empírica - a partir de um estudo de caso baseado na análise das aulas de eletromagnetismo ministradas por um distinto professor de física da Universidade de São Paulo.

A escolha pela condução do estudo de caso em um curso de eletromagnetismo ministrado no ensino superior se deve principalmente ao fato de que neste nível a estruturação teórica da física por meio da matemática é abordada de maneira mais explícita e frequente. Assim, temos inúmeros exemplos para identificar as características deste processo e possíveis estratégias didáticas para ensiná-lo em situações reais de sala de aula. Entretanto, conforme evidenciaremos no decorrer da tese, acreditamos que muitos dos aspectos analisados neste contexto podem ser transponíveis para o ensino médio.

Diante do exposto, é possível sintetizar as pretensões dessa investigação na seguinte pergunta: Que habilidades estão relacionadas com o caráter estruturantelestrutural da matemática na física e como as mesmas podem ser abordadas no contexto educacional?

Os objetivos que emergem de tal pergunta são os seguintes:

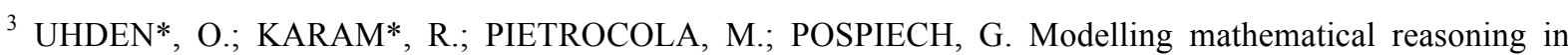
physics education. Publicado online em 20 de outubro de 2011 na revista Science \& Education. *Ambos os autores contribuíram igualmente para este trabalho.
} 
* Explicitar o caráter estrutural da matemática na física por meio de estudos históricos e epistemológicos;

* Identificar e exemplificar - a partir dos estudos referidos no item anterior e da análise de aulas ministradas por um professor em nível superior - um conjunto de categorias para classificar diferentes abordagens didáticas da relação entre matemática e física;

* Inferir estratégias a serem utilizadas no ensino de física, bem como na formação de professores, visando à utilização da matemática como instrumento de pensamento para compreender o mundo físico.

A linha de raciocínio que guia esta investigação é a seguinte:

Fato - Os alunos usam matemática em física como ferramenta de cálculo e não costumam interpretar fisicamente o significado de expressões matemáticas;

Axioma - Não existem "pré-concepções" sobre como pensar os fenômenos do mundo a partir de estruturas matemáticas, ou seja, esta habilidade não é inata;

Consequência - Logo, os alunos agem assim porque foram ensinados/incentivados a proceder desta maneira na educação formal;

Conclusão - Portanto, para que este quadro seja alterado, é preciso investir na formação de professores (inicial e continuada), focando tanto a abordagem de questões epistemológicas sobre o tema, como estratégias didáticas para tratá-lo em contextos de ensino;

Hipótese de investigação - A análise de aulas ministradas por um professor experiente e comprometido com a aprendizagem de seus alunos pode fornecer elementos que contribuam para elucidar características do processo de estruturação matemática de teorias físicas e sugerir estratégias didáticas pertinentes para ensiná-lo em situações reais de sala de aula.

Esta tese está dividida em sete capítulos. Por acreditar que esta pesquisa não pode prescindir de uma análise histórico-epistemológica do tema, o primeiro capítulo é destinado a este fim. Físicos e matemáticos que refletiram sobre as relações entre matemática e física (Einstein, Poincaré, Wigner, Feynman, Dirac, entre outros) assim como filósofos que também se debruçaram sobre o tema (Paty, Bochner, Zahar, Bachelard, Gingras, Boniolo, entre outros) são as principais fontes citadas e analisadas. O objetivo desse capítulo é aprofundar a discussão sobre o caráter estrutural da matemática na física, combater falsos reducionismos/consensos/chavões, mostrar os pontos de convergência e divergência nas visões desses autores e evidenciar uma ampla gama de possibilidades distintas para se pensar sobre essas relações. Esse estudo é fundamental para a sequência do trabalho, pois fornece diversos exemplos que evidenciam a estruturação matemática de teorias físicas e apresenta 
aspectos do caráter histórico da construção dessa relação. Dessa forma este capítulo fundamenta a necessidade de investigação deste tema sob o ponto de vista epistemológico.

Considerando que a questão de pesquisa está associada a um problema enfrentado por pesquisadores em ensino de física, o Capítulo 2 destina-se a uma breve revisão da literatura recente. Trabalhos que se propuseram, de alguma forma, a refletir sobre o papel da matemática no contexto do ensino de física são apresentados e discutidos. Entre as diferentes abordagens dos mesmos, é possível destacar a importância da modelagem matemática para o ensino de física; as estratégias cognitivas utilizadas na resolução de problemas e as justificativas fornecidas pelos alunos quando estes fazem uso de estruturas matemáticas para resolver problemas de física; a compreensão dos alunos sobre as equações da física, entre outros. Os desenhos metodológicos e resultados destas pesquisas são apresentados também para evidenciar as lacunas que nosso trabalho pretende preencher: foco na perspectiva do ensino e fundamentação epistemológica. Além disso, neste capítulo apresentamos um modelo teórico alternativo aos encontrados na literatura, o qual foi construído para evidenciar a distinção entre habilidades técnicas e estruturais.

Os aspectos metodológicos do desenvolvimento da pesquisa são apresentados no Capítulo 3. Primeiramente, o estudo de caso é justificado em função do estágio inicial do problema investigado. Em seguida, um estudo piloto realizado por meio da gravação de 10 aulas de relatividade restrita é descrito. Os resultados preliminares do mesmo indicam a pertinência da investigação das aulas deste professor em particular e apontam para o surgimento de algumas de nossas categorias de análise. $\mathrm{O}$ estudo definitivo, o qual consiste da análise das 40 aulas de um curso de eletromagnetismo ministrado por este professor, é descrito e o uso do software videograph como ferramenta de análise das aulas é justificado. Tanto os conteúdos específicos, relatividade e eletromagnetismo, como o professor ministrante, foram selecionados com o objetivo de investigar momentos em que o processo de estruturação matemática da física foi explicitamente abordado em um contexto de ensino.

As oito categorias de análise são apresentadas e justificadas no Capítulo 4. Trechos das aulas são utilizados para exemplificar aspectos característicos de cada categoria e argumentos epistemológicos fundamentam a seleção das mesmas. Com o objetivo de evidenciar a interação dinâmica entre as abordagens representadas pelas categorias em uma escala temporal, o Capítulo 5 apresenta a categorização de 19 episódios de ensino, recortados das gravações das aulas, com o auxílio do software videograph. Os episódios foram divididos entre explicações conceituais (matematização de conceitos físicos fundamentais do 
eletromagnetismo e interpretação física de operações matemáticas que integram as equações de Maxwell) e a resolução de problemas-tipo (campo elétrico gerado por distribuições de cargas, aplicações das equações de Maxwell, entre outros).

Para acessar as intenções didáticas e justificativas do professor para as estratégias identificadas ao longo das aulas, realizamos uma entrevista semiestruturada com o mesmo, a qual é descrita e analisada no Capítulo 6. No último capítulo da tese, utilizamos a ferramenta de análise para realizar comparações preliminares entre aulas ministradas por diferentes professores e abordagens de materiais didáticos. As conclusões da pesquisa são apresentadas na forma de um conjunto de proposições que se referem ao ensino de aspectos relativos à maneira matemática de pensar os fenômenos do mundo em aulas de física. Por fím, as perspectivas futuras deste estudo são esboçadas. 


\section{1 - ABORDAGEM EPISTEMOLÓGICA DE RELAÇÕES ENTRE FÍSICA E MATEMÁTICA}

\subsection{UMA PROFÍCUA RELAÇÃO DE INTERDEPENDÊNCIA}

A matemática é a melhor criação humana para investigação da natureza. Seus principais conceitos, métodos e teoremas foram derivados do estudo da natureza. (KLINE, 1959, p. vii)

O estranho na física é que mesmo para as leis mais fundamentais nós ainda precisamos de matemática. (FEYNMAN, 1985, p. 39)

Matemática, da palavra grega mathema $(\mu \alpha ́ \theta \eta \mu \alpha)$ - que pode ser traduzida como "algo que foi aprendido ou entendido" ou ainda "conhecimento passível de ser aprendido" (BOCHNER [1966], 1981, p. 24) - é geralmente associada ao estudo de quantidades, formas e estruturas, estando relacionada à busca por padrões, rigor, verdade e beleza. Física, do grego phisiké ( $(v ́ \sigma ı)$ - que significa natureza - é comumente vista como a ciência que se propõe a compreender os fenômenos naturais e a descrever as leis fundamentais que regem o universo. Seria correto supor que a primeira estuda objetos pertencentes a um mundo abstrato, criado independentemente por nossa imaginação, enquanto a segunda lida com o mundo físico/concreto e "real"?

As citações do matemático Morris Kline (1908-1992) e do físico Richard Feynman (1918-1988) refutam de maneira veemente essa noção de aparente independência. De fato, a história nos fornece inúmeras evidências da existência de complexas e profundas relações entre física e matemática, bem como da importância dessa influência mútua para o desenvolvimento de ambas.

Uma breve incursão na história do desenvolvimento de conceitos matemáticos nos mostra que vários deles têm suas origens associadas a problemas genuinamente físicos. Este fato é muito bem ilustrado por Henri Poincaré (1854-1912) quando o mesmo, colocando-se como um matemático, afirma que:

O desejo de conhecer a natureza teve a mais constante e feliz influência sobre o desenvolvimento da matemática. [...] o físico nos propõe problemas cuja solução espera de nós. Mas ao nos propor esses problemas, já pagou com muita antecedência o favor que lhe poderemos prestar, se conseguirmos resolvê-los (POINCARÉ [1905], 1995, p. 94).

Ilustremos essa influência por meio de uma sucinta reflexão sobre as origens de três importantes e consolidados ramos da matemática: 


\section{Cálculo diferencial e integral}

O desenvolvimento do cálculo diferencial e integral, cujas raízes encontram-se no método da exaustão, está profundamente relacionado com a saga humana rumo à compreensão do movimento e sua dificuldade pode ser ilustrada pelos paradoxos de Zenão. $\mathrm{Na}$ verdade, os conceitos centrais do cálculo - a derivada e a integral - têm suas raízes em dois aspectos intrínsecos à natureza: a variabilidade e a multiplicidade. A noção de derivada tem sua origem no problema da tangente, o qual é materializado pela noção de velocidade instantânea.

O conceito de integral está ligado ao problema do cálculo de comprimentos, áreas e volumes, que por sua vez é equivalente à determinação da distância percorrida por um móvel a partir da análise de sua velocidade ao longo do tempo. Do ponto de vista filosófico, a integral propiciou interpretações em termos de aproximações ou de compensações de erros nas medições científicas, mas, ao mesmo tempo, uma manifestação de que além da finitude da percepção sensorial, existe um infinito que a transcende e que pode ser aproximado assintoticamente pela experiência humana e pela razão (BOYER, 1949).

A análise de Fourier

A análise de Fourier é um tópico extremamente complexo e fundamental da matemática, uma vez que está associado a uma profunda compreensão do conceito de função. De maneira geral, seu estudo se inicia com a tentativa de representar funções genéricas a partir de séries (somas) de funções trigonométricas, as quais foram denominadas séries de Fourier. A representação mais geral da relação entre uma função qualquer e uma série trigonométrica é dada pela transformada de Fourier.

Como evidência de nossa argumentação é interessante notar que problemas físicos motivaram o desenvolvimento da análise de Fourier. Na raiz de seu surgimento, encontramos o problema da descrição matemática do perfil de uma corda elástica sujeita a deformações, tópico estudado pelos físicos (e também matemáticos!) Jean d'Alembert (1717-1783), Leonard Euler (1707-1783) e Daniel Bernoulli (1700-1782). O método proposto por Bernoulli - e contestado por Euler - consiste em resolver o problema geral de oscilações em cordas por meio de uma soma infinita de harmônicos de ondas estacionárias. Matematicamente, isso significa representar o perfil de uma onda qualquer por uma soma de senos e cossenos. Em sua formulação analítica da teoria do calor, Joseph Fourier (1768-1830) aplica de maneira inovadora as séries trigonométricas para solucionar a equação de 
propagação do calor, a qual tem uma estrutura parecida à equação de onda deduzida por d'Alembert ${ }^{4}$.

\section{$A$ análise vetorial}

O formalismo vetorial que conhecemos hoje tem uma história conturbada e extremamente motivada pela tentativa de representação matemática dos fenômenos eletromagnéticos. Evidências deste fato são encontradas quando refletimos sobre as origens de termos como "fluxo", "divergente" e "rotacional", os quais carregam consigo uma imagem dinâmica de fenômenos físicos (hidrodinâmica). De fato, o intrínseco caráter tridimensional do eletromagnetismo e a "estranha" relação entre grandezas translacionais e rotacionais (considere por exemplo o campo magnético gerado por uma corrente elétrica) foram importantes fontes de motivação para o desenvolvimento da análise vetorial que utilizamos atualmente.

Um interessante episódio que evidencia a importância da Física para a criação de tal formalismo foi o debate ocorrido no final do século XIX entre os defensores da utilização dos quatérnions $^{5}$ - Peter Tait (1831-1901) e Cargill Knott (1856-1922) - e dos vetores - Josiah Willard Gibbs (1839-1903) e Oliver Heaviside (1850-1925). Apesar de suas inquestionáveis raízes no sistema dos quatérnions, a análise vetorial de Gibbs e Heaviside acaba prevalecendo devido à habilidade de seus defensores (principalmente Heaviside) em apresentá-la de uma maneira menos abstrata e com inúmeras aplicações diretas aos fenômenos do eletromagnetismo (SILVA, 2002).

Naturalmente, não temos o intuito nem de esgotar os exemplos possíveis, tampouco de dar a impressão de que o desenvolvimento de todo e qualquer conceito matemático ocorre a partir de um problema físico. Entretanto, os três exemplos mencionados fornecem argumentos suficientes para contrapor aqueles que defendem uma matemática totalmente

\footnotetext{
${ }^{4}$ A semelhança formal entre a propagação de uma onda e do calor é a seguinte: Descrevemos a amplitude de uma onda em um ponto do espaço através de uma função de sua posição e do instante considerado $(A=f(r, t))$. Para o problema do calor, Fourier estava interessado em determinar a temperatura em um ponto de um corpo em um dado instante, a qual também é uma função da posição e do tempo $(T=f(r, t))$. A equação de onda unidimensional pode ser deduzida aplicando considerações dinâmicas a um segmento infinitesimal de uma corda e sua versão tridimensional tem a forma $\frac{\partial^{2} A}{\partial t^{2}}=c^{2} \nabla^{2} A$. A equação de difusão do calor pode ser obtida a partir do princípio da conservação de energia e da relação entre fluxo de calor e diferença de temperatura. Utilizando a notação moderna, a equação de difusão do calor é tem a forma $\frac{\partial T}{\partial t}=k \nabla^{2} T$. Para uma apresentação didática da história da análise de Fourier ver Davis e Hersh (1982, p. 255-270).

${ }^{5}$ Os quatérnions foram desenvolvidos inicialmente por Hamilton a partir da tentativa de ampliar a representação geométrica dos números complexos para o espaço tridimensional. Uma das principais críticas de seus opositores é que neste sistema as partes escalar e vetorial não são tratadas separadamente. Para um aprofundamento sobre a história do formalismo vetorial ver (1985) e Silva (2002).
} 
independente do mundo físico. De fato, preocupados com a postura de isolamento adotada por muitos matemáticos no início do século vinte, Richard Courant (1888-1972) e David Hilbert (1862-1943) alertam:

\begin{abstract}
A intuição física sempre desempenhou um papel vital para os problemas e métodos matemáticos. Entretanto, tendências e modismos recentes têm contribuído para $o$ enfraquecimento das conexões entre matemática e física; os matemáticos deram as costas para as raízes da matemática, concentraram seus esforços no refinamento e enfatizaram o lado postulacional da matemática, muitas vezes ignorando a unidade de sua ciência com a física e outros campos de conhecimento. Em muitos casos os físicos pararam de apreciar certas atitudes dos matemáticos. Esta mudança é, sem dúvida, uma séria ameaça para a ciência como um todo. (COURANT; HILBERT [1924], 1993, p. viii, grifo nosso).
\end{abstract}

O interesse principal de nossa pesquisa localiza-se, entretanto, no sentido inverso dessa relação, ou seja, na importância da matemática para a física. Trata-se de um tema extremamente rico, porém complexo e multifacetado. Sendo assim, vamos explorar as visões de alguns filósofos e cientistas que se debruçaram sobre essa questão sem objetivar, é claro, estabelecer conclusões definitivas e gerais.

Comecemos com a visão de Poincaré, o qual em sua obra $O$ valor da ciência (publicada em 1905) disserta com propriedade sobre o tema justamente por ter trabalhado nessa interface. Refletindo sobre a importância da linguagem matemática para descrição das leis da Física, Poincaré aponta que, mesmo considerando que as leis provenham da experiência, para enunciá-las é preciso uma linguagem especial, uma vez que a linguagem corrente é demasiado pobre e muito vaga para exprimir relações tão delicadas, tão ricas e tão precisas. Portanto, “eis a primeira razão pela qual o físico não pode prescindir da matemática; ela lhe fornece a única língua que ele pode falar" (p. 91). Assim, quando o matemático puro persegue um objetivo puramente estético e se esforça para aprimorar essa linguagem, mesmo que não esteja imediatamente preocupado com aplicações, está contribuindo para criar uma língua mais apta a satisfazer o físico.

Outra razão pela qual o físico depende da matemática é, segundo Poincaré, a necessidade de generalização que este possui. É fato que ao realizarem experiências os físicos buscam identificar regularidades. Porém, a experiência é sempre individual, e a lei é sempre geral; a experiência é apenas aproximada, mas a lei é precisa. Assim, para enunciar a lei é preciso generalizar. Tal generalização é comumente representada por uma relação matemática (equação) entre grandezas físicas.

Nessa busca pela generalização de uma lei, um dilema se estabelece uma vez que "toda verdade particular pode ser estendida de uma infinidade de maneiras" (p. 91). Diante dessa dificuldade, a matemática fornece um poderoso instrumento: as analogias. "O espírito 10 
matemático, que desdenha a matéria, nos ensinou a conhecer as analogias verdadeiras e profundas, as que os olhos não veem, mas a razão identifica" (p. 92). O poder da utilização de analogias fica claro quando se evidencia que uma única equação, como a de Laplace (laplaciano), é aplicada na teoria de atração newtoniana, na do movimento dos líquidos, na do potencial elétrico, na do magnetismo, na propagação do calor e em muitas outras. Outro exemplo é o conceito de fluxo que, advindo da hidrodinâmica, possui análogos na teoria do calor e no eletromagnetismo. Essa importância do raciocínio analógico para a física também é evidenciada nas palavras de Feynman:

[...] as equações de muitas situações físicas diferentes têm exatamente a mesma aparência. Obviamente, os símbolos podem ser diferentes - uma letra é substituída por outra - mas a forma matemática das equações é a mesma. Isto significa que, tendo-se estudado um assunto, adquirimos imediatamente um conhecimento direto e preciso sobre as soluções do outro problema (FEYNMAN; LEIHTON; SANDS, 2008, v. 2, p. 12-1, grifo nosso).

Outro filósofo que refletiu de maneira explícita sobre o papel da matemática na criação de teorias físicas foi Elie Zahar (1980). Segundo ele, é possível distinguir duas vantagens essenciais para a matematização de conceitos físicos:

\section{i) Ganho de conteúdo através da tradução para uma Linguagem Matemática}

Geralmente, o físico parte de um princípio intuitivo, mas quando ele é capaz de traduzir este princípio em alguma teoria matemática, o mesmo é geralmente modificado, uma vez que ganha "uma estrutura extra e passa a ser uma afirmação física mais poderosa" (ZAHAR, 1980, p. 4). De acordo com este autor, esse é o caso da formulação matemática da óptica conduzida por Fresnel, pois "sua suposição original de que a luz é uma onda é obviamente mais fraca que sua final hipótese de que a onda é representada pela função $\operatorname{sen}(2 \pi t / T)$ ". A formalização da hidrodinâmica no século XVIII também evidencia esse caráter. Uma citação de d'Alembert (1752 apud PATY, 2003, p. 117, grifo nosso) é emblemática para expressar este "ganho de conteúdo a partir da tradução para uma linguagem matemática":

É somente com o auxílio desses cálculos, que conseguimos penetrar no interior dos Fluidos e descobrir as funções de suas partes, as ações que elas exercem mutuamente umas nas outras, esses inúmeros átomos que compõem um Fluido e que parecem ao mesmo tempo unidos e divididos, dependentes e independentes uns dos outros.

Outro exemplo que parece corroborar essa função da matematização é encontrado na formalização do eletromagnetismo. Segundo Heinrich Hertz (1857-1894), a representação dos fenômenos eletromagnéticos por equações matemáticas contribuiu não só para uma apresentação elegante e sintética dos mesmos, mas também propiciou um acréscimo de conteúdo: 
Não se pode evitar a sensação de que essas fórmulas matemáticas têm uma existência independente e inteligência própria, que são mais sábias do que nós, mais sábias até que seus descobridores, que delas retiramos mais do que originalmente nelas colocamos. (HERTZ apud STEINER, 1998, p. 13, grifo nosso).

\section{ii) Interpretação realista de entidades matemáticas}

A segunda maneira na qual a matemática desempenha um papel central na física, segundo Zahar (1980), é quando uma entidade matemática é fisicamente interpretada. Naturalmente, nem toda entidade matemática precisa ser interpretada fisicamente, porém existem vários exemplos bem sucedidos dessa interpretação. Talvez um dos casos mais notáveis seja a previsão da existência da anti-partícula por Paul Dirac (1902-1984) em 1928, a partir da admissão de um valor negativo para a solução de sua equação de onda relativística, e sua posterior comprovação experimental com a detecção do pósitron em 1932. Igualmente interessante é a descoberta da existência de ondas eletromagnéticas a partir das equações de Maxwell ou a previsão formal da existência dos neutrinos feita por Wolfgang Pauli (19001958). No caso particular dos neutrinos, Paty (1995) revela a evolução da "partícula matemática à partícula física":

[...] essa partícula, tão importante para nossas concepções atuais sobre a estrutura da matéria e a organização do mundo, e tão real, era ignorada antes de 1930, e só teve, durante mais de vinte anos, a condição de uma simples hipótese matemática. [...] A observação da absorção dos neutrinos só ocorreu em 1953, ou seja, vinte e três anos depois da formulação dessa "partícula matemática", graças à possibilidade de se obterem fluxos intensos dela e de se dispor de um absorvedor suficientemente volumoso [...] isso ilustra o poder da matemática, que parece, assim, mais do que a simples linguagem da física, pois serve à própria construção da física, e sem ela a explicação do conteúdo da hipótese não seria possível. (PATY, 1995, p. 243, 246 e 251, grifo nosso).

O objetivo dessa seção foi levantar evidências da existência de uma profícua relação de interdependência entre matemática e física, a qual fica sintetizada nas palavras de Poincaré (1995, p. 90, grifo nosso):

O matemático não deve ser para o físico um simples fornecedor de fórmulas; é preciso que haja entre eles uma colaboração mais íntima. A física matemática e a análise pura não são apenas potências limítrofes, que mantêm relações de boa vizinhança; penetram-se mutuamente, e seu espírito é o mesmo.

Entretanto, é preciso cautela para não cairmos em certas armadilhas quando refletimos sobre essa complexa relação. Ao longo da seção, temos tido uma preocupação constante em utilizar episódios históricos para fundamentar nossa argumentação. Essa postura nos parece mais coerente em virtude da complexidade/diversidade da relação entre matemática e física. Ao dissertar de maneira geral sobre o papel da matemática na física, sem definir um problema 
e um contexto histórico específico, corre-se o risco de se chegar a conclusões excessivamente reducionistas ou erroneamente generalizadas. Dessa forma, concordamos com o posicionamento de Paty quando o mesmo alerta que:

Quando nos interrogamos sobre a coincidência (ou harmonia) entre uma teoria física que fornece representações de fenômenos da natureza e os conceitos e teorias matemáticas que servem para exprimi-la, somos por vezes tentados a adotar uma postura de generalização, sem levar em conta a especificidade de cada caso e período histórico, não fazendo referência a sistemas particulares de racionalidade física e matemática definidos em um determinado estado de elaboração dos objetos dessas ciências. Portanto, tudo que podemos dizer com alguma certeza sobre a relação entre matemática e física, só tem sentido quando se analisa um determinado momento, historicamente situado, tanto no que diz respeito às formas matemáticas disponíveis como aos problemas físicos específicos (PATY, 1994, p. 403, grifo nosso).

Nesse sentido, dizer simplesmente que a matemática é a linguagem ${ }^{6}$ na qual a física se exprime, por exemplo, implica em jogar em uma "vala comum" uma infinidade de nuances e especificidades dessa complexa relação. Com o objetivo de diferenciar a intensidade do papel da matemática, em cada caso, Paty sugere que as teorias físicas fazem uso de estruturas matemáticas em diversos níveis.

Segundo ele, no nível mais "fraco" os elementos matemáticos assumem um caráter de instrumento externo, vazios de conteúdo físico e sem qualquer carga "semântica". A utilização de estruturas matemáticas para representar grandezas físicas (elementos geométricos, números reais, matrizes, etc.) e a escolha de unidades que podem ser modificadas aleatoriamente sem modificar a teoria física são exemplos deste nível. Assim, no nível "fraco" a linguagem matemática assume um caráter de simples descrição, podendo até mesmo ser considerada prescindível.

Por outro lado, no nível mais "forte", a matemática penetra na própria construção do conceito físico. Este é o caso da definição de velocidade como $d x / d t$, de força como $m \cdot d^{2} x / d t^{2}$, de entropia como $S=k \cdot \ln W$ ou ainda na abstração geral de leis físicas através de princípios como o da relatividade ou da ação mínima (PATY, 1995, p. 251-252). Logo, no nível "forte"

\footnotetext{
${ }^{6}$ Naturalmente, essa afirmação depende do conceito de linguagem que se adota. Sem a intenção de nos aprofundarmos sobre o tema, neste trabalho vamos adotar a noção tradicional de linguagem como um sistema de signos que têm a função de comunicar ideias e representar conceitos. Assim, é possível defender que, em muitos casos, a matemática é realmente mais do que a linguagem (comunicação e representação) da física. Percebemos uma crítica semelhante em Feynman: "Matemática não é somente outra linguagem. Matemática é linguagem mais raciocínio, linguagem mais lógica. Matemática é uma ferramenta para o pensamento." (FEYNMAN, 1985, p. 40). Para o físico estadunidense, mesmo que seja possível traduzir leis físicas expressas matematicamente para a linguagem natural - citando como exemplo a lei da gravitação universal de Newton e a lei das áreas de Kepler - é somente a matemática que nos permite conectar essas proposições aparentemente distintas e mostrar como elas são equivalentes. Para uma visão da matemática como linguagem estruturante do conhecimento físico consultar Pietrocola (2002).
} 
a matemática é tida como estruturante do pensamento físico e indispensável para a constituição de seus conceitos. Iremos explorar melhor essa categorização mais adiante quando analisarmos a diferenciação entre habilidades técnicas e estruturais.

Por fim, outra armadilha comum é confundir relações de interdependência com identidade. Dessa forma, é preciso que sejam consideradas as principais diferenças entre as/os posturas/enfoques dos matemáticos e físicos. Entre as mais evidentes, encontramos a não necessidade de uma comprovação empírica em matemática e a não exigência de certos atributos do rigor matemático em teorias físicas.

Para melhor explorar tais diferenças recorremos a Feynman, o qual propõe duas tradições distintas de se pensar a matemática: a babilônica e a euclidiana. Para Feynman, aprender matemática segundo a tradição babilônica é aprender algo partindo de vários exemplos concretos para depois atingir a regra geral. Tudo seria preparado para calcular os resultados finais. A menção à Babilônia se justifica, pois a matemática desenvolvida antes dos gregos, pelos egípcios e babilônios, tinha um caráter de conhecimento prático. As principais fontes, que são os papiros egípcios e as tábuas de argila babilônicas, contêm um conjunto de regras para resolverem problemas práticos do cotidiano desses povos (EVES, 2004).

Por outro lado, a tradição euclidiana está associada à ideia de que é possível provar teoremas a partir de um conjunto de axiomas primitivos. Uma questão que parece ser fundamental nessa tradição é a definição do conjunto de axiomas a partir dos quais os teoremas são demonstrados. Essa é uma preocupação central para os matemáticos e um exemplo disso é a formalização da geometria proposta por David Hilbert (1862-1943).

De acordo com Feynman, em física o método mais apropriado é o babilônico. Segundo ele, a necessidade de achar o que é mais fundamental, os axiomas primitivos, não é tão importante para os físicos. Como exemplo, Feynman mostra que é possível deduzir a lei das áreas a partir da asserção da existência de uma força central. A questão que se poderia levantar seguindo a tradição euclidiana, portanto, é a seguinte: "é mais importante, mais básico, é um melhor axioma, dizer que a força tem a direção do sol ou que áreas iguais são varridas em tempos iguais?” (FEYNMAN, 1985, p. 35). Mostrando que em situações diferentes cada uma dessas asserções pode parecer mais essencial do que a outra, Feynman argumenta que esse tipo de preocupação não reflete uma atitude comum dos físicos, sendo inclusive prejudicial para o próprio desenvolvimento da física. 
Explicitando as principais diferenças entre o fazer e o pensar de matemáticos e físicos Feynman argumenta:

Os matemáticos lidam somente com a estrutura do raciocínio e realmente não se importam sobre o que eles estão falando. [...] Mas o físico atribui um significado para todas as suas frases. Física não é matemática e matemática não é física. Uma ajuda a outra. Mas em física é preciso ter uma compreensão da conexão das palavras com o mundo real. [...] Matemáticos gostam de fazer o seu raciocínio tão geral quanto possível. [...] O físico está sempre interessado no caso especial, ele nunca está interessado no caso geral. Ele está falando sobre algo, ele não está falando de maneira abstrata sobre qualquer coisa (FEYNMAN, 1985, p. 55-56, grifo nosso).

De maneira semelhante, Paty alerta para a supervalorização do papel da lógica matemática para a física:

Pensar que, no raciocínio intermediário de tipo matemático, cada termo, cada relação tenha necessariamente uma transcrição física, significaria colocar em princípio que as entidades matemáticas são mais reais que a própria realidade física - o que nos levaria a uma ontologia pitagórica - e considerar que a lógica tem, por si mesma, esse poder de engendrar novas propriedades dos objetos físicos. Ao contrário, como Einstein percebera com muita propriedade, "por si só, o pensamento lógico não pode nos fornecer conhecimento sobre o mundo da experiência: tudo o que conhecemos da realidade vem da experiência e nela resulta. Proposições puramente lógicas são completamente vazias em relação à realidade" (PATY, 1995, p. 255, grifo nosso).

Dessa forma, concluímos nossa defesa da existência de uma profícua relação de interdependência entre matemática e física chamando atenção para a necessidade de uma argumentação situada e do reconhecimento das diferenças epistemológicas entre essas duas áreas do conhecimento. $\mathrm{Na}$ próxima seção refletimos sobre outra questão extremamente interessante e complexa: Como se deu a construção histórica da matematização da física? 


\subsection{ASPECTOS DO CARÁTER HISTÓRICO DA MATEMATIZAÇÃO DA FÍSICA}

A história da ciência é a história da eliminação gradual de deuses e demônios e da transformação de noções vagas sobre luz, som, força, processos químicos e outros fenômenos em números e relações quantitativas. (KLINE, 1959, p. 180).

Indagar-se sobre a historicidade da matematização da física é uma tarefa longe de ser trivial, uma vez que se trata de uma questão tão antiga quanto a própria filosofia ${ }^{7}$. Apesar de ser possível localizar no século XVII as origens do que conhecemos hoje como física, debates sobre a aplicabilidade do pensamento matemático para a compreensão dos fenômenos naturais remontam à antiguidade clássica ${ }^{8}$. Sendo assim, longe de objetivarmos um estudo detalhado e cronológico na presente seção, optamos por recorrer a alguns trabalhos ${ }^{9}$ que destacaram aspectos e momentos importantes do extenso e conturbado processo histórico de matematização da física.

A obra do epistemólogo francês Michel Paty contém uma vasta análise de diversos episódios desse processo. Em um de seus principais artigos sobre o tema (PATY, 2003), o autor faz uma reflexão histórica sobre a noção de grandeza física, apontando como a mesma está inicialmente associada a qualidades e vai gradativamente se transformando em quantidades. Adicionalmente, Paty mostra de que maneira a noção tradicional de grandezas físicas, como quantidades expressas numericamente e medidas experimentalmente, foi sendo estendida para priorizar aspectos relacionais e estruturais. Segundo ele, essa análise é fundamental para entendermos as razões do privilégio dado à matematização para a construção de conceitos e teorias em física.

Esse resgate histórico inicia-se na antiguidade, em especial na obra de Aristóteles, onde a ideia de grandeza física era essencialmente associada a qualidades que poderiam ser diferenciadas por níveis de intensidade, mas sempre de maneira qualitativa. Um importante movimento na direção da quantificação ocorre na idade média, com os escolásticos das

\footnotetext{
7 "Não existe nenhuma outra questão que tenha sido fonte de tão belas e nobres especulações como a indagação se o uso da matemática nas ciências físicas, como um instrumento de prova e um meio de demonstração, é oportuno ou não; em outras palavras se ele traz benefícios ou se é perigoso e prejudicial" (MAZZONI, 1597 apud KOYRÉ, 1943, p. 420).

8 "É muito bem sabido que Platão acreditava que a matemática era particularmente apropriada para investigações físicas, sendo essa a razão pela qual ele mesmo tenha recorrido a ela para explicar os mistérios do universo físico. Mas Aristóteles tinha uma visão diferente e explicou os erros de Platão por seu grande apego à matemática" (MAZZONI, 1597 apud KOYRÉ, 1943, p. 420-21). Considere, ainda, a crença da escola pitagórica sobre a essência matemática do mundo, os trabalhos de Arquimedes, o desenvolvimento da óptica, da astronomia, entre outros exemplos (um abrangente estudo sobre o tema é encontrado em Bochner (1981)).

${ }^{9}$ Principalmente Paty (1994, 2003), Kline (1959) e Gingras (2001).
} 
universidades de Oxford e Paris, quando os mesmos começam a analisar a variação temporal da "qualidade do movimento" e inventam o conceito de impetus ${ }^{10}$.

$\mathrm{O}$ caminho rumo à quantificação passa pelos trabalhos de Galileu ${ }^{11}$, o qual tem um papel importante para a inserção do tempo ${ }^{12}$ como conceito (quantidade) fundamental para o estudo quantitativo do movimento. De fato, existe muito mais na obra de Galileu do que uma interpretação superficial de sua famosa citação "a matemática é a linguagem do universo"13 possa sugerir.

$\mathrm{Na}$ verdade a abordagem de Galileu ao problema da queda dos corpos, por exemplo, é muito semelhante à atitude de um matemático. Primeiramente, ele se propõe a fornecer "somente" uma descrição quantitativa do movimento, em vez de buscar uma explicação causal para o mesmo. A relação entre distância percorrida e tempo, a qual podemos escrever na notação atual como $d=k \cdot t^{2}$, generaliza de maneira compacta uma quantidade infinita de informações precisas. Porém, como aponta Kline (1959), essa fórmula "não diz nada sobre o porquê uma bola cai nem se outras bolas caíram no passado ou se continuarão caindo no

${ }^{10}$ Naturalmente, a contribuição dos escolásticos para a matematização da ciência é muito mais ampla e complexa do que esta breve menção (CLAGETT, 1959; GRANT, 1977; LINDBERG, 1980). Porém, um aprofundamento sobre o tema foge aos objetivos desta pesquisa.

${ }_{11}$ Ao citarmos a obra de como um importante exemplo histórico de uma abordagem matemática para a investigação da natureza, não temos a intenção de defender que o mesmo foi o único responsável por adotar tal postura, ou seja, acreditamos ser importante combater distorções históricas que apresentam o desenvolvimento da ciência como "incríveis feitos de gênios isolados". De fato, muitos historiadores mostraram que diversos conceitos encontrados nas publicações de Galileu já estavam presentes em estudos anteriores como nos trabalhos dos pensadores do Merton College, conforme destaca Truesdell (1968, p. 30): "Pesquisas recentes nos provam que as principais propriedades cinemáticas dos movimentos uniformemente acelerados, ainda atribuídas a Galileu em livros-texto de física, foram descobertas e comprovadas por estudiosos do Merton College William Heytesbury, Richard Swineshead e John of Dumbleton - entre 1328 e 1350. Seus trabalhos distinguiram a cinemática - geometria do movimento - da dinâmica - a teoria das causas do movimento. Suas abordagens eram matemáticas. Eles conseguiram formular um conceito bastante claro de velocidade instantânea, o que significa que prefiguraram os conceitos de função e derivada, e mostraram que o espaço percorrido por um móvel em movimento uniformemente acelerado em um determinado tempo é o mesmo que o percorrido por um movimento uniforme cuja velocidade é a média das velocidades maiores e menores do movimento acelerado. Em princípio, as qualidades da física grega foram substituídas, pelo menos para os movimentos, por quantidades numéricas que têm governado a ciência ocidental desde então. Este trabalho foi rapidamente difundido em França, Itália e outras partes da Europa. Quase imediatamente, Giovanni da Casale e Nicole Oresme encontraram uma forma de representar os resultados por gráficos geométricos, introduzindo a conexão entre a geometria e o mundo físico que se tornou um hábito característico do pensamento ocidental". Sendo assim, fazemos menção à obra de Galileu nesta seção com o objetivo caracterizar elementos desse olhar matemático para o mundo e também porque encontramos na mesma diversos exemplos claros dessa "nova" maneira de investigar a natureza. Novamente, um resgate histórico mais detalhado foge aos objetivos de nosso trabalho.

${ }^{12}$ De maneira retrospectiva, podemos perceber a importância da quantificação do tempo ao notarmos que inúmeras leis fundamentais da física são evolutivas, ou seja, são representadas por equações diferenciais nas quais o tempo é a variável independente e suas soluções são funções temporais de outras grandezas.

13 “A filosofia está escrita neste grande livro que está sempre aberto diante de nós: refiro-me ao universo; mas o mesmo não pode ser lido antes de termos aprendido a sua linguagem e de nos termos familiarizado com os caracteres em que está escrito. Ele está escrito em linguagem matemática e as letras são triângulos, círculos e outras figuras geométricas, sem as quais é humanamente impossível entender uma só palavra; sem estes meios vagamos num obscuro labirinto" (GALILEI [1623], 1983). 
futuro. Ela fornece somente uma informação quantitativa sobre como uma bola cai” (p. 179). Apesar de parecer uma limitação quando comparada a formulações mais explicativas, essa mudança de foco para descrições quantitativas influenciou sobremaneira o desenvolvimento da ciência moderna.

Outro aspecto importante do caráter matemático da obra de Galileu é a semelhança de sua linha de argumentação com o estilo encontrado em clássicos da matemática como os Elementos de Euclides. Tal modelo consiste em demonstrar proposições a partir de definições e axiomas utilizando uma linguagem geométrica. Os axiomas ou princípios fundamentais no caso de físicos como Galileu, Newton e d'Alembert, são obtidos através de um complexo misto de observação, experimentação, formulação de hipóteses, argumentos racionais e a crença de que a natureza é simples, ordenada e regida por leis.

Porém, tal ordem não é facilmente encontrada num primeiro olhar para os fenômenos naturais. Se observarmos quedas de corpos de diferentes formas, tamanhos e massas, certamente não identificaremos qualquer tipo de padrão ou regularidade. Dessa forma, Galileu fez uma série de abstrações e idealizações para atingir a essência dos fenômenos naturais por ele estudados. Segundo Kline (1959), “essa atitude é precisamente a mesma que o matemático adota quando estuda figuras geométricas. Ele elimina suas estruturas moleculares, cores, espessuras, cheiros para ser capaz de investigar as propriedades básicas dessas figuras" (p. 176). Assim, através do exercício intelectual (experiências de pensamento) de eliminar o atrito, a resistência do ar e desconsiderar irregularidades nas formas dos corpos, Galileu adotou uma postura semelhante à de um matemático para estudar as grandezas essenciais do movimento e selecionar aquelas que seriam passíveis de quantificação. Um exemplo emblemático desse processo de idealização é encontrado em sua investigação sobre as leis básicas do movimento do pêndulo ${ }^{14}$.

A defesa da legitimidade de se investigar a natureza por meio do pensamento matemático é, segundo o historiador Alexander Koyré (1892-1964), o cerne da principal obra de Galileu:

[...] é o direito à ciência matemática, à explicação matemática da natureza, em oposição àquela não-matemática do senso comum e da física aristotélica, muito mais do que a oposição entre dois sistemas astronômicos, que constitui o tema central dos Diálogos sobre dois máximos sistemas do mundo. De fato o Diálogos é muito mais uma obra de filosofia do que de ciência pela simples razão de que a solução do problema astronômico dependia da constituição de uma nova física; que por sua vez implicava na solução do problema filosófico

\footnotetext{
${ }^{14}$ Para uma análise detalhada sobre aspectos históricos, filosóficos e pedagógicos dos estudos sobre o movimento do pêndulo ver Matthews, Gauld e Stinner (2005). 
da aplicabilidade da matemática na constituição da ciência da natureza. (KOYRÉ, 1943, p. 419)

Em sua análise histórica sobre o processo de transformação da noção de grandeza física, e consequentemente sobre a legitimação da matematização da física, Paty (2003) dá um papel de destaque para as contribuições do pensamento de Descartes. De fato, no início de suas "Regras para a direção do espírito", Descartes defende a importância de um método para a emissão de "juízos sólidos e verdadeiros" sobre todas as investigações do espírito humano. Na Regra IV ele explicita sua crença na superioridade e segurança do pensamento matemático para tais investigações, concebendo a noção de matemática universal (mathesis universalis):

Refletindo mais atentamente, pareceu-me por fim óbvio relacionar com a Matemática tudo aquilo em que apenas se examina a ordem e medida, sem ter em conta se é em números, figuras, astros, sons, ou em qualquer outro objeto que semelhante medida se deve procurar; e, por conseguinte, deve haver uma ciência geral que explique tudo o que se pode investigar acerca da ordem e da medida, sem as aplicar a uma matéria especial: esta ciência designa-se pelo vocábulo já antigo e aceito pelo uso de Matemática universal, porque esta contém tudo o que contribui para que as outras ciências se chamem partes da Matemática. (DESCARTES [1628], 2002, p. 7, grifo nosso).

Dessa forma, a física, como uma tentativa de compreender os fenômenos do mundo deveria, por princípio, adotar a maneira matemática de pensar. Isso implica em abstrair conceitos supérfluos e selecionar variáveis relevantes para o entendimento de fenômenos, conforme fica evidente na seguinte passagem da Regra XIII:

[...] se me pergunta a minha opinião sobre a natureza do som, atendendo precisamente a estes três fatos: três cordas A, B, C, produzem o mesmo som e, entre elas, B é, por hipótese, duas vezes mais grossa que $\mathrm{A}$, sem ser mais comprida mas esticada por um peso duas vezes mais pesado, ao passo que $\mathrm{C}$ não é mais grossa que $\mathrm{A}$, mas apenas duas vezes mais comprida e esticada por um peso quatro vezes mais pesado, etc. Percebe-se assim facilmente como é que todas as questões imperfeitas se podem reduzir às perfeitas. Vê-se também como é preciso observar esta regra para que uma dificuldade bem compreendida seja abstraída de todo o conceito supérfluo e reduzida a uma forma tal que já não tenhamos o pensamento ocupado neste ou naquele assunto em particular, mas apenas em comparar certas grandezas entre si. (DESCARTES [1628], 2002, p. 26, grifo nosso).

É na Regra XIV que encontramos uma definição de grandeza como sendo "a extensão real do corpo abstraída de todo o resto" e uma criteriosa descrição dos conceitos de dimensão, medida, unidade e figura. Portanto, para Descartes, a física, sendo uma ciência que estuda relações entre grandezas (ordem e medida) sujeitas a proporções, não pode prescindir do uso da matemática em seus métodos.

$\mathrm{Na}$ tentativa de localizar momentos relevantes para a matematização da física, a publicação dos "Princípios matemáticos da filosofia natural” por Newton em 1687 é, indiscutivelmente, um marco importante. Em seu artigo "O que a matemática fez com a 
física?", Gingras (2001) apresenta um interessante estudo que cobre um período de aproximadamente dois séculos, tendo como ponto de partida a publicação dos Principia de Newton. Segundo Gingras, essa análise evidencia três principais consequências da matematização da física:

1 - Social: O uso da matemática teve o efeito de excluir atores da participação legítima nos discursos de filosofia natural, uma vez que contribuiu para a criação de uma ciência privada, na qual só os que possuem um adequado conhecimento de matemática podem participar.

2 - Epistemológica: A matematização da física mudou o próprio significado do termo explicação. A necessidade de explicar por meio de mecanismos físicos foi gradualmente substituída por formulações matemáticas estruturadas logicamente.

3 - Ontológica: A matematização contribuiu para o "desaparecimento de substâncias" como vórtices, fluidos, éteres ou o calórico. O tratamento teórico cada vez mais abstrato fez com que essas imagens concretas se tornassem obsoletas e desnecessárias.

Em relação à consequência social, são particularmente interessantes os inúmeros protestos contrários à matematização da física citados por Gingras ao longo do artigo. Um dos principais argumentos dos opositores à aplicação da matemática ao estudo da natureza está associado à imprecisão dos fenômenos naturais. Esse argumento, já presente em Aristóteles $^{15}$, fica evidente nas críticas apresentadas pelo físico e matemático francês Joseph Privat de Molières (1677-1742) quando o mesmo defende que "princípios físicos não são tão precisos quando aplicados aos fenômenos" (1733, apud GINGRAS, 2001, p. 389) e também no alerta do físico experimental francês Jean-Antoine Nollet (1700-1770) ao mencionar que "é perigoso que um físico desenvolva muito gosto por geometria, pois em física nunca encontramos nem precisão nem certeza" (apud GINGRAS, 2001, p. 389).

Outro forte argumento contrário à matematização é que a mesma provoca uma drástica redução no número de atores em condições de participarem da construção da ciência. Isso ia de encontro, por exemplo, às convicções do matemático e filósofo francês LouisBertrand Castel (1688-1757), o qual defendia que a filosofia natural deveria "ser acessível ao homem comum e portanto não somente a matemática superior, mas também experimentos não facilmente reprodutíveis deveriam ser excluídos dos métodos científicos aceitáveis" (GINGRAS, 2001, p. 391). Reações contrárias à tal exclusão provocada pela metodologia

\footnotetext{
15 “[...] a precisão da matemática não deve ser demandada em todos os casos, mas somente nos casos de coisas que não são materiais. Assim, seu método não é o método da ciência natural." (ARISTÓTELES apud GINGRAS, 2001, p. 389). 
adotada no trabalho de Newton também são encontradas na argumentação de M. Massière ${ }^{16}$ : "parte da filosofia de Newton que concerne o movimento dos planetas consiste puramente de cálculos [...] para mim, que não sou um calculista, preciso admitir que me sinto revoltado com esse novo tipo de filosofia” (1759, apud GINGRAS, 2001, p. 394).

Gingras ilustra o "ressentimento dos excluídos" com curiosos relatos que evidenciam não somente um tom de indignação, mas também de extrema ironia. Ainda em 1826, numa tentativa de explicar a gravitação em termos mecânicos, J. Mangin manifesta sua reprovação às abordagens descritivas newtonianas:

Reconheço que todos os cálculos analíticos dos defensores do sistema de atração são plenamente capazes de assustar muitos leitores, mas ainda é verdade que esses cálculos são apenas baseados em suposições, uma vez que a causa física da atração é desconhecida. (MANGIN, 1826, apud GINGRAS, 2001, p. 395, grifo nosso) ${ }^{17}$.

Dentre as manifestações de revolta mais inusitadas, encontramos a do conde Bernard Germaine de Lacépède (1756-1825):

[...] seguindo o exemplo do grande Newton, vou envolver minhas hipóteses com mantos geométricos e algébricos para torná-las invisíveis aos olhos e críticas dos não iniciados. Se alguém criticar tal obscuridade, citarei d'Alembert e outros que modestamente admitem a existência proposições na obra prima do grande filósofo inglês que não são acessíveis até para os mais competentes geômetras. (LACÉPÈDE, 1784 apud GINGRAS, 2001, p. 394, grifo nosso).

A menção a d'Alembert reflete a posição do físico e matemático francês como um dos principais defensores da matematização da física. Essa defesa fica evidente no trecho a seguir:

[...] é tarefa dos cálculos confirmar a existência dessas causas [gravitação] através da determinação exata dos efeitos produzidos e da comparação de tais efeitos com resultados experimentais. [...] não é suficiente que um sistema satisfaça o fenômeno apenas de maneira vaga e geral, ou que forneça explicações plausíveis para alguns deles: os detalhes e os cálculos precisos são decisivos; somente eles podem dizer se podemos adotar, rejeitar ou modificar uma hipótese. (D'ALEMBERT, 1749 apud GINGRAS, 2001, p. 392-93, grifo nosso).

Assim, Gingras defende que a matemática contribuiu para o surgimento de uma ciência privada (em oposição a pública), acessível somente àqueles que possuem treinamento adequado. Os não integrantes, tendo que se contentar com um entendimento superficial do que realmente estava acontecendo, não poderiam mais ser considerados participantes dessa comunidade. Para d'Alembert, a era da física verbal (ou literal) estava acabada, pelo menos no que concerne o sistema newtoniano (p. 393).

\footnotetext{
${ }^{16} \mathrm{M}$. Massière, Réflexions critiques sur le système de l'attraction (Nice, 1759), p. v.

${ }^{17} \mathrm{~J}$. Mangin, Le tombeau de l'attraction universelle ou démonstrations incontestables de la fausseté du système de l'attraction newtonienne (Verdun, 1826), 13.
} 
Se o trabalho de Newton é um marco na direção da matematização da mecânica, em outros campos como estudos sobre o calor, eletricidade e magnetismo, personagens com abordagens puramente qualitativas e experimentais ainda encontram espaço até meados do século XIX. Porém, seguindo a tradição newtoniana, era uma questão de tempo para que os trabalhos de Fourier para o calor e de Maxwell para o eletromagnetismo dessem uma formulação matemática a essas teorias. No último caso, Gingras cita a reação de Michael Faraday (1791-1867) ao tratamento matemático dado por James Clerk Maxwell (1831-1879) às suas intuições: "inicialmente eu fiquei quase assustado quando vi tal força matemática tomar conta do tema". Com ares semelhantes aos ressentimento de exclusão previamente citados, Faraday questiona Maxwell:

Existe algo que eu gostaria muito de lhe perguntar. Quando um matemático que se engaja em investigar ações e resultados físicos chega em suas conclusões, não poderiam estas serem expressas em linguagem comum de maneira clara, completa e definitiva ao invés de por meio de fórmulas matemáticas? (FARADAY, 1852 apud GINGRAS, 2001, p. 397).

Em uma de suas aulas inaugurais, Maxwell, que havia sido formado na tradição newtoniana, revela sua concepção sobre o fazer ciência argumentando que "a filosofia natural é, e precisa ser, matemática, isto é, a ciência na qual leis que relacionam quantidades são tratadas de acordo com princípios do raciocínio rigoroso" (MAXWELL, 1852, apud GINGRAS, 2001, p. 397).

As citações de Maxwell e d'Alembert ilustram o que Gingras chamou de consequência epistemológica da matematização da física, uma vez que a própria concepção sobre o que seria considerado aceitável como uma explicação física foi alterada. Segundo o autor, explicações que envolviam mecanismos físicos - como os vórtices de Descartes, as engrenagens de Maxwell ou as diferentes tentativas de explicação da gravitação através de modelos mecânicos - foram sendo gradualmente substituídas por formulações matemáticas.

Naturalmente, Gingras deixa claro que esse processo não se deu de maneira harmoniosa e unânime. Estudioso dos Principia, Louis-Bertrand Castel faz questão de enfatizar critérios de demarcação defendendo a tese de que o que Newton fez não é física. Para ele, a física se ocupa de promover explicações mecânicas (associadas a mecanismos), tarefa esta bastante distinta dos objetivos de um geômetra. Nos trechos a seguir (CASTEL, 1753 apud GINGRAS, 2001, p. 400-01, grifos nossos), Castel apresenta uma empenhada, e até certo ponto agressiva, defesa dessa tese:

"Para Newton, pensar e calcular, raciocinar e calcular, filosofar e calcular são todos sinônimos" 
"Na verdade, permitam-me dizer, com o extremo respeito que é preciso ter por Newton, que só existe geometria em seu sistema e que a boa física irá desaparecer se o deixarmos continuar. [...] Eu admiro seu raciocínio geométrico profundo, mas não há uma só palavra de raciocínio físico em sua obra".

"Geometria é geometria somente através da simplicidade abstrata de seu objeto. Apenas isso faz com que ela seja precisa e demonstrativa. Entretanto, o objeto da física é muito mais vasto. É isso que a torna difícil e obscura. Mas ninguém se torna um melhor físico por ser um melhor geômetra."

O foco das críticas de Castel está na natureza/qualidade das explicações encontradas na obra de Newton, pois ele não as reconhece como físicas. Em uma das passagens de seu livro "Verdadeiro sistema de física geral de Newton, exposto e analisado em paralelo com o de Descartes; no âmbito dos físicos comuns", Castel analisa a relação entre a primeira lei de Kepler e a existência de uma força centrípeta inversamente proporcional ao quadrado da distância do planeta ao sol, a qual é apresentada na proposição XI do livro I dos Principia com uma argumentação puramente geométrica. O trecho a seguir ilustra seus principais argumentos contrários a esse tipo de explicação:

O que existe de físico nessa demonstração ou explicação? Será que alguém pouco acostumado à maneira newtoniana, sobretudo se tiver um pouco de habilidade com a maneira de Descartes, diria que existe algum tipo de explicação ou demonstração nesse caso? A força que atua nos planetas é inversamente proporcional ao quadrado da distância, logo, conclui Newton, os planetas descrevem órbitas elípticas e o sol ocupa um dos focos. Ou essa razão [inverso do quadrado da distância] é uma consideração totalmente matemática (geométrica) ou não passa de um fato da experiência e da observação. A forma elíptica do movimento dos planetas também é um fato da observação. Newton deduziu este daquele, mas isso não explica nada. É uma relação entre dois fatos, o que é bom. Mas um não explica o outro, um não é a causa nem a razão do outro. (CASTEL, 1743, p. 97, grifo nosso).

Sendo marca registrada das abordagens de Galileu e Newton, essa eliminação da busca pela causa primeira também é encontrada em outros importantes trabalhos como os de Fourier $^{18}$, Biot ${ }^{19}$ e Maxwell. Na verdade, a análise da evolução dos trabalhos de Maxwell revela, num intervalo de tempo menor, um processo semelhante ao que ocorreu na escala estudada por Gingras, uma vez que explicações por meio de mecanismos físicos (fluidos, engrenagens, elasticidade) foram gradualmente sendo substituídas por equações matemáticas que descrevem relações entre cargas e campos. Analisando episódios mais recentes da física moderna e baseando-se na concepção einsteiniana sobre o método da física teórica, Rivadulla

\footnotetext{
18 "As causas primeiras são desconhecidas por nós, mas são sujeitas a leis simples e constantes". (FOURIER, 1822, p. i).

19 "Não digo explicar, mas calcular, isto é, deduzir matematicamente". (BIOT, 1816 apud GINGRAS, 2001, p. 403).
} 
(2005) defende que "um construto físico recebe uma explicação teórica quando pode ser deduzido matematicamente a partir de um construto mais geral” (p. 169).

A terceira consequência apontada por Gingras, a qual está de certa forma ligada à segunda, é a "dissolução de substâncias no ácido da matemática”. O declínio da argumentação mecanicista, o que o autor a chamou de consequência ontológica da matematização da física, pode ser novamente comprovada na evolução da obra de Maxwell, no formalismo lagrangeano ou no tratamento analítico dado ao calor por Fourier. De fato, se olharmos para a estruturação de teorias modernas como a relatividade geral e mecânica quântica, detectaremos a impossibilidade de se associar modelos mecânicos a entes fundamentais das mesmas como tensores e funções de onda.

Na próxima seção, analisamos alguns posicionamentos de cientistas e filósofos sobre as razões para a eficácia da matemática nas ciências físicas e utilizamos exemplos de teorias do século XX para evidenciar que a matematização da física atingiu níveis nunca antes imaginados por pensadores como Galileu, Descartes e Newton. 


\subsection{POSICIONAMENTOS FILOSÓFICOS E A “REVOLUÇÃO METODOLÓGICA” DO SÉCULO XX}

Nossa experiência até o presente momento justifica a crença de que a natureza é a realização do que é matematicamente mais simples. Estou convencido de que construções puramente matemáticas nos possibilitam descobrir os conceitos e leis que os conectam, o que consiste na chave para o entendimento dos fenômenos da natureza. A experiência pode naturalmente nos guiar na escolha de conceitos matemáticos úteis, mas não pode ser a fonte a partir da qual os mesmos são deduzidos. A experiência se impõe como o único critério da utilização de uma construção matemática para a física. Mas o princípio verdadeiramente criador se encontra na matemática (EINSTEIN [1934], 1956, p.116-17).

Inúmeros exemplos históricos bem sucedidos nos fazem refletir sobre os motivos da efetividade da matemática para a descrição de fenômenos físicos. De fato, muitos cientistas e filósofos se debruçaram sobre esta questão, incluindo Albert Einstein $(1879-1955)^{20}$ e Richard Feynman (1918-1988) ${ }^{21}$. Para Johannes Kepler (1571-1630), James Jeans (18771946), Paul Dirac (1902-1984), entre outros, essa aplicabilidade poderia ser explicada assumindo que Deus seja um matemático:

Parece que um dos aspectos essenciais das leis físicas da natureza é que elas são descritas por teorias matemáticas de extrema beleza e poder, sendo necessário um bom conhecimento matemático para entendê-las. Temos que aceitar isso. Talvez seja possível explicar a situação afirmando que Deus é um matemático do mais alto nível e que usou matemática muito avançada para construir o universo (DIRAC, 1963, p. 53, grifo nosso).

Uma das opiniões mais radicais sobre o tema é dada por Eugene Wigner. Em seu influente artigo sobre a "Incompreensível/Desarrazoada efetividade da matemática nas ciências naturais" o físico defende que:

O milagre da aplicabilidade da linguagem matemática para a formulação das leis da física é uma dádiva maravilhosa a qual nós não entendemos nem merecemos. Nós devemos agradecer por ela e esperar que a mesma permaneça válida no futuro e que ela ampliará, para melhor ou pior, para nosso prazer, e até mesmo para nosso espanto, nosso entendimento sobre o mundo (WIGNER, 1960, p. 14, grifo nosso).

Apesar dessas manifestações de deslumbramento e atribuições divinas, muitos filósofos têm colocado o tema da aplicabilidade como uma séria questão de investigação e expressado uma posição contrária a dádivas incompreensíveis. Zahar (1980) diverge da tese da incompreensível efetividade da matemática argumentando que "a harmonia entre matemática e física é estabelecida forçadamente e não pré-estabelecida” (p. 5). Dessa forma,

\footnotetext{
20 "Como pode a Matemática, sendo acima de tudo um produto do pensamento humano, independente da experiência, se adaptar tão admiravelmente à realidade objetiva?" (EINSTEIN [1934], 1956, p. 119)

${ }^{21} \mathrm{Eu}$ acho fascinante que seja possível predizer o que irá acontecer através da matemática, a qual consiste simplesmente em seguir certas regras as quais nada tem a ver com fenômeno original (FEYNMAN, 1985, p. 171).
} 
segundo ele, a chamada harmonia "não é um milagre, mas sim o resultado de um árduo processo de ajuste mútuo" (p. 7).

Segundo Boniolo e Budinich (2005), existem cinco linhas de pensamento diferentes que permitem interpretar as razões pelas quais a matemática é tão eficaz para descrever fenômenos físicos:

1 - Linha platônica: a matemática é eficaz porque o mundo é intrinsecamente matemático;

2 - Linha de Galileu: ela é eficaz porque existe uma forte homogeneidade entre o mundo físico e a matemática;

3 - Linha de Berkeley: matemática é eficaz porque ela é apenas uma boa ferramenta;

4 - Linha de Kant 1: matemática é eficaz porque nós constituímos cognitivamente o mundo de uma maneira matemática;

5 - Linha de Kant 2: matemática é eficaz na física porque é somente graças a ela que somos capazes de construir conceitos de objetos sobre os quais não temos experiência direta (BONIOLO; BUDINICH, 2005, p. 76).

Também em oposição à tese de Wigner, os autores defendem que o problema filosófico da efetividade da matemática para a física é um "falso problema", especialmente quando se analisa o papel da matemática nas teorias da física moderna e contemporânea. Segundo eles:

A teoria física não é algo ao qual a matemática pode ser adicionada externamente, e assim possibilitando o questionamento sobre sua eventual efetividade. As teorias da física moderna e contemporânea são signos físico-matemáticos. Eles são algo que não pode ser dividido em uma parte matemática e uma não matemática. [...] Assim, refletir sobre o problema da efetividade da matemática é refletir sobre um falso-problema, ou seja, o problema não existe uma vez que matemática é uma parte indivisível da física moderna e contemporânea (BONIOLO; BUDINICH, 2005, p. 86, grifo nosso).

A interpretação de teorias físicas como signos físico-matemáticos (F-M) é baseada em ideias da teoria semiótica de Charles Peirce (1839-1914). Segundo essa teoria, o signo é uma espécie de conexão entre o objeto (no caso o mundo físico) e seu interpretante (o físico). Através de uma releitura da teoria de Peirce, Boniolo e Budinich (2005) exploram os três aspectos complementares do signo físico-matemático: ícone (signo como uma entidade em si), índice (relação do signo com o mundo físico), e símbolo (relação do signo com o interpretante) (Fig. 1). 


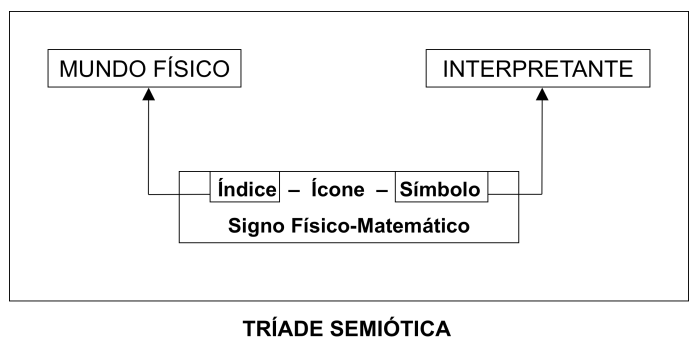

Figura 1: Aspectos complementares do signo físico-matemático (BONIOLO; BUDINICH, 2005, p. 79).

Interpretar um signo F-M como um ícone é tratá-lo de maneira independente, considerando que o mesmo possa ser manipulado como uma entidade em si, sem qualquer relação com o objeto. A maneira tradicional de trabalhar com esse aspecto é focar na organização lógico-dedutiva do signo, isto é, nas regras internas à sua estrutura.

Apesar da possibilidade de se encarar o signo como uma entidade em si (ícone), é preciso considerar seu valor intencional de indicar algo no mundo físico. Focar na relação do signo com o mundo físico é encará-lo como índice. Segundo os autores, indicar significa essencialmente:

1 - a asserção da existência de algo além do signo físico-matemático; 2 - a possibilidade de checar se essa indicação é correta (p. 81).

A função mais importante do índice é a descoberta de novas entidades a partir da atribuição de significado a entidades matemáticas inventadas ou deduzidas. Tratando um signo F-M com ícone, é possível manipulá-lo e extrair, da lógica, resultados que não haviam sido pensados quando os mesmos foram construídos. Mas o tratando como um índice é possível pensar que exista algo no mundo físico, instigando alguém a investigar se esse algo realmente existe. As descobertas da antipartícula e do neutrino, previamente mencionadas, são exemplos da função do signo F-M como índice.

Quando nos perguntamos como e por que um signo F-M é construído, somos levados a considerar o fator humano, ou seja, a relação do signo com o interpretante (símbolo). Nesse caso, é imprescindível considerar tanto o contexto histórico da época em que o signo é criado, como o problema específico para o qual o signo propõe uma solução. A restrição histórica é óbvia: Galileu não realizou seus estudos em linguagem algébrica e Maxwell não utilizou o cálculo tensorial porque essas estruturas ainda não estavam plenamente desenvolvidas em suas épocas. A escolha do signo está naturalmente vinculada às estruturas matemáticas disponíveis no momento em que a teoria é criada (matemática pré-fabricada). Em alguns casos, como o método das fluxões de Newton, os diagramas de Feynman ou a "função" delta 
de Dirac, essas estruturas são criadas pelos próprios físicos para formalizar suas teorias (BONIOLO; BUDINICH, 2005).

A análise de cada um dos três elementos (ícone, índice e símbolo) do signo F-M tem uma função didática, porém, tratam-se naturalmente de aspectos complementares. Encará-los independentemente pode levar a distorções como esquematizadas na Figura 2:

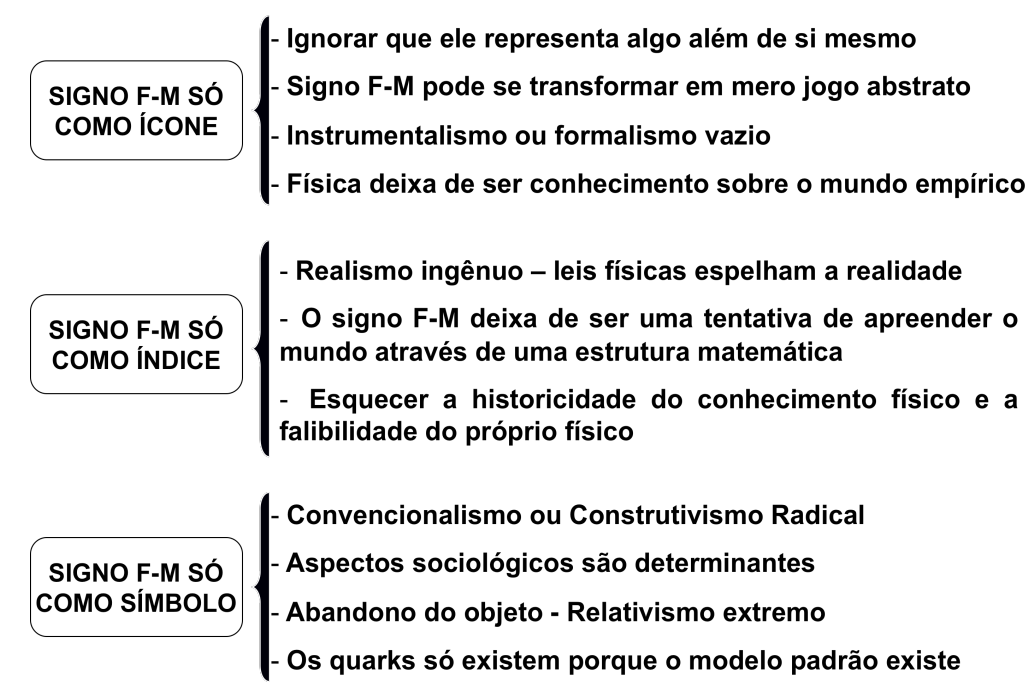

Figura 2: Distorções oriundas do tratamento de cada aspecto do signo de maneira independente. Síntese de nossa autoria.

A tese central do trabalho de Boniolo e Budich (2005) é a de que existe uma revolução metodológica na física do século XX, a qual foi encabeçada pelos trabalhos de Dirac. Uma citação do próprio Dirac ilustra essa maneira de pensar:

O método mais poderoso para se avançar atualmente é empregar todos os recursos da matemática pura na tentativa de aperfeiçoar e generalizar o formalismo que constitui a base da física teórica, e, após cada sucesso nessa direção, tentar interpretar as entidades matemáticas em termos de entidades físicas (DIRAC, 1931, apud BONIOLO; BUDINICH, 2005, p. 87, grifo nosso).

Dessa forma, a relação entre a matemática, o signo F-M e o mundo físico, precisa ser considerada sob outra ótica. De acordo com a releitura de Peirce por Boniolo e Budinich (2005), é possível interpretar que Dirac esteja sugerindo que se deva primeiramente trabalhar com o signo como ícone, para em seguida considerar seu caráter intencional de índice.

Nesse sentido, o pensamento matemático assume o papel de poderoso criador de novos signos físico-matemáticos, e assim, torna-se um promotor da descoberta de novos aspectos fenomenológicos do mundo físico (BONIOLO; BUDINICH, 2005, p. 89, grifo nosso).

Gaston Bachelard (1884-1962) defende que esta mudança na metodologia da Física já está presente nos trabalhos de Einstein com a Relatividade. Para o filósofo francês, no início da formalização da física a matemática assumiu um papel de linguagem, sendo responsável pela quantificação das grandezas físicas e expressão de suas relações: 
Repetiu-se vezes sem fim que as matemáticas eram uma linguagem, um simples meio de expressão. Criou-se o hábito de considerá-las como ferramentas à disposição de uma razão consciente de si própria, senhora de ideias puras dotadas de uma transparência prématemática. Tal segmentação podia ter um sentido nos inícios do espírito científico, quando as imagens primeiras da intuição tinham uma força sugestiva e ajudavam a teoria a constituirse. Por exemplo, se se admitir que a ideia de atração é uma ideia simples e clara, poder-se-á dizer que as expressões matemáticas das leis de atração não fazem mais que precisar casos particulares, ligar conjuntamente algumas consequências, como a lei das áreas, que têm, também elas, um sentido claro e direto na intuição primária (BACHELARD [1938], 1995, p. 42-43, grifo nosso).

Porém, Bachelard defende que esse papel de simples ferramenta não é mais suficiente para o que ele chamou de novo espírito científico. De maneira semelhante à postura de Dirac previamente citada, Bachelard argumenta que:

[...] nas novas doutrinas, ao afastar-se das imagens ingênuas, o espírito científico tornou-se de algum modo mais homogêneo: doravante, está inteiramente presente no seu esforço matemático. Ou ainda, para maior precisão, é o esforço matemático que constitui o eixo da descoberta, é a expressão matemática a única que permite pensar o fenômeno. Há alguns anos, dizia-nos Langevin: "O Cálculo Tensorial conhece melhor a Física que o próprio Físico." O Cálculo Tensorial é [...] um instrumento matemático que cria a ciência física contemporânea como o microscópio cria a microbiologia. Não há novos conhecimentos sem o domínio deste instrumento matemático novo. (BACHELARD [1938], 1995, p. 43, grifo nosso).

Paty (1993) também defende que essa mudança (revolução metodológica segundo Boniolo e Budinich) já pode ser encontrada quando comparamos as abordagens de Einstein à relatividade restrita e geral. Mais especificamente, Paty argumenta que o formalismo matemático adquire um papel heurístico na teoria da relatividade geral. De fato, essa teoria foi consolidada a partir da modificação formal na maneira como os problemas eram tratados geometricamente, o que só foi possível quando o conceito de curvatura oriundo da métrica de Riemann, o cálculo tensorial e o cálculo diferencial e absoluto de Ricci e Levi-Civitta foram incluídos no formalismo. Em suas notas autobiográficas o próprio Einstein explicita a mudança em seu pensamento provocada pela relatividade geral:

Aprendi algo mais com a teoria da gravitação: nenhuma coleção de fatos empíricos, por mais abrangente que seja, pode levar a essas equações complexas. Uma teoria deve ser testada pela experiência, mas não é possível construir uma teoria partindo da experiência. Equações complexas como as do campo gravitacional só podem ser encontradas através da descoberta de uma condição simplesmente matemática. (EINSTEIN [1949], 1982, p. 84).

Inúmeros exemplos dessa "revolução metodológica" são apresentados e discutidos em profundidade pelo filósofo Mark Steiner em seu livro "A aplicabilidade da matemática como um problema filosófico". A principal ideia defendida pelo autor é a de que as analogias matemáticas são as principais fontes de descoberta dos físicos. Segundo ele, essa atitude de confiar na matemática para adivinhar as leis da natureza baseia-se em critérios 
eminentemente humanos como conveniência e beleza, sendo portanto classificada como antropocêntrica.

Steiner cunhou o termo "analogias pitagóricas" para aquelas que não podem ser expressas em qualquer outra linguagem que não em matemática pura. No quarto capítulo de seu livro, ele se propõe a defender a nada trivial tese de que as principais descobertas da física contemporânea foram baseadas em analogias pitagóricas. Para isso, ele faz uma análise dos caminhos que os físicos seguiram para fazerem tais descobertas e apresenta um conjunto de seis estratégias pitagóricas, as quais parecem explicitar a noção de revolução metodológica proposta por Boniolo e Budinich (2005). Sem o objetivo de nos aprofundarmos em detalhes ${ }^{22}$, iremos apresentar cada uma dessas estratégias e indicar quais teorias/descobertas estão, segundo Steiner, associadas a cada uma delas.

(1) Uma equação $E$ foi deduzida a partir de um conjunto premissas $A$. A equação tem soluções para as quais $A$ não são mais válidas; mas somente porque elas são soluções de $E$, alguém as procura na natureza. Por que trata-se de uma analogia pitagórica? Uma maneira tradicional de se "deduzir" uma equação diferencial é começar com uma função $f$, já tida como "fisicamente real"; e em seguida diferenciando $f$, obter uma equação para a qual $f$ seja uma solução. (Normalmente haverão diversas equações possíveis, logo não há problema em adivinhar). Admitir que outra solução da equação, $g$, também seja "fisicamente real" é portanto uma analogia entre $f$ e $g$ mediada pela equação. A analogia se torna pitagórica se $f$ e $g$ não forem fisicamente análogas, de tal forma que é somente a equação que as relaciona. (STEINER, 1998, p. 76-77).

Para Steiner, essa foi a estratégia utilizada por Maxwell ao propor, mesmo sem evidências empíricas de sua existência, o termo da corrente de deslocamento para manter o princípio de conservação da carga, fazendo assim com que a radiação eletromagnética se tornasse uma possibilidade matemática. Outro caso citado é a descoberta da equação de Schrödinger que governa as ondas de matéria:

Schrödinger começou com uma onda senoidal de frequência definida, baseado na analogia óptico-mecânica, onde a frequência é dada pela energia. Ao escrever a equação de "onda" a partir das derivadas, Schrödinger abstraiu completamente essa intuição, terminando com uma equação sem correspondente na óptica clássica, com soluções que não tinham significado físico direto e sem quaisquer qualidades de ondas.[...] Aparentemente, somente o fato de ser solução da equação de Schrödinger era condição suficiente para se acreditar na sua existência. (STEINER, 1998, p. 81).

A segunda estratégia proposta por Steiner é a seguinte:

(2) Resultados apontados pelo formalismo são procurados na natureza mesmo quando é razoável duvidar de sua existência. Não há qualquer razão a priori para acreditar que qualquer solução de uma equação tenha uma interpretação física. Não há nada de errado do ponto de vista lógico em descartar certas soluções de equações e isso é feito com frequência (por exemplo, soluções da equação de Schrödinger sem condições de contorno). Entretanto, o

\footnotetext{
${ }^{22}$ Para uma leitura mais detalhada recomendamos o livro (STEINER, 1998). 
cientista pitagórico trabalha com a hipótese de que uma possibilidade matemática poderá ser realizada pela natureza. (STEINER, 1998, p. 82).

Essa estratégia é claramente identificada na descoberta da antipartícula por Dirac, quando o mesmo atribui significado físico às energias negativas de sua equação, e dos buracos negros por Karl Schwarzschild (1873-1916), por meio da interpretação física de sua solução simetricamente esférica da equação de Einstein.

(3) Suponha que uma família de "objetos" seja classificada utilizando uma estrutura matemática $S$. Então, conjectura-se que essa estrutura, ou alguma estrutura relacionada $T$, deva classificar outras famílias de objetos mesmo que, na situação atual: (a) $S$ não é redutível a uma propriedade física e (b) a relação entre $S$ e $T$ não é redutível a uma relação física. (STEINER, 1998, p. 84).

Esse raciocínio parece estar amplamente presente em física de partículas quando argumentos de simetria são aplicados a diversos fenômenos e levam a descobertas fundamentais. Uma detalhada exposição, exemplificada pelos abstratos (sem correspondentes físicos) conceitos de spin e isospin, e pela argumentação de Gell-Mann para a teoria dos quarks, ilustram o uso dessa estratégia na defesa de Steiner.

(4) Equações são formuladas através de analogias com as formas matemáticas de outras equações, mesmo com a existência de pouca ou nenhuma motivação física fundamentar tal analogia. (STEINER, 1998, p. 94).

O primeiro exemplo dessa estratégia pitagórica é o previamente mencionado caso da dedução da equação de campo de Einstein. As duas primeiras condições que a mesma deveria atender - a equação deve ser de segunda ordem e linear nas segundas derivadas - são justificadas por Einstein a partir de uma analogia (pitagórica) que garantiria à sua equação as mesmas propriedades matemáticas da equação de Poisson para o potencial gravitacional. Outro exemplo citado é o desenvolvimento da mecânica matricial por Heisenberg, Born e Jordan a partir de analogias (pitagóricas) com as equações clássicas da mecânica hamiltoniana.

(5) Uma lei refutada é utilizada para testar novas leis - a "velha" lei é estipulada para ser um caso especial ou limite de qualquer "nova" lei.

(6) Uma lei refutada - falsa por definição - é utilizada mesmo assim para deduzir novas leis. (STEINER, 1998, p. 105-6).

Essas estratégias sugerem que as estruturas matemáticas são mais robustas do que as leis que elas representam fisicamente, isto é, são "descompromissadas" com sua interpretação física, e esse apego às estruturas pelos físicos evidencia uma atitude pitagórica. Nas palavras de Steven Weinberg (apud STEINER, 1998, p. 109) "muito frequentemente belas 
matemáticas sobrevivem em física, mesmo quando os princípios físicos através dos quais elas foram desenvolvidas não são mais considerados corretos".

Os diversos exemplos apresentados nessa seção objetivaram evidenciar que, se no surgimento da ciência moderna no século XVII já era difícil conceber uma física sem matemática, atualmente essa tarefa é certamente impossível, dado o nível de abstração e distanciamento da realidade das teorias atuais. Tal impossibilidade é explicitada nas palavras do físico e matemático inglês Roger Penrose:

Uma das coisas notáveis acerca do comportamento do mundo é que ele parece fundamentar-se na matemática num grau totalmente extraordinário de precisão. Quanto mais entendemos sobre o mundo físico, quanto mais profundamente entramos nas leis da natureza, mais parece que o mundo físico quase se evapora e ficamos apenas com a matemática. (PENROSE, 1998, p. 19, grifo nosso).

A física desenvolvida ao longo do último século nos fornece inúmeros exemplos de uma relação ainda mais imbricada entre matemática e física, a qual está associada à uma "revolução metodológica" desta ciência (BONIOLO; BUDINICH, 2005). Sendo assim, a habilidade de pensar o mundo a partir estruturas matemática parece ser cada vez mais essencial para uma compreensão dos métodos da ciência. Essa constatação nos leva a refletir de maneira crítica sobre os limites/distorções de ensinarmos física sem utilizar matemática, inclusive na escola básica. Começamos a relacionar esta análise epistemológica com questões associadas ao ensino de física na próxima seção. 


\subsection{SÍNTESE DA ABORDAGEM EPISTEMOLÓGICA E IMPLICAÇÕES PARA O ENSINO}

Este capítulo teve como objetivo aprofundar a discussão sobre as relações entre física e matemática, evidenciar a complexidade do tema, destacar aspectos históricos da matematização da física, mostrar pontos de convergência e divergência nas visões de filósofos e cientistas, e evidenciar uma ampla gama de possibilidades distintas para interpretar a natureza dessas relações dependendo do episódio estudado e de seu contexto histórico. No decorrer da tese, faremos referência a vários dos posicionamentos aqui apresentados.

Objetivamos também combater reducionismos/chavões comumente presentes em diversos ambientes em que o tema possa ser pertinente como materiais didáticos, de divulgação científica, discursos de professores, etc. Alguns exemplos típicos são:

A matemática é a linguagem da física

A fisica é uma aplicação da matemática

A matemática é utilizada como ferramenta de cálculo em física

O importante na física são os conceitos, não a matemática

A matemática é independente da realidade física

Meu aluno não aprende física porque não sabe matemática

A fisica do problema acabou, daqui para frente é só matemática

Cada uma dessas afirmações reflete uma tentativa ingênua de generalizar/simplificar uma complicada, histórica e imbricada relação, sendo portanto falsa. As duas últimas estão relacionadas com o contexto de ensino, são incrivelmente comuns e revelam sérias consequências da ausência de uma reflexão epistemológica adequada na formação de professores de ambas as disciplinas.

Com a intenção de sintetizar o que foi exposto nessa abordagem epistemológica e fornecer uma revisão bibliográfica para os que se interessarem pelo tema, apresentamos o quadro resumo a seguir, no qual são relacionados os principais trabalhos que fundamentaram este capítulo e as ideias centrais de cada um. 


\begin{tabular}{|c|c|}
\hline Autor(es) & Ideias principais \\
\hline $\begin{array}{l}\text { Bachelard } \\
(1995)\end{array}$ & $\begin{array}{l}\text { - Matemática como linguagem descritiva é insuficiente para o novo espírito científico } \\
\text { - O esforço matemático constitui o eixo da descoberta, é a expressão matemática a única que } \\
\text { permite pensar o fenômeno }\end{array}$ \\
\hline $\begin{array}{l}\text { Bochner } \\
(1981)\end{array}$ & $\begin{array}{l}\text { - Análise da importância de conceitos matemáticos básicos (multiplicação, funções, números } \\
\text { reais, complexos, entre outros) para a física por meio de estudos de caso }\end{array}$ \\
\hline $\begin{array}{l}\text { Boniolo et al. } \\
\quad(2005)\end{array}$ & $\begin{array}{l}\text { - Coleção de artigos contendo diversos posicionamentos filosóficos sobre o tema } \\
\text { - Discussão de inúmeros estudos de caso e abordagens interdisciplinares }\end{array}$ \\
\hline $\begin{array}{l}\text { Boniolo e } \\
\text { Budinich } \\
(2005)\end{array}$ & $\begin{array}{l}\text { - } 5 \text { posicionamentos filosóficos para justificar a efetividade da matemática na física } \\
\text { - Releitura da semiótica de Peirce: Signo físico-matemático como ícone, índice e símbolo } \\
\text { - Revolução metodológica de Dirac: do ícone para o índice }\end{array}$ \\
\hline $\begin{array}{l}\text { Einstein } \\
(1956)\end{array}$ & $\begin{array}{l}\text { - Pensamento matemático puro como chave para o entendimento da natureza } \\
\text { - Método da física teórica e geometria euclidiana: valor dedutivo dos princípios físicos }\end{array}$ \\
\hline $\begin{array}{l}\text { Feynman } \\
(1985)\end{array}$ & $\begin{array}{l}\text { - Necessidade de matemática para as leis fundamentais da física } \\
\text { - Tradições babilônica e euclidiana: físico faz matemática babilônica } \\
\text { - Física } \neq \text { Matemática: físicos se interessam por casos específicos e concretos }\end{array}$ \\
\hline $\begin{array}{l}\text { Gingras } \\
(2001)\end{array}$ & $\begin{array}{l}\text { - O que a matemática fez com a física? - Abordagem histórica (1700-1900) das } \\
\text { consequências social, epistemológica e ontológica da matematização da física }\end{array}$ \\
\hline $\begin{array}{l}\text { Kline } \\
(1959)\end{array}$ & $\begin{array}{l}\text { - Matemática e o mundo físico - Diversos exemplos de como fenômenos do mundo físico } \\
\text { influenciaram o desenvolvimento de teorias matemáticas }\end{array}$ \\
\hline $\begin{array}{l}\text { Koyré } \\
(1943) \\
\end{array}$ & $\begin{array}{l}\text { - Profunda análise da física aristotélica e das razões para seu caráter não matemático } \\
\text { - Galileu e Platão: a importância da obra de Galileu para a matematização da física }\end{array}$ \\
\hline $\begin{array}{c}\text { Paty } \\
(1994)\end{array}$ & $\begin{array}{l}\text { - Necessidade de análise detalhada, caso a caso, para não cometer falsas generalizações } \\
\text { - Mecânica e cálculo diferencial, Hidrodinâmica e derivadas parciais - Das matemáticas } \\
\text { mistas à física matemática }\end{array}$ \\
\hline $\begin{array}{c}\text { Paty } \\
(1995)\end{array}$ & $\begin{array}{l}\text { - Níveis "fraco" e "forte" - Neutrino: da partícula matemática à física } \\
\text { - Incapacidade da lógica em fornecer conhecimento sobre o mundo da experiência }\end{array}$ \\
\hline $\begin{array}{l}\text { Paty } \\
(2003)\end{array}$ & $\begin{array}{l}\text { - História da noção de grandeza física: de qualidades para quantidades - Importância do } \\
\text { pensamento de Descartes - Extensão da noção de grandeza física para enfatizar aspectos } \\
\text { estruturais e relacionais }\end{array}$ \\
\hline $\begin{array}{l}\text { Poincaré } \\
(1995)\end{array}$ & $\begin{array}{l}\text { - Objetivo estético e físico da análise matemática - Importância da física para a matemática e } \\
\text { vice-versa - O poder da analogia formal }\end{array}$ \\
\hline $\begin{array}{l}\text { Steiner } \\
(1998)\end{array}$ & $\begin{array}{l}\text { - “Analogia pitagórica” como estratégia responsável pelo sucesso da física contemporânea } \\
\text { - Análise detalhada da aplicação de analogias pitagóricas em suas principais descobertas }\end{array}$ \\
\hline $\begin{array}{l}\text { Wigner } \\
(1960)\end{array}$ & $\begin{array}{l}\text { - Questiona a possibilidade de se entender a efetividade da matemática nas ciências } \\
\text { - Produz considerável impacto e estimula diversas discussões filosóficas }\end{array}$ \\
\hline $\begin{array}{l}\text { Zahar } \\
(1980)\end{array}$ & $\begin{array}{l}\text { - Razões para a matematização da física: 1) Ganho de conteúdo através da tradução para uma } \\
\text { linguagem matemática e 2) Interpretação realista das entidades matemáticas }\end{array}$ \\
\hline
\end{tabular}

Quadro 1: Resumo das principais ideias dos trabalhos analisados.

Muitos pesquisadores têm se dedicado a estudos epistemológicos visando a promover melhorias no contexto educacional e é justamente este o objetivo deste capítulo para o desenvolvimento de nossa pesquisa. A abordagem epistemológica evidenciou a complexidade e pluralidade da relação entre matemática e física. Zahar (1980), Bachelard (1995), Poincaré (1995), Feynman (1985) e Paty (1994, 1995 e 2003) destacam a importância da matemática como estruturante/constituinte de teorias físicas e refutam a visão da mesma como uma dispensável ferramenta descritiva. Gingras (2001) e Paty (2003) nos apresentam uma análise da construção histórica da legitimação do uso da matemática nas ciências físicas. Boniolo e Budinich (2005) mencionam que não é mais possível separar a física em uma parte 
matemática e outra não matemática e Steiner (1998) defende que todas as grandes descobertas da física contemporânea foram baseadas em profundas analogias matemáticas, as quais chamou de "pitagóricas". Feynman (1985) argumenta que é impossível explicar honestamente a beleza das leis da natureza de uma forma que as pessoas possam realmente sentir, sem que se tenha um profundo conhecimento de matemática.

Assim, o ensino de física deveria ser capaz de desenvolver no aluno a habilidade de utilizar a matemática como instrumento para pensar o mundo físico. Entretanto, quando voltamos nossa atenção para a forma como a matemática vem sendo abordada em aulas de física, muitas vezes detectamos uma exacerbada ênfase em seu caráter técnico. Não raro, fórmulas são apresentadas sem justificativas, problemas numéricos são resolvidos de maneira algorítmica e acrítica, expressões matemáticas não são acompanhadas de interpretações físicas, fazendo com que os estudantes criem uma aversão aos aspectos matemáticos da física por não compreenderem os motivos de tal formalização.

Essa constatação tem motivado diversos pesquisadores em ensino de física a defender uma abordagem mais "conceitual". Tendo como argumento o fato de que os alunos não gostam/entendem de matemática, fala-se em privilegiar questões teóricas, em eliminar as complicadas equações, em focar na compreensão dos fenômenos que nos cercam. Porém, diante do caráter essencialmente matemático da física evidenciado neste capítulo cabe-nos questionar: Até onde se consegue chegar com tal abordagem? Que física é essa que se pretende ensinar abrindo mão do formalismo matemático? Dessa forma, apesar de concordarmos com a crítica à ênfase no papel instrumental da matemática, não acreditamos que a solução passe por uma eliminação completa dos aspectos formais, independentemente do nível escolar que se considere.

Defendemos, portanto, que um esforço de pesquisa é necessário para romper a ilusória dicotomia "conceitual-formal" em favor de uma compreensão conceitual da física auxiliada pelo formalismo matemático. Naturalmente, tal desafio não é tarefa trivial, pois há um abismo entre as constatações epistemológicas e a realidade de uma sala de aula. Evidentemente, o levantamento histórico-filosófico realizado neste capítulo não nos fornece elementos necessários para entender como as complexas relações entre matemática e física podem ser ensinadas e aprendidas num contexto educacional. Porém, as imbricadas relações que ele aponta nos levam a acreditar que enfrentar este desafio não é somente necessário, mas inevitável. 
Certamente, esse necessário esforço sistemático de pesquisa envolve várias esferas como a formação de professores, estudo de concepções dos alunos, elaboração de materiais didáticos, discussão de currículos, entre outros. Neste trabalho, pretendemos contribuir para tal esforço propondo uma categorização de diferentes fatores associados à abordagem de relações entre matemática e física em contextos de ensino. Examinaremos como o processo de estruturação matemática de conceitos físicos é incorporado ao discurso de um professor experiente através de um estudo de caso realizado a partir da análise das aulas de um curso de eletromagnetismo ministrado por ele. Tal análise nos permitirá levantar hipóteses sobre diversos aspectos que precisam ser considerados quando se pretende ensinar os alunos a pensar matematicamente o mundo físico.

No próximo capítulo fazemos uma sucinta revisão de trabalhos que se propuseram a refletir sobre o papel da matemática no ensino de física e que, dessa forma, também foram fontes de inspiração para nossa categorização. Em seguida, apresentamos e fundamentamos a diferenciação entre habilidades técnicas e estruturais, bem como um modelo teórico que desenvolvemos para distingui-las em situações didático-pedagógicas. 


\section{2 - RELAÇÕES ENTRE FÍSICA E MATEMÁTICA NO ENSINO}

\subsection{ANÁLISE CRÍTICA DE TRABALHOS PRESENTES NA LITERATURA}

Fazemos um desserviço aos estudantes quando tratamos o entendimento conceitual separadamente do uso de representações matemáticas. (SHERIN, 2001, p. 482)

Apesar de ser um assunto de extrema relevância para o ensino de física e um dilema comumente enfrentado por qualquer professor dessa disciplina, não é possível encontrar na literatura muitas pesquisas que se dedicam a investigar as relações entre física e matemática no ensino. Nesta seção pretendemos resumir alguns dos trabalhos que se dedicaram a essa questão, identificando seus pressupostos teóricos e aspectos metodológicos. A seleção dos artigos se deu pela influência que os mesmos tiveram para o desenvolvimento de nossa pesquisa, principalmente no que diz respeito à concepção de nossas categorias de análise.

$\mathrm{O}$ assunto oferece inúmeras possibilidades de investigação. Pode-se analisar as concepções de alunos, as dificuldades que os mesmos encontram ao resolverem problemas de física que demandem o uso de matemática, as estratégias utilizadas por professores, sequências didáticas, aspectos da formação de professores, entre outras. Para os objetivos dessa seção, dividimos os artigos selecionados em três grupos: 1 - Modelagem matemática de fenômenos físicos, 2 - Compreensão de fórmulas da física e 3 - Uso de matemática na resolução de problemas de física.

Na perspectiva da modelagem matemática de fenômenos físicos, considera-se a ideia de que o estudante deva ser capaz de elaborar modelos a partir da interpretação de dados e identificação de variáveis, além de construir várias representações dos mesmos e transitar por elas. Em um dos trabalhos que possuem este enfoque, Angell et al. (2008) defendem que "o ensino de Física deve dar aos estudantes uma visão da natureza da Física como uma atividade de modelização, treinando-os para que se tornem capazes de construir e de interpretar modelos" (ANGELL et al., 2008, p. 257).

Os autores propõem que a capacidade de modelização está fortemente associada à habilidade de transitar entre cinco maneiras diferentes de representar um fenômeno físico:

i) Conceitualmente - utilizando palavras, mencionando conceitos e princípios;

ii) Graficamente - construindo um gráfico relacionando as quantidades envolvidas;

iii) Pictoricamente - desenhando esquemas e figuras que representem o fenômeno;

iv) Experimentalmente - realizando e interpretando um experimento e

v) Matematicamente - a partir de relações algébricas (fórmulas). 
Uma das conclusões deste trabalho é que a tarefa mais árdua para o estudante no processo de modelagem é transitar entre o mundo "real", aquele dos dados gerados pela experimentação, e o mundo matemático, através da tradução do fenômeno em uma equação. Para os autores, a tradução de uma representação matemática para uma gráfica pode ser complexa para muitos estudantes, mas o processo inverso é ainda mais difícil. Em nossa visão, isso pode ser causado por uma falta de conhecimento de estruturas matemáticas por parte dos estudantes. Por exemplo: os dados podem indicar uma periodicidade, mas os estudantes, sem conhecerem as funções trigonométricas, não conseguem traduzi-los em uma equação matemática.

As atividades descritas pelo artigo envolvem a tradução/interpretação de medidas em modelos e equações matemáticas. As mais simples do ponto de vista formal são aquelas que envolvem relações lineares do tipo tensão versus deformação (lei de Hooke). São propostas também situações mais complexas, como as que envolvem resistência do ar (função quadrática) ou ainda forças de natureza magnética (funções irracionais).

Sem dúvida, a capacidade de extrair uma relação matemática a partir de um conjunto de dados experimentais é extremamente importante para o físico e deve ser trabalhada no contexto educacional. Encontramos inúmeros exemplos históricos dessa tentativa de "decifrar" a lei escondida por trás dos dados. Um episódio que reflete essa postura é encontrado, por exemplo, no trabalho de Kepler, quando o mesmo, em função de sua grande habilidade matemática e crença na harmonia do universo, interpreta os dados astronômicos coletados por Thyco Brahe e deduz suas leis que descrevem o movimento dos planetas.

Entretanto, do ponto de vista epistemológico, essa postura nos dá uma impressão de que a matemática é vista como uma linguagem descritiva; como uma "caixa de ferramentas". Usando a terminologia de Paty (1995), podemos dizer que as atividades propostas fazem uso da matemática em um nível "fraco". Estamos interessados, porém, em analisar a possibilidade de se abordar o nível mais "forte" da matemática como fundamental para a estruturação teórica da física (KARAM; PIETROCOLA, 2009a; PIETROCOLA, 2010; UHDEN et. al, 2011).

Para ilustrar uma possível limitação da estratégia de modelagem, suponhamos uma atividade aparentemente semelhante às descritas por Angell et al. (2008). Imaginemos uma aula prática na qual os estudantes medem diferentes períodos de um pêndulo simples variando o comprimento do mesmo. Plotando os dados em um gráfico que relaciona o comprimento $(\mathrm{L})$ com o período $(\mathrm{T})$, é possível perceber claramente que não se trata de uma 
relação linear. Procurando na "caixa de ferramentas", pode-se descobrir que um modelo no qual L é proporcional ao quadrado de T se adequa ao fenômeno. Porém, a fórmula conhecida (para pequenas amplitudes) é $T=2 \pi \sqrt{\frac{L}{g}}$. A pergunta difícil de ser respondida é a seguinte: como obter o número $\pi$ a partir da análise dos dados? Esse número não é encontrado na natureza, ele não pertence ao mundo real! Aliás, o pêndulo descrito pela equação também não existe! Assim, parece-nos que uma estratégia de ensino unicamente centrada em "adivinhar" as funções matemáticas que descrevem um determinado fenômeno físico, sem uma discussão pertinente sobre modelos teóricos e princípios impostos pela razão, tende a transmitir uma ideia distorcida, ou pelo menos restrita, das possibilidades de se utilizar o pensamento matemático para compreender a natureza.

Outro aspecto que é de fundamental importância para essa apreensão matemática do mundo físico é a compreensão de fórmulas físicas. Não raro, muitos estudantes substituem cegamente dados em equações físicas sem qualquer compreensão conceitual de seus cálculos. Dessa forma, é imprescindível pensar em estratégias didáticas que propiciem aos estudantes a habilidade de "ler" equações e interpretar seus significados.

Um influente trabalho que visa a compreender/definir "Como estudantes entendem equações da física" é a tese de Bruce Sherin (2001). Sherin entrevistou 5 pares de estudantes de física de nível superior durante a resolução de 7 problemas não tradicionais criados para fomentar discussões conceituais sobre o significado de equações físicas. A principal ideia defendida por Sherin é a de que os estudantes aprendem a entender equações da física em termos de formas simbólicas, as quais estão associadas a ideias simples e fundamentais. Num total de 21 categorias divididas em 7 grupos, cada forma simbólica é relacionada a um esquema conceitual e possui um padrão de símbolos em uma equação.

Analisemos dois exemplos para ilustrar como funciona a categorização proposta por Sherin. Uma forma simbólica pertencente ao grupo Termos que competem é chamada de balanceamento. Ela é identificada quando duas influências, cada uma associada a um lado da equação, são balanceadas de tal forma que o sistema está em equilíbrio. Seu símbolo padrão é representado por $\square=\square$ e o uso de palavras como "estão balanceadas" ou "em equilíbrio" são fortes indícios dessa estrutura de pensamento. Em um dos problemas propostos para os estudantes, é necessário igualar a força de resistência do ar à força peso para determinar a velocidade terminal. A equação $F_{R}=P$ seria interpretada como forças competindo e atingindo o equilíbrio, representando, portanto, essa noção mais geral denominada balanceamento. 
Outra forma simbólica, pertencente ao grupo Termos como quantidades, é denominada Base \pm mudança e tem como símbolo padrão $\square \pm \Delta$. Quando identificada, essa categoria representa uma noção geral de que dois termos contribuem para o total, sendo que um é o valor base (ou inicial) e o outro é a variação. Dependendo da interpretação dos estudantes, as equações $\mathrm{p}_{1}=\mathrm{p}_{2}+\mu \mathrm{gh}, \mathrm{x}_{\mathrm{f}}=\mathrm{x}_{\mathrm{o}}+\mathrm{vt}$ ou $\mathrm{T}_{\mathrm{f}}=\mathrm{T}_{\mathrm{i}}+\mathrm{Q} / \mathrm{mc}$ poderiam ser identificadas nessa categoria. De maneira geral, Sherin defende que a compreensão/identificação dessas estruturas fundamentais por trás de equações físicas indica um entendimento profundo do significado das mesmas.

Refletindo sobre como abordar o desafio da compreensão de fórmulas em contextos de ensino, Bagno et al. (2008) desenvolveram um interessante instrumento, o qual é apresentado no Quadro 2.

\section{A atividade: "Interpretação de uma fórmula"}

\section{Trabalho individual}

1. Identifique as componentes da fórmula, utilizando a tabela a seguir.

\begin{tabular}{|c|c|c|}
\hline Componente & Significado físico & \\
\hline 2. Mostre a equivalência de unidades em ambos os membros da equação.
\end{tabular}

3. Especifique as condições de aplicação da fórmula.

4. Descreva a relação entre os componentes da fórmula a partir de um gráfico.

5. Analise casos especiais e limites de aplicação da fórmula utilizando a tabela a seguir:

\begin{tabular}{|l|l|l|}
$\mathrm{O}$ caso especial & A forma da fórmula nesse caso & $\mathrm{O}$ significado da fórmula nesse caso \\
\hline
\end{tabular}

6. Interprete o significado de termos (multiplicados ou divididos)

7. Elabore uma explicação verbal para a fórmula.

Trabalho em grupo

Discuta em grupo cada uma das questões acima. Se julgar necessário, altere sua resposta.

Discussão na classe

Após a discussão na classe, preencha novamente os itens acima.

Tarefa de casa

1. Essa fórmula faz sentido para você? Por que (ou por que não)?

2. Descreva uma situação do dia-a-dia ou um problema físico no qual essa fórmula se aplica.

3. Descreva um caso especial do cenário ou do problema físico acima.

4. Que mudanças seriam necessárias no cenário/problema do item 3 para que essa formula não pudesse mais ser aplicada?

Reflexão individual

1. O que você aprendeu com a atividade?

2. No que a discussão em grupo acrescentou para seu entendimento?

3. No que a discussão na classe acrescentou para seu entendimento?

4. O que ainda não está claro para você? 
A ideia principal dessa "ferramenta de aprendizagem" é propor questões conceituais sobre fórmulas físicas, como identificar a grandeza física associada a cada um de seus termos, analisar casos particulares e restrições, e escrever o significado global da fórmula usando as próprias palavras. A atividade se inicia quando os alunos recebem uma determinada fórmula e respondem às questões propostas, primeiro individualmente e depois em grupo.

Os resultados dessa atividade levantaram os erros mais comuns cometidos pelos estudantes. Em relação à manipulação de unidades, 64\% dos estudantes (amostra de 206) ou não responderam ou as manipularam incorretamente. Um exemplo de manipulação incorreta para a fórmula $\mathrm{x}_{\mathrm{f}}=\mathrm{x}_{\mathrm{o}}+\mathrm{v}_{\mathrm{o}} \cdot \mathrm{t}+\frac{1}{2}$ a.t $\mathrm{t}^{2}$, por exemplo, foi o seguinte: $[$ Metro $]=[$ Metro $]+$ $\frac{[\text { Metro }]}{2}$. Em relação às condições de aplicação, foi possível notar que a maioria dos estudantes (42\%) escreveu condições simplesmente técnicas, como "usamos essa fórmula quando temos que calcular uma variável e todas as outras são conhecidas”. Essa postura representa uma visão da fórmula como um algoritmo de cálculo e evidencia os estilos de problemas que os estudantes estão mais acostumados.

Para a questão que solicitava uma explicação verbal para a fórmula, $42 \%$ dos alunos não responderam. Dos 58\% restantes, $31 \%$ fizeram apenas uma tradução da fórmula em palavras; $\Delta \mathrm{x}=\mathrm{v} . \Delta \mathrm{t}$ seria explicada verbalmente por "deslocamento é igual à velocidade vezes o intervalo de tempo". Isso reflete a dificuldade de interpretação das fórmulas e o ineditismo da tarefa para os alunos.

Os trabalhos de Sherin (2001) e Bagno et al. (2008) trazem importantes contribuições para a pesquisa sobre o entendimento de fórmulas no ensino de física. Entretanto, um aspecto fundamental relacionado a uma compreensão mais profunda não foi abordado por ambos. Trata-se da demonstração de fórmulas a partir de princípios físicos. Consideremos, por exemplo, a fórmula que representa a lei da refração da luz (lei de Snell-Descartes $\frac{\sin \theta_{1}}{\operatorname{sen} \theta_{2}}=\frac{v_{1}}{v_{2}}$ ). O que significa entender essa fórmula? Além dos itens abordados no questionário de Bagno et al. (2008) ou da identificação de uma forma simbólica conforme Sherin (2001), a capacidade de demonstrar essa relação a partir de princípios físicos como os de Fermat e Huygens, ou ainda pela aplicação das equações de Maxwell e condições de contorno na superfície que separa os meios, revela uma compreensão mais profunda de seu significado. Apesar da falta de consenso sobre o que significa entender uma equação física, defendemos que o processo de demonstrar uma fórmula a partir de princípios físicos pode ser 
extremamente enriquecedor e elucidar aspectos fundamentais da relação entre matemática e física.

Naturalmente, é preciso investigar as possibilidades de compreensão desse processo em função do conteúdo específico e do nível escolar dos estudantes. A equação horária do movimento uniformemente variado, $\mathrm{x}_{\mathrm{f}}=\mathrm{x}_{\mathrm{o}}+\mathrm{v}_{\mathrm{o}} \cdot \mathrm{t}+\frac{1}{2} \mathrm{a} \cdot \mathrm{t}^{2}$, por exemplo, pode ser deduzida por integração das relações entre posição, velocidade e aceleração, admitindo essa última como constante. Porém, caso os estudantes não dominem o cálculo diferencial e integral, é possível obter essa fórmula a partir da área do gráfico $\mathrm{v}$ x $\mathrm{t}$. Voltaremos à discussão sobre a demonstração de fórmulas na sequência da tese.

O terceiro grupo de artigos analisados envolve pesquisas que investigaram o raciocínio utilizado por estudantes ao resolverem problemas de física e a função da matemática nesse processo. Descreveremos de maneira sucinta os recentes trabalhos de Tuminaro e Redish (2007) e Bing e Redish (2009). Ambos usaram uma metodologia semelhante: gravaram estudantes resolvendo problemas e discutindo seus raciocínios em pequenos grupos. O objetivo central desses artigos é levantar/categorizar atitudes e estilos de pensamento diferenciados dos estudantes.

Em Tuminaro e Redish (2007), uma estrutura teórica é proposta com o objetivo de analisar e descrever o pensamento matemático de estudantes universitários (primeiros anos) ao resolverem problemas de física. Essa estrutura é uma tentativa de responder a duas questões: Quais são as ferramentas cognitivas envolvidas no pensamento matemático utilizado na física? Por que os estudantes cometem os erros que cometem quando usam matemática na física?

A ferramenta teórica de análise é composta por seis estruturas hierárquicas (Jogos Epistêmicos - Epistemic Games), as quais descrevem o raciocínio apresentado pelos alunos durante a resolução de problemas de física. Segundo Tuminaro e Redish (2007), essas estruturas estão associadas a um conjunto de regras e estratégias que guiam o questionamento dos estudantes. A metáfora dos jogos faz alusão a um processo que segue certas regras; que tem um começo, meio e fim. Assim, na interpretação dos autores, quando os alunos resolvem os problemas, comportam-se como se estivessem seguindo as regras de um jogo.

Nesse artigo são propostos seis jogos epistêmicos. O mais simples (e intelectualmente "pobre") é chamado Recursive Plug-and-Chug e representa situações nas quais os estudantes substituem cegamente quantidades em fórmulas físicas obtendo respostas numéricas sem as interpretar conceitualmente. Para cada categoria, é proposto um fluxograma que ilustra as 
etapas pelas quais os estudantes passam quando escolhem este "jogo". A Figura 3 ilustra o fluxograma do jogo Recursive Plug-and-Chug:

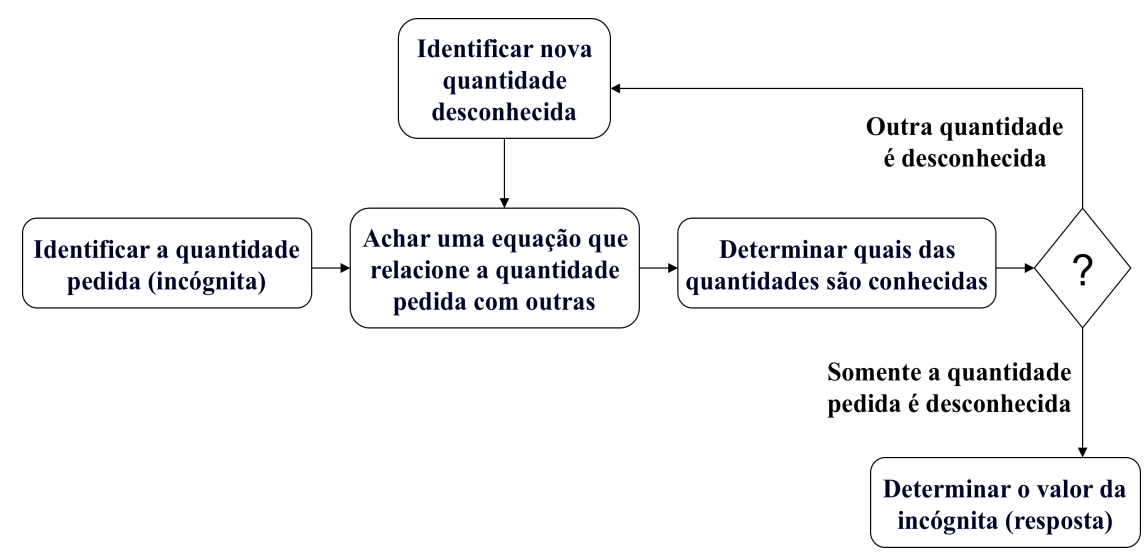

Figura 3: Jogo epistêmico Recursive Plug-and-Chug (TUMINARO; REDISH, 2007, p. 8).

De acordo com as suas expectativas em relação ao que deve ser feito para resolver o problema, os estudantes escolhem diferentes jogos. Tuminaro (2004) divide os seis jogos epistêmicos identificados em três grupos associados à expectativas/atitudes diferenciadas, conforme esquematizado no quadro a seguir.

\begin{tabular}{|c|c|c|}
\hline Procura de equações & Significando qualitativamente & Significando quantitativamente \\
\hline Recursive plug-and-chug & Explicando o mecanismo físico & Interpretando a matemática \\
\hline Transliteração para a matemática & Análise pictórica & Pensando matematicamente \\
\hline
\end{tabular}

Quadro 3: Jogos epistêmicos divididos em três grupos (TUMINARO, 2004, p. 83).

Essa classificação nos parece bastante coerente e passível de generalização. Como estamos interessados em investigar o uso da matemática como instrumento de pensamento, focamos nosso olhar na terceira coluna. De acordo com essa classificação, o jogo epistêmico mais complexo é o Mapping Meaning to Mathematics ("Pensando matematicamente") e envolve a habilidade de traduzir uma estória conceitual da física em entidades matemáticas e relacioná-las com a mesma estória. A Figura 4 ilustra o fluxograma desse jogo:

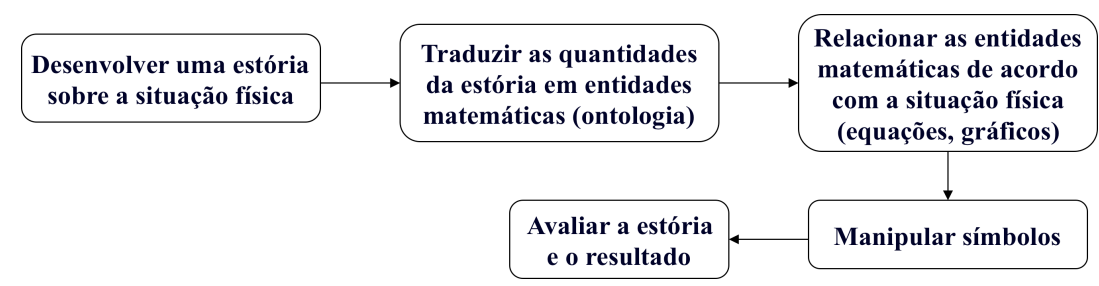

Figura 4: Jogo epistêmico Mapping Meaning to Mathematics (TUMINARO; REDISH, 2007, p. 6).

Este foi reconhecidamente o menos "jogado" e a mencionada tradução foi a tarefa mais difícil para os estudantes que participaram desta pesquisa. $\mathrm{O}$ episódio citado como exemplo deste jogo está relacionado com o seguinte problema: 
Na figura abaixo três partículas carregadas estão alinhadas e separadas por uma distância d. As cargas $\mathrm{q}_{1}$ e $\mathrm{q}_{2}$ estão fixas. A carga $\mathrm{q}_{3}$ é livre para se mover, mas está em equilíbrio (resultante eletrostática que atua sobre ela é nula). Se a carga $\mathrm{q}_{2}$ tem o valor $\mathrm{Q}$, qual deve ser o valor da carga $\mathrm{q}_{1}$ ?

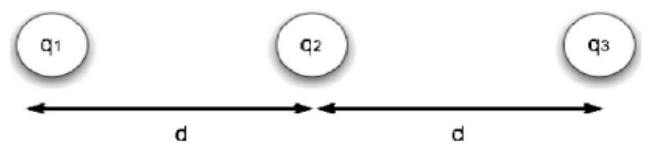

Figura 5: Problema das três cargas (TUMINARO; REDISH, 2007, p. 19).

Três alunos discutem suas estratégias de resolução. Selecionamos um trecho dessa transcrição e o apresentamos a seguir:

A1: Certo, então, como q3 não está se movendo, as duas forças que nela atuam são iguais. A que empurra e a que puxa. Logo, a $F$ de $q 2$ em q3 é igual a $F_{q 2 \rightarrow q 3}=\frac{K Q q 3}{d^{2}}$. E, então a $F$ de q1 em q3 é igual a $F_{q 1 \rightarrow q 3}=\frac{K x Q q 3}{4 d^{2}}$ porque a distância é duas vezes maior, logo será $4 d$ ao quadrado.

A1: Daí, eu usei $x Q$ para a carga em q1, porque sabemos que de certa forma ela estará relacionada à carga $Q$, nós só precisamos achar o fator que a relaciona com ela. Então, eu igualei as duas, cancelei q3 e K e o d ao quadrado e isso resultou em x igual a 4. Então, xq é igual a $4 Q$.

A2: Bem, não deveriam ser iguais e opostas?

A1: Sim, você poderia colocar o sinal negativo.

A3: Eu não usei a equação de Coulomb, eu só... mas foi semelhante a isso.

A2: Esse é um ótimo jeito de demonstrar.

A1: Posso ganhar o meu A agora?

Trecho extraído de Tuminaro e Redish (2007, p. 16).

É impossível não reconhecer que o raciocínio de A1 é elaborado e original. Interessante é a maneira como ele lida com a situação, "ignorando" os sinais das cargas no cálculo, e o recurso de chamar a carga q1 de xQ. Isso demonstra um uso consciente da linguagem matemática e não uma cega substituição de valores em uma fórmula. Podemos, porém, questionar sobre as limitações do problema proposto. Parece-nos um exercício típico, um problema fechado, tão criticado por pesquisadores em ensino de física. A fórmula de Coulomb, por exemplo, é fornecida como dado? Foi previamente deduzida experimentalmente? Formalmente?

Para aprofundar a discussão, podemos levantar outros questionamentos: por que a força elétrica é inversamente proporcional ao quadrado da distância? Qual a razão da semelhança entre a fórmula de Coulomb e a lei da atração universal de Newton? É possível enunciar a lei de Coulomb de outra maneira? Com outro formalismo? Perguntas dessa natureza estão relacionadas ao desenvolvimento de habilidades estruturais, as quais serão abordadas na próxima seção. 
Com algumas semelhanças metodológicas, mas com uma amostra de estudantes de nível mais avançado, Bing e Redish (2009) propõem um mecanismo (Epistemological Framig) que tem como objetivo modelar o pensamento dos estudantes e examinar as garantias/justificativas oferecidas pelos mesmos quando utilizam a matemática para resolver problemas de física. Os autores alertam que muitas coisas distintas podem ser consideradas como "usar matemática na física". Em Bing (2008), uma situação hipotética é apresentada com o objetivo de ilustrar esse fato. Por propiciar uma rica discussão e exemplificar as quatro categorias propostas pelo trabalho, vamos descrevê-la sucintamente.

A cena se passa em um departamento de física. É início de semestre e existem quatro turmas diferentes para a cadeira de Física Geral 1. Na semana que antecede o início das aulas, os quatro professores (Alfa, Beta, Gama e Delta) se reúnem para discutir vários itens como planejamento, avaliações, etc. Todos eles são extremamente dedicados e comprometidos com o aprendizado de seus alunos. Os professores concordam que a matemática é muito importante para a física e decidem colocar uma ênfase no pensamento matemático durante suas aulas. Logo no início do curso, a equação horária do movimento uniforme $\left(\mathrm{x}_{\mathrm{f}}=\mathrm{x}_{\mathrm{o}}+\right.$ $\mathrm{v} . \Delta \mathrm{t})$ deverá ser abordada. Após a reunião, cada professor retorna a sua sala e inicia a preparação do que será tratado na primeira aula.

$\mathrm{O}$ professor Alfa olha atentamente para a equação $\mathrm{x}_{\mathrm{f}}=\mathrm{x}_{\mathrm{o}}+\mathrm{v} . \Delta \mathrm{t}$ e conclui: essa fórmula representa um esquema de cálculo. Se o móvel parte da posição $\mathrm{x}_{\mathrm{o}}=3 \mathrm{~m}$ e mantém uma velocidade $\mathrm{v}=4 \mathrm{~m} / \mathrm{s}$ durante um tempo $\Delta \mathrm{t}=2 \mathrm{~s}$, então a equação nos diz como calcular a posição final $\mathrm{x}_{\mathrm{f}}$. Basta fazer $3+4 .(2)=11 \mathrm{~m}$. O professor Alfa prepara outros exemplos desse tipo para sua aula com o objetivo de rever algumas técnicas básicas da álgebra. Ele pretende mostrar que, seguindo este esquema e dominando técnicas algébricas, é possível manipular a expressão e isolar, por exemplo, o tempo. Basta "subtrair $\mathrm{x}_{0}$ de ambos os membros e dividilos por v".

Do outro lado do corredor, o professor Beta tem uma reação diferente quando pensa em abordar essa equação com seus alunos. Ele olha para a equação e se dá conta do quão apropriadamente a matemática serve como modelo para um sistema físico. O Dr. Beta pretende mostrar a seus alunos como $\mathrm{x}_{\mathrm{f}}=\mathrm{x}_{\mathrm{o}}+\mathrm{v} . \Delta \mathrm{t}$ expressa uma ideia física. Velocidade é quanto o corpo se move em uma unidade de tempo (um segundo, por exemplo). A quantidade $\Delta$ t representa o intervalo de tempo (em segundos, por exemplo). Logo, ao multiplicarmos a velocidade pelo intervalo de tempo, descobrimos qual foi o deslocamento do móvel. Empolgado com seu raciocínio, o professor Beta pensa em escrever essa equação em termos 
conceituais: "a posição final do móvel é igual à sua posição inicial somada ao seu deslocamento".

Algumas salas ao lado, o professor Gama tem outra visão para a abordagem da respectiva fórmula: "Ah, o mais importante de $\mathrm{x}_{\mathrm{f}}=\mathrm{x}_{\mathrm{o}}+\mathrm{v} . \Delta \mathrm{t}$ é que se trata de uma regra conveniente para a cinemática! Existem outras regras importantes como $\mathrm{x}_{\mathrm{f}}=\mathrm{x}_{\mathrm{o}}+\mathrm{v}_{\mathrm{o}} \cdot \mathrm{t}+\frac{1}{2}$ a.t $\mathrm{t}^{2}$ ou $\mathrm{v}_{\mathrm{f}}^{2}=\mathrm{v}_{\mathrm{o}}^{2}+2 . \mathrm{a} . \Delta \mathrm{x}$. Vou apresentá-las e conversar com meus alunos sobre a importância de se aplicar a regra correta para cada problema. Por exemplo, $\mathrm{x}_{\mathrm{f}}=\mathrm{x}_{\mathrm{o}}+\mathrm{v}$. $\Delta \mathrm{t}$ só é válida se a aceleração for nula”. Para concluir sua exposição, o professor Gama planeja comentar como a matemática fornece artifícios convenientes para poupar o tempo do físico. $\mathrm{Na}$ prática, ninguém começa pelos princípios absolutamente fundamentais toda vez que resolve um problema. Os físicos gostam de cortar caminhos e as fórmulas os ajudam a fazer isso. Nesse sentido, a matemática é poderosa porque proporciona esses atalhos.

O professor Delta pensa em um enfoque ainda diferente dos outros para sua aula: "A grande vantagem de se usar matemática na física é que é possível desenvolver uma rede de ideias interconectadas. A matemática fornece uma estrutura formal, uma lógica que conecta profundamente diferentes aplicações. Vou mostrar a meus alunos como $\mathrm{x}_{\mathrm{f}}=\mathrm{x}_{\mathrm{o}}+\mathrm{v} . \Delta \mathrm{t}$ se encaixa em uma rede mais ampla de ideias matemáticas”. Dr. Delta pretende mostrar como esta fórmula pode ser deduzida da definição de velocidade média $\mathrm{v}_{\mathrm{m}}=\frac{\Delta x}{\Delta t}$. Ele decide chamar a atenção para o fato de que existe uma estrutura "final é igual à inicial mais variação" que também é encontrada em outras fórmulas como $\mathrm{v}_{\mathrm{f}}=\mathrm{v}_{\mathrm{o}}+\mathrm{a} . \Delta \mathrm{t}$. Voltando ainda mais na essência, ele percebe que $\mathrm{x}_{\mathrm{f}}=\mathrm{x}_{\mathrm{o}}+\mathrm{v} \cdot \Delta \mathrm{t}$ é solução de um conjunto de equações diferencias do tipo $\frac{d^{2} x}{d t^{2}}=k$, para o caso particular em que $\mathrm{k}=0$.

Os quatro estereótipos representam as categorias escolhidas a partir da análise dos dados (gravações de alunos resolvendo problemas e debatendo seus métodos) dessa pesquisa. Os episódios analisados por Bing e Redish (2009) exemplificam esses estilos de pensamento e evidenciam momentos em que os alunos migram de um estilo para outro.

O primeiro estilo de pensamento é chamado Calculation (Rotina de Cálculo). Quando o utiliza, o aluno demonstra uma confiança na estrutura do formalismo matemático e aplica um conjunto de regras algorítmicas. Nesse caso, parece haver uma crença de que seguir rigorosamente uma sequência de etapas encadeadas logicamente deve fornecer um resultado confiável. Ao aplicar este tipo de raciocínio, o estudante faz um uso intenso de símbolos e raramente menciona o significado físico dos mesmos. Trata-se da conhecida atitude de se 
"deixar levar pelo formalismo" ou ainda, citando uma expressão muito usada pelo professor analisado em nossas gravações, "basta rodar a manivela".

O segundo estilo é chamado de Physical Mapping (Interpretação Física). Nele, os alunos baseiam seus argumentos apontando a qualidade da relação entre a estrutura matemática e a situação física. A crença subjacente é a seguinte: se a matemática está de acordo com o mundo físico, podemos confiar nela. Modelos mecânicos (a luz enrosca nos elétrons), diagramas e gestos são indicadores deste tipo de raciocínio.

Em alguns episódios, os pesquisadores encontraram momentos em que os estudantes fazem afirmações sem apresentar justificativas, evocando um tipo de autoridade para resultados matemáticos (ou físicos). Esse foi identificado como um terceiro estilo de pensamento chamado Invoking Authority (Invocando Autoridade). A ideia central nesse estilo é que informações oriundas de fontes autoritárias (tabelas, livros-texto, professor, etc) são aceitas como justificativas para a resolução de problemas. Há um entendimento de que resolver cada problema a partir de seus princípios iniciais é uma "perda de tempo". Consulta de valores em tabelas (o momento de inércia da esfera é $2 / 5 . \mathrm{MR}^{2}$ ), menção a regras ou teoremas matemáticos ("pela regra da cadeia"; "aplicando o teorema de Pitágoras"), são atitudes que demonstram esse tipo de raciocínio.

O quarto estilo de pensamento é denominado Mathematical Consistency (Consistência Matemática). Quando classificados nesta categoria, os alunos demonstram compreender que uma estrutura matemática pode ser utilizada para modelar situações físicas diferentes. Identificar uma consistência com outra maneira "mais familiar" é uma possível fonte de justificação. Em fórmulas aparentemente desconexas como $x(t)=x_{0}+v_{o} t+a t^{2} / 2$ e $\mathrm{q}(\mathrm{t})=\mathrm{A} \cdot \cos (\omega \mathrm{t}+\theta)$ por exemplo, existem analogias formais profundas evidenciadas na semelhança das equações diferenciais que as geraram.

Os quatro estilos identificados são resumidos no quadro a seguir.

\begin{tabular}{|c|c|c|c|c|}
\hline & $\begin{array}{c}\text { Rotina de } \\
\text { Cálculo }(\alpha)\end{array}$ & $\begin{array}{l}\text { Interpretação } \\
\text { Física }(\beta)\end{array}$ & $\begin{array}{c}\text { Invocando } \\
\text { Autoridade }(\gamma)\end{array}$ & $\begin{array}{c}\text { Consistência } \\
\text { Matemática }(\delta)\end{array}$ \\
\hline $\begin{array}{c}\text { Justificativa } \\
\text { Oferecida }\end{array}$ & $\begin{array}{l}\text { Seguir corretamente } \\
\text { etapas algorítmicas } \\
\text { leva a um resultado } \\
\text { confiável }\end{array}$ & $\begin{array}{l}\text { Adequação entre } \\
\text { matemática e } \\
\text { interpretações } \\
\text { físicas comprovam o } \\
\text { resultado }\end{array}$ & $\begin{array}{l}\text { Citar uma regra ou } \\
\text { resultado autoritário } \\
\text { dá crédito }\end{array}$ & $\begin{array}{l}\text { Similaridade ou } \\
\text { conexão lógica com } \\
\text { outra ideia } \\
\text { matemática serve } \\
\text { como validação }\end{array}$ \\
\hline $\begin{array}{c}\text { Indicadores } \\
\text { Comuns }\end{array}$ & $\begin{array}{l}\text { * Foco na correção } \\
\text { técnica } \\
\text { * Encadeamento } \\
\text { matemático: } \\
\text { "preciso disso para } \\
\text { ter aquilo" }\end{array}$ & $\begin{array}{l}* \text { Menção a modelos } \\
\text { materiais } \\
* \text { Uso de figuras e } \\
\text { diagramas } \\
* \text { Enfase em gestos } \\
\text { demonstrativos }\end{array}$ & $\begin{array}{l}\text { * Citar uma regra de } \\
\text { maneira dogmática } \\
* \text { Mencionar fontes } \\
\text { autoritárias (tabelas, } \\
\text { teoremas, etc) }\end{array}$ & $\begin{array}{l}* \text { Analogia com } \\
\text { outra ideia } \\
\text { matemática } \\
\text { * Categorização }\end{array}$ \\
\hline
\end{tabular}

Quadro 4: Adaptado de Bing e Redish (2009, p. 10). 
Os autores fazem questão de enfatizar que os estilos presentes nos raciocínios dos alunos e exemplificados pelos quatro professores hipotéticos, ilustram aspectos importantes no que diz respeito a usar matemática na física e que suas abordagens estão igualmente corretas. De acordo com Bing e Redish (2009), todos elas enfatizam um aspecto do pensamento matemático que é frequentemente útil para os físicos e não se deve pensar que haja uma hierarquia entre os enfoques.

Porém, parece-nos que o enfoque do professor Alfa é excessivamente técnico e a matemática assume, nessa visão, um mero caráter ferramental. O professor Gama clama uma autoridade que em certos momentos pode até ser justificada, mas acreditamos que seja necessária uma espécie de "autorização" para se comportar de tal maneira. A aplicação do teorema de Pitágoras para alguém que já teve uma experiência significativa de compreender sua dedução, por exemplo, é completamente diferente daqueles que sempre o encararam como uma regra "mágica". É preciso estar ciente dos perigos inerentes a se fazer juízos de valor. Entretanto, sendo coerente com os propósitos de nossa pesquisa, devo confessar que, na possibilidade de escolha, seria um dos alunos do professor Delta.

Apesar de não ter sido o foco desse trabalho, acreditamos que as quatro caricaturas presentes na estória podem fornecer um interessante instrumento para a análise da maneira como os professores de física abordam a matemática em suas aulas. Podemos conjecturar que, na prática, nenhum professor se encaixaria em somente uma dessas categorias. $\mathrm{O}$ mais provável é que haja um espectro, algo semelhante às zonas de um perfil epistemológico, conforme proposto por Bachelard ([1940], 1974). Em uma mesma aula, o professor pode transitar entre esses quatro aspectos. Certamente, isso também deve ser dependente do conteúdo físico específico e do nível de escolaridade dos estudantes. Essa hipótese será considerada em profundidade no estudo de caso que realizamos a partir da análise das aulas de um professor experiente e diferenciado.

De maneira geral, uma revisão bibliográfica dos principais trabalhos que investigaram as relações entre física e matemática num contexto de ensino nos mostra duas lacunas que pretendemos preencher com esta pesquisa. Primeiramente, não se encontra considerações históricas e/ou epistemológicas sobre o tema em praticamente nenhum dos trabalhos. Temos a impressão que os autores consideram que o papel da matemática na física é bem conhecido e consensual. A ausência de um posicionamento filosófico faz com que diferentes aspectos e especificidades dessa complexa relação não sejam tratados com a devida atenção. A importância do estudo histórico-filosófico para nossa pesquisa ficará evidente na 
categorização proposta para analisar diversos aspectos do caráter matemático da física presentes em aulas ministradas em nível superior.

Em segundo lugar, poucos são os trabalhos que investigaram essa questão sob a ótica do ensino. Naturalmente, as visões ingênuas e distorcidas encontradas em pesquisas sobre concepções de estudantes são fortemente influenciadas pela maneira como as relações entre matemática e física foram tratadas nas aulas que os mesmos tiveram. Assim, é imprescindível pensar em estratégias instrucionais que visem ampliar a visão dos estudantes sobre essas relações, abordando diversos aspectos desde os mais instrumentais/técnicos até os mais estruturais. O estudo de caso realizado fornece vários exemplos de possíveis abordagens num contexto de ensino, principalmente em relação ao papel da matemática como instrumento de pensamento para a física. Na próxima seção fundamentamos a distinção entre caráter técnico e estrutural da matemática no ensino de física. 


\subsection{HABILIDADES TÉCNICAS E ESTRUTURAIS}

As operações com expressões simbólicas são essenciais para as ciências físicas, mas na realidade elas pertencem somente à matemática. Todas as conexões com o fenômeno [físico] original podem ser deixadas de lado pela mente durante essas operações, e o matemático que as elabora pode ter dúvidas se seus resultados serão aplicados em geometria dos corpos rígidos, hidrostática ou eletricidade. Mas como estamos engajados no estudo da Filosofia Natural, devemos nos esforçar para formular nossos cálculos de tal maneira que cada passo possa ser interpretado fisicamente. Dessa forma, desenvolveremos habilidades muito mais úteis do que aquelas associadas a cálculos sem significado: a aplicação de princípios e a interpretação dos resultados (MAXWELL [1860] in HARMAN, 1990, p. 672).

Essa citação foi extraída de uma aula inaugural proferida por Maxwell no King’s College em 1860. A mensagem é clara: os cálculos têm importância fundamental para a física (filosofia natural naquele contexto), porém eles devem sempre estar vinculados à aplicação de princípios e à interpretação física de cada uma de suas etapas. De maneira semelhante, Pietrocola (2002) defende que "não se trata apenas de saber matemática para poder operar as teorias físicas que representam a realidade, mas saber apreender teoricamente o real através de uma estruturação matemática” (PIETROCOLA, 2002, p. 111).

Refletindo sobre possíveis maneiras de se usar matemática em física - tanto do ponto de vista epistemológico como didático-pedagógico - parece-nos plausível considerar a existência de uma dicotomia (talvez dualidade seja mais apropriado) entre duas maneiras distintas de pensar/agir (modus operandi): uma que trata a matemática de maneira técnica (instrumental/procedimental), vazia de significado físico, e outra estrutural (relacional/organizacional), sempre associada a interpretações físicas como recomenda Maxwell. Em trabalhos recentes (KARAM; PIETROCOLA, 2009a, 2009b; PIETROCOLA, 2010; UHDEN et al., 2011), consideramos essa possibilidade do ponto de vista do ensino e aprendizagem propondo uma diferenciação entre habilidades técnicas e estruturais ${ }^{23}$. De maneira semelhante, Pospiech (2006) defende que os estudantes devem reconhecer que a matemática é tanto uma ferramenta valiosa para a física, como tem um fundamental papel para a estruturação teórica desta ciência. Nesta seção e na próxima vamos explorar essa diferenciação com profundidade.

A primeira categoria refere-se ao campo mais "interno" da matemática, mais especificamente ao domínio instrumental de algoritmos, regras, fórmulas, gráficos, equações,

\footnotetext{
${ }^{23}$ Vale destacar novamente a relação estrutural (produto) e estruturante (processo), e ressaltar que ambas estão contempladas categoria habilidades estruturais. 
etc. Tradicionalmente, essas habilidades são desenvolvidas no contexto do ensino da matemática como disciplina e nem sempre estão relacionadas com qualquer tipo de aplicação e/ou situação-problema. Na pesquisa realizada por Bing e Redish (2009), essa postura foi chamada de "Rotina de Cálculo" e ilustrada pelo enfoque dado pelo professor Alfa. Em Paty (1995) esse caráter instrumental foi identificado como nível "fraco" de uso da matemática em física. $\mathrm{Na}$ aula inaugural de Maxwell, o físico inglês destaca que todas as conexões com o fenômeno físico original são deixadas de lado pela mente quando se opera com matemática de maneira procedimental.

Não raro, professores de física vinculam o insucesso de seus estudantes à falta dessas habilidades técnicas e frequentemente reclamam que seus estudantes não sabem: "dividir com vírgula, isolar uma variável, construir um gráfico, resolver uma equação, calcular um determinante, etc, etc, etc...". O tão comum bordão "a física do problema já acabou, daqui para frente é só matemática" também ilustra uma visão meramente operacional. Além disso, muitos educadores que defendem uma abordagem conceitual da física criticam, com razão, o excessivo foco no aprendizado de procedimentos matemáticos presente em livros didáticos.

De fato, a capacidade de manipular tecnicamente muitas das "ferramentas matemáticas" (habilidades técnicas) é necessária para um bom desempenho dos estudantes na disciplina de física (HUDSON; MCINTIRE, 1977; HUDSON; LIBERMAN, 1982). Entretanto, apesar de necessária, essa condição está longe de ser suficiente, ou seja, não é possível afirmar que os estudantes que as dominam serão bem sucedidos em física. Ao realizarem testes para medir o conhecimento técnico de fundamentos de Álgebra e Trigonometria no início de um curso de Física Básica, Hudson e McIntire (1977) constataram que o mesmo serviu como um instrumento que possibilitou "a previsão do fracasso, mas não a garantia do sucesso" dos estudantes (HUDSON; MCINTIRE, 1977, p. 470).

Essa insuficiência é justificada por Redish (2005) quando o mesmo sustenta que "utilizar matemática em ciências (principalmente em física) não é somente fazer matemática" (p. 1). Segundo o autor, o uso da matemática na física tem um objetivo diferente, pois se destina a representar sistemas físicos, ao invés de expressar relações abstratas. Além disso, Redish (2005) argumenta que a matemática utilizada na física possui uma semiótica diferente: "é quase como se a "linguagem" da matemática que se usa na física fosse diferente daquela ensinada pelos matemáticos" (REDISH, 2005, p. 1). Como físico, o autor fornece os seguintes argumentos para fundamentar essas diferenças:

- Nós [os físicos] damos nomes diferentes às constantes e às variáveis;

- Nós ocultamos/ofuscamos a distinção entre constantes e variáveis; 
- Nós utilizamos símbolos para representar ideias em vez de quantidades;

- Nós misturamos as "coisas da Física" com "coisas da Matemática" quando interpretamos as equações;

- Nós atribuímos significado aos nossos símbolos; (REDISH, 2005, p. 2).

Alguns problemas são apresentados por Redish (2005) com o objetivo de exemplificar situações propícias para lidar com essas diferenças. Dentre eles, encontramos o clássico experimento do carrinho de Fletcher, no qual tradicionalmente deve-se calcular a aceleração do sistema e a tração no fio que une os blocos (Fig. 6):

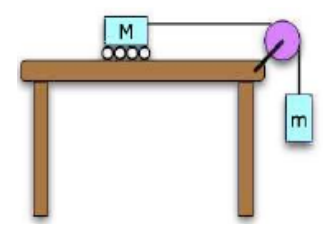

Figura 6: Problema do carrinho de Fletcher (REDISH, 2005, p. 5).

$\mathrm{O}$ autor propõe que se solicite aos estudantes que calculem a aceleração do sistema para casos extremos/limites como $\mathrm{m} \rightarrow 0, \mathrm{M} \rightarrow 0, \mathrm{~m} \gg \mathrm{M}$ ou $\mathrm{M} \gg \mathrm{m}$. Dessa forma, é possível "exemplificar uma postura que consiste em considerar uma gama de experimentos ao invés de um único e também evidencia a habilidade física de tratar constantes (massas) como variáveis" (REDISH, 2005, p. 5).

Em concordância com a diferença semântica proposta por Redish, Pospiech (2006) e apresenta o seguinte quadro relacionando conceitos matemáticos e seus respectivos correspondentes, com interpretações e significados distintos, na física.

\begin{tabular}{|l|l|}
\hline \multicolumn{1}{|c|}{ Matemática } & \multicolumn{1}{c|}{ Física } \\
\hline Números & Números com unidades \\
\hline Fração & Relação \\
\hline Função em sentido abstrato & Relações funcionais entre grandezas físicas \\
\hline Objetos geométricos & Representações simbólicas de sistemas físicos \\
\hline Derivada & Taxa de variação \\
\hline Integral & Soma de infinitos infinitesimais \\
\hline
\end{tabular}

Quadro 5: Representações diferentes em matemática e física (POSPIECH, 2006, p. 8).

Tuminaro (2004) também sustenta que a matemática utilizada na física possui uma semântica diferente daquela ensinada pelos professores de matemática. Essa defesa é fundamentada em três dimensões: 1) os estudantes têm dificuldade de mapear/traduzir conceitos dos cursos de matemática para os cursos de física; 2) existem diferenças consideráveis entre a matemática ensinada nos cursos de matemática e a matemática necessária nos cursos de física (citando como exemplos as diferenças entre Força e Resultante das Forças, constantes universais e parâmetros experimentais, variáveis dependentes e independentes, condições iniciais e de contorno, entre outros) e 3) os 
estudantes acham que existe uma diferença entre a "matemática das aulas física" e a "matemática das aulas de matemática" (essa afirmação é baseada na análise das falas dos próprios alunos).

Pensemos em um simples exemplo para ilustrar essas possíveis diferenças semânticas (KARAM; PIETROCOLA, 2009a). Consideremos as seguintes equações físicas: V = R.i, $\mathrm{E}=$ h.f e $\mathrm{v}=\lambda$.f. Matematicamente, todas essas expressões poderiam ser encaradas como uma relação linear do tipo $\mathrm{y}=\mathrm{kx}$. Graficamente, é possível representar uma função linear como uma reta que passa pela origem e cuja inclinação (tangente do ângulo $(\alpha)$ que a reta faz com a horizontal) é dada pela constante k (Figura 6). Aqui, x tradicionalmente representa a variável independente, y a variável dependente e $\mathrm{k}$ a constante de proporcionalidade.

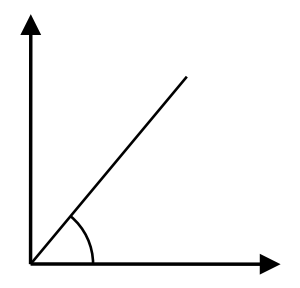

Figura 7: Gráfico da função linear $\mathrm{y}=\mathrm{kx}$ para $\mathrm{x} \geq 0$

Uma rápida discussão sobre a situação física que cada uma das fórmulas representa evidencia que, apesar da estrutura matemática aparentemente semelhante, existem diferenças extremamente significativas entre as mesmas. Em primeiro lugar não é tão nítida a separação entre variáveis dependentes e independentes. Na relação entre tensão e corrente (conhecida por lei de $\mathrm{Ohm}$ ), por exemplo, é possível medir a corrente para obter a tensão, medir tensão para obter a corrente ou ainda, talvez o mais comum, seja medir tensão e corrente para se obter a resistência de um fio condutor. Em contraposição, para a relação $E=$ hf, não existe o menor sentido prático em se determinar a constante, uma vez que se trata de um valor universal conhecido como constante de Planck. Enquanto a resistência de um fio pode mudar, a constante de Planck sempre será igual a $\mathrm{h}=6,626 \times 10^{-34} \mathrm{~J}$.s. Outra diferença notável é que a energia (E) de um fóton não é uma função contínua de sua frequência (f), uma vez que, para uma determinada frequência, a energia só pode assumir valores múltiplos de hf. Essa hipótese, conhecida como quantum de ação, é justificada no trabalho em que Einstein detecta uma incoerência formal na tentativa de explicar a emissão de radiação térmica conciliando as funções contínuas da teoria eletromagnética de Maxwell com as funções discretas que representam somas sobre átomos e elétrons da termodinâmica (EINSTEIN, 1905). 
Para a equação fundamental da ondulatória $(\mathrm{v}=\lambda . \mathrm{f})$ a diferença semântica é ainda mais gritante. Isso porque a velocidade e a frequência de uma onda dependem de fatores diferentes. Enquanto a velocidade é influenciada pelas características do meio (elasticidade e inércia), a frequência é dependente apenas da fonte. Dessa forma, uma alteração na frequência de uma onda não provoca uma mudança em sua velocidade e vice-versa! $\mathrm{O}$ comprimento de onda $\lambda$ está longe de ser uma constante. $\mathrm{Na}$ realidade é justamente esse parâmetro que varia para garantir a validade da equação e não haveria sentido físico algum em se traçar uma reta ( $\mathrm{v}$ x f) na qual $\lambda$ representasse a inclinação.

Exemplos como os citados acima são ilustrativos para refletirmos sobre como enfrentar as dificuldades que os estudantes enfrentam ao aplicar matemática para resolverem problemas de física. Uma prática bastante comum nas universidades e escolas brasileiras, quando se detecta dificuldades dessa natureza, é recomendar aos estudantes que participem de cursos de Matemática Básica, nivelamento, preparação para o cálculo e similares. Parecenos, entretanto, que essa prática não se sustenta diante da constatação de que não basta saber matemática para usá-la conscientemente como instrumento de pensamento em física.

Dessa forma, o enfoque nas habilidades estruturais é tarefa legítima do ensino de física, enquanto que as habilidades técnicas seriam aprendidas em aulas de matemática. Entretanto, é importante enfatizar que apesar de a "matemática das aulas de matemática" ser diferente da necessária nas aulas de física, isso não significa que o ensino de matemática consiste em treinar os estudantes para a aplicação rotineira de regras e algoritmos sem sentido. De fato, dualidades semelhantes à que propomos para o ensino de física já são consideradas há um bom tempo por pesquisadores da educação matemática ${ }^{24}$ e por fornecerem elementos interessantes para nossa análise, vamos explorá-las brevemente.

Skemp (1976) propõe duas maneiras distintas de se classificar o entendimento no ensino de matemática: instrumental e relacional. A primeira consiste em memorizar regras prontas, sem saber explicar por que elas são válidas, e aplica-las em exercícios padrão. Alguns exemplos familiares são: "divide pelo de baixo e multiplica pelo de cima", "iguala as casas decimais e corta as vírgulas", "todo número elevado a zero é igual a 1", "quadrado do primeiro mais duas vezes o primeiro pelo segundo mais o quadrado do segundo", entre muitas outras. Tal maneira de olhar para o conhecimento matemático dá a impressão de que este consiste em um conjunto de regras sem sentido a serem memorizadas ("dogmas" que

\footnotetext{
${ }^{24}$ Algumas delas são: conhecimento matemático como conceitual e procedimental (HIEBERT, 1986), abstrato e algoritmico (HALMOS, 1985), processo e produto (DAVIS, 1975), dialético e algorítmico (HENRICI, 1974), operacional e estrutural (SFARD, 1991), instrumental e relacional (SKEMP, 1976). 
devem ser respeitados) fazendo com que a maioria dos estudantes tenha uma aversão à matemática. $\mathrm{Na}$ verdade, quando professores desta disciplina adotam uma postura instrumental em suas aulas, estão fazendo um grande desserviço para seus alunos, não só porque impedem que os mesmos percebam como a matemática se estrutura a partir de proposições simples e lógicas, portanto compreensíveis, mas também porque dificultam um entendimento mais profundo sobre o significado das operações e conceitos matemáticos, impossibilitando a compreensão da utilização destes na construção de modelos, habilidade essencial para se pensar os fenômenos físicos.

Por outro lado, se o estudante for capaz de explicar as razões que justificam a validade de regras da matemática, terá, segundo Skemp (1976), um entendimento relacional desta disciplina. Cada uma das quatro regras mencionadas anteriormente passaria a fazer sentido para o estudante, se o mesmo compreendesse profundamente que: "para adicionar frações multiplicamos numerador e denominador pelo mesmo número - o que não altera a fração - a fim de obter frações equivalentes com mesmo denominador", "ao multiplicarmos por múltiplos de dez o dividendo e o divisor - o que não altera o valor da divisão - eliminamos os números decimais", "ao substituirmos o expoente zero por $(a-a)$, obtemos uma divisão na qual o numerador é igual ao denominador resultando, portanto, em 1", "geometricamente, percebemos que a área de um quadrado de lado $(a+b)$ é equivalente à área do quadrado de lado $a$ mais a área do quadrado de lado $b$ somada às áreas de dois retângulos de lados $a b$ ". Dessa forma, enfocando o entendimento relacional os estudantes não necessitariam memorizar um vasto arsenal de relações, mas passariam a ser capazes de deduzi-las a partir de um pequeno conjunto de proposições totalmente plausíveis. Naturalmente, a abordagem instrumental tem vantagens como a praticidade e agilidade de se utilizar regras e algoritmos prontos para resolver problemas mais complexos. Entretanto, acreditamos que as mesmas só poderiam ser usadas como ferramenta se os estudantes desenvolverem previamente um entendimento relacional sobre as mesmas. Assim, uma profunda compreensão das razões que justificam a validade das regras seria uma espécie de autorização para se utiliza-las de maneira rotineira.

Mas seria possível atingir uma compreensão conceitual sem qualquer tipo de domínio procedimental? Essa diferenciação entre conhecimento conceitual e procedimental de matemática (HIEBERT, 1986) é amplamente adotada na comunidade de pesquisa em educação matemática. Porém, as relações entre esses dois tipos de abordagem ainda estão longe de serem consensuais entre os pesquisadores (SCHNEIDER; STERN, 2010). As 
principais questões de pesquisa envolvem a ordem natural de aquisição desses dois tipos de conhecimento, a ordem ideal para sua aquisição e consequentemente seu ensino, bem como a influência do conhecimento conceitual sobre o procedimental e vice-versa (RITTLEJOHNSON; ALIBALI, 1999).

A influente categorização proposta por Sfard (1991) pretende eliminar uma concepção dicotômica sobre esses aspectos, reforçando seu caráter dual. Segundo a autora, os conceitos matemáticos podem ser considerados de duas maneiras distintas: operacionalmente - como processos - e estruturalmente - como objetos. Contrariamente à classificação de opostos como algoritmico/abstrato, procedimental/conceitual e instrumental/relacional, os termos operacional e estrutural são, para a autora, "duas faces de uma mesma moeda".

Sua defesa é baseada em uma análise histórica do desenvolvimento dos conceitos matemáticos fundamentais de número e função. Tal análise visa a evidenciar que ambos os conceitos (número e função) estiveram inicialmente associados a processos e só posteriormente atingiram o status de objetos. No caso dos números, a autora mostra que os processos de contagem e medição precederam o tratamento formal do número como uma entidade abstrata. De maneira semelhante, as funções surgiram de relações de dependência entre grandezas (muitas vezes físicas) e foi necessário um longo processo para que as mesmas adquirissem um status de objeto (entidade) matemático. Sem a intenção de adotar uma postura excessivamente generalista ou reducionista, Sfard (1991) defende que existe uma tendência hierárquica entre as maneiras operacional e estrutural de conceber conceitos matemáticos:

Quando ampliamos nossa visão e olhamos para a matemática como um todo (pelo menos para grandes partes dela), percebemos que existe uma espécie de hierarquia, na qual o que é concebido de maneira operacional em um nível passa a ser concebido estruturalmente num nível superior. Tal hierarquia emerge de uma série de reificações, cada uma iniciando onde a outra termina, cada uma adicionando um novo elemento ao sistema complexo de noções abstratas. (SFARD, 1991, p. 16).

Seria então possível pensar em tal hierarquia também para a aprendizagem de conceitos matemáticos? Sfard (1991, p. 16-23) dá uma resposta positiva a essa hipótese defendendo que, no contexto psicológico, a precedência de concepções operacionais sobre estruturais pode ser considerada como uma invariante do processo de aprendizagem. Seguindo sua análise histórica e inspirada em teorias piagetianas, a autora propõe três estágios para a estruturação de um conceito matemático por parte do aprendiz: interiorização, condensação e reificação. A primeira está associada a processos realizados sobre objetos previamente conhecidos, os quais darão origem a um novo conceito: contagens para o 
conceito de número, subtrações para os números negativos, cálculos com raízes quadradas para os números complexos e substituição de valores em uma fórmula no caso do conceito de função. Na fase da condensação o estudante passa a ser capaz de pensar sobre esses processos como um todo, sem a necessidade recorrer a detalhes. Para os números negativos ele adquire a capacidade de combinar operações de adição e multiplicação de números positivos e negativos, para os complexos essa fase representa a percepção de que pode ser útil extrair a raiz quadrada de um número negativo mesmo que isso não represente um objeto matemático e no caso das funções suas representações são ampliadas por gráficos, tabelas, funções compostas e inversas. Por fim, um salto qualitativo, quase instantâneo, é dado quando o estudante começa a pensar nos processos como entidades em si, consolidando a fase da reificação. Os números negativos, complexos e as funções passam a ser vistos como entidades abstratas e podem ser tratados estruturalmente.

Ao confrontarmos as categorizações de Sfard (1991) e Skemp (1976) podemos ter a impressão de que as mesmas são contraditórias, ainda mais se considerarmos nossa defesa de que o entendimento relacional deva preceder o instrumental e a colocação de Sfard (1991) de que o operacional precede o estrutural. Acreditamos, porém, que seja possível, e até necessário, manter o foco num entendimento relacional durante o processo de estruturação de um conceito matemático nas fases propostas por Sfard (1991). De fato, a abordagem operacional que leva à estruturação de um conceito não é instrumental, mas sim relacional. Se os processos/cálculos/manipulações iniciais forem realizados de uma maneira puramente mecânica e acrítica, sem preocupação com a identificação de padrões e regularidades ou uma reflexão constante sobre os "porquês" das regras, as fases seguintes não serão atingidas. Portanto, por se referirem a aspectos distintos e possuírem categorizações que se complementam, as mesmas não são contraditórias uma vez que é o foco no entendimento relacional que garante o sucesso da estruturação conceitual em matemática.

De maneira análoga às pesquisas em educação matemática, é justamente no entendimento relacional dos porquês do uso da matemática na física que estamos interessados. Assim, pretendemos focar nossa pesquisa no desenvolvimento de habilidades estruturais, as quais estão associadas à capacidade de se fazer um uso organizacional da matemática em domínios externos a ela (especialmente em física) (PIETROCOLA, 2010) e de compreender as razões para a relação de dependência mútua entre física e matemática. Em outras palavras, podemos entendê-las como a habilidade de pensar matematicamente os fenômenos do mundo físico, ou seja, de utilizar estruturas matemáticas (lógicas, dedutivas, 
seguras) para a construção teórica de conceitos e explicações físicas. Tendo como base o que foi exposto previamente, as habilidades estruturais referem-se ao nível "forte" proposto por Paty (1995), à percepção do ganho de conteúdo através da tradução para uma linguagem matemática (ZAHAR, 1980), ou ainda às categorias "Interpretação Física" e "Consistência Matemática” de Bing e Redish (2009).

O problema com o qual nos deparamos é o seguinte: como definir, caracterizar e exemplificar tais habilidades? E ainda, como abordá-las num contexto de ensino? É relativamente fácil criticar uma abordagem excessivamente técnica na qual o formalismo é vazio de significado, isto é, sabemos o que não queremos; mas afinal, o que queremos?

Para tentar responder a essas perguntas, seguimos duas linhas complementares de investigação: uma epistemológica e outra empírica. Num primeiro momento, buscamos posicionamentos de físicos, matemáticos e filósofos, muitos dos quais foram descritos no primeiro capítulo. Em seguida, analisamos um conjunto de aulas de física ministradas por um professor diferenciado e experiente que hipoteticamente aborda esse caráter estruturante da matemática em suas aulas. A análise das aulas foi fundamental para um melhor entendimento sobre as habilidades estruturais e também sobre estratégias didáticas que visem o desenvolvimento das mesmas. No próximo capítulo descrevemos os aspectos metodológicos e justificamos a importância do estudo de caso para a abordagem de nosso problema de pesquisa. Antes de concluirmos este capítulo, apresentamos na próxima seção um modelo teórico que foi desenvolvido para representar a diferenciação entre habilidades técnicas e estruturais. À guisa de síntese, apresentamos o quadro a seguir que ilustra aspectos dessa dualidade proposta para analisar a multiplicidade dos usos da matemática no ensino de física.

\begin{tabular}{|l|l|}
\hline Caráter técnico/instrumental/procedimental & Caráter estrutural/relacional/organizacional \\
\hline $\begin{array}{l}\text { Usar uma fórmula para resolver problemas } \\
\text { quantitativos }\end{array}$ & $\begin{array}{l}\text { Demonstrar uma fórmula a partir de princípios } \\
\text { físicos }\end{array}$ \\
\hline Como/quando uso essa equação? & Por quê essa equação é assim? \\
\hline Plug-and-chug & Significado físico de expressões matemáticas \\
\hline $\begin{array}{l}\text { Professor } \text { Alfa: Manipulação de algoritmos de } \\
\text { cálculo }\end{array}$ & Professor Beta: Foco na interpretação física \\
\hline $\begin{array}{l}\text { Professor Gama: Argumentos de autoridade, } \\
\text { regras prontas }\end{array}$ & Professor Delta: Consistência matemática \\
\hline Nível Fraco - descrição e comunicação & Nível forte - conceituação e estrutura \\
\hline Ferramenta de cálculo & Instrumento de pensamento \\
\hline $\begin{array}{l}\text { Ler uma equação de maneira literal. Ex.: } \\
\text { Explicar } \Delta \mathrm{x}=\text { v. } \Delta \text { t como “deslocamento é } \\
\text { igual à velocidade vezes o intervalo de tempo }\end{array}$ & $\begin{array}{l}\text { Mostrar equivalência entre asserções físicas } \\
\text { aparentemente distintas (ex. lei da gravitação } \\
\text { universal e lei das áreas) }\end{array}$ \\
\hline Semelhanças superficiais & Analogias profundas \\
\hline
\end{tabular}

Quadro 6: Aspectos da dualidade técnico-estrutural para analisar o uso de matemática no ensino de física. 


\subsection{A NECESSIDADE DE UM MODELO ALTERNATIVO PARA A FÍSICA ${ }^{25}$}

Considerando nosso interesse em investigar as implicações didático-pedagógicas das relações entre física e matemática, as pesquisas sobre modelagem matemática podem, em tese, fornecer elementos que contribuam para nosso problema. Nesta seção, exploramos um grupo de modelos já existente que têm a função de representar as atividades cognitivas envolvidas no processo de modelagem matemática, os quais são denominados ciclos de modelagem (ver BORROMEO FERRI, 2006; HAINES; CROUCH, 2010). Tendo em vista que estes ciclos pretendem representar "o processo de tradução entre o mundo real e a matemática em ambos os sentidos" (BLUM; BORROMEO FERRI, 2009, p. 45), parece razoável usá-los no domínio da física também. No entanto, veremos que a tentativa de transferir os ciclos de modelagem para a física implica em considerar uma distinção clara entre um modelo físico e um matemático ${ }^{26}$ e limita as possibilidades de se analisar a matematização da física em diversos níveis. Devido à complexa relação de imbricação entre física e matemática exposta no Capítulo 1, vamos argumentar em favor de um modelo alternativo para analisar o papel da matemática em física.

De acordo com Borromeo Ferri (2006), existem diferentes representações de ciclos de modelagem. Comum a todos é o modelo matemático, o qual é conectado ao resto do mundo pela matematização e interpretação. A maior diferença entre os ciclos aparece quando eles modelam aspectos da realidade. Os que se concentram em processos cognitivos levam em conta o papel dos modelos mentais (ver Fig. 8). A realidade passa a ser descrita como uma situação real acessada por uma representação mental, a qual é idealizada em um modelo dessa situação real. Outros ciclos de modelagem não levam em conta os modelos mentais. Em vez disso, eles partem da situação real para um modelo dessa situação ou mesmo diretamente para o modelo matemático (exemplos podem ser encontrados em BORROMEO FERRI 2006).

\footnotetext{
${ }^{25} \mathrm{O}$ modelo que será apresentado nesta seção foi publicado em Uhden et al. (2011).

${ }^{26}$ Segundo Hesse (1953), "a principal justificativa para o uso da palavra "modelo" no sentido amplo é devida ao fato de que teorias físicas puramente matemáticas funcionam essencialmente da mesma forma que modelos fisicamente imagináveis, em serem capazes de sugerir linhas de ação para a explicação de fatos experimentais. Às vezes é possível classificar esses modelos de maneira clara como "mecânicos" "elétricos" "matemáticos" e assim por diante, mas normalmente um modelo será um misto de diferentes tipos. (HESSE 1953, p. 200, grifo nosso). Para uma discussão mais aprofundada sobre as limitações em se considerar separadamente os modelos matemático e físico consultar o artigo (UHDEN et al., 2011).
} 


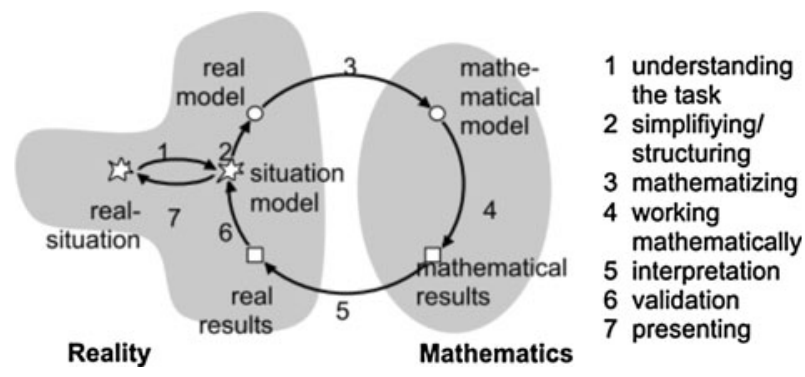

Figura 8: Ciclo de modelagem de Blum e Leiß (2005)

Consideremos a possibilidade de aplicação do ciclo de modelagem proposto por Blum e Leiß (2005) ao domínio da física. Transferimos os aspectos importantes para um novo diagrama desse ciclo (ver Fig. 9a e 9b). A estrutura original ainda é a mesma, mas restringimos o modelo de realidade ao domínio da física e nos concentramos nos processos de tradução. Acabaremos com regiões que representam o mundo, o modelo físico e o domínio da matemática. Os processos de tradução estabelecem as conexões entre as três áreas: a simplificação e a validação conectam o mundo ao modelo físico enquanto que a matematização e a interpretação conectam o modelo físico à matemática. As operações matemáticas (item 3) pertencem ao campo interno do modelo matemático.

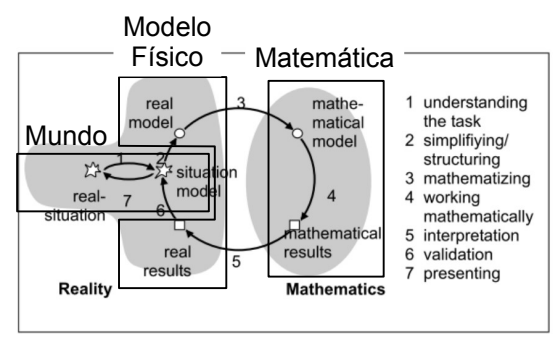

(a)

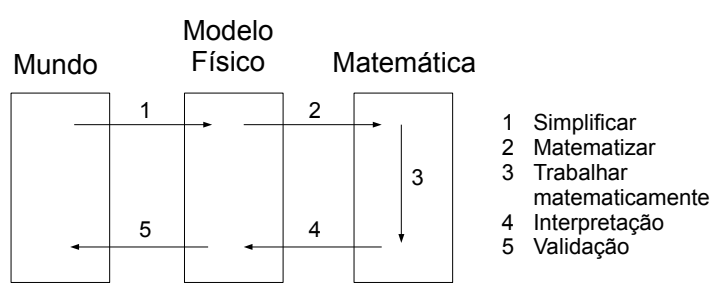

(b)

Figura 9: Ciclo de modelagem de Blum e Leiß (2005) adaptado ao domínio da física.

Utilizar este ciclo em física pode ser útil para representar etapas do processo de construção de modelos matemáticos de fenômenos físicos e, de fato, alguns pesquisadores já propuseram modelos semelhantes para esse contexto (ver, por exemplo, REDISH, 2005, p. 6). Entretanto, tendo em vista as reflexões histórico-epistemológicas do Capítulo 1 e nosso intuito de caracterizar as habilidades estruturais de maneira mais profunda, acreditamos que o mesmo possui limitações/distorções. Dessa forma, propomos um modelo alternativo para ser utilizado no domínio da física.

Entre as motivações principais para esse modelo estão: 1) obter uma imagem mais fiel da relação de imbricação entre física e matemática; 2) permitir uma distinção entre habilidades técnicas e estruturais; 3) representar diferentes níveis de matematização; 4) possibilitar maior flexibilidade em relação à ordem das etapas. Dessa forma, a noção de 
interdependência entre física e matemática deve ser proeminente, tendo em mente que o papel da matemática pura e do raciocínio qualitativo não podem ser negligenciados. O modelo deve, portanto, ter uma parte inseparável de matemática e física (modelo físico-matemático), análogo ao signo físico-matemático proposto por Boniolo e Budinich (2005), bem como um elemento de raciocínio qualitativo e uma parte de pura matemática. Assim, seria possível distinguir claramente entre o caráter estrutural e técnico da matemática na física. As habilidades estruturais seriam indicadas pela parte inseparável, enquanto que o trabalho matemático puramente técnico corresponderia ao campo independente da matemática, de maneira semelhante ao que é feito no ciclo de modelagem.

Além disso, seria interessante analisar mais profundamente as habilidades estruturais, ou seja, principalmente, matematização e interpretação. Por exemplo, se considerarmos a matematização da noção de rapidez e compararmos duas formulações matemáticas diferentes para o conceito de velocidade $\left(v=\frac{\Delta x}{\Delta t}\right.$ e $\left.\vec{v}=\frac{d \vec{r}}{d t}\right)$ deveríamos ser capazes de representar o maior grau (nível) de matematização (abstração e generalização) da segunda. Essa ideia pode ser representada considerando uma dimensão (eixo) para o nível de matematização. Se uma seta nessa dimensão - representando o processo de matematização ou interpretação dependendo de seu sentido - possuir comprimentos diferentes, o resultado será uma diferenciação do grau (nível) de matematização.

Condensando as ideias expostas em uma representação esquemática, o resultado de nosso modelo alternativo aparece na Figura 10. A Física passa a ser representada por uma estrutura imbricada, um modelo físico-matemático, contendo um eixo vertical (infinitamente denso) que representa os níveis de matematização. Além disso, como nos ciclos de modelagem, há uma região referente à matemática pura. A física qualitativa pura é representada pelo primeiro nível do modelo físico-matemático, no qual o grau de matematização é nulo. Mas como uma diferença importante para o ciclo de modelagem tradicional, essa é apenas a primeira etapa de um processo de construção teórica (matemática) de conceitos físicos. A física qualitativa não é um modelo distinto em si mesmo. 


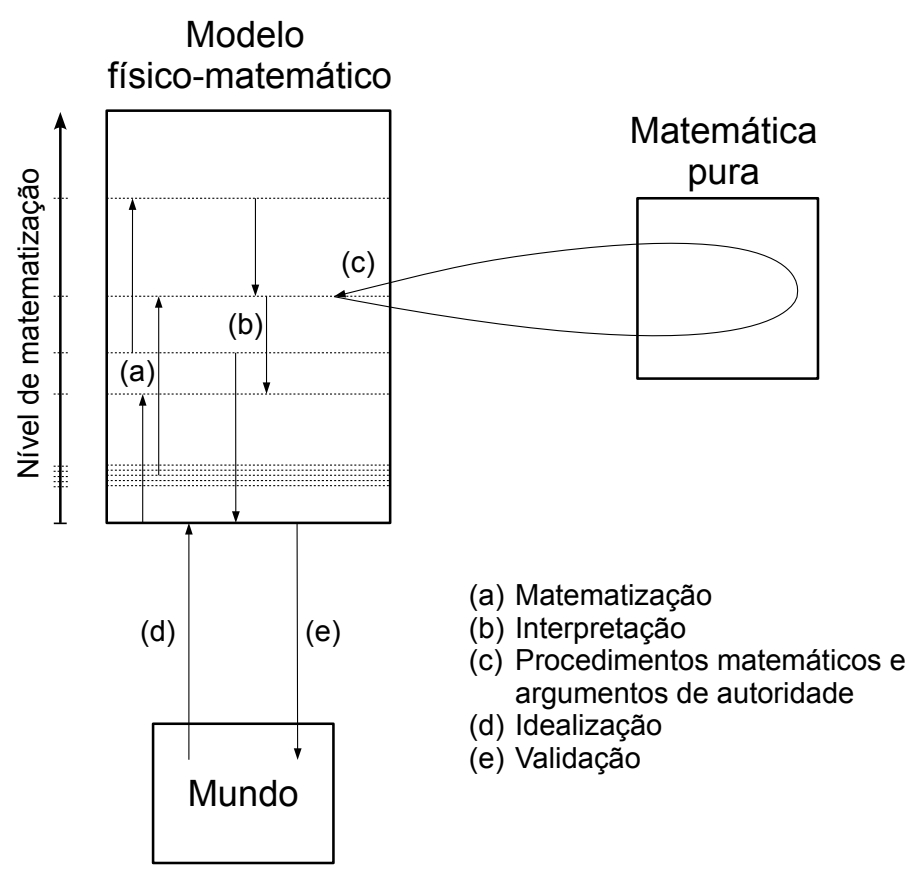

Figura 10: Modelo alternativo para analisar as relações entre matemática e física (UHDEN et al., 2011).

Com essa estrutura, a matematização e interpretação estão incluídas no modelo físico-matemático através da movimentação na direção vertical, propiciando assim uma representação distinta do ciclo de modelagem. Isto é indicado pelo grupo de flechas "(a)" e “(b)" na Figura 10 de tal forma que a alteração no comprimento de uma flecha permite distinguir entre diferentes graus de matematização. Referindo-se novamente ao exemplo da velocidade, a declaração "distância sobre tempo" estaria em um nível inferior ao da fórmula $v=\frac{\Delta x}{\Delta t}$, que por sua vez estaria disposta abaixo do nível correspondente à representação diferencial vetorial $\vec{v}=\frac{d \vec{r}}{d t}$.

Mover-se na direção oposta (setas “(b)") representa interpretar o significado físico de expressões matemáticas. Isto está relacionado com a capacidade de "ler" equações matemáticas, interpretar seu significado físico com o uso de palavras e esquemas, identificar casos especiais e limites ou ainda de fazer previsões físicas a partir do formalismo. Esta é uma habilidade crucial para uma compreensão profunda do papel da matemática na física. Vários episódios históricos, tais como a previsão da antimatéria ou a relação massa-energia, são exemplos notáveis de sucesso na interpretação do significado físico das estruturas matemáticas. Assim, movimentos na direção vertical do modelo físico-matemático estão associados a habilidades estruturais, uma vez que pertencem à estrutura teórica interna da física. 
Além disso, a "seta" curvilínea “(c)" refere-se às manipulações/operações matemáticas técnicas como os cálculos. Ela representa as habilidades técnicas - os casos de se "fazer somente matemática". Ela está relacionada ao domínio instrumental de regras algorítmicas (por exemplo, isolar uma variável, operar com frações, diferenciar/integrar uma função e resolver uma equação), à simples consulta de uma relação em uma tabela (por exemplo, regras de diferenciação, identidades trigonométricas e momentos de inércia) ou à evocação de propriedades e teoremas usando argumentos de autoridade (por exemplo, os teoremas de Pitágoras, Stokes ou a propriedade associativa). Este processo é caracterizado pela ausência de qualquer referência física. Portanto, a seta se move a partir do modelo físicomatemático para a matemática pura e depois retorna a seu ponto de partida. Por estabelecer claramente essa diferença entre as setas dentro do modelo físico-matemático - "(a)" e "(b)" e a "seta" curvilínea “(c)" que deixa a física em direção à matemática pura, a diferenciação entre habilidades estruturais e técnicas é ilustrada de maneira esquemática.

Finalmente, vale destacar que este modelo alternativo mantém algumas relações características do ciclo de modelagem. As setas “(d)" e "(e)" continuam representando as traduções entre o resto do mundo e o modelo físico-matemático: idealização e validação. Comparando com a Figura 9b, pode-se observar que todos os processos do ciclo de modelagem original ocorrem nesta versão revisada, mas estão dispostos de uma maneira diferente, possibilitando a utilização das setas em uma ordem mais flexível.

Consideremos um exemplo para melhor ilustrar algumas possíveis aplicações deste modelo alternativo. O exemplo escolhido é o problema clássico da queda livre, ou seja, descrever o movimento de um corpo abandonado de uma certa altura que cai devido à ação da gravidade $\left(g=10 \mathrm{~m} / \mathrm{s}^{2}\right)$. Mais especificamente, o objetivo é determinar a posição do corpo em função do tempo $(s=s(t))$. Compararemos duas abordagens para lidar com este problema, as quais denominaremos "didática" e "abstrata-direta", e evidenciamos suas diferenças em relação ao uso da matemática com o auxílio do modelo proposto. Acreditamos que o exemplo da queda livre é pertinente não somente por sua relevância histórica, mas também porque o mesmo é amplamente ensinado em aulas de física em diversos níveis.

Primeiramente, deve ficar claro que o problema já é idealizado, devido ao fato de que as dimensões do corpo e a resistência do ar são negligenciados, e matematizado, uma vez que o tempo e o espaço são representados por números reais. Portanto, o processo de resolução se inicia em um nível de matematização não nulo dentro do modelo físico-matemático. 
A abordagem didática é concebida por uma matematização gradual. Ela começa pelo reconhecimento de que o problema não envolve uma relação linear: com o passar do tempo, o corpo vai cada vez mais rápido e, portanto, percorre distâncias maiores em iguais períodos de tempo. Reconhecer esta não-linearidade, que é uma propriedade básica do movimento acelerado, já é um movimento na direção da matematização, mas o caso particular de aceleração constante ainda não está identificado.

A identificação da aceleração constante é feita através do reconhecimento - por exemplo, pela realização de um experimento ou utilizando uma simulação - de que o aumento da velocidade é de $10 \mathrm{~m} / \mathrm{s}$ por segundo. De fato, a unidade $\mathrm{m} / \mathrm{s}^{2}$ fornece exatamente a variação da velocidade por segundo. Novamente, avançou-se na direção da matematização, especificando-se o constante aumento da velocidade.

Em uma etapa seguinte, a taxa constante de mudança de velocidade pode ser representada de diferentes maneiras, como uma tabela associando valores de $v$ a instantes $t$, um gráfico cartesiano ( $v$ versus $t$ ) ou ainda uma equação $v=10 t$. Mais uma vez, a equação e o gráfico correspondem a um nível mais elevado de matematização, o que nos prepara para um passo crucial antes da dedução final: interpretar a área abaixo do gráfico como o deslocamento $s(t)$ do corpo.

Uma possível maneira de tirar essa conclusão é partir da análise do gráfico de movimento uniforme: a região limitada pelo gráfico e os eixos coordenados tem a forma de um retângulo e, assim, é determinada pelo produto de duas dimensões que correspondem a $v$ e $t$. Como velocidade vezes intervalo de tempo é igual ao deslocamento $s(t)$ para o caso de movimento uniforme, a área do retângulo é interpretado como o deslocamento do corpo durante esse intervalo de tempo. Portanto, a quarta etapa é no sentido da interpretação, uma vez que uma entidade matemática (área de um retângulo) está relacionada a uma grandeza física (deslocamento).

A conclusão geral de que a área abaixo do gráfico ( $v$ versus $t$ ) é igual ao deslocamento $s(t)$ também para os casos em que a velocidade varia baseia-se na abstrata concepção de velocidade como derivada da posição em relação ao tempo, uma relação que pode não ser acessível para os alunos, dependendo do nível escolar. Portanto, o processo de conceber a área abaixo do gráfico como o deslocamento para o caso de movimento uniformemente acelerado é baseado em plausibilidade e analogia. Apesar disso, representa uma espécie de matematização que nos eleva a um nível ainda mais alto matematizado no modelo. Agora 
temos uma representação matemática do deslocamento de um móvel (área abaixo do gráfico $v$ versus $t$ ) que se relaciona a velocidade de uma forma mais geral.

Com a fórmula $v=g t$ para a aceleração constante, o gráfico $v$ versus $t$ correspondente e a interpretação da área abaixo do gráfico como o deslocamento $s(t)$, a expressão solicitada pode ser algebricamente deduzida:

$$
s(t)=\frac{1}{2} v t=\frac{1}{2}(g t) t=\frac{1}{2} g t^{2}
$$

Agora consideremos uma abordagem mais abstrata e direta para o problema. A posição do corpo está sendo solicitada e a aceleração é dada. O raciocínio é bastante simples: A aceleração é a segunda derivada temporal da posição $\left(a(t)=d^{2} s / d t^{2}\right)$. Uma vez que é a aceleração é constante $(a(t)=g)$, obtemos uma equação diferencial linear de segunda ordem que deve ser resolvida a fim de encontrar a solução $s=s(t)$. O processo de resolução fornece duas constantes que devem ser interpretadas como a velocidade inicial e posição inicial do corpo. A solução geral obtida é: $s(t)=s_{0}+v_{0} . t+g t^{2} / 2$. Como a posição e velocidade iniciais são nulas, a equação solicitada é $s(t)=g t^{2} / 2$.

Os processos de resolução são representados esquematicamente em nosso modelo na Figura 11 o que possibilita visualizar as principais diferenças entre as abordagens. A "didática" (Fig. 11a) é composta por cinco flechas representando processos graduais de matematização e uma seta no sentido inverso designando interpretação. O caminho todo ocorre dentro do modelo físico-matemático, o que significa que os elementos matemáticos utilizados estiveram sempre estreitamente relacionados com correspondentes físicos.

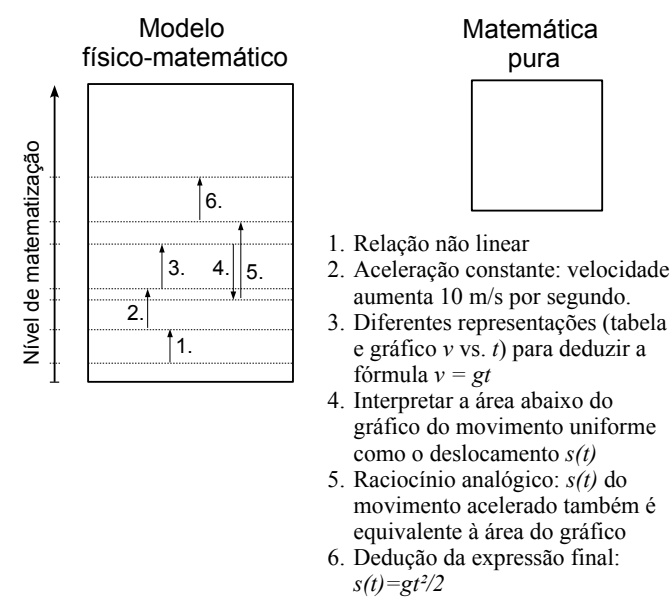

(a)

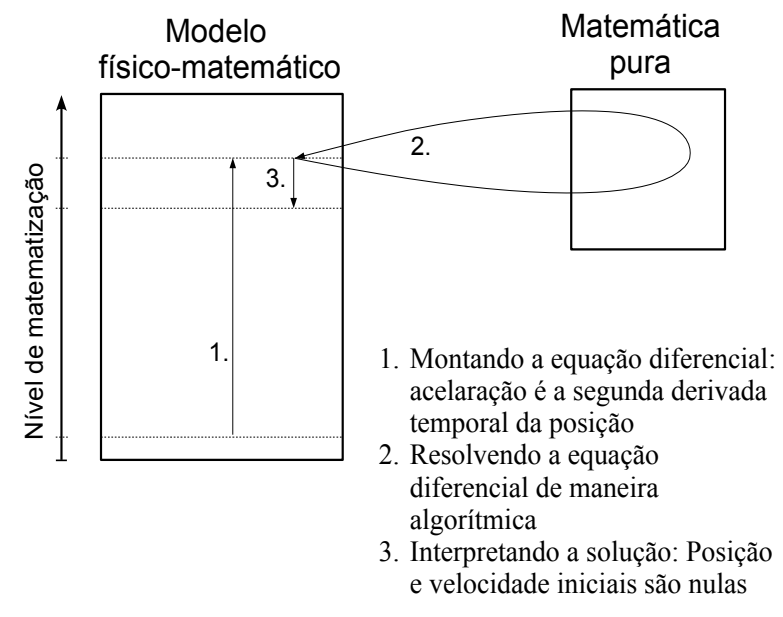

(b)

Figura 11: Duas abordagens para o problema da queda livre representadas em nosso modelo alternativo. 
A abordagem abstrata-direta (Fig. 11b), no entanto, é mais rápida e concisa. A primeira longa seta ilustra o alto grau de matematização envolvido no conceito de aceleração como a segunda derivada temporal da posição. A partir daí, uma equação diferencial é obtida e resolvida procedimentalmente, ou seja, sem qualquer raciocínio físico, mas apenas seguindo regras internas de matemática. O resultado da equação é então interpretado fisicamente e a mesma função $\left(s(t)=g t^{2} / 2\right)$ é obtida.

A representação de ambas as abordagens em nosso modelo evidencias diferentes maneiras de usar matemática para resolver o problema e, assim, possui implicações para o ensino e aprendizagem. A "didática" consiste em um caminho gradual na direção da matematização, enquanto que a "abstrata" vai direto para a elaborada relação entre aceleração e posição. Esta é representada por uma seta maior, um grau de matematização que dificilmente seria alcançado para os alunos sem um domínio significativo do cálculo diferencial e integral. Este alto nível permite lidar com o problema de uma maneira mais geral, uma vez que este método pode ser aplicado a muitos outros problemas com sucesso, porém, a desvantagem é que ele se "descola" do contexto físico dado seu alto grau de abstração. Por outro lado, apesar de a abordagem didática ser mais restrita, a mesma é mais concreta e fortemente vinculada a um contexto físico. Outra diferença importante é a presença de procedimentos técnicos, ou seja, matemática pura (seta curvilínea), realizada na abordagem "abstrata" na resolução algorítmica da equação diferencial, ao passo que a “didática” sempre mantém conexão entre uma representação matemática e seu significado físico. Embora o raciocínio abstrato seja mais poderoso, o processo de derivar a fórmula pode vir a ser meramente técnico se o conceito de aceleração como a segunda derivada temporal da posição não for profundamente compreendido.

Nas duas últimas seções construímos elementos para caracterizar uma diferenciação entre habilidades técnicas e estruturais quando se analisa o uso de matemática no ensino de física. Nosso exemplo hipotético ilustrou maneiras distintas de se abordar o problema da queda livre e sua análise tem implicações didático-pedagógicas. Refletindo sobre uma postura "ideal" de ensino, parece-nos razoável advogar em favor do caminho gradual de matematização (abordagem didática), principalmente se o objetivo for elucidar o papel estruturante da matemática na física. Se a instrução for realizada em nível universitário, o objetivo final deve ser possibilitar aos alunos raciocinar da maneira geral e abstrata. No entanto, eles devem ser capazes de explicar o significado físico de seus cálculos matemáticos. 
Passemos agora do exemplo hipotético para a análise de situações concretas de sala de aula. Estamos interessados em compreender como se dá a interação entre habilidades técnicas e estruturais no contexto do ensino de física. Para isso, conduzimos um estudo de caso a partir da análise das aulas de um professor experiente e diferenciado. No próximo capítulo, descrevemos e fundamentamos a metodologia adotada em nossa pesquisa. 


\section{3 - ASPECTOS METOdOLÓGICOS DO DESENVOLVIMENTO DA PESQUISA}

\subsection{APRESENTAÇÃO E JUSTIFICATIVA DO ESTUDO DE CASO}

A complexidade do fenômeno educacional leva a reflexões sobre as metodologias de pesquisa mais adequadas para descrevê-lo. Durante muito tempo, almejou-se decompor os fenômenos educacionais em suas variáveis básicas, analisando-as isoladamente, como no estudo de fenômenos físicos, para compreendê-los de maneira integral. Acreditava-se que estudos analíticos e quantitativos, consolidados em premissas de neutralidade e independência, seriam necessários e suficientes para as pesquisas neste ramo. Entretanto, Lüdke e André (1986) apontam que, com o desenvolvimento das pesquisas em educação,

foi-se percebendo que poucos fenômenos nessa área podem ser submetidos a esse tipo de abordagem analítica, pois em educação as coisas acontecem de maneira tão inextricável que fica difícil isolar as variáveis envolvidas e mais ainda apontar claramente quais são as responsáveis por determinado efeito (LÜDKE; ANDRÉ, 1986, p. 3)

Frente ao desafio de captar essa realidade dinâmica e complexa, as autoras defendem as abordagens qualitativas de pesquisa como alternativas mais convenientes para a análise dos fenômenos educacionais. Ao contrário da perspectiva de realização de pesquisas por pessoas que não estejam envolvidas com o processo, situadas acima da esfera de atividades comuns, as pesquisas educacionais podem e devem ser realizadas dentro das atividades normais do profissional da educação, tornando-as um instrumento de enriquecimento do próprio trabalho. Segundo Bogdan e Biklen (apud LÜDKE; ANDRÉ, 1986), as pesquisas qualitativas possuem como características principais:

- Adotar o ambiente natural como fonte de dados e promover um contato mais direto e prolongado do pesquisador com o mesmo;

- Utilizar uma diversidade de dados descritivos como relatos de entrevistas, citações, condições do ambiente, fotografias, entre outros, com o objetivo de caracterizar a situação da maneira mais completa possível;

- Centrar o foco mais no processo do que no produto;

- Buscar compreender o ponto de vista dos participantes do estudo.

Assim, diferentemente das pesquisas quantitativas tradicionais, a pesquisa em educação não necessita preconizar a comprovação de hipóteses definidas previamente. As autoras destacam que 
O fato de não existirem hipóteses ou questões específicas formuladas a priori não implica a inexistência de um quadro teórico que oriente a coleta e a análise dos dados. $\mathrm{O}$ desenvolvimento do estudo aproxima-se a um funil: no início há questões ou focos de interesse muito amplos, que no final se tornam mais diretos e específicos. O pesquisador vai precisando melhor esse foco à medida que o estudo se desenvolve (LÜDKE; ANDRÉ, 1986, p. 13).

A citação de Lüdke e André (1986) reflete de maneira precisa o desenvolvimento desta pesquisa. Desde o início, tínhamos intenção de investigar relações entre matemática e física num contexto de ensino, mas o refinamento de nossas questões de pesquisa, bem como da metodologia mais adequada para respondê-las, foram sendo delineados ao longo do estudo. Chegamos a pensar em elaborar sequencias didáticas para serem aplicadas em nível médio, entrevistar professores de matemática e física, analisar livros didáticos, entre outras.

O desenho metodológico da pesquisa foi sendo esboçado quando definimos como objetivo investigar profundamente o papel do raciocínio matemático em aulas de física, mais especificamente de exemplificar e caracterizar habilidades estruturais e a interação destas com um uso instrumental da matemática (habilidades técnicas). Sendo assim, julgamos mais pertinente adotar uma abordagem qualitativa de pesquisa. Diante do ineditismo de nosso enfoque e da ausência de categorias para tal análise na literatura, a realização de um estudo de caso $^{27}$ nos pareceu mais apropriada. Segundo Gerring (2007, p. 40) "estudos de caso tendem a ser mais úteis quando o assunto a ser pesquisado ainda não foi explorado de maneira sistemática ou quando o mesmo é considerado sob uma nova perspectiva".

Os itens expostos a seguir (BASSEY, 1999, p. 58) definem de maneira precisa o estudo de caso no contexto educacional como um estudo empírico que é:

- conduzido em um contorno determinado no tempo e espaço (i.e. uma singularidade);

- $\quad$ sobre aspectos interessantes de uma atividade educacional, programa, instituição ou sistema;

- principalmente em seu contexto natural e dentro de padrões éticos de respeito às pessoas;

- para informar os julgamentos de praticantes e decisões de políticas públicas;

- ou os teóricos que estejam investigando temas semelhantes;

- de tal forma que sejam coletados dados suficientes para que o pesquisador possa:

\footnotetext{
${ }^{27}$ Ao contrário do experimentador, que manipula variáveis para determinar relações causais, ou do analista que faz perguntas padronizadas a grandes e representativas amostras de indivíduos, o pesquisador de um estudo de caso observa as características de uma unidade individual - uma criança, uma classe, um professor, uma escola ou uma comunidade. O propósito de tal observação é investigar profundamente e analisar intensivamente os diversos fenômenos que constituem o ciclo da unidade com o objetivo de estabelecer generalizações sobre a população em geral a que a unidade pertence. (COHEN; MANION, 1989, p. 124-5).
} 
(a) explorar significativamente múltiplos aspectos do caso,

(b) criar interpretações plausíveis para o que for encontrado,

(c) testar a confiabilidade dessas interpretações,

(d) para construir um argumento relevante,

(e) para relacionar o argumento com pesquisas representativas da literatura,

(f) para transmitir de forma convincente esse argumento à comunidade,

(g) para fornecer uma linha de argumentação lógica e coerente ${ }^{28}$, possibilitando a outros pesquisadores validar ou contestar os resultados, ou ainda construir argumentos alternativos.

Ficará evidente no decorrer do desenvolvimento da tese que nossa pesquisa atende a todos os itens listados por Bassey (1999). Em função de nosso interesse em um discurso mais elaborado sobre a relação entre física e matemática, o estudo de caso foi realizado a partir da análise de aulas de física em nível superior ministradas no Instituto de Física da Universidade de São Paulo. Durante o primeiro semestre de 2009, foram gravadas 10 aulas (1h $45 \mathrm{~min}$ cada, totalizando aproximadamente 17 horas de gravação) de uma disciplina de Física Básica do curso de bacharelado em Física, as quais fizeram parte de um módulo sobre a teoria da relatividade restrita. No segundo semestre de 2009, todo o curso de Física 3 (Eletromagnetismo - 40 aulas) foi gravado. A primeira gravação teve um caráter de estudo piloto e a escolha pelo tema se justifica por se tratar de um conteúdo reconhecidamente contra-intuitivo, logo, possivelmente mais dependente do formalismo matemático como instrumento de pensamento. O curso de Física 3 foi escolhido como estudo definitivo porque além de ser tradicionalmente conhecido como um "divisor de águas" em cursos de física, o eletromagnetismo é reconhecidamente uma teoria física altamente estruturada matematicamente.

É importante ressaltar que a escolha pela filmagem das aulas de um professor em particular foi premeditada. Além de ter se disponibilizado e autorizado a gravação de suas aulas, postura nem sempre comum nos departamentos de física, o professor escolhido é amplamente reconhecido por alunos e colegas em função de sua abordagem diferenciada, uma vez que costuma "dialogar" com o formalismo matemático, buscando interpretar as entidades matemáticas fisicamente e expondo características intrínsecas do fazer física. As avaliações de seu desempenho docente atestam o altíssimo grau de satisfação dos alunos em

\footnotetext{
${ }^{28} \mathrm{O}$ termo no original em inglês é audit trail e é utilizado metaforicamente, uma vez que trata-se de um termo técnico associado a uma sequencia de etapas (baseadas em provas) que documentam o processamento real de uma transação em uma organização ou sistema. 
relação às suas aulas ${ }^{29}$. Além disso, sua longa experiência profissional, especificamente lecionando os cursos de relatividade restrita e eletromagnetismo ${ }^{30}$, bem como sua diferenciada trajetória pessoal ${ }^{31}$, agregam elementos que justificam a pertinência de uma análise mais profunda de sua prática através de um estudo de caso. Seguindo uma metodologia semelhante àquela utilizada pelos pesquisadores que se dedicaram a entender a Resolução de Problemas a partir da análise do desempenho de experts, acreditamos que escolhemos um expert (físico e professor) para analisar a maneira como o mesmo expõe e discute o papel da matemática nas teorias físicas (Relatividade Restrita e Eletromagnetismo).

Desde o início, nosso olhar esteve voltado para os momentos nos quais o professor abordou, implícita ou explicitamente, o papel das estruturas matemáticas nas teorias físicas. Porém, a maneira como olhamos para os dados foi sendo aprimorada pelas leituras históricofilosóficas feitas ao longo do caminho, pela própria observação das aulas e também pelos recursos utilizados para a análise de dados qualitativos. Inicialmente, as aulas de relatividade restrita do estudo piloto possibilitaram a identificação de episódios de ensino nos quais diversos aspectos filosóficos sobre a relação entre física e matemática foram explicitamente discutidos com os alunos. Para o estudo definitivo no curso de eletromagnetismo, a utilização do software videograph possibilitou um olhar mais detalhado para o fenômeno, levando à identificação/definição de categorias de análise e posteriormente uma representação dinâmica da interação entre as mesmas numa escala temporal. Essa análise dinâmica foi realizada separando os trechos analisados em dois grupos: explicações conceituais e resolução de problemas.

Naturalmente, precisamos estar cientes de que o discurso realizado em um ambiente de sala de aula é intencional, dependente do contexto e do público alvo, e não necessariamente é um reflexo da maneira como o professor pensa. Entretanto, entendemos que as opções feitas por ele na preparação e exposição de suas aulas podem fornecer alguns indícios sobre sua maneira de encarar o papel da matemática nas teorias físicas e também sobre a influência de seu discurso nas concepções dos estudantes. Para acessar as intenções

\footnotetext{
${ }^{29}$ Por meio de uma consulta feita à Comissão de Avaliação de Disciplinas (CAD) do Instituto de Física da USP, tivemos acesso às avaliações dos cursos (Física 3 e 4) ministrados por este professor nos semestres de 2005/2, 2006/1, 2006/2 e 2009/2 (ver Anexo 1). Os resultados comprovam uma aprovação praticamente unânime dos alunos evidenciando um altíssimo grau de satisfação pelo desempenho do docente por parte dos discentes.

${ }^{30}$ Tivemos acesso ao histórico das disciplinas que o professor já ministrou no Instituto de Física desde o ano de 1975. Física 3, o curso investigado neste estudo de caso, foi ministrado em 16 semestres (filmamos as aulas do $16^{\circ}$ ), o que evidencia a larga experiência deste professor e reforça a pertinência de uma análise mais profunda deste caso.

${ }^{31}$ É interessante notar que, além de sua formação como físico, o professor investigado estudou filosofia da ciência na Inglaterra.
} 
didáticas do professor - bem como suas opções teórico-metodológicas - de maneira mais eficaz, conduzimos duas entrevistas semiestruturadas (totalizando aproximadamente e 2 horas) com o professor, as quais forneceram elementos extras para a validação de nossas categorias de análise.

As categorias serão descritas e exemplificadas no Capítulo 4. Na próxima seção descrevemos brevemente os principais resultados obtidos a partir da análise das aulas de relatividade restrita no estudo piloto, os quais corroboraram nossa hipótese de que o estudo de caso com este professor seria pertinente e foram importantes para o processo de consolidação das categorias. 


\subsection{ESTUDO PILOTO: AULAS DE RELATIVIDADE RESTRITA}

As aulas sobre relatividade restrita que constituem os dados do estudo piloto ${ }^{32}$ são parte integrante do curso de Física 4, o qual abrange também circuitos elétricos, linhas da transmissão, ondas eletromagnéticas e campos em meios materiais. As razões para a escolha dessas aulas para o estudo piloto são: 1) Este era o curso ministrado pelo professor no semestre em que decidimos investigar sua prática e 2) A relatividade, além de extremamente dependente do formalismo matemático, seria abordada em apenas dez aulas, o que facilitaria nossa avaliação sobre a pertinência de gravar outras aulas deste professor. Os temas das dez aulas gravadas nesta etapa da pesquisa são descritos a seguir:

Aula 1 - Relatividade: impacto e princípios

Aula 2 - Dilatação do tempo

Aula 3 - Contração do espaço e quebra de simultaneidade

Aula 4 - Transformações de Lorentz

Aula 5 - Transformações de Lorentz: aplicações

Aula 6 - Adição de velocidades

Aula 7 - Relatividade: transformações de campos e densidades

Aula 8 - Eletromagnetismo: mudanças de referencial 1

Aula 9 - Eletromagnetismo: mudanças de referencial 2

Aula 10 - Os campos de uma carga em movimento uniforme

Para ilustrar os principais resultados da análise dessas aulas, selecionamos trechos das transcrições nos quais a discussão do papel da matemática na relatividade esteve presente. Inicialmente, contextualizamos brevemente a situação que motivou cada episódio, transcrevemos trechos retirados das gravações das aulas e analisamos as diversas concepções presentes no discurso do professor.

\section{Aula 1 - Relatividade e a mudança na maneira de se fazer física: discussão explícita do papel da matemática no pensamento físico}

Logo na primeira aula sobre relatividade, o professor optou por uma discussão de natureza epistemológica enfatizando que essa teoria representou uma revolução na maneira de se fazer física. Destacou que antes dela havia uma crença de que as teorias físicas deveriam ser formuladas a partir da experiência (indutivismo) e que a mesma forneceu uma espécie de "liberdade", uma vez que possibilitou que físicos criassem teorias a partir de

\footnotetext{
${ }^{32}$ Os principais resultados do estudo piloto foram apresentados em Karam e Pietrocola (2009b, 2010), Karam,
} Pietrocola e Pospiech (2011) e Pospiech e Karam (2010). 
argumentos lógicos, buscando primeiramente consistência matemática e coerência interna em seus princípios, e posteriormente verificando resultados experimentais. Citou o caso da teoria das supercordas como um exemplo atual de uma teoria que, apesar de não apresentar comprovações experimentais, concentra seus esforços na busca pela consistência matemática e é reconhecida pela comunidade física; postura essa que, segundo ele, não seria permitida antes de 1900. O professor reforça que a relatividade foi responsável por essa revolução na maneira de encarar a física e chega a dizer que foi Einstein quem "liberou". Nesse momento, um aluno faz uma pergunta que demanda uma resposta explícita sobre a enigmática relação entre matemática e física.

A1: Professor, nessas especulações, supondo-se que a teoria seja comprovada, o quanto dessas especulações pode-se considerar que é uma ferramenta matemática e o quanto que é um fenômeno fisico?

Professor: Essa talvez seja a questão mais complicada da física - ou uma das mais complicadas - qual é a relação entre matemática e física? Como o Dirac chegou à antipartícula? Ele resolveu uma equação (escreve a equação $\mathrm{E}^{2}=\mathrm{p}^{2} \mathrm{c}^{2}+\mathrm{m}^{2} \mathrm{c}^{4}$ no quadro). $O$ que sai da conta é uma coisa quadrada. E dai tira uma raiz e fala a raiz com sinal menos tinha um significado. Portanto, isso deve existir. [...] O que você normalmente faz com o sinal menos, você diz que não tem significado físico, ele não fez isso, ele disse tem significado fisico. Ele previu que deveria ter estados com energia negativa, interpretou isso direito e cinco anos depois os caras mediram o anti-elétron pela primeira vez. [...] $\boldsymbol{E}$ daí você fica pasmo! Como pode esse conjunto de símbolos ter alguma relação com o mundo material? TEM! [...] Eu acho que é mais fácil você falar de religião do que falar dessa relação aqui. Ela é uma relação realmente misteriosa. Ela entra fundo fundo fundo no nosso modo de pensar. O que é interessante na física é o seguinte: a gente consegue associar esses símbolos na nossa mente se você quiser. Parece que a sua mente tem uns tentáculos matemáticos que conseguem tocar o mundo material de algum jeito de longe. $O$ seu dedo não toca, a sua mente toca. Isso é esquisito. Mas para a gente trabalhar nisso não é preciso explicitar essa relação e isso é uma coisa muito legal em Física. Você não precisa ser capaz de fazer um discurso sobre a relação entre física e matemática para fazer física. [...] Não é preciso ter uma consciência explícita e verbal sobre o que estamos fazendo.

Pela questão levantada pelo aluno, é possível perceber que o mesmo parece crer em uma distinção entre o que é "apenas" ferramenta matemática do que é o fenômeno físico. Estudos filosóficos condenam esse tipo de distinção entre partes matemática e não matemática da física, conforme vimos nos argumentos de Boniolo e Budinich (2005) no Capítulo 1. Em sua resposta, o professor chama a atenção para a importância e complexidade do tema e opta por refletir sobre um caso específico, em vez de falar genericamente sobre o assunto. Essa postura está em concordância com a recomendação de Paty (1994) previamente citada. 
O exemplo escolhido é emblemático, pois revela que um resultado obtido no interior de uma estrutura lógica, aparentemente oriundo de operações abstratas, pode ser interpretado fisicamente e, em seguida, detectado experimentalmente. $\mathrm{O}$ fascínio/espanto com a relação entre os símbolos e o mundo real fica claro quando o professor confessa que você fica pasmo, e seu deslumbramento é semelhante às opiniões de Wigner e Feynman citadas anteriormente.

Ao defender que a relação entre Matemática e Física entra fundo no nosso modo de pensar e que a mente possui tentáculos matemáticos que tocam o mundo, o professor parece corroborar a hipótese de que a matemática é estruturante do pensamento físico (PIETROCOLA, 2002), refutando assim a noção da mesma como mera ferramenta/instrumento da física. Entretanto, a mensagem final deste episódio é reveladora, pois evidencia que um físico profissional não precisa ter consciência dessa relação para fazer física de boa qualidade. A sensação é a de que, em certos casos, quando o físico opta por "ignorar conscientemente" questões de ordem filosófica/metafísica, e encara a matemática como uma ferramenta de trabalho, isso o possibilita avançar em suas pesquisas. Essa certamente é uma mensagem importante para um público alvo de futuros bacharéis em física, mas cabe-nos questionar se a mesma se justificaria no contexto da educação básica.

\section{Aula 3 - Intuição versus pensamento rigoroso na Relatividade}

No início da terceira aula, o professor alerta que relatividade é um assunto muito difícil e que exige pensamento rigoroso. Neste trecho, a discussão sobre o papel do pensamento matemático está mais implícita.

Professor: O que nós estamos vendo agora é relatividade. Relatividade é uma coisa muito difícil de aprender. Porque ela viola nossa intuição. Não só viola nossa intuição, mas também viola o que a gente pode fazer com a intuição [...] Tem hora em que você não pode usar a intuição. Porque você comete erros. Qual é jeito de aprender relatividade? Tem que ser um pouco rigoroso no pensamento. Por exemplo, toda vez que você fizer relatividade oral, disser "o tempo dilata” você errou. Isso é verdade em um caso específico. "O espaço contrai”, também errou. [...] Qualquer generalização que você faça está errada. [...] Então qual é o jeito? O jeito é usar as Transformações de Lorentz!

Naturalmente, os anos de experiência como físico profissional e professor foram determinantes para perceber os possíveis erros e armadilhas conceituais quando se aprende relatividade ou se trabalha com ela. Sua mensagem é um alerta; é necessário um pensamento rigoroso, pois a intuição falha. Seu comentário sobre o erro ao se fazer relatividade oral é um indício de que a linguagem natural não é adequada para tratar dessa teoria física e ao dizer que o jeito correto é usar as Transformações de Lorentz, fica evidente que o rigor 
previamente mencionado está associado a uma estrutura matemática consistente (transformações de quadrivetores).

Em outro momento, na mesma aula, o professor volta a chamar a atenção para as perigosas generalizações, para o comum excesso de sensacionalismo, e para os erros decorrentes do uso da intuição na resolução de problemas de relatividade.

Professor: Dilatação do tempo e contração do espaço é um deslumbramento superficial da relatividade. UAU! Só que quando você põe o pé no chão tem muita coisa por trás. Tem isso também [...] É fácil administrar isso, tem que conter a ansiedade. A gente só entende isso através da conta. Qual é a mensagem: você vai ter que aprender muito bem como é que se faz a conta. E na hora que a coisa engrossar, se você souber a regra que faz a conta você vai lá e acerta. E aí você constrói uma intuição a posteriori. Meio esquisito isso, é uma limitação minha, não consigo ter intuição sobre isso. Tudo bem, aprende a conta. Aprende a usar as Transformações de Lorentz.

Essa passagem é central para os objetivos desta pesquisa. Quando o professor diz que só se entende através da conta ele destaca a função imprescindível do formalismo matemático, especialmente em uma situação em que nossa intuição clássica falha. Sua recomendação em seguida é ainda mais dramática, pois envolve o abandono de uma intuição física (a priori), ou seja, o professor sugere que o estudante não tente prever o que vai acontecer. O conselho é que primeiramente o estudante aprenda a fazer a conta e a mensagem é a seguinte: "mergulha no formalismo", veja onde ele te leva, e só então construa uma intuição sobre o que foi feito. Essa atitude está coerente com o que Boniolo e Budinich (2005) chamaram de Revolução Metodológica de Dirac (ver Capítulo 1). Nesse sentido, as Transformações de Lorentz não poderiam ser encaradas como uma simples ferramenta, mas como um poderoso recurso que liberta nosso pensamento das falsas impressões sensoriais. Segundo Paty (1995), esse seria um exemplo da "forte” relação da física com a matemática, uma vez que esta penetra na própria construção do conceito físico.

\section{Aulas 1-10 - Esquema para a interpretação conceitual das Transformações de Lorentz}

É interessante notar que, apesar das Transformações de Lorentz serem apresentadas formalmente somente na quarta aula, o professor as discute conceitualmente desde a primeira aula utilizando um esquema que parece ter papel central no curso como um todo (ver Figura 12). 
Mundo Platônico - Absolutos

(Inacessível à experiência humana)

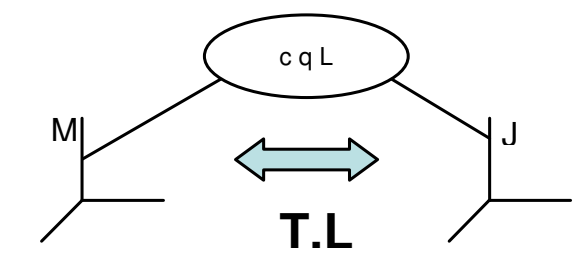

Projeções do mundo absoluto nos referenciais. Medidas acessíveis.

Figura 12: Esquema explicativo do significado das Transformações de Lorentz presente em quase todas as aulas de relatividade.

Em linhas gerais, a ideia do esquema é que existe um mundo absoluto (platônico) onde estão grandezas absolutas, isto é, independentes do referencial, como a carga elétrica $(q)$, a velocidade da luz $(c)$ e a Lagrangeana $(L)$. Esse mundo não é acessível à experiência humana, pois não existe fisica absoluta. Um artifício didático muito interessante utilizado pelo professor é escrever as grandezas pertencentes a este mundo sempre com giz branco. $\mathrm{O}$ que é acessível à experiência humana são as projeções coloridas desse mundo nos referenciais, os quais são comumente representados por nomes de pessoas como João e Maria. Um evento é definido por quatro coordenadas (três espaciais e uma temporal) e as mesmas são coloridas, uma vez que podem variar dependendo do referencial. A ocorrência do evento é branca (absoluta), mas a descrição do mesmo é colorida.

Nesse contexto, as Transformações de Lorentz (TL) são encaradas como operações matemáticas que permitem estabelecer uma relação entre as coordenadas de um evento definidas em um referencial e outro que se move relativamente a este com velocidade constante. Se um evento tem coordenadas $\left(\mathrm{x}_{\mathrm{M}}, \mathrm{y}_{\mathrm{M}}, \mathrm{z}_{\mathrm{M}}, \mathrm{t}_{\mathrm{M}}\right)$ no referencial de Maria representado em vermelho - as coordenadas do mesmo evento no referencial de João $\left(\mathrm{x}_{\mathrm{J}}, \mathrm{y}_{\mathrm{J}}\right.$, $\left.\mathrm{z}_{\mathrm{J}}, \mathrm{t}_{\mathrm{J}}\right)$ - referencial amarelo - podem ser obtidas através das TL.

Destacamos a importância de interpretar fisicamente o significado das expressões matemáticas, como uma habilidade (estrutural) fundamental para combatermos a aplicação cega de relações matemáticas sem sentido, tão comum no ensino de física em diversos níveis. Assim, fomos encontrando diversas evidências de que analisar aulas ministradas por professores diferenciados e experientes como este, pode fornecer interessantes elementos didático-pedagógicos para o enfoque na interpretação de expressões matemáticas no ensino de física. 


\section{Aula 4 - Demonstração das Transformações de Lorentz}

Nesse episódio relatamos como foi conduzido o processo de dedução das Transformações de Lorentz. Destacamos a habilidade do professor em expor as condições/hipóteses físicas impostas por Einstein e as operações matemáticas que as representam.

Professor: De onde saem as Transformações de Lorentz? A questão é a seguinte: será que existe um conjunto de regras que me permitam, se eu souber o vermelho, saber o amarelo? [...] O Einstein quando pensou isso falou o seguinte: o que eu gostaria que permanecesse de fundamental em um referencial e no outro. Ele fala o seguinte: se o tempo nesse referencial for uniforme - o que é tempo ser uniforme? [...] Tempo uniforme é o tempo que passa com a mesma velocidade. Isso estamos acostumados a pensar. O que seria o tempo não uniforme? Seria como se o tempo fosse "empelotado". Tem um lugar onde o tempo é mais denso e outro onde ele é menos denso. [...] O que é tempo uniforme? Experimentalmente isso quer dizer que hoje é igual a amanhã. [...] Pergunta: que dia que é bom para fazer experimento com o LHC? Ai alguns físicos vão no oráculo e ele fala assim: melhor dia é 17 de setembro às 15:30. Vai lá no horóscopo, lê isso (risos). É isso? NÃO! Qualquer dia está bom. Por que? Porque tem uma hipótese subjacente, de que o tempo e o espaço não terão mudado de um dia para o outro. O tempo não pode ser uniforme em um referencial e não uniforme no outro.

Depois da hipótese da simetria contínua de translação no tempo, o professor passa a esclarecer as condições relacionadas ao espaço:

Professor: E além disso, tem propriedades do espaço que devem ser mantidas. O espaço é homogêneo. Significa que ele não é empelotado. Não tem densidades de espaço diferentes aqui e ali. De novo se você quiser pensar no plano experimental, se você pegar seu laboratório e mudar de lugar ele tem que dar o mesmo resultado? Se você puser o laboratório em um caminhão e fizer a experiência no Amazonas tem que dar a mesma coisa? TEM! Então o experimento não pode depender do local onde você faz. Do ponto de vista físico, todas as posições do universo são equivalentes. E isso tem que se manter no outro referencial também. E tem outra; o espaço é isotrópico, essa direção é equivalente a essa outra. Se você pegar seu laboratório e virar, nada acontece. Ok?

Com frequência as hipóteses da uniformidade do tempo e da homogeneidade do espaço, bem como as consequências das mesmas, não são profundamente abordadas nas aulas de física. Pelo tempo destinado a essa discussão, fica evidente que ela tem um papel central para o professor. Na sequência, ele menciona explicitamente qual estrutura matemática deve ser usada para que as condições sejam mantidas. Em nossa interpretação, essa habilidade (estrutural) de identificar os aspectos essenciais que justificam o uso de uma estrutura matemática específica (transformação linear) para representar uma imposição sobre o mundo físico (simetrias) reflete uma elaborada compreensão do papel da matemática como instrumento de pensamento da física. 
Professor: A manutenção dessas propriedades faz com que essa regra seja extremamente simples. Isso daqui tem que ser uma matriz (Transformação Linear - Escreve $x_{J}=a_{11} x_{M}+$ $\left.a_{12} \cdot y_{M}+a_{13} \cdot z_{M}+a_{14 .} t_{M}\right)$. Por que essa regra tem que ser linear? Porque essa é a única regra que mantém as características do tempo e do espaço nos dois referenciais (Simetria). Se você tivesse um $x$ ao quadrado aqui, isso mudaria tudo. Se o espaço é homogêneo no referencial amarelo, ele não seria mais no vermelho.

\section{Aula 7 - Covariância das equações de Maxwell nas transformações de campos}

No início da sétima aula de relatividade, o professor alerta seus alunos que aquela aula é cheia de contas, mas que o mais importante é que eles entendam o significado físico da conta. Disse também que iria parar de abordar problemas de Cinemática Relativística a passaria a trabalhar com os problemas enfrentados por Einstein na tentativa de aplicar o princípio da relatividade ao eletromagnetismo.

O esquema previamente apresentado é retomado. O objetivo agora é escrever as leis do eletromagnetismo (Equações de Maxwell) em um referencial (Maria - vermelho) e aplicar as transformações de Lorentz para escrever as componentes dos campos elétrico e magnético medidas por outro referencial (João - amarelo), o qual se movimenta uniformemente em relação ao primeiro. O recurso didático das cores está tão impregnado no discurso do professor que ele chega a dizer tentará amarelar as equações vermelhas. A imposição feita é que o eletromagnetismo seja covariante, ou seja, as equações de Maxwell precisam ter a mesma forma nos dois referenciais. Em uma etapa da dedução matemática das transformações dos campos, é preciso considerar que as expressões que representam as componentes dos mesmos sejam iguais, garantindo assim a desejada covariância. Nesse exato momento $^{33}$, um aluno manifesta certo receio quanto à validade lógica dessa suposição, o que motiva uma profunda reflexão sobre como a física se relaciona com a matemática por parte do professor.

\footnotetext{
${ }^{33}$ A dedução das transformações entre campos é realizada a partir de uma combinação das leis de Faraday $\left(\nabla \times \vec{E}=-\frac{\partial \vec{B}}{\partial t}\right)$ e Gauss magnética $(\nabla \cdot \vec{B}=0)$ em cada referencial, juntamente com a aplicação das transformações de Lorentz $\left(x_{J}=x_{M} ; y_{J}=\gamma\left(y_{M}-v t_{M}\right) ; z_{J}=z_{M} ; t_{J}=\gamma\left(t_{M}-\frac{v}{c^{2}} y_{M}\right)\right)$ para relacionar as derivadas espaciais e temporais nos dois referenciais pela regra da cadeia. Após "amareladas" (referencial de João) as derivadas, a componente $\mathrm{x}$ da lei de Faraday no referencial vermelho (Maria) é escrita como $\frac{\partial}{\partial y}\left(\gamma E_{z_{M}}-v \gamma B_{x_{M}}\right)-\frac{\partial}{\partial z}\left(E_{y_{M}}\right)+\frac{\partial}{\partial t}\left(\gamma \frac{v}{c^{2}} E_{z_{M}}+\gamma B_{x_{M}}\right)=0$. A igualdade é então imposta quando essa expressão é comparada com a componente $\mathrm{x}$ da lei de Faraday no referencial amarelo (João) obtendo as seguintes relações: $E_{z_{J}}=\gamma\left(E_{z_{M}}-v B_{x_{M}}\right) ; E_{y_{J}}=E_{y_{M}} ; B_{x_{J}}=\gamma\left(\frac{v}{c^{2}} E_{z_{M}}+B_{x_{M}}\right)$. Foi precisamente essa etapa que gerou a profunda discussão que destacamos nessa aula.
} 
A2: Não estou muito bem convencido de que essas componentes aqui tem que ser iguais àquelas lá.

Professor: Pessoal, essa é uma pergunta muito central no que é fazer física. Você consegue demonstrar, do ponto de vista matemático, que isso daqui é igual a isso? A resposta é não! Só que física só liga para a matemática quando é importante. E agora eu não ligo. Eu não quero fazer uma coisa lógica. Física não é lógica. A física tenta montar uma imagem da natureza. E ai o cara que fez isso ele torce para isso ser possível. [...] Eu cheguei aqui, e desejo ardentemente que eu consiga levar minha teoria para frente. Eu gostaria muito que essa coisa fosse igual àquela lá. Escrevo esse desejo como uma verdade provisória. Se eu conseguir, achar uma regra que seja coerente, que não tenha furos, vou acreditar que isso é verdade. Por quê? Porque eu quero acreditar no primeiro princípio da relatividade. Por quê? Porque ele é bonito.

Provavelmente, a pergunta do aluno foi motivada por um hábito de demonstrar logicamente toda e qualquer afirmação física. Nessa manifestação, o professor vê uma grande oportunidade de romper com essa crença e destacar que a física é extremamente dependente da matemática, mas não se resume a ela. Essa postura está em ressonância com o posicionamento de Feynman (1985) quando o mesmo enfatiza que "física não é matemática e matemática não é física" e de Paty (1995) quando argumenta que "por si só, o pensamento lógico não pode nos fornecer conhecimento sobre o mundo da experiência" (ver Capítulo 1).

Insistindo em uma possível demonstração lógica, outro aluno clama por uma forma mais rigorosa de provar a validade da igualdade, e a relação entre matemática e física é novamente discutida profundamente.

\section{A3: Não existe nenhuma forma mais rigorosa de demonstrar isso?}

Professor: Pois é, não existe rigor! O rigor é isso. Esse é o rigor máximo possível na física [...] Ou seja, isso significa que a física é feita de "um montão" de intuição com "um montão" de lógica. Essa conta está certa do ponto de vista matemático? Certíssima! [...] A matemática está super presente lá dentro. Mas a matemática me carrega... [...] Você colocar intuição e matemática é mais do que só matemática, não é menos. Você transforma a matemática no seu escravo, não no seu patrão. O patrão sou eu! A física! Eu que mando. Por quê? Porque eu quero entender o mundo, e o mundo não é feito de matemática, é feito dessa coisa esquisita. Essa aula é fundadora porque isso que foi o grande progresso do século $X X$, foi esse salto. A lógica serve reformular as linguagens e transformar uma coisa nela mesma. O primeiro princípio da relatividade não é lógico. Ele é um desejo. A visão ideal de que o mundo deveria ser daquele jeito. A matemática fala assim, aqui você cometeu erro, isso não é coerente. [...] Não tem jeito de você saber mais a partir do menos sem dar saltos.

Defendemos que essa discussão de alto nível só foi possível porque o professor escolheu realizar a demonstração da fórmula relativística da transformação dos campos elétrico e magnético, e não apenas fornecer seu resultado final. Assim, a imposição do princípio da relatividade como um desejo físico fica localizada num momento específico da 
dedução, no qual duas componentes precisam ser igualadas. Este exemplo ilustra nosso argumento de que a demonstração de fórmulas a partir de princípios físicos pode revelar aspectos intrínsecos da relação entre matemática e física.

A mensagem final do episódio é que somente a lógica não nos permite extrapolar o mundo em que vivemos, é preciso dar saltos. Esses saltos não ocorrem com frequência na história da Ciência e normalmente são conseguidos após anos de muito esforço e pensamento lógico-dedutivo. De acordo com essa concepção, a matemática guia o raciocínio do físico, mostra os erros por ele cometidos, mas não é suficiente para propiciar os saltos necessários para a criação de suas teorias. Dessa forma, o princípio da relatividade não é logicamente demonstrável.

De maneira geral, o estudo piloto corroborou nossa hipótese de que a análise das aulas deste professor em particular forneceria importantes elementos para entendermos como abordar o caráter estruturante da matemática em aulas de física. Foi possível identificar inúmeros momentos em que habilidades estruturais - como a interpretação física de expressões matemáticas, a demonstração de fórmulas a partir de princípios físicos e o privilégio do pensamento matemático rigoroso sobre limitações da intuição sensorial - foram abordadas. Assim, tomamos a decisão de gravar todas as aulas do curso de eletromagnetismo no segundo semestre de 2009, dessa vez com um olhar mais apurado para os momentos onde o papel da matemática seria abordado. Entretanto, estávamos interessados não somente em identificar e exemplificar a abordagem de habilidades técnicas e estruturais em episódios de ensino, mas também de perceber como se dá a interação entre elas em uma escala temporal. Dessa forma, recorremos à utilização de um software denominado videograph o qual foi concebido justamente para a análise qualitativa de dados registrados em vídeo. $\mathrm{O}$ uso do software foi fundamental para o refinamento de nossas categorias e para uma percepção mais da dinâmica de todo o processo. Na próxima seção descrevemos o estudo definitivo realizado no curso de eletromagnetismo e a metodologia utilizada para a análise de duas aulas. 


\subsection{ESTUDO DEFINITIVO: CURSO DE ELETROMAGNETISMO - ANÁLISE COM O VIDEOGRAPH}

As aulas do curso de Física 3 (eletromagnetismo) foram gravadas no segundo semestre de 2009. De maneira semelhante ao estudo piloto, a gravação foi centrada no professor e uma atenção especial foi dada aos momentos em que o papel da matemática foi abordado. O material didático utilizado no curso consiste em uma apostila (notas de aula) elaborada tanto pelo professor analisado como por outros professores que ministram a mesma disciplina no Instituto de Física. Os 40 capítulos dessa apostila representam o planejamento (ideal) das 40 aulas a serem ministradas ao longo do curso:

Aula 1 - O universo físico

Aula 2 - O eletromagnetismo

Aula 3 - A matéria e o eletromagnetismo

Aula 4 - Fenômenos

Aula 5 - Densidades de carga

Aula 6 - Integrais múltiplas

Aula 7 - Integrais múltiplas

Aula 8 - Carga elétrica: propriedades

Aula 9 - Princípio da superposição

Aula 10 - Princípio da superposição

Aula 11 - Princípio da superposição

Aula 12 - Fluxo

Aula 13 - Lei de Gauss

Aula 14 - Lei de Gauss: Aplicações I

Aula 15 - Lei de Gauss: Aplicações II

Aula 16 - Forças conservativas e energia potencial

Aula 17 - Energia potencial: Aplicações

Aula 18 - Potencial eletrostático

Aula 19 - Gradiente

Aula 20 - Densidade de energia eletrostática

Aula 21 - Auto-energia: Aplicações

Aula 22 - Auto-energia: Cargas puntiformes

Aula 23 - Divergente: Lei de Gauss diferencial

Aula 24 - Rotacional: "Lei de Faraday" 
Aula 25 - Resumo da eletrostática: Características elétricas dos nucleons

Aula 26 - Corrente elétrica

Aula 27 - Baterias e condutores metálicos

Aula 28 - Lei de Ohm

Aula 29 - Leis de Gauss magnética e de Biot e Savart

Aula 30 - Lei de Biot e Savart: Aplicações

Aula 31 - Lei de Ampère

Aula 32 - Força de Lorentz

Aula 33 - Força de Lorentz: Efeito Hall

Aula 34 - Lei de Faraday

Aula 35 - Lorentz ou Faraday: movimento relativo entre fio com corrente e espira

Aula 36 - Lorentz ou Faraday

Aula 37 - Auto-indução

Aula 38 - Energia do campo magnético

Aula 39 - Corrente de deslocamento

Aula 40 - Equações de Maxwell

O material didático utilizado é diferenciado se o compararmos com o que é comumente encontrado no mercado editorial ${ }^{34}$. As principais características que o diferenciam são: 1) Intensa presença de discussões epistemológicas (Por exemplo: O que é física? Qual a relação entre física e matemática? Como o eletromagnetismo pensa o mundo?) e de definições precisas de termos essenciais para a argumentação com o auxílio do dicionário; 2) Poucos exemplos (problemas-tipo) são apresentados e discutidos em profundidade, sendo que cada etapa de sua resolução é cuidadosamente justificada; 3) Um reduzido número de problemas (quase todos literais) e questões (conceituais) são propostos ao final de cada capítulo. Os alunos são orientados a utilizar este material como um apoio para o estudo individual, mas o mesmo não é necessário para o devido acompanhamento das aulas.

A avaliação da disciplina foi realizada por meio de quatro provas individuais ${ }^{35}$. A média final $M$, que precisa ser maior ou igual a 5,0 para a aprovação, é calculada da seguinte forma: $M=0,3$ (soma das duas melhores notas entre as três primeiras provas) $+0,4$ (nota da

\footnotetext{
${ }^{34}$ Referimo-nos aos clássicos Halliday; Resnick e Krane (2003), Young e Freedman (2003), Tipler (1984) e similares.

${ }^{35}$ As quatro provas aplicadas durante o semestre encontram-se no Anexo 2.
} 
quarta prova). Dos 81 alunos matriculados no início do semestre analisado, 11 abandonaram o curso após a primeira prova, sendo que 59 dos 70 restantes obtiveram êxito e foram $\operatorname{aprovados}^{36}$. Isso resulta em um índice de $84 \%$ de aprovação o que, apesar de não termos realizado um levantamento detalhado, indica um rendimento muito acima da média para o primeiro contato de estudantes de graduação com o tema.

Uma análise prévia do planejamento do curso nos aponta para momentos nos quais a imbricada relação entre matemática e física seria abordada. Conceitos centrais como carga, densidade e corrente elétricas seriam tratados e devidamente matematizados. Operações matemáticas como derivadas, integrais múltiplas, operadores vetoriais (nabla: gradiente, divergente e rotacional), entre outras, teriam interpretações físicas no contexto eletromagnético de campos e cargas. Cada uma das equações de Maxwell seria abordada nas formas integral e diferencial. Dessa forma, nossa atenção foi concentrada em tais momentos.

Após assistirmos a todas as aulas, selecionamos 19 episódios para uma análise mais detalhada. Esta seleção seguiu basicamente dois critérios: 1) a relevância e grau de matematização do tema (por exemplo, a matematização dos conceitos de densidade de carga e corrente elétrica, a interpretação física de expressões matemáticas como os operadores diferenciais vetoriais e a explicação das equações de Maxwell) e 2) a existência de episódios de ensino nos quais alunos fazem intervenções que indicam dificuldades na compreensão da utilização do formalismo matemático do eletromagnetismo. Os episódios selecionados possuem início e fim determinados e foram divididos em "Explicações conceituais" e "Resolução de problemas". Uma análise mais detalhada da categorização dos mesmos é apresentada no Capítulo 5.

A ferramenta utilizada para a análise dos trechos selecionados é o software videograph. Com este recurso, é possível categorizar momentos do discurso do professor e obter uma linha do tempo que ilustra como o mesmo se desenvolve no decorrer de uma aula. Uma etapa importante para o tipo de observação estruturada que pretendemos, é definir uma unidade de tempo para realizar a categorização (JANÍK; SEIDEL, 2009). Após algumas tentativas, percebemos que 20 segundos eram suficientes para o nível de precisão que desejávamos. A Figura 13 ilustra a interface do programa durante o processo de categorização. É possível visualizar as três janelas (Video, Timeclip e Codeview) com as quais trabalhamos simultaneamente durante a codificação. No momento exato do registro da Figura 13, os 20 segundos entre 34:40 e 35:00 estão sendo categorizados e transcritos. Estes

\footnotetext{
${ }^{36}$ Uma lista com as notas de todas as avaliações dos alunos, mas sem os nomes, encontra-se no Anexo 3. 84
} 
20 segundos foram categorizados simultaneamente como Matematização (M1 - Idealização), Analogia (A1 - Exemplos do cotidiano) e Representações visuais (V1-gestos). As categorias de análise são devidamente apresentadas, exemplificadas e justificadas no Capítulo 4.

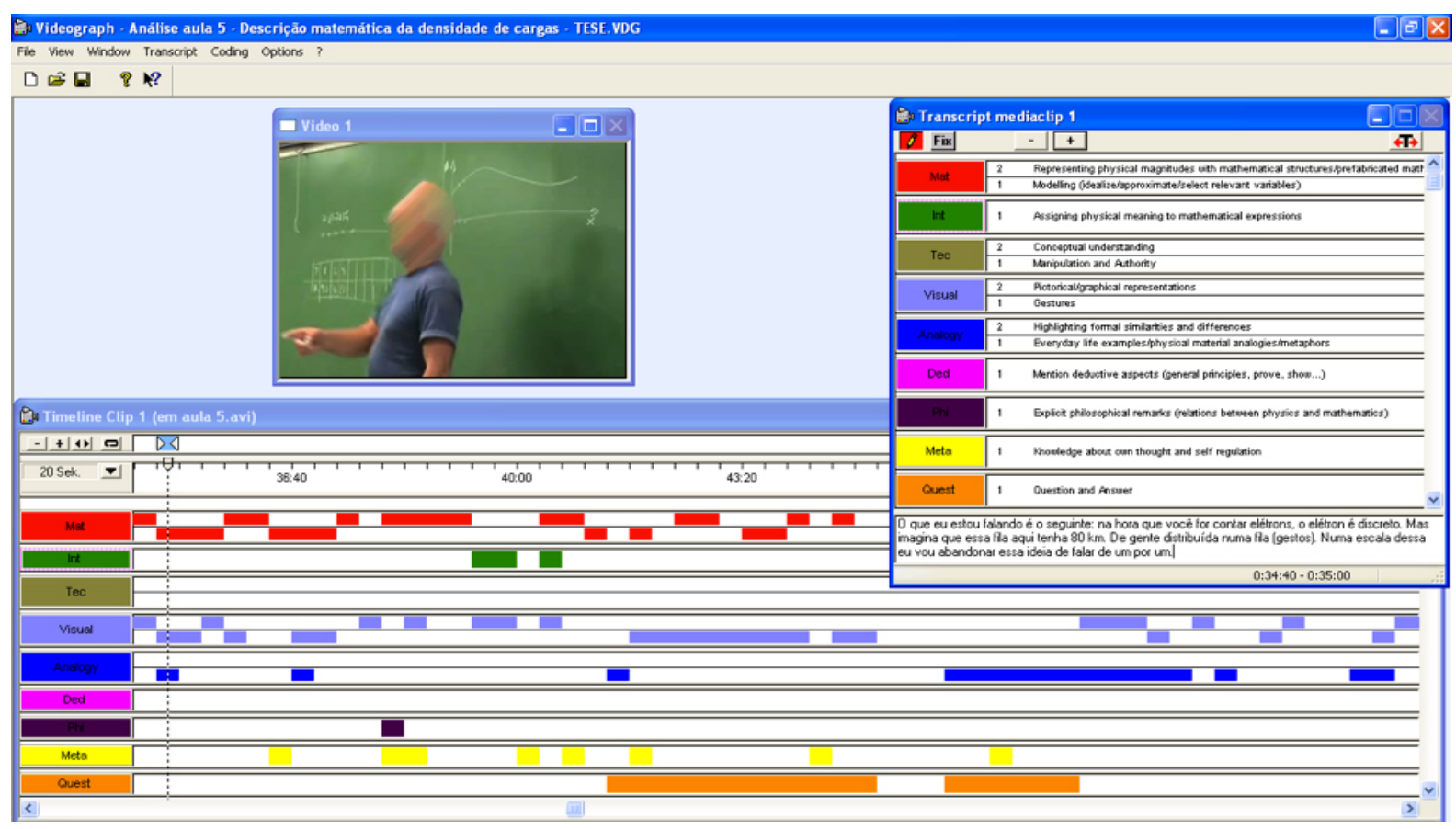

Figura 13: Interface do videograph durante a categorização.

É interessante notar que o próprio processo de categorização utilizando o videograph auxilia na definição das categorias. Utilizando os diagramas fornecidos pelo programa e trechos das aulas foi possível apresentar e discutir a concepção das categorias com colegas e professores. Objetivando minimizar o grau de subjetividade da categorização, realizamos duas sessões de validação das mesmas.

As sessões foram organizadas da seguinte forma: primeiramente, as categorias foram apresentadas e a categorização de um pequeno trecho de aula foi exposta e justificada. Em seguida, quatro colegas pesquisadores categorizaram cinco pequenos trechos (em torno de 7 min) individualmente. Por fim, as categorizações realizadas por eles foram comparadas com a realizada previamente por nós. A categorização inicial já revelou um nível satisfatório de concordância (entre 60-70\%), o qual foi elevado (cerca de 80 \%) após uma discussão coletiva sobre as interpretações e critérios utilizados.

Por fim, duas entrevistas de aproximadamente uma hora cada foram conduzidas com o professor, visando a investigar as justificativas do mesmo para as diferentes abordagens representadas em cada categoria. Tais entrevistas também serviram como validação (interna) da categorização. No próximo capítulo, cada categoria é devidamente apresentada, fundamentada e exemplificada com fragmentos das aulas. 


\section{4 - CATEgorias de ANÁLISE}

Neste capítulo apresentamos nossas categorias de análise, descrevendo detalhadamente cada uma delas, exemplificando-as com fragmentos do discurso do professor e procurando justificar as escolhas por meio de argumentos diversos, fundamentados tanto em epistemologia como aspectos didático-pedagógicos. Na realidade, reconstruir o processo que levou à consolidação dessas categorias não é uma tarefa elementar. Muitos foram os fatores que o influenciaram, dentre os quais estão principalmente:

- Reflexões histórico-epistemológicas sobre as relações entre matemática e física (Capítulo 1)

- Categorias semelhantes presentes na literatura (Capítulo 2)

- Análise detalhada (videograph) das aulas deste estudo de caso

- Experiência prévia do pesquisador com situações de ensino e aprendizagem

- Discussões com colegas, professores e pesquisadores em diversas ocasiões

Assim, parafraseando Reichenbach, apresentamos o contexto da justificação, cientes da impossibilidade da reconstrução do contexto da descoberta. Cada categoria é acompanhada por um retângulo que indica sua cor na categorização com o videograph. Neste capítulo utilizaremos somente fragmentos isolados de diversas aulas para caracterizar elementos que nos levaram a identificar cada categoria em particular. No próximo capítulo, analisaremos episódios de ensino (explicações conceituais e resolução de problemas) para evidenciar a dinâmica interação das mesmas numa escala temporal. 
A etapa inicial do desenvolvimento de uma ciência física consiste na descoberta de um sistema de quantidades das quais seus fenômenos possam depender. A próxima etapa é a descoberta da forma matemática das relações entre essas quantidades. Após isso, a ciência pode ser tratada como uma ciência matemática e a verificação das leis é realizada por uma investigação teórica sobre as condições em que determinadas quantidades podem ser medidas com maior precisão, seguida por uma realização experimental destas condições e medição das quantidades. (MAXWELL, 1890, p. 257).

A primeira categoria de análise é denominada matematização e está relacionada com o processo de tradução do mundo físico (concepções sobre a natureza, observações fenomenológicas e dados experimentais) para a matemática (estruturas e fórmulas matemáticas). Tal processo foi representado por flechas verticais crescentes (a) em nosso modelo exposto no Capítulo 2 (ver Figura 10). Ser bem sucedido nessa tradução depende da capacidade de pensar matematicamente, que envolve não apenas uma compreensão significativa de conceitos matemáticos e suas teorias, mas também a capacidade de abstrair, idealizar e modelar a realidade. Na verdade, trata-se de um processo extremamente complexo e muitas vezes ignorado em aulas de física. Observamos que o professor deu uma atenção especial e dedicou um tempo considerável à matematização ao longo do curso. Esta abordagem ocorreu principalmente na introdução de uma nova ideia ou conceito.

Identificamos duas etapas (subcategorias) que representam frequentemente uma ordem cronológica e hierárquica da matematização, as quais denominamos $M 1$ Modelização e M2 - Estruturas matemáticas. Descrevemos e exemplificamos cada uma das subcategorias a seguir.

M1 - Modelização (idealização/aproximação/seleção de variáveis relevantes)

Tendo em vista a intrínseca complexidade do mundo físico, a construção de representações matemáticas de fenômenos passa por um processo de modelização, o qual envolve idealizações, aproximações e seleção de variáveis relevantes. Conforme mencionamos no Capítulo 1 com o exemplo de Galileu, essa postura já envolve uma "atitude matemática", sendo considerada portanto a etapa inicial da matematização. Os fragmentos a seguir, retirados de diferentes aulas, ilustram momentos em que o discurso do professor foi categorizado como M1:

Uma estrada, você pode aproximar como uma coisa unidimensional. O comprimento é muito maior do que a largura. Fio de cabelo, você pode aproximar por uma coisa unidimensional. Fio de cabelo tem uma dimensão, não tem! Tem 3. (Aula 5-36:40-37:00) 
Se tiver abelha voando mais rápido, tem mais fluxo? Sim. Então tem essa noção de que o fluxo dessas abelhas aqui é proporcional à velocidade delas. (Aula 12 - 25:00-25:20)

Nesse problema é útil para definir energia potencial do sistema colocar um zero em algum lugar. E essa origem fica simples se eu tomar a origem no infinito. (Aula 16 - 1:07:201:07:40)

No momento a gente pode fazer a mesma coisa de um jeito mais "pedestre" [sem utilizar a função de Dirac] que é o seguinte. Se você tiver uma distribuição infinita. A carga for um ponto, fala tudo bem, supõe que ela é uma bolinha. (Aula 23 - 1:22:20-1:22:40)

Além de notar que as idealizações e aproximações são feitas normalmente de maneira explícita, é interessante perceber que nessa etapa inicial de construção de um modelo, o professor costuma chamar a atenção de seus estudantes para a distinção entre realidade e representações da realidade. Tal postura fica evidente na seguinte fala:

Fio elétrico tem densidade de carga? A pergunta é a seguinte. Você pega esse fio aqui e corta com a mente. Não é físico. Você secciona, corta com sua mente, matematicamente. (Aula 5-41:40-42:00)

O professor está preocupado em esclarecer que os modelos físico-matemáticos não podem ser encontrados na natureza, por se tratarem de abstrações construídas pela mente humana. Isso pode soar um tanto óbvio num primeiro momento, mas a menção explícita e incisiva parece indicar que o professor discorda de tal obviedade. O corte matemático é uma tentativa de esclarecer a diferença entre um corte real e outro mental (de comprimento infinitesimal $d x$ ).

M2 - Estruturas matemáticas (matemática pré-fabricada)

Alguns filósofos utilizam uma analogia conhecida como matemática pré-fabricada e comparam a atitude de alguns físicos à de "uma pessoa que vai ao mercado da matemática para pegar o que precisa para construir sua teoria" (BONIOLO; BUDINICH, 2005, p. 83). Representar grandezas contínuas por números reais, grandezas que envolvem direção por vetores, estados quânticos por matrizes, localizar pontos utilizando diversos sistemas de coordenadas, são alguns exemplos de utilização da matemática pré-fabricada. O uso de estruturas matemáticas para representação de grandezas físicas ocorre normalmente após a construção de um modelo (M1). Os trechos a seguir exemplificam tal uso:

Eu sei a força que cada um causa sobre mim. Mas como é que eu vou calcular o conjunto? Tem que somar tudo. Tudo bem? Aí, qual é o problema? Eu tenho que de alguma maneira inventar uma função matemática que descreva o jeito que vocês estão distribuídos. (Aula 5 - 16:00-16:20) 
Por isso a gente define fluxo de um vetor através de uma superficie pela integral dupla da projeção (produto escalar) entre o vetor que eu estou considerando e o vetor unitário normal à superfície (Aula 12 - 25:20-26:00 adaptado)

De maneira semelhante à subcategoria anterior, o professor costuma destacar que as estruturas matemáticas são construções da mente humana e não podem ser encontradas na natureza:

E aí você tem o instrumento de pensamento (branco). O que é o instrumento de pensamento, instrumento de pensamento não existe. Mas daí você inventa. É a matemática. Você põe a coordenada aqui. A coordenada não existe. Você que pôs. Ela não está na natureza. Mas você põe a coordenada lá e vai contando a distância. (Aula 5 - 1:00:40-1:01:00)

Por fim, há um importante aspecto qualitativo que precisa ser enfatizado quando analisamos a maneira com a qual um professor de física faz uso de estruturas matemáticas em suas aulas. Para que haja uma compreensão profunda desse processo, o estudante precisa ser capaz de identificar os aspectos essenciais do fenômeno que justificam o uso de uma estrutura matemática em particular (KARAM; PIETROCOLA, 2009a). Segundo Redish (2005), para construir uma representação matemática de uma noção física, é preciso "entender quais estruturas matemáticas estão disponíveis e quais são os aspectos das mesmas que são relevantes para as características físicas que se pretende modelar” (REDISH, 2005, p. 7). Nesse sentido, não basta saber operar mecanicamente as "ferramentas" matemáticas como funções, logaritmos, matrizes ou vetores. É necessário identificar os aspectos essenciais dessas estruturas para utilizá-las no processo de modelagem de fenômenos físicos.

Vejamos alguns exemplos: As funções trigonométricas (seno e co-seno) são úteis na física quando se deseja decompor um vetor em componentes ortogonais ou quando se quer modelar um fenômeno periódico (ondas, circuitos elétricos, etc.). As matrizes (vetores e tensores) são úteis quando os estados de um sistema físico são representados por agrupamentos de números que não podem ser interpretados individualmente, e também quando a ordem passa a ser um fator importante, tendo em vista a não comutatividade do produto matricial. Recorrendo novamente à analogia da matemática pré-fabricada, seria como se o pesquisador fosse capaz de identificar em que corredor do "mercado da matemática" estaria localizada a estrutura necessária para a modelagem de um determinado fenômeno físico.

Esse aspecto essencial foi recorrentemente enfatizado durante as aulas analisadas, isto é, o professor teve uma preocupação constante em justificar a utilização de determinadas estruturas matemáticas conforme notamos nos seguintes trechos: 
Para manter as simetrias do espaço e do tempo, essa regra precisa ser uma transformação linear (Aula 4 - estudo piloto)

Passa assim? (gestos com a apostila) Não. Passa agora? (idem) Sim. Fluxo é o resultado final. Como é que eu vou dizer matematicamente que assim passa e que assim não passa. (Aula 12-21:00-21:20)

Pessoal, seguinte, o cheiro é vetorial? O cheiro de alguma coisa é um vetor? Temperatura é vetor? Não é! Você sente o cheiro e acabou, tudo bem? O cachorro é capaz de construir um vetor através de um escalar. Tudo bem isso? Então a ideia de gradiente é essa. (Aula 19 18:40-19:20)

Então o problema do i é que ele é um escalar. E se eu quiser ser mais preciso eu tenho que usar um vetor. Que vetor que eu vou usar? Vou usar um vetor na direção da velocidade. De modo que se a carga tiver indo para cá e eu puser a superfície assim (gestos) tem a noção que ela não atravessa a superficie. E aí a gente vai usar o conhecido conceito de fluxo. Vou pegar essa superficie, colocar uma normal aqui para orientar a superfície. E a corrente vai estar associada ao produto escalar de j com a normal à superfície. (Aula 26-22:40-23:20)

O primeiro trecho reflete a intenção do professor em justificar a necessidade de uma estrutura matemática em particular (transformação linear) em função do desejo físico de manter as simetrias de espaço e tempo. A utilização do produto escalar (projeção) para "dizer matematicamente" como a superfície está orientada - aspecto essencial para a representação da noção de fluxo - é justificada no segundo. A justificativa do uso do gradiente por ser uma estrutura que constrói um campo vetorial (direcional) a partir de um campo escalar é esclarecida no terceiro e a necessidade de se considerar o vetor densidade de corrente para uma representação mas precisa do movimento dos elétrons do que um escalar é elucidada no quarto trecho. Defendemos que a capacidade de identificar aspectos essenciais que justificam o uso de estruturas matemáticas na física é uma habilidade crucial para uma matematização significativa e encontramos diversos exemplos do desenvolvimento da mesma nas aulas analisadas.

Em geral, percebemos que o processo de matematização foi um objetivo consciente das aulas, tanto em função do tempo destinado como da menção explícita à mesma. Notamos também a constante intenção do professor em evidenciar a complexidade desse processo. Entretanto, o processo inverso, ou seja, a interpretação física do formalismo matemático, também se mostrou extremamente relevante, o que nos leva à segunda categoria. 
Interpretação

Em minha longa experiência como professor, sempre me deparei com o fato de que a principal dificuldade enfrentada pelos estudantes, quando entram no território da física teórica, está menos associada a sua forma matemática, e mais ao conteúdo físico das ideias a ela subjacente. Não é o cálculo com equações, mas sim a interpretação das leis da física, o que representa a maior dificuldade para eles. (PLANCK, 1921, p. III).

A análise das aulas mostrou que a preocupação expressa por Planck há quase um século também foi constantemente manifestada pelo professor estudado. Depois de apresentar ou deduzir uma expressão matemática, seja na introdução de um novo conceito ou na resolução de um problema, o foco era direcionado para a interpretação física de seu significado. Em nenhuma situação uma fórmula foi apresentada/deduzida desacompanhada de uma explicação sobre seu significado físico. Isso foi feito com o auxílio de poderosos esquemas e um uso intenso de gestos. Essa segunda categoria é representada pelas flechas verticais decrescentes (b) em nosso modelo (ver Figura 10) e é semelhante à categoria “interpretação física” proposta por Bing e Redish (2009) ilustrada na postura do professor Beta. De maneira geral, o foco na interpretação ocorreu após a resolução de um problema (literal) e da obtenção de uma expressão matemática como resultado. Expressões como "o que significa essa expressão?” ou o que essa equação “diz” evidenciam esse enfoque.

O que significa integrar em dy? [...] Que eu estou somando toda carga contida nessa fita (aponta para desenho no quadro). Qual é o tamanho do resultado da carga, é um número. Então integrar em y é equivalente a fazer isso ó (pega uma folha e a dobra). E aí, se eu integrei em y, sumiu a dimensão y. E o que sobrou é uma barra (dobra a folha deixando-a na forma de uma barra). E aí o que significa integrar em $x$ depois disso? É fazer isso daqui ó; que é a carga total (amassa a folha fazendo uma "bolinha"). (Aula 6-42:20-43:20)

A fórmula do campo elétrico é dada pela seguinte expressão (escreve a lei de Coulomb). [...] O que é importante do ponto de vista geométrico é a seguinte coisa: esse campo depende da distância entre a carga e o ponto que você olha. O que está dito lá é o seguinte. Se você puser uma carga aqui e pergunta, o campo dela existe em torno da carga inteira, sim existe (gestos). Agora, para a gente poder quantificar isso a gente vai ter que escolher um ponto Então escolhe um ponto qualquer, esse. Ai pergunta: Qual o valor da função campo nesse ponto? Se você mudar o ponto, o campo muda. (Aula 9-5:00-6:20)

Por que aparece $Q^{2}$ aqui nessa expressão? Pessoal, a carga $Q$ interage com ela mesma? Sim? Olha o que eu fiz aqui. Eu peguei uma carga e trouxe até aqui (gestos). E ela estava interagindo com o que estava lá já. Na hora que eu puser o "dq zinho" aqui ele interage com o que estava lá (gestos)? Interage, tudo bem? Então a auto-energia é isso. Tem um sistema carregado, mas essa carga interage com essa e é isso que está guardado lá naquela resposta. (Aula 21 - 29:00-30:00)

Vê se tá claro pra você a seguinte coisa. A novidade hoje não é calcular divergente, mas aplica-lo numa situação física. $O$ que o divergente faz? O divergente é uma máquina 
matemática. Que favor ele faz pra você? Ele acha a distribuição de carga, tudo bem? Então, o que deve acontecer? No lugar onde não tem carga, se você calcular o divergente você obtém zero, sim? Isso é uma lei local. O que é uma lei local, o divergente pode ser calculado em diferentes pontos. No ponto onde ele der zero, significa que lá não tem carga. Por outro lado você espera que no lugar onde ele ache carga, ele dê diferente de zero. (Aula 23 $1: 29: 20-1: 30: 20)$

Os exemplos evidenciam que o professor enfatiza a importância do entendimento de expressões matemáticas. Na primeira sentença ele faz uso de gestos com uma folha de papel para dar significado físico a cada integração. Na segunda, o significado da lei de Coulomb é explicitado e notamos que o professor chega a se referir ao que "está dito" na expressão. O termo $\mathrm{Q}^{2}$ no resultado do cálculo da auto-energia de uma superfície esférica carregada é devidamente interpretado e justificado no terceiro trecho. No fragmento do divergente, fica claro que o importante é entender o "favor matemático" que essa operação realiza.

Uma estratégia bastante comum utilizada pelo professor para a interpretação física de expressões matemáticas é exemplificada nos trechos a seguir:

O que você espera da resposta desse problema, se você pegar carga positiva aqui, carga negativa aqui (gestos), vai sobre o eixo y, que direção que o campo deve apontar? Não olha a expressão. Você espera isso. [...] $\boldsymbol{O}$ que acontece se $\boldsymbol{x}, \boldsymbol{y}$ ou zorem iguais a 0 ? Isso é razoável? Faz sentido? [...] Seguinte, se você não esperar nada de uma equação você está perdido. (Aula $9-58: 00-58: 40+1: 00: 00-1: 00: 20$ adaptado)

Se você estiver a uma grande distância do anel, colocar o "a" muito grande, o que você espera? [...] Teria que dar um comportamento do tipo carga puntiforme? Sim? Funciona? Se você colocar " $a$ " muito maior do que " $R$ " aqui (aponta para a expressão), você despreza isso daqui ( $R^{2}$ uma vez que a $>R$ ) e o resultado dá $1 / a^{2}$ (campo coulombiano). Seu resultado precisa ser coerente. (Aula 10 - 55:00-55:40 adaptado)

Essa conta depende de r pequeno? Não essa variável de integração sumiu. E ela depende do $R$ grande? No desenho o que é R. Que conta que eu fiz? O que está por trás dessa expressão? Se você pegar uma carga q e mantiver a carga parada aqui e se você puser a outra carga muito longe, lá longe, no infinito. Aqui não tem força. A força vai pra zero (Aula $16-$ 1:09:40-1:10:40).

Percebemos que a análise de casos especiais/particulares e/ou limites foi intensamente utilizada como recurso para interpretar o significado físico de expressões matemáticas deduzidas em problemas. Depois de obter um resultado matemático, ele costuma incentivar seus estudantes a verificarem a consistência do mesmo comparando-o com suas expectativas físicas em casos particulares como quando o ponto considerado localiza-se em um dos eixos coordenados ou limites quando considera a expressão do campo elétrico em um ponto muito longe do anel carregado ou a energia potencial eletrostática em um ponto no infinito. 
De fato, a importância da interpretação e a pertinência da análise de casos particulares e limites fica evidente na mensagem que o professor manda a seus estudantes após a resolução do problema da determinação do campo elétrico gerado por duas cargas pontuais no final da Aula 9:

O que é importante pra gente... Isso é uma coisa que é muito importante quando você estuda física em qualquer ramo da física ou da matemática. Seguinte: o livro faz uma conta e tem uma expressão. Como é que a gente pode olhar essa expressão quando você lê um livro de física que tem um monte de matemática lá? A primeira leitura que é útil fazer é a seguinte: como é que as informações do problema entraram na expressão do resultado? Isso que a gente tem que seguir. Por que que o campo amarelo depende das variáveis brancas? Você entende isso? As variáveis brancas estão aqui, são as variáveis do ponto [geometria]. Ai brinca um pouco, por exemplo, imagina que você esteja numa altura que é $d / 2$, o que você espera? Não olha a conta! O que você espera do ponto de vista físico? Se a carga estiver na mesma altura do z aqui. Eu estou perguntando o seguinte. (representa a situação com gestos). Aquela carga vermelha está aqui (apagador na mão direita) e o ponto $P$ antes estava em qualquer lugar (mão esquerda no ar). Agora imagina que sua conta, para testar se ela está razoável, imagina que você ponha o ponto $P$ aqui (alinha na vertical a mão esquerda com a direita). O que você espera? Um campo horizontal? Isso dá certo na conta? Então funciona. Tudo bem? (aponta para a expressão do resultado) É um teste que você faz. Em geral é duro você esperar alguma coisa, mas em certas situações particulares é fácil você esperar o que vai acontecer. (Aula 9-49:20-51:40)

O entendimento significativo do formalismo é novamente destacado nesse trecho. Fica claro que o professor aconselha que seus alunos façam um uso consciente da matemática em vez de aplicá-la como uma mera ferramenta. A recomendação de que é especialmente importante saber "como a informação entra e anda na conta" indica que ao obter a expressão final de um problema, muita coisa ainda pode ser aprendida/analisada além da corriqueira colocação de um retângulo em torno da mesma.

A interação entre matematização e interpretação é marca registrada em praticamente todas as aulas analisadas e essas duas categorias representam as principais habilidades estruturais, por se localizarem no interior da estrutura teórica do modelo físico-matemático proposto no Capítulo 2. Em algumas vezes, há uma espécie de superposição (blending) das duas, pois ao mesmo tempo que uma noção física é matematizada, uma expressão matemática passa a ter um significado físico. Por isso, em raras ocasiões trechos de 20 segundos foram categorizados simultaneamente com ambas. Porém, para evitarmos tal superposição, procuramos categorizar como interpretação somente os casos em que o discurso é direcionado ao significado físico de uma expressão matemática dada ou deduzida.

Apesar da relevância de se entender melhor como abordar as categorias matematização e interpretação em aulas de física, também estávamos interessados em 
localizar os momentos em que a matemática assumiu um papel mais ferramental. Uma questão que nos parecia pertinente era entender qual o valor que o professor dava a esse aspecto e como uma abordagem instrumental da matemática era intercalada com as mais estruturais descritas até aqui. Dessa forma, na próxima categoria intitulada técnica, identificamos e exemplificamos os momentos em que a matemática é tratada de uma maneira mecânica, ou seja, regras são evocadas e algoritmos são manipulados sem qualquer vínculo com o mundo físico. 
[...] a primeira coisa que você tem que aprender é matemática. E isso envolve, primeiro, cálculo. E em cálculo, diferenciação. Ora, matemática é um assunto bonito, e tem seus prós e contras também, mas nós estamos tentando entender qual é o mínimo que temos que aprender para os propósitos da física. Assim, a atitude tomada aqui é "desrespeitosa" para a matemática, mas é completamente eficiente. Eu não estou menosprezando a matemática. (FEYNMAN; GOTTLIEB; LEIGHTON, 2008, p. 32-33).

Em diversos momentos da prática profissional de um(a) físico(a), seja como pesquisador(a) ou professor(a), a matemática é tida como um conjunto de regras práticas que fornecem um guia seguro para o desenvolvimento de teorias físicas. Sendo assim, ao "deixarse levar pela segurança do formalismo", o(a) físico(a) economiza um tempo precioso, uma vez que não precisa comprovar a veracidade de cada relação matemática, podendo simplesmente utilizá-la de maneira instrumental. Regras de derivação e integração, teoremas matemáticos (Pitágoras, Gauss, Stokes, etc.), identidades trigonométricas, tabelas contendo momentos de inércia, entre muitos outros exemplos, são ferramentas extremamente úteis para a prática profissional em física.

No modelo proposto no Capítulo 2 (Seção 2.3), a abordagem instrumental da matemática foi representada pela "seta" curvilínea (c) (ver Figura 10). Com essa representação, nosso objetivo foi ilustrar uma "saída" do modelo físico-matemático para um mundo totalmente descompromissado com fenômenos físicos (matemática pura). $\mathrm{Na}$ categorização de Bing e Redish (2009), o caráter técnico é representado tanto pela atitude do professor Alfa, o qual apresenta a fórmula da velocidade como um algoritmo de cálculo, como pelo professor Gama, que utiliza frequentemente argumentos de autoridade ao se referir a expressões matemáticas.

Quando o professor adota essa postura técnica frente ao conhecimento matemático durante as aulas analisadas, é possível identifica-la facilmente. Sua linguagem corporal normalmente indica uma atitude displicente, o que fica evidente quando ele realiza manipulações algébricas de maneira rápida e frequentemente de costas para a turma. Em inúmeras vezes, os alunos percebem algum erro cometido pelo professor durante essas manipulações e ele rapidamente acata as correções dos mesmos, numa atitude que indica certa indiferença.

O interessante, entretanto, é perceber que durante as aulas raramente esse modus operandi técnico aparece isolado. O mais comum é que etapas de matematização e interpretação apareçam intercaladas. Dessa forma, além de descrever os aspectos que caracterizam essa abordagem técnica, é importante identificar quando e com que intensidade 
ela ocorre durante as aulas. Analisamos essa dinâmica interação por meio de vários exemplos no Capítulo 5.

A análise das aulas - bem como reflexões sobre a diferenciação entre entendimento procedimental e conceitual da educação matemática (conforme Hiebert (1986), ver Seção 2.3) - nos levaram a considerar duas subcategorias para descrever esta postura associada ao tratamento da matemática como ferramenta (habilidades técnicas). A primeira, denominada $T 1$ - manipulações algoritmicas e argumentos de autoridade, é técnica (procedimental) nos dois sentidos, uma vez que além de não ter nenhum vínculo com o mundo físico, as regras são citadas e/ou utilizadas sem qualquer justificativa conceitual (matemática). Vejamos alguns exemplos:

Então isso aqui é uma função em X... e esse Y máximo é dado pela equação dessa reta aqui. Qual é a equação da reta? Eu sei que Y máximo deve ser dado pela função alfa X mais beta. Eu sei que para X igual a zero isso daqui é C, então Y máximo de X igual a zero é igual a $C$ e isso faz com que beta seja igual a C. Quando X for D, Y é zero. Então eu sei que Y máximo de Dé igual a zero que é igual a alfa D mais beta. Portanto, alfa é igual a menos beta sobre $D$, igual menos $C$ sobre $D$. Pessoal, em física, a gente não tem problema de autoafirmação com matemática. Então se você quiser olhar a integral lá na tabela olha. O negócio é fazer do jeito mais rápido. Feito isso, esse negócio aqui some... vira Y máximo, que é isso daqui. (Aula 6-51:20-52:40)

Uma vez que você fez isso, você está autorizado a virar a manivela matemática. Então joga lá e começa a manipular. Ok? (Aula 9-44:40-45:00)

Isso daqui (regra da cadeia aplicada a uma função $f(x, y, z, t)$ ) não é uma afirmação relativística, isso daqui é uma coisa de matemática. Essa coisa depende dessas funções aqui, o menos vai sair naturalmente daqui a pouco. [...] Como $x$ depende de todas as variáveis, vale a regra da cadeia para qualquer coisa, porque isso daqui é uma função de função. (Aula 7 - estudo piloto)

O teorema de Gauss diz o que? Se você pegar um vetor A qualquer. Você nem sabe o que é isso do ponto de vista fisico. (escreve o teorema de Gauss para um campo vetorial A). Isso daqui é um teorema matemático geral. (Aula 23 - 35:00-35:40)

Os dois primeiro fragmentos ilustram a atitude procedimental de "girar a manivela" da matemática, parecendo uma espécie de "piloto automático" no qual as "regras de um jogo" são seguidas de maneira desatenta. Adicionalmente, o professor faz questão de frisar que não há problema algum nisso, uma vez que "em física, a gente não tem problema de autoafirmação com matemática. Os dois extratos seguintes exemplificam o evocação de argumentos de autoridade, primeiramente a regra da cadeia e depois o teorema do divergente. Como ambas as relações são apresentadas e não demonstradas ou pelo menos explicadas, a categorização pertinente é T1. 
Em outros momentos, apesar de uma abordagem técnica no sentido de ser dissociada do mundo físico, o professor oferece uma espécie de justificativa (matemática) para a validade de regras, comportando-se como um professor de matemática. Os episódios em que isso ocorreu foram classificados como $T 2$ - Justificativa matemática da técnica. Essa subcategoria também inclui problemas puramente matemáticos que são resolvidos para que os estudantes possam "sentir como o formalismo funciona".

Aluno pergunta: A: Professor, esse r ao quadrado na verdade não é um vetor, né? Professor: Sim e não. Tanto faz. O que é um vetor ao quadrado? Ele vai ser $r$ escalar $r$. Tudo bem? Está claro isso para você? [...] Imagina que um vetor $r$ qualquer tem as componentes $x$ $y$ z. Se você fizer essa conta, isso dá $x^{2}+y^{2}+z^{2}$ que é igual ao módulo do vetor ao quadrado. Se você projetar um vetor sobre ele mesmo dá o módulo do vetor ao quadrado. (Aula 9 13:20-15:00)

Agora a gente vai fazer uma conta com um vetor A qualquer só para entender como o teorema [divergente] funciona. Mas o que o teorema fala, ele fala a seguinte coisa. Que numa superfície fechada qualquer se você calcular o fluxo do vetor $A$, não o que ele é do ponto de vista físico, isso daqui é igual, matematicamente, ao divergente de A integrado em todo o volume. Isso do ponto de vista matemático resolve o problema porque o que vai acontecer é que esse lado, usando o teorema de Gauss, vira uma integral tripla, e ai eu posso igualar os integrandos e pronto. E na hora que eu faço isso eu tenho essa equação (Gauss diferencial), tudo bem? [...] Esse teorema tem uma demonstração formal, mas o que eu queria mais era motivar a discussão e para isso vamos pegar um vetor A qualquer. (Aula 23 - 36:00-37:20)

A pergunta do estudante denota falta de compreensão (matemática) da equivalência entre o produto escalar de um vetor por ele mesmo e o quadrado do módulo do vetor. Isso faz com que o professor abra um parênteses em sua explicação física para justificar matematicamente essa relação, atitude que foi classificada como T2 e ocorre com certa frequência ao longo das aulas. O segundo trecho retrata uma abordagem comumente utilizada, na qual o professor cria "brinquedos matemáticos" para que os estudantes se familiarizem com "as regras do jogo". No caso do teorema do divergente, um campo vetorial A é fornecido, sem qualquer significado físico, e os lados esquerdo e direito da igualdade que representa o teorema são calculados para que sua equivalência seja percebida. Apesar de não se tratar de uma demonstração formal, o objetivo é que os alunos aprendam como operar com novas estruturas matemáticas e adquiram um certo entendimento sobre seu funcionamento.

Muito do que se critica em relação ao excesso de tratamento matemático dado no ensino de física está associado ao caráter técnico/instrumental representado por esta categoria, o qual, apesar de importante, pode ser extremamente prejudicial para uma profunda compreensão da íntima relação entre matemática e física se não for acompanhado por 
argumentos de matematização e interpretação. Em diversos momentos a desvalorização de uma atitude meramente mecânica é expressa nas palavras do professor:

Pessoal seguinte: O que é que eu estou pedindo para você entender? Não é como integrar uma função de duas variáveis, não é isso. O que a gente tem que entender é o que você está fazendo quando você integra. Qual é o significado de você integrar primeiro uma coisa e depois a outra. [...] Ok isso? Ai você vira a manivela e faz a conta. (Aula 6-44:20-44:40)

(Após escrever o elemento de volume como $d V=d r . r . d \theta . r . \operatorname{sen} \theta . d \varphi$ utilizando coordenadas esféricas): Pessoal, vamos fazer um acordo? Isso daqui não pode errar na hora da prova, ok? Na prova desse curso, você não precisa lembrar nenhuma equação física. Você não precisa lembrar quanto é a integral de x.dx. Mas isso daqui (aponta par a expressão de dV) não é lembrar, é entender o significado geométrico disso daqui. Isso daqui é outra coisa, isso daqui é um conceito. (Aula 7 - 1:07:00-1:09:00)

(Após uma profunda e longa explicação conceitual sobre as condições (simetrias) e princípios físicos (relatividade e constância de c) necessários para a obtenção das transformações de Lorentz e da justificativa para o uso de transformações lineares): $O$ Einstein impõe que se valer isso para o vermelho, tem que valer isso para o amarelo. E as transformações de Lorentz saem daí. Isso está feito na apostila, não vou fazer a conta porque tem que fazer uma álgebra, ficar mudando variável e tal e eu não queria perder tempo com isso. Mas isso está feito na apostila e esses coeficientes são determinados. (Aula 7 - estudo piloto)

Nesses fragmentos o professor manifesta claramente um juízo de valor. Saber integrar uma função de duas variáveis, lembrar uma fórmula de integração ou resolver um sistema de quatro equações para quatro incógnitas através de manipulações algébricas não são tão importantes quanto entender o significado físico das operações.

No início da aula 5, o professor gasta um bom tempo passando uma mensagem importante aos estudantes, na qual ele explicita a diferenciação entre habilidades técnicas (saber fazer) e estruturais (saber por quê, para quê e quando usar):

O curso de física é o seguinte, você entra de um jeito e tem que sair de outro. E espera-se que você ganhe algumas habilidades nesse curso. Tem coisas que são relativamente fáceis, tem coisas que são mais dificeis e esse curso começa com as mais fáceis e chega nas mais dificeis. Quais são as coisas mais dificeis? Se você fosse um artesão que está aprendendo carpintaria, o que você faz, você entra na oficina lá, e aí você tem um ano de aula de formão. Como o formão funciona, como afia o formão. E depois tem mais um ano de aula de martelo. E dai você vai fazendo essas coisas, só que isso não é carpintaria. Carpintaria você tem que entender como é que faz um projeto. Eu quero fazer uma mesa, você tem que fazer a mesa. Então uma coisa é você saber manipular os instrumentos, outra coisa é você saber utilizar esses instrumentos em uma situação qualquer. O que é difícil num problema de física em geral, é saber qual instrumento que eu uso qual hora. Se eu te der um problema de lista de exercícios, pessoal lista de exercícios não é física. É muito importante fazer exercício, porque você tem que aprender como é que usa o formão. Tem que aprender isso, se não você não é carpinteiro. Mas só isso não chega, qual a diferença da lista de exercício e da física maior? Lista de exercícios tem uma moldura dada pelo curso, ou pelo assunto particular que 
a gente está tratando e o exercício tem q ser resolvido nessa moldura. Mas o que eu quero dizer, no eletromagnetismo, nos vamos querer uma coisa mais dificil de vocês, que você seja capaz não só de fazer isso, mas seja capaz de olhar sua caixa de ferramentas e falar o seguinte, o que eu faço, que hora que eu uso o que? Isso exige maturidade e treino.

Assim, é possível considerar dois níveis distintos ao se utilizar matemática para tentar compreender os fenômenos da física. No primeiro, a matemática está sempre relacionada com grandezas físicas (matematização e interpretação) enquanto que no segundo ela não tem nenhum vínculo com este e segue suas próprias regras internas. Possivelmente, diferentes pesos dados a esses dois enfoques durante aulas/explicações de física são determinantes para avaliarmos a qualidade das mesmas e, consequentemente, para uma melhor compreensão do pensamento matemático como estruturador de teorias físicas por parte dos estudantes.

Com o objetivo de visualização dessa diferenciação, representamos as três categorias apresentadas até agora no modelo apresentado na Seção 2.3 (ver Figura 14). Essas categorias - as quais são normalmente mutuamente exclusivas - formam um conjunto no qual ações/processos são analisadas(os), indicando “o quê" o professor estava fazendo (matematizando, interpretando ou manipulando) em cada unidade de tempo analisada (20 s) e é possível representar cada ação com setas que ilustram movimentos.

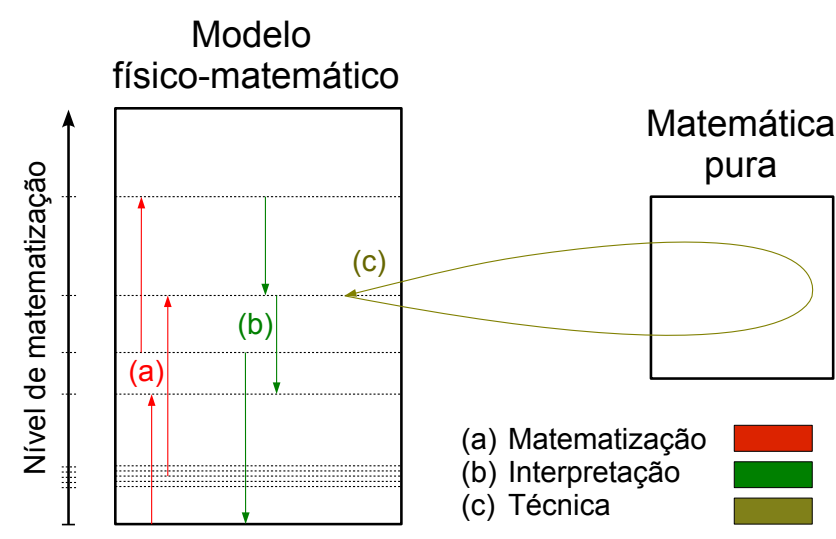

Figura 14: Categorias matematização, interpretação e técnica representadas no modelo proposto na Seção 2.3 .

Além de identificarmos "o quê" o professor estava fazendo (matematização, interpretação ou técnica) durante o processo de categorização das aulas, fomos percebendo a necessidade de criar categorias para a analisar a maneira "como" o professor efetuava tais etapas, as quais muitas vezes estavam associadas a estratégias didáticas. Essa intenção nos leva à próxima categoria de análise, a qual está relacionada com o intenso uso de representações visuais durante as aulas. 
As palavras da linguagem, escrita ou falada, não parecem desempenhar qualquer papel no meu mecanismo de pensamento. As entidades fisicas que parecem constituir os elementos do meu pensamento são certos signos e imagens mais ou menos nítidas. (EINSTEIN em HADAMARD, 1949, p. 142).

Sem dúvida, podemos dizer que essa categoria "saiu dos dados", uma vez que não tínhamos qualquer intenção prévia de conceber uma categoria para analisar o uso de representações visuais antes de assistirmos às aulas. Porém, quanto mais assistíamos o professor em ação, mais notávamos que recursos semióticos visuais como gestos e representações pictóricas (desenhos, gráficos, diagramas, etc.) desempenhavam um papel fundamental para a construção de significados durante as explicações. Em um momento da entrevista, o professor justifica esse intenso uso de representações visuais dizendo que "o conhecimento da física é silencioso" e não pode plenamente ser representado por palavras, daí a necessidade de se utilizar outros recursos semióticos.

Essa insuficiência é corroborada pelo trabalho do físico e linguista estadunidense Jay Lemke. Analisando uma série de artigos científicos publicados nos periódicos de maior prestígio internacional, o autor argumenta que:

a ciência não é feita nem comunicada somente através da linguagem verbal. Nem pode ser. Os "conceitos" da ciência não são conceitos verbais, apesar de possuírem componentes verbais. Eles são híbridos semióticos, simultaneamente e essencialmente verbais-tipológicos e matemáticos-gráficos-operacionais-topológicos. Os gêneros textuais da ciência foram (e são) fundamentalmente gêneros multimidiáticos. Para fazer ciência, falar ciência, ler e escrever ciência é necessário combinar discurso verbal, expressões matemáticas, representações gráfico-visuais e operações motoras do mundo natural (incluindo o ser humano). (LEMKE, 1998, p. 89)

Dessa forma, ao definirmos uma categoria para identificar os momentos onde representações visuais foram utilizadas nas explicações do professor, podemos visualizar essa complexa significação multimidiática ocorrendo ao longo das aulas e o papel que as mesmas tiveram. Neste capítulo vamos nos restringir a exemplos pontuais onde esses recursos visuais são utilizados e uma análise mais ampla será apresentada no Capítulo 5. Naturalmente, precisamos fazer uso de imagens ("fotos" das aulas) para exemplificar essa abordagem. Utilizamos um recurso para impossibilitar a identificação do professor.

V1-Gestos

Nem todo gesto feito pelo professor é identificado nessa categoria, somente aqueles que tiveram função explicativa. Apresentamos alguns exemplos desse uso a seguir: 


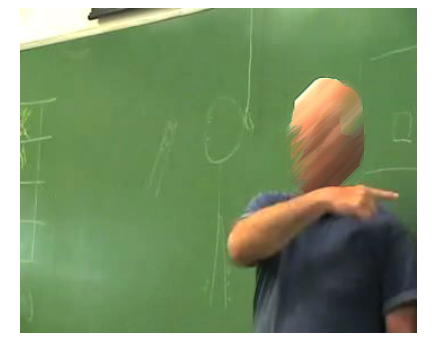

Figura 16: Fotografia Aula 5

(Analogia pessoa/carga) O que ia acontecer? Ele, que está nessa ponta, ia causar uma força assim em mim. (Aula 5-15:20-15:40)

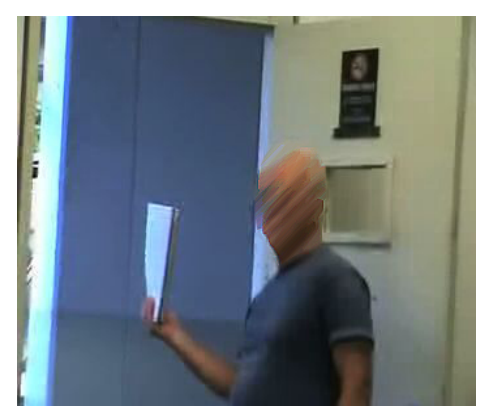

Figura 19: Fotografia Aula 12

Se você puser a superfície assim. Pessoal, tem ar fluindo através dessa superficie? (Aula 12 15:00-15:20)
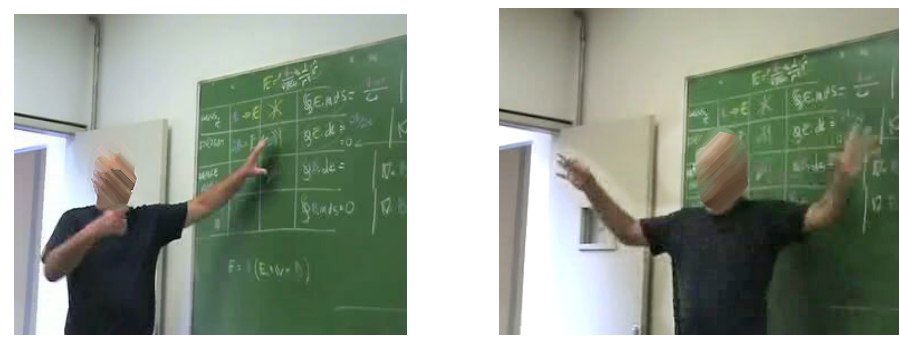

Figura 17: Fotografia Aula 24 Figura 18: Fotografia Aula 24

Então o objeto matemático adequado para descrever coisas que fazem assim (faz movimentos circulares com o dedo) é o rotacional. E isso daqui (aponta para o divergente) é o objeto matemático para descrever coisas que fazem assim (gesto abrindo os braços) (Aula 24 - 1:45:00-1:45:20)

Nesses trechos fica claro que a linguagem gestual desempenha um papel fundamental na explicação. Inúmeros exemplos como esses podem ser encontrados ao longo de todo o curso, o que evidencia, na prática, o caráter não verbal do conhecimento físico.

V2 - Representações pictóricas

A segunda subcategoria representa outro recurso muito utilizado pelo professor, que consiste em formular explicações com o auxílio de desenhos, diagramas, gráficos. Com frequência, o professor faz uso de cores diferentes para designar diferentes entidades e incorpora essa designação em seu discurso. As fotografias a seguir ilustram esquemas pictóricos centrais para a construção da argumentação: 


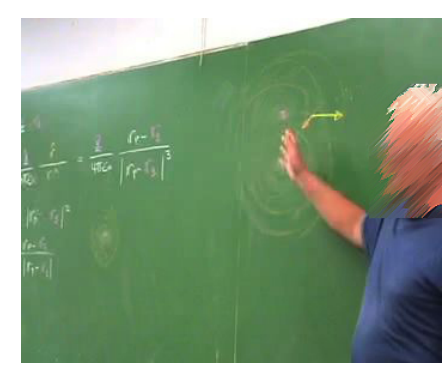

Figura 21: Fotografia Aula 9

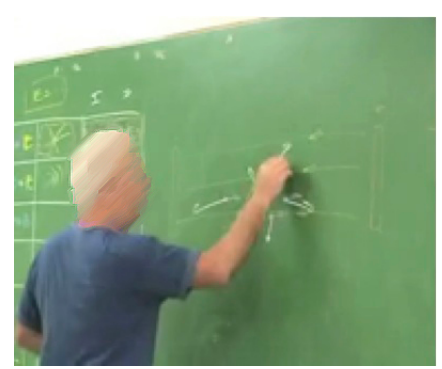

Figura 22: Fotografia Aula 26

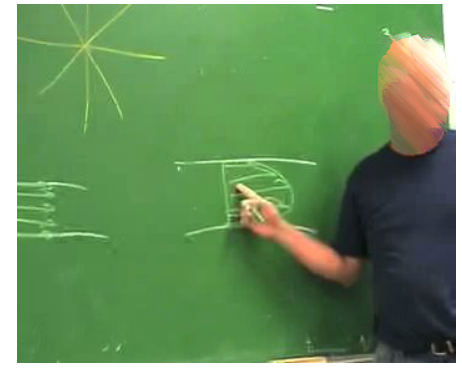

Figura 23: Fotografia Aula 24

Essa carga positiva cria um campo amarelo assim (desenha). A carga azul cria um campo laranja assim (desenha) (Aula 9 19:40-20:00)

Se vc pegar esse sistema e puser uma placa positiva aqui e uma negativa aqui. Aparece um campo elétrico aqui assim (desenha). (Aula 26-19:20-19:40)

Isso daqui (aponta para o desenho) é rotacional? (Aula 24 - 1:43:40-

Extremamente interessante é perceber como esquemas muito semelhantes podem ser facilmente encontrados nos originais do próprio Maxwell conforme a figura a seguir:
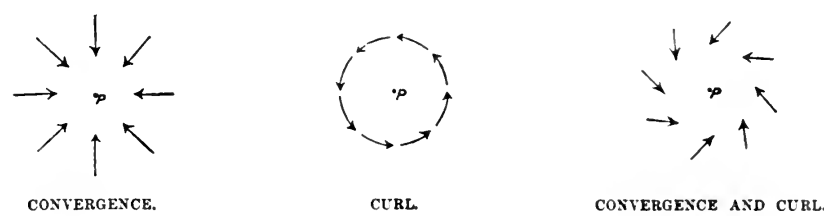

Figura 24: Representações pictóricas de campos convergente (puro), rotacionais (puro) e misto.

(MAXWELL, 1890, p. 265)

No prefácio de sua grande obra intitulada Mecânica Analítica, Lagrange adverte sobre o caráter inovador de seu trabalho:

O leitor não encontrará nenhuma figura nesse trabalho. Os métodos que aqui proponho não necessitam de qualquer construção geométrica ou raciocínio mecânico: mas somente operações algébricas, sujeitas a regras uniformes e regulares. (LAGRANGE, 1788, p. vi)

Isso certamente representou uma revolução para a época, além de uma possível dificuldade para seus leitores. A ideia subjacente é que representações visuais "limitam" o pensamento às impressões sensoriais e o formalismo algébrico o libertaria das mesmas. De fato, tanto na história da física como da matemática é possível identificar um movimento contínuo de abstração no sentido de libertar a mente de representações concretas. Inegavelmente, existem muitas vantagens nesse processo. Um exemplo clássico seria nossa impossibilidade de representar geometricamente o espaço quadridimensional, superada pela facilidade de representar algebricamente um ponto no espaço $\mathrm{R}^{4}$ pelas coordenadas $(\mathrm{x}, \mathrm{y}, \mathrm{z}$, 102 
w) e até mesmo calcular a distância entre dois pontos nesse sistema ${ }^{37}$. Entretanto, quando consideramos aspectos cognitivos e didático-pedagógicos, é prudente ponderar que tais representações concretas desempenham uma importante função.

Dessa forma, podemos especular que a utilização de múltiplos recursos semióticos tem alguma relação com a qualidade das explicações. Essa hipótese parece encontrar ressonância na teoria de Lemke (1998) quando o mesmo fala sobre a multiplicação de significados:

[...] o princípio da multiplicação funcional em gêneros multimidiáticos nos mostra como podemos significar mais, construir significados nunca antes possíveis e não "significáveis" de outra forma, quando esse processo ocorre dentro e através de diferentes modalidades semióticas (ou seja, linguagem natural, representações visuais, matemática, etc.) (LEMKE, 1998, p. 94)

Assim, parece coerente concluir que ao utilizar representações visuais frequentemente, o professor utiliza esse "princípio multiplicativo" para construir explicações mais significativas. Nessa mesma linha, chamou-nos a atenção o recorrente uso de metáforas e analogias durante as aulas. Essa categoria é descrita e exemplificada na sequência.

${ }^{37} d_{A B}=\sqrt{\left(x_{B}-x_{A}\right)^{2}+\left(y_{B}-y_{A}\right)^{2}+\left(z_{B}-z_{A}\right)^{2}+\left(w_{B}-w_{A}\right)^{2}}$ 
E eu valorizo mais do que tudo as Analogias, meus mestres mais confiáveis. (KEPLER apud POLYA, 1954, p. 12).

Quando nos deparamos com um fenômeno desconhecido, é natural que o concebamos teoricamente a partir do que já é conhecido. Encontramos inúmeros exemplos dessa estratégia em situações cotidianas: falamos em embarque mesmo quando entramos em um avião (e não em um barco); sacamos dinheiro de um caixa automático (e não o retiramos de um saco); ao utilizarmos o correio eletrônico, anexamos um arquivo clicando no botão que tem a figura de um clipe. Em física, utilizamos uma estratégia semelhante quando falamos em fluxo do campo elétrico, ondas de matéria ou densidade de carga.

De fato, o raciocínio por similaridades é uma das grandes fontes para o desenvolvimento de teorias físicas. O papel essencial de analogias nesta ciência pode ser evidenciado em diversos exemplos: Modelo atômico planetário de Rutherford; Similaridade entre a lei de Coulomb e de Newton; Comparação entre motores térmicos e quedas d'água feita por Carnot; Analogia entre eletricidade e calor de Thomson; Aplicação da hidrodinâmica aos fenômenos do eletromagnetismo por Maxwell; A analogia ópticomecânica de Hamilton; O uso desta analogia por Schrödinger na dedução de sua equação; entre outros. Essencialmente, analogia é similaridade em um nível mais conceitual, uma vez que é estritamente dependente das intenções do pensador que a idealiza (POLYA, 1954). Segundo Gentner (2002), “a intuição básica por trás do pensamento analógico é a crença de que quando existem paralelos entre diferentes situações, é provável que existam outros ainda não conhecidos" (GENTNER, 2002, p. 106). Nesse sentido, argumentos analógicos podem ser utilizados para generalizar conceitos, teorias e métodos de tal forma que eles "se tornam aplicáveis a classes de objetos que não são mais do mesmo tipo em relação àqueles que os originaram" (TZANAKIS, 1998, p. 69).

Para caracterizar o papel do raciocínio analógico em física com mais profundidade, Hesse (1972) propõe uma diferenciação entre analogia material e formal. Segundo a autora, as analogias materiais ocorrem quando há uma semelhança física entre os sistemas - um gás como um conjunto de pequenas esferas por exemplo - enquanto que as analogias formais ocorrem quando as mesmas relações dedutivas associam tanto sujeitos como objetos de sistemas similares, sem a necessidade de que haja uma semelhança material entre eles - por exemplo, um circuito RLC e um sistema massa-mola. Nesta última comparação, dois fenômenos físicos consideravelmente diferentes são representados pela mesma equação 
diferencial $^{38}$ e, associando termos correspondentes, é possível fazer correlações interessantes como considerar a indutância como a "massa" de um circuito. A distinção entre esses dois tipos de analogias não é trivial, mas Hesse salienta que apesar de ser aceitável que dois sistemas tenham apenas analogia formal, o contrário não parece ser possível uma vez que "se há analogia material, há presumivelmente alguma semelhança estrutural que poderia - pelo menos em princípio - ser formalizada" (HESSE, 1972, p. 355).

Durante as aulas, o professor faz uso de um amplo leque de analogias e metáforas para a construção de novos conceitos. Na maioria dos casos, isso foi feito através de exemplos concretos de situações do cotidiano e comparações entre diferentes fenômenos físicos. Em outros momentos, o aspecto formal e unificador de estruturas matemáticas foi ressaltado. Por esse motivo, criamos duas subcategorias para analisar o uso desse tipo de argumentação no decorrer das aulas.

A1-Analogias materiais, exemplos do cotidiano e metáforas

Quando um novo conceito é apresentado, o professor costuma utilizar um vasto arsenal de situações do cotidiano e analogias com outros fenômenos físicos. A elevada frequência com a qual esses recursos são usados na aulas é ilustrada na quantidade de exemplos apresentada a seguir:

(Introdução do conceito de densidade superficial de carga): A gente pode falar em densidade populacional do Brasil? Você pega o Brasil aqui (desenha). Se isso daqui for a costa, a gente pode falar em densidade superficial? São Paulo tá aqui, Rio, tem uma cidadezinha aqui (desenha). Deve ser possível construir uma função que descreva a quantidade de pessoas por $\mathrm{km}^{2}$ e isso vai depender o $\mathrm{km}^{2}$ considerado, tudo bem? Se você considerar um $\mathrm{km}^{2}$ aqui, pode chegar num lugar vazio. Vai numa fazenda no interior, 2 pessoas por $\mathrm{km}^{2}$. São Paulo, avenida paulista, pega um $\mathrm{km}^{2}$ matemático, quantas pessoas tem lá dentro, um monte! (Aula 5 - 48:20-49:40)

(Introdução do conceito de fluxo de um campo vetorial) Pessoal, tem que projetar alguma coisa? Qual o fluxo de luz da lâmpada através dessa superfície aqui? Passa luz? (Aula 12 20:40-21:00) Pessoal abelhas, imagina um enxame de abelhas entrando por essa porta. Existe fluxo de abelhas por essa superficie? (22:20-22:40) Posso falar em fluxo de $\mathrm{g}$ - o $\mathrm{g}$ da gravidade - através desse ds? (26:20-26:40) Se você pegar uma rua. E contar o número de carros que passa na rua. Você já viu que tem aquele fio lá que o carro deixa um sinal quando passa em cima do fio. Esse fluxo de carros na rua é em quantas dimensões? (33:20$33: 40)$

A energia potencial desse sistema vai ser devido ao seguinte fato: Para eu pegar a carga daqui e colocar aqui eu, observador externo, preciso fornecer trabalho. Eu forneço mais

${ }^{38}$ A semelhança formal entre as duas equações diferenciais que modelam ambos os sistemas é evidente: $m \frac{d^{2} x}{d t^{2}}+c \frac{d x}{d t}+k x=F(t) \quad$ sistema massa-mola $\quad L \frac{d^{2} q}{d t^{2}}+R \frac{d q}{d t}+\frac{1}{c} q=V(t) \quad$ circuito RLC 
trabalho, mais trabalho. Na hora que eu parar a carga aqui, eu comprimi uma mola, sim? Concordam que eu fiz algo como comprimir uma mola? (Aula 16 - 1:11:20-1:11:40)

Pessoal, cachorro sabe calcular gradiente? Sim, ele sabe. Como? Você pega uma sala escura e fecha o cachorro num canto lá. Ai você pega e põe um bife aqui (aponta para o outro canto). O cachorro vai fazer uma abordagem sistemática ao problema? (risos) O bife aqui e o cachorro começa a fazer isso e isso (desenha um zigue e zague varrendo toda a área da sala). Ele vai pela lógica e fala assim, com certeza o bife está aqui. Estou excluindo as possibilidades... É isso que ele faz, não! Como é que ele faz? Ele levanta o nariz e faz o que? Ele sente o cheiro. Se ele levantou o nariz assim e sentiu o cheiro ele sabe onde o bife está? Com uma cheirada ele sabe? Não! Com uma cheirada ele sabe que tem um bife, tudo bem? [...] Onde está o bife? Ele tem que fazer o que? Aí sim ele calcula o gradiente. Se eu entrei na porta aqui e o bife está lá. O que ele faz, ele se move ao acaso (gira a cabeça). E aí, o que ele vai medir? Ele vai medir onde que o cheiro aumenta, tudo bem? Em relação ao que tinha antes. E ai sistematicamente ele faz isso e acha o bife, tudo bem? Calculou o gradiente? Sim! Pernilongo acha você como? Calculando o gradiente. Você acha que o pernilongo acha você ao acaso? Opa, encontrei um ser humano! (risos) (Aula 19 - 14:2017:40).

Pessoal, o que é um rodamoinho? Tufão, que você vê na televisão. Qual é o rotacional do tufão? [...] Se você entrar no olho do tufão e pegar a velocidade lá, a integral da velocidade num caminho fechado dá zero? Não! Liquidificador. Pega a água que tá girando dentro, o rotacional é zero? Não! [...] Imagine que você está na beira de um rio lá, não fazendo nada... Ai você pega uma palha, tira da boca e joga no rio. A palha vai dizer para você se o regime é rotacional ou não? Sim, se ela começar a girar... (assim) o rotacional é isso. Se ela andar em linha reta, só deslizar, o regime é irrotacional. (Aula 24 - 1:37:20-1:39:40)

Pensa em uma estação de metrô que é igualzinho. Se você pegar o trem andando no túnel lá. Você pode tratar a quantidade de pessoas que anda por unidade de área através de [...] pessoas por segundo? Pode! O cara chegou na estação e saiu todo mundo junto assim, não! Cada um foi para um lado. Então a técnica matemática de descrever o fluxo dessa coisa é outra. Tem que ter uma técnica mais poderosa. E a técnica mais poderosa é o j. (Aula $26-$ $36: 40-37: 20)$

William Thomson, mais conhecido como Lord Kelvin, disse: "Eu nunca me satisfaço (intelectualmente) até o momento em que eu consigo fazer um modelo mecânico. Se eu consigo fazer um modelo mecânico de algo, eu posso entendê-lo" (THOMSON 1884, apud DARRIGOL, 2000, p. 178). Os trechos das aulas refletem uma atitude constante do professor em procurar exemplos concretos para oferecer ao aluno um arsenal de imagens complementares, com as quais ele se identifica. Fica claro que no processo de construção teórica de um conceito, o professor opta por uma abordagem no sentido do concreto para o abstrato. Durante a entrevista, tivemos a oportunidade de questioná-lo sobre o porquê dessa postura e no Capítulo 6 relatamos seus argumentos. Em outros momentos a discussão sobre analogias se deu mais no âmbito de semelhanças (e também diferenças) formais, ou seja, nas estruturas matemáticas. Assim, optamos por criar outra subcategoria para analisa-los. 
A2 - Analogias formais e diferenças

De acordo com Hesse (1953, p. 202), "uma analogia em física é uma relação, ou entre duas hipóteses, ou entre uma hipótese e resultados experimentais, na qual certos aspectos de ambas(os) podem ser descritos pelo mesmo formalismo matemático". Este último aspecto é particularmente importante para o desenvolvimento de novas teorias a partir de semelhanças no formalismo. Para o caso do eletromagnetismo, Silva (2007) evidencia tal importância ao analisar as analogias formais construídas por Thomson (Eletricidade e fluxo de calor; Deformações elásticas e campo) e Maxwell (Fluido incompressível e eletricidade) para a estruturação conceitual da teoria eletromagnética.

Em sua Teoria Analítica do Calor, Fourier (1822, p. xiv) destacou o poder da analogia formal, argumentando que "a análise matemática associa fenômenos os mais diversos e descobre as analogias ocultas que os unem". De maneira semelhante, Steiner $(1998$, p. 3) defende que "os cientistas foram capazes de elaborar as leis do mundo subatômico através de analogias matemáticas" ${ }^{\text {39 }}$ e no Capítulo 1 já nos referimos à citação de Feynman na qual ele destaca que "as equações de muitas situações físicas diferentes têm exatamente a mesma aparência”. (FEYNMAN; LEIHTON; SANDS, 2008, v. 2, p. 12-1).

Em momentos pontuais do curso, o professor destacou a importância de analogias formais e ressaltou estruturas matemáticas unificadoras, como notamos nos trechos a seguir:

Na aula de hoje a gente aprendeu quais são as estratégias de pensamento para tratar distribuições de coisas. Isso daqui é muito geral, pode ser carga, pode ser massa, pode ser população. Pode ser qualquer coisa que seja distribuída no espaço. Pessoal, cosmologia, estrelas, galáxias, Parsec, você inventa um negócio desses, tem sentido isso. A gente usa o mesmo modo de pensar, isso daqui é muito geral. (Aula 5 - 1:28:20-1:29:00)

Toda vez que você trabalha com hidrodinâmica - abelhas, água, ar - o fluxo é algo que passa através de uma superficie. Eles pegaram essa formulação matemática e a utilizaram em situações diversas. [...] Mas existem diferenças importantes. O campo elétrico não flui, ele não possui nenhuma velocidade. (Aula 12 - 37:20-39:40 - adaptado)

Existe uma lei de Gauss para a gravitação? Sim. Se você puser a Terra aqui dentro. Tem um $g$ em tudo que é lugar aqui. Qual é o fluxo de g através dessa superfície matemática? Aí você pega uma superfície matemática. Essa coisa verde. O verde é matemático. Qual é o fluxo de $g$ através dessa superfície aqui? E aí o que a lei de Gauss fala é que isso é igual à massa da Terra. [...] Qual é o análogo à massa na lei de Gauss? A carga! (Aula 12 - 40:00-40:40)

A matemática necessária já estará feita. Por quê? Essa lei aqui (lei de Ampère-Maxwell) ainda que a gente não tenha visto o conteúdo físico dela, ela é, do ponto de vista matemático parecida com essa (lei de Faraday). Então, se você entendeu a matemática dessa (Faraday)

\footnotetext{
${ }^{39}$ Steiner chamou essas analogias mais profundas de analogias pitagóricas (ver Seção 1.3)
} 
você entende a matemática dessa (Ampere-Maxwell). E aqui em baixo a mesma coisa, ainda que a gente não tenha falado o que é um campo magnético, mas como não tem carga magnética, isso daqui (escreve a lei de Gauss magnética) é sempre zero. (Aula 24 - 31:2032:00)

Então o teorema de Stokes é uma espécie de teorema de Gauss com uma dimensão a menos. Aqui tem integral dupla com tripla (aponta para o teorema de Gauss). Aqui tem uma integral simples com uma integral dupla (aponta para o teorema de Stokes). (Aula 24 - 43:00-43:20)

Chamar atenção para semelhanças formais faz com que o estudante se concentre no que é essencial, ao invés de memorizar várias fórmulas aparentemente desconexas. De acordo com Feynman, essa postura permite que, "tendo-se estudado um assunto, adquirimos imediatamente um conhecimento direto e preciso sobre as soluções de outros problemas" (FEYNMAN; LEIHTON; SANDS, 2008, v. 2, p. 12-1). Porém, além das semelhanças, é importante ressaltar também as diferenças, preocupação também constantemente manifestada pelo professor como no caso do fluxo de água ter uma velocidade e do campo elétrico não. 
Nós reverenciamos a Grécia antiga como o berço da ciência ocidental. Lá, pela primeira vez o mundo testemunhou o milagre de um sistema lógico que procedeu passo a passo com tal precisão que cada uma de suas proposições era absolutamente indubitável. Este triunfo admirável do raciocínio deu ao intelecto humano a confiança necessária em si mesmo para suas realizações posteriores. Se Euclides não conseguiu acender o seu entusiasmo juvenil, então você não nasceu para ser um pensador científico. (EINSTEIN [1934], 1956, p. 164).

Sem dúvida, uma das noções mais importantes do pensamento matemático, a qual foi desenvolvida principalmente pelos matemáticos/filósofos gregos, é a de prova/demonstração. Provar um teorema significa partir de um conjunto de postulados/axiomas tidos como evidentes e, por deduções lógicas, ser capaz de demonstrar sua veracidade. Este estilo de raciocínio é amplamente utilizado nos Elementos de Euclides, obra que constitui um marco histórico por representar um modelo de racionalidade, mesmo quase 2500 anos após a sua primeira publicação.

Apesar do controverso debate filosófico em torno da "veracidade" dos axiomas, bem como da busca pelo conjunto mais fundamental dos mesmos, a ideia da prova está intimamente relacionada à capacidade de se responder aos porquês. Quando se estuda a demonstração do Teorema de Pitágoras presente nos Elementos (Proposição 47, Livro I), e se percebe que é possível concluir que o "quadrado da hipotenusa é igual à soma dos quadrados dos catetos" porque "se quantidades iguais forem retiradas de coisas iguais os restantes permanecem iguais", a sensação de segurança desse pensamento e veracidade de sua conclusão é indescritível. Por razões como essa, é possível entender porque Bachelard afirma que a força da matemática reside no fato dela ser "um pensamento seguro de sua linguagem"

É interessante notar a influência desse raciocínio lógico-dedutivo em várias obrasprimas da física, desde o nascimento da ciência moderna. Uma breve folheada nos Principia de Newton é suficiente para evidenciar a semelhança no estilo de apresentar definições, axiomas e, em seguida, demonstrar teoremas com o uso do raciocínio geométrico. A expressão Q.E.D., que em português tomou a forma C.Q.D. (como queríamos demonstrar), é encontrada muitas vezes no clássico do físico inglês. Einstein também foi claramente influenciado pelo estilo de pensamento presente na obra de Euclides. Em sua biografia, conta-se que ele teve seu primeiro contato com os Elementos aos dez anos de idade por indicação de um estudante de medicina (Max Talmud) que frequentava sua casa. A influência

\footnotetext{
40 apud Paty (1995).
} 
desse pensamento é confirmada na postura adotada em seu primeiro artigo sobre a relatividade especial, no qual a apresentação da teoria é feita a partir de dois postulados. O trecho a seguir deixa muito claro o apreço de Einstein pela maneira de pensar da geometria euclidiana e a semelhança da mesma com a física:

Um sistema completo da física teórica consiste em conceitos e leis básicas para interrelacionar esses conceitos e nas consequências a serem derivadas por dedução lógica. São a essas consequências que nossas experiências particulares correspondem, e é a derivação lógica das mesmas em um trabalho puramente teórico que ocupa, de longe, a maior parte do livro. Isto é exatamente análogo à geometria euclidiana, exceto que nesta as leis básicas são chamados de "axiomas", e que nesse campo não há preocupação de que as consequências tenham que se corresponder com qualquer experiência. (EINSTEIN [1934], 1956, p. 164-5, grifo nosso).

Assim, para Einstein, a busca pela dedução das leis da natureza a partir de um conjunto de princípios fundamentais está no coração do método da física teórica:

O método da física teórica tem como fundamento um conjunto de postulados ou "princípios" a partir dos quais as conclusões podem ser deduzidas. O físico precisa primeiro descobrir os princípios para só então deduzir as conclusões deles (EINSTEIN, [1934], 1956, p. 110).

A escolha desses princípios físicos fundamentais, segundo ele, não é tarefa fácil, pois exige muita intuição e uma compreensão profunda da experiência. O princípio da relatividade, bem como os de conservação (massa, carga, energia) e simetria, são exemplos deste tipo de alicerce de teorias físicas. Comentando sobre o poder do princípio do tempo mínimo para a dedução das leis da óptica geométrica, Feynman (2008) argumenta que:

Para o desenvolvimento adicional da ciência, queremos mais do que apenas uma fórmula. Primeiramente, temos uma observação, depois temos os números que medimos e depois temos uma lei que resume todos os números. Mas a real glória da ciência é que podemos descobrir uma maneira de pensar tal que a lei é evidente. (FEYNMAN; LEIHTON; SANDS, 2008, v. 1, p. 26-3, grifo nosso).

Diante dos argumentos (epistemológicos) apresentados, defendemos que, no ensino de física, esse caráter lógico-dedutivo deveria ser abordado e, por isso, optamos por criar esta categoria. Demonstrações aumentam o conhecimento dos estudantes sobre a origem das equações físicas e permitem que os mesmos penetrem na estrutura interna da física, evitando assim a memorização artificial de fórmulas matemáticas sem sentido. Alguns exemplos são a dedução da lei da refração da luz pelo princípio de Huygens ou de Fermat e das leis cinemáticas de Kepler a partir das leis dinâmicas de Newton. Na verdade, diferentes maneiras de obter a mesma fórmula também podem proporcionar discussões interessantes, uma vez que exemplificam a flexibilidade da matemática (DIEKS, 2005).

A demonstração de fórmulas da física no contexto de ensino ainda é um tema que demanda uma pesquisa sistemática. Pouco se sabe sobre a capacidade dos alunos e 110 
professores em lidar com esse processo. Não raro, as demonstrações aparecem em apêndices de livros didáticos e raramente são objeto de avaliação. É preciso investigar os limites e possibilidades desse enfoque para diversos conteúdos específicos e níveis escolares. Um risco que nos parece iminente é fazer com que a demonstração vire uma sequência monótona de etapas lógicas, sem que a formulação matemática dos princípios físicos seja claramente compreendida. $\mathrm{Na}$ análise das aulas de física, estivemos atentos aos momentos em que o caráter dedutivo da estruturação teórica da física esteve presente no discurso do professor. Identificamos não somente momentos em que demonstrações foram apresentadas e discutidas, mas também quando aspectos desse caráter foram mencionados em expressões como "podemos mostrar/provar/deduzir a partir de", “esse é um dos grandes princípios/pilares da física" e similares.

Ainda que essa abordagem não tenha sido tão frequente durante as aulas, ilustramos momentos em que o aspecto dedutivo foi explicitamente abordado nos trechos a seguir:

(Discussão ao final da resolução de um problema para calcular o fluxo do campo elétrico de uma carga pontual através de um disco) Na conta aconteceu isso porque eu usei essa expressão aqui (lei de Coulomb) e nessa expressão o campo cai com o quadrado, sim? E aí o que está acontecendo é o seguinte, o campo cai com o quadrado, mas a superficie aumenta com o quadrado e o produto da superfície vezes o campo é igual. Qual é a ideia da lei de Gauss? A ideia é inverter a ordem lógica dessas duas afirmações. E ela eleva essa constância do fluxo a uma verdade maior do que aquela lá. Isso é a coisa importante. Então agora tem uma inversão de valores. A gente começou acreditando nisso que é uma verdade empírica, mas [...] o que a fisica fez foi falar que isso daqui (constância do fluxo) é mais importante. E seu eu falar que isso daqui é mais importante, o que eu aprendo? Eu sei agora, porque o campo cai com 1 sobre $r^{2}$. (Aula 12 - 1:41:20-1:42:40)

Mas a questão é a seguinte, será que você consegue calcular e chegar a uma expressão E é igual a alguma coisa a partir dessa equação (lei de Gauss)? (Aula 14 - 27:20-27:40)

Pessoal, carga elétrica é uma grandeza conservada. Esse é um dos pilares mais sólidos da física de hoje. [...] E daqui para frente essa lei (equação da continuidade) vem parar no quadro de honra das coisas realmente importantes. Isso daqui é realmente importante. (Aula $26-1: 37: 00-1: 37: 20+1: 47: 40-1: 48: 00)$

A mensagem do primeiro trecho é bastante instrutiva para a compreensão do processo de estruturação teórica em física: A lei de Gauss é mais geral, ela é elevada à categoria de princípio fundamental e a lei de Coulomb passa a ser uma proposição que poder ser deduzida a partir dela. Com isso, a presença do "misterioso" $4 \pi$ na expressão de Coulomb pode ser devidamente justificada com a dedução desta a partir da lei de Gauss (dedução feita na Aula 14). No terceiro fragmento, o status da conservação da carga elétrica como um dos grandes princípios fundamentais é destacado. 
Durante a entrevista, questionamos o professor sobre a importância de se realizar demonstrações em aulas de física. Uma preocupação sobre a real possibilidade de um aprendizado físico versus uma realização mecânica e autoritária de etapas lógicas e truques algébricos foi manifestada. Seus argumentos são apresentados em detalhe no Capítulo 6.

As duas últimas categorias, analogia e dedução, referem-se a importantes aspectos epistemológicos do conhecimento físico e foram concebidas previamente a análise das aulas. Em vários momentos durante o curso o discurso do professor se deu de maneira mais geral e distanciada sobre os processos da física e do pensamento, uma espécie de meta-análise que nos leva às próximas categorias. 
Como um cientista perfeitamente competente pode se preocupar com epistemologia? Não há trabalho mais valioso a ser feito em sua especialidade? Isso é o que eu ouço muito dos meus colegas e pressinto esse pensamento de muitos outros. Mas eu não posso compartilhar este sentimento. Quando eu penso nos melhores alunos que eu encontrei em minha experiência como professor, isto $e ́$, aqueles que se distinguiram por sua independência de julgamento e não apenas por sua rapidez de raciocínio, posso afirmar que todos tinham um interesse vigoroso em epistemologia. Eles se engajavam com extremo interesse nas discussões sobre objetivos e métodos da ciência, e eles mostraram de forma inequívoca, através da defesa tenaz de seus pontos de vista, que o assunto parecia importante para eles. (EINSTEIN, 1916 apud HOWARD, 2005, p. 34-35).

A citação de Einstein mostra a importância de discussões sobre epistemologia da física para que os estudantes desta ciência adquiram uma "independência de julgamento". De fato, a posição de Einstein como um epistemólogo de primeira, além de sua inquestionável qualidade como físico, coloca-o num seleto e restrito grupo de pensadores. Sua concepção sobre a inseparabilidade desses dois campos fica evidente quando o mesmo defende que "Ciência sem epistemologia torna-se um esquema vazio. Epistemologia sem ciência - se é que tal coisa pode sequer ser imaginada - é primitiva e confusa" (EINSTEIN, 1949 apud HOWARD, 2005, p. 34).

A preocupação com discussões filosóficas é marca registrada das aulas do professor analisado. Sua formação específica/incomum - com períodos de estudos de filosofia da física na Inglaterra - o credencia de maneira diferenciada a conduzir esse tipo de discussão, o que fica claro ao longo do curso analisado. Em muitos momentos das aulas - frequentemente durante os primeiros 20 minutos ou quando uma questão de um aluno suscita tal discussão o discurso do professor adquire um caráter filosófico intenso, sendo que uma série de aspectos sobre o fazer física, como por exemplo "o que é uma teoria”, "qual a relação da matemática com a física", "qual a relação entre teoria e experimento" "modelo e realidade", entre muitos outros, são tratados e discutidos. Devido à frequência e ampla diversidade desse enfoque, é impossível reproduzir aqui a profundidade das discussões. Tentaremos exemplifica-las com alguns fragmentos extraídos das aulas.

Qual é a relação entre matemática e física? Essa é uma relação muito complexa. [...] é nesse sentido que a matemática é importante, ou seja, a gente pensa em física usando uma linguagem e a matemática é um instrumento de pensar o mundo. [...] do ponto de vista da física, como que a maioria dos físicos usa matemática? A gente usa matemática de um jeito bastante intuitivo. Claro que o rigor matemático é importante, mas quando a gente trabalha em física a gente não se preocupa em geral com isso, é parte do jeito que a gente se 
relaciona com o mundo, que é diferente do jeito que o matemático se relaciona. Na física a gente usa a intuição na matemática. Não é só as coisas totalmente demonstráveis, tem que ter um intuição. O nosso pensar é um pensar ligado ao mundo material. Vários teoremas matemáticos foram intuídos por físicos, o cara não demonstrou. O teorema de Stokes é um exemplo. (Aula 6-1:20-6:00)

Na fisica existe muita opinião, ou seja, a ciência não tira a sua participação direta do processo. Os físicos tem opinião a respeito dos problemas de física. Então, o que você vai encontrar no conhecimento da física não é uma coisa uniforme. Cada pessoa se relaciona com esse conjunto de conhecimento de acordo com sua personalidade, isso é uma coisa muito importante. Então para você ter cidadania em física, você tem que ter opinião. Agora para ter opinião lá dentro, não é só dizer "eu acho" isso, a sua opinião tem que ser baseada em coisas que permitam a você dialogar com a comunidade. (Aula 7 - 2:40-4:00)

Pessoal, física é duro. Por que física é duro? Vários motivos. Um dos motivos é a presença da matemática na física. Qual é o problema da matemática? Ela é extremamente eficiente e útil, mas ela só ganha sentido se a gente costurar o símbolo em alguma coisa. Tudo bem isso? [...] O que estou fazendo no curso de eletromagnetismo, estou fazendo a inserção cultural do símbolo, tudo bem? (Aula 9-37:40-38:40)

O que é uma teoria física? Não sei. Ninguém conseguirá discursar adequadamente sobre o que é uma teoria física, da mesma forma que ninguém conseguirá discursar adequadamente sobre o que é um ser vivo. A gente consegue falar verdades parciais a respeito de um ser vivo. Mas você não consegue esgotar esse conceito com palavras. Como que a gente sabe o que é um ser vivo? Interagindo com eles. Dai a gente ganha conhecimento que esta localizado em uma outra esfera da nossa inteligência que é uma esfera não verbal. Você não pode falar, você sabe, mas não pode falar. Teoria é mais ou menos isso. Se você quiser falar alguma coisa da teoria, qual é a atitude mais prudente. Vai lá e olha o eletromagnetismo. Eo que você conseguir falar sobre o eletromagnetismo é bom porque o eletromagnetismo é uma teoria. (Aula 39-2:40-4:20)

Outros inúmeros exemplos poderiam ser citados, pois o discurso filosófico do professor é muito vasto e profundo. A mensagem é clara: não basta fazer física, é preciso refletir sobre o que significa fazer física. Esse tipo de discussão não é comumente encontrada em aulas de física básica e acaba delegado a disciplinas específicas como "história e filosofia da física". Os diversos exemplos encontrados na análise deste curso mostram que é possível (e desejável) fazer física e pensar sobre este fazer de maneira concomitante, o que nos leva a conjecturar que a presença de discussões filosóficas pode ser um importante critério para avaliar a qualidade do discurso didático. 


\begin{abstract}
Metacognição refere-se ao conhecimento sobre os próprios processos cognitivos de um indivíduo ou sobre qualquer coisa relacionada a eles, por exemplo, aspectos relevantes para a aprendizagem de informações ou dados. [...] Metacognição referese, entre outras coisas, ao monitoramento ativo e à consequente regulação desses processos, os quais estão geralmente a serviço de objetivos concretos [a resolução de problemas]. (FLAVELL, 1976, p. 232).
\end{abstract}

Pensar sobre o próprio pensamento tem se demonstrado um importante hábito para desenvolver habilidades que nos tornem bons resolvedores de problemas. Em educação matemática, o incentivo ao pensamento metacognitivo resultou no desenvolvimento de estratégias didáticas que propiciem momentos para os estudantes reflitam sobre seus enfoques e dificuldades ao resolverem problemas, discutindo-os de maneira explícita com seus colegas. Segundo Schoenfeld (1987, p. 190), a pesquisa em metacognição tem focado em três aspectos:

1 - Seu conhecimento sobre seus próprios processos de pensamento. Quão precisamente você é capaz de descrever seu próprio pensamento?

2 - Controle ou regulação própria. Quão bem você acompanha o que está fazendo quando (por exemplo) está resolvendo problemas, e quão bem (se é que chega a fazer isso) você utiliza essas informações para orientar suas ações para resolver problemas?

3 - Crenças e intuições. Que ideias sobre matemática (ou ciência) você traz para trabalhar com matemática (ciência) e como isso interfere na maneira como você faz matemática (ciência)?

Ao longo das explicações do professor de nosso estudo de caso, notamos uma preocupação constante do mesmo em incentivar esse tipo de reflexão metacognitiva, o que nos motivou a considerar esta categoria. Em inúmeros momentos ele faz pausas e questiona seus estudantes: "Agora pergunta para você se você entendeu isso mesmo", "Não pense que isso é fácil", "A gente demora muito para entender isso". Esses momentos foram categorizados como Metacognição e nos parecem um outro grande diferencial desse professor. Nossa percepção é que ele está perfeitamente ciente das dificuldades que ele próprio teve para entender os conceitos do eletromagnetismo e as explicita para os estudantes, ao invés de fazer parecer como se tudo fosse fácil e evidente. Nossa percepção foi confirmada nas entrevistas realizadas, as quais são descritas no Capítulo 6. Ilustramos esse incentivo à metacognição nos seguintes trechos: 
Agora pensa um pouco se você entendeu o problema direitinho, não mais ou menos. Não é assim na hora em que eu estava falando você teve a impressão que entendeu. Você entendeu isso? Porque a gente vai ficar fazendo isso durante três semanas. Tudo bem o problema? (Aula 5 - 16:20-17:00)

Isso daqui parece simples, mas só que você errou um negócio desses aqui, você errou tudo. Então precisa tomar cuidado. (Aula 9 - 36:00-36:20) Seguinte: NEM BRINCA COM ISSO! "Ele falou, mas eu vou fazer do meu jeito." Isso é sério!? Por que você não consegue levar o problema adiante desse jeito. (Aula 9 - 37:20-38:00) Em geral, as pessoas que tem dificuldade de costurar o símbolo na conta, o "cara" começa a resolver um problema e não entende que hora que o problema acabou. Para ele o problema é fazer uma conta e ele vai fazendo conta conta conta... Ai ele já respondeu o que foi perguntado e continua fazendo conta conta conta... (risos) Ele não conseguiu entender que hora que a conta acaba, porque ele obteve a grandeza que ele queria obter. A gente não pode trabalhar desse jeito. (Aula $9-$ 42:40-44:00)

Pessoal, muito legal ele ter perguntado isso. A pergunta dele indica uma confusão. Mas essa confusão ocorre sempre com todo mundo que estudou esse negócio. E se ela não ocorreu com você, é porque você não percebeu isso ainda. Ela está ocorrendo e você não sabe. (Aula $12-37: 00-37: 20)$

Tudo bem? Isso é muito difícil. Você não vai ter nunca uma conta mais fácil do que essa. Só que cada passo da conta é recheado com um discurso complicado. E precisa ser feito para justificar o que autoriza você a dar cada passo. (Aula 14 - 45:00-45:40) O problema tem simetria, mas ela não é suficiente pra resolver o problema. E aí a gente fica na seguinte situação: a lei de Gauss é válida, ou seja isso daqui $\left(q / \varepsilon_{0}\right)$ é igual a isso (Integral dupla de E escalar $n$ dA) mas você não consegue efetuar os passos intermediários para isolar $E$. Pessoal, isso é bastante difícil. Por isso eu falei, demora duas semanas para a gente entender isso daqui. (Aula 14 - 47:00-48:40)

A monitoração do processo, os conselhos sobre como proceder e o reconhecimento da complexidade dos conceitos e problemas envolvidos ficam evidentes no discurso do professor. Sua atitude contrasta com uma postura comum de apresentar o conteúdo físico através de um desenvolvimento linear, lógico e implicitamente trivial, descartando a possibilidade de que os estudantes apresentem dificuldades em sua compreensão. 


\section{Quadro resumo das categorias}

No quadro a seguir apresentamos um resumo da descrição de cada uma das categorias de análise, juntamente com exemplos de fragmentos das aulas que ilustram sua abordagem.

\begin{tabular}{|c|c|c|c|}
\hline \multicolumn{2}{|c|}{ Categoria } & Descrição & \multirow[b]{2}{*}{$\begin{array}{l}\text { Exemplos das aulas } \\
\text { Então o problema do i é que ele é um } \\
\text { escalar. E se eu quiser ser mais } \\
\text { preciso eu tenho que usar um vetor } \\
\text { (j, densidade de corrente). }\end{array}$} \\
\hline Matematização & $\begin{array}{l}\text { M2 Estruturas } \\
\text { Matemáticas }\end{array}$ & $\begin{array}{l}\text { Estruturas matemáticas são utilizadas para } \\
\text { representar grandezas físicas e suas relações. } \\
\text { Aspectos essenciais são identificados e } \\
\text { justificativas físicas são oferecidas. }\end{array}$ & \\
\hline 1 & M1 Modelização & $\begin{array}{l}\text { Idealizações, aproximações e seleção } \\
\text { variáveis relevantes são abordadas } \\
\text { maneira explícita. }\end{array}$ & $\begin{array}{l}\text { Se a carga estiver concentrada num } \\
\text { ponto fica dificil. Mas supõe que ela } \\
\text { seja uma bolinha. }\end{array}$ \\
\hline \multicolumn{2}{|l|}{ Interpretação } & $\begin{array}{l}\text { Estruturas matemáticas são interpretadas } \\
\text { fisicamente. Casos particulares e limites são } \\
\text { comumente utilizados. }\end{array}$ & $\begin{array}{l}\text { O que significa integrar em dy? [...] } \\
\text { O que essa expressão fala? [...] O } \\
\text { que acontece se } x, y, z \text { forem nulos? }\end{array}$ \\
\hline \multirow[t]{2}{*}{ Técnica } & $\begin{array}{l}\text { T2 Entendimento } \\
\text { Conceitual }\end{array}$ & $\begin{array}{l}\text { Explicações conceituais para regras } \mathrm{e} \\
\text { procedimentos matemáticos são dadas. A } \\
\text { justificativa é somente matemática. }\end{array}$ & $\begin{array}{l}\text { Imagina um vetor } r \text { qualquer de } \\
\text { componentes } x \text { y } z \text {. Se você fizer essa } \\
\text { conta, isso dá } x^{2}+y^{2}+z^{2} \text { que é igual } \\
\text { ao módulo do vetor ao quadrado. }\end{array}$ \\
\hline & $\begin{array}{l}\text { T1 Manipulação } \\
\text { e Autoridade }\end{array}$ & $\begin{array}{l}\text { Manipulações técnicas são realizadas e } \\
\text { argumentos de autoridade são evocados. } \\
\text { Postura displicente. }\end{array}$ & $\begin{array}{l}\text { Agora você está autorizado a virar a } \\
\text { manivela matemática. Então joga lá } \\
\text { e começa a manipular. }\end{array}$ \\
\hline \multirow[t]{2}{*}{ Visual } & V2 Pictórico & $\begin{array}{l}\text { Desenhos, diagramas e esquemas são } \\
\text { utilizados como fonte de explicação. }\end{array}$ & $\begin{array}{l}\text { A carga positiva cria um campo } \\
\text { amarelo assim (desenha). A negativa } \\
\text { cria um campo laranja assim. }\end{array}$ \\
\hline & V1 Gestual & $\begin{array}{l}\text { Gestos desempenham um papel essencial } \\
\text { para a construção de significados. }\end{array}$ & $\begin{array}{l}\text { O objeto matemático adequado para } \\
\text { descrever coisas que fazem assim } \\
\text { (gira o dedo) é o rotacional. }\end{array}$ \\
\hline \multirow[t]{2}{*}{ Analogia } & A2 Formal & $\begin{array}{l}\text { Semelhanças e diferenças formais são } \\
\text { destacadas. Caráter unificador de estruturas } \\
\text { matemáticas é esclarecido. }\end{array}$ & $\begin{array}{l}\text { Eles pegaram essa formulação } \\
\text { matemática e utilizaram em situações } \\
\text { diversas. [...] Mas existem diferenças } \\
\text { importantes. }\end{array}$ \\
\hline & A1 Material & $\begin{array}{l}\text { Diferentes situações cotidianas, analogias e } \\
\text { metáforas são utilizadas para a significação } \\
\text { de conceitos abstratos. }\end{array}$ & $\begin{array}{l}\text { Cachorro sabe calcular gradiente? } \\
\text { Sabe. [...] Como ele consegue achar } \\
\text { um bife numa sala escura? }\end{array}$ \\
\hline \multicolumn{2}{|l|}{ Dedução } & $\begin{array}{l}\text { Aspectos do caráter lógico-dedutivo do } \\
\text { conhecimento físico são mencionados. } \\
\text { Fórmulas são deduzidas a partir de princípios } \\
\text { físicos. }\end{array}$ & $\begin{array}{l}\text { A lei de Gauss inverte a ordem } \\
\text { lógica dessas duas afirmações. Ela } \\
\text { eleva a constância do fluxo a uma } \\
\text { verdade maior do que aquela (Lei de } \\
\text { Coulomb). }\end{array}$ \\
\hline \multicolumn{2}{|l|}{ Epistemologia } & $\begin{array}{l}\text { Discussões filosóficas são conduzidas. } \\
\text { Diversos aspectos do fazer física são } \\
\text { problematizados. }\end{array}$ & $\begin{array}{l}\text { Na física a gente usa A gente usa } \\
\text { matemática de um jeito bastante } \\
\text { intuitivo. O nosso pensar é mais } \\
\text { ligado ao mundo material. }\end{array}$ \\
\hline \multicolumn{2}{|l|}{ Metacognição } & $\begin{array}{l}\text { Estudantes são encorajados a refletirem sobre } \\
\text { seus próprios pensamentos. Dificuldades } \\
\text { para a compreensão de conceitos abstratos } \\
\text { são frequentemente explicitadas. }\end{array}$ & $\begin{array}{l}\text { Essa confusão ocorre sempre com todo } \\
\text { mundo que estudou esse negócio. E se } \\
\text { ela não ocorreu com você, é porque } \\
\text { você não percebeu isso ainda. Ela está } \\
\text { ocorrendo e você não sabe. }\end{array}$ \\
\hline
\end{tabular}

Quadro 7: Resumo das categorias de análise. 
Este capítulo teve o objetivo de apresentar cada categoria de análise detalhadamente por meio de exemplos extraídos das aulas e justificar suas escolhas através de argumentos epistemológicos e didáticos. Essa compreensão minuciosa de cada categoria é fundamental para nossa intenção de investigar como as complexas relações entre matemática e física foram abordadas nas aulas analisadas. De fato, tal complexidade fica evidente diante da diversidade de aspectos que o professor aborda em seu discurso. Adicionalmente, os exemplos apresentados neste capítulo nos permitem levantar hipóteses sobre as possíveis relações entre as opções didático-epistemológicas feitas pelo professor e a qualidade de suas aulas, principalmente no que diz respeito à discussão sobre os múltiplos papéis desempenhados pela matemática na física. Entretanto, somente com exemplos de cada uma das oito categorias não conseguimos visualizar como as abordagens representadas pelas mesmas foram desenvolvidas no decorrer das aulas. Essa necessidade nos leva a considerar uma análise mais detalhada de recortes das aulas, a qual será apresentada no próximo capítulo com o auxílio de diagramas temporais elaborados pelo software videograph. 


\section{5 - EPISÓDIOS DE ENSINO}

Consideramos episódios de ensino como recortes das aulas nos quais um determinado conceito é explicado ou um problema é resolvido, de tal forma que seja possível identificar claramente um início e um fim. A categorização de uma aula inteira, além de excessivamente trabalhosa e de não fornecer uma análise suficientemente precisa, muitas vezes não é adequada para o sistema de categorias apresentado no capítulo anterior em função do interesse específico de nossa pesquisa. Como nosso foco está voltado para a abordagem de relações entre física e matemática no contexto do ensino, os episódios foram selecionados a partir da localização dos momentos em que essa abordagem se deu de maneira facilmente identificável. A matematização de conceitos físicos fundamentais do eletromagnetismo (densidade de carga, fluxo de um campo vetorial, corrente elétrica), a interpretação física de operações matemáticas que integram as equações de Maxwell (gradiente, divergente, rotacional, integrais de linha e superfície) e a resolução de problemas-tipo (campo elétrico gerado por distribuições de cargas, aplicações das equações de Maxwell, entre outros) consistem, portanto, os temas dos 19 episódios de ensino selecionados. Sem o compromisso de esgotar todos os tópicos tratados no curso, procuramos identificar como se deu a interação dinâmica das abordagens descritas pelas categorias de análise ao longo das aulas.

Conforme o procedimento de categorização descrito no Capítulo 3, cada intervalo de 20 segundos do episódio foi transcrito e categorizado. A Figura 25 mostra a janela de codificação do software videograph que possui as oito categorias de análise descritas no Capítulo 4 acrescidas de um qualificador (Question - cor laranja) que serviu para diferenciar os momentos em que a aula foi expositiva, daqueles em o discurso tomou a forma de um diálogo entre professor e alunos, normalmente motivado por perguntas de ambos. 


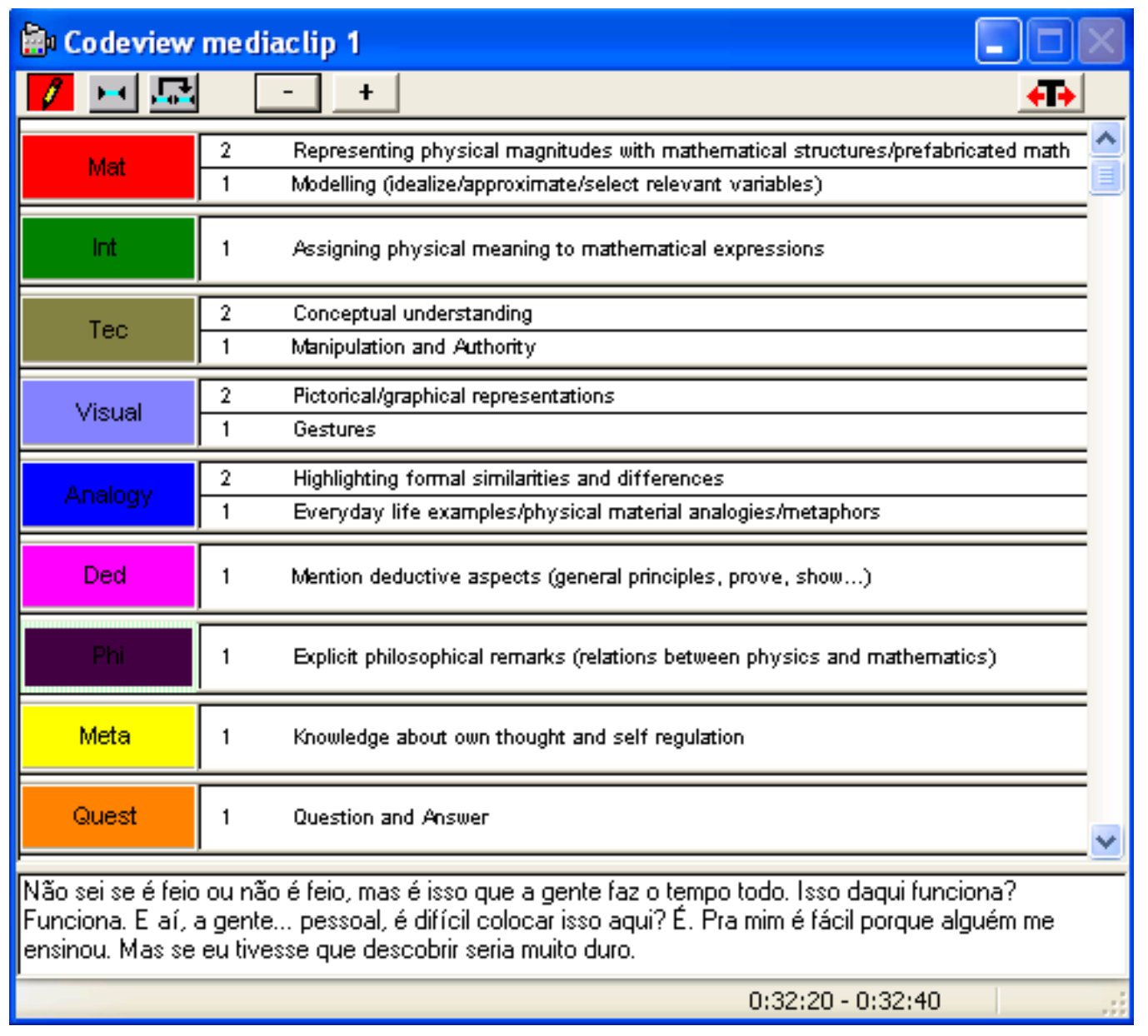

Figura 25: Sistema de categorias no videgraph

\section{Quadro resumo do eletromagnetismo}

Para uma melhor compreensão da estrutura do curso, antes de analisarmos os 19 episódios selecionados é importante mencionar um quadro resumo utilizado pelo professor em praticamente todas as aulas e explicar o papel que o mesmo desempenha. Este quadro é apresentado como uma síntese da teoria eletromagnética, ou seja, ele contém todo o conteúdo abordado no semestre. Habitualmente, o professor dedica os minutos iniciais de cada aula (em torno de $20 \mathrm{~min}$ ) para a construção do quadro e uma discussão de natureza fortemente metacognitiva (regulação) e epistemológica é conduzida. O discurso nunca é igual e a representação do quadro vai sendo gradualmente modificada. No início do curso, o mesmo contém mais palavras e representações pictóricas. Ao final, ele é repleto de equações.

$\mathrm{O}$ quadro apresenta essencialmente as quatro equações de Maxwell juntamente com a força de Lorentz. Em alguns momentos, a lei de Coulomb e de Biot-Savart também são incluídas como informações externas ao quadro e, a partir da vigésima sexta aula, a equação 120 
da continuidade passa a integrá-lo. Na última aula do curso, o professor o apresenta e discute a sua versão final.

O quadro resumo é apresentado pela primeira vez na terceira aula. A Figura 26 mostra essa versão inicial. Notamos que nenhuma equação é escrita, somente símbolos representando relações causais $\left(q \rightarrow \vec{E}, \partial_{t} \vec{B} \rightarrow \vec{E}, I \rightarrow \vec{B}, \partial_{t} \vec{E} \rightarrow \vec{B}\right)$ e representações pictóricas que fornecem imagens das linhas de campo. O professor utiliza um "código de cores" para discernir entre carga e corrente (vermelho), campo elétrico (amarelo) e campo magnético (azul). Abaixo das equações de Maxwell, podemos observar a expressão da força de Lorentz.

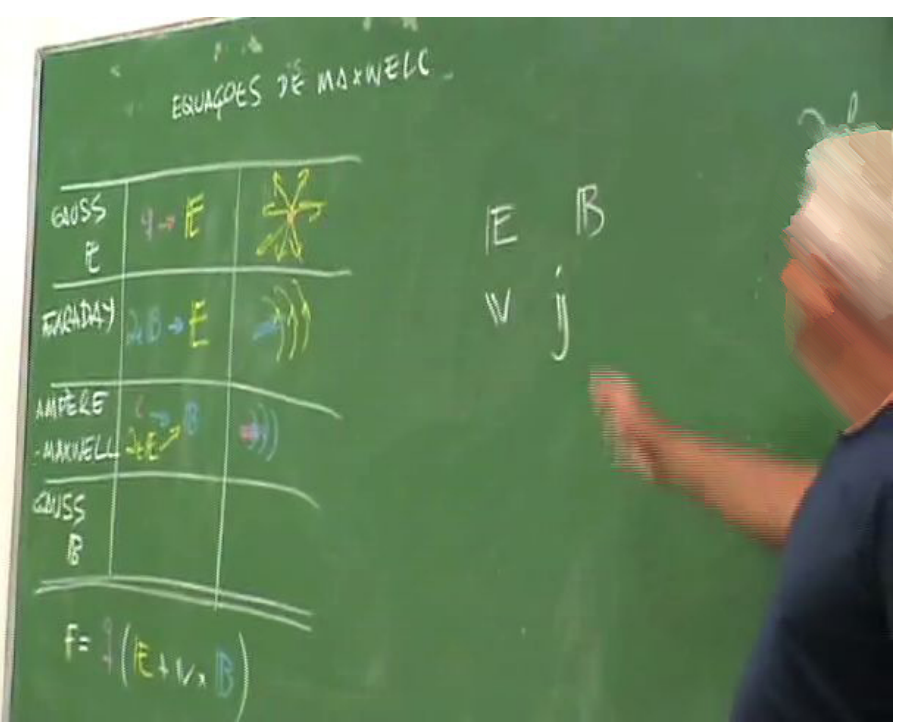

Figura 26: Quadro resumo do eletromagnetismo - Aula 3

As colocações apresentadas a seguir ilustram o discurso do professor nessa apresentação inicial (Aula 3):

6:00 - 6:20 A teoria do eletromagnetismo se propõe a explicar como que um conjunto de cargas elétricas que está aqui (gesto) dialoga com um outro conjunto de cargas.

7:40 - 8:20 Existem quatro leis e o conjunto das leis é chamado equações de Maxwell. Esse é um caso típico em que o todo é maior do que a soma das partes.

9:40 - 10:00 O que a lei de Gauss diz? Se você pegar uma carga parada ela cria campo elétrico $(q$ seta $\vec{E})$

10:20 - 11:00 A lei de Gauss magnética diz que não existe o análogo magnético da carga. [...] Não existe monopólo magnético.

14:40 - 15:00 A lei de Ampère fala que corrente cria campo magnético (i seta $\vec{B}$ ).

20:20 - 21:00 A lei de Faraday vai falar que existe um outro mecanismo de criar campo elétrico. Ele pode ser criado ou por carga ou por variação temporal de campo magnético. 
25:40 - 26:20 As quatro equações de Maxwell dizem como os campos são criados. E a força de Lorentz vai falar como uma carga sente os campos.

A multiplicidade de representações do quadro evidencia a consciência do professor sobre o fato de que os conceitos científicos são híbridos semióticos (LEMKE, 1998). Além disso, nota-se que o professor está desde o início comprometido com o significado físico das equações ao enfatizar o que cada lei “diz”, incentivando seus alunos a interpretarem a física por trás das expressões matemáticas. Em inúmeros momentos a importância do quadro é ressaltada e sua compreensão profunda é anunciada como o objetivo principal do curso.

24:20 - 25:20 Quero chamar atenção para uma coisa: quando você estuda um assunto desse tipo (eletromagnetismo) você tem que olhar tanto as árvores como a floresta. Se você não entender a floresta, você fica perdido lá. Você olha para uma árvore, para outra árvore e não sabe onde você está. E dai você não consegue ser operacional nessa coisa. Então por isso que você tem que entender a floresta que é isso daqui (aponta para o quadro). A gente vai ficar olhando para a floresta toda aula. Sempre tem que se referir à floresta. O que você tem que saber no fim, não é isso, mais isso, mais isso, é tudo isso daqui junto. A aula 40 do curso é isso daqui, você tem que saber isso daqui (aponta para o quadro).

A metáfora é poderosa e ilustra muito bem um problema comumente encontrado no ensino de física: o aprendizado de árvores sem que se tenha uma compreensão da floresta. Isso costuma provocar nos estudantes uma sensação de desorientação e de falta de sentido sobre o que é ensinado. Ao enfocar a importância do quadro frequentemente, os alunos adquirem um panorama claro e geral sobre o objetivo do curso, além de serem capazes de identificar em que região da floresta eles se encontram em cada aula. Esse tipo de discurso metacognitivo, de auto-regulação, está presente em muitos outros momentos do curso. Na Aula 31, dedicada a uma formulação mais precisa da lei de Ampère, o professor volta a falar sobre a importância do quadro, conforme descrito no trecho seguir. Em seu discurso, fica clara a dificuldade inerente ao aprendizado da teoria eletromagnética (normalmente tida como um "divisor de águas" em cursos de física), o que ressalta a pertinência do estudo de caso. A mensagem de que tudo o que precisa ser conhecido para se resolver um problema de eletromagnetismo está no quadro promove uma sensação de segurança e coerência da teoria:

Aula 31 - 43:00 - 46:40 Eletromagnetismo é a primeira teoria moderna que você vê na sua vida acadêmica. A única teoria que você tinha visto aqui até agora era a mecânica. Eletromagnetismo é a primeira coisa nova. Física moderna é muito mais isso que mecânica. A gente não está acostumado com isso daqui. Qual é a grande dificuldade que a gente encontra em usar essas equações? Por que que toda aula eu escrevo isso aqui (quadro resumo)? Isso daqui é absurdamente importante. Na hora que você estiver desesperado pra resolver um problema, tem que desenhar esse quadro. [...] isso daqui promove um tipo de razão, de racionalidade, que você não consegue só com a memória. Isso é mais que a sua memória, isso liberta a sua memória. A solução do problema está aqui dentro. Não existe problema cuja solução não esteja aqui dentro. Só que isso é uma caixa de ferramentas 
complexa. E a dificuldade não está em falar que isso faz isso. É como o problema da prova, se eu dou uma esfera... Aquilo lá é problema de criança. Porque eu coloquei uma moldura pra você e falei: trabalha dentro dessa moldura. Aí você pega a lei e aplica. Qual a dificuldade do eletromagnetismo? A dificuldade é pular de um lado pra outro quando é necessário. Então você tem que entender porque você sai daqui e vai pra lá... isso é muito mais difícil. Quando você começa a fazer isso aqui, você começa a fazer física de gente grande. Então a função do quadro é essa. O que é eletromagnetismo? Eletromagnetismo é isso que está escrito aqui. Agora a gente tem que ganhar destreza em usar as ferramentas particulares. É isso que a gente vai fazer agora. Então, que exercícios de criança que a gente vai fazer agora?

A versão final do quadro é apresentada na Aula 39 (ver Figura 27). Nela vemos todas as equações de Maxwell e a equação da continuidade representadas em quatro colunas (símbolos indicando relações causais, desenhos simbolizando linhas de campo, as equações na forma integral e diferencial) juntamente com a expressão da força de Lorentz.

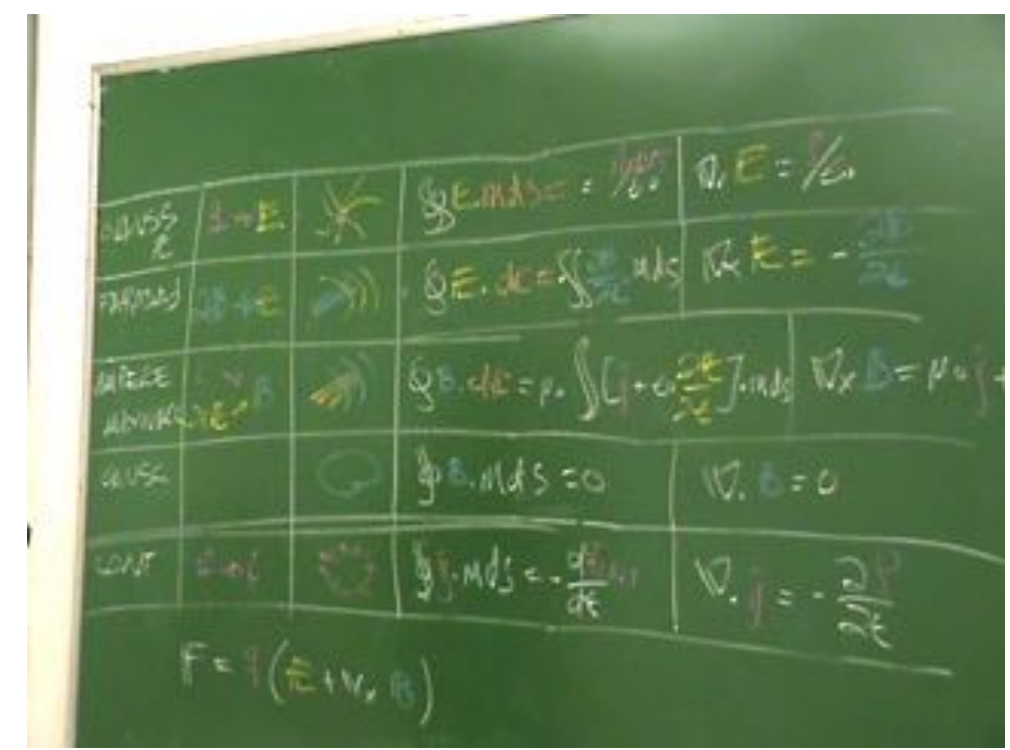

Figura 27: Quadro resumo do eletromagnetismo - Aula 39

Seguimos para a análise dos 19 episódios selecionados, os quais, utilizando a linguagem do professor, abordam molduras do conjunto formado pela teoria eletromagnética. Como a apresentação e discussão do quadro resumo ocorre no início de praticamente todas as aulas, os episódios raramente tem início no minuto (0:00). 
Episódio 1: Densidade de carga (1, 2 e 3 dimensões)

Aula 5-Duração: $28 \min$ (31:00-59:00)

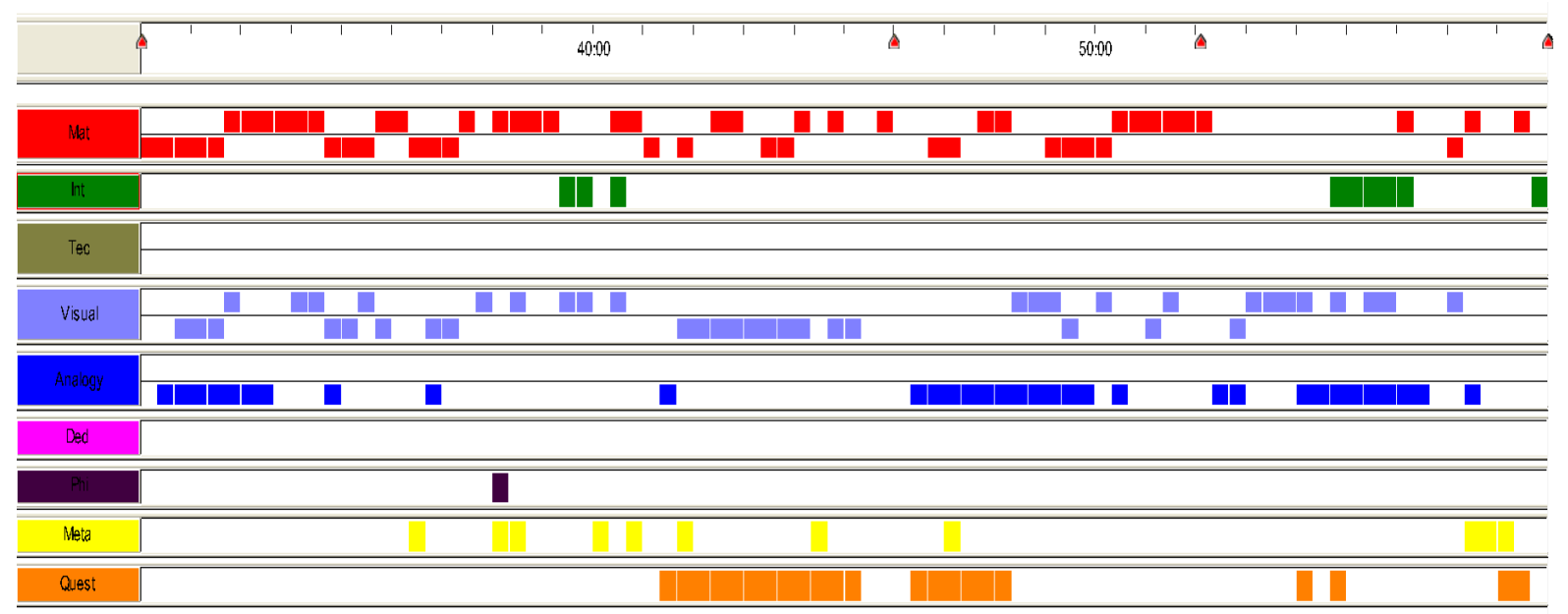

Figura 28: Diagrama Episódio 1 - Aula 5 - Densidade de carga

O conceito densidade de carga tem importância central no eletromagnetismo e é extremamente abstrato. O objetivo da Aula 5 foi justamente abordar e matematizar este conceito. No recorte analisado, as situações uni, bi e tridimensionais são respectivamente consideradas. A categoria matematização está presente em praticamente todo o trecho, sendo que as aproximações e idealizações envolvidas na construção matemática de cada caso $(1,2$ e 3 dimensões) são explicitamente mencionadas:

36:40 - 37:20 Uma estrada, você pode aproximar por uma coisa unidimensional. $O$ comprimento é muito maior do que a largura. Fio de cabelo, você pode aproximar por uma coisa unidimensional. Fio de cabelo tem uma dimensão? Não tem! Tem 3. Mas como ele é muito mais comprido do que a seção transversal a gente aproxima para uma linha. Em muitas situações a gente fala em densidade linear de carga.

46:40 - 47:00 A: A massa de uma folha de papel. P: A folha de papel tem quantas dimensões? 3. Só que duas delas são muito maiores que a espessura, então é razoável pensar na folha, a folha não é bidimensional.

Além disso, as estruturas matemáticas utilizadas na descrição da densidade de carga são apresentadas e devidamente justificadas:

38:20 - 39:00 Você põe a coordenada lá e vai contando a distância (desenha). Isso é x. Qual é a estratégia de pensar. Você vai lá, corta esses pedacinhos. E cada pedacinho desses mede $d x$. Ai você vê quantos elétrons têm nesse intervalo. Isso daqui é o dq. Dá a carga contida naquele pedacinho. Isso daqui é uma função matemática que descreve. Ela vai variar de ponto para ponto.

50:20 - 51:20 A densidade superficial é uma função normalmente chamada de sigma. Isso daqui ( $\left.d^{2} q / d^{2} A\right)$ tá certo. Isso daqui é uma diferencial de $2^{a}$ ordem. Por que? Porque na linha eu tive que cortar um dx. E aqui esse negócio é duas vezes pequeno. Porque eu cortei isso 
daqui em fatias assim (vertical) e depois cada fatia assim (horizontal). Então eu cortei duas vezes, isso daqui é um $d^{2}$. E é essa função ai que descreve a densidade de cargas no bastão ou na esfera, que pode ser não uniforme.

58:00 - 59:00 A: Prof, ali naquelas equações, o sr. falou que não são derivadas. Mas na hora de manipular matematicamente, elas funcionam como se fossem? P: Depende do caso, sim. Se eu escrever uma função $x$, por exemplo, dai você pode derivar, integrar isso. Mas o que é importante é que originalmente ela não é uma derivada. É uma contagem por área.

Outro caráter facilmente perceptível deste episódio é a presença intensa da categoria analogia. Várias situações cotidianas são apresentadas para que os estudantes tenham uma imagem "concreta" do abstrato conceito de densidade de carga:

\section{1:20 - 31:40 Pessoal, essa sala tem uma distribuição de massa humana?}

48:00 - 48:20 Tem densidade de energia térmica na Terra? Tem, por isso que tem inverno e verão. No verão o sol joga mais energia por $\mathrm{km}^{2}$ do que no inverno.

48:20 - 48:40 A gente pode falar em densidade populacional do Brasil?

52:20 - 52:40 Qual é a ideia da densidade volumétrica? Por exemplo, qual é a densidade volumétrica de massa da Terra? Tem sentido fazer essa pergunta? A Terra é uma esfera. A massa tá distribuída uniformemente?

O aspecto extremamente visual da exposição do professor, evidenciado no uso de gestos e representações pictóricas durante as explicações, é constatado pela intensa presença da categoria visual no diagrama do videograph da Figura 28. Pelo caráter de introdução de um conceito, não notamos a presença das categorias técnica nem dedução. A categoria interpretação aparece de maneira pontual, quando professor discute um exemplo hipotético:

39:00 - 39:40 Por exemplo: O que significaria, do ponto de vista matemático, uma função assim: $\lambda=\alpha . x$, onde alfa é uma constante? O que significa isso? Significa que se você pegar o seu corpo físico (essa coisa assim). Imagina que x seja esse ponto. O que está dito lá é que na região próxima desse ponto não tem carga e daí a carga aumenta gradativamente.

E novamente quando interpreta o significado de um gráfico que apresenta três curvas (azul, verde e laranja) que relacionam a densidade de massa da Terra com seu raio:

54:40 - 56:00 Azul é uma boa candidata? Não. Por que? Porque ela tá falando que a quantidade de massa por volume é constante e de repente ela cai fora da superficie, então não pode. A verde? O que ela propõe como resposta ao problema. Que a Terra é meio oca por dentro, ok? Se você acreditar em disco voador, tudo bem. Curva verde: A Terra é oca por dentro e tem umas cavernas da onde saem discos voadores, tudo bem? (risos) Isso daqui está dizendo assim: não tem massa no centro da Terra. Laranja tá dizendo o que? Que o centro da Terra é mais denso e a densidade vai caindo a medida que a gente vai se aproximando da superfície. O que é o modelo meio vigente. Tem metais fundidos pesados no centro da Terra. 
Por fim, notamos a presença de comentários pertencentes à categoria metacognição espalhados pelo trecho:

38:00 - 38:20 E aí você tem o instrumento de pensamento. O que é o instrumento de pensamento, instrumento de pensamento não existe. Mas daí você inventa. É a matemática. Você põe a coordenada aqui. A coordenada não existe. Você que pôs. Ela não tá na natureza. Mas você põe a coordenada lá e vai contando a distância.

57:20 - 58:20 Por favor não ache que isso é fácil. Parece fácil, mas a experiência que a gente tem com esse tipo de coisa aqui. É muito fácil e tal, dai metade das pessoas vai lá e erra questões desse tipo. Significa que metade das pessoas passaram reto por isso daqui e não aprenderam o que tinham que aprender. Então, não acha que isso daqui é banal. Não acha que é óbvio. "Já sei" e tal. Para com isso.

Toda a Aula 5 (aproximadamente 80 minutos) foi dedicada à construção do conceito matemático de densidade de carga e inúmeras situações concretas ilustraram estratégias para descrever distribuições matematicamente. Isso evidencia a crença do professor na não trivialidade deste conceito e na importância de uma discussão duradoura e significativa.

Episódio 2: Expressão matemática do campo coulombiano Aula 9 - Duração: 11 min 40 s (4:20-16:00)

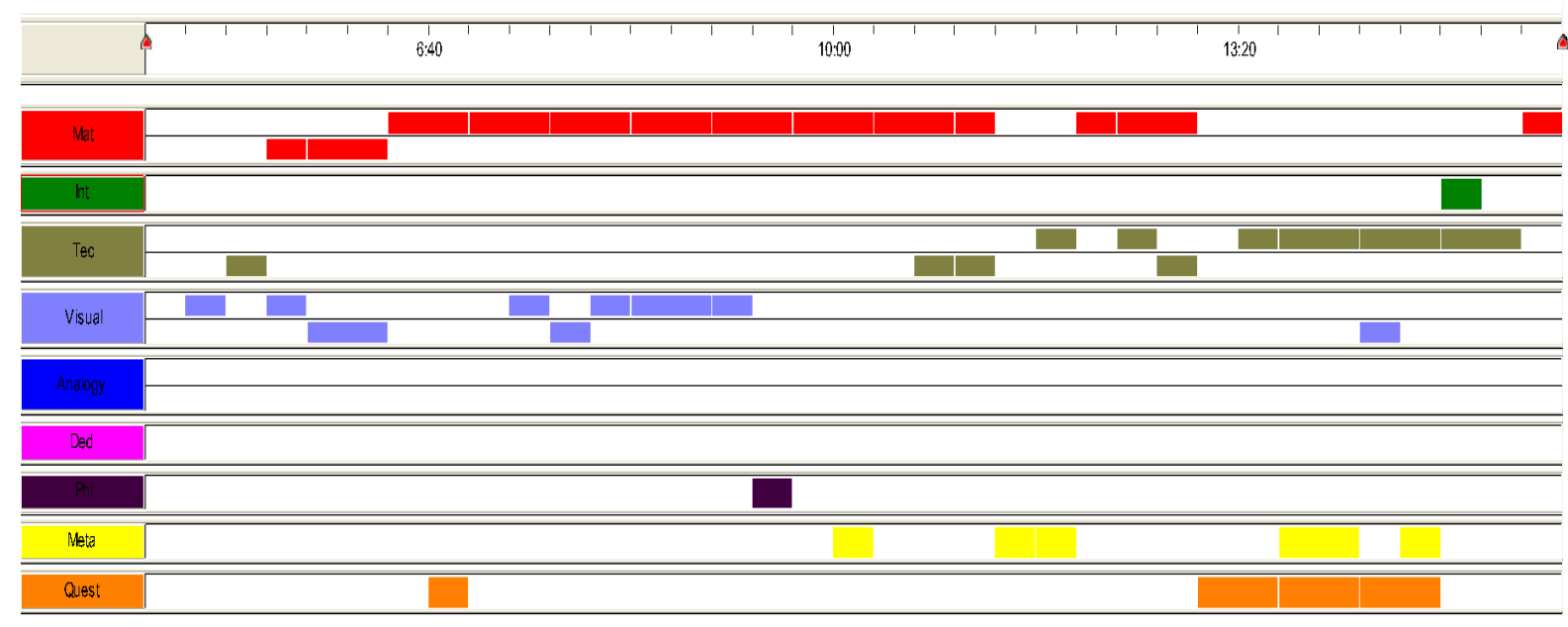

Figura 29: Diagrama Episódio 2 - Aula 9 - Expressão matemática do campo coulombiano

O trecho do Episódio 2 refere-se ao início da Aula 9, na qual o professor apresenta a expressão matemática do campo coulombiano gerado por uma carga pontual e resolve problemas associados a ela. Na verdade, essa expressão havia sido apresentada na aula anterior como um resultado experimental e neste trecho o objetivo é discutir mais detalhadamente sua estrutura matemática e cada um de seus elementos, por isso notamos a intensa ocorrência da categoria matematização (M2). O episódio se destaca pela justificativa da utilização estruturas como vetores, módulos e versores, além de observações feitas pelo 
professor sobre erros comumente cometidos pelos alunos (metacognição). O fragmento analisado inicia-se com uma discussão sobre o caráter geométrico da fórmula:

5:20 - 6:20 O que é importante do ponto de vista geométrico é a seguinte coisa: esse campo depende da distância entre a carga e o ponto que você olha. Se você puser uma carga aqui (gestos) e pergunta, o campo dela existe em torno da carga inteira, sim existe (gestos). Agora, para a gente poder quantificar isso a gente vai ter que escolher um ponto. Então escolhe um ponto qualquer, esse (gestos com a mão). Ai pergunta: Qual o valor da função campo nesse ponto? E aí o que entra na descrição da função campo neste ponto aqui é a distância deste ponto até essa carga, tudo bem? Se você mudar o ponto, o campo muda.

O discurso do professor evidencia a complexidade da expressão matemática e sua ênfase na significação física da mesma. Tal ênfase exemplifica o enorme salto que é dado quando se apresenta uma fórmula sem explicitar seu significado detalhadamente. Em seguida, o problema de representar o campo coulombiano por $\vec{E}=\frac{Q}{4 \pi \varepsilon_{0}} \frac{1}{r^{2}} \hat{r}$ é discutido com profundidade:

6:40 - 7:40 Pessoal, essa não é a maneira mais conveniente de escrever isso daqui, porque se eu tiver uma carga só você põe a origem do sistema de coordenadas em cima da carga e pronto. No caso que tem muitas cargas, o jeito mais útil/prático de escrever é o seguinte. Você põe a carga aqui e diz qual é o ponto que você quer olhar, que é esse ponto P aqui. Aí você escolhe um sistema de coordenadas qualquer onde você vai localizar a carga.

Depois de convencionado e desenhado um sistema de coordenadas cartesianas espaciais, os vetores $\vec{r}_{q}$ (posição da carga) e $\vec{r}_{p}$ (posição do ponto) são definidos. Nesse momento, um comentário interessante (epistemologia) sobre a natureza dos dois vetores envolvidos é feito:

9:00 - 9:40 Esse vetor aqui (aponta para $\vec{r}_{q}$ ) ele não é um vetor físico. Ele não está na natureza. Não está na natureza porque você que escolheu colocar o sistema de coordenadas lá. Você poderia ter escolhido aqui e seria outra coisa. Esse outro vetor aqui $\left(\vec{r}_{p}\right)$ também não é físico. Mas esse aqui $\left(\vec{r}=\vec{r}_{p}-\vec{r}_{q}\right)$ é um vetor importante. Ele diz qual é a posição do ponto em relação à carga.

No decorrer da substituição de $\vec{r}$ por $\vec{r}_{p}-\vec{r}_{q}$, o professor chama atenção para o erro comum de se escrever $\vec{r}^{2}$ como $\vec{r}_{p}^{2}-\vec{r}_{q}^{2}$. Nesse momento, um aluno o questiona sobre a diferença entre o quadrado de um vetor e o quadrado do módulo de um vetor, o que faz com que o professor concentre seu discurso na explicação conceitual matemática (técnica T2) do produto escalar de um vetor por ele mesmo. No fragmento a seguir, notamos também o incentivo do professor às perguntas dos estudantes:

14:00 - 15:00 Então vamos entender isso direito. Isso daqui é ele escalar ele mesmo, por exemplo: Imagina que um vetor $r$ qualquer tem as componentes $x$ y $z$. Se você fizer essa conta, o que você vai fazer? Vai pegar essa componente e multiplicar por ela mesma. Isso dá 
$x^{2}+y^{2}+z^{2}$ que é igual ao módulo do vetor ao quadrado. Ou seja, se você projetar o vetor sobre ele mesmo (gestos), dá o módulo dele ao quadrado, tudo bem? E daí tanto faz, você usar uma notação ou outra, tudo bem? Sim isso, pergunta? Pessoal, se isso não estiver absolutamente claro para você por favor pergunta.

Por fim, a expressão de Coulomb com a nova convenção dos vetores $\vec{r}_{q}$ e $\vec{r}_{p}$ resulta em $\vec{E}=\frac{Q}{4 \pi \varepsilon_{0}} \frac{\vec{r}_{p}-\vec{r}_{q}}{\left|\vec{r}_{p}-\vec{r}_{q}\right|^{3}}$, o que pode ser erroneamente interpretado como se o campo elétrico variasse com o inverso do cubo da distância. Essa possibilidade é prontamente refutada:

15:00 - 16:00 Ok, então aqui aparece ao cubo no denominador. Isso quer dizer que a lei de Coulomb diz que o campo cai com 1 sobre $r^{3}$, não! Esse 3 aqui é esse 2 aqui mais o 1 desse daqui. É útil escrever isso daqui em vez de pegar o vetor e o módulo dele outra vez. Tudo bem, pergunta? Esse é o melhor jeito de representar campos de uma carga qualquer. E o que a gente vai fazer na aula de hoje é um monte de exercícios e usar isso daí.

A partir desse instante o professor começa a resolver o problema de determinar o campo elétrico gerado por um sistema de duas cargas pontuais, o qual dura aproximadamente 50 minutos. Claramente, esse problema não tem uma mera função de aplicação, mas desempenha um papel fundamental na explicação teórica da lei de Coulomb. Por se tratar da resolução de um problema, apresentamos a análise detalhada do mesmo posteriormente no Episódio 15.

Episódio 3: Fluxo de um campo vetorial Aula 12 - Duração: $32 \min 40$ s (12:20-45:00)

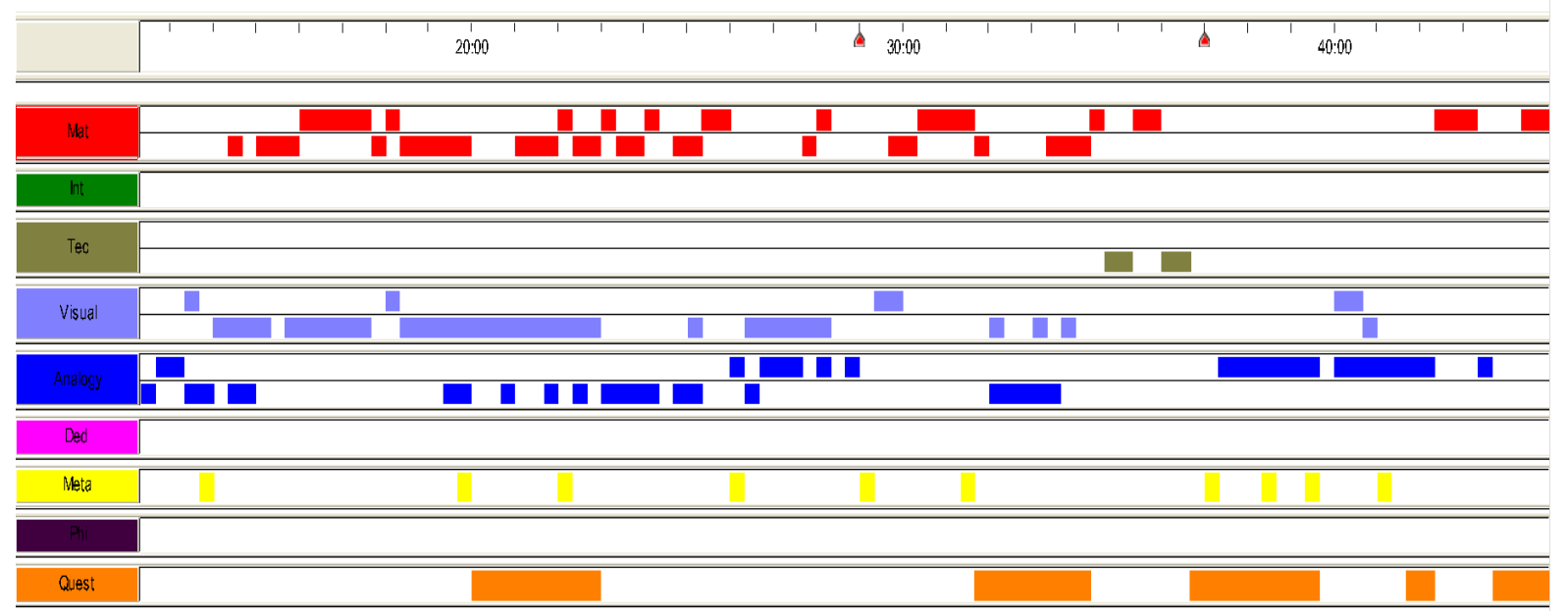

Figura 30: Diagrama Episódio 3 - Aula 12 - Fluxo de um campo vetorial

O conceito de fluxo de um campo vetorial está presente nas quatro equações de Maxwell, tendo portanto um papel fundamental para a compreensão do eletromagnetismo. Por esse motivo, o professor dedica toda a Aula 12 para uma exposição cuidadosa e gradativa 
que tem como objetivo principal construir e significar uma representação matemática para esse conceito.

Partindo da noção intuitiva dos estudantes sobre a ideia de fluxo, o professor vai gradativamente identificando as grandezas relevantes para sua descrição (matematização):

14:20 - 14:40 Como é que a gente pensa em fluir desse jeito? Não existe a noção de fluxo a menos que você apoie uma superficie matemática na porta. Tudo bem isso? Então a gente só pode falar fluxo através de uma superficie.

15:00 - 15:20 (vira a apostila e a deixa paralela ao plano da porta) Tem ar fluindo através dessa superfície? Sim. Pessoal, muda? (gira apostila) Então a noção de fluxo depende do jeito que você coloca a superfície. Então, do ponto de vista matemático a gente vai ter que levar isso em conta.

20:40 - 22:20 Pessoal, tem que projetar alguma coisa? Qual o fluxo de luz da lâmpada através dessa superfície aqui? Passa luz? Não. Passa (gira a apostila)? Sim. Só uma coisa: Fluxo é o resultado final. Como é que eu vou dizer matematicamente que assim passa e que assim não passa.

A: Tem que ser perpendicular ao fluxo.

A: Põe um ângulo aí.

P: Você não pode falar perpendicular ao fluxo porque fluxo é o resultado da conta. Tudo bem, tem que ser perpendicular a alguma coisa. Qual é a grandeza relevante?

Esse versor e o quê da luz? A direção da luz? Tudo bem? Como é que você quantifica? Que vetor entra na conta?

Nestes fragmentos notamos as diversas estratégias utilizadas pelo professor para que os estudantes identifiquem a necessidade de considerar a direção entre o vetor e a normal à superfície para o cálculo do fluxo, em vez de simplesmente mencionar uma fórmula. De maneira semelhante à do Episódio 1, no qual o conceito de densidade de carga foi apresentado, o conceito de fluxo de um campo vetorial é gradualmente abordado com o auxílio de inúmeras situações cotidianas e analogias:

13:20 - 13:40 A ideia é a seguinte: se você pegar um líquido. O que é fluxo de água, como você pensa nesse problema? Pensa num rio. Imagine que você queira (desenha) [...] tem um rio, água aqui andando.

20:40 - 21:00 Qual o fluxo de luz da lâmpada através dessa superfície aqui? Passa luz?

22:20 - 22:40 Pessoal abelhas, imagina um enxame de abelhas entrando por essa porta. Existe fluxo de abelhas por essa superficie?

26:20 - 26:40 Posso falar em fluxo de g - o g da gravidade - através desse ds?

De maneira complementar aos exemplos cotidianos e analogias com outras áreas da física, notamos também a presença intensa da categoria A2 (analogias formais), quando o 
professor destaca que a mesma estrutura matemática pode ser utilizada para representar diversos fenômenos:

13:00 - 13:20 Esse vetor pode ser qualquer coisa, $\vec{F}$ genérico. Pode ser campo elétrico, magnético, velocidade, campo gravitacional pode ser qualquer coisa.

37:40-38:00 Ai as pessoas pegaram essa formulação matemática aqui e disseram: a gente pode usar isso daqui em outros casos.

Nesse sentido, não somente as semelhanças, mas também as diferenças são importantes quando se usa o mesmo formalismo matemático são destacadas. $\mathrm{O}$ principal problema é que a palavra fluxo nos remete a uma ideia de movimento, ou seja, de algo que esteja passando ou fluindo através de uma superfície. Entretanto, quando falamos em fluxo do campo elétrico ou gravitacional, não existe a noção de velocidade. Ciente desse comum erro de interpretação, o professor o aborda explicitamente quando discute o cálculo do fluxo do campo gravitacional:

26:20 - 27:40 Posso falar em fluxo de g? O g da gravidade? Através desse ds? Posso e a gente faz isso. Mas dai a palavra fluxo não é boa. Porque quando eu falo em velocidade, de fato tem uma abelha que estava aqui e depois tá do lado de cá. A abelha atravessou a superficie matemática mesmo. Então quando eu falo em fluxo de velocidade, a palavra fluxo é boa porque tem a sensação de que tem algo passando lá dentro. Tem g passando através da superficie? Não tem. O g tá parado aqui. [...] O fluxo no sentido de passar não existe. Mas a gente usa a palavra fluxo então. A gente fala em fluxo da gravidade.

Essa aula tem uma grande interação entre o professor e os estudantes, o que pode ser observado pela incidência do qualificador Questões (laranja) na Figura 30. A importância dada às perguntas é evidenciada pelo tempo dedicado às respostas e pela elaboração cuidadosa das explicações. Tal importância é notada na resposta dada pelo professor para a pergunta do aluno no trecho a seguir:

31:40 - 34:00 A: Professor, o fluxo não tem que ser em 3 dimensões?

$P:$ Que número de dimensões tem o fluxo?

P: Volta ao problema original. O que é fluxo? No caso de água ou abelha. Você vai contar o que passa através de uma superfície. Se você pegar uma rua. E contar o número de carros que passa na rua. Que você já viu que tem aquele fio lá que o carro deixa um sinal quando passa em cima do fio. O contador de carro. Esse fluxo na rua é em quantas dimensões? $O$ escoamento de carros em quantas dimensões ele se dá? Em duas. Tudo bem que carro na rua é um problema bidimensional? Não é igual abelha, ar... que tá voando em tudo quanto é lugar. Não tem carro na terceira dimensão. Tem o cegonheiro que passou. O guincho e tal. Mas esquece esses casos patológicos (risos). Então o movimento do carro na rua é bidimensional. E aí o fluxo será através do que? De uma linha. A superfície não é importante. Você conta numa linha. A gente generaliza isso. Existe fluxo em uma dimensão aproximada tipo carro. 
A questão da dimensionalidade do fluxo é tratada de maneira clara e com recurso a situações concretas. O exemplo do contador de carros nos remete a uma maneira muito útil de se raciocinar em matemática: o pensamento analógico. O tipo de raciocínio ilustrado pelo exemplo do carro é semelhante àquele que nos permite conjecturar sobre a existência da quarta dimensão, a partir das relações entre dimensões inferiores. Após este exemplo, ficamos tentados a questionar: Seria possível conceber um fluxo em quatro dimensões projetado num volume tridimensional?

Outra resposta longa e bastante instrutiva do ponto de vista didático é dada após a aplicação do conceito para o cálculo do fluxo do campo gravitacional $(\vec{g})$ na superfície de uma mesa de lados $a$ e $b$. A pergunta de um aluno mostra que o mesmo ainda está confuso com a utilização palavra fluxo para coisas que não fluem. Ciente da complexidade dessa abstração, o professor discursa novamente sobre esse problema de interpretação durante três minutos:

36:20 - 39:40 P: Então o fluxo dá - gab. Tudo bem? Pergunta aqui?

A: Nesse caso o g seria o $10 \mathrm{~m} / \mathrm{s}^{2}$ ?

$P: \dot{E}$

A: Mas assim, que nem. Daí o g não seria uma aceleração? E daí teria que usar velocidade?

P: Pessoal, muito legal ele ter perguntado isso. A sua pergunta indica uma confusão. Mas essa confusão ocorre sempre com todo mundo que estudou esse negócio. E se ela não ocorreu com você, é porque você não percebeu isso ainda. Ela está ocorrendo e você não sabe. Então legal ele ter chamado atenção. Pessoal, olha a confusão desse problema. Isso daqui é um abuso de linguagem. Toda vez que você trabalha com mecânica dos fluidos -e abelha é um fluido para esse problema aqui, uma coisa andando, água, ar qualquer coisa dessas - o fluxo é uma coisa que passa através da superfície, tudo bem? Essa é a motivação original. Ai as pessoas pegaram essa formulação matemática aqui e disseram: a gente pode usar isso daqui em outros casos. E aí você pode usar em casos onde de verdade o $g$ não passa. Ele falou em um problema interessante. O g é uma aceleração, porque eu não falo em velocidade?[...]

Quando eu passei daqui para cá eu dei um enorme salto abstrato. Eu peguei essa definição que foi inventada para fluidos e apliquei numa situação em que a coisa não flui. Então a natureza desse vetor aqui para o cálculo do fluxo é uma coisa absolutamente irrelevante. Ai você vai falar assim, o fluxo do vetor gravidade g. Isso tem sentido? Matematicamente tem. Eu falo, fluxo é isso daqui. É uma violência. A gente pega um problema que é concreto e agora eu estou usando numa situação diferente. Eu estou transportando a natureza matemática dessa coisa para cá, mas o problema da interpretação não é tão importante. Isso é uma enorme fonte de problema para a gente. Porque esse nome induz a gente a pensar que tem uma coisa andando. Não tem!

Esse trecho reflete uma extrema consideração e respeito do professor pela pergunta do aluno, além da consciência de que esta dúvida é fonte de problemas para os outros estudantes. O pensar sobre o pensar (metacognição) é exemplificado em inúmeras partes deste discurso. 
É interessante perceber que em nenhum momento durante a explicação o fluxo do campo elétrico é abordado. Na realidade, a estratégia utilizada pelo professor de trabalhar primeiramente com o campo gravitacional faz com que um estudante perceba esta analogia e mencione a semelhança com o campo elétrico:

40:00 - 42:20 Existe lei de Gauss para na gravitação? Sim. Se você puser a Terra aqui dentro. Tem um $\mathrm{g}$ em tudo que é lugar aqui. Aí você pega uma superfície matemática. Essa coisa verde (desenha). O verde é matemático. Qual é o fluxo de g através dessa superfície aqui? E aí o que a lei de Gauss fala é que isso é igual à massa da Terra. [...] Tem g fluindo através da mesa, não. Mas tem g em cima da mesa, tem.

A: De campo elétrico vai ser então da mesma forma, ele não vai estar passando. Ele vai estar lá.

P: Exatamente. Mesma coisa para o campo elétrico. Ele não está passando, ele está lá parado. E aí o que a lei de Gauss vai dizer? O que é análogo à massa no caso da lei de Gauss? A carga.

Por fim, a pertinência da analogia gravitacional é novamente comprovada quando a pergunta de um estudante antecipa o problema resolvido pelo teorema de Gauss:

43:40 - 45:00 A: Prof. no caso da Terra...[...] fazer só em ds, não em dV. Pegar um volume para achar a massa da Terra.

A: Por que eu ia fazer a pergunta da carga. Se você teria que fazer uma casca esférica em volta da carga?

P: Pessoal a pergunta dele é o seguinte: O lado esquerdo da equação (lei de Gauss) é uma superficie. O lado direito vai ser o que? No caso da Terra, a massa. Dai como é que você calcula a massa da Terra? Você vai ter que integrar sobre o volume. Então no fundo isso daqui é uma integral sobre o volume. Ela tá escondida aqui.

A Aula 12 é um exemplo claro da abordagem diferenciada e da multiplicidade de recursos utilizados por este professor, bem como de sua larga experiência com os principais problemas de aprendizagem apresentados pelos estudantes. Parece-nos bastante profícuo avaliar a pertinência do uso de trechos como este na formação de professores de física, inclusive daqueles que trabalharão no ensino médio. A qualidade desta aula será contrastada com a análise de uma aula "tradicional" sobre o mesmo tema, a qual será apresentada no Capítulo 7. 
Episódio 4: Significado da lei de Gauss elétrica (forma integral)

Aula 14 - Duração: 18 min 40 s (04:40-23:20)

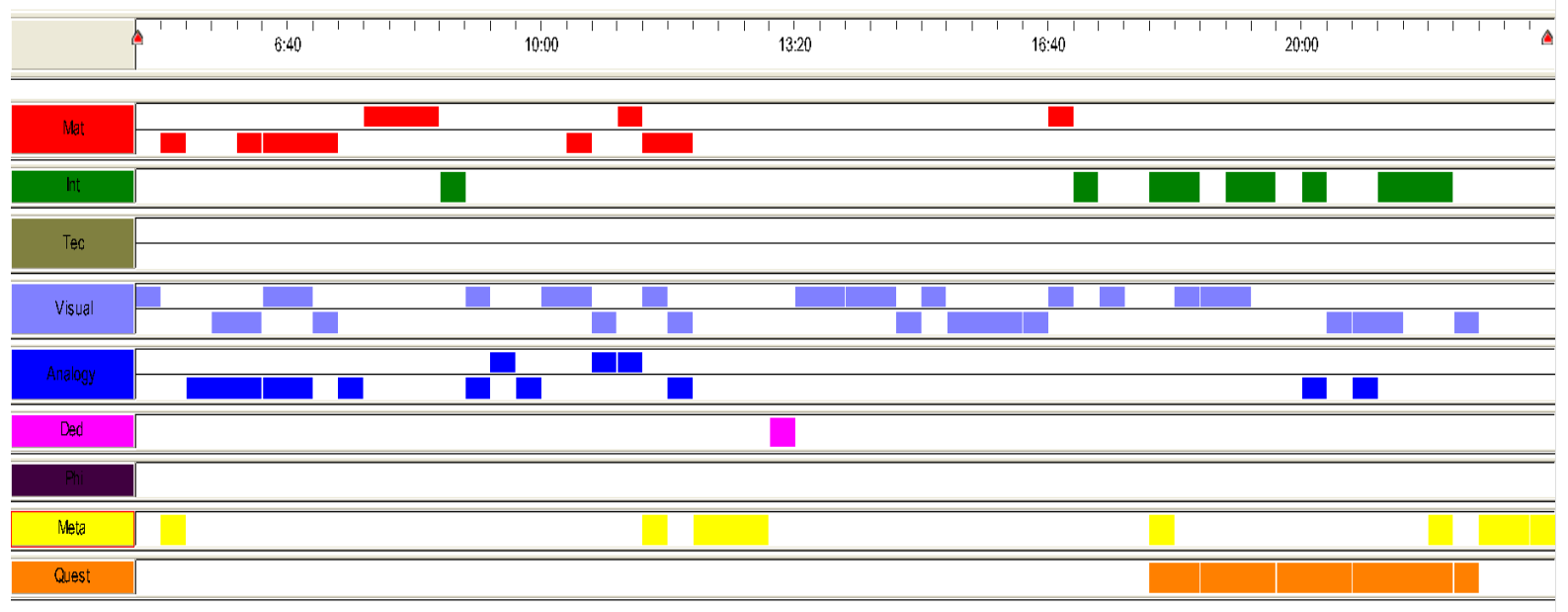

Figura 31: Diagrama Episódio 4 - Aula 14 - Significado da lei de Gauss

O Episódio 4 refere-se ao início da Aula 14, na qual a lei de Gauss elétrica na forma integral $\left(\oiint \vec{E} . \hat{n} d S=\frac{q_{\text {int }}}{\varepsilon_{0}}\right)$ é tratada. O diagrama (Figura 31) ilustra vários recursos visuais, momentos iniciais de matematização e questões motivando a interpretação no fim do episódio. De uma maneira geral, há um cuidado especial do professor em diferenciar o cálculo do fluxo através de uma superfície aberta (que foi tratado nas aulas anteriores) do cálculo do fluxo total em uma superfície fechada. Essa diferença é inicialmente abordada através de uma analogia entre carga/campo e lâmpada/luz:

05:20 - 07:20 O que é fluxo através de uma superficie fechada? Por exemplo, se você pegar a luz que tá saindo da lâmpada e eu pegar uma superfície fechada assim (gesticula). Pergunta: Tem fluxo de luz através dessa superficie? E a resposta de acordo com a noção de fluxo usada na superfície fechada é não. Por que? Porque a luz entrou de um lado e saiu do outro. Tudo bem? E aí o fluxo tem sinal. Se você pegar uma lâmpada aqui (desenha) e puser uma superficie matemática aqui (desenha uma superficie fechada fora da lâmpada). E perguntar qual é o fluxo de luz através dessa superficie. Essa palavra fluxo para superficie fechada ela não tem o mesmo significado de superficie aberta. Se você puser um livro aqui. Tem fluxo de luz na página do livro, certamente tem. Por isso a gente consegue enxergar. Mas, se eu for pegar uma superficie fechada, a normal a superficie é assim (desenha). E aí, quando eu calculo o fluxo através dessa superficie esse lado contribui negativamente, esse lado positivamente e o fluxo total dá zero. Tudo bem qual é a diferença? É um pouco sutil esse negócio aí.

A analogia com a lâmpada desempenha um papel interessante, porém as limitações (A2) da mesma são explicitamente mencionadas.

08:40 - 11:20 Qual é o conteúdo dessa equação (lei de Gauss) comparada com esse exemplo? Ele tá dizendo o que? A lei de Gauss diz que a carga elétrica é o que? Ela é uma 
lâmpada elétrica, sim? Nesse aspecto ele é análogo a uma lâmpada. Ou seja, a carga gera campo. Gerar não é uma palavra boa. Para a luz é boa, para a carga não. Porque gerar pressupõe uma ação. O campo tá saindo da carga? Não! Ele tá sempre lá. [...]

Se você pegar uma carga aqui e encerrar a carga por meio de uma superficie qualquer. (desenha) Esse negócio laranja é matemático. A gente vai sempre colocar a normal à superficie para o lado de fora. (desenha). O que significa o seguinte, se houver produção de campo aqui, ou seja se essa carga for positiva você vai ter coisas saindo por tudo quanto é lado (gestos) e portanto isso daqui vai dar uma coisa positiva. Se você tiver uma carga negativa, você vai ter campo entrando aqui. Carga negativa com a analogia da lâmpada estragou de vez, você tem uma anti-lâmpada? Será que tem um objeto aqui que se eu quisesse escurecer a sala eu poderia ligar e ele ia chupar luz? Não tem, carga elétrica tem isso. Ai a gente tem um fluxo globalmente negativo.

No decorrer da aula, o professor alerta seus alunos para o fato de que pensar em superfícies fechadas é diferente e que trabalhar com a lei de Gauss é extremamente difícil. Mesmo havendo campo elétrico em diversos pontos de uma região, se o fluxo resultante em uma superfície fechada for nulo, significa que não existe carga elétrica (excesso) em seu interior. A não diferenciação entre fluxo e campo elétricos já foi apontada por pesquisas recentes (SINGH, 2006) como sendo uma das principais confusões cometidas por estudantes de graduação. Dessa forma, percebemos o empenho do professor em abordar essa diferenciação de maneira explícita.

O exemplo de uma esfera metálica sendo carregada é tratado e, com uma argumentação bastante concreta (mecanicista), o professor explica que na situação de equilíbrio as cargas se concentram na superfície, por isso o campo elétrico no interior da esfera é nulo. Isso o permite concluir, pela lei de Gauss, que não há cargas elétricas no interior da esfera, conclusão que não é compreendida por um aluno. A pergunta do mesmo induz uma explicação mais detalhada sobre o significado da lei de Gauss, destacando novamente o papel relevante da interação professor-aluno nessas aulas:

17:40 - 19:40 Isso é o jeito de a gente demonstrar que quando você joga a carga no metal, depois do equilíbrio toda a carga tá na superficie. O metal não consegue guardar carga lá dentro. Pergunta nisso?

A: Eu não entendi por que o fato de dar zero mostra que não tem carga lá dentro.

P: Lei de Gauss. O que é isso daqui (aponta para a lei de Gauss)?

Pessoal essa pergunta dele é uma pergunta importante porque a gente tem que se acostumar com o que está escrito aqui. Qual é a condição de aplicabilidade dessa equação? Isso que é dificil de a gente perceber. Quando que se aplica isso? Pega uma superficie matemática qualquer aqui, ai coloca uma normal para fora (desenho). Pode ter um campo elétrico num ponto aqui. Esse campo elétrico pode ter sido criado por uma carga aqui (fora da superfície) ou aqui (dentro). E aí tá cheio de campo elétrico por aqui. E o que a lei de Gauss diz é o seguinte: se você calcular o fluxo do campo elétrico somar em todos os pedaços, isso vai dar a quantidade de carga dentro. Isso para qualquer superficie. A mensagem é, se tiver carga 
aqui dentro (desenha carga e campo) você vai ter campo com essa cara aqui. Não precisa ser paralelo, pode ser assim (desenha). Aí você calcula o fluxo dá um certo valor. E esse valor, devido a essa relação aqui (lei de Gauss), esse valor é o mesmo que a quantidade de carga.

Este trecho está localizado no final do episódio e podemos perceber que a discussão sobre a interpretação (verde) da lei de Gauss foi motivada pela manifestação do aluno (laranja). Para complementar sua argumentação, o professor aborda uma situação mais concreta na qual ele precisa determinar se existe carga elétrica no interior de uma sala, mas não pode entrar na mesma. A tentativa de interpretação do significado físico da lei de Gauss é evidenciada novamente pelo termo "o que a lei diz?":

20:00 - 21:40 Pessoal, imagina que você queira fazer um aparelho de detectar carga. Na verdade esse aparelho existe, é um aparelho matemático chamado divergente, nós vamos ver isso mais tarde. Imagina que você tem uma região e eu não posso entrar dentro dessa sala. E eu quero saber: será que existe carga lá dentro? O que eu vou fazer, vou ficar no lado de fora e vou medir o campo elétrico em toda a volta. E ai para cada pedaço eu posso pegar e fazer a seguinte conta. Vai ter um campo elétrico. Estou fora da sala. Não consigo entrar. (vai até a porta com a apostila na mão). Eu quero saber se tem carga na sala ou não. Aí eu vou aqui, ponho a normal, calculo o produto escalar do campo elétrico e a normal aqui. Faço isso em todos os pontos (gestos). E ai se esse resultado der zero, significa que a quantidade total de carga é zero. Não quer dizer que não pode ter uma carga negativa aqui e uma positiva aqui, pode. O que a lei de Gauss diz. Essa lei é muito rica, mas uma das maneiras de ler a lei é a seguinte: se você medir o campo sobre a superficie, você sabe se tem carga dentro ou não. Tudo bem isso?

Esse exemplo elucida a busca constante do professor pela reificação em suas explicações, ou seja, ele procura lidar com conceitos extremamente abstratos - superfície fechada, normal em cada ponto, produto escalar entre o vetor campo elétrico e a normal - de maneira concreta - paredes da sala, giz na apostila, gestos, projeções. Tal reificação tem uma função "alfabetizadora" dado que os estudantes não tem familiaridade com esses termos antes do curso de Física 3. Durante a entrevista (Capítulo 6), o professor apresenta uma série de justificativas para esse enfoque. 
Episódio 5: Energia Potencial Eletrostática

Aula 16-Duração: 28 min 40 s (48:40-1:17:20)

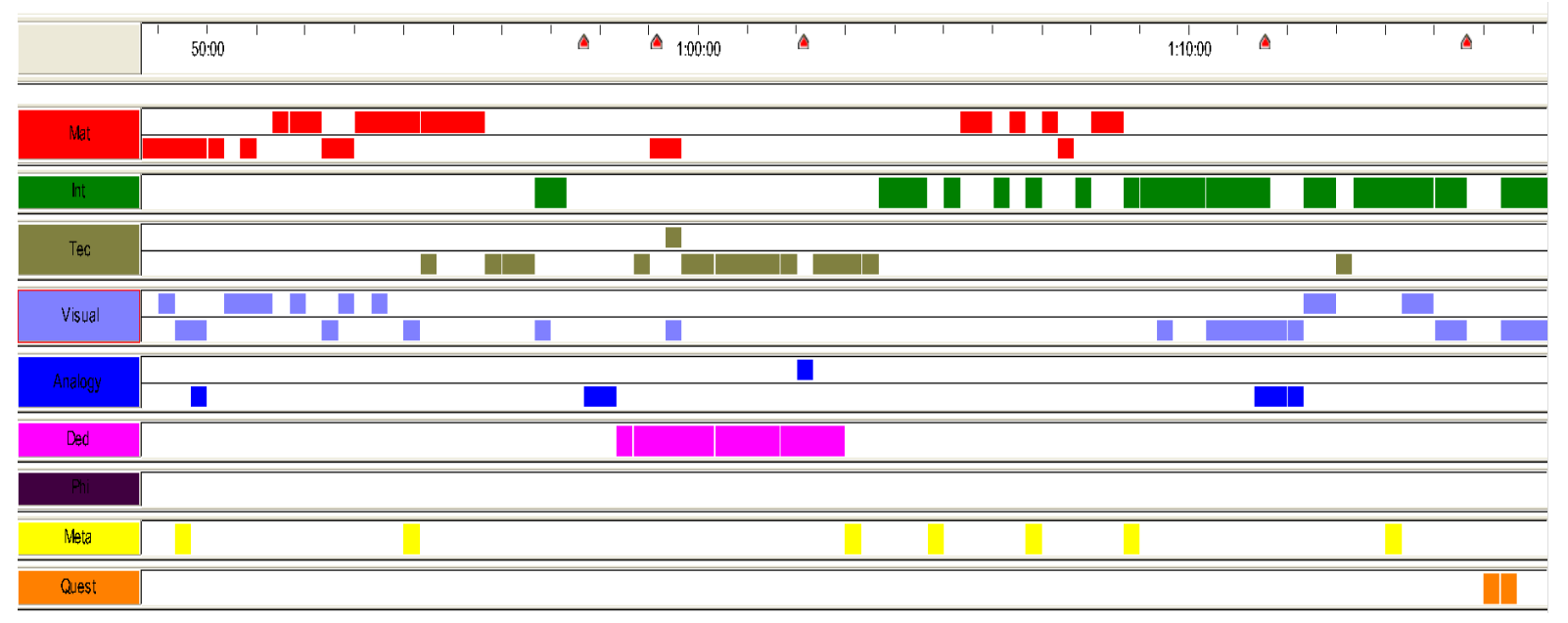

Figura 32: Diagrama Episódio 5 - Aula 16 - Energia Potencial Eletrostática

O conceito de energia potencial eletrostática de um sistema é extremamente abstrato e esta aula tem o propósito de apresentá-lo de maneira clara e gradativa. O diagrama da Figura 32 mostra que praticamente todas as categorias (exceção da epistemologia) foram abordadas. O trecho inicia-se com o cálculo do trabalho realizado por uma força externa para deslocar uma carga de prova $(+q)$ de uma posição $A$ até uma posição $B$, localizada mais próxima de uma outra carga fixa $(+Q)$. O fato de que é necessário um trabalho (um esforço) para deslocar a carga de prova é apresentado de maneira extremamente concreta (reificação):

49:40 - 50:00 Qual é o trabalho que o campo realiza? Você sai de um ponto A e vem até aqui um ponto B. Vem do seguinte jeito. Você pega a carga aqui e... Você não vai soltar a carga. Você pega e traz a carga aqui com a mão, devagarzinho e põe a carga lá no ponto $B$.

Em seguida, para o cálculo do trabalho, é necessário escrever uma expressão para a força elétrica que atua na carga $(+q)$ durante o deslocamento. A necessidade de se efetuar uma integração, dado que a força varia durante o deslocamento $(\vec{F}=\vec{F}(\vec{r}))$, é explicitamente mencionada:

52:20 - 53:20 O que acontece quando eu mexo essa carga? Você vai andando com a carga aqui. A força aqui (mais próximo de B) é diferente de quando era aqui (A) (gestos)? Sim, ela varia de ponto a ponto. Tanto que, em um lugar intermediário, a força vai ser maior. E aqui (B) vai ser maior ainda. Então a gente tá mexendo uma carga em presença de uma força variável.

Utilizando a lei de Coulomb para representar o campo elétrico da carga Q e a expressão da força de Lorentz, a força que atua na carga $q$ é descrita e o trabalho para movimentá-la de $\mathrm{A}$ até $\mathrm{B}$ é calculado de maneira técnica obtendo $\tau_{A \rightarrow B}=\frac{q Q}{4 \pi \varepsilon_{0}}\left(\frac{1}{r_{A}}-\frac{1}{r_{B}}\right)$. 
Como o movimento é no sentido contrário ao da força elétrica que atua na carga, o trabalho precisa ser negativo. Um erro comumente cometido pelos alunos é colocar o sinal negativo na expressão, o que é desencorajado pelo professor antes de efetuar o cálculo:

54:00 - 54:20 Ai tem aquela coisa, eu estou andando assim (aponta o sentido do movimento contrário à força), mas eu não vou por o sinal menos lá. Porque isso daqui já vai estar contido no extremo de integração.

E verificado (interpretado) após a obtenção da expressão matemática do trabalho:

56:40 - 57:00 Que sinal tem o trabalho? Sem olhar a expressão, olha o desenho. Estou andando assim (aponta o sentido), que sinal que eu espero? Um trabalho negativo, pergunta, isso daqui (expressão) é negativo? $r_{B}$ é menor que $r_{A}$, portanto $1 / r_{B}$ é maior que $1 / r_{A}$, esse número é maior que esse então dá negativo, saiu com o sinal correto.

Nesse momento, inicia-se a dedução do teorema trabalho-energia $\left(\tau_{A \rightarrow B}=\frac{1}{2} m v_{B}^{2}-\right.$ $\left.\frac{1}{2} m v_{A}^{2}\right)$ a partir de princípios da mecânica ( $2^{\mathrm{a}}$ lei de Newton). Por esse motivo, notamos a presença da categoria dedução (rosa) no diagrama da Figura 32. Essa dedução é feita de maneira essencialmente técnica (T1), sendo que manipulações ("girar a manivela") são efetuadas e regras de derivação são evocadas. Tal tipo de abordagem é incomum nas aulas analisadas. Habitualmente, o professor ou avisa os alunos que a dedução "passo a passo" pode ser encontrada na apostila ou evoca alguma relação utilizando argumentos de autoridade. Durante a entrevista, o questionamos sobre a importância de realizar deduções matemáticas a partir de princípios físicos em suas aulas e ele mencionou que isso depende muito do que se pode aprender com cada demonstração. Parece-nos que neste caso, o professor optou por fazer toda a dedução do teorema trabalho-energia, em vez de simplesmente enunciá-lo, porque tinha a intenção de mostrar aos estudantes como é possível conectar duas partes aparentemente separadas da física (mecânica e eletricidade) por meio do formalismo matemático. Isso fica evidente na ênfase dada em seu discurso após a dedução:

01:02:00 - 01:04:40 Então esse negócio aqui (teorema trabalho-energia) veio da mecânica, esse negócio aqui (trabalho da força elétrica) veio do eletromagnetismo. Agora como é o mesmo trabalho, pega junta os dois. E a gente aprende então a seguinte coisa: $\frac{1}{2} m v_{B}^{2}-$ $\frac{1}{2} m v_{A}^{2}=\frac{q Q}{4 \pi \varepsilon_{0}}\left(\frac{1}{r_{A}}-\frac{1}{r_{B}}\right)$. Agora você pega e fica olhando isso com força! Fica olhando lá. E uma hora você vai ter a seguinte ideia: por que você não junta tudo que tem A de um lado e tudo que tem $B$ do outro? Então faz isso: $\frac{1}{2} m v_{B}^{2}+\frac{q Q}{4 \pi \varepsilon_{0}} \frac{1}{r_{B}}=\frac{1}{2} m v_{A}^{2}+\frac{q Q}{4 \pi \varepsilon_{0}} \frac{1}{r_{A}}$. Qual é a importância de escrever isso desse jeito? A importância é a seguinte: Parece que você inventou uma coisa que é constante. Porque ela é a mesma em qualquer ponto. Então é por isso que a gente chama isso $\left(\frac{q Q}{4 \pi \varepsilon_{0}} \frac{1}{r_{B}}\right)$ de energia potencial no ponto B. Porque as coisas se 
arrumaram desse jeito aqui e o U ficou somado à energia cinética e a gente chama isso daqui $\left(\frac{q Q}{4 \pi \varepsilon_{0}} \frac{1}{r_{A}}\right)$ de $U_{A}$ e portanto isso daqui expressa a conservação da energia.

Uma aparente inconsistência é então mencionada dado que o trabalho da força elétrica para deslocar a carga de $A$ até $B$ é $U_{A}-U_{B}$ e não o contrário como seria esperado. Tal problema é resolvido convencionando-se que a diferença de energia potencial entre dois pontos é menos o trabalho da força elétrica para movimentar uma carga $q$ entre esses dois pontos. Em seguida, uma discussão sobre a necessidade de convenção de uma origem para representar a energia potencial de um sistema formado por duas cargas e sobre o significado físico da energia potencial é conduzida:

01:07:20 - 01:07:40 Nesse problema é útil colocar um zero, uma origem. E essa origem fica simples se eu a tomar no infinito. Se $r_{A}$ tender a infinito, nessa conta aqui (trabalho da força elétrica), isso daqui ( $\left.1 / r_{A}\right)$ vai pra zero e a expressão simplifica, então por isso a gente costuma definir a energia potencial; não é obrigatório mas é muito útil: $U_{R}=-$ integral de infinito até $R$ (escreve a integral). Se eu estivesse dando aula na Poli eu teria abreviado essa discussão da origem das coisas. Mas a gente que faz Física tem que saber isso. O olhar da gente é diferente. A gente não quer aplicar isso, mas quer entender de onde vem.

Nos minutos finais do trecho a exposição é quase toda classificada como interpretação. O resultado do cálculo do trabalho da força elétrica e sua relação com a energia potencial eletrostática motivam a interpretação física do procedimento matemático. Como a força elétrica é conservativa, seu trabalho independe do caminho percorrido. Em vez de apresentar isso de maneira autoritária, o professor busca identificar a independência do caminho na conta, o que legitima a abordagem da categoria interpretação:

01:09:20 - 01:14:00 Energia potencial do sistema de duas cargas depende da distância de que modo? Depende do r pequeno? Não essa variável de integração sumiu. Ela depende do $R$ grande (distância final entre as cargas). No desenho o que é R? O que está por trás dessa expressão? A seguinte ideia. Se você pegar uma carga $Q$ e a mantiver parada aqui e se você puser a outra carga q muito longe, lá longe, no infinito. Aqui não tem força. A força vai pra zero. E ai eu associo esse ponto e falo que a energia potencial desse sistema é zero. Isso é verdade pelo seguinte: no infinito aqui e puser infinito mais um metro não tem trabalho. Porque não tem força. Então eu coloco o referencial lá. Aí à medida que eu começo a andar aqui dentro, eu ando ao longo dessa linha de campo (desenha). E quando eu estou aqui nesse ponto, tem uma força pequenininha, quando eu ando aqui a força aumenta, aumenta, aumenta (pega o giz e vai aproximando da carga). E a energia potencial desse sistema vai ser devido ao seguinte fato: Para eu pegar a carga daqui e colocar aqui eu, observador externo, preciso fornecer trabalho. Eu forneço mais trabalho, mais trabalho. Na hora que eu parar a carga aqui, eu comprimi uma mola, sim? O sistema quer ficar comprimido? Não, se eu soltar a carga vai embora. Porque tem uma força de repulsão. [...]

Nessa expressão aqui $\left(U_{R}=-\int_{\infty}^{R} d r \frac{q Q}{4 \pi \varepsilon_{0}} \frac{1}{r^{2}}\right)$ o vetor $r$ é o vetor variável desde aqui (carga $Q$ ) até o ponto final que tá aqui (posição final). E esse negócio aqui (distância entre $Q$ e o ponto final) eu vou chamar de $R$ grande. E o $R$ grande aparece no extremo de integração. Se 
eu efetuar a conta, eu tenho esse resultado aqui: $U_{R}=\frac{q Q}{4 \pi \varepsilon_{0}} \frac{1}{R}$. Isso significa o seguinte. $O$ caminho percorrido já sumiu na conta que é essa parte aqui. Ai você integra, a energia potencial do sistema só depende da posição final que é o R. Ou seja, depende de onde você parou, só.

Por fim, uma definição geral de energia potencial é proposta:

01:16:20 - 01:16:40 Como é que você caracteriza esse armazenamento de energia? A ideia é a seguinte: Energia potencial é uma energia de configuração. Toda vez que você fizer um desenho do sistema. Ou seja, pega o sistema aqui faz assim (gestos com as duas mãos ilustrando a posição relativa entre duas cargas). Isso aqui tem uma energia potencial, fez assim (muda a posição das mãos), tem outra energia potencial. (muda de novo) assim outra energia potencial. Então a energia potencial é uma energia associada à configuração. Ou seja custa, é essa a mensagem, não é de graça você pegar uma carga no infinito e colocar aqui. Tem uma história isso. E essa história é uma história energética porque eu tive que colocar energia no sistema. Tudo bem isso? Significa que configurar o sistema desse jeito aqui custou. E a energia potencial portanto é a energia da configuração.

Uma explicação satisfatória para a energia potencial eletrostática de um sistema de duas cargas não pode ser fornecida sem uma detalhada e técnica abordagem matemática, como o cálculo do trabalho da força elétrica (dependente de $r$ ) por meio de uma integral. Além disso, é necessário saber interpretar fisicamente os cálculos, como a conclusão da independência do caminho percorrido obtida da análise da integral. Por esse motivo, notamos a presença de praticamente todas as categorias de análise neste episódio. Parece-nos que o mesmo corrobora a defesa de Feynman de que "é impossível explicar honestamente a beleza das leis da natureza de uma forma que as pessoas possam realmente sentir, sem que se tenha um profundo conhecimento de matemática" (FEYNMAN, 1985, p. 35).

Episódio 6: Significado físico do Gradiente

Aula 19-Duração: 19 min 20 s (10:20-29:40)

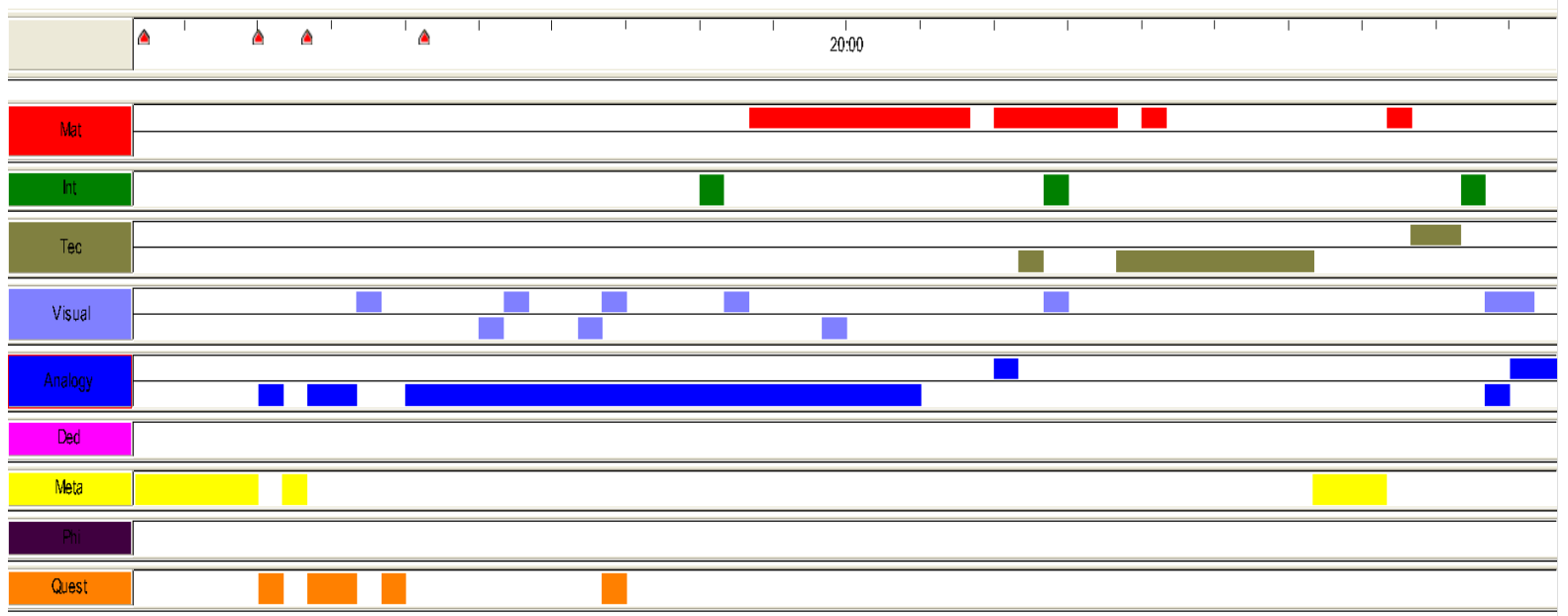

Figura 33: Diagrama Episódio 6 - Aula 19 - Significado físico do Gradiente 
Cálculos que envolvem o operador diferencial $\nabla$ são reconhecidamente uma grande fonte de problemas para os estudantes de física. Apesar de tradicionalmente abordados de maneira abstrata nos cursos de cálculo, o eletromagnetismo fornece uma série de situações que motivam a criação do cálculo vetorial e um conjunto de imagens que contribuem para a compreensão dos conceitos envolvidos em tais operações. De fato, a relação histórica entre os operadores diferenciais e os fenômenos eletromagnéticos tem motivado alguns autores a proporem materiais didáticos voltados para uma abordagem integradora (SHEY, 1996; FLEISCH, 2008).

Cientes da importância dos cálculos que envolvem o operador $\nabla$, uma vez que o mesmo está presente nas quatro equações de Maxwell quando escritas na forma diferencial, e das dificuldades comumente apresentadas por estudantes para sua compreensão, nossa atenção esteve concentrada nos momentos em que essas operações foram explicadas nas aulas analisadas. Nos próximos três episódios, apresentamos trechos nos quais as operações gradiente, divergente e rotacional foram respectivamente abordadas.

O Episódio 6 refere-se à aula em que o conceito de gradiente de um campo escalar foi tratado. Este trecho inicia-se com a apresentação de um esquema destinado a sintetizar o estudo da eletrostática (ver Figura 34), por meio de uma representação das relações entre seus principais conceitos.

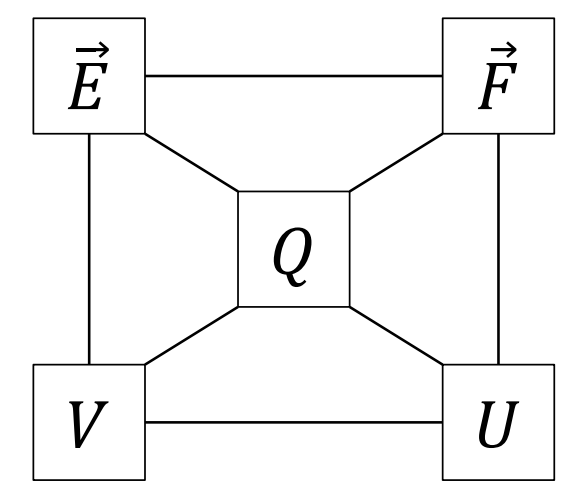

Figura 34: Esquema síntese da eletrostática - Aula 19

O esquema é utilizado pelo professor para discursar sobre o que já foi feito no curso e para localizar o objetivo desta aula (auto-regulação - metacognição):

10:20 - 12:00 Nós falamos dos quatro conceitos importantes da eletrostática. (Desenha o esquema da Figura 34). Que são campo elétrico, força elétrica, potencial e energia potencial. Nós estamos aprendendo a transitar nesse quadro aqui. Você sabe ir e voltar da força para o campo. A gente aprendeu nessa expressão $\left(V=-\int_{\infty}^{R} \vec{E} . d \vec{c}\right)$ na aula passada a sair daqui (campo) e chegar aqui (potencial). Andar daqui para cá (potencial e energia) eu também sei, é só multiplicar por Q, mesma coisa nos dois casos (campo e força). Na aula 
passada a gente discutiu como é que eu faço isso (ir de E para V). Que é essa coisa aqui (aponta para a expressão $\Delta V=-\int_{A}^{B} \vec{E} . d \vec{c}$ ). A questão agora é o contrário, se eu te der o potencial como é que eu acho E. Tudo bem o problema que está sendo resolvido na aula de hoje? É o problema inverso. E aí, se eu sei andar aqui eu sei andar aqui (força para energia potencial) também. Se eu te der a energia potencial do sistema a gente sabe calcular as forças, se eu te der o potencial, você sabe calcular o campo. É isso que a gente vai fazer agora, é para isso que serve o gradiente.

Em seguida, a categorização nos mostra que o recurso a analogias foi intensamente utilizado na introdução do significado físico desta operação. Mais de dez minutos são dedicados a menção de situações concretas onde o gradiente está presente, sendo que o inusitado exemplo de um cachorro que procura um bife no interior de uma sala escura desempenha um papel fundamental para a explicação deste conceito:

13:00 - 17:20 Pessoal, onde que gradiente aparece na natureza?

A: Pressão

P: Existe gradiente na atmosfera? No tempo? A moça do tempo mostra gradiente para você? Sim, claro. Pega o Brasil aqui (desenha) Ela fala assim, frente fria. Tudo bem? Isso é gradiente. Outro exemplo na natureza de gradiente?

A: Qualquer área de fluxo?

P: Então fala uma.

A: Calor se propagando numa barra.

P: Calor se propagando numa barra tem gradiente? Tem.

Pessoal, cachorro (risos) sabe calcular gradiente?

Sim, ele sabe. Como? Você pega uma sala escura e fecha o cachorro num canto lá. Aí você pega e põe um bife aqui (aponta para o canto). Ai você solta o cachorro naquela porta lá. E o que o cachorro vai fazer? [...] Como é que ele faz? Ele levanta o nariz e faz o que? Ele sente o cheiro. Se ele levantou o nariz assim e sentiu o cheiro ele sabe onde o bife está? Com uma cheirada ele sabe? Não! Com uma cheirada ele sabe que tem um bife, tudo bem? Ele é informado só dessa coisa. Existe o bife. Onde está o bife? Ele tem que fazer o que? Aí sim ele calcula o gradiente. Pelo seguinte: Se eu entrei na porta aqui e o bife está lá, por exemplo. Levantei o nariz, tudo bem, tem um bife. Só isso que eu sei. O que ele faz, ele se move ao acaso (gira a cabeça) (gesto circular com o dedo). E aí, o que ele vai medir? Ele vai medir onde que o cheiro aumenta, tudo bem? Em relação ao que tinha antes. E aí sistematicamente ele faz isso e acha o bife, tudo bem? [...] Calculou o gradiente? Sim!

A pertinência deste exemplo é constatada porque o mesmo não só fornece uma profícua imagem qualitativa do gradiente, como também permite que o professor inicie uma discussão quantitativa sobre as estruturas matemáticas envolvidas no mesmo:

18:00 - 20:20 O que o gradiente faz pra você, que informação ele dá para o cachorro do bife? O cachorro vem aqui (ponto na sala), ele sente que tem o bife, daí ele dá uma cheirada circular em volta aqui (desenha). O cachorro não precisa disso, ele é mais esperto, mas suponhamos um cachorro matemático (risos). Ele vai lá, dá uma cheirada circular em volta e vai lembrando em que direção que estava a variação máxima do cheiro. Pessoal, seguinte, o cheiro é vetorial? O cheiro de alguma coisa é um vetor? Temperatura é vetor? Cheiro é vetor? Não é! Você sente o cheiro do bife e acabou, tudo bem? A informação tem um bife, onde que está o bife você não sabe. O cachorro é capaz de construir um vetor através de um 
escalar? Tudo bem isso? Então a ideia de gradiente é essa. Isso aqui é um campo escalar de cheiro. Se de fosse unidade de temperatura você tem, 15 graus aqui 15,5 aqui, 17. [...] Em cada ponto uma temperatura. Isso não tem direção. Não tem nenhum vetor lá dentro. Mas na hora que você põe várias temperaturas uma do lado da outra. O que a gente chama de um campo de temperaturas. Qual é a diferença de uma temperatura e de um campo? Temperatura, fala assim, 15 graus aqui. Pergunta: existe um campo de temperatura nessa sala? (aponta em várias direções). Chego mais perto da lâmpada. Cada lugar, se você medir finamente, você pode colocar uma Temperatura diferente em cada ponto. Isso dai é um mapa de temperaturas, você pode por numa tabela, num computador no que for, mas de qualquer jeito você tem um campo de temperatura.

Por fim, esse conjunto de imagens concretas (cachorro, cheiro, temperatura, pressão) para visualizar o significado físico do gradiente é utilizado como estratégia de pensamento que também se aplica ao caso eletrostático que se pretende analisar:

20:20 - 21:40 E aí temperatura e pressão e cheiro não tem direção. São coisas escalares, mas é possível; dentro de um campo tem um vetor escondido. [...] Dentro de um escalar tem um vetor escondido, ok? No nosso problema o escalar é esse daqui (aponta para potencial). E aí pergunta como é que eu acho o vetor elétrico, campo elétrico escondido dentro do potencial. Tudo bem o problema? Que tem um vetor escondido aqui dentro? Isso daqui não é um vetor. (aponta para a fórmula do potencial) Mas na hora que você calcula o $V$ em vários lugares diferentes você tem um vetor escondido. E ai o vetor escondido tem uma técnica para achar, qual é a técnica? Gradiente.

A discussão sobre a pertinência do uso dessas imagens concretas e cotidianas para a explicação de conceitos abstratos foi conduzida durante a entrevista tendo como base essa estratégia de pensar no gradiente a partir do exemplo do cachorro. O professor revela sua crença na pertinência/eficácia desse recurso e o justifica com detalhes ao longo da entrevista, conforme explicitado no Capítulo 6.

A partir deste instante inicia-se uma apresentação mais técnica que tem como objetivo final obter a relação entre campo e potencial elétricos. Partindo da ideia de que uma variação diferencial de potencial $d V$ equivale a um pequeno trabalho associado ao campo elétrico $-\vec{E} \cdot d \vec{c}$, o produto escalar entre os vetores $\vec{E}$ e $d \vec{c}$ é representado em coordenadas cartesianas, resultados demonstrados previamente são evocados (justificativa para o sinal de menos), regras de derivação (diferencial de uma função de várias variáveis $V(x, y, z)$ ) e argumentos de autoridade são utilizados para obter o resultado $\vec{E}=-\nabla V$; motivo pelo qual notamos a presença da categoria técnica nos minutos finais do episódio. Após mencionar a analogia do cachorro novamente e mostrar que a relação obtida faz a volta (do potencial para o campo) no esquema resumo da eletrostática, o professor resolve um problema (não analisado neste episódio) no qual o campo escalar referente a um potencial hipotético é fornecido e o campo elétrico (vetorial) a ele associado é calculado. 
Episódio 7: Significado físico do Divergente

Aula 23 - Duração: 20 min 40 s (1:12:00-1:32:40)

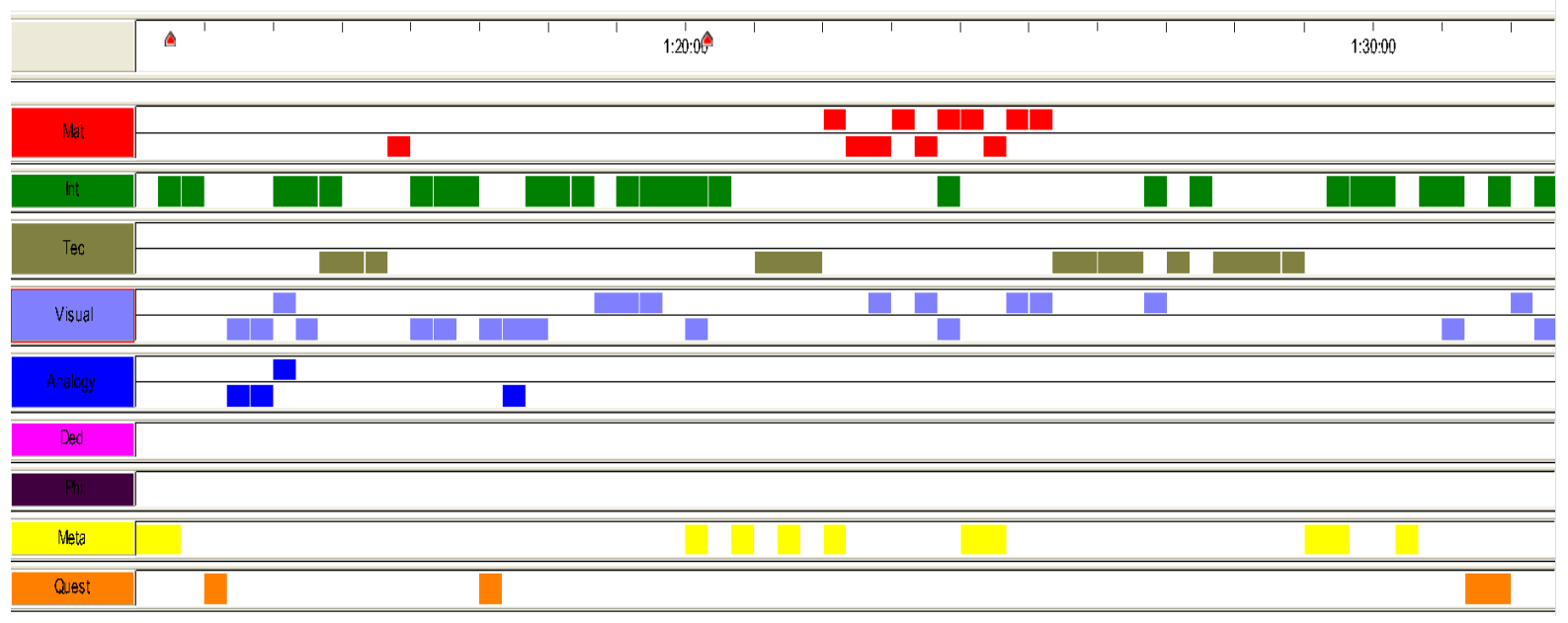

Figura 35: Diagrama Episódio 7 - Aula 23 - Significado físico do Divergente

O Episódio 7 refere-se ao final da Aula 23 quando o professor discursa sobre o significado físico do divergente do campo elétrico. Diferentemente do episódio anterior, o recurso das analogias praticamente não é utilizado nessa explicação e a discussão fica restrita ao divergente de um campo vetorial específico (elétrico). A aula é iniciada com a dedução da lei de Gauss na forma diferencial a partir da representação da carga interna $\left(q_{\text {int }}\right)$ como uma integral volumétrica $\left(q_{\text {int }}=\iiint \rho d V\right)$ e do teorema de Gauss (divergente) $\oiint \vec{F} . \hat{n} d S=$ $\iiint \nabla \cdot \vec{F} d V$ para um campo vetorial $\vec{F}$ genérico. Esse teorema é apresentado como um resultado oriundo da matemática (técnica T1 - autoridade) e uma demonstração formal não é realizada na aula nem fornecida na apostila. Entretanto, objetivando uma compreensão sobre como o teorema "funciona", ambos os "lados" da equação que o expressa são calculados para uma superfície cúbica localizada numa região "imersa" no campo vetorial $\left(\vec{F}=x^{2} \hat{\imath}+x y \hat{\jmath}+\right.$ $\left.\left(y^{2}-z^{2}\right) \hat{k}\right)$ e sua igualdade é verificada para este caso.

Em seguida, o divergente do campo elétrico de uma carga pontual (Campo coulombiano: $\vec{E}=\frac{Q}{4 \pi \varepsilon_{0}} \frac{\vec{r}}{r^{3}}$ ) é calculado, obtendo zero como resultado. Esse resultado é visto por alguns estudantes como inconsistente e é neste instante que o episódio se inicia, uma vez que a explicação é direcionada à interpretação do significado físico do divergente. Por esse motivo, desde o início a categoria interpretação (verde) aparece intensamente no diagrama da Figura 35.

01:12:00 - 01:12:40 Eu fiz essa conta para chamar atenção para esse problema: Qual é o significado dessa coisa. Pessoal qual é a diferença da lei de Gauss na forma diferencial e na forma integral? O que o divergente mede? O que é o divergente de alguma coisa? Você tem 
que entender isso, senão você não consegue entender se o que eu estou fazendo descreve ou não a natureza. Qual é a intuição do divergente?

Um erro comum relacionado aos operadores diferenciais é confundir gradiente, divergente e rotacional (FLEISCH, 2008). A resposta de um aluno dizendo que o divergente "está ligado à direção como a analogia feita com o cachorro" ilustra essa confusão. Isso faz com que o professor retome a explicação do significado físico do gradiente utilizando novamente analogias. $\mathrm{Na}$ sequência o foco para a interpretação do divergente é redirecionado:

01:14:40 - 01:18:40 Agora o que é o divergente? [...] Quem dá isso é o teorema de Gauss. O teorema de Gauss me diz o que? Aplicado ao campo elétrico, por exemplo. (escreve o teorema). A lei de Gauss é essa, agora você pega esse lado (direito) e transforma em um integral de volume. Ai você compara isso com isso. Só que para você poder entender, compara num volume pequenininho, numa regiãozinha. Ai o que o divergente faz, ele é uma máquina matemática que faz que favor para você? Qual é a informação contida aqui dentro? Se você pegar uma regiãozinha do espaço se o divergente nesse ponto aqui for positivo (gesto representando uma pequena região do espaço) o que significa isso nessa equação?

A: Que tem uma carga lá dentro.

P: Significa o que? O que tem no interior da minha caixinha aqui?

A: Uma distribuição de carga que tá emitindo.

P: Pois é, tem alguma coisa que cria campo. Emitir não é uma palavra boa porque não sai, mas ele cria. Pessoal, o divergente parece um contador Geiger. É essa a intuição dele. Ele é uma máquina que; você coloca o divergente aqui dentro; e aí se o divergente for não nulo significa que essa região tem algo que cria coisas, nessa regiãozinha. Então o que ele faz, a máquina matemática; se o divergente aqui for não nulo, significa que aqui nessa regiãozinha está sendo criado algo. Se for negativo significa que tá sendo absorvido. Se for zero significa que não tá sendo criado nem absorvido. O que não quer dizer que não tenha alguma coisa passando por aqui. Então o que o divergente acusa é isso, naquele ponto tem ou não tem um criador de campo. No caso do eletromagnetismo o criador de campo é carga.

Assim, com essa interpretação do divergente é possível compreender porque o resultado do cálculo do divergente do campo elétrico em um ponto qualquer (exceto a origem) é nulo: não existe uma distribuição de carga numa pequena região que envolve este ponto. Para lidar com a singularidade da carga pontual, detectada na indeterminação do campo elétrico na origem, o professor menciona que a ferramenta matemática apropriada é chamada "função" delta de Dirac e que os estudantes ainda irão aprender a lidar com a mesma. Para o momento atual, é possível fazer uma idealização e considerar que a carga esteja distribuída em uma esfera de raio $R$ :

01:22:20 - 01:24:00 No momento, a gente pode fazer a mesma coisa de um jeito mais "pedestre" que é o seguinte. Se você tiver uma distribuição infinita. A carga for um ponto, fala tudo bem, supõe que ela é uma bolinha. Em vez de pegar a carga puntiforme, dá um raio pra ela. O que acontece? Agora essa função pode ter um $\rho$ finito. Você pega uma carga e distribui numa região. O problema da carga puntiforme que você pega um monte de coisa 
num ponto só. Matemática, o ponto não tem dimensão, então isso dá uma densidade infinita. [...] Veja bem, o que aparece na lei de Gauss (diferencial) não é carga, é $\rho$ ! Qual é a densidade de carga desse objeto puntiforme aqui? Então a função que descreve isso é a seguinte, aqui nesse ponto a densidade é zero. Aqui nesse ponto (carga) ela é infinita! Porque tem uma carga, numa região que não tem tamanho, tudo bem?

Considerando a carga distribuída em uma esfera de raio $\mathrm{R}$, o divergente passa a ser aplicado em duas regiões $(r<\mathrm{R}$ e $\mathrm{r}>\mathrm{R}$ ), sendo que ao realizar o cálculo para o interior da esfera, o resultado esperado $\left(\nabla \vec{E}=\frac{\rho}{\varepsilon_{0}}\right)$ é obtido pelo professor. O episódio é então finalizado com uma discussão sobre as diferentes visões associadas às duas formas (integral e diferencial) da lei de Gauss:

01:29:20-01:31:20 Vê se tá claro pra você a seguinte coisa. A novidade hoje não é calcular divergente, mas aplicar numa situação física. $O$ que o divergente faz? O divergente é uma máquina matemática. Ele acha a distribuição de carga, tudo bem? Então, o que deve acontecer? No lugar onde não tem carga, se você calcular o divergente dá zero, sim? Isso é uma lei local. O que é uma lei local, o divergente pode ser calculado em diferentes pontos. No ponto onde ele der zero, significa que lá não tem carga. Por outro lado você espera que no lugar onde ele ache carga, ele dê diferente de zero. Foi o que aconteceu. Qual é a mensagem? A gente tem que mudar o olhar. Essa coisa aqui (forma integral) você olha o conjunto das coisas, essa (forma diferencial) a gente olha de ponto a ponto e isso daqui vai dizer para você onde não tiver carga isso daqui é zero, onde tiver isso é diferente de zero. Então ele é uma coisa que ele olha o problema microscopicamente, aqui aqui aqui (aponta) e dai ele vai tendo uma valor diferente dependendo de onde você estiver.

A última situação abordada nessa aula (não pertencente ao episódio) é o cálculo do divergente do campo elétrico dado pela expressão $\vec{E}=\lambda \frac{y \hat{\imath}-x \hat{\jmath}}{r^{3}}$. O resultado deste cálculo indica que o divergente é nulo em todos os pontos do espaço e o professor questiona os alunos sobre os motivos para este resultado. A aula é finalizada com uma representação gráfica deste campo evidenciando que o mesmo se trata de um rotacional "puro". O professor destaca que campos como este existem na natureza, mas não são gerados por cargas estáticas. Assim, a discussão para o significado físico do rotacional e da lei de Faraday é preparada. 
Episódio 8: Significado físico do Rotacional

Aula 24 - Duração: 10 min 40 s (1:34:40-1:45:20)

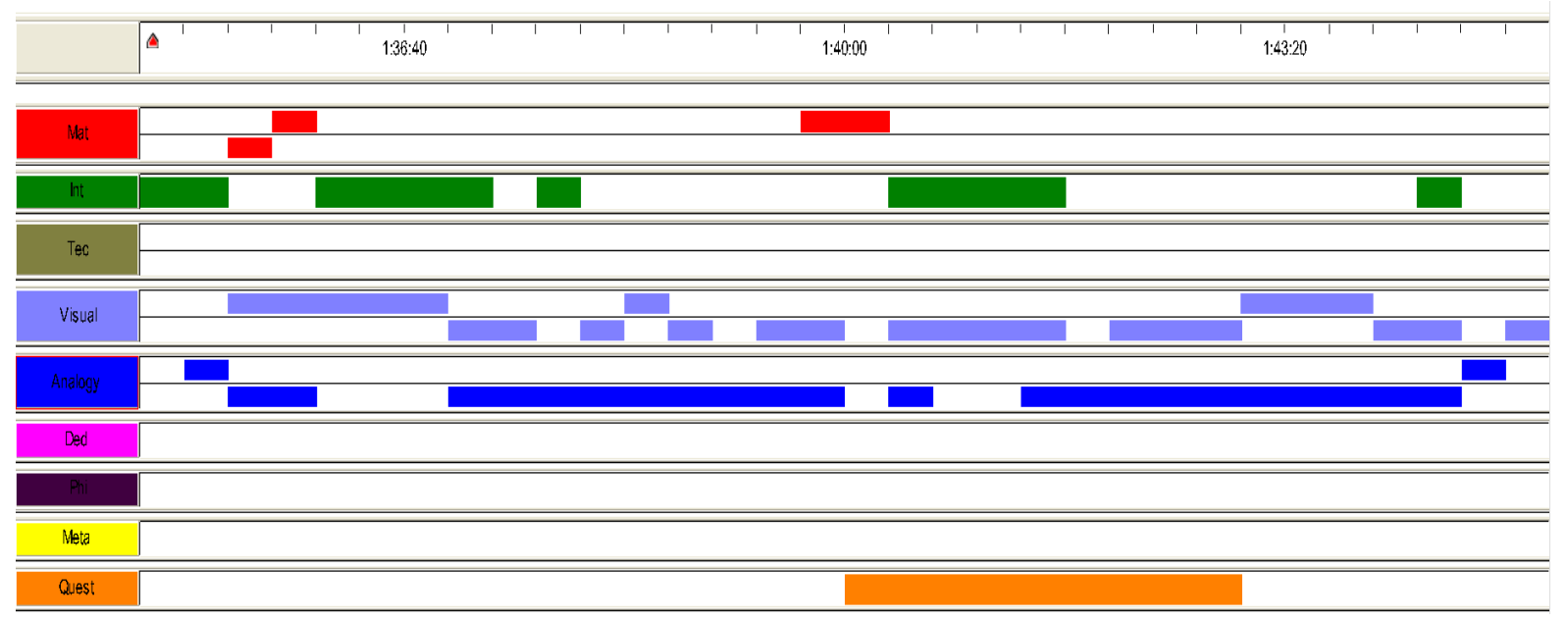

Figura 36: Diagrama Episódio 8 - Aula 24 - Significado físico do Rotacional

A Aula 24 tem uma estrutura relativamente semelhante à da aula anterior. O teorema de Stokes é apresentado sem demonstração de maneira analógica ao de Gauss: "é o teorema de Gauss com uma dimensão a menos". As convenções relacionadas ao formalismo - regra da mão direita, orientação do caminho fechado, superfície apoiada no caminho, sentido da normal, etc. - são detalhadamente esclarecidas com auxílio de muitas representações pictóricas. Assim como na aula anterior, ambos os "lados" da equação que expressa o teorema de Stokes $\left(\oint \vec{F} . d \vec{c}=\iint \nabla \times \vec{F} . \hat{n} d S\right)$ são calculados para um caminho retangular localizado numa região "imersa" no campo vetorial $\left(\vec{F}=x^{2} \hat{\imath}+x y \hat{\jmath}+\left(y^{2}-z^{2}\right) \hat{k}\right)$ e sua igualdade é verificada para este caso. Em seguida, o professor mostra que o rotacional do campo eletrostático é nulo. Na realidade, a demonstração feita é mais geral, pois prova que qualquer campo radial (dependente de $\vec{r}$ ) tem rotacional nulo. Tal demonstração tem um papel importante, pois permite concluir que nas situações que possuem cargas em movimento não é possível pensar os fenômenos em termos de energia potencial.

O momento que sucede tal demonstração marca o início deste episódio, uma vez que a discussão se concentra no significado físico do rotacional:

01:34:40 - 01:35:40 Qual é o significado físico do rotacional? Físico não, geométrico. Ele funciona de que jeito? Do mesmo jeito que a gente interpretou o significado físico do divergente via teorema de Gauss, a gente vai interpretar o rotacional via teorema de Stokes. Então a interpretação do rotacional sai dessa relação aqui (Stokes). Ai ela é interpretada como? Pega um caminhozinho pequeno em torno do ponto em que você calculou o rotacional. Imagina que você esteja calculando o rotacional da velocidade por exemplo. 
Diferentemente da explicação do significado físico do divergente, a utilização de analogias com situações cotidianas volta a ser um recurso extremamente utilizado para a explicação do rotacional. Campos de velocidade, escoamento de água, movimento de partículas em um gás, liquidificador, tufão, entre outros, são mencionados antes do campo elétrico. Por esse motivo, a categoria analogias aparece em praticamente todo o episódio:

01:36:40 -01:39:20 Então o rotacional positivo significa o que? Aí você vai lá e olha para o outro lado da conta que deu origem a isso (Stokes) o que é? É a projeção. Se você olhar de cima. O caminho a ser percorrido assim (desenha). Isso daqui é o rotacional saindo. O lado esquerdo (da equação do teorema de Stokes) é o que? Você vai pegar a velocidade projetar aqui, a velocidade projetar aqui. Isso dá não nulo. Qual é a interpretação disso? Turbulência. Se você tiver uma região do gás ou da água fazendo assim (gesticula uma rotação com o dedo). O que é um rodamoinho? Tufão, que você vê na televisão. Qual é o rotacional do tufão? [...]

Se você entrar no olho do tufão e pegar a velocidade lá, a integral da velocidade num caminho fechado dá zero? Não! Liquidificador. Pega a água que tá girando dentro, o rotacional é zero? Não! Se você deixar um rio correndo em regime laminar, ou seja a água anda todinha assim (gestos com os braços sem indicar rotação). Ai o rotacional desse campo de velocidade é zero, ou seja se você pegar uma água que tem velocidade sempre assim (desenha linhas de corrente paralelas). Pega um caminho fechado assim (desenha um quadrado). Qual é a integral de V sobre esse caminho fechado? Zero? Por que? Aqui você ganha aqui é zero e aqui você perde a mesma quantidade. Isso é o que a gente chama em fluidos de regime irrotacional. A água desliza sem rodar. [...]

Então tem situações, tufão, rodamoinho, turbulência onde isso ocorre. Aí pergunta se você pega um objeto físico e pergunta [...] Você tá na beira do rio lá, não fazendo nada... Aí você pega uma palha e joga no rio. A palha vai dizer para você se o regime é rotacional ou não? Sim, se ela começar a girar... (assim) o rotacional é isso. Se ela andar em linha reta assim (gestos) o regime é irrotacional.

Alguns alunos começam a realizar perguntas (laranja na Figura 36) com o objetivo de verificar o entendimento do conceito. O comentário de um estudante sugere que ele concluiu que só existe rotacional em um ponto no eixo de rotação, o que é refutado pelo professor com auxílio de gestos e analogias:

01:41:40 - 01:43:00 A: Então no caso da água escoando pela pia. O único ponto onde eu não tenho rotacional nulo, ou seja diferente de zero, vai ser no centro, no eixo de rotação. Porque se eu deslocar um pouco esse ponto ele já vai ser rotacional nulo porque ele não é um eixo de rotação.

P: Pessoal, como a água vai para o buraco da pia. Se o buraco estiver aqui (aponta), vc me solta lá, põe uma palha naquele buraco, eu vou fazer isso (gira) tudo bem? Agora a pergunta dele é o seguinte, a água está escoando por aqui (aponta) e eu estou num lugar aqui (afastase do buraco). Será que eu tenho rotacional ou não em torno desse ponto? Calcula o rotacional aqui. Pode ser que sim, pode ser que não. Provavelmente terei um pouquinho. Porque provavelmente eu não farei esse movimento assim ó (gesticula com o corpo sem girar) Em volta da pia. Provavelmente eu farei isso (gira). Você joga um negocinho lá e você vai ver se ele roda ou não roda. Mas eu diria que muito provavelmente aquele lá tem um rotacional pequeno também. 
De maneira semelhante à explicação do gradiente, o rotacional do campo elétrico é mencionado somente no final do episódio:

01:44:40 - 01:45:20 Para que a gente usa rotacional em Eletromagnetismo? Olha lá (quadro resumo com as equações de Maxwell no canto esquerdo do quadro). Qual é o problema da gente. Para esse tipo de campo (aponta para linha da lei de Faraday). Eu estou falando exatamente que tem alguma coisa que cria linhas de campo circulares. Então o objeto matemático adequado para descrever coisas que fazem assim (gira o dedo) é isso daqui (rotacional). E isso daqui (divergente) é o objeto adequado para descrever coisas que fazem assim (gesticula com os braços "espalhando").

Essa última citação deixa claro como a busca pela compreensão e representação dos fenômenos do mundo físico motivou a criação de conceitos matemáticos. Além disso, parafraseando Devlin (2000), percebemos como o pensamento matemático possibilitou a visualização dos invisiveis fenômenos do eletromagnetismo. Os gestos e imagens concretas corriqueiramente utilizados durante as explicações dos operadores diferenciais (com menos intensidade para o divergente) parecem propiciar um nível de compreensão mais profundo em relação ao tratamento puramente abstrato dos mesmos comumente presente nos cursos de cálculo. Adicionalmente, essa abordagem parece ser mais coerente quando consideramos o desenvolvimento histórico das representações matemáticas do eletromagnetismo (SILVA, 2002).

Isso nos permite conjecturar sobre a possibilidade de comparar aulas ministradas por professores diferentes sobre o mesmo tema (por exemplo sobre o significado dos operadores diferenciais em um curso de eletromagnetismo) através da ferramenta de análise que propomos nessa pesquisa. Voltaremos a considerar essa possibilidade no Capítulo 7.

Episódio 9: Corrente elétrica e densidade de corrente Aula 26-Duração: 10 min 40 s (16:00-26:40)

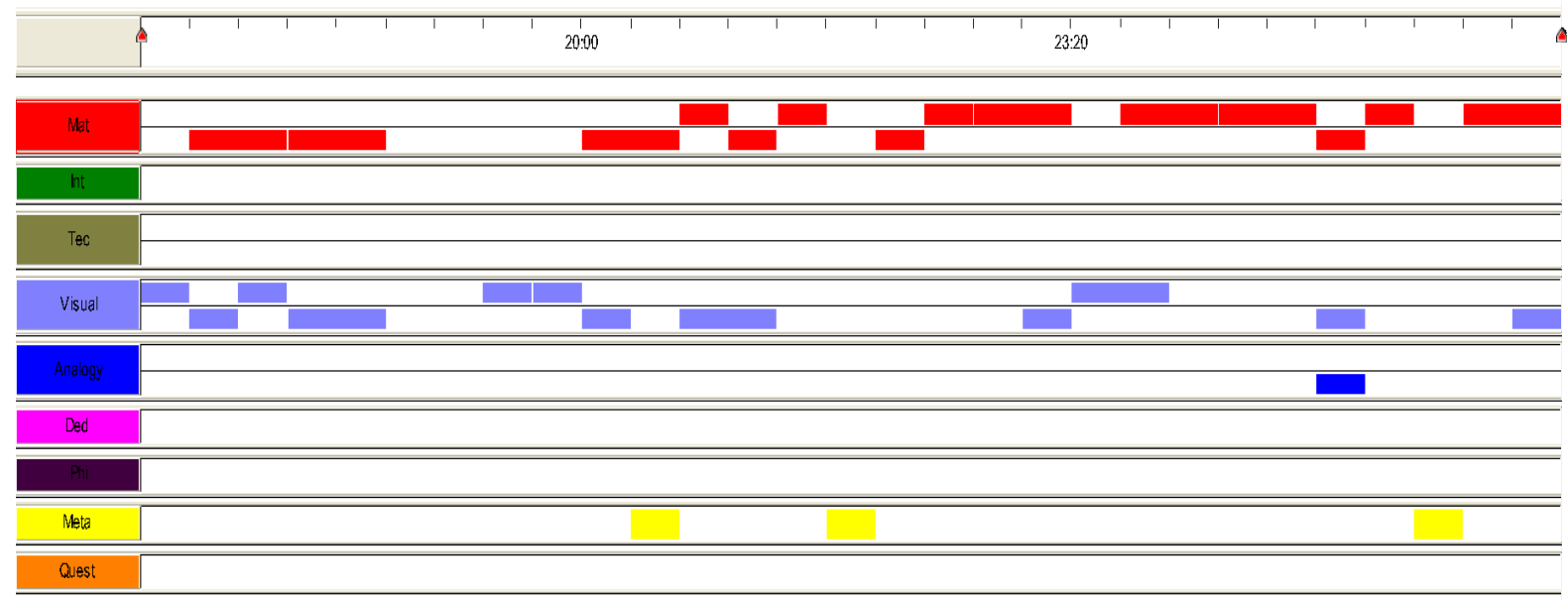

Figura 37: Diagrama Episódio 9 - Aula 26 - Corrente elétrica e densidade de corrente 
A Aula 26 tem como objetivo introduzir e matematizar outro conceito fundamental do curso: a corrente elétrica. Por esse motivo notamos que o episódio selecionado é praticamente todo categorizado como matematização (em vermelho, Figura 37), a qual é auxiliada por um frequente uso de gestos e representações pictóricas (visual). Este episódio tem início no momento em que a noção de corrente elétrica é introduzida. Muito provavelmente, os alunos já devem ter estudado este conceito no ensino médio, entretanto, a corrente elétrica nesse nível é tradicionalmente abordada como o movimento de elétrons em um fio. Ciente deste fato, o professor apresenta uma situação física mais complexa para introduzir essa noção:

00:17:00 - 00:17:20 Se você pegar os elétrons dentro do Sol (desenha). Vai ter elétron de tudo quer velocidade com qualquer velocidade (gestos). Ai se você quiser perguntar existe corrente elétrica nesse sistema? Pessoal, o que é corrente elétrica? Qual é a ideia? A ideia é a seguinte, você pega uma superficie matemática e coloca aqui (desenha). E o que é corrente elétrica através dessa superfície. Você vai perguntar tem uma quantidade de carga passando de um lado para outro que seja não nula. Em geral, num sistema caótico, não. Imagina que aqui nesse lugar tem um monte de elétrons andando para tudo quanto é lado (gestos). [...]

O que poderia dar origem a uma corrente elétrica. Por exemplo se você conseguisse privilegiar um lado em relação ao outro. Como você pode fazer isso? [...] Se você pegar esse sistema aqui e puser uma placa positiva aqui e uma negativa aqui (desenha). Aparece um campo elétrico aqui assim (desenha). [...] Se você contar quantos elétrons passam através dessa superficie, você vai ter uma quantidade que passa mais para lá do que para cá.

A escolha deste exemplo permite que o professor apresente a necessidade de considerar a direção do movimento dos elétrons como um fator relevante para a representação matemática da corrente elétrica. Isso motiva a discussão sobre que conceito matemático (matemática pré-fabricada) utilizar para descrever esse movimento de maneira mais precisa. Dessa forma, a diferenciação entre corrente elétrica (escalar) e densidade de corrente (vetorial) é abordada, o que evidencia a habilidade do professor em identificar os aspectos essenciais que justificam a utilização de uma estrutura matemática específica para a utilização da mesma na construção de um conceito físico:

20:20 - 23:20 No colégio a gente fala muito em corrente elétrica. Por que? Toda vez que você tiver fio, falar em corrente elétrica é suficiente - $U=R i$ - tem um fio lá, passa um $i$ e tudo bem. Mas se a gente quiser fazer uma descrição mais precisa desse movimento, a corrente elétrica não é a melhor quantidade. Por que? Pega esse sistema aqui. As cargas em média estão andando para cá. Tem carga andando para cá, para cá (gestos), mas em média anda mais para lá. Qual é a corrente através dessa superficie (gesto com a apostila)? Zero, tudo bem? Isso significa que a coisa mais apropriada para descrever a corrente não é a quantidade total de carga que passa, mas eu tenho que dar uma informação a respeito de qual é a superfície que eu estou usando. E por isso, em vez de $i$, a gente trabalha com um conceito chamado densidade de corrente. [...] Pensa o seguinte, eu tenho que fazer uma grandeza matemática que descreva isso que eu estou falando. Que as cargas estão andando de um lado para o outro, sim? Corrente é o que? Carga com velocidade, tudo bem? Então isso sugere para a gente que usar um vetor é melhor que usar um escalar. Sim? A corrente 
elétrica que você mede lá em Ampères. Aquilo lá é um número, não diz para onde que a corrente está indo. Então o problema do i é que ele é um escalar. E se eu quiser ser mais preciso eu tenho que usar um vetor. Que vetor que eu vou usar? Vou usar um vetor na direção da velocidade. De modo que se a carga tiver indo para cá e eu puser a superfície assim (gestos) tem a noção que ela não atravessa a superficie.

O recursos a analogias e situações cotidianas (A1) não é tão utilizado como nas aulas em que as noções de densidade de carga e fluxo de um campo vetorial foram matematizadas. Uma possível justificativa para esta diferença é que a analogia entre corrente elétrica e um líquido fluindo, por exemplo, carrega consigo a ideia de movimento de cargas elétricas em um fio, noção esta que o professor pretende combater. Em um momento posterior da aula (não pertencente a este episódio) o professor chega a fazer uma analogia que ilustra a diferença entre corrente elétrica $(i)$ e densidade de corrente $(\vec{J})$ de maneira concreta:

36:20 - 37:20 Qual é a diferença fisica entre o $\vec{\jmath}$ e o i? Quando que um ou o outro é útil? Pensa em uma estação de metrô que é igualzinho. Se você pegar o túnel do trem andando lá. Você pode tratar a quantidade de pessoas que anda por unidade de área através de [...] pessoas por segundo? Pode! O metrô chegou na estação e saiu todo mundo junto assim, não! Cada um foi para um lado. Então a técnica matemática de descrever o fluxo dessa coisa é outra. Tem que ter uma técnica mais poderosa. E a técnica mais poderosa é o $\vec{\jmath}$.

No final deste episódio, a expressão matemática da densidade de corrente é escrita retomando o conceito fundamental de fluxo:

23:20 - 26:20 [...] se a carga tiver indo para cá e eu puser a superfície assim (gestos) tem a noção que ela não atravessa a superfície. E ai a gente vai usar o conhecido conceito de fluxo. Vou pegar essa superficie, colocar uma normal aqui para orientar a superficie. E a corrente vai estar associada ao produto escalar de $\vec{\jmath}$ com a superficie. Se vc pegar um monte de cargas que se movem nessa direção assim por exemplo (desenha) e você puser uma superficie matemática aqui (desenha). E essa superficie tem uma normal torta assim em relação a essa velocidade. E se ela tem um tamanho ds eu vou falar que o di através dessa superficie vai ser igual ao que? Ao fluxo, ou seja di $=\vec{\jmath} . n d S[\ldots]$ di corresponde a que? Qual grandeza? Vai corresponder a alguma coisa que é $d q / d t$ Nessa expressão o que é $d q$. Como é que você pensa em corrente elétrica? Carga em movimento. [...] Você senta aqui e fica contando quantas cargas passam por unidade de tempo. [...] Cuidado, isso daqui (dq/dt) não é uma derivada. [...] Por que isso não é uma derivada? Pessoal tem alguma carga variando? Não! Derivada é uma variação.

Ao construirmos representações matemáticas para fenômenos do mundo físico, precisamos definir claramente que aspectos da natureza desejamos representar e, consequentemente, que estruturas matemáticas estão disponíveis para modelar tais aspectos. O exemplo da diferença entre $i$ e $\vec{\jmath}$ ilustra muito bem a habilidade de selecionar variáveis relevantes e as vantagens de se escolher o formalismo matemático mais adequado para expressá-las. Ao representar o movimento de elétrons pelo vetor densidade de corrente, 
ganhamos em precisão e generalidade. A abordagem explícita dessa diferenciação nesta aula é altamente instrutiva para os alunos.

Ao final da Aula 26 o professor retoma o conceito de densidade de corrente para tratar de um dos princípios fundamentais do eletromagnetismo: a conservação da carga. Assim, o próximo episódio retrata como a equação da continuidade foi tratada.

Episódio 10: Equação da continuidade

Aula 26 - Duração: 11 min 20 s (1:36:40-1:48:00)

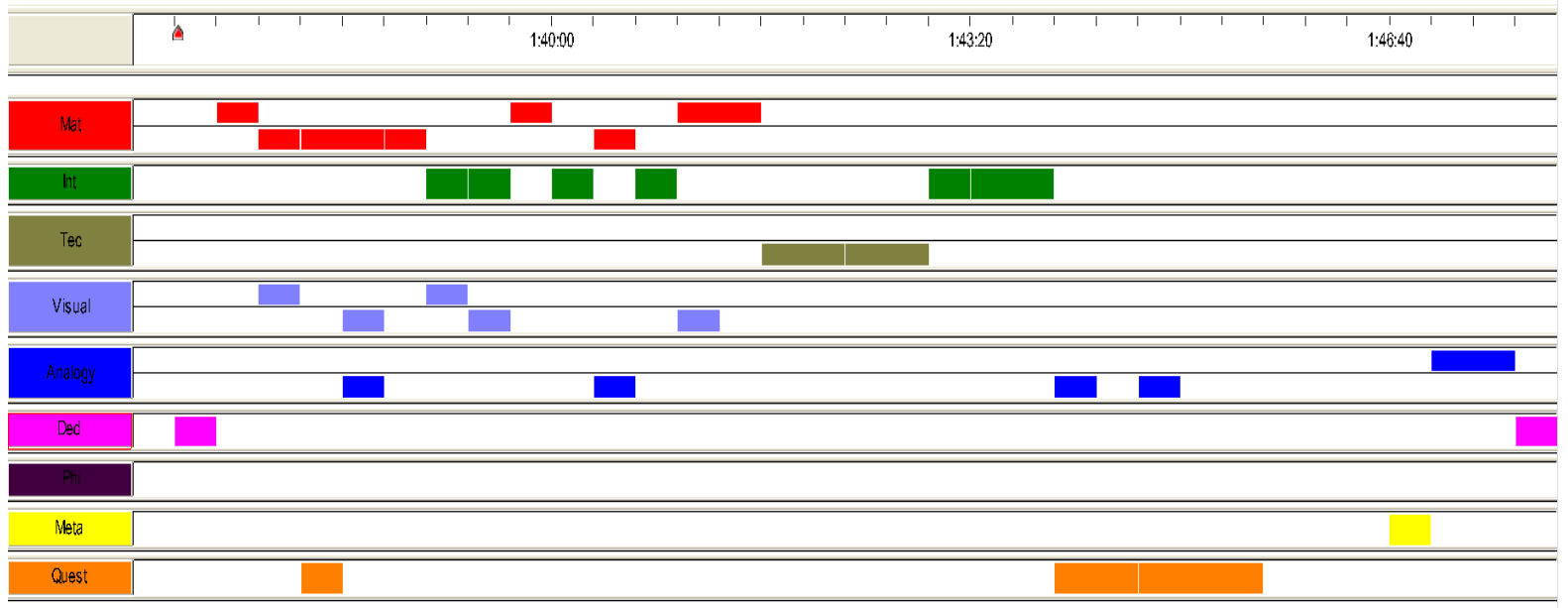

Figura 38: Diagrama Episódio 10 - Aula 26 - Equação da continuidade

Em pouco mais de 10 minutos, a equação da continuidade foi representada matematicamente, manipulada tecnicamente (autoridade), interpretada fisicamente, analogias foram empregadas como recurso explicativo e a utilidade dessa estrutura matemática unificadora para pensar outros fenômenos da física (A2) foi destacada. A incidência de praticamente todas as categorias de análise num espaço tão curto de tempo faz deste episódio um caso interessante a ser analisado, pois nos permite conjecturar sobre uma eventual associação entre múltiplas abordagens e qualidade de uma aula que aborda a multifacetada relação entre física e matemática. Tal multiplicidade também foi a razão para selecionarmos este trecho para a utilização de nossa ferramenta de análise por outros pesquisadores na seção de validação das categorias.

A equação da continuidade é apresentada, nas próprias palavras do professor, como a representação de um dos pilares mais sólidos da física:

01:37:00 - 01:37:40 Pessoal, carga elétrica é uma grandeza conservada. Esse é um dos pilares mais sólidos da física de hoje. Como é que eu expresso matematicamente a conservação da carga elétrica. Isso é a equação da continuidade. 
Em seguida a ideia física da conservação da carga é apresentada da seguinte maneira: 01:38:00 - 01:39:00 Pega uma superfície matemática fechada (desenha) e pergunta a seguinte coisa: a quantidade de carga dentro dessa superficie pode variar?[...] Como? Carga entrando e saindo, tudo bem? Isso pode. Uma carga pode sair lá e "tum" morrer lá dentro? Ou pode nascer uma carga lá dentro? Não pode. A ideia de conservação da carga está baseada nesse fato: numa superfície fechada pode entrar e sair carga e a quantidade de carga lá dentro pode variar. Só que o único mecanismo possível de variação é entrar e sair.

Assim, a noção de entrar e sair é representada pelo fluxo de carga que passa através da superfície matemática fechada:

01:39:20 - 01:40:20 Qual é o significado disso ( $\oiint \vec{\jmath} . \hat{n} d S$ ) nessa superficie aqui? [...] Isso corresponde a quanta carga passa por unidade de tempo nessa superfície. Então, isso é igual $a d q / d t$.

Este trecho reflete a dificuldade de identificar se o processo é de matematização ou interpretação, o que fica evidente na aparência intercalada dessas categorias em momentos deste episódio (Figura 38). O discurso do professor está tão imbricado ("qual o significado disso?" "então representamos matematicamente por isso") que às vezes até nossa unidade temporal de análise (20 s) se torna insuficiente para representar em que direção (da representação matemática para o mundo físico ou vice-versa) o processo está ocorrendo. Tal abordagem exemplifica claramente nosso argumento em favor de uma profunda relação entre matemática e física.

Após escrever a equação da continuidade na forma integral $\left(\oiint \vec{\jmath} \cdot \hat{n} d S=-\frac{d q}{d t}\right)$ e justificar o sinal de menos pela convenção de orientar a normal para fora da superfície (carga entrando = fluxo negativo) a forma diferencial da mesma é escrita evocando o teorema de Gauss (técnica T1 - autoridade). Por fim, o professor destaca que a estrutura de pensamento representada por essa equação é utilizada em muitas outras áreas da física (A2) ao mencionar a importância do teorema de Noether:

01:46:40 - 01:48:00 Esse teorema pensa o mundo dessa maneira aqui. Superfície fechada, se tem uma grandeza conservada, ela só pode variar se entrar pela fronteira. E aí o seguinte, isso vale por exemplo para a conservação da energia; ela pode ser descrita matematicamente desse jeito. A energia dentro de um sistema pode variar? Pode, mas ela tem que entrar e sair pela superfície. Então, em energia a gente vai falar o que? Que a quantidade de energia no interior da superfície em função do tempo está relacionada ao fluxo de energia através da superficie. Existem vetores que a gente usa para descrever fluxo de energia, tudo bem? Então fluxo de qualquer coisa conservada a gente pode usar isso daí. Então essa lei é uma lei extremamente importante.

A importância da equação da continuidade como representação de um princípio de conservação e, portanto, de um dos “axiomas" mais sólidos da física, é novamente 
confirmada quando o professor mostra que a mesma não é satisfeita na lei de Ampère e justifica a inserção da corrente de deslocamento. A análise da aula em que a inserção do “termo de Maxwell” é tratada será apresentada no Episódio 13.

Episódio 11: Lei de Ampère

Aula 31 - Duração: 21 min (18:20-39:20)

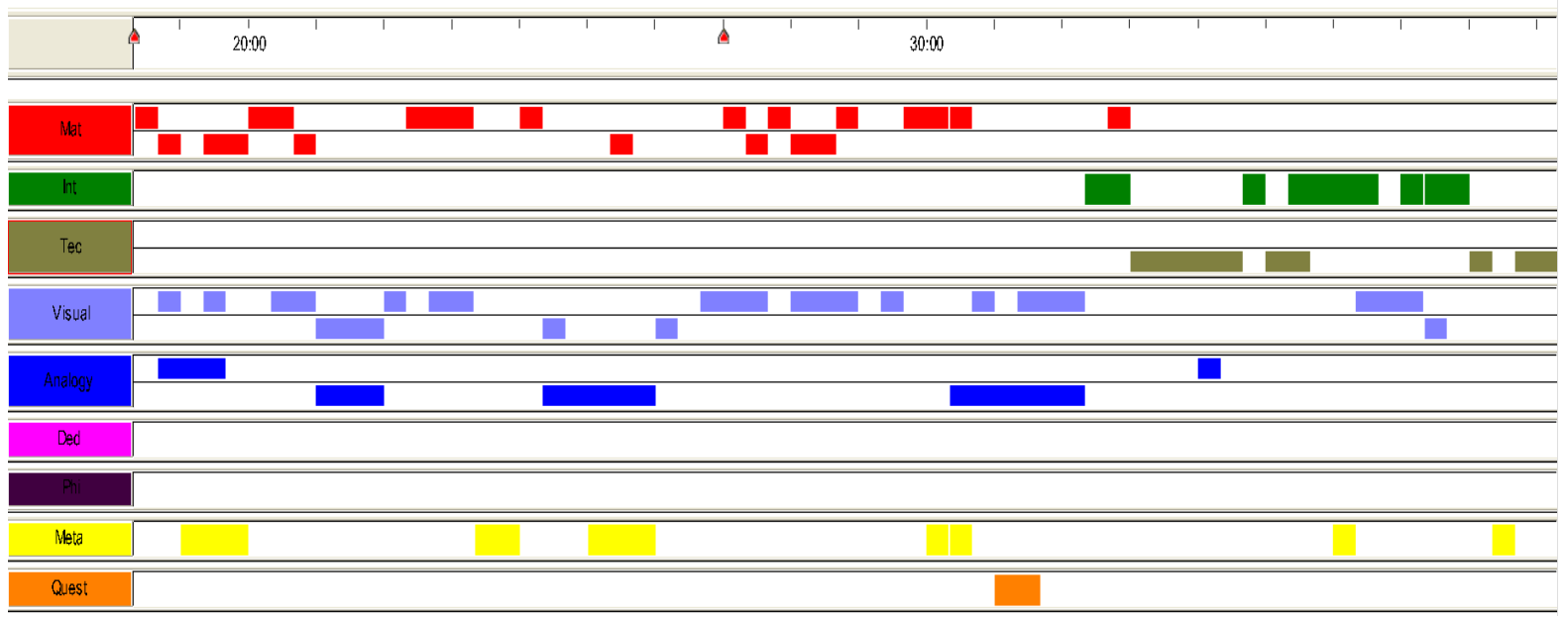

Figura 39: Diagrama Episódio 11 - Aula 31 - Lei de Ampère

As equações de Maxwell são abordadas de maneira gradativa desde a terceira aula por meio das discussões iniciais auxiliadas pelo quadro resumo, o qual vai ficando cada vez mais complexo/completo à medida que o curso se aproxima do fim. Nesta aula o foco principal é a lei de Ampère (tanto na forma integral $\oint \vec{B} \cdot d \vec{c}=\mu_{0} I_{\text {int }}$ como diferencial $\nabla \times \vec{B}=\mu_{0} \vec{\jmath}$ ). Os 21 minutos deste episódio são dedicados a uma cuidadosa apresentação das convenções do formalismo (orientação do caminho fechado, superfície matemática apoiada no caminho, sentido da normal), auxiliada por um uso intenso representações visuais, uma poderosa analogia e comentários de natureza metacognitiva (vide novamente a multiplicidade da abordagem na categorização na Figura 39). O professor utiliza o que foi visto anteriormente de maneira a identificar semelhanças formais (A2) com o que está sendo apresentado no momento, o que faz com que as explicações sejam mais diretas. A busca pelo estabelecimento de relações com o que foi previamente exposto no curso fica evidente no início deste episódio:

18:40 - 19:40 Quais são as condições de aplicação da lei de Ampère? São as mesmas condições, a matemática disso daqui (aponta para a lei de Faraday no quadro) é igual à matemática disso daqui (lei de Ampère no quadro). O que a gente faz? A gente pega um caminho fechado (desenha). Talvez isso daqui seja a coisa mais difícil de começar a aprender a lei de Ampère. Como é que eu armo a geometria que está por trás? Ela é armada assim: você pega um caminho qualquer, você tem direito de escolher o caminho. Do mesmo jeito que aqui (lei de Gauss) você tem direito de pegar uma superfície qualquer. Claro que 
num problema de verdade existem superficies gaussianas mais úteis que outras, mas você tem direito de escolher a superficie que você quiser. E você tem direito de escolher o caminho que você quiser.

Para apresentar os abstratos instrumentos de pensamento da lei de Ampère - caminho matemático fechado e superfície matemática orientada - bem como a arbitrariedade da escolha da superfície apoiada, uma analogia poderosa é utilizada e o foco na reificação é notório:

21:00 - 22:40 Pessoal, por exemplo: você pode pegar um arame assim (gestos) e você coloca uma bolha de sabão em cima do arame (gestos), tudo bem? Se o arame for assim (gesto "entortando" o arame) e não for plano também não tem problema, você consegue apoiar uma bolha de sabão lá em cima, tudo bem? Ok isso? [...] Isso dai é uma superfície possível se você pegar a bolha e fizer qualquer coisa com ela (gestos ilustrando várias bolhas sendo formadas em várias direções). Isso é uma superfície apoiada no caminho. Tudo bem? Então você tem que ter um caminho e você pega uma superfície e apoia, puxa pra cá (gestos) tanto faz, da volta assim, de qualquer jeito no fim a superficie tem que terminar aqui (no caminho). Então o desenho é isso daqui: para um mesmo caminho, pode ser apoiada numa superfície plana, pode ser apoiada lá pra dentro assim (desenha), todas essas são superfícies apoiadas no caminho.

Em seguida, o caráter arbitrário das convenções é novamente ressaltado:

23:20 - 24:00 Então a regra básica para você usar essa lei é sempre essa geometria básica, pega um caminho, orienta o caminho; seguinte, você é que tem que fazer isso. Se eu fizesse para você seria fácil. Te dou a superficie e o caminho orientado e "se vira". Não é assim. Vou te dar um problema e você vai ter que pegar e fazer tudo isso sozinho. Esse que é o problema. Você tem que pegar, escolher o caminho, orientar o caminho, colocar a superficie em cima e escolher a normal à superfície. Tudo isso é uma opção sua.

A necessidade de definição de uma superfície para o significado de interno e externo do termo $I_{\text {int }}$ da lei de Ampère é problematizada utilizando novamente uma situação cotidiana/concreta:

24:20 - 27:20 O que é corrente interna? Pergunta: se você pega a porta, imagina que tem uma corrente elétrica passando por aqui, dá para você dizer que a corrente fura o caminho? Corrente consegue furar um caminho? Não! Eu estou dentro da sala? (parado na frente da porta). Pessoal, eu não sei! A gente tem que abandonar a nossa relação ingênua com o problema. Eu atravessei a porta, não sei. A porta não é atravessável. O que é atravessável? É uma superficie matemática apoiada sobre a porta. Isso dá para atravessar. Então, quando eu falo dentro e fora da sala, a gente imagina que tem uma superfície matemática aqui e aí sim existe o conceito de eu atravessar, tudo bem isso? É super importante, não pode ser ingênuo, se for ingênuo você erra. [...] Então o que é I interno nessa expressão? É a corrente que fura. Coloca a superficie aqui, coloca a normal à superficie assim, se tiver uma corrente q fura, ou seja ela entra por um lado e sai por aqui (desenha) isso é considerado uma corrente que furou uma superfície apoiada num caminho. Então a matemática tem que ser meio rigorosa. 
A descrição da corrente interna $I_{\text {int }}$ pela integral que representa o fluxo da densidade de corrente, além de mais precisa, permite a dedução da forma diferencial da lei de Ampère. Portanto, o professor substitui o termo $I_{\text {int }}$ pela integral do fluxo de $\vec{\jmath}$. Porém, comete (de maneira consciente) o erro de escrever o símbolo da integral dupla sobre uma superfície fechada. Certamente, as décadas de experiência deste professor já forneceram inúmeras evidências de que esse é um erro muito cometido pelos alunos. A analogia com a bolha de sabão é novamente abordada para diferenciar o cálculo do fluxo em superfícies fechadas e abertas:

29:40 - 32:20 Por isso que outra maneira de escrever esse resultado $I_{\text {int }}=\oiint \vec{\jmath} . \hat{n} d S$. Isso daqui está certo? (aponta para o símbolo da integral sob uma superfície fechada) Isso é a integral dupla sobre uma superficie fechada? Pessoal, essa superfície é fechada ou aberta? [...] Aberta.... e por isso que tem um caminho. Então o caminho, ele serve pra definir uma superficie aberta. Pessoal, como é que você faz uma bolha de sabão. Como é que a bolha nasce? Tudo bem, sabão. Pega o sabão lá, e aí com é que você constrói a bolha?

A: Pega um caminho.

P: Se você pega um caminho pra fazer uma bolha de sabão?

A: Uma fôrma

P: Como é que é uma fôrma?

A: Redonda.

P: Uma esfera?

A: Um círculo

P: Um círculo? Então você pega um arame ou um pedaço de plástico assim... Aí você pega e molha isso daqui... Molhou? O que você vai ter? Vai ter uma superfície do tipo lei de Ampère. Ok isso? Você tem uma película de sabão apoiada nisso aqui aí você assopra isso. Na hora que você assopra você vai ter o quê? Vai ter uma configuração que olhada de lado... quando você sopra ele começa a fazer isso... mais isso (desenha o bolha sendo formada) isso daqui assim... aí a bolha descola e aí vira a lei de Gauss... isso aqui é a superfície fechada, a bolha. Mas isso daqui não é fechada, é aberta.

É difícil não se impressionar com o vasto arsenal de recursos analógicos do professor. Sua explicação é diametralmente oposta a uma postura abstrata e vazia de significado que comumente encontramos em aulas que primam pelo "formal pelo formal". Certamente, esse conjunto de imagens concretas contribui para uma compreensão mais profunda do significado das leis do eletromagnetismo.

Na parte final do episódio, a lei de Ampère na forma diferencial $\left(\nabla \times \vec{B}=\mu_{0} \vec{J}\right)$ é deduzida. O teorema de Stokes é novamente evocado (T1), porém agora uma "intuição física" sobre o seu significado é apresentada, por isso notamos trechos de interpretação (verde na Figura 39) no fim do trecho analisado:

34:20 - 38:00 O que o teorema de Stokes fala? Fala o seguinte: se você calcular a integral de qualquer coisa num caminho fechado, isso é igual ao fluxo do rotacional de $\vec{F}$ sobre uma superficie apoiada nesse caminho. Então, o que o teorema de Stokes relaciona alguma coisa 
sobre o perímetro, a borda da superfície e alguma coisa que o ocorre lá dentro. Se a gente pegar essa relação (Stokes) e usar lá em cima (Ampère integral) a gente tem que $\oint \vec{B} . d \vec{c}=$ $\iint(\nabla \times \vec{B}) . \hat{n} d S$. [...] Pessoal, qual o significado fisico do rotacional? Isso daqui explica pra gente qual o significado físico do rotacional. É daqui que a gente ganha uma intuição. Rotacional é o quê? Pensa num circuito pequeno. Esse caminho pequenininho aqui. [...] $O$ rotacional projetado sobre essa normal aqui seja um número positivo... isso significa o que? A normal disso aponta assim (desenha). Se esse rotacional vezes a normal for um número positivo, significa que o rotacional também aponta pra cá (desenha o vetor na direção e sentido da normal). O que significa o rotacional apontar pra cá? Olhando só isso daqui (lado direito) é duro. Mas aí você fala: o rotacional tá associado com isso (lado esquerdo). E esse lado aqui (esquerdo) você entende. O que significa esse número aqui ser positivo? Significa que na hora que você deu a volta. Se eu ampliar esse desenho aqui (desenha um círculo), você projeta $B$ aqui, $B$ aqui, e $B$ aqui (representa o vetor campo magnético tangencial em vários pontos do círculo). Isso significa que existe uma coerência de mudanças no sentido $B$, de modo que a projeção de $B$ sobre o caminho é diferente de zero. Então, o rotacional corresponde a ideia que o campo roda assim (gestos).. A intuição é essa. $O$ rotacional ser paralelo a $\hat{n}$ o campo roda assim. Se fosse negativo, rodava ao contrário. $E$ se for zero não roda pra lugar nenhum. Então a intuição do rotacional é isso... ela dá que direção que o campo está rodando elementarmente, ok?

Os abstratos recursos de pensamento necessários para a compreensão das equações de Maxwell (fluxos representados por integrais de superfície, integrais de linha indicando circulação de campos) foram aplicados a tantas situações desde o início do curso que a lei de Faraday é apresentada de uma maneira muito mais direta, como veremos no próximo episódio.

Episódio 12: Lei de Faraday

Aula 34 - Duração: 9 min 40 s (28:00-37:40)

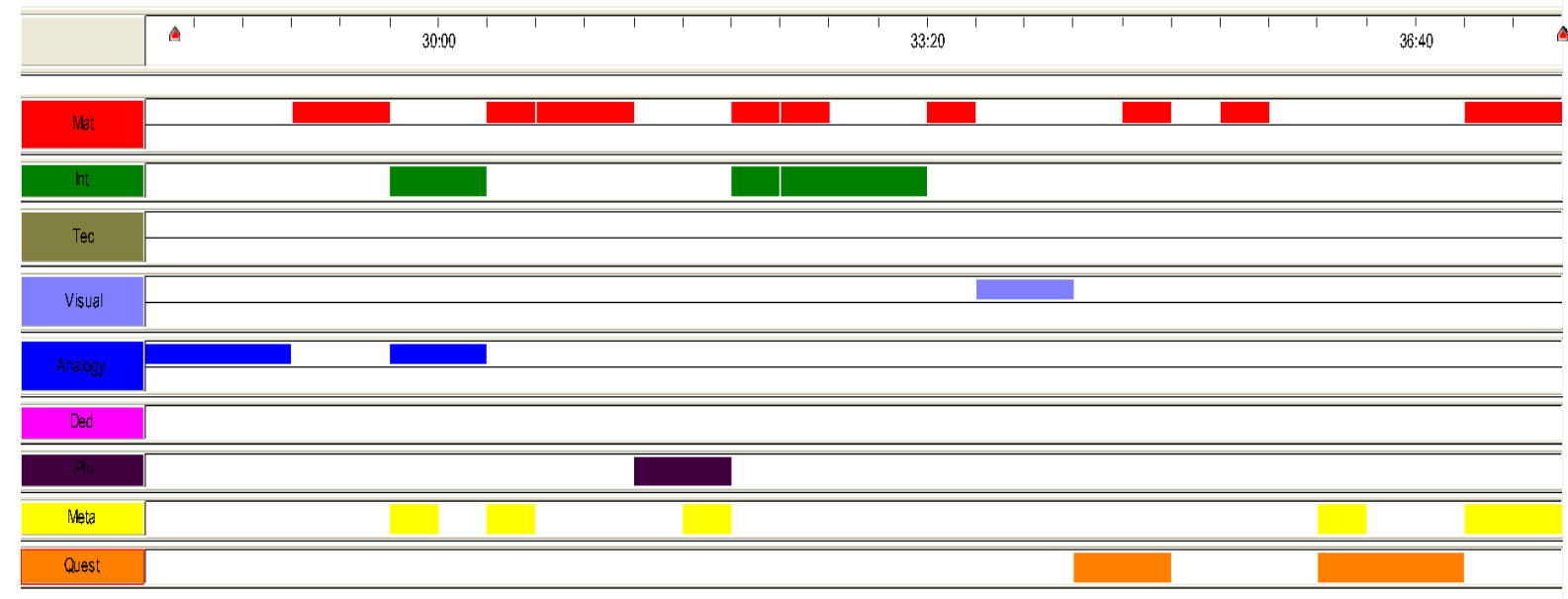

Figura 40: Diagrama Episódio 12 - Aula 34 - Lei de Faraday 
A apresentação da forma diferencial da lei de Faraday na Aula 34 é baseada em uma analogia (formal - A2) com a lei de Ampère. Assim, a mesma é extremamente direta, sem a utilização de qualquer analogia material, gestos ou representações pictóricas.

28:00 - 28:40 Do ponto de vista formal, pelo mesmo jeito que a gente usa o teorema de Stokes, essa relação aqui (lei de Ampère na forma integral no quadro resumo) do ponto de vista integral vira essa (Ampère diferencial). Essa daqui (Faraday na forma integral) também tem a forma diferencial que é $\nabla \times \vec{E}=-\frac{\partial \vec{B}}{\partial t}$. Por que rotacional de $\vec{E}$ ? Porque a matemática que gera isso aqui é essa equação. Aí você troca a letra e acabou.

Em seguida a discussão passa a ser dedicada a um aspecto extremamente técnico sobre uma interpretação errônea do significado desta lei. O problema está em identificar a real fonte desse campo elétrico gerado pelo campo magnético. Em muitos livros didáticos de ensino superior (e também de ensino médio), o campo elétrico da lei de Faraday é explicado como oriundo de uma variação temporal do fluxo do campo magnético, fato que o professor defende que deva ser "desaprendido". Tecnicamente a diferença pode ser expressa da seguinte forma: é possível dizer que a variação temporal do fluxo do campo magnético $\frac{d}{d t} \emptyset_{\vec{B}}$ é igual ao fluxo da variação temporal do campo magnético $\emptyset_{\frac{\partial \vec{B}}{\partial t}}$ ? Aparentemente essa identidade parece razoável. Vejamos como o professor aborda esse problema:

29:40 - 33:40 Quem já aprendeu lei de Faraday, agora você precisa prestar atenção na seguinte discussão: qual o significado fisico disso aqui (aponta para $\iint \frac{\partial \vec{B}}{\partial t}$. $\hat{n} d S$ )? Isso aqui é um fluxo? Claramente é um fluxo porque j escalar n qualquer coisa é um fluxo. Lei de Gauss elétrica: integral de escalar nds aqui. Isso daqui é o fluxo. Como é que você expressa esse fluxo? Isso aqui, se você quiser falar em fluxo isso daqui é fluxo de $\frac{\partial \vec{B}}{\partial t}$. Isso daqui $\left(\frac{\partial \vec{B}}{\partial t}\right)$ flui. Em alguns livros e principalmente no colégio com grande frequência, as pessoas escrevem isso daqui assim $\frac{d}{d t} \emptyset_{\vec{B}}$ Pergunta: isso daqui é igual a isso? ( $\frac{d}{d t} \emptyset_{\vec{B}}=\emptyset_{\frac{\partial \vec{B}}{\partial t}}$ ?) A pergunta é: posso tirar a d/dt fora dessa integral? Pode? Não. As vezes pode, muitas vezes pode, em geral não. [...] tem até livro de curso superior que ensina isso. Se você vai olhar o Feynman, ele vai discutir com cuidado que você não pode tirar essa coisa e existem situações onde correntes que fluem através de contornos que se deformam, onde isso daqui ( $\left.\int \frac{\partial \vec{B}}{\partial t} . \hat{n} d S\right)$ não é equivalente a isso (d/dt do fluxo de B). Então você não pode tirar o d/dt para fora da integral em geral. E aí, a versão oficial desse curso aqui é a seguinte: que a causa física da corrente é $\frac{\partial \vec{B}}{\partial t}$, não é o fluxo de B. Sim isso não é linha de campo passando lá, não é isso. A física não é essa. Essa não é a visão da natureza. Linha de campo andando assim, não tem nada a ver. [...] E o legal é o seguinte: essa coisa do fluxo vai embora aqui nessa relação $\left(\nabla \times \vec{E}=-\frac{\partial \vec{B}}{\partial t}\right)$. Aqui a gente não fala mais de fluxo. Então a lei de Faraday microscópica diz como é a relação entre $\vec{E}$ e $\vec{B}$ de verdade. 
A insistência do professor em ressaltar que uma representação está errada reflete a sutileza da imbricada relação entre matemática e física. De fato, durante essa argumentação ficou novamente bastante difícil discernir entre matematização e interpretação (32:00-33:00 na Figura 40), pois da mesma forma que o professor menciona que $\emptyset_{\frac{\partial \vec{B}}{\partial t}}$ é a maneira correta de representar matematicamente o que ocorre fisicamente (matematização), na frase seguinte ele diz que $\frac{d}{d t} \emptyset_{\vec{B}}$ "não é a visão da natureza" (interpretação). Parece-nos que o conceito "fluxo de $\frac{\partial \vec{B}}{\partial t}$ " é tão intrinsecamente matemático que essa distinção começa a esvanecer. A ausência de referentes concretos intensamente presentes em inúmeros episódios anteriores (analogias materiais, situações cotidianas, representações visuais) também evidencia o caráter abstrato deste conceito físico. De fato, a física moderna e contemporânea é repleta de conceitos que não possuem uma referência imediata no mundo físico, como no caso da função de onda ou do isospin. As "analogias pitagóricas" mencionadas no Capítulo 1 (STEINER, 1998) começam a surgir como recurso fundamental para a conceituação em física. Outro exemplo disso é a inserção do termo corrente de deslocamento por Maxwell a partir de argumentos formais sem qualquer evidência empírica. Vemos como o professor apresenta e justifica tal inserção no próximo episódio.

Episódio 13: Corrente de deslocamento

Aula 39 - Duração: 27 min 20 s (18:40-46:00)

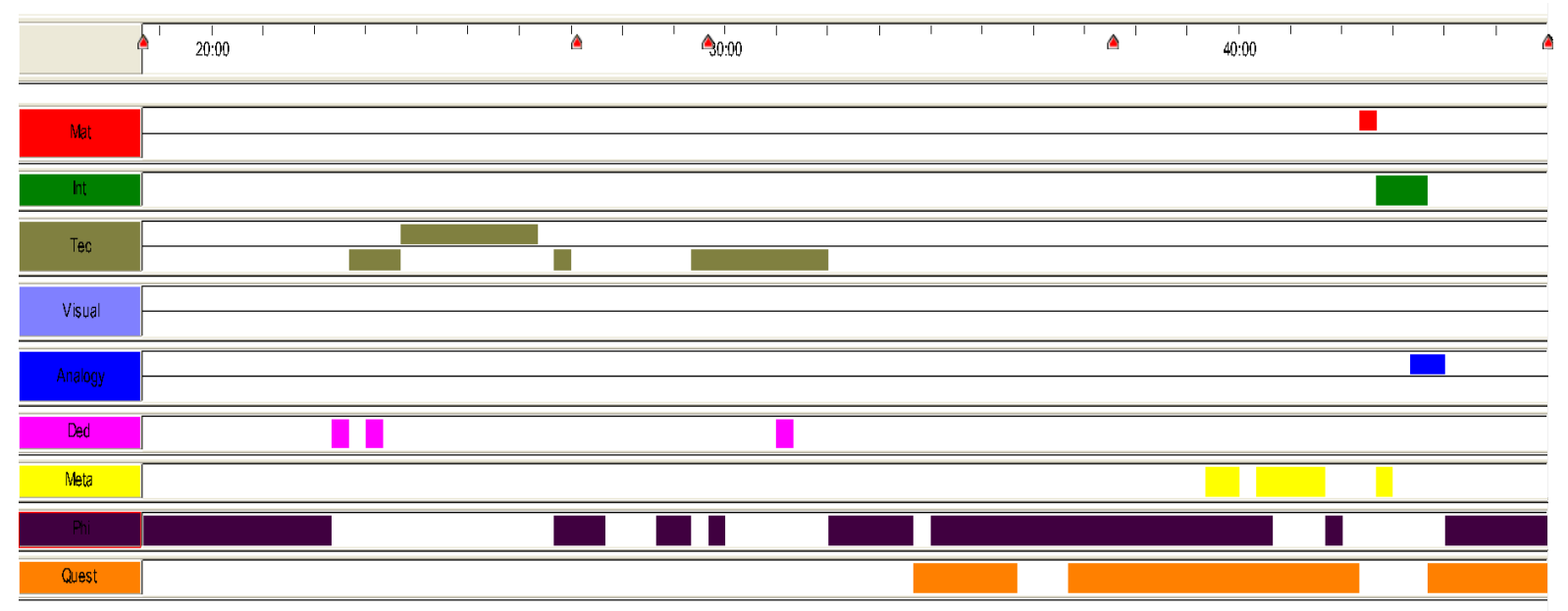

Figura 41: Diagrama Episódio 13 - Aula 39 - Corrente de deslocamento

Certos casos históricos são especialmente propícios para se investigar aspectos da profunda relação entre física e matemática. A inserção do termo "corrente de deslocamento" na lei de Ampère é certamente um deles e, por esse motivo, sabíamos que trechos desta aula 
seriam analisados, mesmo antes de a assistirmos. Apesar da extrema dificuldade de se refazer o processo histórico que levou Maxwell à proposição do termo (CHALMERS, 1975), de maneira retrospectiva, esta formulação oferece um "prato cheio" para os que se interessam em investigar a relação experimento-teoria, uma vez que os efeitos produzidos pela "corrente de deslocamento" eram muito pequenos para serem detectados com os métodos disponíveis na época de sua proposição. Segundo Poincaré (1995, p. 93), Maxwell estava "profundamente impregnado do sentido da simetria matemática"41. Para Steiner (1998) a inserção da corrente de deslocamento para atender à equação da continuidade é um claro exemplo histórico da utilização de uma "analogia pitagórica" (ver Seção 1.3).

Este episódio inicia-se no momento em que uma incoerência no quadro resumo é detectada e termina quando o professor mostra que a nova formulação da lei de Ampère (agora Ampère-Maxwell) resolve tal incoerência. Percebemos um padrão bastante incomum se compararmos com os outros episódios analisados. Quase não estão presentes as categorias matematização e interpretação, uma vez que a argumentação é feita em cima de uma incoerência formal. É notável a presença da categoria epistemologia na Figura 41 e fica evidente que o professor elegeu esse estudo de caso para suscitar discussões de natureza epistemológica com os estudantes. Tal foco é evidenciado já na discussão que precede a manipulação de equações e está centrado nos motivos pela busca de coerência nas leis físicas: 18:40-22:20 Uma teoria não pode ter uma incoerência. Tudo bem que aqui fora se você pegar aquela redoma que eu desenhei lá que tem esses conceitos (escreve $\vec{E}, \vec{B}, q, \vec{x}, t$ ). Que é o domínio da lógica. Tudo bem que essas ideias são tiradas de lugares não lógicos, mas uma vez que a gente fez isso, e a gente jogou essas ideias aqui dentro, a gente quer que isso seja lógico. É possível ter duas teorias da física? Pois é. A gente acredita que não. A gente não sabe se não... a gente acredita que não. Por que a gente acredita que não? Provavelmente por causa dos judeus. O que os judeus fizeram? Os judeus inventaram a religião monoteísta.[...] Mas por que a minha pergunta: por que a gente acha que só existe uma teoria física? E se você vai traçar essa história... pessoal, tudo tem história. Se você vai traçar essa história, você vai olhar a seguinte coisa: que a hipótese mais plausível é que o fato de o Deus judeu acabou influenciando a cultura ocidental de maneira muito forte, que é o cristianismo, ser único... e além disso uma concepção de Deus que Deus era uma espécie de sopa na qual você vive a sopa influencia você, você não influencia a sopa... isso acaba virando a ideia de que o mundo tem leis e que o mundo tem coerência. Ok, isso? Então essa ideia nova, ele é uma ideia construída, mas uma vez que ela foi construída, você fala assim: eu quero coerência? Quero. E ai o que é legal é o seguinte: Que você impõe a coerência e anda pra frente. Então isso que é a coisa super interessante. Você poderia deixar barato... tudo bem, tanto faz, aqui é assim e assim... aqui é aqui, lá é lá... e não dá. Mas a física não pensa assim tudo é a mesma coisa. Em pensando assim, a gente quer coerência.

${ }^{41}$ A versão de que a busca por simetria tenha influenciado o pensamento de Maxwell é descartada por Bork (1963), quando o mesmo defende que tal argumento aparece somente nos trabalhos de Heaviside. 
Esse tipo de discurso é relativamente incomum de ser encontrado em aulas de física e é extremamente formativo. Através dele, o professor procura ressaltar como a relevância do critério da coerência interna atua como um princípio (heurístico) fundamental para o fazer física. A relação da coerência com a crença monoteísta judaica é resultado de uma profunda reflexão e ilustra como nosso pensamento é influenciado histórica e culturalmente, sendo, portanto, a manifestação de um coletivo.

Em seguida, a incoerência é apontada da seguinte forma:

1 - A lei de Ampère na forma diferencial é escrita e, como a mesma é uma igualdade vetorial, o divergente é aplicado a ambos os membros da equação (técnica A1):

$$
\nabla \cdot(\nabla \times \vec{B})=\mu_{0}(\nabla \cdot \vec{\jmath})
$$

2 - O resultado do lado esquerdo da equação é nulo, pois o divergente do rotacional de qualquer vetor é nulo. Para não apresentar essa afirmação com um argumento de autoridade matemática, o professor efetua o cálculo do divergente do rotacional de um vetor qualquer (trecho categorizado como técnica A2).

$$
0=\mu_{0}(\nabla \cdot \vec{\jmath})
$$

3 - Pela equação da continuidade (Episódio 10) o divergente de $\vec{\jmath}$ é igual a $-\frac{d \rho}{d t}$, logo a incoerência é detectada:

$$
0=\mu_{0}(\nabla \cdot \vec{\jmath})=\mu_{0}\left(-\frac{d \rho}{d t}\right)
$$

Ao fazer referência à contribuição de Maxwell, o professor evita dizer que o mesmo raciocinou da maneira exposta e prefere uma posição prudente argumentando que é muito difícil entender como Maxwell pensava:

27:00-29:20 O Maxwell, historicamente, não colocou o termo desse jeito. Ele pensou de outro jeito. O pensamento do Maxwell é difícil da gente chegar nele com o que a gente sabe hoje. Porque a gente é treinado a pensar no eletromagnetismo desse jeito e o Maxwell pensava de outro jeito. Ele acreditava, em particular, que o espaço continha uma matéria. [...] Então é duro de a gente pegar e entender o que ele pensava diretamente. [...] E aí, depois do Maxwell veio Einstein, trinta anos depois. Depois do Einstein esse eletromagnetismo foi passado a limpo. E isso que a gente estuda aqui é a versão pós Einstein do eletromagnetismo. Os conceitos são um pouco diferentes.

A correção da incoerência, inclusão do termo $\mu_{0} \varepsilon_{0} \frac{\partial \vec{E}}{\partial t}$ na expressão da lei de Ampère, é apresentada sem justificativa prévia, o que o professor chama de "colocar o termo com a mão". Em seguida, o mesmo mostra como a nova forma da lei corrige a incoerência utilizando a lei de Gauss na forma diferencial. A partir daí, como podemos ver no diagrama da Figura 41, a discussão é inteiramente epistemológica, duradoura e os estudantes têm 160 
participação ativa com várias perguntas (laranja na Figura 41). Importantes aspectos epistemológicos do fazer física são abordados:

32:40 - 46:00 É feio fazer isso que eu fiz? Botar o termo com a mão. Tudo bem, você pode achar feio ou bonito, mas é isso que a gente faz o tempo todo. Esse tipo de física que dá prêmio Nobel para as pessoas. [...] Ele pega lá, tem uma coisa que não funciona e ele faz funcionar. [...]

A: Professor, eu li vários autores diferentes tentando entender o por que desse acréscimo. E eu não consegui em nenhum deles. Tem alguma comprovação experimental?

P: Muitíssimas. Pessoal, tudo bem, isso é outra questão. Eu podia falar: tá comprovado experimentalmente é assim. Mas o que eu queria é o seguinte: a gente tem que aproveitar e olhar pra entender como a física é feita. Então aqui tem duas etapas. Uma dela é quando eu coloquei esse termo aqui e vi que ele faz a coisa funcionar do ponto de vista matemático. A outra questão é a seguinte: isso daqui é validado experimentalmente e ai que a fase seguinte. Se não for a gente vai ter que jogar fora isso daqui. Se for a gente vai em frente. O fato de ter funcionado é apenas um conforto inicial que me dá confiança que eu estou no bom caminho. Mas ai tem um monte de coisas que tem que ser feitas pra mostrar isso daqui.

$[\ldots]$

Pessoal, física é igual futebol. Se você tá lá na área assim, levou uma bolada, bateu na sua barriga e a bola entrou... gol. Se você puder dar um chapéu no cara, driblar... beleza. Mas bateu na barriga e entrou, funcionou. Então tá bom. É isso. Porque a gente está em uma situação difícil. Você não tem luxo de falar assim: vou descartar o gol porque ele não foi feito da maneira mais elegante possivel. Ninguém faz isso. Em fisica a gente também não faz isso. Conseguiu entender de um jeito de trás pra frente... beleza. Mas tem que funcionar.

[...]

A: Em ciência a gente poderia dizer que a comprovação experimental é o argumento mais forte em física?

$P:$ É, mas não só. Como é que ando? Olha o meu andar. O que é que eu faço? Eu ponho o peso me um pé, ai o outro pé faz assim, aí eu apoio o peso nesse pé aqui e ponho o pé assim. E a gente só anda porque faz isso. Ou seja, o andar é um diálogo entre as duas pernas. Agora você pergunta qual a perna mais importante, a esquerda ou a direita? Não tem. Mas o diálogo é contínuo. Então tem horas.. por exemplo nessa hora aqui, a teoria veio antes. E se você for um físico teórico, a hora que você acha isso você fala "eu acertei"... não tem conversa. E aí, para os outros, talvez eu tenha que fazer experimento. Mas pra mim não precisa. Eu já sei que eu estou certo. Então a física não é construída de um jeito só, ela é construída muitos jeitos diferentes. E é igual futebol mesmo, tem gol de tudo que é jeito. Entrou é gol. [...]

A: Nesse caso eu estou adicionando uma interpretação ali, ao campo magnético... seria a variação do campo elétrico. Isso, nesse caso, foi adicionado como uma inconsistência matemática, porque a parte experimental da teoria até certo ponto funciona. Existe alguma precedência da coerência da teoria com a verificação?

$P$ : Não. Durante muito tempo, as pessoas tentaram achar um padrão para o funcionamento da ciência. E eles desistiram. Todos os filósofos desistiram de fazer isso. Talvez tenham alguns padrões muito profundos. Mas a ideia de que tem um método ou qualquer coisa, isso ai foi abandonado. Por que? Porque você vai olhar o desenvolvimento, um é de um jeito, o outro é de outro ai você pega o cara que fez não sei o que, ele agiu assim, o outro agiu assado. Então, não tem regra. O que torna você entrar na pesquisa de física mais complicado. Se tivesse uma regra era só você ser treinado. Você não pode ser treinado. Então você tem que ser outra coisa. Dá pra fazer isso? Dá. Mas isso não é um treinamento. Então, a mensagem disso aqui é que... a pergunta que cabe é a seguinte: nesse caso teve 
precedência? Teve. Terá no caso seguinte? Não necessariamente. Pode ser que sim, pode ser que não. Como eu falei... a imagem melhor que eu tenho da ciência é andar. Se apoia no pé do experimento, se apoia do pé da teoria e é desse jeito que você anda. Gingando. Sendo que esse diálogo não é feito pela mesma pessoa. Então, hoje coma fisica especializada... então eles são áreas de competência .... mas aí essas áreas dialogam.

Este debate ilustra muito bem a pertinência de se discutir as relações entre matemática e física em casos específicos e tirar conclusões localizadas. Alguns alunos procuram generalizar a relação de precedência entre teoria e experimento da inserção da corrente de deslocamento, mas o professor faz questão de enfatizar que não existe regra geral.

Os episódios apresentados até aqui estiveram ligados à introdução de conceitos do eletromagnetismo (densidade de carga, fluxo, energia potencial, corrente elétrica), interpretações físicas de operadores vetoriais e à abordagem das equações de Maxwell. Em alguns momentos (geralmente no início do curso e na apresentação de conceitos), a utilização de analogias materiais desempenhou um papel fundamental para a explicação, em outros (mais no final do curso e no estabelecimento de semelhanças no formalismo) o discurso se deu de maneira mais formal e abstrata. $\mathrm{O}$ amplo foco dedicado à matematização é facilmente identificado e a interpretação teve um papel de destaque depois de abordagens instrumentais da matemática. O caráter visual/multimidiático da exposição também foi amplamente exemplificado. Além disso, comentários de natureza metacognitiva, discussões epistemológicas e menções ao caráter dedutivo do conhecimento físico foram identificados em momentos pontuais. Resumimos as principais características de cada um dos episódios apresentados até aqui no quadro a seguir:

\begin{tabular}{|c|c|}
\hline Episódio: Conceito & Características principais \\
\hline $\begin{array}{l}\text { Ep. } 1: \text { Densidade de carga } \\
(1,2 \text { e } 3 \text { dimensões }) \\
\text { Aula } 5-28 \text { min } \\
(31: 00-59: 00)\end{array}$ & $\begin{array}{l}\text { Matematização da noção de densidade de carga; Aproximações e } \\
\text { idealizações explicitadas; Muitas situações concretas e analogias } \\
\text { materiais; Intenso uso de gestos e representações pictóricas; Interação } \\
\text { professor-aluno. }\end{array}$ \\
\hline $\begin{array}{l}\text { Ep. 2: Expressão matemática } \\
\text { do campo coulombiano } \\
\text { Aula } 9-11 \text { min } 40 \mathrm{~s} \\
(4: 20-16: 00)\end{array}$ & $\begin{array}{l}\text { Criteriosa representação matemática dos termos da expressão do campo } \\
\text { coulombiano e justificativa para o uso de estruturas matemáticas; } \\
\text { Explicações conceituais de matemática. }\end{array}$ \\
\hline $\begin{array}{l}\text { Ep. 3: Fluxo de um campo } \\
\text { vetorial } \\
\text { Aula } 12-32 \min 40 \mathrm{~s} \\
(12: 20-45: 00)\end{array}$ & $\begin{array}{l}\text { Matematização da noção de fluxo de um campo vetorial; Muitas } \\
\text { situações concretas e analogias materiais; Analogias formais com fluxo } \\
\text { do campo gravitacional; Intenso uso de gestos e representações } \\
\text { pictóricas; Incentivo à metacognição; Interação professor-aluno. }\end{array}$ \\
\hline $\begin{array}{l}\text { Ep. 4: Significado da lei de } \\
\text { Gauss elétrica } \\
\text { Aula } 14-18 \min 40 \mathrm{~s} \\
(04: 40-23: 20)\end{array}$ & $\begin{array}{l}\text { Diferenças formais entre fluxo em superfícies abertas e fechadas; } \\
\text { Analogia carga-lâmpada; Interpretação da lei de Gauss: analisar a } \\
\text { existência de carga o interior investigando a superfície. }\end{array}$ \\
\hline
\end{tabular}




\begin{tabular}{|c|c|}
\hline $\begin{array}{l}\text { Ep. 5: Energia Potencial } \\
\text { Eletrostática } \\
\text { Aula } 16-28 \min 40 \mathrm{~s} \\
(48: 40-1: 17: 20)\end{array}$ & $\begin{array}{l}\text { Energia potencial como trabalho realizado pelo campo; Relação } \\
\text { eletrostática e mecânica; Dedução teorema trabalho-energia; } \\
\text { Interpretação física do desenvolvimento matemático indicando } \\
\text { independência do caminho percorrido; Abordagem múltipla: quase } \\
\text { todas as categorias presentes. }\end{array}$ \\
\hline $\begin{array}{l}\text { Ep. 6: Significado físico do } \\
\text { Gradiente } \\
\text { Aula } 19-19 \min 20 \mathrm{~s} \\
(10: 20-29: 40)\end{array}$ & $\begin{array}{l}\text { Inusitada situação concreta de um cachorro que procura um bife pelo } \\
\text { "campo de cheiro" como recurso principal para a explicação do } \\
\text { conceito de gradiente de um campo escalar; Analogias entre campos de } \\
\text { temperatura, cheiro, pressão e potencial elétrico. }\end{array}$ \\
\hline $\begin{array}{l}\text { Ep. 7: Significado físico do } \\
\text { Divergente } \\
\text { Aula } 23-20 \min 40 \mathrm{~s} \\
(1: 12: 00-1: 32: 40)\end{array}$ & $\begin{array}{l}\text { Poucas analogias e situações concretas; Exposição centrada na } \\
\text { interpretação física do divergente do campo elétrico: divergente faz o } \\
\text { favor matemático de localizar onde tem carga; Diferenças entre formas } \\
\text { diferencial e integral; Teorema de Gauss apresentado como verdade } \\
\text { matemática. }\end{array}$ \\
\hline $\begin{array}{l}\text { Ep. 8: Significado físico do } \\
\text { Rotacional } \\
\text { Aula } 24-10 \min 40 \mathrm{~s} \\
(1: 34: 40-1: 45: 20)\end{array}$ & $\begin{array}{l}\text { Rotacional como medida de circulação do campo; Analogia com } \\
\text { movimento de fluidos (liquidificador, tufão, rodamoinho; etc); } \\
\text { Interpretação do caráter vetorial do rotacional; Teorema de Stokes } \\
\text { apresentado como verdade matemática. }\end{array}$ \\
\hline $\begin{array}{l}\text { Ep. 9: Corrente elétrica e } \\
\text { densidade de corrente } \\
\text { Aula } 26-10 \text { min } 40 \mathrm{~s} \\
(16: 00-26: 40)\end{array}$ & $\begin{array}{l}\text { Representação matemática da noção de corrente elétrica; Diferenciação } \\
\text { entre corrente }(I) \text { e densidade de corrente }(\vec{\jmath}) \text {; Justificativas para a } \\
\text { utilização do formalismo vetorial para representar o movimento de } \\
\text { cargas de maneira mais precisa. }\end{array}$ \\
\hline $\begin{array}{l}\text { Ep. 10: Equação da } \\
\text { continuidade } \\
\text { Aula } 26-11 \min 20 \mathrm{~s} \\
(1: 36: 40-1: 48: 00)\end{array}$ & $\begin{array}{l}\text { Conservação da carga elétrica como um dos princípios fundamentais da } \\
\text { física; Representação matemática desta conservação pela equação da } \\
\text { continuidade; Abordagem múltipla: quase todas as categorias em um } \\
\text { curto espaço de tempo; Importância da estrutura formal de pensamento } \\
\text { para a física atual (teorema de Noether). }\end{array}$ \\
\hline $\begin{array}{l}\text { Ep. 11: Lei de Ampère } \\
\text { Aula } 31-21 \text { min } \\
(18: 20-39: 20)\end{array}$ & $\begin{array}{l}\text { Cuidadosa apresentação de convenções do formalismo da lei de } \\
\text { Ampère (orientação do caminho fechado, superfície matemática } \\
\text { apoiada no caminho, sentido da normal); Uso intenso de representações } \\
\text { visuais; Poderosa analogia com bolha de sabão; Interpretação do } \\
\text { teorema de Stokes e intuição do rotacional }\end{array}$ \\
\hline $\begin{array}{l}\text { Ep. 12: Lei de Faraday } \\
\text { Aula } 34-9 \text { min } 40 \mathrm{~s} \\
(28: 00-37: 40)\end{array}$ & $\begin{array}{l}\text { Analogia formal entre lei de Ampère e lei de Faraday: semelhança entre } \\
\text { fluxo do vetor densidade de corrente e fluxo de } \frac{\partial \vec{B}}{\partial t} \text {. Discussão sobre } \\
\text { diferenças entre } \frac{d}{d t} \emptyset_{\vec{B}} \text { e } \emptyset_{\frac{\partial \vec{B}}{\partial t}} \text {. Apresentação com caráter extremamente } \\
\text { abstrato, sem analogias materiais, situações concretas ou representações } \\
\text { visuais. }\end{array}$ \\
\hline $\begin{array}{l}\text { Ep. 13: Corrente de } \\
\text { deslocamento } \\
\text { Aula } 39-27 \text { min } 20 \mathrm{~s} \\
(18: 40-46: 00)\end{array}$ & $\begin{array}{l}\text { Padrão incomum; Corrente de deslocamento apresentada como termo } \\
\text { que conserta incoerência na lei de Ampère e mantém a validade da } \\
\text { equação da continuidade; Foco em discussões filosóficas: busca por } \\
\text { coerência, ideia de lei física, relação experimento-teoria, contexto da } \\
\text { descoberta; Interação professor-aluno }\end{array}$ \\
\hline
\end{tabular}

Quadro 8: Resumo dos episódios de explicações conceituais (1 a 13).

Seguimos agora para a análise de episódios nos quais problemas foram resolvidos. De fato, muitas pesquisas que investigaram as relações entre matemática e física em contextos de ensino o fizeram em situações de resolução de problemas (TUMINARO; REDISH, 2007; BING; REDISH, 2009; WALSH et al. 2007, entre outros). Naturalmente, essas situações 
fornecem excelentes oportunidades para se analisar as estratégias utilizadas por estudantes, bem como as principais dificuldades enfrentadas pelos mesmos, porém poucos trabalhos investigaram este tema sob a ótica do ensino. Problemas foram rotineiramente resolvidos pelo professor ao longo do curso. De maneira geral, notamos que os problemas não foram numerosos, porém levaram muito tempo para serem resolvidos. Isso mostra que os mesmos não são tidos como meras aplicações do conteúdo, mas sim, que desempenham um papel importante para a compreensão da teoria eletromagnética. Uma criteriosa seleção de problemas exemplares ${ }^{42}$ promove constantes discussões conceituais e evidencia a influência da experiência adquirida pelo professor na escolha dos mesmos. Os seis episódios seguintes referem-se a situações de resolução de problemas e ilustram a maneira como o professor conduziu este processo em suas aulas.

Episódio 14: Problema da placa carregada

Aula 6-Duração: 25 min (32:00-57:00)

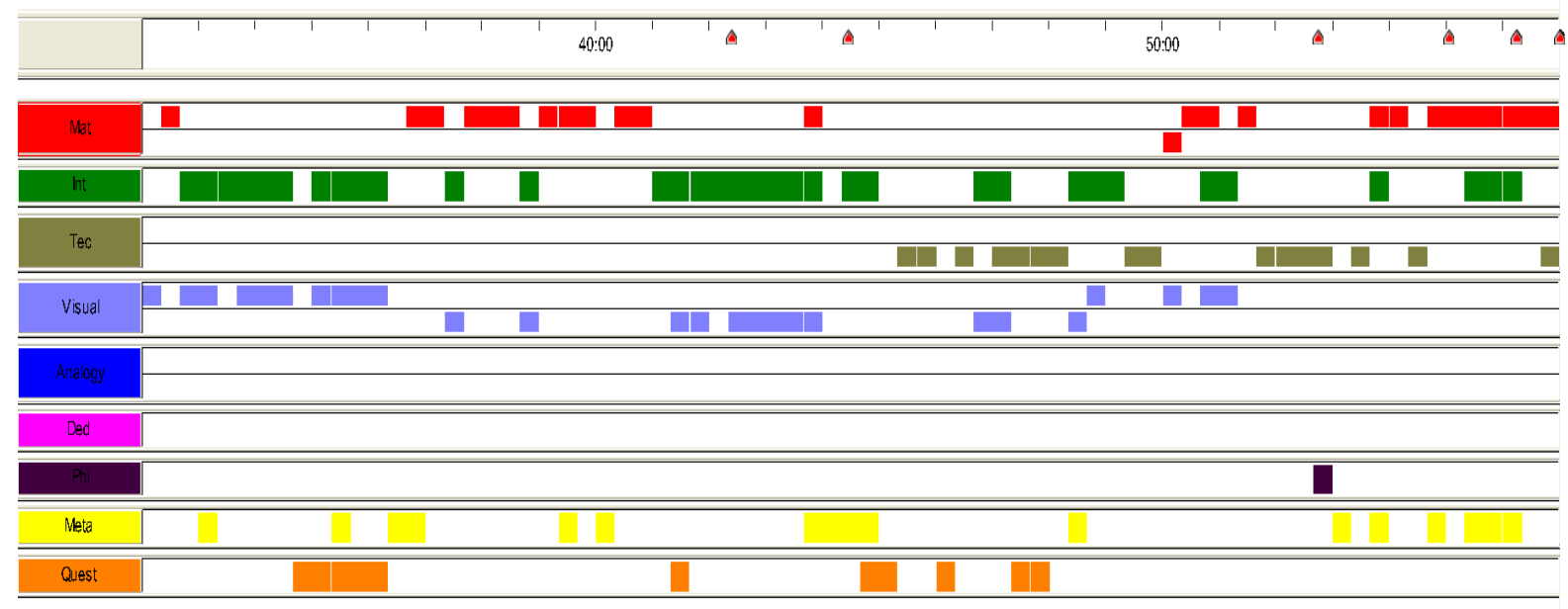

Figura 42: Diagrama Episódio 14 - Aula 6 - Problema da placa carregada

Enunciado do problema: Calcule a carga total de uma placa retangular de lados D (horizontal) e C (vertical) cuja densidade superficial de cargas é dada pela expressão $\sigma=(a x+b) y$.

Para resolver este problema de uma maneira puramente procedimental seriam necessários, no máximo, 5 minutos. O que faz então com que o professor gaste 25 minutos da aula com a resolução do mesmo? O diagrama nos fornece alguns indícios. Percebemos uma

\footnotetext{
${ }^{42}$ Segundo Kuhn ([1969] 2001), a resolução de problemas exemplares, bem como o estudo de suas soluções padronizadas, constituem uma atividade básica na educação dos membros de uma comunidade científica. Dessa forma, percebemos que tanto a escolha dos exemplares como a maneira como eles foram abordados no curso, estão em sintonia com a perspectiva kuhniana sobre o papel da resolução de problemas para a formação dos futuros licenciados e bacharéis (ZYLBERSTAJN, 1998).
} 
intensa presença da categoria interpretação (verde na Figura 42), que está associada ao significado físico da representação de densidades superficiais por funções do tipo $f=f(x, y)$ e das operações de integração para a obtenção da carga. Gestos e figuras são recursos intensamente utilizados para auxiliar a explicação. Notamos também que, em vários momentos, comentários de natureza metacognitiva (amarelo na Figura 42) são feitos com o objetivo de incentivar a reflexão sobre processos cognitivos durante a resolução. Além disso, trechos de matematização e cálculos procedimentais (técnica) também são identificados.

O problema é proposto da seguinte forma:

32:00-34:00 Imagina que você tenha uma placa de carga retangular carregada assim (desenha) e ela está carregada com essa função aqui $\sigma=a x+b$. Se você tiver que fazer um desenho da carga contida nessa placa, como ele seria? Uma possibilidade é colocar a densidade de pontos. Então, aqui a carga é mais fraca (pinta o retângulo). À medida que você vai andando a carga vai ficando mais concentrada, só nessa direção assim (traços mais fortes mais distantes da origem). Isso daqui é muito importante, você olhar essa função e saber o que a função representa na natureza. Por exemplo uma outra possibilidade de sigma, seria você ter uma coisa assim: $\sigma=(a x+b) y$. Que cara que tem a distribuição de cargas dada por essa função? Então ela varia em 2 direções (desenha), ela é fraquinha aqui e cresce nessa direção (vertical). E aí ela fica forte para o lado de cá também. Aqui ela é bem forte (pinta) Ela cresce pra cá (direita) e cresce para lá (cima). Cada função que você der representa um distribuição particular de cargas.

A pergunta de um aluno indica que o significado de uma função densidade não depender de y ainda não está claro, o que motiva uma explicação mais detalhada.

34:40 - 36:20 A: Ali na primeira, a dimensão em y não tem, né?

P: Pessoal não tem dimensão de y, o que significa isso?

A: Significa que ela tem um crescimento linear.

[...] Vamos lá pessoal, a pergunta dele, independer de y aqui significa o que? Por exemplo, você pega uma fita (vertical) assim. A fita é branca, porque é a matemática que está cortando. Se você pegar essa fita e corta em pedaços assim. Todos eles de mesmo tamanho aqui (desenha retângulos na mesma fita vertical). Pergunta: onde que tem mais carga, aqui (pedaço inferior da fita) ou aqui (pedaço superior da fita)?

A: Igual

P: Igual, então é isso que está sendo dito. Agora se você comparar esse (fita vertical da esquerda) com esse (da direita) aqui (direita) tem mais. E aqui continua igual a esse (mesma fita vertical). Enquanto que, nesse outro caso $(\sigma=(a x+b) y)$ (desenhas fitas verticais $e$ horizontais). Nesse quadrado (baixo) aqui tem mais do que esse (cima). Estou pegando áreas iguais para facilitar a vida. Então aumenta para cá (cima) e para cá também (direita), ok?

Em seguida o elemento de carga é escrito como $d^{2} q=\sigma d x d y$ e a carga total é representada pela integral definida pelas dimensões do retângulo $\int_{0}^{D} d x \int_{0}^{C} d y \cdot \sigma$, utilizando uma notação um pouco diferente da comumente usada nos cursos de cálculo. Após essa etapa 
de matematização, o foco é novamente direcionado para a interpretação do significado de realizar cada uma das integrações através de gestos com uma folha de papel:

42:00 - 44:20 Então isso significa a seguinte coisa (pega uma folha de papel). Que integrar em y. Você tem todas as cargas contidas aqui (gestos verticais na folha). Isso é equivalente a fazer isso ó (dobrando a folha, transforma-a numa barra horizontal). Ok isso? E aí, se eu integrei em y, sumiu a dimensão y. E o que está aqui na frente é uma barra, ok? E o que significa integrar em $x$ depois disso? É fazer isso daqui assim ó (amassa a barra transformando-a em uma bola de papel). Tudo bem? [...] Ai a alternativa é que eu posso primeiro somar a vertical. Você pega isso daqui (folha) que é uma coisa que tem duas dimensões e você vai lá e integra assim (dobra a folha transformando-a em uma barra vertical). E dai dá uma barra vertical. Que nesse caso seria escrever essa conta assim (integral invertendo a ordem de dx e dy). Então na hora que você integrar assim dá a mesma coisa. Então é uma questão de gosto ou de estratégia matemática que for mais fácil.

O cálculo integral é essencial para praticamente todos os ramos da física. Muitas vezes, a resolução de um problema implica em saber quais técnicas de integração são aplicadas a uma função em particular. Isso faz com que estudantes reflitam menos sobre o que os cálculos representam fisicamente e mais sobre como resolver as integrais (técnica). Neste trecho, vemos que a maior importância é dada à intepretação do significado da operação de integração, o que é feito de maneira muito original e concreta. Dizer que integrar em $\mathrm{x}$ depois de ter integrado em y é amassar uma folha de papel primeiramente na forma de uma barra e depois de uma bola, faz com que as operações ganhem sentido. A postura do professor evidencia uma ênfase no papel estruturante da matemática na física.

Porém, isso não significa que a parte operacional da matemática não seja abordada. Conforme observamos no diagrama (Figura 42) a categoria técnica aparece e representa momentos em que a "manivela foi girada", ou seja, que a integral foi calculada de maneira procedimental. É interessante notar como a postura do professor muda durante essa abordagem, pois o mesmo normalmente faz os cálculos de costas para a turma e de maneira displicente.

Uma pequena alteração no problema mostra como explorar as potencialidades do mesmo e propicia uma discussão profunda sobre representações matemáticas e significados físicos. Tal alteração consiste em supor que a placa seja triangular (mantém-se as bases do retângulo e constrói-se um triângulo traçando sua diagonal). $\mathrm{O}$ professor insiste em questionar os estudantes sobre "como a informação da forma do corpo entrou na conta" e em alguns trechos fica difícil separar a matematização da interpretação:

50:00 - 50:20 O que muda na conta se eu tiver meio corpo aqui agora? Ou seja, a pergunta é: Onde, nessa conta aqui, vai entrar a informação que o corpo é um triângulo e não é um retângulo? 
53:40 - 56:00 Onde a informação sobre a forma do corpo entra? Ela vai entrar no seguinte lugar: antes eu pegava essa variável aqui (y) e integrava de zero a C. Por que? Porque o corpo era assim e eu queria ir daqui até lá e tudo bem. Pra cada ponto era a mesma distância Y que eu andava. Agora não. Agora eu vou tirar isso daqui (tira o limite superior) $e$ colocar aqui Y máximo, dado por aquela função (reta de $C$ até D). Feito isso, esse negócio aqui (limite superior) some vira $Y$ máximo. Então você tem uma função de $X$ que é diferente. $O$ que a gente tem que prestar atenção? A forma do objeto entra no extremo da integração. Pessoal, a carga total da placa inteira e meia placa é diferente? Por que ela e diferente? Como é que a conta sabe disso? É essa a nossa questão. Gente, a conta tem que ser informada do que você está fazendo. Então em cada ponto, você tem que pegar e jogar a informação lá dentro. Cada informação entra em um lugar. A informação da densidade entra aqui embaixo. A informação da forma entra lá em cima (limites de integração).

Parece-nos que um dos grandes diferenciais deste professor é o tipo de perguntas feitas por ele e isso fica exemplificado neste trecho. Uma interessante possibilidade que surge é investigar como o mesmo problema seria resolvido por outros professores e comparar seus enfoques e abordagens. Assim, poderíamos definir critérios objetivos que justificariam por que uma determinada aula é melhor do que outra, pelo menos no que diz respeito à abordagem das relações entre matemática e física. Vamos explorar estas e outras possibilidades de desdobramento de nossa pesquisa no Capítulo 7.

Episódio 15: Problema do campo de duas cargas pontuais Aula 9-Duração: $48 \min$ (16:20-1:04:20)

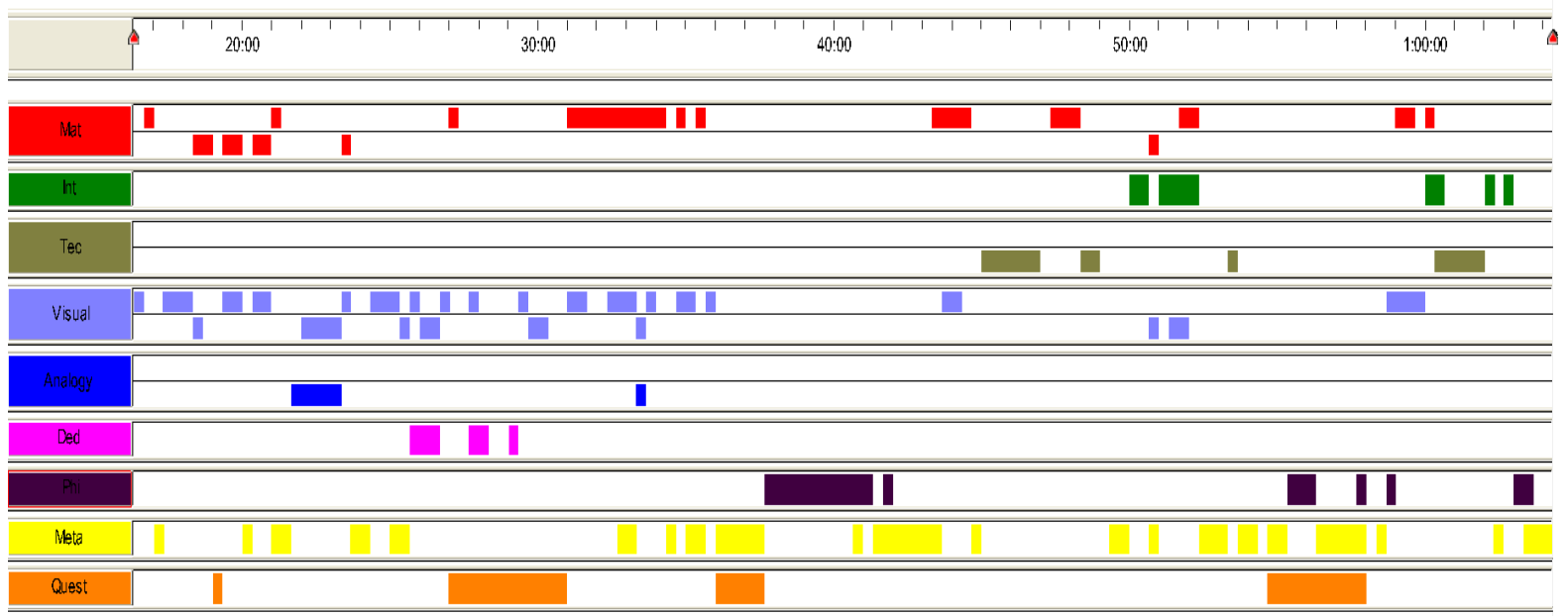

Figura 43: Diagrama Episódio 15 - Aula 9 - Problema do campo de duas cargas pontuais

Enunciado do problema: Calcule o campo elétrico criado por duas cargas puntiformes $+q$ e - $q$ separadas por uma distância $d$.

Assim como no episódio anterior, se este problema fosse resolvido com objetivo de aplicar a lei de Coulomb, não levaria mais de 10 minutos. Entretanto, trata-se do problema 
que levou mais tempo para ser resolvido em todo o curso. Durante os 48 minutos deste episódio, todas as categorias de análise são identificadas, conforme pode ser visto na Figura 43, mostrando uma abordagem extremamente variada e configurando-se como um interessante exemplar para evidenciar as múltiplas facetas da relação entre física e matemática. Em especial, chama-nos atenção a quantidade de comentários de natureza metacognitiva e epistemológica (amarelo e roxo, respectivamente, na Figura 43). A interação com os alunos também é intensa (laranja na mesma figura) e as representações visuais desempenham um papel essencial na apresentação do problema. Após a manipulação algébrica (técnica) a discussão se volta para a interpretação física do resultado obtido através da análise de diversos casos particulares.

O início da resolução é dedicado a uma discussão conceitual sobre o princípio da superposição e à representação matemática dos vetores essenciais para a resolução do problema. Para diferenciar o campo criado por cada uma das cargas, o professor utiliza um "código de cores": o campo da carga $+q$ é desenhado em amarelo, o da carga $-q$ em laranja e o campo resultante em verde, o que faz com que a explicação seja muito visual. Ao mencionar a importância deste exemplar para a sequência do curso, o professor discute como a energia potencial depende da configuração do sistema e está localizada no campo. Nesse momento, uma analogia (azul escuro) com a energia potencial gravitacional do sistema Terraapagador é abordada.

Muitos aspectos merecem destaque neste episódio, mas devido a sua extensão, vamos nos concentrar nos principais. Uma longa discussão epistemológica é conduzida no meio do episódio. Esta discussão é motivada pela pergunta de um aluno e o professor percebe um momento propício para abordar de maneira explícita a importância de dar significado ao formalismo matemático. A pergunta surge quando o professor insiste que é essencial representar geometricamente cada um dos vetores envolvidos $\left(\vec{r}_{p}\right.$ - posição do ponto genérico, $\vec{r}_{q}$ vermelho e azul - posição de cada uma das cargas) e entender o que cada um deles representa no problema. Nesse instante, um aluno sugere outra abordagem:

36:00-37:00 A: Não é mais fácil jogar tudo na equação e depois se preocupar com a geometria do problema?

$P$ : Como é que você vai jogar tudo na equação sem saber o que é $\vec{r}_{p}$ e $\vec{r}_{q}$ ?

A: Trabalha como vetor, simbólico.

P: Mas ele simboliza o que?

A: Não posso colocar $\vec{r}_{p}$ menos $\vec{r}_{q}$ sobre...isso menos...

P: Pode, mas se você não fizer esse desenho você não sabe do que está falando. E esse é o problema. $\vec{r}_{q}$ é $\vec{r}_{q}$ mas você não consegue saber o que é $\vec{r}_{q}$. O seu formalismo não está costurado no problema. 
A sugestão do aluno ilustra uma postura comumente encontrada em pesquisas que investigam como os estudantes resolvem problemas de física (TUMINARO; REDISH, 2007). A interpretação do significado físico é deixada de lado e rapidamente os cálculos envolvendo as variáveis e as fórmulas conhecidas começam a ser manipulados. Resolver um problema passa a ser um jogo abstrato que objetiva calcular a variável desconhecida a partir da aplicação de fórmulas que contêm os dados fornecidos pelo problema. Cabe-nos questionar: por que os estudantes utilizam essa estratégia tão frequentemente? É bastante razoável concluir que os mesmos estão acostumados a fazer isso também porque seus professores, ao resolverem problemas, procedem dessa forma. Por esse motivo, o professor resolve interromper a resolução do problema para discutir de maneira muito profunda sobre a maneira como a física lida com a relação entre os símbolos e seus significados. Apesar da extensão do trecho a seguir, optamos por transcrevê-lo porque o mesmo exemplifica a abordagem das categorias epistemologia e metacognição, e evidencia o esforço do professor em ressaltar para o estudante (e para toda a classe) que sua sugestão revela uma postura que deve ser evitada.

37:00 - 42:20 Seguinte: NEM BRINCA COM ISSO! "Ele falou mas eu vou fazer do meu jeito..." Isso é sério! Por que você não consegue levar o problema adiante desse jeito. Sem entender o que... CALMA! (Anda para outro lugar da sala) (Sai da discussão do problema) Pessoal, fisica é duro. Por que física é duro? Um dos motivos é a presença da matemática na física. Qual é o problema da matemática? Ela é extremamente eficiente e útil, mas ela só ganha sentido se a gente costurar o símbolo em alguma coisa. Tudo bem isso? O que é costurar o símbolo? (Desenha um símbolo desconhecido no quadro)

Se eu disser que a coisa que isso daqui simboliza é uma das piores coisa que já aconteceram na história da humanidade, qual é a sua reação para isso? Eu diria provavelmente não é reação nenhuma. Agora se eu chegar para você e falar que isso aqui (desenha uma cruz) é uma das piores coisas que aconteceram na história da humanidade (risos). Você pode ter uma reação dentro de você. O que diferencia para você, isso disso? É que isso (cruz) é um símbolo com significado. Isso (outro) é um símbolo sem significado. Isso é o nome da China em chinês. (risos) Se tiver um chinês na sala, isso é ofensivo. Se você não for e não souber chinês você não entende. A mensagem é: o significado dos símbolos não está no desenho. Culturalmente nós aprendemos a costurar um significado nisso daqui (cruz).

E aí isso representa uma coisa para você e isso não representa. Mas não é um problema do desenho, sim da inserção cultural do desenho. $O$ que estou fazendo no curso de Eletromagnetismo, estou fazendo a inserção cultural do símbolo, tudo bem? Aqui aparece $E$, não escrevo uma letra a cada dia para cá, sempre escrevo a mesma. Até podia... Hoje decidi chamar isso de X. Você nunca ia aprender Eletromagnetismo desse jeito. Então o que estou fazendo, é o que a gente trabalha em física, estou fazendo a inserção cultural do símbolo. Esse símbolo simboliza o que? Aí vou lá e desenho a áurea, faço a conta e a gente tem que aprender a costurar o símbolo na realidade. Ou seja, esse E simboliza o que? Tudo bem isso? E ai entra a questão dele (volta para a posição do problema). Se você começar a fazer a conta sem entender o que o símbolo representa, a sua conta não tem significado. Sim? Por isso que eu tenho que entender qual é o significado do símbolo. $r$ pode designar 
qualquer coisa que eu quiser, mas eu resolvi chamar de $r$ o vetor posição, convencionalmente. A física é econômica nisso, a gente procura usar todo mundo a mesma linguagem para não criar bagunça desnecessária. Então isso cola o símbolo num significado. E na hora que eu escrever $r$ lá eu estou pensando nisso. Tudo bem? Essa coisa de entender o significado do símbolo é absolutamente importante. Se não você corre o risco de fazer uma conta e não entender que conta você fez.

Não é possível saber se todo o discurso do professor surtiu o efeito desejado. Durante o "sermão", o aluno poderia estar "fingindo" que concordava enquanto pensava: "depois eu faço do meu jeito". Porém, qual seria então a melhor reação de um professor nesse momento? Deixar que o aluno acredite que sua estratégia é eficaz?

Muito do que diz respeito à utilização da matemática como estrutura de pensamento para os fenômenos da física não é intuitivo, não é "construído pelo estudante" e, portanto, precisa ser ensinado. Dessa forma, essa manifestação clara e explícita sobre como proceder para "costurar o símbolo" nos parece ser a postura mais desejável.

Outro aspecto extremamente enfatizado neste episódio é a importância da interpretação física da expressão matemática obtida no final da resolução de um problema. Se, para muitos, o problema chegou ao fim e basta desenhar um retângulo envolvendo a expressão final, o professor reforça que ainda há muito a ser aprendido quando analisamos o que as expressões representam fisicamente:

49:20 - 50:40 O que é importante pra gente... Isso é uma coisa que é muito importante quando você estuda física. Seguinte: o livro faz uma conta e tem uma expressão. Como é que a gente pode olhar essa expressão quando você lê um livro de fisica que tem um monte de matemática lá? A primeira leitura que é útil fazer é a seguinte: como é que as informações do problema entraram na expressão do resultado? Isso que a gente tem que seguir. Por que que o campo amarelo depende das variáveis brancas? Você entende isso? As variáveis brancas estão aqui, são as variáveis do ponto. Por que ele depende? Porque a influência dessa carga sobre esse ponto depende da localização do ponto.

Uma estratégia bastante profícua para a interpretação física de expressões matemáticas é analisar casos limites e particulares, como notamos no discurso que segue:

50:40 - 53:00 Aí brinca um pouco, por exemplo. Imagina que você esteja numa altura que é $d / 2$. O que você espera? Não olha a conta! O que você espera do ponto de vista físico? Se a carga estiver na mesma altura do z aqui. Eu estou perguntando o seguinte. (representa a situação com gestos). Aquela carga vermelha está aqui (apagador na mão direita) e o ponto $P$ antes estava em qualquer lugar (mão esquerda no ar). Agora imagina que sua conta, para testar se ela está razoável, imagina que você ponha o ponto $P$ aqui (alinha na vertical a mão esquerda com a direita). O que você espera? Um campo horizontal? Isso dá? Então funciona. Tudo bem? (aponta para a expressão do resultado) É um teste que você faz. Em geral é duro você esperar alguma coisa, mas em certas situações particulares é fácil você esperar o que vai acontecer. Imagina que você tenha posto a carga, não só na horizontal, mas aqui em cima do eixo y (gesticula a situação). O que você espera? Que o campo aponte 
na direção y, tudo bem? Pessoal, verdade? Matematicamente, como é que você coloca o ponto P em cima do eixo $y$ ? Fala $x=0$ (aponta para a expressão). Se você tiver no $z=d / 2$ vai sobrar apenas essa componente. Então você vê que sua conta funciona. [...] Se isso daqui não funcionar, você cometeu algum erro. Ela funcionou em casos particulares, tem que funcionar em casos gerais. Mas se isso daqui não funcionou, é um indício, é um sinal vermelho piscando lá: tem um erro! Vai buscar que você esqueceu alguma coisa lá.

Muitas mensagens sobre como proceder para ter sucesso na resolução de um problema de física são proferidas neste episódio. Se os alunos as aprenderão, dependerá muito da dedicação dos mesmos quando enfrentarem os problemas sozinhos. Para Polya (1945), aprender a resolver problemas é semelhante a praticar um esporte como natação: é preciso treinar. Entretanto, saber teoricamente quais técnicas de braçadas otimizam o esforço muscular e levam a um melhor desempenho é fundamental. Assim, os comentários sobre as heurísticas deste professor têm o objetivo de orientar os estudantes nesse sentido.

Vivenciar a situação é certamente essencial. Prova disso, é que o mesmo aluno que fez a sugestão de trabalhar simbolicamente sem interpretar o significado dos vetores faz um comentário no final do episódio, revelando que o mesmo estava tentando verificar se conseguiria resolver o problema seguindo sua estratégia:

54:40 - 58:00 A: Eu tentei escrever aquilo lá... Falei, vou fazer o errado agora. E dá uma loucura mesmo!

P: Obrigado (risos)

A: Verdade. Tem que saber muito de Álgebra Linear para sair disso. A coisa toda então é escolher o sistema de coordenadas e como montar esse problema é mais importante que a conta?

$P: E$ Éa importante quanto. [...] Você tem que ter o domínio total sobre tudo que você faz. Você tem que entender o que é cada símbolo que você usa. [...] Essa história da você entender o que o símbolo representa é a coisa mais importante. O jogo da física é esse. $\boldsymbol{E}$ jogar os símbolos na natureza, tirar os símbolos e extrair a natureza de volta.

Enquanto o estudante propôs uma abordagem que reflete uma visão meramente instrumental da matemática para resolver o problema, o professor faz questão de apontar inúmeros aspectos que caracterizam o papel estruturante que o pensamento matemático desempenha na física. 
Episódio 16: Problema do fluxo através do disco

Aula 12 - Duração: 34 min 40 s (1:08:00-1:42:40)

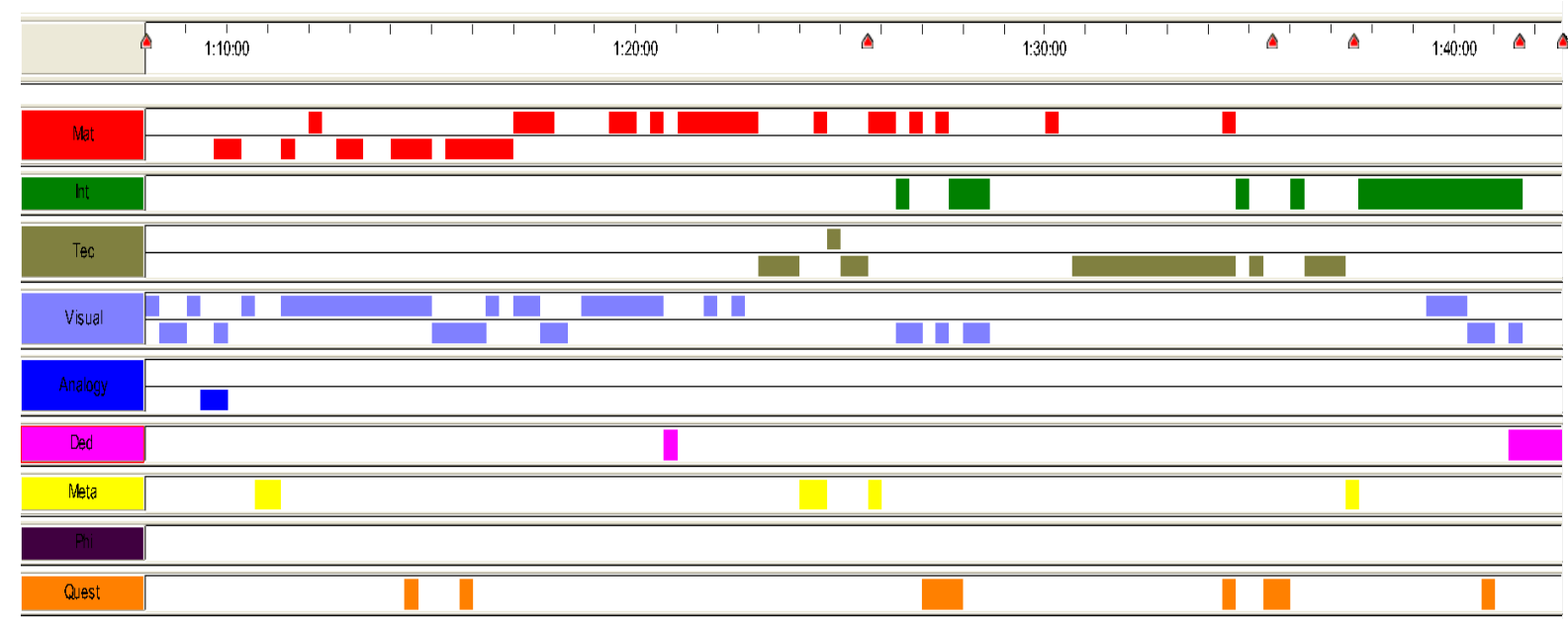

Figura 44: Diagrama Episódio 16 - Aula 12 - Problema do fluxo através do disco

Enunciado do problema: Calcule o fluxo do vetor campo elétrico criado uma carga puntiforme e positiva $q$, situada na origem do sistema de coordenadas, sobre uma superfície circular de raio $a$, paralela ao plano $x y$, cujo centro está sobre o eixo $z$ e dista $h$ da origem.

Este problema foi cuidadosamente selecionado para fazer a transição entre o cálculo do fluxo do campo elétrico através de uma superfície e a interpretação da lei de Gauss elétrica. A compreensão das etapas de sua resolução demanda uma explicação minuciosa das variáveis envolvidas, a qual pertence à primeira metade do episódio (matematização) e é conduzida com muitos gestos e representações pictóricas, como pode ser visto na Figura 44. No último terço do diagrama, percebemos um longo período de manipulações algébricas (técnica) realizadas para a obtenção da expressão matemática representa o fluxo. Porém, é nos momentos finais, quando tal expressão é interpretada (verde na Figura 44), que se localiza a principal mensagem a ser desvendada pela análise da relação entre as variáveis presentes no resultado.

A situação é bastante complexa, uma vez que o fluxo em um elemento de superfície depende do ponto considerado e o campo elétrico também varia de acordo com o ponto. Assim, é preciso considerar não somente a distância do ponto à carga como a inclinação do vetor campo elétrico. Além disso, devido à geometria do problema, o sistema de coordenadas mais apropriado é o cilíndrico. Estes e outros aspectos relativos ao tratamento matemático do problema são esclarecidos nos instantes iniciais:

01:14:00 - 01:14:40 Pergunta: qual é o tamanho dessa flecha comparado com o tamanho dessa flecha? (compara ponto sobre o eixo z com outro mais afastado). Menor, maior ou igual? [...] Menor. Por que? Porque está mais longe. Esse daqui está a essa distancia e esse 
daqui a essa. Então a flecha cai aqui e ela vai crescendo aqui e vai ficando menor aqui na ponta.

01:15:40 - 01:16:40 Pega um elemento da superfície aqui (no eixo z) e um aqui (afastado), qual deles tem maior fluxo? [...]

A: O primeiro

P: Por que?

A: Ele está mais perto da carga.

P: Por dois motivos. Primeiro porque nesse ponto aqui (próximo) a flecha é maior (gestos). Segundo que nesse ponto aqui a projeção da flecha sobre a normal é máxima. Tudo bem? Quando eu venho para cá (afasta-se do centro) o campo fica torto assim (gestos). Além de ficar menor. E o que interessa para calcular o fluxo é a projeção do campo sobre a normal. Então, na verdade, nesse ponto aqui, apenas essa componente vertical que contribui para o fluxo, ok?

01:16:40 - 01:18:20 Então a gente está numa situação que é um pouco diferente do ponto de vista matemático da situação anterior, porque em cada dS que você pegar o fluxo muda, sim? [...] Como é que você faz a conta, a gente pega um dS aqui, a gente vai cortar isso em coordenadas cilíndricas que é a linguagem boa para isso, esse negócio aqui (desenha) é o dS e essa flechinha aqui verde é a normal, tudo bem? Nessa superfície, todas as normais são paralelas, então eu estou falando o seguinte. Se o dS é isso e nesse ponto a normal é isso, se eu vier para cá (gestos com a apostila mudando de posição) também a normal é isso. Se eu tivesse uma esfera (gira a apostila com um giz apontando na direção normal) isso não seria verdade a normal anda junto com o dS, mas aqui a normal é uma só.

Um bom tempo é dedicado à análise de variáveis relevantes, representação das grandezas físicas através de estruturas matemáticas e justificativas para o uso das mesmas em cada situação particular. Isso demonstra que a matematização é um processo difícil que demanda muito tempo e explicações claras. Naturalmente, o "girar a manivela" também faz parte da resolução do problema conforme representado no diagrama. Resumimos o desenvolvimento dos cálculos até o resultado final a seguir:

$$
\begin{gathered}
\overrightarrow{\mathrm{E}}_{\mathrm{P}}=\frac{\mathrm{q}}{4 \pi \varepsilon_{0}} \frac{\left(\overrightarrow{\mathrm{r}}_{\mathrm{P}}-\overrightarrow{\mathrm{r}}_{\mathrm{q}}\right)}{\left|\overrightarrow{\mathrm{r}}_{\mathrm{P}}-\overrightarrow{\mathrm{r}}_{\mathrm{q}}\right|^{3}} \operatorname{com} \vec{r}_{q}=0 \mathrm{e} \vec{r}_{P}=r \cos \theta \hat{\imath}+r \operatorname{sen} \theta \hat{\jmath}+h \hat{k} \\
\mathrm{~d}^{2} \Phi_{\overrightarrow{\mathrm{E}}}=\overrightarrow{\mathrm{E}} \cdot \hat{\mathrm{n}} \mathrm{d} S=\left[\frac{\mathrm{q}}{4 \pi \varepsilon_{0}} \frac{\mathrm{rcos} \theta \hat{\imath}+\mathrm{rsen} \theta \hat{\jmath}+\mathrm{h} \hat{\mathrm{k}}}{\left(\mathrm{r}^{2}+\mathrm{h}^{2}\right)^{3 / 2}}\right] \cdot[\mathrm{rdrd} \theta \hat{\mathrm{k}}]=\frac{\mathrm{q}}{4 \pi \varepsilon_{0}} \frac{\mathrm{rhdrd} \theta}{\left(\mathrm{r}^{2}+\mathrm{h}^{2}\right)^{3 / 2}} \\
\Phi_{\overrightarrow{\mathrm{E}}}=\int_{0}^{\mathrm{a}} \mathrm{dr} \int_{0}^{2 \pi} \mathrm{d} \theta \frac{\mathrm{q}}{4 \pi \varepsilon_{0}} \frac{\mathrm{rhdrd} \theta}{\left(\mathrm{r}^{2}+\mathrm{h}^{2}\right)^{3 / 2}}=\frac{q}{2 \varepsilon_{0}}\left[1-\frac{1}{\sqrt{1+a^{2} / h^{2}}}\right]
\end{gathered}
$$

Logo depois das manipulações algébricas, feitas de maneira rápida e displicente, o professor faz questão de chamar a atenção dos estudantes para a discussão que sucede: 
01:36:00 - 01:36:20 Isso daqui é a conta, agora qual é a interpretação da conta, que é MUITO mais legal.

01:37:20 - 01:38:40 Agora o seguinte: Não pensa que você vai almoçar daqui a pouco, não pensa que você está com pressa,... Seguinte: deixa o seu coração puro (risos) Porque sem brincadeira, esse resultado aqui ele contém uma chave dos grandes mistérios da natureza. E para entender isso dai você tem que pensar a seguinte coisa: [...] qual é o significado da resposta depender apenas de $a^{2} / h^{2}$ ? Isso significa o que? Tudo bem, depende e tal. Mas isso daqui é o dedo que tá apontando para que realidade mais interessante?

E é neste momento que o vínculo com a lei de Gauss, objetivo principal da resolução do problema, é abordado:

01:38:40 - 01:41:40 Imagina a seguinte coisa. Se você pegar o disco e dobra; põe um disco maior. O fluxo aumenta?[...] Dobra o raio do disco, o raio do disco o que é a, o fluxo aumenta. Se você dobrar a distância e ao mesmo tempo dobrar o raio do disco, o que acontece? Nada! Tudo bem? Qual é o significado disso? Significado é o seguinte, se você pegar (desenha). Olhando de novo aqui, y e z. Você pega um disco aqui, com essa distancia. Ai você dobra a distancia e dobra o tamanho do disco. Ou seja você pega uma outra situação que é essa situação verde aqui o fluxo é o mesmo, sim? Então na verdade o fluxo depende do que? Ele depende do seguinte: se você desenhar um cone assim. Qualquer disco apoiado no interior do cone tem o mesmo fluxo, tudo bem isso?

Pergunta: do ponto de vista físico por que essa coisa aconteceu assim? Eu estou aqui (gestos com os braços) eu vou mais longe aumenta o disco, vou mais longe aumenta o disco, o fluxo é constante. Por que isso acontece? De que jeito que cresce a área do disco quando você faz isso (gestos aumentando a distancia). Quadrático? E por que o negócio é constante?

A: Porque a densidade do campo também cai com o quadrado.

P: Porque a densidade do campo cai ao quadrado? Sim

Então, a conta aconteceu isso porque na hora que eu fiz a conta eu usei essa expressão aqui (Coulomb) e nessa expressão o campo cai com o quadrado, sim? E aí o que está acontecendo é o seguinte: o campo cai com o quadrado, a superficie cai com o quadrado. O campo fica mais fraco, mas a superfície é maior. $\boldsymbol{E}$ de certa forma o produto da superfície vezes o campo é igual.

Dessa forma, a constância do fluxo emerge como uma interpretação da expressão matemática do resultado final. Na sequência, o professor reflete sobre a hierarquia das afirmações evidenciando o caráter lógico dedutivo (rosa) da estruturação teórica da física:

01:42:00 - 01:42:40 Pessoal, qual é a ideia da lei de Gauss? A ideia é inverter a ordem lógica dessas duas afirmações. E ela eleva essa constância do fluxo a uma verdade maior do que aquela lá (Coulomb). Tudo bem? Isso que é a coisa importante. Então agora tem uma inversão de valores. A gente começou acreditando nisso (Coulomb) porque é uma verdade empírica. Mas agora eu chego lá e falo que a constância do fluxo ocorreu. Coincidência, tudo bem. Mas dai você vai lá e olha. O que a física fez foi falar assim: ISSO daqui é mais importante. E se eu falar que isso daqui é mais importante, o que eu aprendo? Eu sei agora POR QUE o campo cai com $1 / r^{2}$. 
Podemos dizer que ciência (física em particular) é uma maneira que encontramos de fornecer explicações para os fenômenos. Explicar está associado à ideia de responder a indagações causais: “Por quê?”. Neste trecho, o professor ressalta o caráter lógico-dedutivo da estruturação teórica da física com propriedade, passando uma importante mensagem a seus estudantes sobre como esta ciência funciona e ilustrando uma das principais razões para seu caráter intrinsicamente matemático. Segundo Rivadulla (2005, p. 169), "um construto físico recebe uma explicação teórica quando pode ser deduzido matematicamente a partir de um construto mais geral". Para este caso específico, o professor demonstra que a lei de Coulomb pode ser deduzida matematicamente a partir de um construto mais geral (a lei de Gauss). Novamente, notamos como a argumentação sobre relações entre física e matemática é mais profícua quando analisamos casos específicos, em vez de argumentarmos de maneira geral.

Episódio 17: Problema do campo do fio infinito e síntese três casos Aula 15 - Duração: 9 min 20 s (1:28:00-1:37:20)

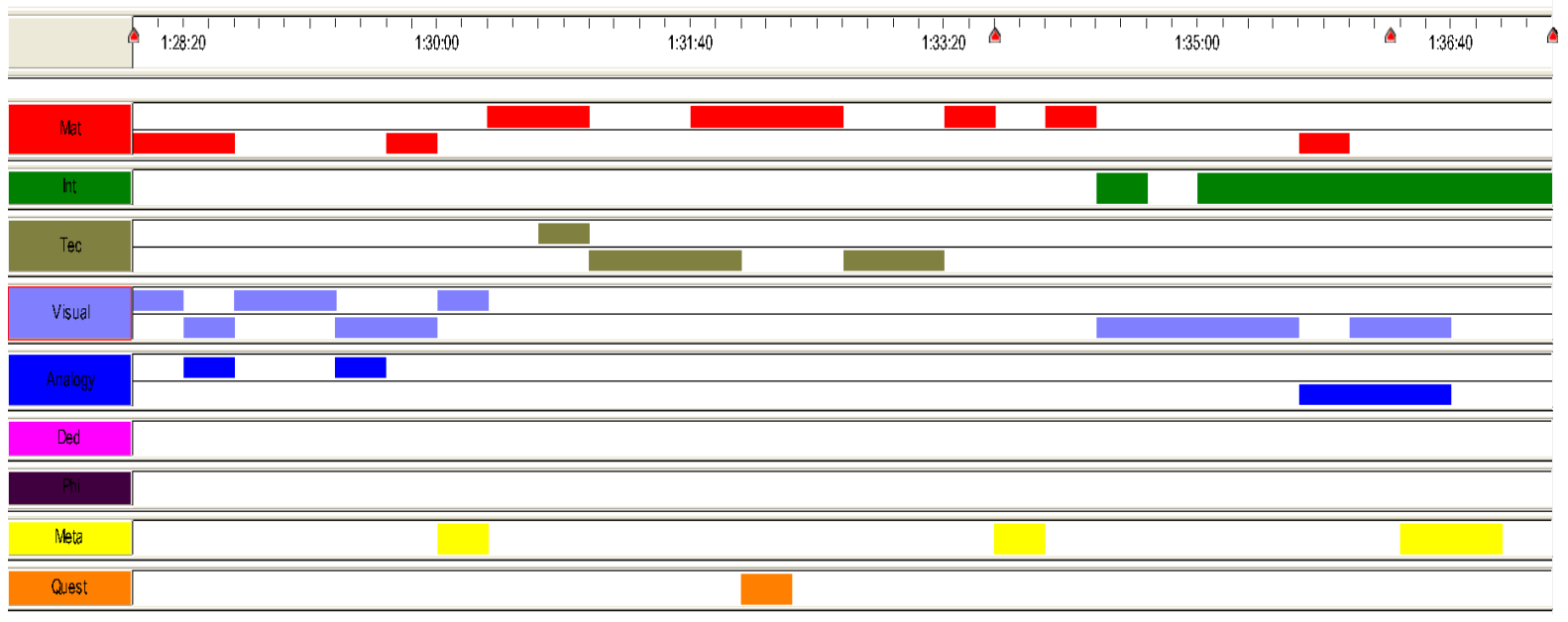

Figura 45: Diagrama Episódio 17 - Aula 15 - Problema do campo do fio infinito e síntese dos três casos

Enunciado do problema: Calcule, usando a lei de Gauss, o campo elétrico criado por todo o espaço por um fio infinito, carregado com densidade linear de carga $\lambda$, positiva e uniforme.

As Aulas 14 e 15 são destinadas à resolução de problemas (exemplares) de aplicação da lei de Gauss. Uma dificuldade inerente a esta classe de problemas é perceber se a situação possui simetria suficiente para que possa ser resolvida com a lei de Gauss, ou seja, para que o campo elétrico possa "ser retirado da integral". Em cada exemplo resolvido, o professor faz questão de explicitar os motivos pelos quais isso é possível e menciona outros casos em que, apesar de válida, a lei de Gauss não é adequada para a determinação do campo elétrico. Neste décimo sétimo episódio, o problema do campo elétrico criado por um fio infinito carregado é 
resolvido e, no início da resolução, o problema anterior (plano infinito) é mencionado para ressaltar semelhanças e diferenças formais (A2):

01:28:20 - 01:29:00 Pelo mesmo motivo de antes (plano infinito), se não for infinito eu não sei a direção do campo. Pergunta: que cara tem a direção do campo num fio de cabelo infinito carregado uniformemente? Fica um campo assim (gestos indicando direção radial) tudo bem? A diferença do plano é que do plano é sempre assim (gestos indicando linhas paralelas). O fio ele vai fazer assim (gestos). Ou seja, se eu olhar o fio de lado. Eu vejo isso (desenha linhas radiais) se eu olhar daqui. Pessoal, seguinte, você fica até o final da aula que você vai ter um barato daqui a pouco.

Assim, percebemos porque os minutos iniciais do episódio são classificados como analogias formais (A2) e representações visuais (V1 e V2) na Figura 45. Além disso, uma justificativa para a necessidade de se considerar a idealização do fio infinito também é oferecida com base na argumentação anterior. No final deste trecho o professor anuncia que “o melhor está por vir", que consiste em uma síntese dos três casos (ponto, fio e plano), a qual revela uma profunda intepretação (representada em verde na referida figura) sobre a relação entre a lei de Gauss e as dimensões do espaço.

01:33:40 - 01:35:40 Ok! O que a gente aprendeu usando lei de Gauss pra três situações? Se eu pego uma carga puntiforme, como é que cai o campo de uma carga puntiforme com a distância (escreve $\left.1 / r^{2}\right)$ ? Como é que cai a do fio infinito ( $\left.1 / r\right)$. Como é que cai do plano infinito $\left(1 / r^{0}\right)$. Tudo bem? Qual a imagem da natureza que a gente pode ter a respeito desse negócio aqui? Se você pegar um plano infinito. Por que que o plano não cai com a distância? Porque não tem noção de distância a um plano infinito. Essa coisa não existe. Se você pegar o plano infinito que é essa coisa aqui e fizer assim "prrrrrr"... comprimir o plano nessa direção aqui ... como um fio ... o que acontece? Em uma dimensão você não tem noção de distância na outra você tem. E aí então o campo cai com $1 / r$, ou seja, de certa forma a lei de Gauss está dizendo como o campo se dilui no espaço. Assim (folha aberta), a partir dessa distribuição, o campo não se dilui me direção nenhuma. Você fez isso (enrola o papel no formato de uma barra) agora nessa direção (eixo da barra) ele não consegue se diluir porque ainda é infinito, mas nessa (radial) ele consegue, então o campo cai com 1/r. Se você pegar um fio infinito "prrrrrr"e apertar até virar uma bolinha, você tem duas direções pro campo diluir... portanto ele cai com 1 sobre $r^{2}$.

Para tornar a explicação mais plausível e concreta, analogias materiais (A1) são utilizadas:

01:36:00 - 01:37:20 Se eu pego uma lâmpada dessa aqui (lâmpada fluorescente da sala), como é que cai a luz com a distância perto dela? Aqui a lâmpada não é infinita, mas se você estiver bem pertinho você pode considerar como infinita. Como a intensidade da luz cai com a distância? 1/r [...] Pega uma lâmpada incandescente, uma bolinha, como é que a luz cai com a distância? $1 / r^{2}$ Imagina um plano infinito [...] talvez, se você for uma mosca e tiver sentada num outdoor desses grandes, ou seja, se tiver muito perto dele, que cara que vai ter a luz que sai de lá? A luz sai assim ó (gestos indicando direção paralela), a luz não faz isso (gestos indicando divergência). Então esse jeito de pensar da lei de Gauss dá uma imagem da natureza que essas quedas aqui têm a ver com as dimensões do espaço. Então a lei de 
Gauss que a gente tá terminando agora - não vai mais falar muito dela - vai usar muito mas não vai falar muito... o conteúdo muito importante dela é o seguinte: ele ensina pra gente que esse 2 aqui tem a ver com as dimensões do espaço e esse 1 aqui tem a ver com as dimensões do espaço.

O "barato" anunciado trata-se de uma interpretação complexa e não usual sobre as consequências de se representar conceitos físicos matematicamente. Se inicialmente utilizamos estruturas matemáticas (coordenadas no espaço tridimensional) para construir representações abstratas de "regiões de ação" (campo elétrico já é uma noção extremamente abstrata), é natural que, devido à coerência interna dessas estruturas, a dedução de relações aparentemente "inesperadas" seja propiciada pelo formalismo. O discurso do professor evidencia de maneira clara esse caráter interconectado/unificador do uso da matemática para pensar os fenômenos eletromagnéticos.

Episódio 18: Problema da auto-energia da esfera Aula 21 - Duração: 62 min 20 s (18:00-1:20:20)

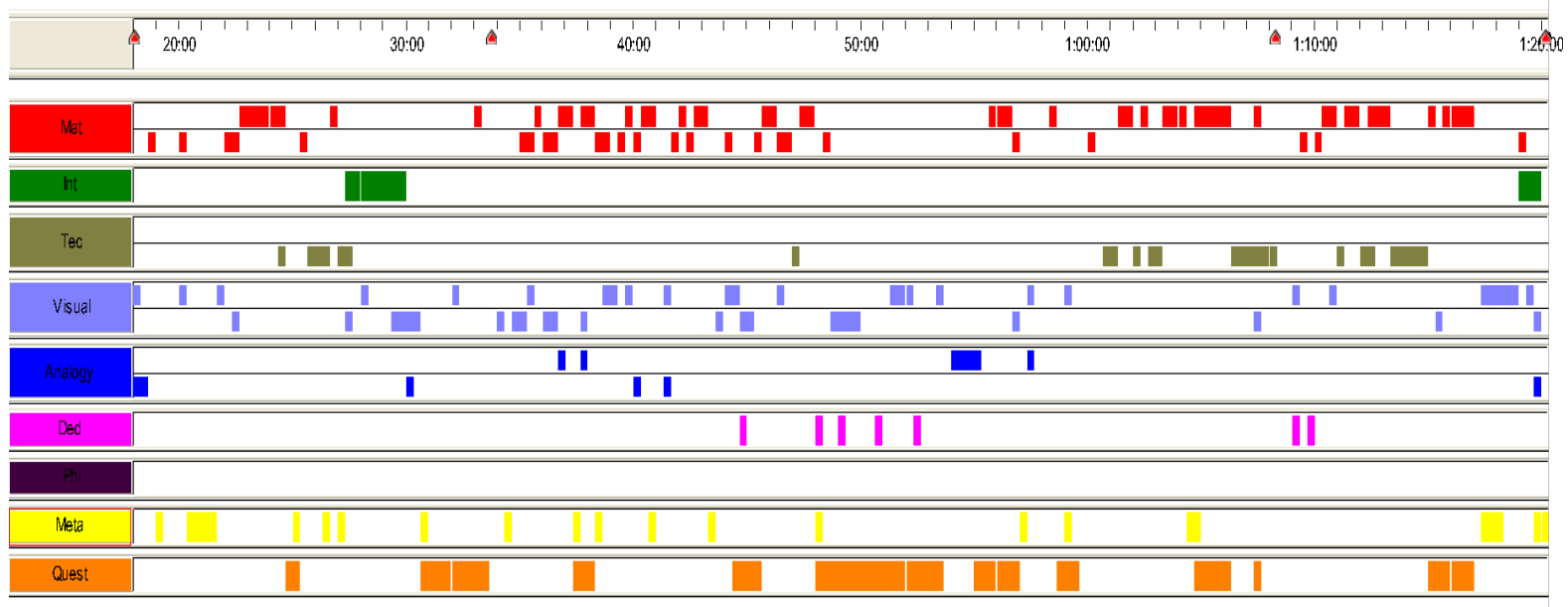

Figura 46: Diagrama Episódio 18 - Aula 21 - Auto-energia da esfera

Enunciado do problema: Calcule a auto-energia de uma superfície esférica de raio $R$ que está carregada com uma carga total $Q$.

Em física, o conceito de energia é extremamente abstrato, tem um papel unificador e é um típico exemplo de um conceito que não pode ser separado de sua formulação matemática. Se por um lado a energia cinética pode ser associada à energia do movimento, a energia potencial pode ser amplamente entendida como a energia associada à configuração. Assim, a abstrata noção de auto-energia de um sistema está relacionada ao trabalho necessário para colocá-lo em uma determinada configuração. Ela nos remete, portanto, a questões sobre o passado do sistema, ou seja, a processos que foram responsáveis por seu estado atual. 
Esta aula é dedicada quase que inteiramente à resolução de um único problema: a determinação da auto-energia de uma superfície esférica carregada. $\mathrm{O}$ alto grau de abstração deste problema e do conceito em si, faz com que recursos a situações cotidianas sejam praticamente inexistentes. $\mathrm{O}$ aspecto mais interessante a ser destacado é que o mesmo problema é resolvido de três maneiras diferentes, as quais envolvem raciocínios distintos do ponto de vista filosófico. Entretanto, o resultado final obtido é o mesmo, o que mostra não só a flexibilidade da matemática (DIEKS, 2005) como também a coerência interna de teorias físicas estruturadas matematicamente.

A primeira maneira de pensar no problema consiste em calcular o trabalho necessário para carregar a esfera levando cargas infinitesimais $(d q)$ do infinito até sua superfície. Em uma configuração intermediária, ou seja, com a esfera ainda não totalmente carregada com a carga $Q$, mas sim com uma carga intermediária $q$, o potencial na superfície da esfera vale:

$$
V=\frac{q}{4 \pi \varepsilon_{0}} \frac{1}{R}
$$

A energia potencial de um elemento de carga $(d q)$ colocado sobre esta superfície, que está associada ao trabalho necessário para trazer este elemento do infinito até a superfície da esfera, é dada por:

$$
d U=d q V=d q \frac{q}{4 \pi \varepsilon_{0}} \frac{1}{R}
$$

Assim, para obter a energia total do sistema, integra-se "sobre todas as viagens", fazendo com que a carga da esfera varie de zero até $Q$ :

$$
U=\int_{0}^{Q} d q \frac{q}{4 \pi \varepsilon_{0}} \frac{1}{R}=\frac{1}{2} \frac{Q^{2}}{4 \pi \varepsilon_{0}} \frac{1}{R}
$$

Esse cálculo foi conduzido de maneira muito cuidadosa, sendo que cada abstração foi detalhadamente esclarecida. Sua longa duração (12 minutos - 22:00-34:00) contrasta com a aparente simplicidade da resolução do problema em três linhas. Erros comuns associados à identificação de variáveis e limites de integração são explicitamente mencionados, a validade da utilização da expressão do campo coulombiano para o caso da distribuição esférica é novamente justificada e perguntas sobre situações semelhantes são respondidas. Ao final da resolução do problema pelo Método 1, alguns aspectos da expressão do resultado final (fator $1 / 2$ e a dependência do quadrado da carga $Q$ ) são interpretados:

27:40-30:00 Pergunta: qual é a origem do fator 1/2 na conta? Aparece essencialmente porque o preço de cada viagem é diferente. Se você fizer um gráfico do trabalho ele é assim (desenha o gráfico de uma relação linear): a primeira viagem é de graça e à medida que você anda as viagens vão ficando mais caras. Então isso daqui é uma média da viagem entre a última viagem e a primeira. Então esse 1/2 é sempre característico desse tipo de sistema. [...] Pergunta: por que aparece $Q^{2}$ aqui? Isso fisicamente indica o que? Pessoal, a carga $q$ 178 
interage com ela mesma? [...] Sim. Olha o que eu fiz aqui: eu peguei uma carga e trouxe aqui (gestos). E ela estava vindo e ela estava interagindo com o que estava lá já. Sim? Na hora que eu puser o dq zinho aqui ele interage com o que estava lá? Interage, ok isso? Então é exatamente essa a ideia da auto-energia. Tem um sistema, tudo bem, tá carregado, mas, essa carga interage com essa. E é isso que está guardado lá naquela resposta.

O segundo método consiste em determinar o trabalho necessário para comprimir uma esfera carregada com carga $Q$ de raio infinito até a mesma possuir um raio fixo $R$. Esta situação também nos remete a uma possível "história" da esfera, mas tem diferenças formais importantes. Por exemplo, agora não tem mais sentido integrar em $d q$ uma vez que a carga total é $Q$ desde o início. O professor alerta o estudantes para o fato de que esta maneira de raciocinar é mais difícil e isso é percebido pela duração muito mais longa da resolução do problema pelo Método 2 (35 minutos - 34:00-1:09:00).

O raciocínio, chamado de "mais elegante" pelo professor, consiste em retirar um elemento de área $d S$ e considerar a influência do restante da esfera sobre este elemento. $\mathrm{O}$ principal problema para o cálculo do trabalho para comprimir a esfera é determinar a expressão da força necessária para deslocar o elemento de área $(\vec{F}=d q \vec{E}=\sigma d S \vec{E})$. Para a determinação desta força, o campo elétrico em pontos muito próximos da esfera $\left(\frac{q}{4 \pi \varepsilon_{0}} \frac{1}{(R+\delta)^{2}} \cong \frac{\sigma}{\varepsilon_{0}}\right)$ é subtraído do campo criado pelo elemento de área carregado $\left(\frac{\sigma}{2 \varepsilon_{0}}\right)$. Para se ter uma ideia do elevado nível de abstração do raciocínio, este elemento de área $d S$ precisa ser considerado como um plano infinito de cargas para pontos muito próximos a sua superfície. Assim, o campo elétrico resultante, que representa o campo elétrico criado pelo restante da esfera no ponto onde se localiza o elemento de área, é $\frac{\sigma}{2 \varepsilon_{0}}$ e o trabalho para mover $d S$ de uma distância $d r . \hat{r}$ é dado por:

$$
d \tau^{\prime}=\sigma d S \frac{\sigma}{2 \varepsilon_{0}} \hat{r} \cdot d r \hat{r}=d S \frac{\sigma^{2}}{2 \varepsilon_{0}} d r
$$

Para realizar este trabalho em toda a superfície $S$ da esfera:

$$
d \tau=4 \pi r^{2}\left(\frac{Q^{2}}{4 \pi r^{2}}\right) \frac{1}{2 \varepsilon_{0}} d r=\frac{1}{2} \frac{Q^{2}}{4 \pi \varepsilon_{0}} \frac{1}{r^{2}} d r
$$

Uma dificuldade formal deste problema é que a densidade superficial da esfera varia e, portanto, a variável $r$ precisa permanecer no integrando até o final da integração. Por fim, calcula-se a integral para comprimir a esfera de $r=\infty$ a $r=R$, obtendo o mesmo resultado do Método 1:

$$
\tau=\int_{\infty}^{R} \frac{1}{2} \frac{Q^{2}}{4 \pi \varepsilon_{0}} \frac{1}{r^{2}} d r=-\frac{1}{2} \frac{Q^{2}}{4 \pi \varepsilon_{0}} \frac{1}{R} \text { e } U=\frac{1}{2} \frac{Q^{2}}{4 \pi \varepsilon_{0}} \frac{1}{R}
$$


Os dois primeiros métodos tem uma filosofia semelhante, pois ambos referem-se ao que ocorreu no "passado" da esfera até que a mesma adquirisse a carga $Q$. Entretanto, o terceiro método abandona completamente a noção de evolução temporal e considera a expressão que relaciona a densidade volumétrica de energia eletrostática numa região do espaço com o campo elétrico nesta região $\left(\frac{d U}{d V}=\frac{\varepsilon_{0}}{2} E^{2}\right)$. Como o campo elétrico nos pontos externos à esfera é $\vec{E}=\frac{Q}{4 \pi \varepsilon_{0}} \frac{1}{r^{2}} \hat{r}$, a energia total obtida integrando a densidade em todo o espaço onde existe campo elétrico é:

$$
U=\iiint \frac{\varepsilon_{0}}{2}\left(\frac{Q}{4 \pi \varepsilon_{0}} \frac{1}{r^{2}}\right)^{2} d V=\frac{\varepsilon_{0}}{2} \frac{1}{2}\left(\frac{Q}{4 \pi \varepsilon_{0}}\right)^{2} 4 \pi \int_{R}^{\infty} \frac{1}{r^{4}} r^{2} d r=\frac{1}{2} \frac{Q^{2}}{4 \pi \varepsilon_{0}} \frac{1}{R}
$$

Ao final do episódio, o professor apresenta uma síntese das três estratégias de pensamento utilizadas para resolver o problema e destaca que a superioridade da última:

01:17:20 - 01:20:20 Pessoal, simbolicamente, esses três jeitos são representados assim: Isso é a viagem do dq. (desenha) Método um. Método dois, você pega uma esfera maior e comprime a esfera (desenha). E o método três, a gente olha isso daqui do seguinte jeito: tem campo, tem energia aqui. Esse método (3) é o mais básico, mais profundo, mais microscópico, mais tudo. E ele tem dentro dele uma mensagem que é muito importante. Imagine aqui que você pegue uma casca esférica como a gente pegou lá com o campo fora da mesma junto com sua dele. Ele é mais denso perto da esfera e vai diluindo lá pra fora. Imagine que agora você pegue fisicamente e comprima a esfera para essa esfera laranja agora (desenha uma esfera menor no interior da primeira). Pergunta: a energia, mantendo a carga constante, aumentou? A energia no sistema aumentou? Sim, porque para comprimir eu tive que realizar trabalho. Pergunta: o campo muda aqui (região externa à esfera inicial)? Quando eu comprimo a esfera daqui pra cá? Não muda. Então você olha a seguinte coisa: a energia já distribuída no espaço se mantém igual. E o trabalho que você realizou, foi parar onde? Foi parar nessa regiãozinha aqui (entre esfera menor e maior), que agora você teve que encher de campo. Isso, de novo, traz a mensagem que quando você comprime um sistema de cargas você deposita energia no espaço. E a energia vai ficando uma espécie de rastro, uma pegada da passagem da carga. Então a carga passou por lá, ela deixou energia atrás. Se você pensar nisso direito, isso é muito esquisito. Porque você faz uma coisa aqui, você vai deixando energia lá trás. A energia vai ficando no espaço. Então essa ideia de campo é uma ideia bastante estranha. Mas por outro lado é muito interessante.

O fato de que a energia está localizada no campo é enfatizado em inúmeros momentos ao longo do curso. Na discussão final do episódio, o professor faz questão de destacar que a terceira maneira de pensar é mais útil. Sua afirmação parece estar em ressonância com a ideia de "dissolução das substâncias no ácido da matemática" (GINGRAS, 2001), tão exemplificada em teorias da física moderna e contemporânea.

Antes de passarmos para o próximo episódio, cabe-nos refletir sobre a seguinte questão: Como é possível chegarmos ao mesmo resultado por caminhos qualitativamente tão 
diferentes? Em termos didáticos, o que aprendemos com isso? Não seria melhor escolher somente um método? Essa abordagem múltipla não traz "complicações desnecessárias” para o estudante?

Em uma palestra sobre a relação da física com a matemática, Feynman (1985) ressalta esse caráter flexível do uso da matemática como instrumento de pensamento na física e provavelmente discordaria da inutilidade de se resolver o mesmo problema de diversas maneiras. Para ilustrar seu ponto de vista, ele enuncia dois fatos conhecidos da teoria gravitacional newtoniana: 1) Existe uma força atuando sobre um planeta em órbita em torno do Sol, a qual aponta na direção deste; 2) O raio-vetor imaginário que liga o planeta ao Sol "varre" áreas iguais em tempos iguais. Feynman argumenta que, apesar de ser possível expressar essas afirmações utilizando a linguagem natural, sem a matemática é impossível mostrar que as mesmas são equivalentes:

Eu posso the explicar ambas afirmações [força central e lei das áreas] cuidadosamente, mas não conseguirei lhe explicar por que elas são equivalentes. $\mathrm{A}$ aparente enorme complexidade da natureza, com todas suas leis e regras esquisitas, cada uma das quais the foi cuidadosamente explicada, estão, na verdade, profundamente interconectadas. Entretanto, se você não apreciar a matemática, você não consegue perceber que, dentro da imensa variedade dos fatos, a lógica te permite ir de um para outro. (FEYNMAN, 1985, p. 40-41, grifo nosso).

No decorrer de sua palestra, de maneira semelhante ao que foi abordado neste episódio, Feynman apresenta três maneiras qualitativamente diferentes de se conceber os fenômenos gravitacionais: 1) Força gravitacional newtoniana (ação à distância); 2) Força determinada por variação de um potencial gravitacional (local no tempo e espaço); e 3) Princípio de ação mínima (abandona-se a ideia de causalidade). Em seu característico tom de ironia, Feynman enfatiza como a matemática permite conciliar as diferentes "preferências pessoais" representadas por diferentes "posicionamentos filosóficos". Entretanto, o físico estadunidense menciona também como essas três maneiras possuem diferenças "psicológicas" importantes, uma vez que indicam caminhos diferentes quando se pretende utilizá-las para analisar situações mais amplas e complexas. Sendo assim, traçando um paralelo, a abordagem do professor indica não só que o mesmo acredita no valor formativo de se resolver o mesmo problema por diversos caminhos, mas também na importância de anunciar (de maneira retrospectiva) que uma delas (terceira) tem se mostrado mais eficiente. 
Episódio 19: Problema do campo magnético criado por um pedaço de fio Aula 30 - Duração: 20 min 40 s (1:12:00-1:32:40)

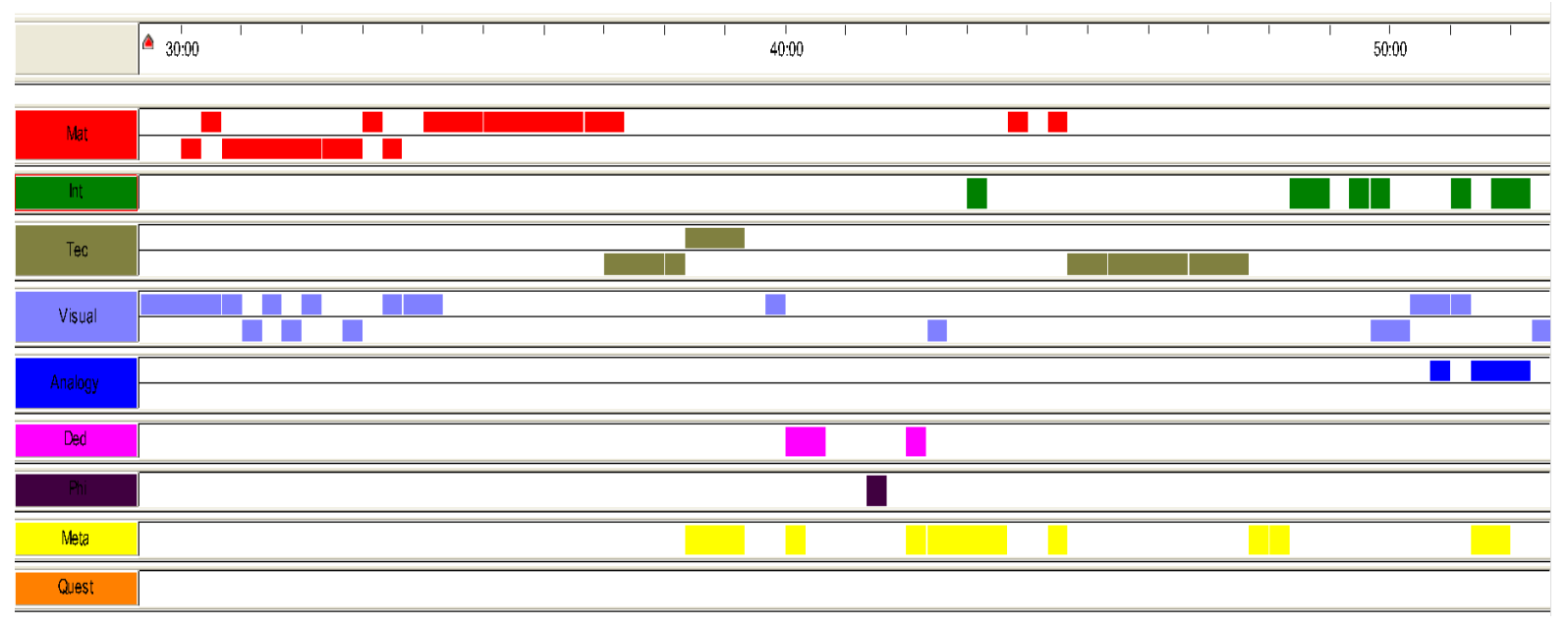

Figura 47: Diagrama Episódio 19 - Aula 30 - Problema campo magnético criado por pedaço de fio

Enunciado do problema: Calcule o campo magnético num ponto $P$ distante $a$ do centro de um fio de comprimento $L$, percorrido por uma corrente $I$.

A resolução deste problema tem uma estrutura semelhante à do Episódio 15, no qual o problema da determinação do campo elétrico de um sistema formado por duas cargas pontuais é resolvido aplicando a lei de Coulomb, porém agora a explicação é mais rápida e direta. O problema analisado neste episódio envolve a aplicação da lei de Biot-Savart, sendo que a preocupação inicial do professor é dedicada à identificação dos vetores relevantes para o problema e à representação dos mesmos em coordenadas cartesianas. Isso justifica a intensa presença da categoria matematização no início do episódio:

33:00 - 35:40 Então a gente tem que localizar os vetores importantes. Nesse problema o $\vec{r}_{q}$ verde é o que? Ele é o vetor que localiza a posição de um pedaço de fio relativamente à origem. Então ele é isso daqui (desenha o vetor que localiza a carga). $\vec{r}_{p}$ é isso (desenha o vetor que localiza o ponto). Então a intensidade do campo depende desse vetor aqui (liga o extremo de $\vec{r}_{q}$ com o extremo de $\vec{r}_{p}$ e constrói o vetor $\vec{r}_{p}-\vec{r}_{q}$ ) e o campo aqui é dado por uma flecha assim (desenha). De acordo com esse desenho, então, o que eu tenho que calcular? $\vec{r}_{q}$ verde, que é a posição do pedaço do fio, ele é dado por essa coordenada vezes $\hat{k}$ (escreve $\left.\vec{r}_{q}=z \hat{k}\right)$. O $\vec{r}_{p}$ laranja nesse desenho aqui, ela está contido no plano xz e portanto ele é $a \hat{\imath}+c \hat{k}$. Aí o que a lei de Biot-Savart diz: que a contribuição do campo é essa aqui (escreve a lei na forma $d \vec{B}=\frac{\mu_{0}}{4 \pi}$. I.d $\left.\vec{l} \times \frac{\left(\vec{r}_{p}-\vec{r}_{q}\right)}{\left(\vec{r}_{p}-\vec{r}_{q}\right)^{3 / 2}}\right)$. O que é $d \vec{l}$ nesse problema? $d \vec{l}$ é esse vetor aqui que é paralelo ao fio $d \vec{l}=d z \hat{k}$. 
Ao se realizar as operações com um produto vetorial é preciso respeitar as convenções do formalismo. Ciente de que este é um erro comum cometido pelos estudantes, a importância da não arbitrariedade da ordem dos eixos é mencionada.

38:20 - 39:20 Pessoal, uma coisa que a gente não presta atenção é o seguinte: na matemática, todas as regras de fazer produto vetorial que a gente sabe estão associadas a escrever os eixos nessa ordem aqui (desenha eixos coordenados). E a gente fala $i j k, i j k e$ essa ciclicidade só vale para esse desenho. Ela não vale para esse desenho aqui (troca $x$ por y) Tudo bem isso? Então isso não é tanto faz. Você não pode colocar na ordem que você quiser. Você tem que colocar na ordem dada aqui.

A resolução da integral (parte operacional) se destaca pelo caráter excessivamente ferramental. Resultados são retirados da tabela, substituições de variáveis . Durante todo esse processo o professor está virado para o quadro, postura comum durante os momentos de "girar a manivela". Por fim, o resultado final é apresentado e se inicia uma discussão focada na sua interpretação e na diferença entre a simetria esférica do campo elétrico criado por uma carga parada e a simetria cilíndrica do campo magnético criado por cargas em movimento.

49:20 - 52:40 O que esse resultado carrega além dele? Esse resultado foi feito para esse desenho aqui, mas pelo tipo de conta que a gente faz, a gente pode esperar a seguinte coisa: que o módulo de B vai ser o mesmo ao longo desse círculo aqui (gesto). Isso é importante. Você dá uma volta aqui e o módulo de $\vec{B}$ é sempre o mesmo.[...] E isso daqui tem uma simetria cilíndrica Olha esse problema de frente, o I tá saindo assim, regra da mão direita, o $\vec{B}$ é assim. Isso é o que dá o caráter de vórtice desse problema. Pessoal, o campo elétrico é criado radialmente. Se você puser uma carga elétrica aqui ele vai criar campo assim (desenha linhas radiais). O desenho intuitivo disso é esse aqui (desenha linhas circulares). Então o que a corrente faz? Olha esse problema do ponto de vista de topologia. Isso daqui (carga elétrica) é esfericamente simétrico, sim? Isso cria uma coisa que é simétrica esfericamente em todo o espaço. Você consegue ter uma corrente elétrica esfericamente simétrica? Dá para ter corrente esfericamente simétrica? [...] Não. Esse problema tem que tipo de simetria? Cilíndrica. Então é isso que a gente está vendo aqui, que o campo magnético tem uma simetria cilíndrica, porque carga é uma bolinha, mas a velocidade dela assimetriza o problema. Ela é uma dimensão particular. Aí você tem uma coisa que perde a simetria esférica e ganha a cilíndrica. Então a simetria do campo magnético é sempre uma simetria de vórtices.

Assim como o comentário feito no final do Episódio 17 de que as expressões dos campos elétricos do ponto, fio e plano mostram como a lei de Gauss está associada às dimensões do espaço, a conclusão de que a velocidade "assimetriza" o problema revela profundas conexões quando se utiliza o formalismo matemático para representar o espaço na descrição de fenômenos eletromagnéticos. Adicionalmente, o professor explicita um aspecto nada trivial neste problema: a mudança no tipo de simetria, de esférica para cilíndrica, provocada pelo movimento das cargas. 
A análise dos seis últimos episódios relacionados com a resolução de problemas reforça que os mesmos têm um papel de destaque no curso e se configuram como ocasiões muito pertinentes para se abordar o caráter estruturante do pensamento matemático na física. O longo tempo dedicado à formulação matemática e à interpretação física dos resultados, bem como os inúmeros comentários de natureza metacognitiva alertando sobre possíveis erros, levam-nos a conjecturar que muitos desses fatores estão associados à excelente avaliação que este professor recebe de seus estudantes (conforme Anexo 1). Sua postura contrasta com a maneira tradicional de se tratar a resolução de problemas como simples aplicações. Novamente, a possibilidade de se investigar como outros professores resolvem o mesmo problema em suas aulas e contrastar suas abordagens com nossas categorias de análise parece promissora. Por exemplo, se ao analisarmos um problema sendo resolvido na aula de um outro professor hipotético e constatarmos que: 1) A formulação matemática do problema foi simplesmente apresentada sem maiores explicações; 2) Muito tempo foi dedicado à manipulações algébricas e ao uso de regras matemáticas com argumentos de autoridade e 3) Após obtido o resultado final, o professor considera o problema por encerrado e parte para o próximo; identificaríamos um padrão completamente diferente do que geralmente encontramos neste estudo de caso.

Apesar de pesquisas educacionais apontarem a impossibilidade de se estabelecer uma relação causal direta entre qualidade do ensino e da aprendizagem (SHUELL, 1996; OSER; BAERISWYL, 2001; SEIDEL; PRENTZEL, 2006), parece-nos razoável considerar que a forma como estudantes resolvem problemas está relacionada com a maneira com a qual foram ensinados, mais especificamente com a maneira pela qual o professor seleciona os exemplos e os resolve nas aulas. Na literatura específica, encontramos diversos relatos sobre estudantes que resolvem problemas mecanicamente, têm dificuldades em estabelecer conexões entre cálculos e fenômenos e consideram o problema como encerrado quando chegam a um resultado final. O jogo identificado como Plug-and-Chug por Tuminaro e Redish (2007), por exemplo, exemplifica muito bem essa maneira acrítica de substituir valores cegamente em uma fórmula e obter um resultado sem significado. O costume de dedicar um bom tempo à matematização inicial e à interpretação final (padrão matematização-técnica-interpretação) encontrado em vários momentos das aulas reflete uma mensagem implícita (às vezes explícita) de focar em aspectos estruturais em detrimento daqueles meramente instrumentais. 
A exemplo do Quadro 8, construído para sintetizar os treze primeiros episódios, as principais características de cada um dos seis episódios relacionados à resolução de problemas são resumidas no quadro a seguir:

\begin{tabular}{|c|c|}
\hline Episódio & Cara \\
\hline $\begin{array}{l}\text { Ep. 14: Problema da placa } \\
\text { carregada } \\
\text { Aula } 6-25 \mathrm{~min} \\
(32: 00-57: 00)\end{array}$ & $\begin{array}{l}\text { oco na interpretação do significado de funções matemáticas que descrevem } \\
\text { ensidades superficiais e do processo de integração para determinação da } \\
\text { arga total; Intenso uso de gestos (folha de papel); Alternância técnica e } \\
\text { terpretação; Ênfase na importância de se entender "como a informação } \\
\text { nda na conta". }\end{array}$ \\
\hline $9-48 \min$ & $\begin{array}{l}\text { onga duração; Padrão matematização-técnica-interpretação; Ênfase na } \\
\text { epresentação matemática das variáveis relevantes por vetores; Destaque } \\
\text { ara a discussão de natureza epistemológica sobre a importância de se } \\
\text { costurar o significado no símbolo" motivada pela pergunta de um } \\
\text { studante; Diversos momentos de incentivo à metacognição. }\end{array}$ \\
\hline $40 \mathrm{~s}$ & $\begin{array}{l}\text { onga duração; Padrão matema } \\
\text { suais; Exposição clara das var } \\
\text { cnica; Destaque para o caráter lóg } \\
\text { onstância do fluxo (Gauss) passa } \\
\text { ependência do inverso do quadrado }\end{array}$ \\
\hline $\begin{array}{l}\text { Ep. } 1 \\
\text { camp } \\
\text { síntes } \\
\text { Aula } \\
(1: 28\end{array}$ & $\begin{array}{l}\text { enção explícita às condições necessárias para a aplicação da lei de Gauss; } \\
\text { ealizações justificadas; Diferenças formais entre plano e fio infinito; } \\
\text { estaque para a síntese dos três casos (ponto, fio e plano) no final do } \\
\text { isódio: interpretação da relação entre a lei de Gauss e as dimensões do } \\
\text { paço. }\end{array}$ \\
\hline $\begin{array}{l}\text { Ep. 18: Problema da auto- } \\
\text { energia da esfera } \\
\text { Aula } 21-62 \min 20 \mathrm{~s} \\
(18: 00-1: 20: 20)\end{array}$ & $\begin{array}{l}\text { Toda a aula dedicada à resolução de um problema; Alto nível de abstração } \\
\text { do conceito e do problema; Idealizações cuidadosamente explicitadas; } \\
\text { Utilização de estruturas matemáticas (construção de diferenciais e } \\
\text { integração) devidamente justificadas; Interação professor-aluno; Destaque } \\
\text { para o fato de que o mesmo problema é resolvido de três maneiras } \\
\text { diferentes; Síntese final das três estratégias de resolução e valorização da } 3^{\text {a }} \text {. }\end{array}$ \\
\hline $\begin{array}{l}\text { Ep. 19: Problema do } \\
\text { campo magnético criado } \\
\text { por um pedaço de fio } \\
\text { Aula } 30-23 \min 20 \mathrm{~s} \\
(29: 20-52: 40)\end{array}$ & $\begin{array}{l}\text { Padrão matematização-técnica-interpretação; Ênfase na representação } \\
\text { matemática das variáveis relevantes por vetores e nas regras do produto } \\
\text { vetorial; Resolução procedimental com argumentos de autoridade (tabela); } \\
\text { Diferenças formais entre a simetria radial do campo elétrico de uma carga } \\
\text { parada e cilíndrica do campo magnético de uma carga em movimento; } \\
\text { velocidade da carga como "direção que assimetriza" o problema. }\end{array}$ \\
\hline
\end{tabular}

Quadro 9: Resumo dos episódios de resolução de problemas (14 a 19).

Diante da complexidade e pluralidade das relações entre física e matemática, seria incoerente se identificássemos um padrão constante nos episódios. Em vez disso, percebemos múltiplas abordagens com diferentes aspectos desta inter-relação sendo enfatizados, dependendo do momento do curso, do tópico específico e também de fatores imprevisíveis como perguntas de alunos. Parece-nos que é exatamente esse caráter plural encontrado ao longo da análise dos episódios que constitui um dos principais diferenciais das aulas deste professor. 
Naturalmente, outros trechos poderiam ter sido selecionados e analisados. Entretanto, tendo em vista nosso interesse em investigar a abordagem do caráter estruturante/estrutural do pensamento matemático num contexto de ensino de física e exemplificar a dinâmica interação entre as categorias de análise durante as aulas, defendemos que esta seleção focada na introdução de conceitos fundamentais, interpretações de operações matemáticas principais, explicações das equações de Maxwell e resolução de problemas exemplares, atendeu nossos anseios de maneira satisfatória.

Refletindo sobre o problema sob a ótica do ensino, muitas perguntas interessantes emergem da análise da prática deste professor. Por que motivo ele utiliza esta ou aquela estratégia? Qual a sua intenção didática? Que crenças sobre como os estudantes aprendem o levam a escolher um determinado tipo de abordagem? Que funções ele atribui a comentários de natureza metacognitiva e discussões epistemológicas? Por que alguns teoremas matemáticos são apresentados com argumentos de autoridade enquanto outros são demonstrados? Qual o papel desempenhado por tantas analogias materiais? Que imagem ele pretende transmitir quando efetua manipulações algébricas de maneira displicente?

Para acessar esse nível de reflexão sobre a prática, conduzimos uma entrevista semiestruturada com o professor e apresentamos uma análise de suas respostas a estas e outras questões no próximo capítulo. 


\section{6 - REFLETINDO SOBRE A PRÁTICA: A ENTREVISTA COM O PROFESSOR}

A entrevista foi realizada em dois encontros, teve uma duração total de aproximadamente 2 horas e meia e foi conduzida em um tom de conversa informal. Trata-se de uma entrevista semiestruturada porque não tínhamos um conjunto fixo de perguntas determinadas previamente e sim uma série de tópicos a serem abordados. O objetivo principal foi fazer com que o professor refletisse sobre os motivos que o levam a adotar as principais estratégias que identificamos no decorrer do curso, principalmente em relação ao papel da matemática na física. Dessa forma, as perguntas estiveram relacionadas às nossas categorias de análise, porém sem citá-las explicitamente. Trechos das aulas foram utilizados como exemplos para motivar a discussão. Em vários momentos o professor fez referência à sua experiência profissional (físico e professor) e também pessoal (aluno), o que tornou a conversa ainda mais interessante e reflexiva. De maneira geral, a entrevista também serviu como uma espécie de validação interna das categorias, uma vez que pudemos perceber se os aspectos que identificamos nas aulas foram considerados como relevantes pelo professor.

Dividimos este capítulo em seções nas quais o professor aborda questões específicas como o uso intenso de analogias materiais e situações cotidianas, o papel das manipulações técnicas, das demonstrações, a importância da metacognição, entre outras, na ordem em que foram tratadas. Naturalmente, apresentamos uma síntese dos principais pontos discutidos, ou seja, utilizamos uma prática conhecida na literatura como cherry picking ao selecionarmos os trechos que nos interessam ${ }^{43}$.

A análise da prática deste professor já tinha se revelado uma estratégia profícua e as concepções que ele revela nas respostas reforçam mais ainda a pertinência do estudo de caso. As perguntas feitas pelo entrevistador (pesquisador), indicado pela legenda $E$, e as respostas do professor $(P)$ são apresentadas a seguir, agrupadas por temas relacionados às categorias. A ordem de apresentação representa a ordem em que as mesmas foram abordadas.

\section{Uso de situações concretas, metáforas e analogias durante a explicação}

E - Uma coisa que me chamou a atenção é um recurso que você usa de maneira recorrente que é trabalhar com algumas coisas muito concretas. Eu chamaria até de exemplos do cotidiano. Vou te dar alguns exemplos: para falar de gradiente você diz que um cachorro está em uma sala escura e vai achar um bife usando o faro; você está falando de densidade, distribuição de carga, você fala sobre a densidade populacional do Brasil; você fala de

\footnotetext{
${ }^{43}$ A transcrição completa da entrevista encontra-se no Anexo 4.
} 
corrente elétrica e densidade de corrente, você fala de pessoas em um metrô. Por que você faz uso dessas imagens concretas em suas aulas? Qual a importância disso pra você??

$P$ - Eu não vejo isso como um recurso pedagógico. Eu não faço isso como estratégia de ensino. Esse é o meu íntimo e como ser humano eu partilho essa sensação global com o estudante. A ideia é partilhar a minha vida com ele, me partilhar com ele.

O professor deixa claro que não vê o uso de analogias materiais como recurso pedagógico, mas sim como uma maneira de partilhar sua maneira de ver o mundo com o estudante. Essa partilha revela um dos principais objetivos do ensino superior que é justamente possibilitar a convivência entre iniciantes e profissionais experientes. Para melhor explorarmos esse importante aspecto de suas aulas, insistimos na busca por justificativas.

E - Isso tem a ver com sua experiência pessoal? Como você vê essas coisas e como você aprendeu?

$P$ - Tem menos razão nisso. [...] O que é uma analogia? É uma frase, ou falada, ou feita matematicamente, que carrega uma estrutura da qual você não pode falar. O exemplo do gradiente é muito legal pois ninguém fala de cachorro. Fala de outras coisas, mas não de cachorro, e o aluno entende. [...] Tudo que você quer saber está nesse exemplo. Você entende mais ou menos como o cachorro funciona? A gente tem uma experiência direta com cachorro. E o conhecimento com o qual a gente opera é um conhecimento que deixa de ser formal e deixa de ser verbal. [...] E quando você fala do bife do cachorro, você está dizendo assim: aquela relação do cachorro com o cheiro, é uma relação que o cachorro sabe e ele não conhece gradiente. Então significa que a noção de gradiente foi tirada do mundo. $O$ gradiente não existe. O gradiente é uma construção humana. Se você pegar na natureza, não tem gradiente. Ele está fora do mundo. Então o mundo veio antes. [...] Aí, as pessoas que fizeram matemática e etc., eles tiraram dessa propriedade do mundo e colocaram no mundo da linguagem. E aí, se você não fizer de volta a ponte com o mundo, a linguagem é apenas uma linguagem e ela não serve pra uma quantidade de coisas. [...] O que eu sinto é que o entendimento do gnóstico que dá barato. O aluno pensa no gradiente e no bife e "uau", aquilo entra de um jeito dentro dele... e isso não é uma estratégia de ensino.

Muitos são os elementos importantes deste trecho. Primeiramente, o professor justifica o uso intenso de analogias argumentando que por meio delas é possível abordar aspectos não verbais do conhecimento. Além disso, o professor deixa claro sua visão de que operações matemáticas como o gradiente foram criadas a partir do mundo e que a linguagem é uma construção humana para pensar sobre este mundo. Dessa forma, é essencial manter essa ligação com o original para evitar um tratamento distanciado da "linguagem pela linguagem". Tal visão é evidenciada, por exemplo, no discurso do professor após a sugestão de um aluno para resolver o problema sem interpretar previamente o significado dos símbolos (Episódio 15). Notamos também uma crença do professor de que analogias como a do 
cachorro fazem com que "o aluno aprenda", por isso procuramos identificar as razões para tal convicção.

E - Me chama atenção quando você diz: ele aprende assim. Você dá essa disciplina há mais de 20 anos. $O$ exemplo do cachorro surgiu em algum momento, não tinha antes. Então isso também te dá subsídios para você acreditar que o exemplo do cachorro ou essas estratégias, de uma maneira geral, são importantes[...] Quando você fala "ele aprende assim", o que sustenta esse seu argumento?

P - Nada. Porque sustentar quer dizer o quê? Eu vou de novo querer jogar esse problema para o mundo das palavras. E aí sim eu posso querer persuadir alguém que isso é melhor... [...] Esse exemplo do bife eu poderia mostrar pra uma pessoa que nunca pensou nisso e ele poderia achar legal e ensinar a partir disso. Isso é transmissivel nesse contexto, alguém que nunca pensou pode vir a pensar. O que eu acho que é desejável...isso não dá pra medir se acontece ou não, eu acho. Quando eu dou aula de gradiente pra um cara, o cara se apropria do gradiente e passa a ser um instrumento operacional dele [...] . Se eu tivesse feito um discurso formal a respeito do instrumento isso não passaria. Ele passa quando o cara tem esse entendimento imediato, sem mediação, gnóstico [...] Por outro lado, eu acho que não existe maneira de demonstrar isso, de você provar que isso é bom com alguma medida.

E - Essa é uma pergunta recorrente pra gente que está na educação: como é que você sabe que aprendeu, como é que você sabe que essa maneira é melhor. Mas eu também, muitas vezes, sou um pouco cético em relação à possibilidade de responder isso de uma maneira muito objetiva.

$P$ - Olha, tem uma outra medida, que é a medida que a gente faz do outro lado, dos alunos, $e$ poderia perguntar pra ele se ele aprendeu [...] Nas duas turmas que se formaram esse ano eu fui escolhido paraninfo. É claro que isso me deixa muito contente, mas não é por isso que eu estou falando aqui. É porque isso indica algo. É um curso que ele teve dois anos antes de se formar e ele sente que tem alguma coisa que sobrou lá. E eu acho que essa coisa que sobrou tem muito a ver com essas coisas aí e ela não é, eu acho, um resultado da nossa relação pessoal. Porque a minha relação com os estudantes, quando eu era mais novo, era mais fácil e isso tinha uma componente pessoal razoável. Mas com esse pessoal não tem. [...] O que talvez sobra é uma postura frente ao conhecimento. Isso que eu suspeito que tenha sido uma coisa que os caras apreciaram. Agora como é que você vai medir postura? [...] E aí uma coisa que todo mundo pode fazer é olhar o seu curso e ver de quem você lembra como professor. Quem te deu Álgebra 1? Já esqueceu... tem um monte de caras que passaram um semestre falando várias coisas na minha frente, várias horas por semana e eu nem lembro quem era. E ai tem três ou quatro que eu lembro. Por que você lembra?

Apesar de estar convicto de que a aprendizagem é mais significativa com o recurso a analogias, o professor tem dúvidas em relação à possibilidade de se obter medidas objetivas para comprová-la. Novamente, ele reforça sua defesa de que a analogia do bife faz com que o estudante se aproprie da ferramenta matemática do gradiente. Adicionalmente, o professor considera outra possível evidência da eficácia dessa estratégia que é o excelente resultado da avaliação de seu desempenho didático pelos alunos. Entretanto, ele procura enfatizar que não se trata de uma boa relação pessoal, mas sim de uma postura frente ao conhecimento. Mesmo 
que de maneira inconsciente, a postura de um professor frente ao conhecimento ensina muito. Naturalmente, medir postura não é tarefa trivial, mas de certa forma nossa ferramenta teórica fornece indícios de tal postura por revelar ênfases em diferentes aspectos da relação entre física e matemática ao longo das aulas.

E - Quando você ministra outras disciplinas, quando você pensa em outros campos da física, a sua maneira de operar continua a mesma? Essa é uma preocupação constante ou em alguns momentos você encontra dificuldade de fazer essa conexão mais próxima do concreto?

$P$ - A dificuldade ela depende muito do assunto. Os assuntos que se prestam mais... e também quando você se esfregou no curso você vai percebendo coisas que antes não tinha percebido. A história do bife surgiu no meio do curso, significa que se eu tivesse parado antes eu nunca teria pensado nisso. Isso tem a ver com a minha trajetória pessoal porque... de certa forma eu estou tentando consertar o mundo pra que as pessoas não sofram o que eu sofri. E o que eu sofri? Eu fazia engenharia e ai vim pra física... a física eu achava um ambiente muito mais legal que a engenharia, uma coisa de empatia pessoal. Aí eu fui fazer física de partículas, que envolve bastante matemática. O jeito que a coisa era discutida lá era extremamente formal. Eu tinha aula de mecânica quântica absolutamente formal. Quando eu terminei meu mestrado eu resolvi desistir de fazer fisica. Fui pra Inglaterra e tal. Outra coisa, se você for olhar a história de alguns problemas, os grandes físicos que fizeram as coisas formais, a primeira coisa que ele fez foi olhar pelo mundo... como é a régua, mexe assim... fez uma continha. Ai outro cara pegou aquela conta e levou a conta em diante, outro cara levou a conta em diante e ai virou uma matemática assim. Mas o primeiro cara ele olhou no mundo. Quando eu te dou formalismo a gente perde esse contato, essa relação que ela está lá dentro pois o cara que fez pôs e o cara que estudou muito enxerga também. Mas o cidadão comum não enxerga. Então isso vira um discurso autoritário. Isso é uma coisa que é marca registrada da minha geração é que a gente é muito contra autoridade. [...] Eu acho legal não ter autoridade, não ter chefe. E não é que não tem autoridade, eu respeito a autoridade de pessoas, mas é o autoritarismo [...] isso talvez pode ter uma componente pedagógica, eu nunca tinha pensando nisso, estou pensando agora pela primeira vez - essa coisa de você dar as coisas formais, pra mim tem um cheiro de uma violência... de um ritual eclesiástico... que você é obrigado a acreditar, a entrar nesse rito. Ajoelha lá, por que? Porque levanta na hora da missa... Aí você é obrigado a entrar nesse rito; na hora que pintar o 2 lá você deriva e tal. Ou seja, a porta por onde essas coisas entram para mim ela carrega uma dose de violência enorme. Por outro lado é um produto bonito, no fim. Então o problema é a introdução.

A experiência pessoal do professor vem à tona nessa passagem. Inicialmente, ele concorda que existem assuntos que se prestam mais a associações com situações cotidianas, mas revela que a busca por exemplos como o do cachorro é uma preocupação constante na preparação de suas aulas. O motivo para tal postura é sua experiência pessoal de quase ter desistido de fazer física pela excessiva ênfase no caráter formal dada nas aulas que o professor assistiu quando era estudante. Para ele, ao enfocar os aspectos formais, comete-se 
uma violência com os estudantes por distanciá-los da relação com o mundo físico. Esse distanciamento fica ilustrado de maneira brilhante por um poema recitado pelo professor.

P - Esse é um poema de um cara chamado José Paulo Paes. Esse é o discurso com qual eu mais concordo sobre o que é a educação formal. A minha intuição sobre o que é a educação formal está concretizada nesse poema:

Pavloviana

José Paulo Paes

"a comida, a sineta, a saliva, a sineta, a saliva, a saliva, a saliva, a saliva, a saliva

o mistério, o rito, a igreja, o rito, a igreja, a igreja,

a igreja, a igreja, a igreja

a revolta, a doutrina, o partido,

a doutrina, o partido, o partido,

o partido, o partido, o partido,

a emoção, a ideia, a palavra,

a ideia, a palavra, a palavra,

a palavra, a palavra, a palavra"

$P$ - É por isso que se você fizer essa coisa da analogia, ela mexe com a coisa daqui pra cá (sentido oposto ao poema).

E - Ela vai buscar alguma coisa. Faz o caminho inverso.

$P$ - A emoção, a ideia, a palavra, na gênese essas coisas estão juntas e tem um nível hierárquico. A santíssima trindade é essa coisa aí. E aí a trindade você vai jogando fora, jogando fora e sobra só palavra. [...] O que a gente deveria fazer para falar sobre isso, a gente deveria ler isso e ficar quieto.

A limitação do uso de palavras para representar ideias e emoções é expressa de maneira primorosa no poema. Além disso, a menção de que a ênfase na última linha de cada estrofe sintetiza um dos principais problemas da educação formal é digna de reflexão. Analisando diversas manifestações do professor nas aulas como "podemos falar em densidade populacional do Brasil", "a palha vai dizer para você se o regime é rotacional" ou "pensa numa estação de metrô que é igualzinho", percebemos que as mesmas são manifestações de seu esforço em trilhar o caminho no sentido inverso do poema para buscar a origem, a essência, a conexão das representações com o mundo. 


\section{Uso de representações visuais (gestos e figuras)}

E - A sua aula é muito visual, no sentido gestual e pictórico. A sua apostila tem várias funções na aula. Ela não é só o seu material de apoio. Ela é por onde as linhas de fluxo passam. A porta tem diversas funções. Desenhos. Isso também está associado a essa maneira de que representar o conhecimento por palavras é um aspecto pequeno de uma coisa maior?

$P$ - Sem dúvida. Isso daí tem uma componente sessenta e oito nisso dai. Quando eu puder fazer uma demonstração com um aparelho moderno e uma gambiarra, eu vou preferir uma gambiarra. Eu acho que um Volks é um carro muito mais democrático do que o Honda. Por que? Porque se o Volks quebrasse, eu, sem saber grande coisa, poderia fazer alguma coisa ali. Você conhece o conceito de reificação? Esse aspecto de reificação está presente na minha prática profissional.

$P$ - Tem dois conceitos que foram muito discutidos - e isso tem uma componente política aí que é alienação e reificação. O que é alienação? [...] eu chego pra você e digo: você quer entrar em uma pós-graduação? Você pode ou não entrar, mas se você quiser, você ter que fazer o que eu quero. Isso significa que eu estou chupando a sua alma e você passa a ser um servo meu, do sistema. Então esse negócio de fazer uma demonstração com gambiarra... [...] Claro que se você for fazer física vai ter que usar o aparelho sofisticado. Mas essa coisa de você colocar ao alcance do cidadão comum, aí tem esse caráter de dizer "você também é proprietário dessa coisa". Física não é o que os caras fazem no laboratório, é o que você pode fazer. Então é meio isso de transferir a propriedade do conhecimento para o cara. Isso é uma componente que ela é intencional e ideológica. [...] Não deixa o cara te roubar. Eu estou lutando aqui para não roubarem do meu e você também luta para não roubarem do seu. Só isso. E aí cada um segue a sua vida, você não precisa seguir as minhas ideias, segue as suas. Mas você é proprietário de um pedaço da relação.

O intenso uso de gestos e representações pictóricas nas aulas parece estar associado à busca do professor pela reificação, que está relacionada com a apropriação do conhecimento pelo estudante. Notamos também uma crítica ao sistema educacional e de pesquisa, quando o professor menciona a frequente alienação dos estudantes provocada por imposições feitas aos mesmos nos cursos de pós-graduação.

E - As representações visuais então são uma espécie de gambiarra nesse sentido do formalismo?

$P$ - Não. Com a gambiarra eu estou lutando contra a alienação, acho. O visual, ele tem a ver com a ideia de que o conhecimento da física é silencioso. É o movimento contrário dessa coisa aqui (poema). Porque a imagem que você tem da natureza é importante. E não é uma imagem visual, é uma imagem em um outro espaço platônico que a gente tem na cabeça, que tem a ver com a visão mas não é igual. É relacionado com a visão. Se eu falo "cubo" pra você, você tem um cubo guardado dentro da sua cabeça. Ele foi visual um dia, mas ele já um conceito que transcendeu essa coisa visual.

Neste trecho fica mais claro que o caráter visual das aulas do professor está associado com o aspecto silencioso do conhecimento físico, o que evidencia o posicionamento de 192 
Lemke (1998) quando o mesmo afirma que conceitos científicos são híbridos semióticos. Além disso, notamos que os gestos e desenhos também colaboram para a busca pelas conexões com o mundo, ilustrada pelo movimento no sentido oposto ao poema.

\section{Explicitar idealizações no processo de matematização}

E - Vamos pensar nesse movimento de matematização de uma ideia, quer dizer, ou de abstração, num sentido de descolar da realidade [...]Você com frequência faz questão de mencionar isso de maneira explícita: "olha, esse sistema de referência ele não está na natureza, ele é um instrumento de pensamento", [...] "isso aqui não é bem um quadrado, não é bem unidimensional". Qual é a importância de deixar isso de uma maneira clara nesse processo de abstração? E eu percebo que isso leva um tempo bastante grande da aula para construir as abstrações. Queria que você falasse um pouco sobre os motivos de fazer isso de maneira explícita, de deixar claro... você está fazendo um modelo, que isso é um instrumento de pensamento.

$P$ - Eu acho que é o mesmo movimento de você explicitar para o cara que o nosso discurso é uma construção. Quando eu faço isso na aula, eu faço porque eu acho legal. Eu fico feliz em fazer isso. Agora, se você me perguntar por que eu fico feliz com isso, eu acho que é porque na aula e no conhecimento ele tem um elemento religioso. [...] Essa relação é mais construída do que a gente costuma acreditar. Então, isso é apenas para partilhar a minha sensação que, sei lá, você pega um sistema de referência (gesticula três eixos) aquilo lá é uma coisa falsa. Entre aspas. Mas aqui não é o mundo, é uma representação do mundo. $A$ física e o discurso do conhecimento são representações do mundo. E essa representação ela é falha, necessariamente, porque ele pega apenas um pedaço da nossa relação com ele. Pega dez por cento da parte do mundo que dá pra gente cobrir com verbos, palavras, símbolos e etc.

Em inúmeros momentos ao longo das aulas notamos que o professor explicita o caráter humano das representações, como em "esse sistema de referência não está na natureza", "você faz um corte matemático no fio" ou "o branco é a matemática, é você pensando". A resposta do professor mostra que ele julga importante explicitar isso para os estudantes para que os mesmos percebam que o conhecimento físico é uma construção humana que dá conta de uma pequena parcela do mundo.

\section{Importância da interpretação}

E-Eu pensei em identificar nesse processo e aí reflete uma frase que você falou uma vez, em um determinado momento você falou assim: a fisica sai da natureza, mas tem que voltar pra natureza. Então pensar a matematização como um processo. Você matematizou, você chegou em uma estrutura. E isso é muito fácil de identificar quando você resolve um problema. [...] Chama atenção também que problemas tem uma duração, tem uma importância muito grande. Levam cinquenta, sessenta minutos. [...] Mas me chama atenção que depois que terminou a conta, aí começa um processo de volta. Começa um discurso de dizer o que é que essa conta está me dizendo no mundo física, qual o significado disso. Então, eu queria te perguntar se pra você, soa razoável que a gente possa falar [...] em dois movimentos: um, por 
exemplo, eu vou caminhando no sentido de matematização, aí eu chego, eventualmente aí eu opero com isso, eu uso a ferramenta, a estrutura e chego no final e retorno. Aí eu começo a me perguntar o que isso significa, e se isso for zero e tal. Eu queria te perguntar se isso é razoável, se você se identifica, se você acha plausível falar nesse processos de matematizar alguma coisa e interpretar. Trazer o formalismo de volta para o mundo real.

$P$ - Eu acho isso fundamental, mas por que isso é importante? [...] Uma coisa que acontece é o escolismo. $O$ conhecimento deixa de ser alguma coisa que vai ser propriedade sua e passa a ser a moeda de você poder ter sucesso na escola. Ai quando você termina o problema na prova, você põe um retângulo em volta da fórmula e acabou. Aquilo lá é onde você queria chegar. Na apostila eu acho que eu cito a coisa do dedo da lua. É um provérbio chinês que fala que o dedo serve para apontar para a lua, o bobo olha para o dedo e uma pessoa inteligente olha para a lua. Então esse construto aí que é o resultado formal da coisa, ele é um dedo. E aí é a hora de você começar a ter o barato. Aí se você parar lá: (olhando para o dedo) resolvi: e é igual a não sei quanto, quatro terços pi etc... Se você parar lá...você deixou de fazer tudo... pegou a parte mais legal que você tinha da atividade e falou "eu agora parei antes". É a mesma coisa de você falar assim: vamos almoçar em um restaurante legal. Aí você vai, pega o trânsito, para na porta e não entra no restaurante. É meio isso. Toda essa discussão se dá no contexto do mercado de livros. Porque esse grandes livros, tipo Halliday, eles não fazem isso de propósito. Porque na hora que você olhar a linha pontilhada, se torna meio que um caminho pessoal. [...] E ai isso não vende. Porque se ele optar por um ele deixou o outro de lado. [...] Então eles não colocam questão de interpretação, de nada pessoal ...é o dedo. [...] Isso não é só gostoso, é útil também. Se você olhasse esses resultados de uma conta que você calcula campo elétrico de sei lá o que, se você olha aquela expressão final ... que diálogo bizarro entre os vários elementos. $O$ elemento da geometria com elemento da carga, um foi parar em baixo, ou tem a raiz de três no outro... Aquela expressão é uma espécie de bolo que você colocou vários ingredientes e ele se amalgamou lá e virou aquela expressão compacta, mas de certa forma você vê de que maneira que as ideias de vários setores diferentes são misturadas naquela expressão. Isso também é um negócio legal.

Em sua resposta o professor demonstra achar plausível a imagem de movimentos em sentidos opostos (matematização e interpretação) representada no modelo teórico da Seção 2.3. Durante as aulas, esses processos ficam exemplificados em frases como "o jogo da física é esse: é jogar símbolos na natureza, tirar os símbolos e extrair a natureza de volta". A importância de se extrair a natureza de volta é destacada em sua metáfora: "o importante é olhar para a lua, não para o dedo". Observamos novamente uma crítica ao sistema educacional, ao "escolismo", quando o mesmo aponta que na escola há uma sobrevalorização do produto na forma de um resultado correto, em detrimento do processo para a obtenção do mesmo e principalmente da avaliação crítica do resultado final. É essa avaliação/interpretação do resultado a posteriori que constitui "a melhor parte da atividade", pois permite explicitar ao estudante a profunda inter-relação entre os símbolos e o que eles representam fisicamente, “o diálogo bizarro entre os elementos". Isso justifica o padrão matematização-técnicainterpretação encontrado em muitos dos episódios referentes à resolução de problemas. 


\section{Papel da abordagem operacional da matemática (técnica)}

E - Eu queria conversar um pouco com você sobre o papel que a parte operacional, técnica, que você chama de "girar a manivela". Qual você acha que é o papel que essas coisas tem nas suas aulas? Eu vou te dizer a minha impressão e aí a gente conversa um pouco sobre isso. Eu percebo que você faz isso. Isso faz parte das suas aulas. O girar a manivela. Resolvendo uma integral, chama isso de U e deriva etc. Mas você passa uma imagem claramente de... não sei se eu uso a palavra displicência, ou algo de ser mecânico. [...] A imagem que você passa é diferente quando você está fazendo essas coisas. Qual é o papel, pra você, desse processo de girar a manivela nas aulas?

$P$ - Talvez tenha o papel e a maneira que eu me relaciono com ele. São duas coisas. O papel é o seguinte: isso em física é absolutamente importante. Se você olhar meu trabalho de pesquisa, se você pegar o número de horas que eu trabalho, a maior parte do tempo eu estou fazendo isso. Por outro lado, eu considero que isso é uma coisa que pertence a um outro domínio do conhecimento, que é importante, mas ele na aula... a aula é uma outra coisa. [...] Na aula você não pode fazer tudo. A aula é uma janela que você oferece para o estudante. Você não pode aprender lá. Você vai lá, eu dou a aula e você diz que aprendeu tudo aquilo. Isso é impossível. A parte técnica, por exemplo, fazendo uma analogia: um cara que toca violino, a mão dele tem que saber muito para ele ser um bom violinista. Eu não posso ensinar a sua mão a saber as coisas. Você tem que praticar. Aí você erra, pratica, erra, pratica. Então, eu sinto que na aula não dá para ensinar isso. Então qual a função da aula? É situar o conhecimento. Tá tudo meio confuso. Por que eu faço isso? Grande parte do ensino que eu tive, eu nunca fui na sala do professor dos meus colegas e ver o jeito que ele ensina... então eu não sei isso. Os alunos sabem mais que eu. Mas a sensação das aulas que eu tive, e eu tenho a intuição que de certa forma ela se perpetua, a pessoa sente que se ela fizer a conta inteirinha na lousa e fizer todas as passagens, aquilo é uma aula boa. Porque aquilo é um material que você viu uma vez na vida, seguiu a sequência da conta, toma nota, se apropria, codifica pra você mesmo aquele conhecimento, você depois reproduz... Você sabe o que quer dizer a palavra explicar? Essa palavra "plica" é a mesma origem da palavra "prega"... uma roupa você faz uma prega. E isso que dizer dobra. [...] Então explicar é você eliminar as dobras. Então você explica, você alisa algo que está engruvinhado. E aí se você pegar o conhecimento de um certo tema, tem muitas coisas engruvinhadas. O que eu sinto que normalmente é a opção que é feita é desengruvinhar bem a matemática. O formal. Mencionando pouco as outras coisas. Eu sinto, por exemplo, da minha experiência pessoal de trabalhador na área, que a ligação entre a matemática e a natureza é bastante complicada e ela ocorre de muitas maneiras. [...] É como se houvesse muitas dobras escondidas que você tivesse que abrir e essa imagem eu não acho ruim, não. Essa coisa engruvinhada é uma coisa que você só olha o lado de fora dela. E quando você começa a abrir que você percebe que tem uma outra dimensão, no sentido matemático mesmo, do conhecimento que é interno lá dentro e tem várias dimensões internas. [...] Então eu gosto de aproveitar a aula para tentar abrir essas outras coisas, sendo que para os alunos que a gente tem aqui, eles têm o treino matemático. Eles fazem isso bastante bem em outro lugar. Então, na aula, não vale a pena gastar muito tempo. Tem coisas mais importantes pra gastar o tempo da aula. [...] Você tem no espaço múltiplas dimensões, vários eixos de valores, de dimensões do problema e aí a gente não pode ficar em um só. E aí a gente fez toda a matemática e você se vira com os outros. Isso é muito duro. Eu diria que a maioria das pessoas se ela não for incitada a fazer isso ela não fará. [...] Então, o que eu gosto de fazer na aula é pegar a multidimensionalidade desse espaço de eixos de dimensões do conhecimento e exercitar um pouco cada uma delas. E na verdade, com isso eu espero estar 
mostrando que existe o espaço. [...] Agora, por outro lado, o exercício do eixo da técnica é super importante, mas por outro lado ele é técnico. [...] Eu acho que a coisa da técnica, você não aprende uma vez só. Você tem que repetir isso porque você não entende direito. [...] Pra terminar esse tema, e por que eu tenho uma atitude meio displicente? É meio para... ai é meio uma atitude política. Mostrando que tem isso aí, mas isso é só um pedaço. Eu não acho que isso é o máximo. Isso é uma coisa modesta. Importante, porém parte. Modesta é uma palavra errada. É uma parte. Não venha com a atitude de que isso aí é tudo porque não é.

Muitos aspectos que corroboram a qualidade da abordagem didática deste professor são explicitados neste trecho. Como ele mesmo menciona, parece que existe um consenso implícito no ensino de física em nível superior de que a qualidade de uma aula está diretamente ligada à capacidade do professor em efetuar procedimentos lógico-operacionais de maneira clara e racional. Posicionando-se de maneira contrária a tal consenso, o professor esclarece que apesar da parte lógico-formal ser um importante aspecto do fazer física, ela é apenas uma das diversas facetas que precisam ser explicadas nesse grande emaranhado que é o conhecimento físico. Essa concepção se reflete na multiplicidade de categorias identificadas em muitas de suas aulas. Além disso, notamos também uma postura reflexiva sobre sua concepção de docência, quando o professor expressa sua consciência dos limites da relação entre ensino e aprendizagem, defendendo que existem coisas que não podem ser ensinadas e que a função da aula é oferecer uma "janela ao estudante".

E - Eu vejo que em alguns casos você até fala "essa conta está feita na apostila", por exemplo. É comum e às vezes proposital que foi um 2 lá e o aluno fala "foi um 2 lá" e você fala "ah! um 2. Pronto". É essa imagem que você está mostrando mesmo: errei uma coisa, desculpa e pronto. [...] Me parece que é um fato que a tradição ou a maioria dos professores de física dão um peso muito grande para essa parte técnica. Então o que me interessa começar a olhar mais pra frente é o contraste, o tempo, a ênfase dada a essa parte operacional e técnica em professores diferentes. [...] Por que você acha que esse excessivo foco na abordagem técnica é tão comum em aulas de física?

P - Olha, tem uma razão cínica que eu não sei qual é o peso dela no processo, mas isso daí é fácil. Esse fato pesa em alguma coisa em algum lugar. Eu não acho que é um fato preponderante, mas ele tem essa coisa. [...] É fácil em dois sentidos porque eu digo, é fácil e é ingênuo, talvez. É ingênuo porque se você teve aula desse jeito você vai lá e reproduz e fácil porque você não precisa criticar o que você está fazendo, você vai lá e faz. Tem uma coisa que sempre me surpreende na educação que é o seguinte: muitas vezes as pessoas apresentam uma coisa que pra elas foi muito difícil de aprender, como se fosse fácil. Elas falam "tá vendo aqui" e isso daí custou um tempão para ela chegar nisso. Quando era ela um aluno ela não entendia isso. Então eu não sei se isso também envolve uma imagem de como é que a gente funciona com o ser humano inteligente. Se eu achei o caminho das pedras, se eu contar pra você, você vai entender direto. Ou seja, isso dai talvez vá a ideia antiga de que a gente é uma página em branco para ser escrita do que uma estrutura na qual os conhecimentos dialogam com as coisas pré-existentes, que você tem que mudar coisas, rearrumar coisas, o que é muito mais difícil. Então, não sei, estou chutando...essa componente está lá presente. E também tem uma coisa que se você sair dessa coisa, você se 
compromete mais, porque essa forma é uma coisa sobre a qual ninguém diverge. Então, de certa forma, esse é o núcleo de comunicação da física e aí a gente só fala acerca de unanimidades. E talvez esse seja o motivo. Eu ensino as unanimidades da física que é a conta... como eu passo de uma linha pra outra e aí não tem dúvida, todo mundo vai fazer meio igual. [...] Isso pode ter a ver com o mercado editorial. Os livros texto não autorais de grande massa... [...] os livros escritos para as massas eles precisam vender. [...] Então o texto foge de questões de interpretação do mundo porque isso poderia reduzir o âmbito de possíveis compradores do livros. [...] E aí como a gente é baseado na coisa do livro texto, continuamente, a gente vai lá e pega o livro texto e acha que aquilo lá é o que é... adota o livro texto pra você e para os alunos e vai fazendo isso. [...] Então quando você dá a matemática você está dando o oficial.

Nesta passagem, o professor conjectura sobre as possíveis razões para a predominância de abordagens formais no ensino de física: ao ensinar as "unanimidades" da física o docente está seguro, foge das incertezas, das subjetividades e não precisa assumir uma postura crítica em relação ao que está fazendo. Além disso, o professor acredita que muitos docentes privilegiam aspectos formais/técnicos por terem uma concepção ingênua de que basta explicar de maneira clara e detalhada que o estudante será capaz de entender: “eu já achei o caminho das pedras e posso mostrá-lo para meu aluno".

\section{Discussões epistemológicas nas aulas}

E-Associado a isso, [...] eu vejo uma preocupação, vamos dizer assim... epistemológica... falar sobre essa relação e eu vou falar especificamente de matemática e fisica. Eventualmente isso te diferencia...não é tão comum achar um professor que pare e pense: qual é o papel da matemática na fisica. Você tem comentários... momentos em que você para pra pensar sobre a construção da ciência. Acredito que isso se deva à sua inquietação pessoal e à sua formação em epistemologia, em pensar sobre essas coisas. A pergunta está associada a que importância você dá a esses comentários epistemológicos na aula?

$P$ - A separação entre algo que a gente chama de física e epistemologia ela é artificial. Ela não está no mundo. A gente que fez, sociologicamente, em algum momento. E eu acho que se você praticar um pouco, você vai ver que a epistemologia está em todo lugar. Eé até um jogo divertido... você vai olhando e achando esses componentes muito fortes. Até esse negócio da etimologia também, se você vê esse negócio da palavra "explicar"... quando me contaram isso eu fiquei muito feliz. Isso é legal porque é auto contido... quando você explicou, você explicou a palavra explicar. [...] Então a possibilidade de fazer isso ela está na linguagem verbal e está na linguagem simbólica também e está na nossa relação com o mundo. [...] Tem um preconceito aí, de algum jeito. E é só tirar o preconceito que isso acontece sozinho. Claro que pra você tirar o preconceito dá trabalho. Mas então essa coisa na aula, talvez é uma defesa contra o preconceito. Eu sei que você não pega todo mundo, mas tem uns caras que são mais sensíveis a esse tipo de coisa e pra eles isso é bom.

Comentários de natureza epistemológica são muito comuns na aula do professor e sua resposta possui semelhanças ao alerta de Einstein sobre o preconceito dos pares em relação à 
epistemologia, bem como à crença do físico alemão de que esse tipo de discussão promove ao estudante a necessária "independência de julgamento". De fato, mesmo que de maneira inconsciente, todo professor de física manifesta posicionamentos sobre a construção desta ciência em suas aulas. Assim, fazendo isso de maneira explícita como na introdução da corrente de deslocamento na Aula 39, o professor pretende incentivar os estudantes a refletirem constantemente sobre os processos da construção de conceitos físicos. Entretanto, é importante ressaltar que tal discussão é mais profícua quando localizada em um episódio particular.

\section{Demonstrações nas aulas}

E - Tem outro item que eu queria perguntar. [...] eu estou falando sobre as demonstrações, ou deduções, em que você vai partir de alguns princípios e você vai demonstrar alguma proposição. Posso dar um exemplo concreto. Talvez seja melhor pra gente discutir. $O$ teorema de Gauss e o teorema de Stokes. Nas suas aulas você fala assim: olha, isso é um teorema matemático. E você não apresenta a demonstração formal do teorema matemático mas você mostra que ele é válido em uma situação. Você faz isso para os dois. [...] Então a pergunta, de maneira geral, é essa: demonstrações, partir de princípios, articular a maneira dedutiva, qual é o papel desses processos nas suas aulas?

$P$ - Tem a ver como é que você aproveita o tempo da aula e o que é possível você aprender. $\boldsymbol{A}$ minha sensação quando demonstraram coisas na minha frente é que ela é muito mais sociológica do que lógica. No seguinte sentido, eu falo assim: tudo bem. Esse cara estudou bastante, ele é uma pessoa honesta. Ele não está me enganando. Então o que ele está fazendo é correto. Mas eu não consigo, dada uma situação complexa de demonstração, se for uma coisinha pequena tudo bem, mas se for uma coisa complexa, eu não consigo seguir aquelas coisas e ser crítico... pensar "nossa, será que essa hipótese realmente se sustenta? Será que isso realmente é assim”. Isso não dá. Você vai engolindo aquele negócio lá. E aí, no fim tudo fica respaldado pelo fato de um cara honesto ter feito isso na sua frente. [...] A atitude intelectual frente a essa coisa, é essa. Por outro lado, é óbvio que se alguém demonstrou o teorema e os matemáticos criticaram isso... isso é muito importante porque tem o respaldo deles no resultado. Então é legal que aquele resultado tenha sido criticado e etc. Mas eu acho que a demonstração não permite a crítica. E para a física é muito mais importante você ter uma intuição... a intuição do teorema é melhor do que a demonstração, porque a demonstração... no limite você poderia falar que ela é uma truculência... porque eu falo assim "olha, é assim, você entendeu?" (aponta para o papel) E aí o que você faz lá? Não faz nada, vai engolindo. E aí terminou e está ali demonstrado. E aí o que você faz com isso? Você entendeu? Não entendeu. Porque você não é capaz de entender daquele jeito. Tem um monte de passagens lá. Mas por outro lado, aí você tem um negócio que está registrado em algum lugar que é do jeito que deve ser feito. Feito isso, você tem que ir pra casa e seguir aquele negócio. Mas se é pra ser assim, você vai, segue em casa direto dai você ganha intuição. A intuição seria assim: quando você usa, quando ele é útil, quando não é, etc. Ou seja, situar o teorema no contexto naquele instante, que também é o primeiro contato... isso é diferente, não estou falando que em todos lugares vai ser assim. Se você tiver uma formação mais madura, ai você pode fazer outras coisas. Mas naquela primeira vez que você vê, é muito melhor falar pra que ele serve. 
Em sua reposta o professor revela um posicionamento crítico em relação à efetividade de se realizar demonstrações em sala de aula. Seu principal argumento é que muitas vezes o aluno não consegue acompanhar o processo de demonstração de maneira crítica a ponto de compreender profundamente as razões para cada uma de suas etapas e, dessa forma, a demonstração adquire um caráter autoritário. Especificamente para o caso dos teoremas de Gauss e Stokes, o professor acredita que adquirir uma intuição sobre "como os teoremas funcionam" é mais importante do que saber demonstrá-los formalmente. Em seguida, o questionamos sobre a possibilidade de se considerar critérios para avaliar a pertinência de se realizar determinadas demonstrações em sala de aula.

E - Você acha que um dos fatores pode ser também a questão da maturidade? Porque quando você diz: eu vejo a demonstração, eu não entendo. Eu tenho que aceitar com uma espécie de autoridade. É possível, talvez, falar que tem demonstrações e demonstrações? Porque, por exemplo, eu estou lembrando da nossa conversa lá do curso de relatividade que as transformações de Lorentz, passo a passo, você não chegou a demonstrar. Tinha o processo de rodar a manivela. Você estruturou. Os princípios... as asserções são essas e admitindo essas asserções eu chego nisso daqui. Mas em uma aula que você faz a demonstração das transformações de Lorentz para os campos. Você vai passo a passo fazendo as demonstrações. Você faz todo o destrinchar. E naquela época a gente conversou e você falou "aqui tem valores que me mostram alguma coisa do processo criativo, ou das angústias que eu acho importante mostrar e aqui não teria”. Então você acha que existem demonstrações e demonstrações?

$P$ - Por exemplo, esse negócio do curso de relatividade, isso eu acho importante porque isso talvez ensine naquela situação lá, como é que a gente pensa na transformação dos campos... que é uma coisa dura da gente entender; mudança de referencial dos campos. Então aquele caso lá, é um caso onde eu acredito que o conteúdo central do curso está sendo importante. Porque no teorema de Gauss não, porque é um teorema da mecânica dos fluidos lá. Como o teorema de Pitágoras, eu não iria demonstrar isso nunca em uma aula. Mesmo que o cara nunca tivesse visto, eu ia pegar alguns exemplos e fazer lá. A série de Taylor eu faço assim, por exemplo. Uso a calculadora, expande ali, primeira ordem não sei o que. Porque ai é mais uma coisa que... eu diria que é uma demonstração de uma técnica e não de uma coisa que traga um conteúdo epistemológico sobre o tema central do curso. Essa é a diferença. Quer dizer, não é uma política e ponto. Tem hora que sim e hora que não.

Portanto, parece que a utilidade de se conduzir demonstrações de proposições a partir de princípios físico está relacionada com o conteúdo específico e com as possíveis mensagens que tais demonstrações podem transmitir aos estudantes. O professor insiste que a “demonstração de uma técnica", como a regra da derivada do produto por exemplo, não é tão importante em aulas de física por não envolver temas centrais do curso. 


\section{Importância da metacognição ("isso não é fácil" e quadro resumo)}

E - Você falou que às vezes na educação as pessoas não se dão conta do quão difícil foi pra elas mesmas aprenderem e essa consciência se reflete nas suas aulas... é uma espécie de metacognição. Você explicita isso, você incentiva isso. Você incentiva que o aluno pare, pense e não ache que aquilo é fácil.

$P$ - Só para completar, tem uma outra coisa: se você fala "veja como isso é fácil", inibe a sua pergunta... que também pode ser um instrumento pedagógico. Porque você mantém sua aula no trilho, você segue o horário que você planejou.

E - Você bloqueia essa via.

P - Ela é incipiente. Ela se manifesta com dificuldade. Ela foi muito reprimida e vão continuar sendo reprimidos...ai ela não se manifesta e acabou.

Os comentários de natureza metacognitiva são frequentes nas aulas do professor. Eles envolvem o incentivo à auto-regulação ("agora para e pensa de você entendeu isso direito"), a explicitação de processos de pensamento (“como é que a gente pensa nesse problema”), bem como a consciência da complexidade do tema ("não acha que isso é fácil"). Em relação a este último aspecto, o professor destaca que ao transmitir uma ideia de trivialidade o educador inibe a pergunta do estudante, fazendo com que a aula se torne um monólogo. Conforme veremos na Seção 7.1, essa é uma diferença relevante quando comparamos a postura deste professor com outro mais "tradicional".

Outro recurso que tem claramente uma função metacognitiva é o quadro resumo do eletromagnetismo. A seguir, transcrevemos as justificativas do professor para seu intenso uso e também seus esclarecimentos sobre o processo que o levou a conceber o quadro resumo ao longo dos anos de experiência lecionando este curso.

E - É impossível não notar que o quadro que você monta... provavelmente já da primeira ou segunda aula até a última aula, tem papel fundamental no curso inteiro, no seu discurso. Você vai ficar quinze, vinte minutos do início de cada aula montando aquele quadro. Então ele tem um papel central. E uma coisa que me parece muito interessante... as leis com palavras, com figuras, com equações. Vai montando toda aquela estrutura. Eu queria te perguntar quando que ele nasce, como ele foi sendo aprimorado... qual a importância? Por que você acha que esse quadro é tão importante no curso como um todo?

$P$ - Eu não sei se isso seria universal em qualquer curso, mas nesse curso é porque o ícone são as equações de Maxwell mais a força de Lorentz. Então é uma coisa que você depois do curso deveria aprender o significado. Quando eu comecei a dar esse curso, eu não tinha essa visão e eu tive que gastar bastante tempo pensando nisso para recuperar essa ideia que ela dita em algum lugar assim... mas que ela nunca é enfatizada que o objeto de desejo são as equações de Maxwell. [...] As equações de Maxwell são uma espécie de catedral que é o produto final, tridimensional, superdimensional... de organização daquele conhecimento. E aí, o livro corresponde a uma planta e a passagem por ele é lenta e você é inexperiente. Se você der a planta para um arquiteto ele olha e vê um prédio, mas o cara comum não vê. 
Então você chega lá e fala (mostra uma folha): olha o primeiro andar, aí você passa para o segundo e nem lembra que o primeiro existia e tal. Então, claro que isso está sendo feito espalhadamente. Ai você faz exercício... você puxa um negócio que precisava estar no meio, falar de metais, que não nada a ver com as equações de Maxwell. Então você vai fazendo uma coisa meio fractal, meio desorganizada. Uma espécie de hipertexto. Do mesmo jeito que o hipertexto destrói a sua racionalidade moderna, no sentido de pós-renascentista, essa apresentação destrói a unidade moderna, também no sentido de pós-renascentista do eletromagnetismo. Como se fosse fácil pra gente perceber essas unidades. Isso pra mim foi difícil. Eu tive que militar em cima. Fiquei contente de ter visto isso... achei que isso é um instrumento unificador, é um foco... é um centro. [...] Ai também tem várias coisas legais... a teoria de Maxwell é uma teoria muito importante na física mesmo, particularmente todo mundo acha bonita e eu também acho, mas isso é uma outra relação afetiva que a gente tem, mas ela é importante. $\boldsymbol{E}$ a unidade dela simplifica sua relação com o mundo, porque eu acho que é muito legal se eu te der uma situação inesperada [...] é confortante falar: equações de Maxwell. Corre lá. Você vai ter que sair daí. Então isso eu diria que tem um lance de economia e de força da teoria, de saber que aquilo lá tem que dar conta.

No decorrer da entrevista, todas as posturas ilustradas pelas oito categorias mostraram-se aspectos relevantes que deveriam ser considerados quando se aborda o papel da matemática na física em um contexto de ensino. Assim, conforme mencionado previamente, a entrevista também teve papel de validação interna das categorias. Além disso, tivemos acesso de maneira clara e direta às intenções didáticas do professor e às justificativas dadas pelo mesmo para o comportamento identificado ao longo do curso, o que nos revelou aspectos sobre os quais não teríamos acesso analisando somente seu discurso didático. Dessa forma, a abordagem diferenciada que encontramos ao longo das aulas foi elucidada ao longo de seus depoimentos por sua busca constante em partir do concreto (situações cotidianas, analogias) para construir abstrações, por sua tentativa de evitar demonstrações formais que os estudantes não consigam acompanhar de maneira crítica, por sua postura de não sobrevalorizar o papel ferramental da matemática e de enfatizar a importância da interpretação física de expressões matemáticas. Além disso, a postura incomum identificada nos episódios também foi corroborada por aspectos pessoais como seu comprometimento com a aprendizagem dos alunos, o reconhecimento da complexidade do tema que ensina e das dificuldades comumente enfrentadas pelos estudantes, sua visão crítica sobre os limites e possibilidades de uma relação de causa e efeito entre ensino e aprendizagem, sua experiência pessoal de quase ter desistido da física e sua posição contrária ao autoritarismo, à alienação e à padronização dos livros texto.

Seguindo a sequência utilizada para a categorização dos episódios, apresentamos um quadro resumo que sintetiza as justificativas e crenças manifestadas pelo professor ao longo da entrevista para as abordagens identificadas em cada uma de nossas categorias de análise. 


\begin{tabular}{|c|c|}
\hline Categorias & Justificativas/crenças/experiências \\
\hline $\begin{array}{l}\text { Matematização } \\
\text { explicitada }\end{array}$ & $\begin{array}{l}\text { É preciso explicitar para o aluno que o nosso discurso é uma construção; Eu fico } \\
\text { feliz em fazer isso na aula; Essa relação é mais construída do que a gente costuma } \\
\text { acreditar; A física e o discurso do conhecimento são representações do mundo; } \\
\text { Essa representação ela é falha, necessariamente, porque ele pega apenas um } \\
\text { pedaço da nossa relação com ele. }\end{array}$ \\
\hline $\begin{array}{l}\text { Importância da } \\
\text { interpretação }\end{array}$ & $\begin{array}{l}\text { Escolismo: O conhecimento deixa de ser propriedade sua e passa a ser a moeda } \\
\text { de você poder ter sucesso na escola; O dedo serve para apontar para a lua, o bobo } \\
\text { olha para o dedo e uma pessoa inteligente olha para a lua; Esse construto do } \\
\text { resultado formal é um dedo; Se você parar lá, você deixou de fazer tudo; Na } \\
\text { expressão final você vê que existe um diálogo bizarro entre os vários elementos. }\end{array}$ \\
\hline $\begin{array}{l}\text { Papel da abordagem } \\
\text { operacional da } \\
\text { matemática (técnica) }\end{array}$ & $\begin{array}{l}\text { Isso em física é absolutamente importante; A aula é uma janela que você oferece } \\
\text { para o estudante; Eu sinto que na aula não dá para ensinar isso, a prática é } \\
\text { necessária; Consenso implícito e falso: se o professor fizer a conta inteirinha na } \\
\text { lousa, aquilo é uma aula boa; Ensinar somente as coisas formais é uma violência, } \\
\text { parece um ritual eclesiástico que você é obrigado a acreditar; Razão para postura } \\
\text { displicente: é uma atitude política de mostrar isso é só uma parte; Ensinar isso daí } \\
\text { é fácil porque você não precisa criticar o que você está fazendo; São as } \\
\text { unanimidades da física (conta), todo mundo vai fazer meio igual; Problema dos } \\
\text { livros texto; Quando você dá a matemática você está dando o oficial. }\end{array}$ \\
\hline $\begin{array}{l}\text { Representações } \\
\text { visuais (gestuais e } \\
\text { pictóricas) }\end{array}$ & $\begin{array}{l}\text { O conhecimento da física é silencioso; É o movimento contrário do poema (José } \\
\text { Paulo Paes); A imagem que você tem da natureza é importante; Ela não é uma } \\
\text { imagem visual, é pertence a um outro espaço platônico que a gente tem na } \\
\text { cabeça. }\end{array}$ \\
\hline $\begin{array}{l}\text { Uso de analogias, } \\
\text { metáforas e situações } \\
\text { cotidianas }\end{array}$ & $\begin{array}{l}\text { A noção de gradiente foi tirada do mundo; Os físicos que fizeram as coisas } \\
\text { formais olharam primeiro para o mundo; O que os alunos apreciam é a postura } \\
\text { frente ao conhecimento; Isso tem a ver com a minha trajetória pessoal porque eu } \\
\text { estou tentando fazer com que as pessoas não sofram o que eu sofri; Poema que } \\
\text { representa a intuição sobre o que é a educação formal (palavra, palavra, palavra). }\end{array}$ \\
\hline $\begin{array}{l}\text { Demonstrações nas } \\
\text { aulas }\end{array}$ & $\begin{array}{l}\text { A minha sensação quando demonstraram coisas na minha frente é que ela é muito } \\
\text { mais sociológica do que lógica; Esse cara estudou bastante, ele é uma pessoa } \\
\text { honesta, então o que ele está fazendo é correto. Mas eu não consigo seguir } \\
\text { aquelas coisas e ser crítico; Eu acho que a demonstração não permite a crítica e } \\
\text { para a física é muito mais importante você ter uma intuição do teorema; Muitas } \\
\text { vezes se trata da demonstração de uma técnica e não de uma coisa que traga um } \\
\text { conteúdo epistemológico sobre o tema central do curso; Essa é a diferença, tem } \\
\text { hora que sim e hora que não. }\end{array}$ \\
\hline $\begin{array}{l}\text { Discussões } \\
\text { epistemológicas nas } \\
\text { aulas }\end{array}$ & $\begin{array}{l}\text { A separação entre física e epistemologia é artificial; Se você praticar um pouco, } \\
\text { verá que a epistemologia está em todo lugar; Tem um preconceito aí, então essa } \\
\text { discussão na aula é uma defesa contra o preconceito; Eu sei que você não pega } \\
\text { todo mundo, mas tem uns caras que são mais sensíveis a esse tipo de coisa e pra } \\
\text { eles isso é bom. }\end{array}$ \\
\hline $\begin{array}{l}\text { Importância da } \\
\text { metacognição ("isso } \\
\text { não é fácil" e quadro } \\
\text { resumo) }\end{array}$ & $\begin{array}{l}\text { O que sempre me surpreende na educação é que muitas vezes as pessoas } \\
\text { apresentam uma coisa que pra elas foi muito difícil de aprender, como se fosse } \\
\text { fácil; Se você fala "veja como isso é fácil", inibe a pergunta; Ela (pergunta) é } \\
\text { incipiente, se manifesta com dificuldade; O ícone do curso são as equações de } \\
\text { Maxwell mais a força de Lorentz; Não é fácil pra a gente perceber essas unidades. } \\
\text { Isso pra mim foi difícil; O quadro é um instrumento unificador, é um foco. }\end{array}$ \\
\hline
\end{tabular}

Quadro 10: Resumo da reflexão sobre a prática relacionada a cada categoria de análise. 


\section{Impressões sobre as categorias e a utilidade do diagrama do videograph}

Ao final da entrevista, apresentamos nosso sistema de categorias ao professor e esclarecemos que a conversa foi conduzida de tal forma a buscar suas justificativas e intenções didáticas relativas a cada uma. Em seguida, mostramos os diagramas de alguns episódios de ensino e o questionamos sobre sua pertinência e utilidade.

$P$ - Eu estou com medo disso pelo seguinte: se um tecnocrata pega isso daqui, o cara vai começar a ir no concurso e levar uma maquininha dessa, em vez de focar na aula que o cara dá, ele vai ficar fazendo isso e se ele tiver um padrão do que ele considera o ideal, ele vai dar nota pela máquina.

E - Aí ele deturpou totalmente. Eu tenho esse cuidado na minha cabeça. Essa imagem é legal, ela me mostra uma diferença, mas ela não é suficiente. É preciso analisar o que está sendo abordado mais profundamente de maneira qualitativa.

$P$ - Como instrumento de pensamento eu acho muito interessante porque isso mostra de uma maneira visual e você não entra no mérito... se eu faço uma analogia, você não diz se ela é boa ou não...isso não aparece aí e eu acho legal. Então eu não tem julgamento de mérito. Mas é um dado quantitativo, o que é sempre legal, porque senão você fala assim "gostei porque a analogia dele foi fantástica”, mas não é isso. É usar ou não analogias. Isso aí aparece claramente no quadro de cima. Então eu acho um instrumento muito legal. Porque uma coisa é perceber que a aula é diferente, outra coisa é ver como é que a pessoa está usando o tempo disponível no espaço de categorias que você tem lá e isso é muito legal. $[\ldots]$

$P$ - Isso aí mostra o uso do espectro de possibilidades e a escolha que você vai fazendo. E evidentemente isso reflete por trás o que é saber alguma coisa, porque eu diria que isso é um mapa de cada cabeça. [...] Uma coisa que eu acho marcante da minha aula é que ela tenta ser o menos autoritária possível. Que isso eu acho que é bom para o conhecimento. Isso é uma postura frente ao conhecimento. Agora uma coisa que poderia ser olhada, que eu nunca olhei assim, é o seguinte: essa variação das categorias, o colorido, são movimentos de trazer a pessoa para dentro da aula, ou seja, de ampliar um diálogo. Isso é uma preocupação que eu tenho e talvez essa variedade reflita isso. De dizer "você tá entendendo?", pega o cara com a mão assim... puxar o cara de volta para dentro, individualmente.

A percepção do professor sobre a pertinência das categorias e a utilidade da ferramenta de análise foi positiva. Ao observar alguns diagramas com codificações de suas aulas, o mesmo conjectura que a multiplicidade de aspectos abordados (diagrama colorido) pode refletir sua tentativa constante em "trazer o aluno para a aula". Quando, na Seção 2.1, discutimos o trabalho de Bing e Redish (2009), no qual os autores ilustram quatro posturas didáticas diferentes (professores alfa, beta, gama e delta) para explicar uma fórmula, já prevíamos que o mais provável seria supor que um professor pode manifestar as quatro em uma única aula e que o ideal seria pensarmos em um espectro, uma espécie de perfil que 
ilustraria a ênfase dada a cada uma delas, bem como a ordem em que as mesmas foram manifestadas. A hipótese que nos parece plausível é que não só a ordem em que cada aspecto é abordado, mas também a diversidade dos mesmos em uma aula, sejam critérios que nos permitam avaliar a qualidade da mesma. Dessa forma, poderíamos utilizar nossa ferramenta para comparar aulas e identificar critérios objetivos que nos permitam julgar que uma foi melhor do que a outra. Exploramos esta e outras hipóteses que emergem de nossa pesquisa, e apontamos alguns dos possíveis desdobramentos da mesma no último capítulo. 


\section{7 - CONCLUSÕES E DESDOBRAMENTOS DA PESQUISA}

\section{1 - ANÁLISES COMPARATIVAS PRELIMINARES}

Um dos principais resultados de nossa pesquisa é a proposição de uma ferramenta teórica para classificar abordagens de ensino de física em relação à ênfase no caráter intrinsecamente matemático da construção desta ciência. Tal ferramenta, a qual consiste nas oito categorias de análise, foi amplamente utilizada para a categorização dos 19 episódios de ensino apresentados no Capítulo 5. Nesta seção, a aplicamos novamente com o intuito de avaliar a possibilidade de sua utilização em estudos comparativos.

\subsection{1 - COMPARAÇÃO ENTRE DUAS AULAS SOBRE FLUXO}

Com o objetivo de testar a eficácia de nossa ferramenta de análise para identificar diferenças nos "espectros" adotados por diferentes professores ao ensinarem o mesmo tema, categorizamos uma aula "tradicional" ministrada por outro professor num contexto semelhante $^{44}$. O tema escolhido foi a introdução do conceito de fluxo de um campo vetorial em função de sua importância central para o curso de eletromagnetismo, dado que o mesmo faz parte de todas as equações de Maxwell (forma integral). Optamos por apresentar esse estudo comparativo no capítulo final da tese, pois sua análise ainda é preliminar. Entretanto, acreditamos que este primeiro exemplo já fornece contrastes interessantes que apontam para a pertinência do uso deste instrumento para tal fim. Os diagramas dos trechos referentes à explicação do conceito de fluxo na aula "tradicional" e no estudo de caso são apresentados nas Figuras 48 e 49 respectivamente.

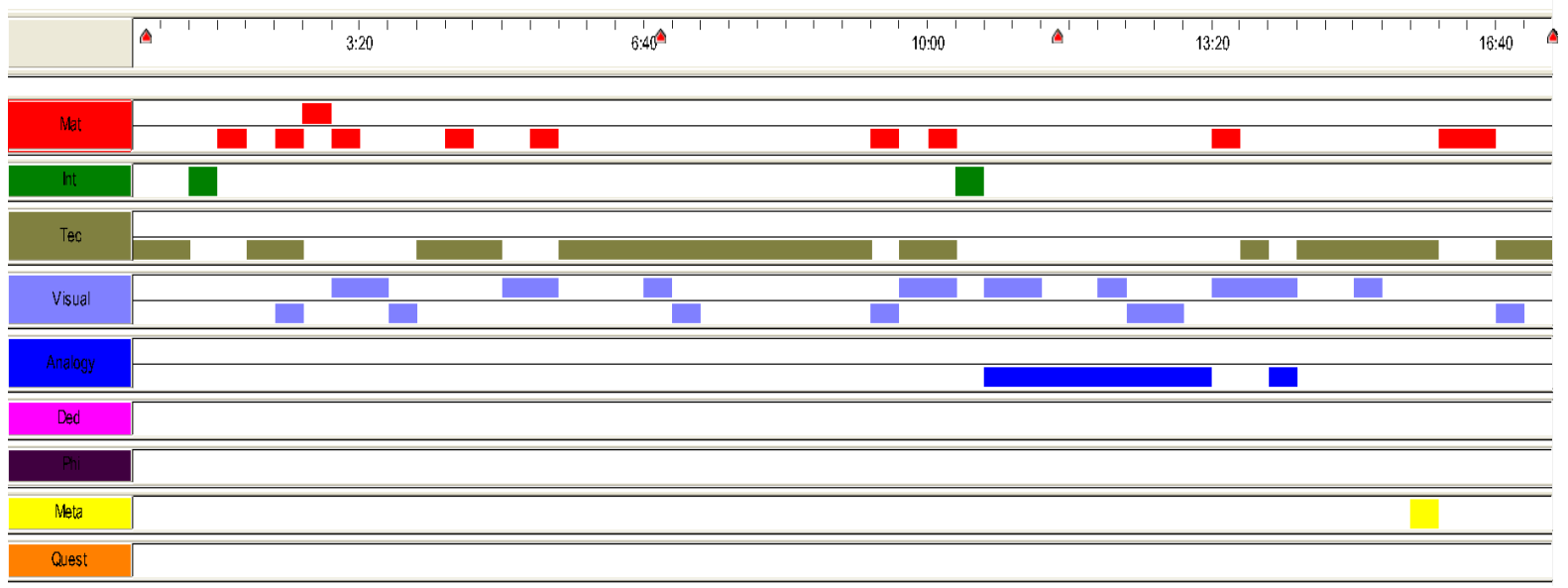

Figura 48: Diagrama da aula "tradicional” de fluxo de campo elétrico (duração $17 \mathrm{~min}$ )

\footnotetext{
${ }^{44}$ Analisamos uma aula ministrada para estudantes do mesmo nível escolar em uma universidade estadunidense e disponibilizada no Youtube (http://www.youtube.com/watch? $\mathrm{v}=$ So_H7iM01hM\&feature=relmfu e http://www.youtube.com/watch?v=Dp-X7t7igRg\&feature=relmfu). Essa análise preliminar foi apresentada em uma comunicação oral na conferência GDCP 2011 em Oldenburg.
} 


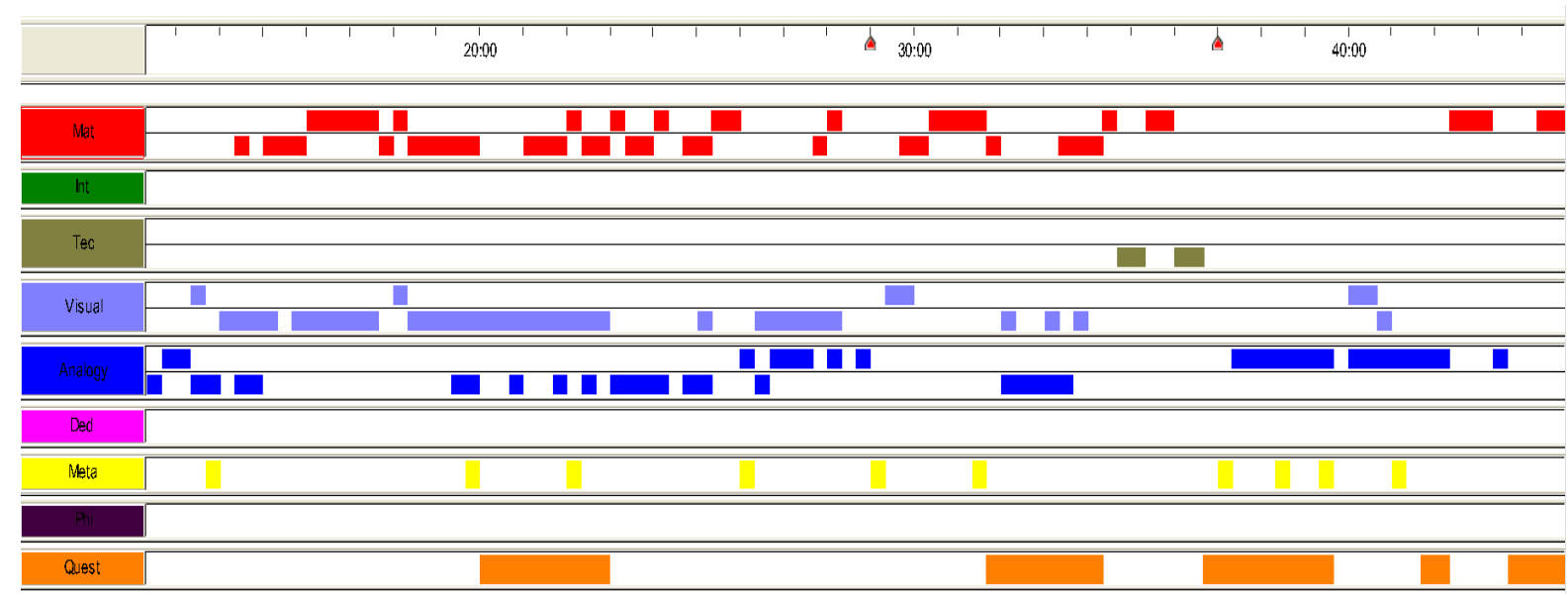

Figura 49: Diagrama da aula de fluxo de um campo vetorial (duração 33 min - Episódio 3)

Olhando somente para os diagramas percebemos algumas diferenças importantes. Primeiramente a explicação do professor do estudo de caso levou quase o dobro do tempo em relação à aula "tradicional". Notamos também diferenças consideráveis quando analisamos as categorias predominantes em cada aula. Salta aos olhos que a categoria técnica está presente em mais da metade da Figura 48. Isso se deve principalmente a dois fatos: primeiro porque este professor utilizou muitos argumentos de autoridade ("isso é definido assim", "vocês sabem isso do cálculo 3") sem apresentar qualquer justificativa e segundo porque nestes 17 minutos ele resolve pequenos "problemas" numéricos para calcular fluxo em diferentes situações.

Os diagramas indicam que ambos utilizam analogias ao longo da explicação, mas o professor investigado em nossa pesquisa o faz ao longo de toda a aula e ressalta não só semelhanças em analogias materiais, mas também semelhanças e diferenças formais (A2). Além disso há uma diferença clara entre o tempo gasto com a matematização do conceito entre os dois diagramas. Por fim, é notável a diferença da interação professor-aluno (qualificador laranja) nas duas aulas. Ela é inexistente na aula "tradicional" e aparece em vários momentos na Figura 48, quase sempre relacionados com comentários de natureza metacognitiva (amarelo).

Naturalmente, os diagramas fornecem imagens de diferentes perfis de abordagens nas aulas, uma espécie de "raio $\mathrm{x}$ " das mesmas, mas é insuficiente para estabelecermos comparações mais precisas. A matematização de um conceito, por exemplo, pode ser feita de diversas formas. Apenas detectar se analogias foram utilizadas não é suficiente para inferir sobre a qualidade das mesmas para explicação de um conceito em particular. Dessa forma, é preciso fazer uma investigação mais detalhada que envolve saber exatamente o que foi 
tratado em cada aula. Selecionamos alguns aspectos para evidenciar o contraste entre as duas abordagens e os apresentamos a seguir. Denominamos P1 o professor da aula tradicional e P2 o professor analisado em nosso estudo de caso:

\section{Introdução do tema}

P1 - A expressão do fluxo do campo elétrico é apresentada logo no início da aula. Assim, a explicação passa a ser conduzida do sentido da fórmula para o significado físico.

0:00-0:40 (Escreve a expressão $\Phi_{E}=\int \vec{E} \cdot d \vec{A}$ no quadro) Fluxo elétrico é a integral de $E$ escalar dA. Essa é a sua definição. Quando você faz o produto escalar entre dois vetores o resultado é um escalar. Então o fluxo é só um escalar, é só um número.

P2 - A postura é completamente diferente. No início da aula o professor procura interagir com os alunos buscando identificar as variáveis relevantes para representar a noção intuitiva de fluxo que os mesmo têm sobre de maneira mais precisa.

12:20 - 14:20 Qual é a ideia de fluxo? É uma ideia importada de mecânica dos fluidos[...] Esse vetor pode ser qualquer coisa, F genérico. Pode ser campo elétrico, magnético, velocidade, campo gravitacional. [...] A ideia é a seguinte: se você pegar um líquido. O que é fluxo de água, como você pensa nesse problema? Pensa num rio. [...] É uma noção razoável falar em fluxo de água. Como é que a gente pensa nesse problema? Parece simples, mas não é. A gente se enrola tecnicamente com essas coisas. Como é que eu penso em fluxo de alguma coisa? Eu estou fluindo através da porta? (abre a porta e sai da sala) (risos) Sim ou não? Como é que você usa essa noção intuitiva? [...]

Além disso, notamos que o professor fala em fluxo de um campo vetorial (genérico), enquanto que o primeiro trata somente do fluxo do campo elétrico.

\section{Justificativas para as variáveis relevantes}

P1 - A dependência do fluxo com o ângulo formado pelo vetor campo elétrico e a normal à superfície é justificada pelo formalismo de maneira autoritária:

6:40-7:20 O que estamos dizendo é simplesmente que se a superficie estiver assim (gestos) o vetor área é perpendicular à superficie. Vocês aprenderam isso no cálculo 3. Quando você tem uma superficie, o vetor normal é definido como um vetor que sai da mesma na direção perpendicular. Então se o vetor E está nessa direção e a perpendicular a superfície está mesma, o produto escalar será somente E.A.

P2 - Um dos objetivos do professor é justamente construir a expressão matemática. Portanto, o movimento é no sentido da modelização e da representação matemática da noção de fluxo. Para isso, muitas situações são abordadas para que os estudantes percebam a necessidade de considerar a projeção entre o vetor e a normal à superfície como relevante para o cálculo do fluxo. Assim, o produto escalar não é apresentado como uma definição, mas sim justificado em função dos aspectos essenciais que se pretende modelar. 
19:00 - 19:40 Então a gente tem metade do problema feito. Você vai pegar a porta (gestos), tem um fluxo de vento e uma superfície matemática. E você põe a normal aqui...Pergunta: como é que eu vou representar matematicamente a ideia de que através dessa orientação passa mais ar do que através dessa? O tamanho da superfície é a mesma. Mas o fluxo depende da orientação. Como vamos expressar essa ideia?

\section{Uso de analogias}

P1 - Uma única analogia (humidade de uma esponja imersa em um fluxo de água) é utilizada pelo professor como recurso explicativo e importantes aspectos referentes às diferenças entre esta situação e o fluxo do campo elétrico não são explicitados. A ideia da analogia é imaginar um fluxo de água (vazão 2 litros/s) que flui através de uma esponja.

11:20 - 12:00 O fluxo através da esponja seria uma descrição do quão molhada ela está ficando. Esse seria o equivalente "aquático" do fluxo elétrico aqui.

P2 - O professor utiliza analogias em praticamente toda a aula. As principais diferenças em relação à aula de P1 são: 1) Várias analogias (água, abelhas, vento, campo gravitacional, carros) são mencionadas e 2) Importantes diferenças são explicitadas como vemos no trecho a seguir:

37:20 - 38:40 Toda vez que você trabalha com mecânica dos fluidos - e abelha é um fluido para esse problema aqui, tem uma coisa andando, água, ar qualquer coisa dessas - o fluxo é uma coisa que passa através da superficie. Essa é a motivação original. Ai as pessoas pegaram essa formulação matemática aqui e disseram: a gente pode usar isso em outros casos. E aí você pode usar em casos onde de verdade o g não passa. Quando eu passei daqui para cá eu dei um enorme salto abstrato. Eu peguei essa definição que foi inventada para fluidos e apliquei numa situação em que a coisa não flui. Então a natureza desse vetor aqui para o cálculo do fluxo é uma coisa absolutamente irrelevante.

\section{Problemas numéricos de aplicação versus literais para a construção do conceito}

P1 - Dois "problemas" numéricos são resolvidos durante os 17 minutos da explicação do conceito de fluxo. O primeiro relaciona o número de linhas de campo que atravessam uma superfície de área $A$ em dois casos onde a concentração das linhas de campo são diferentes. Sua ênfase nos cálculos numéricos faz com que a categoria técnica apareça tão intensamente. No instante 4:50 o professor avisa que "o problema teria que fornecer o valor do campo elétrico" o que parece indicar que um dos principais objetivos da instrução é preparar os alunos para resolverem problemas que serão cobrados em avaliações.

O segundo "problema" é calcular o fluxo de linhas horizontais de campo elétrico através de uma superfície inclinada $40^{\circ}$ com a horizontal. Nesta resolução o professor enfatiza que não se deve utilizar o cosseno do produto escalar de maneira cega (único comentário de natureza metacognitiva), mas sim perceber que o ângulo é medido entre o 
vetor campo elétrico e a normal à superfície, o que neste caso seria $50^{\circ}$. Novamente, percebemos o foco nos tipos de problemas possivelmente cobrados em avaliações.

P2 - Neste trecho de 33 minutos um único problema é resolvido. Trata-se do cálculo do fluxo do campo gravitacional em uma superfície horizontal retangular (mesa) de lados $a$ e $b$. O problema é utilizado como exemplo sistematizar a explicação da formulação matemática do conceito de fluxo e motiva uma importante discussão sobre o fato de o fluxo do campo gravitacional não ter velocidade.

\section{Interação professor-aluno e postura implícita frente ao conhecimento}

P1 - O professor não faz perguntas aos alunos e em nenhum momento ouvimos a voz deles. Além disso, a postura implícita no discurso é a de que o professor irá apresentar aos alunos um conceito de fácil compreensão. Comentários como "eu vou lhes mostrar", "como vocês podem ver" sugerem que a aula se trata de uma apresentação na qual somente uma via de comunicação (do professor para os alunos) está aberta.

P2 - Em vários momentos o professor faz questão de ressaltar que o conceito de fluxo de um campo vetorial é difícil e incita os estudantes a se manifestarem, como ilustram os trechos seguintes:

13:40-14:00 Como é que a gente pensa nesse problema? Parece simples, mas não é. A gente se enrola tecnicamente com essas coisas.

19:40-20:00 Como vamos expressar essa ideia? Pensa como é que eu resolvo esse problema. Você pode ficar aí assim e esperar a resposta. Mas vamos lá, pensa.

26:00-26:20 Pergunta para você se você entendeu isso profundamente, não mais ou menos.

37:00-37:20 Pessoal, muito legal ele ter perguntado isso. A sua pergunta indica uma confusão. Mas essa confusão ocorre sempre com todo mundo que estudou esse negócio. E se ela não ocorreu com você, é porque você não percebeu isso ainda. Ela está ocorrendo e você não sabe. Então legal ele ter chamado atenção.

Esta talvez seja a diferença mais marcante entre as aulas. Em se tratando de uma habilidade tão complexa como utilizar matemática para pensar os fenômenos do mundo físico, parece-nos que explicitar as dificuldades inerentes a este tipo de raciocínio e convidar os alunos a manifestarem suas dúvidas nas aulas é a postura mais adequada do ponto de vista pedagógico. 


\subsection{2 - IDENTIFICANDO SEMELHANÇAS NO LIVRO DE FEYNMAN}

Outra possível comparação é investigar como as relações entre matemática e física são abordadas em diferentes materiais didáticos (tanto de ensino médio e superior) sob a ótica dos aspectos aqui levantados. Durante a entrevista, o professor já havia manifestado seu posicionamento contrário à padronização dos livros texto, os quais, segundo ele, costumam abordar as "unanimidades" da física para venderem mais. Dessa forma, estudos comparativos podem revelar recursos e estruturas diferentes ao longo das explicações presentes nos livros e isso pode ser evidenciado com nossas categorias de análise.

Com o objetivo de averiguar essa possibilidade de uma maneira preliminar, decidimos investigar se as abordagens ilustradas por nossas categorias de análise são identificadas em um livro didático reconhecidamente diferenciado. Trata-se do clássico Feynman Lectures que foi recentemente traduzido para o português (FEYNMAN; LEIHTON; SANDS, 2008). Selecionamos os três primeiros capítulos do volume 2 (1 - Eletromagnetismo, 2 - Cálculo Diferencial de Campos Vetoriais e 3 - Cálculo Integral Vetorial), nos quais as equações de Maxwell são apresentadas e o formalismo do cálculo vetorial é abordado. É importante frisar o caráter incipiente deste estudo, pois não estamos nos comprometendo a fazer uma análise abrangente de tudo que foi tratado nos três capítulos, mas sim identificar manifestações das categorias. Conforme veremos, existem muitas semelhanças com aspectos encontrados nas aulas do estudo de caso.

\section{Quadro resumo: do todo para as partes.}

A estrutura de apresentação do eletromagnetismo é semelhante à encontrada no curso analisado, pois um panorama geral da teoria - as equações de Maxwell - é oferecido logo no primeiro capítulo. De maneira análoga ao quadro-resumo utilizado pelo professor de nosso estudo de caso, Feynman apresenta as quatro leis do eletromagnetismo (Seção 1-4) utilizando uma representação mista entre palavras, símbolos matemáticos e figuras:

Fluxo de $\boldsymbol{E}$ por uma superficie fechada $=\frac{\text { carga interna }}{\epsilon_{0}}$

Circulação de $\boldsymbol{E}$ ao redor de $C=\frac{d}{d t}$ (fluxo de $\boldsymbol{B}$ através de $S$ )

Sendo C é um caminho fechado arbitrário e $S$ uma superfície aberta cujo contorno seja a curva $C$.

Fluxo de B por uma superficie fechada $=0$

$c^{2}($ Circulação de $\boldsymbol{B}$ ao redor de $C)=\frac{d}{d t}($ fluxo de $\boldsymbol{B}$ através de $S)+$ fluxo da corrente elétrica através de $S$ 
Essa maneira de partir do todo para depois investigar as partes parece contrastar com a forma comumente encontrada em livros didáticos mais tradicionais (RESNICK; HALLIDAY; KRANE, 2003; YOUNG; FREEDMAN, 2003; TIPLER, 1984 e similares) de apresentar cada lei separadamente e sintetizar o conjunto somente em um capítulo final intitulado "Equações de Maxwell".

\section{Matematização (idealizações explicitadas e estruturas matemáticas justificadas)}

A representação matemática de grandezas físicas é feita de maneira gradual e minuciosamente explicada. Vejamos, por exemplo, como a descrição dos campos elétrico e magnético por funções vetoriais é esclarecida (Seção 1-2):

Podemos associar a cada ponto $(x, y, z)$ do espaço dois vetores $\boldsymbol{E}$ e $\boldsymbol{B}$ que podem variar no tempo. Os campos elétrico e magnético são, portanto, vistos como funç̃̃es vetoriais de $x, y, z$ e t. Como um vetor é especificado por suas componentes, cada um dos campos $\boldsymbol{E}(x, y, z, t) e$ $\boldsymbol{B}(x, y, z, t)$ representa três funções matemáticas de $x, y, z$ e $t$.

É justamente porque $\boldsymbol{E}$ (ou B) pode ser especificado em cada ponto do espaço que ele é chamado de "campo". Um "campo" é qualquer quantidade física que pode assumir diferentes valores para diferentes pontos do espaço. Temperatura, por exemplo, é um campo - neste caso um campo escalar, que escrevemos como $T(x, y, z)$. A temperatura também pode variar no tempo, neste caso podemos dizer que o campo de temperatura é dependente do tempo e escrever $T(x, y, z, t)$. Outro exemplo é o "campo de velocidades" de um líquido fluindo. Escrevemos $v(x, y, z, t)$ para a velocidade do líquido em cada ponto do espaço no instante t. Este é um campo vetorial.

Percebemos também uma ênfase no caráter unificador dessa estrutura por meio da utilização de analogias formais como recurso explicativo. De fato, analogias (também materiais, mas principalmente formais) são intensamente utilizadas ao longo dos três capítulos.

As aproximações e idealizações são explicitadas conforme exemplificado nos trechos a seguir:

Uma vez que estamos considerando um cubo pequeno, podemos aproximar esta integral pelo valor de $C_{x}$ no centro da face [...] Mas no limite de um cubo infinitesimal, cometeremos um erro desprezivel se calcularmos esta derivada no canto (Seção 3-3)

Assuma que temos uma situação simples, na qual todo o calor foi colocado previamente e o corpo está apenas esfriando. Não há fontes de calor, de forma que o calor se conserva. (Seção 3-4)

O segundo capítulo analisado é direcionado para a estrutura matemática do eletromagnetismo, mais especificamente para a introdução do operador nabla $(\nabla)$ e das possíveis operações (gradiente, divergente, rotacional, laplaciano) a ele associadas. 
Entretanto, a física continua extremamente presente, pois o fenômeno da propagação do calor é utilizado para ilustrar a noção de gradiente. Assim, de maneira semelhante ao exemplo do cachorro (Episódio 6), parece que Feynman pretende apresentar o cálculo vetorial de uma forma de mais útil/concreta para os estudantes se compararmos com o tratamento abstrato comumente dado nos cursos de cálculo.

Esse novo formalismo permite reescrever as equações de Maxwell utilizando a notação diferencial. Justificativas para sua preferência são apresentadas:

Esta notação (forma diferencial) é útil, não apenas por fazer as equações se apresentarem de forma mais simples, mas também porque nos mostra claramente o conteúdo físico das equações sem fazer referência a nenhum sistema de coordenadas arbitrariamente escolhido.

\section{Interpretação _ـ (significado físico dos operadores diferenciais)}

Em vários momentos é possível encontrar Feynman indagando sobre o significado físico de estruturas e expressões matemáticas.

Interpretamos esta equação: o fluxo de calor (por unidade de tempo e por unidade de área) através de qualquer elemento da superficie normal ao vetor unitário n, é dado por h.n. Da mesma forma, podemos dizer que que a componente do fluxo de calor perpendicular ao elemento de superfície $\Delta a_{2}$ é h.n. (Seção 2-2)

Para o caso dos operadores diferenciais, a ênfase na interpretação é clara:

$N a$ verdade, $\Delta T$ é um vetor físico que possui um significado. Ele representa a taxa de variação espacial de $T$. A componente $x$ de $\Delta T$ diz quão rápido T muda na direção $x$. $O$ que significa a direção do vetor $\Delta T$ ? Sabemos que a taxa de variação de T em qualquer direção é a componente de $\Delta T$ naquela direção. Daí segue que a direção de $\Delta T$ é a direção na qual ele possui a maior componente possível - em outras palavras, a direção em que $T$ varia mais rapidamente. $O$ gradiente de $T$ é a direção do declive ascendente mais ingreme (em T). (Seção 2-4)

Vemos agora o "significado" do divergente de um vetor $(\boldsymbol{C})$. O divergente de um vetor no ponto $P$ é o fluxo - o "escoamento" de C para fora - por unidade de volume nas vizinhanças de P. (Seção 3-3)

Nosso resultado é: a circulação de qualquer vetor $\boldsymbol{C}$ ao redor de um quadrado infinitesimal é a componente do rotacional de C normal à superfície, vezes a área do quadrado. (Seção 3-6)

\section{Técnica}

Notamos um possível foco na técnica no segundo capítulo quando regras matemáticas (definições e propriedades dos produtos escalar e vetorial) são evocadas e algumas manipulações algébricas são conduzidas. Entretanto, de maneira geral existe uma preocupação constante em elucidar a veracidade de cada passo e relacioná-lo com algum 
argumento físico/geométrico, de tal forma que raramente temos a sensação de um processo puramente técnico e mecânico.

\section{Recursos visuais}

Naturalmente, não temos acesso ao caráter gestual da aula de Feynman ${ }^{45}$. Porém, a presença constante de figuras ao longo do texto evidencia a importância de recursos visuais em suas explicações.
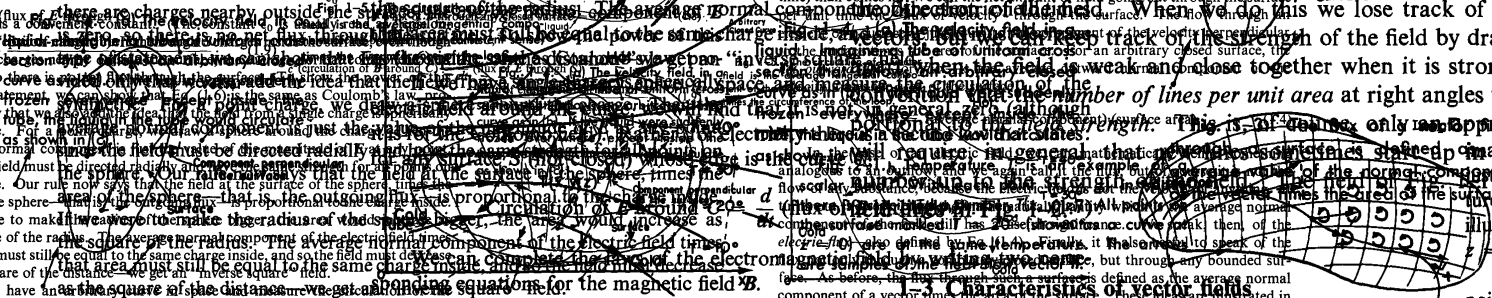

Figura 50: Ilustrações presentes nos capítulos 1, 2 e 3 (v. 2) do livro Lições de Física de Feynman (FEYNMAN; LEIHTON; SANDS, 2008)

\section{Analogias materiais e formais}

De maneira semelhante às aulas do estudo de caso, notamos uma presença constante de analogias durante as explicações de Feynman nestes três capítulos. Entretanto, é possível constatar que as mesmas são normalmente relacionadas a outros fenômenos físicos e a discussão se dá mais no âmbito de semelhanças formais ${ }^{46}$. No primeiro capítulo, conceito de fluxo é apresentado fazendo alusão a ideia de uma quantidade de fluido que escoa através de uma superfície:

Por exemplo, para um campo de velocidades podemos perguntar se a velocidade é sempre para fora da superficie ou, de forma mais geral, se a quantidade de fluido que escoa para fora da superficie (por unidade de tempo) é maior ou menor que a quantidade que flui para dentro. (Seção 1-3)

Porém, ao mencionar o fluxo do campo elétrico, Feynman faz questão de ressaltar que o campo elétrico não possui velocidade, antecipando um possível problema de interpretação da mesma forma que o professor do estudo de caso.

No caso de um campo elétrico, podemos definir matematicamente algo análogo a um escoamento para fora e, novamente, chamamos de fluxo, mas, obviamente, este não é o escoamento de nenhuma substância, porque o campo elétrico não é a velocidade de coisa alguma. (Seção 1-3)

\footnotetext{
${ }^{45} \mathrm{Na}$ realidade é possível encontrar algumas de suas aulas disponíveis na internet e o intenso uso de gestos explicativos é facilmente detectado.

${ }^{46}$ O Capítulo 12 deste volume, intitulado Análogos Eletrostáticos, destaca a importância de analogias formais em física ao apresentar inúmeras situações sendo modeladas pela mesma estrutura matemática utilizada na eletrostática.
} 
Para a explicação da circulação de um campo vetorial, novamente uma analogia bastante esclarecedora é utilizada:

Suponha novamente que estamos pensando num campo de velocidades que descreve o escoamento de um líquido. Podemos fazer a interessante pergunta: o líquido está circulando? Com isto queremos dizer: existe um movimento rotacional ao redor de algum circuito? Suponha que congelemos instantaneamente o fluido em toda parte, exceto no interior de um tubo de calibre uniforme e que se fecha em si mesmo num circuito, como na figura 1-4. Fora do tubo, o líquido para de se mover, mas, em seu interior, ele pode continuar movendo-se devido ao momento do fluido aprisionado - isto é, se o momento numa certa direção ao redor do tubo for maior do que na outra. (Seção 1-3)

\section{Demonstrações (teoremas de Gauss e Stokes)}

Aspectos associados ao caráter dedutivo de teorias físicas são encontrados em alguns momentos, mas o contraste mais nítido aparece na apresentação do teoremas de Gauss e Stokes. Ao contrário da postura adotada nas aulas do estudo de caso, Feynman apresenta demonstrações para os dois teoremas determinando, respectivamente, o fluxo de um campo vetorial $\mathbf{C}$ através das superfícies de um cubo infinitesimal (Gauss) e a circulação de $\mathbf{C}$ ao redor de um pequeno quadrado (Stokes). É difícil dizer que se tratam de demonstrações formais (no sentido do rigor matemático), mas o objetivo parece ser fazer com que os operadores divergente e rotacional "apareçam naturalmente" ao longo das deduções.

\section{Comentários de epistemologia}

Essa é outra marca registrada das aulas de Feynman e encontramos reflexões epistemológicas com frequência nos três capítulos.

Esta é a diferença entre a matemática e a física. Matemáticos, ou pessoas que possuem uma mente muito matemática, geralmente se desencaminham quando "estudam" fisica, porque perdem o aspecto físico. Eles dizem: "vejam, estas equações diferenciais - as equações de Maxwell - são tudo que existe na eletrodinâmica; os físicos admitem que não há nada que não esteja contido nestas equações. Estas equações são complicadas, mas são apenas equações matemáticas e, se eu entendê-las matematicamente em profundidade, entenderei a física em profundidade”. Todavia, as coisas não funcionam assim. Matemáticos que estudam física com este ponto de vista - e há muitos deles - normalmente, fazem poucas contribuições à física e, na verdade, poucas contribuições para a matemática. Eles falham porque as situações físicas do mundo real são tão complicadas que é necessário ter um conhecimento mais amplo das equações. (2-1)

\section{Metacognição}

Comentários de natureza metacognitiva que convidam o leitor a refletir sobre o que está pensando também são encontrados em momentos pontuais.

Você pode estar dizendo: "todo este negócio de fluxos e circulações é bastante abstrato. Os campos elétricos estão em todos os pontos do espaço; então surgem estas 'leis'. Mas o que 
está acontecendo realmente? Por que isto não pode ser explicado, por exemplo, pelo que quer que esteja acontecendo entre as cargas?" Bem, isto depende de seus preconceitos. (1-5)

Talvez você ainda não esteja convencido. Vamos demonstrar de uma forma diferente (apesar de que, se você olhar com cuidado, poderá ver que esta é a mesma prova por um caminho mais cansativo!) (2-3)

Portanto, mesmo em uma análise preliminar dos três primeiros capítulos do segundo volume do livro Lições de Feynman, já é possível identificar uma série de elementos comuns entre o discurso do professor investigado em nosso estudo de caso e a abordagem didática de Feynman. Isso corrobora nossa hipótese de que os aspectos representados por nossas categorias de análise podem nortear a avaliação de abordagens didáticas em relação ao papel da matemática na física. Na próxima seção, apresentamos um conjunto de proposições que sintetizam nossa concepção sobre critérios de qualidade no ensino de física, especificamente no que concerne o aprendizado da maneira matemática de apreender teoricamente os fenômenos do mundo físico. 


\section{2 - CONCLUSÕES}

Dentre as categorias de estudos de caso educacionais propostas por Bassey (1999) nosso estudo encaixa-se na denominada theory-seeking. De fato, dado o estado inicial da pesquisa no tema, estivemos focados mais na busca por uma teoria destinada a investigar a abordagem do caráter estrutural da matemática no ensino de física do que na comprovação de hipóteses previamente estabelecidas. Nosso resultado principal consiste na proposição de uma ferramenta de análise composta de oito categorias e nos permite levantar uma série de hipóteses para serem investigadas por futuros estudos (também qualitativos) que se debrucem sobre o assunto.

Segundo Bassey (1999), um estudo de caso do tipo theory-seeking deve fornecer uma análise dos resultados empíricos fundamentada em evidências suficientes que permitam ao pesquisador o levantamento de proposições a fim de orientar a comunidade (científica e escolar) interessada em questões semelhantes. Assim, seguindo a ordem das categorias de análise, resumimos essas proposições na sequência, as quais refletem nossa visão sobre critérios de qualidade didática em relação ao ensino física centrado no caráter estrutural da matemática. Tais proposições não devem, naturalmente, ser encaradas como um conjunto de regras prescritivas, mas sim como importantes aspectos a serem considerados quando se pretende ensinar física de forma a não negligenciar sua condição de ciência profundamente matematizada.

\section{Matematização}

Quando um professor de física simplesmente apresenta uma fórmula a seus alunos está pulando uma série de etapas fundamentais para seu entendimento. Matematizar, enquanto verbo, implica em uma ação: a construção de uma representação matemática. Em física, para que esta construção seja possível é preciso selecionar aspectos da natureza que se pretende investigar. Assim, a escolha de variáveis relevantes, as idealizações e aproximações inerentes à construção de modelos físico-matemáticos precisam ser explicitadas no discurso de quem os ensina e isso demanda tempo.

Além disso, a utilização de determinadas estruturas matemáticas precisa ser justificada pela identificação dos aspectos essenciais das mesmas que são relevantes para as características físicas que se pretende modelar. Dessa forma, para apreender teoricamente o real por meio de uma estruturação matemática, é preciso ter um olhar diferenciado para a 
natureza. Só assim, é possível enxergar a função seno ao observar um fenômeno periódico qualquer ou um produto vetorial ao lidar com fenômenos espaciais do eletromagnetismo.

Para acessar uma compreensão profunda sobre o processo de matematização parecenos necessária uma maneira alternativa ao que tradicionalmente encontramos em problemas de aplicação típicos do final de capítulos em livros texto. Isso implica em uma alteração no tipo de perguntas que comumente fazemos. Em vez de construirmos situações para que as fórmulas sejam aplicadas para obtenção de resultados numéricos, poderíamos considerar questões alternativas como: Por que o trabalho de uma força é um produto escalar e o torque um produto vetorial? Por que existe um logaritmo na equação de Boltzmann? Por que o $\pi$ aparece na fórmula do pêndulo simples?

Interpretação

Se um professor de física, ao resolver um determinado problema literal com seus alunos, obtém um resultado final e se contenta em colocar um retângulo em torno da expressão matemática, está perdendo uma grande oportunidade para explorar importantes aspectos do profundo diálogo existente entre os símbolos matemáticos e o mundo físico. Em muitas situações, por não termos como prever o comportamento de um determinado sistema físico antecipadamente, deixamo-nos guiar pelo formalismo matemático e a previsão desejada só é possível pela interpretação do resultado final.

Uma estratégia que costuma ser eficiente para essa interpretação é analisar casos particulares e limites. Assim, ao "brincar" com a expressão final substituindo valores e fazendo com que variáveis tendam a zero ou a infinito, ganhamos uma intuição física sobre seu significado. Portanto, de maneira semelhante à matematização, a interpretação física de expressões matemáticas precisa ser incentivada e explicitada em sala de aula.

Novamente, a ênfase neste aspecto deveria implicar em uma alteração no tipo de perguntas que fazemos aos estudantes. Alguns possíveis exemplos são: Como determinada informação andou na conta? Qual termo é responsável por esta ou aquela característica física? Qual o significado físico da expressão (não) depender deste ou daquele fator? O que significa integrar/derivar em relação a esta variável? O que esta expressão diz?

Técnica

O excesso de aplicações de regras e fórmulas sem sentido, manipulações algébricas e argumentos de autoridade no ensino de física é possivelmente a principal razão para que os 
estudantes considerem a matemática somente como uma ferramenta de cálculo para esta ciência. A difundida crença de que habilidades matemáticas são pré-requisitos para o entendimento da física e que cursos de "matemática básica" resolveriam os problemas enfrentados pelos estudantes em relação ao papel da matemática na física, revela que esta concepção está implícita em diversos contextos de ensino de física.

É impossível negar a importância e praticidade do "girar a manivela" matemática para a física. Entretanto, sob o ponto de vista formativo, é desejável que a abordagem técnica seja intercalada por ênfases em matematização e interpretação. Dessa forma, antes que um professor de física trate um construto matemático de maneira procedimental em suas aulas, é preciso explicitar as etapas da construção dessa representação matemática. Se, ao resolver um problema, uma expressão literal for obtida como resultado, seria altamente recomendável interpretar seu significado físico. Em materiais didáticos isso implicaria em reduzir o número excessivo de problemas numéricos de aplicação comumente encontrados em livros texto.

\section{Visual}

A insuficiência da linguagem verbal e matemática para representar os conceitos da física demanda a utilização de recursos semióticos diversos que, combinados, produzem significados mais complexos e legítimos. Assim, representações visuais como gestos, imagens estáticas (desenhos, diagramas, esquemas) e dinâmicas (simulações) precisam ser incorporados ao arsenal de vias comunicativas utilizado por um professor em sala de aula. Em um contexto de ensino, a apresentação de uma fórmula matemática, por exemplo, deveria ser acompanhada de gráficos, desenhos, simulações que captassem seu significado de uma maneira mais ampla.

De acordo com essa multiplicidade de representações que envolvem a significação de um conceito físico, a aprendizagem do mesmo também está associada à habilidade em transitar entre diferentes modos representativos. Essa dimensão é acessada por questões que demandam o estabelecimento de relações (traduções) entre um gráfico, uma expressão matemática, um desenho e uma sentença escrita em linguagem natural, por exemplo.

\section{Analogia}

A utilização de analogias materiais como recurso explicativo no ensino de física remete os estudantes à motivação essencial para a criação de representações matemáticas: o mundo físico. Tais analogias, expressas tanto por semelhanças entre teorias físicas ou por 
situações cotidianas, dão sentido para o formalismo matemática e devem ser abordadas quando possível.

Entretanto, parece-nos fundamental enfatizar as semelhanças formais e explicitar as diferenças fenomenológicas para que a analogia não seja confundida como a descrição do fenômeno. Naturalmente, a percepção de analogias formais não é tarefa elementar para os estudantes, pois normalmente exige o conhecimento de uma ampla gama de fenômenos e suas estruturas matemáticas. Assim, acreditamos que a discussão dessas semelhanças precisa ser feita de maneira explícita. Por exemplo, quando um professor menciona a seus alunos que a fórmula $\mathrm{x}_{\mathrm{f}}=\mathrm{x}_{\mathrm{o}}+\mathrm{v} . \Delta \mathrm{t}$ se encaixa em uma rede mais ampla de ideias matemáticas que representam uma noção geral "final é igual a inicial mais variação", a qual também é encontrada em outras fórmulas como $\mathrm{v}_{\mathrm{f}}=\mathrm{v}_{\mathrm{o}}+\mathrm{a} \cdot \Delta \mathrm{t}$, está desenvolvendo exatamente essa habilidade.

Dessa forma, com o objetivo de evidenciar a importância do raciocínio analógico no ensino de física, uma alternativa interessante é trabalhar com equações semelhantes e questionar os estudantes sobre as razões dessas semelhanças. Alguns bons exemplos são: a leis da gravitação de Newton e a lei de Coulomb; semelhanças matemáticas entre as equações da hidrodinâmica e do eletromagnetismo; fórmulas do período do pêndulo simples e do sistema massa-mola, entre outros. Ilustremos esse tipo de questão com uma atividade hipotética abordada em uma avaliação ou durante uma aula: Você já estudou algumas fórmulas na física que são "parecidas" como $\mathrm{y}=\mathrm{gt}^{2} / 2, \mathrm{~K}=\mathrm{mv}^{2} / 2, \mathrm{~W}=\mathrm{kx}^{2} / 2 \mathrm{e}$ $\mathrm{E}=\mathrm{CV}^{2} / 2$. Quais as razões para as semelhanças entre essas quatro equações?

\section{Dedução}

A demonstração de fórmulas a partir de princípios físicos está intimamente relacionada à possibilidade de se responder por que uma fórmula tem uma estrutura particular. Sendo assim, a ênfase na demonstração em sala de aula propicia um conhecimento profundo sobre a origem de equações físicas e evita a memorização artificial de fórmulas matemáticas sem sentido. Entretanto, existem fórmulas e fórmulas. $\mathrm{F}=$ ma, por exemplo, trata-se da descrição matemática de um princípio físico e não haveria muito sentido em falar em sua demonstração ${ }^{47}$. Outras fórmulas são obtidas pela identificação de regularidades em

\footnotetext{
${ }^{47}$ Naturalmente, a flexibilidade da estruturação teórica permite que uma relação que seja fundamental em uma teoria, seja uma consequência deduzida de princípios em outras. Um exemplo disso é a dedução de $\mathrm{F}=\mathrm{ma}$ a partir do princípio da Mínima Ação no livro de Feynman (FEYNMAN; LEIHTON; SANDS, 2008, v.1, 2008, p. 19-6).
} 
dados experimentais por meio do raciocínio indutivo. Portanto, quando falamos da importância de demonstrações no ensino de física, estamos falando daquelas que efetivamente podem ser deduzidas matematicamente a partir de princípios físicos.

Mencionemos dois exemplos para ilustrar a que tipo de fórmulas nos referimos: 1) A lei da refração da luz $\left(\operatorname{sen} \theta_{1} / \operatorname{sen} \theta_{2}=v_{1} / v_{2}\right)$ e 2) A lei dos gases ideais $(P V=n R T)$. Apesar de poderem ser apresentadas como regularidades identificadas em experimentos (indução), existem princípios físicos e idealizações que permitem que as mesmas sejam deduzidas formalmente. A lei da refração da luz pode, por exemplo, ser deduzida a partir do princípio de Huygens, de Fermat ou ainda pelas próprias equações de Maxwell por meio da aplicação de condições de contorno na superfície que separa os meios. A demonstração tradicional da lei geral dos gases envolve que sejam consideradas uma série de idealizações sobre o movimento de partículas, bem como a aplicação de princípios fundamentais como a conservação do momento linear. Tais demonstrações possuem um valor pedagógico uma vez que exemplificam o caráter intrinsecamente matemático da construção de teorias físicas, devendo, portanto, ser abordadas com mais frequência em aulas de física, inclusive no ensino médio. Além disso, diferentes maneiras de demonstrar a mesma fórmula também podem proporcionar discussões interessantes, uma vez que exemplificam a multiplicidade de possibilidades de construção de explicações teóricas em física.

Naturalmente, assim como existem fórmulas e fórmulas, existem demonstrações e demonstrações, e principalmente diferentes maneiras de se demonstrar. Um risco é iminente é fazer com que a demonstração tenha um caráter autoritário e vire uma sequência monótona/incompreensível de etapas, sem que o vínculo entre o formalismo e mundo físico seja devidamente esclarecido.

\section{Epistemologia}

Para Einstein, ciência sem epistemologia é um esquema vazio e a reflexão constante sobre o fazer ciência propicia uma essencial "independência de julgamento" a seus praticantes. Transportando essa visão para o nosso contexto, refletir de maneira explícita sobre o papel da matemática em aulas de física incentiva uma postura mais crítica dos estudantes sobre a construção teórica desta ciência. Aspectos característicos como a diferenciação entre modelo e realidade ("esse sistema de referência não está na natureza), as maneiras de ver o mundo de matemáticos e físicos ("para o físico o rigor não é tão importante"), ou o caráter sociológico da ciência ("estamos fazendo a inserção cultural do 
símbolo”) são exemplos de discussões dessa natureza. Apesar de ser possível discursar sobre o tema de maneira geral, parece-nos que estes comentários são mais pertinentes quando mencionados em situações específicas, como durante a resolução de um problema ou a demonstração de uma fórmula.

Mesmo sem a necessidade de uma análise detalhada, é fácil perceber que esse tipo de discussão é raramente encontrado em aulas de física ou em materiais didáticos o que contribui para que a "independência de julgamento" mencionada por Einstein seja raramente encontrada. Dessa forma, é preciso abordar discussões epistemológicas de maneira explícita a fim incentivar que os estudantes reflitam sobre os processos de construção teórica da física.

\section{Metacognição}

Associado ao item anterior, mas mais relacionado com os processos cognitivos individuais, o incentivo à metacognição - especificamente em relação ao pensamento matemático na física - precisa ser explicitamente abordado em contextos de ensino. Isso implica em "monitorar" as explicações e resoluções com colocações como as encontradas no estudo de caso: "pergunta para você se entendeu isso profundamente", "como a gente pensa para resolver este problema?”, “o que acabamos de fazer?”, “seria possível resolver de outra maneira?, "não acha que isso é fácil, muitos têm dificuldade quando encontram esse formalismo pela primeira vez", entre outras.

De fato, comentários do tipo "isso não é fácil" contrastam com apresentações racionalmente construídas e aparentemente lógicas comumente encontradas em aulas e livros de física. Muitas vezes, com o legítimo objetivo de tornar sua explicação o mais clara possível, um professor pode inconscientemente transmitir a impressão de que o assunto ensinado é trivial e deveria ser facilmente compreendido pelos estudantes. Isso faz com que as perguntas sejam inibidas, pois, em caso de dúvidas, o estudante se julga incapaz de entender o que deveria ser óbvio. Portanto, o incentivo à metacognição passa também pela explicitação das dificuldades inerentes à aprendizagem da maneira matemática de apreender teoricamente os fenômenos do mundo físico. 


\subsection{DESDOBRAMENTOS}

Chegando ao final desta jornada, experenciamos um misto de alívio pela sensação de uma importante etapa cumprida e inquietação em função dos diversos desdobramentos que vislumbramos para a sequência da pesquisa. Nesta última seção, listamos alguns deles e conjecturamos sobre possíveis estratégias para abordá-los.

\section{Estudos comparativos}

As análises preliminares apresentadas na Seção 7.1 ilustram a maneira como imaginamos que seja possível conduzir estudos de natureza comparativa tanto entre professores como materiais didáticos. A identificação de diferenças ilustradas pelos “espectros" de abordagens do diagrama pode auxiliar na definição de critérios objetivos para avaliarmos a qualidade de uma aula ou de um material didático. Entretanto, são necessários outros estudos dessa natureza para consolidarmos esta noção e a aplicabilidade do recurso para este fim.

O uso de gravações de aulas para estabelecer comparações já vem se estabelecendo como um importante recurso para pesquisas educacionais (JANÍK; SEIDEL, 2009). Nesse sentido, nossas categorias vêm contribuir para um conjunto de pesquisas que visam a identificar padrões em estruturas didáticas (SEIDEL; PRENTZEL, 2006). Estes trabalhos têm categorizado a abordagem de professores sob diversos aspectos como tempo dedicado a explicação conceitual, revisão da aula anterior, resolução de exercícios, atividades experimentais, trabalhos em grupo, entre outros. Tais comparações tem permitido inclusive a identificação de padrões diferentes entre aulas ministradas em contextos diferentes (diferentes países, por exemplo) e inferir sobre possíveis fatores que interferem nas diferenças entre aprendizagem dos estudantes (FISHER; LABUDDE; VIIRI, 2011).

Dado que nossos dados restringem-se ao ensino de eletromagnetismo, outra importante perspectiva do trabalho é aplicar a ferramenta de análise para categorizar aulas de outros tópicos e verificar a dependência dos perfis encontrados em função dos conteúdos específicos. Por exemplo, nosso estudo piloto com relatividade restrita indicou que, pela própria natureza excessivamente abstrata desse conhecimento, a menção a situações cotidianas é muito menos frequente. Assim, poderíamos considerar a pertinência de termos diferentes critérios para avaliar aulas sobre diferentes temas. 


\section{Formação de professores}

Outra possível aplicação da metodologia de investigação aqui proposta é utilizá-la como recurso didático na formação de professores de física. Uma das principais queixas de estudantes de cursos de licenciatura é a falta de conhecimento prático sobre como dar aulas sobre determinados assuntos. Assim, acreditamos que a apresentação e análise de episódios de ensino como os investigados em nossa pesquisa podem fornecer exemplos mais concretos e propiciar discussões profícuas sobre maneiras de se ensinar conteúdos específicos de física. Além disso, os estudos comparativos propostos no item anterior também podem ter um importante papel para enriquecer o debate sobre estratégias didáticas em disciplinas como "prática" ou "metodologia" do ensino de física.

Naturalmente, isso não significa que estejamos defendendo um retrocesso à formação de professores como técnica, no sentido de utilizar estes estudos de caso para "mostrar aos licenciandos como se faz" ao apresentar diagramas do videograph como "perfis ideais" a serem seguidos como roteiros de ensino. Acreditamos mais na possibilidade do uso desta ferramenta de análise para fundamentar/motivar discussões pontuais sobre critérios de qualidade didática.

\section{Foco na aprendizagem}

Em função de nosso recorte, justificado pela escassez de pesquisas voltadas ao tema sob a perspectiva do ensino, não investigamos uma parte essencial do processo: a aprendizagem dos alunos. Assim, uma perspectiva que emerge é investigar como esses aspectos propostos para avaliar a qualidade de aulas são transformados em qualidade de aprendizagem. O desenvolvimento de instrumentos de avaliação e a gravação de grupos de alunos discutindo e explicitando seus argumentos ao resolverem problemas, configuram-se como possíveis estratégias para acessarmos esta fundamental dimensão do processo.

Uma possível alternativa seria, por exemplo, avaliar o desempenho dos estudantes deste professor em comparação ao de alunos de outros professores mais "tradicionais". Entretanto, nesse caso seria imprescindível definir indicativos de aprendizagem do caráter estrutural da matemática e maneiras de acessá-los. Além disso, é preciso que estejamos cientes das limitações em se procurar estabelecer uma relação causal direta entre qualidade didática e de aprendizagem (OSER; BAERISWYL, 2001). 


\section{Outros niveis escolares}

O contexto de nossa análise foi um curso de eletromagnetismo ministrado em nível superior. Dessa forma, outro possível desdobramento da pesquisa é investigar a possibilidade de aplicar métodos semelhantes também no ensino médio. Apesar dos objetivos diferentes dos dois níveis, acreditamos que muitos dos aspectos aqui identificados também sejam aplicáveis às questões pertinentes ao ensino médio. $\mathrm{O}$ uso de situações cotidianas como recurso explicativo, a diminuição de abordagens puramente técnicas e o incentivo à metacognição, por exemplo, são aspectos relevantes que provavelmente independem do nível de ensino considerado.

Com nossa pesquisa, objetivamos ter chamado a atenção da comunidade para a necessidade de um esforço sistemático para que os estudantes compreendam o papel do pensamento matemático como estruturante do conhecimento físico. Além disso, propomos aos pesquisadores (e praticantes) da área uma ferramenta teórica pertinente para investigar a multiplicidade de abordagens das relações entre matemática e física em contextos de ensino e aprendizagem. Naturalmente, não temos a intenção de defender nossas categorias como um sistema definitivo, mas sim como uma proposta inicial para que possamos encarar este problema de maneira mais objetiva.

Acreditamos que uma boa pesquisa começa com uma questão, mas termina com muitas outras. Dessa forma, longe de marcar o fim desta jornada após termos fornecido respostas definitivas, este parágrafo final representa o início de investigações relacionadas com os desdobramentos aqui apresentados e outros que certamente aparecerão ao longo do caminho. Para Fourier, a matemática é uma faculdade da mente destinada a compensar a reduzida duração da vida e a imperfeição dos sentidos. Para Feynman, as duas culturas propostas por C. P. Snow separam os que tiveram a experiência de apreciar a natureza com um olhar matemático daqueles que não a tiveram. Assim, o desejo de fazer com que cada vez mais pessoas experienciem não só a conveniência, mas também o prazer intelectual dessa maneira matemática de ver o mundo, será a principal motivação para a continuidade deste trabalho. 


\section{REFERÊNCIAS BIBLIOGRÁFICAS}

ANGELL, C.; KIND, P. M.; HENRIKSEN, E. K.; GUTTERSRUD, O. An empiricalmathematical modelling approach to upper secondary physics. Physics Education, v. 43, n. 3, p. 256-264, 2008.

BACHELARD, G. A filosofia do não. In: CIVITA, V. (Ed). Os Pensadores XXXVIII. São Paulo: Abril Cultural, 1974. p. 158-245.

O novo espírito científico. Rio de Janeiro: Tempo Brasileiro, 1995. 151 p.

BAGNO, E.; BERGER, H.; BAT-SHEVA, E. Meeting the challenge of students' understanding of formulae in high-school physics: a learning tool. Physics Education, v. 43, n. 1 , p. $75-82,2008$.

BASSEY, M. Case study research in educational settings. Buckingham: Open University Press, 1999. $178 \mathrm{p}$.

BING, T. An Epistemic Framing Analysis of Upper-Level Physics Students' Use of Mathematics. Tese de Doutorado, Physics Education, Universidade de Maryland, College Park, 2008.

BING, T.; REDISH, E. F. Analyzing Problem Solving Using Math in Physics: Epistemological Framing via Warrants. Physical Review Special Topics - Physics Education Research, v. 5, n. 2, 020108, p. 1-15, 2009.

BLUM, W.; BORROMEO FERRI, R. Mathematical modelling: Can it be taught and learnt? Journal of Mathematical Modelling and Application, v. 1, n. 1, p. 45-58, 2009.

BLUM, W.; LEIß, D. "Filling up" the problem of independence-preserving teacher interventions in lessons with demanding modelling tasks. In: BOSCH, M. (Ed.) CERME-4 Proceedings of the Fourth Conference of the European Society for Research in Mathematics Education. Working group 13: Applications and modelling, 2005. p. 16-23.

BOCHNER, S. The Role of Mathematics in the Rise of Science. Princeton: Princeton University Press, 1981. 386 p.

BONIOLO, G.; BUDINICH, P.; TROBOK, M. (Eds.) The Role of Mathematics in Physical Sciences: Interdisciplinary and Philosophical Aspects. Dordrecht: Springer, 2005, 244 p.

BONIOLO, G.; BUDINICH, P.; The Role of Mathematics in Physical Sciences and Dirac's Methodological Revolution. In BONIOLO, G.; BUDINICH, P.; TROBOK, M. (Eds.) The Role of Mathematics in Physical Sciences: Interdisciplinary and Philosophical Aspects. Dordrecht: Springer, 2005. p. 75-96.

BORK, A. M. Maxwell, Displacement Current, and Symmetry American Journal of Physics, v. 31, n. 11, p. 854-859, 1963.

BORROMEO FERRI, R. Theoretical and empirical differentiations of phases in the modelling process. Zentralblatt für Didaktik der Mathematik, v. 38, n. 2, p. 86-95, 2006.

BOYER, C. B. The History of the Calculus and its Conceptual Development. New York: Dover Publications, 1949. 346 p.

CASTEL, L. B. Vrai système de physique générale de M. Isaac Newton. A la portée du commun des physiciens. Paris, 1743. 520 p.

CHALMERS, A. F. Maxwell and the displacement current. Physics Education, v. 10, p. 4549, 1975. 
CLAGetT, M. The Science of Mechanics in the Middle Ages, Madison: University of Wisconsin Press, 1959. 711 p.

COHEN, L.; MANION, L. Research Methods in Education. London: Routledge, 1989. 413 p.

COURANT., R.; HILBERT, D. Methoden der mathematischen Physik. Berlin: SpringerVerlag, 1993. $549 \mathrm{p}$.

CROWE, M. J. A History of Vector Analysis: The Evolution of the Idea of a vectorial system. New York: Dover Publications Inc, 1985. 270 p.

DARRIGOL, O. Electrodynamics from Ampére to Einstein. New York: Oxford University Press Inc, 2000. 532 p.

DAVIS, R. B. Cognitive processes involved in solving simple algebraic equations. Journal of Children's Mathematical Behavior. v. 1, n. 3, p. 7- 35, 1975.

DAVIS, P.; HERSH, R. The mathematical experience. Boston: Houghton Mifflin Company, 1982. 440 p.

DESCARTES, R. Regras para a direção do espírito. Tradução de João Gama. Lisboa: Edições 70, 2002. 128 p.

DEVLIN, K. The Language of Mathematics: Making the Invisible Visible. New York: W. H. Freeman and Company, 2000. 345 p.

DIEKS, D. The Flexibility of Mathematics. In: BONIOLO, G.; BUDINICH, P.; TROBOK, M. (Eds.) The Role of Mathematics in Physical Sciences: Interdisciplinary and Philosophical Aspects. Dordrecht: Springer, 2005. p. 115-130.

DIRAC, P. A. M., The Evolution of the Physicist's Picture of Nature, Scientific American. v. 208, n. 5, p.45-53, 1963.

EVES, H. Introdução à História da Matemática. Tradução Hygino H. Domingues. Campinas: Editora da Unicamp, 2004. 844 p.

EINSTEIN, A. Über einen die Erzeugung und Verwandlung des Lichtes betreffenden heuristischen Gesichtspunkt. Annalen der Physik, v. 17, 1905, p. 132-148.

. Mein Weltbild. Frankfurt: Ullstein Tachenbücher-Verlag, 1956. 201 p.

. Notas autobiográficas. Tradução Aulyde Soares Rodrigues. Rio de Janeiro: Editora Nova Fronteira, 1982. 88 p.

FEYNMAN, R. P. The Character of Physical Law. Cambridge, MA: The MIT Press, 1985. $173 \mathrm{p}$.

FEYNMAN, R. P.; GOTTLiEB, M. A.; LEIGHTON, R. Dicas de física de Feynman: suplemento para a resolução de problemas do Lectures on Physics. Tradução José Eduardo Padilha de Sousa. Porto Alegre, Bookman, 2008. 176 p.

FEYNMAN, R. P.; LEIGHTON, R. B.; SANDS, M. Lições de Física de Feyman. 3 v. Porto Alegre: Bookman, 2008.

FISCHER, H; LABUDDE, P.; VIIRI, J. Teaching patterns and student achievement: Finland, Germany, and Switzerland compared. Simpósio apresentado no evento ESERA 2011 Conference - 5 a 9 de setembro de 2011 Lyon, França. A ser publicado nos proceedings do evento. 
FLAVELL, J. Metacognitive aspects of problem solving. In: RESNICK, L. (Ed.) The nature of intelligence. Hillsdale, NJ: Lawrence Erlbaum Associates, 1976. p. 231-236.

FLEISCH, D. A Students' Guide to Maxwell's Equations. New York: Cambridge University Press, 2008. 134 p.

FOURIER, J. B. J. Théorie analytique de la chaleur. Paris: Firmin Didot, Père et Fils, 1822. $639 \mathrm{p}$.

GALILEI, Galileu. O Ensaiador. 3 ed. São Paulo: Ed. Abril Cultural, Coleção Os Pensadores, 1983.

GENTNER, D. Analogical reasoning, psychology of. Encyclopedia of Cognitive Science. London: Nature Publishing Group, 2002. p. 106-112.

GERRING, J. Case Study Research: Principles and Practices. New York: Cambridge University Press, 2007. 265 p.

GINGRAS, Y. What did mathematics do to physics? History of Science, v. 39, p. 383-416, 2001.

GRANT, E. Physical Science in the Middle Ages. Cambridge: Cambridge University Press, 1977, $128 \mathrm{p}$.

HADAMARD, J. S. The Psychology of Invention in the Mathematics Field. Princeton: Princeton University Press, 1949, 145 p.

HAINES, C. R.; CROUCH, R. Remarks on a modelling cycle and interpretation of behaviours. In: LESH, R.; GALBRAITH, P. L.; HAINES, C. R.; HURFORD, A. (Eds.) Modelling students' mathematical modelling competencies (ICTMA 13). New York: Springer, 2010. p. 145-154.

HALMOS, P. R. Pure thought is better yet... The College Mathematics Journal v. 16, n. 1, p. 14-16, 1985.

HARMAN, P. M. (Ed.) The scientific letters and papers of James Clerk Maxwell v. 2 1862-1873. Cambridge University Press, 1990, 548 p.

HENRICI, P. The influence of computing on mathematical research and education. In: LASALlE, J. P. (Ed.) Proceedings of Symposia in Applied Mathematics, Vol. 20, American Mathematical Society, Providence, 1974. 205 p.

HESSE, M. B. Models in Physics. The British Journal for the Philosophy of Science. v. 4, n. 15, p. 198-214, 1953.

Models and Analogy in Science. In: EDWARDS, P. (Ed.), The Encyclopedia of Philosophy Vol. 5, MacMillan, New York, 1972. p. 354-359.

HESTENES, D. Oersted medal lecture 2002: Reforming the mathematical language of physics. American Journal of Physics, v. 71, n. 2, p. 104-121, 2003.

HIEBERT, J. (Ed.) Conceptual and Procedural Knowledge: The Case of Mathematics. Hillsdale: L. Erlbaum Associates, 1986. 309 p.

HOWARD, D. Albert Einstein as a Philosopher of Science. Physics Today, v. 58, n. 12, p. 34-40, 2005.

HUDSON, H. T.; LIBERMAN, D. The combined effect of mathematics skills and formal operational reasoning on student performance in the general physics course. American Journal of Physics, v. 50, n. 12, p. 1117-1119, 1982. 
HUDSON, H. T.; MCINTIRE, W. R. Correlation between mathematical skills and success in physics. American Journal of Physics, v. 45, n. 5, p. 470-71, 1977.

JANÍK, T.; SEIDEL, T. (Eds.) The Power of Video Studies in Investigating Teaching and Learning in the Classroom. Göttingen: Waxmann Verlag, 2009. 282 p.

KARAM, R. A. S. Matemática como estruturante e Física como motivação: uma análise de concepções sobre as relações entre Matemática e Física. In: VI Encontro Nacional de Pesquisa em Educação em Ciências, 2007, Florianópolis. Anais do VI ENPEC.

KARAM, R. A. S.; PIETROCOLA, M. Habilidades Técnicas Versus Habilidades Estruturantes: Resolução de Problemas e o Papel da Matemática como Estruturante do Pensamento Físico. ALEXANDRIA Revista de Educação em Ciência e Tecnologia, v. 2, n. 2, p.181-205, 2009a.

Discussão das relações entre Matemática e Física no ensino de reatividade: um estudo de caso. Trabalho apresentado no VII Encontro Nacional de Pesquisa em Educação em Ciências - ENPEC, Florianópolis-Brasil, 2009b.

. Recognizing the Structural Role of Mathematics in Physical Thought. In: TASAR, M.F.; ÇAKMAKCI, G. (Eds.). Contemporary science education research: international perspectives. Ankara: Pegem Akademi, v. 1, p. 65-76, 2010.

KARAM, R.; PIETROCOLA, M.; POSPIECH, G. Mathematik im Physikuntericht: Entwicklung struktureller Fähigkeiten. In: HÖTTECKE, D. (Org.) Naturwissenschaftliche Bildung als Beitrag zur Gestaltung partizipativer Demokratie. Proceedings do encontro anual da Sociedade alemã de ensino de Química e Física (GDCP - Gesellschaft für Didaktik der Chemie und Physik). Potsdam, 2010. Berlin: LIT Verlag, p. 173-175, 2011.

KLINE, M. Mathematics and the physical world. New York: Thomas Y Crowell Company, 1959. 482 p.

KOYRÉ, A. Galileo and Plato. Journal of the History of Ideas, v. 4, n. 4, p. 400-428, 1943.

KUHN, T. A Estrutura das Revoluções Científicas, 6a ed. São Paulo: Editora Perspectiva, 2001. $257 \mathrm{p}$.

LAGRANGE, J. L. Méchanique analitique. Paris: Ve Courcier, 1788. 512 p.

LEMKE, J. Multiplying meaning: visual and verbal semiotics in scientific text. In: MARTIN, J.; VEEL, R. (Eds.). Reading science. Londres: Routledge, 1998. p. 87-113.

LINDBERG, D. C. (Ed.) Science in the Middle Ages. Chicago: University of Chicago Press, 1978. $596 \mathrm{p}$.

LÜDKE, M.; ANDRÉ M. E. D. A. Pesquisa em educação: abordagens qualitativas. São Paulo: EPU, 1986. 99 p.

Matthews, M. R.; GAUld, C. F.; STINner, A. (Eds.) The Pendulum: Scientific, Historical, Philosophical and Educational Perspectives. Dordrecht: Springer, 2005. 542 p.

MAXWELL, J. C. The Scientific Papers of James Clerk Maxwell, v. II. Edited by NIVEN, W. D. New York: Dover Publications Inc., 1890, 806 p.

OSER, F. K.; BAERISWYL, F. J. Choreographies of teaching: Bridging instruction to learning. In: RICHARDSON, V. (Ed.), Handbook of research on teaching Washington, DC: American Educational Research Association, 2001. p. 1031-1065. 
PATY, M. Einstein Philosophe: la physique comme pratique philosophique. Collection Philosophie d'Aujourd'hui. Paris: Presses Universitaires de France, 1993, 584 p.

Le caractère historique de l'adéquation des mathématiques à la physique. In: GARMA, S.; FLAMENT, D.; NAVARRO, V. (Eds.) Contra los titanes de la rutina (Contre les titans de la routine) Comunidad de Madrid/C.S.I.C., Madrid, 1994, p. 401-428.

. A matéria roubada. São Paulo: Edusp, 1995. 320 p.

. The idea of quantity at the origin of the legitimacy of mathematization in physics. In: GOULD, C. (Ed.) Constructivism and practice: Towards a social and historical epistemology. Lanham: Rowman and Littlefield, 2003. p. 109-135.

PENROSE, R. O grande, o pequeno e a mente humana. Tradução Roberto Leal Ferreira. São Paulo: Fundação Editora da UNESP, 1998, 196 p.

PIETROCOLA, M. A Matemática como estruturante do conhecimento físico. Caderno Brasileiro de Ensino de Física. v. 19, n. 1, p. 93-114, 2002.

. Mathematics as structural language of physical thought. In: VICENTINI, M.;

SASSI, E. (Ed.) Connecting Research in Physics Education with Teacher Education. New Delhi: Angus \& Grapher Publishers, v. 2, p. 35-48, 2010.

PLANCK, M. Einführung in die Allgemeine Mechanik. Zum Gebrauch bei Vorträgen, sowie zum Selbstunterricht. Leipzig: S. Hirzel, 1921. 226 p.

POINCARÉ, H. O Valor da Ciência. Tradução Maria Helena Franco Martins. Rio de Janeiro: Contraponto, 1995. 173 p.

POLYA, G. How to solve it. Princeton: Princeton University Press, 1945. 253 p.

Mathematics and plausible reasoning. Volume 1: Induction and Analogy in Mathematics. Princeton: Princeton University Press, 1954. 280 p.

POSPIECH, G. Promoting the competence of mathematical modeling in physics lessons. Proceedings of the GIREP 2006 p. 575-583. Modelling in Physics and Physics Education. AMSTEL institute, Faculty of Science, University of Amsterdam, Netherlands. August, 2006.

REDISH, E. Problem solving and the use of math in physics courses. Palestra proferida na conferência World View on Physics Education in 2005: Focusing on Change. Nova Delhi, 2005. Disponível em <http://arxiv.org/pdf/physics/0608268.pdf $>$ Último acesso em 16 de fevereiro de 2012.

RESNICK, R.; HALLIDAY, D.; KRANE, K. S.; Física. Todos os volumes. 5a edição. Rio de Janeiro: Livros Técnicos e Científicos Editora S.A. 2003.

RITTLE-JOHNSON, B.; ALIBALI, M. W. Conceptual and Procedural Knowledge of Mathematics: Does One Lead to the Other? Journal of Educational Psychology, v. 91, n. 1, p. 175-189.

RIVADULLA, A. Theoretical Explanations in Mathematical Physics. In BONIOLO, G.; BUDINICH, P.; TROBOK, M. (Eds.) The Role of Mathematics in Physical Sciences: Interdisciplinary and Philosophical Aspects. Dordrecht: Springer, 2005, p. 161-178.

ROBILOTTA, M. R. O cinza, o branco e o preto - da relevância da história da ciência no ensino de física. Caderno Catarinense de Ensino de Física, v. 5, n. Especial, p. 7-22, 1988.

SCHEY, H. M. Div, grad curl, and all that: an informal text on vector calculus. New York: W. W. Norton \& Company, 1996. 164 p. 
SCHNEIDER, M.; STERN, E. The Developmental Relations Between Conceptual and Procedural Knowledge: A Multimethod Approach. Developmental Psychology, v. 46, n. 1, p. 178-192, 2010.

SCHOENFELD, A. H. What's all the fuss about metacognition? In: SCHOENFELD, A. H. (Ed.) Cognitive science and mathematics education. Hillsdale, NJ: Lawrence Erlbaum Associates, 1987. p. 189-215.

SEIDEL, T; PRENZEL, M. Stability of teaching patterns in physics instruction: Findings from a video study. Learning and Instruction, v. 16, p. 228-240, 2006.

SFARD, A. On the dual nature of mathematical conceptions: Reflections on processes and objects as different sides of the same coin. Educational Studies in Mathematics, v. 22, p. 1-36, 1991.

SHERIN, B. L. How students understand physics equations. Cognition and Instruction, v. 19, n. 4, p. 479-541, 2001.

SHUELL, T. J. Teaching and learning in a classroom context. In: CALFEE, R. C. (Ed.) Handbook of Educational Psychology. New York: Macmillan, 1996. p. 726-764.

SILVA, C. C. Da força ao tensor: Evolução do conceito e da representação matemática do campo eletromagnético. 2002. 250 f. Tese (Doutorado em Ciências) Instituto de Física Gleb Wataghin - UNICAMP, Campinas, 11 de outubro de 2002.

. The Role of Models and Analogies in the Electromagnetic Theory: a Historical Case Study. Science \& Education, v. 16, n. 4, p. 835-848, 2007.

SINGH, C. Student understanding of symmetry and Gauss's law of electricity. American Journal of Physics v. 74, n. 10, p. 923-936, 2006.

SKEMP, R. R. Relational understanding and instrumental understanding. Mathematics Teacher, v. 77, p. 20-26, 1976.

STEINER, M. The applicability of mathematics as a philosophical problem. Cambridge, MA: Harvard University Press, 1998. 215 p.

TIPLER, Paul. A. Física. Todos os volumes. Rio de Janeiro: Editora Guanabara Dois S.A. 1984.

TRUESDELL, C. Essays in the history of mechanics. New York: Springer, 1968. 384 p.

TUMINARO, J. A cognitive framework for analyzing and describing introductory students' use and understanding of mathematics in physics. Tese de Doutorado, Physics Education, Universidade de Maryland, College Park, 2004.

TUMINARO, J.; REDISH, E. F. Elements of a cognitive model of physics problem solving: Epistemic Games. Physical Review Special Topics - Physics Education Research, v. 3, n. 2, 020101, p. 1-22, 2007.

TZANAKIS, C. Discovering by analogy: the case of Schrödinger's equation. European Journal of Physics, v. 19, p. 69-75, 1998.

UHDEN*, O.; KARAM*, R.; PIETROCOLA, M.; POSPIECH, G. Modelling mathematical reasoning in physics education. Publicado online em 20 de outubro de 2011 na Science $\&$ Education. * Ambos os autores contribuíram igualmente. 
WALSH, L. N.; HOWARD, R. G.; BOWE, B. Phenomenographic study of students' problem solving approaches in physics. Physical Review Special Topics - Physics Education Research, v. 3, n. 2, 020108, p. 1-12, 2007.

WIGNER, E. P. The Unreasonable Effectiveness of Mathematics in the Natural Sciences. In Communications in Pure and Applied Mathematics, v. 13, n. 1, p. 1 - 14, 1960. New York: John Wiley \& Sons, Inc.

Disponível em $<$ http://www.ipod.org.uk/reality/reality_wigner.pdf $>$ Último acesso em 16 de fevereiro de 2012.

YOUNG, H. D.; FREEDMAN, R. A.; Física. Todos os volumes. São Paulo: Editora Addison Wesley, 2003.

ZAHAR, E. Einstein, Meyerson and the Role of Mathematics in Physical Discovery. The British Journal for the Philosophy of Science, v. 31, n. 1, p. 1-43, 1980.

ZYLBERSZTAJN, A. Resolução de problemas: uma perspectiva kuhniana. In: VI Encontro de Pesquisa em Ensino de Física, Atas (CD-ROM). Florianópolis, 26 a 30 de outubro, 1998. 


\section{ANEXO 1}

Avaliações do desempenho didático do professor

$$
\begin{gathered}
\text { INSTITUTO DE FÍSICA - USP } \\
\text { CAD-COMISSÃO DE AVALIACCAOO DIDÁTICA } \\
\text { AVALIAÇA CONIINUADA - } 2 \text { SEmEStre de 2005 } \\
\text { QUESTIONÁRIO } 1 \text { - ESTUDANTES }
\end{gathered}
$$

professor e verificar eventuais problemas quas deve ser preenchido por turma, que tem o objetivo de servir de apoio ao e CG. $\quad . \quad$ para solucioná-los sejam tomadas pela CAD

Caso haja algum problema referente à disciplina no decorer do curso, registe seu comentaio

individual ou observacão no site: http /humvif referente à discip Este questionário preenchido devera cad, que será verificado semanalmente.

As linhas após cada questão

fazer críticas construtivas.

Disciplina: (nome) tivicas

Professor(a):

Graduação: $\square$ Diurno

Pós:

Q Mestrado

Noturno

$\square$ Licenciatura

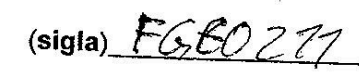

Turma

$\square$ Laboratório

Unidade de origem da turma:

$\square$ Poli $\square$ IME

LLicenciatura

Bacharelado

1. O programa, as datas de provas e o critério de avaliação da disciplina foram apresentados no semestre letivo

$\triangle \operatorname{Sim}$

$\square$ Não

2.Qual é o número médio de alunos presentes às aulas?

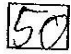

3. As aulas estão sendo ministradas pelo professor responsável pela disciplina?

$$
\text { 区 Sim } \square \text { Näo }
$$

\section{ATENCÄO: Nos retângulos correspondentes às perguntas a seguir, preencha com o} NÚMERO DE ALUNOS que se manifestaram por cada opçäo

\section{AVALIACC̃̃o DA DISCIPLINA}

4. O conteúdo das aulas é coerente com os objetivos propostos no programa?

i) $\sin$

Năo

Parcialmente

5. Você tem consultado a bibliografia indicada pelo professor? 4$] \operatorname{sim}[10]_{\text {Não }}$ 


\section{INSTITUTO DE FÍSICA - USP \\ CAD - COMISSÁO DE AVALIACÁO DE DISCIPLINAS AVALIAÇ:ÃO CONTINUADA - gूj Semestre de $200 \$$ \\ QUESTIONÁRIO 2 - ESTUDANTES}

Este é o questionário da $C A D$, o qual deve ser preenchido por turma, e tem o objetivo de servir de apoio ao professor e fornecer subsidios para o aprimoramento das disciplinas.

Caso haja algum problema referente à disciplina no decorrer do curso, registre seu comentário individual ou observação no site: http://www if.usp.br/cadl, que será verificado semanalmente.

Este questionário preenchido deverá ser entregue na CG ou seção de alunos do IFUSP.

As linhas após cada questão servem para que os alunos façam observaçôes. Procure utilizar esse espaço para fazer críticas construtivas.

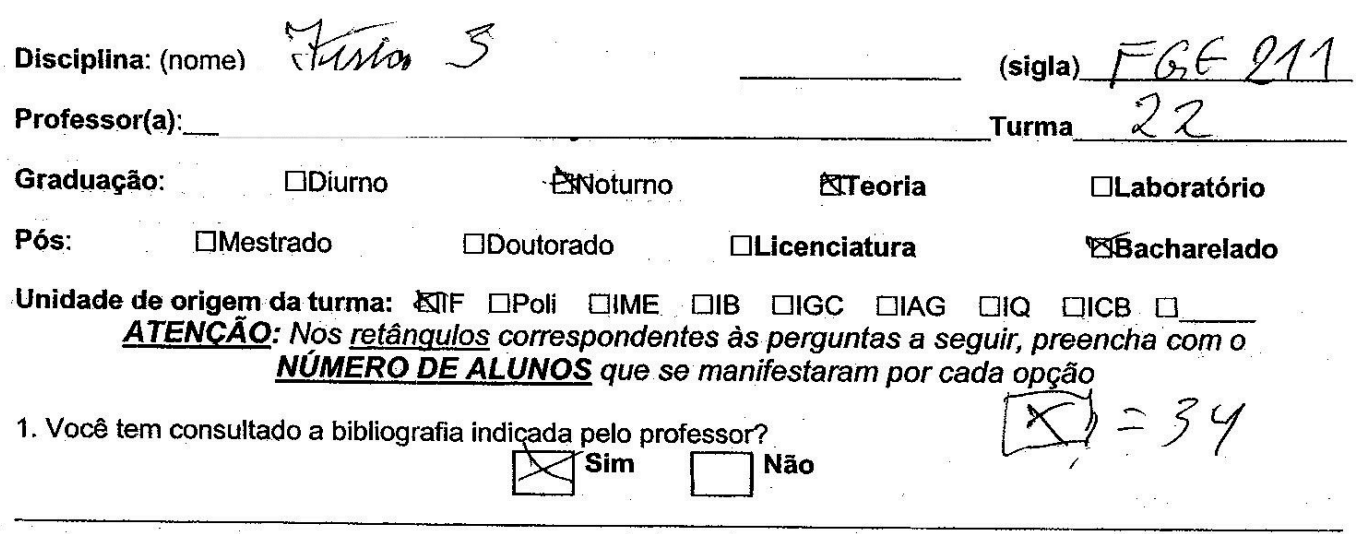

2. A contribuição da bibliografia indicada na compreensão dos conteúdos expostos em aula é:
Xito boa
Boa
Média
Ruím

3. Você tem procurado algum livro na biblioteca e não tem encontrado? Em caso afirmativo, qual? Obs; Essa sugestão será encaminhada para a lista de compras da biblioteca do IFUSP.

\section{Leto}

4. A carga horária desta dișciplina, de acordo com o conteúdo atribuido à mesma, é adequada?

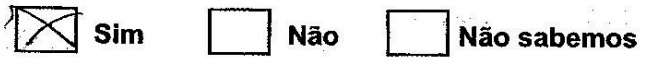

5. O tempo para fazer a prova é suficiente?

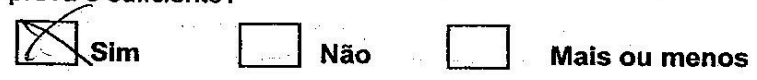

6. O grau de dificuldade da avaliação (nível de provas/relatório) é compatível com o conteúdo apresentado?

$\notin \operatorname{sim} \square$ Não $\square$ Parcialmente




\section{INSTITUTO DE FÍSICA - USP \\ CAD-COMISSÃO DE AVALAAÇÃo DIDÁTICA \\ AVALIAÇÃo CONTINUADA - İ Semestre de 2006 \\ QUESTIONÁRIO 1 - ESTUDANTES}

Este é o novo questionário da $\mathrm{CAD}$, o qual deve ser preenchido por turma, que tem o objetivo de servir de apoio ao professor e verificar eventuais problemas nas disciplinas para que medidas para solucioná-los sejam tomadas
pela $\mathrm{CAD}$ e CG.

Caso haja algum problema referente à disciplina no decorrer do curso, registre seu comentário individual ou observação no site: $\underline{\text { http: } / / w w w}$.if.usp.bricad/, que será verificado semanalmente.

Este questionário preenchido deverá ser entregue na CG ou seção de alunos do IFUSP.

As linhas após cada questão servem para que os alunos façam observaçôes. Procure utilizar esse espaço para fazer críticas construtivas.

Disciplina: (nome) Fisica IV (sigla) FAP 212

Professor(a):

\ Teoria $\square$ Laboratório

Graduação: $\square$ Diurno $\otimes$ Noturno

X Pós-graduação $\square$ Mestrado $\square$ Doutorado

1. Foi apresentado no início do semestre letivo:

O programa da Disciplina: $\square \operatorname{sim} \square$ não.

As datas de provas (provinhas, listas, etc.): $\square \operatorname{sim} \square$ não.

O critério de avaliação: $\square \operatorname{sim} \square$ não.

2.Qual é o número médio de alunos presentes às aulas? 45

3. As aulas estão sendo ministradas:

\ $100 \%$ pelo professor responsável pela disciplina.

$\square \quad 100 \%$ por um monitor.

$\square \quad 100 \%$ por um professor substituto.

Parcialmente por um professor substituto e/ou monitor. (Neste caso explicite abaixo a porcentagem de aulas ministradas pelo substituto e/ou monitor) 
4. O horário e/ou duração da aula, estabelecido na sua matrícula, está sendo cumprido?

$\triangle \operatorname{sim}$

$\square$ não

ATENCÃO: Nos retôngulos correspondentes às perguntas a seguir, preencha com o NÚMERO DE ALUNOS que se manifestaram por cada opção

\section{AVALIAÇÃO DA DISCIPLINA}

5. Há coerência entre os objetivos propostos no programa e o conteúdo das aulas?
$45 \mathrm{Sim}$
Não
Parcialmente

6. Você tem consultado a bibliografia indicada pelo professor? 45 Sim $\square$ Não

7. A bibliografia indicada auxilia na compreensão dos conteúdos expostos em aula? 45 Bastante $\square$ Mais ou Menos $\square$ Pouco Nada

8. O grau de dificuldade da avaliação (nível de provas/relatórios) é compativel com o conteúdo apresentado?
$45 \mathrm{Sim}$
$\square$ Não
Parcialmente
Não tivemos prova/relatório ainda

9. Você tem procurado algum livro na biblioteca e não tem encontrado? Em caso afirmativo, qual? NAO

\section{AVALIACÃO DO(A) PROFESSOR(A)}

10. O profeșsor propõe listas de exercícios? ( \ịm $\square$ não). Em caso afirmativo este trabalho extra-classe contribui para o aprendizado?

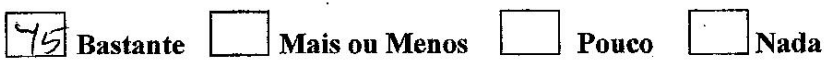


11. Esta disciplina possui monitor? ( $\square$ sim $\square$ não). Em caso afirmativo ó atendimento do monitor tem sido:

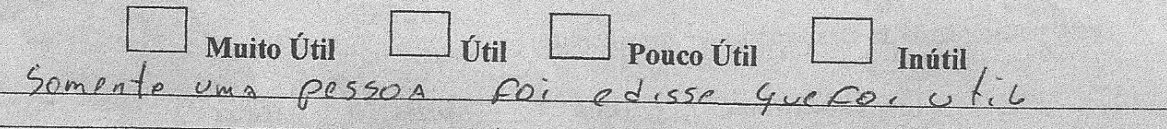

12. A assiduidade e pontualidade do professor pode ser considerada:

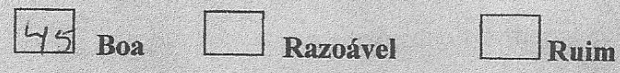

13. A interação (relação) do professor com a classe é:

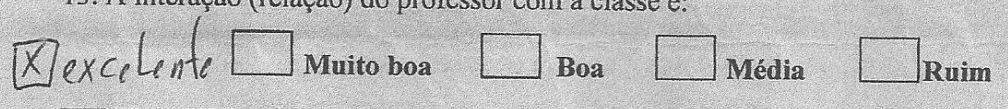

14. A preparação das aulas pelo professor é

45 Muito boa $\square$ Boa $\square$ Regular $\square$ Ruim

15. A didática (capacidade de transmitir o conteúdo da matéria) do professor é:

$\frac{45 \text { Muito boa } \square \text { Boa } \square \text { Regular } \square \text { Ruim }}{\text { NFO e mansuravel - tonda AO inpini to }}$

16. O conhecimento que o professor apresenta ter da matéria é:

Kexcelentc $\square_{\text {Muito bom }} \square_{\text {Bom }} \square_{\text {Regular }} \square_{\text {Ruim }}$

Ele éo mestre do universo

substituir o mayses

17. O professor está disponivel fora da sala de aula para dúvidas ou esclarecimentos?
45 Sim
Não
Não sei

18. O quanto seu professor soube estimular seu senso crítico e seu interesse pelo conteúdo do curso?

45 Muito $\square$ Mais ou menos $\square$ Pouco $\square$ Nada

MO' BaratO




\section{AUTO-AVALIACÃO DA CLASSE}

19. A participação da classe pode ser considerada:

45 Muito boa $\square$ Boa $\square$ Média $\square$ Ruim

20. O interesse da classe pode ser considerado:

45 Muito bom $\square$ Bom $\square$ Médio $\square$ Ruim

21. O empenho dos alunos no aprendizado dessa matéria pode ser considerado:

$$
45 \text { Muito bom } \square \text { Bom } \square \text { Médio } \square \text { Ruim }
$$

Observações adicionais que julgarem pertinentes: (usem folha avulsa se necessário)

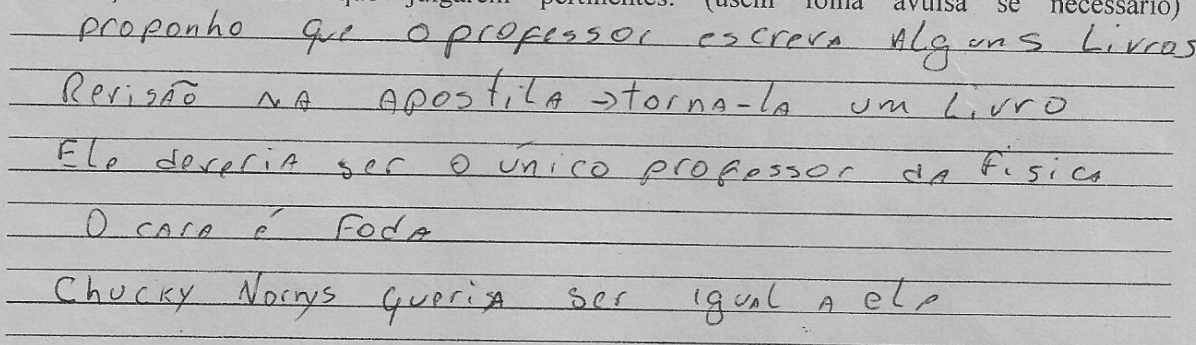

Data:021051 2006

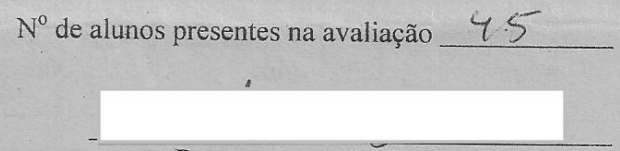

Representante da Turma

e-mail: 


\section{INSTITUTO DE FÍSICA - USP \\ CAD-COMISSÃ́ DE AVALIAÇ̃̃O DIDÁTICA \\ AVALIAÇÃO CONTINUADA - 19 - Semestre de 2006 \\ QUESTIONÁRIO 2 - ESTUDANTES}

Este é o novo questionário da $\mathrm{CAD}$, o qual deve ser preenchido por turma, que tem o objetivo de servir de apoio ao professor e verificar eventuais problemas nas disciplinas para que medidas para solucioná-los sejam tomadas pela $\mathrm{CAD}$ e CG.

Caso haja algum problema referente à disciplina no decorrer do curso, registre seu comentário individual on observação no site: http://www.iff.usp.br/cad/, que será verificado semanalmente.

Este questionário preenchido deverá ser entregue na CG ou seção de alunos do IFUSP.

As linhas após cada questão servem para que os alunos façam observaçōes. Procure utilizar esse espaço para fazer criticas construtivas.

Disciplina: (nome) $\left[\operatorname{sic} \frac{C_{A}}{n} \rightarrow\right.$ (sigla) 212

Professor(a):

Teoria

$\square$ Laboratório

Graduação:

Diurno $\searrow$ Noturno

Q Bacharelado

Licenciatura

Pós-graduação:

Mestrado

Doutorado

Unidade de

origem da turma

(x $\square$ Poli $\square$

IB $\square$ IGC $\square$ IAG $\square$ IQ $\square$ ICB

ATENCÃO: Nos retângulos correspondentes às perguntas a seguir, preencha como

NÚMERO DE ALUNOS que se manifestaram por cada opção.

\section{AVALIACÃO DA DISCIPLINA}

1. Você tem consultado a bibliografia indicada pelo professor? 48 Sim $\square$ Não

2. A carga horária dessa disciplina, de acordo com o conteúdo atribuído à mesma, é adequada?
4.8. Sim
Não
Não sabemos

3. O tempo para fazer a prova é suficiente?

48 Sim

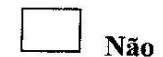

Mais ou menos 
4. O grau de dificuldade da avaliação (nível de provas/relatórios) é compatível com o conteúdo apresentado?

42 Sim $\square$ Não $\square$ Parcialmente

5. Você acha que essa disciplina está contribuindo para sua formação?
4.8 Muito
Mais ou menos
Pouco
Nada

\section{AVALIACÃO DO(A) PROFESSOR(A)}

6. As listas de exercícios propostas pelos professores têm ajudado:

48 Bastante $\square$ Mais ou Menos $\square$ Pouco $\square$ Nada $\square$ Não temos listas

7. $\mathrm{O}$ atendimento do monitor tem sido:

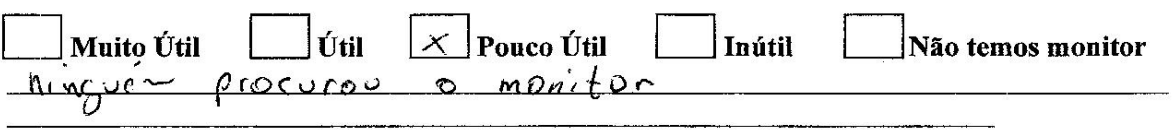

8.

\begin{tabular}{|c|c|c|c|c|}
\hline Quesitos referentes ao professor & $\begin{array}{c}\text { Muito } \\
\text { boa }\end{array}$ & Boa & Média & Ruim \\
\hline Interação com a classe & 48 & & & \\
\hline Preparação das aulas & 48 & & & \\
\hline Didática (capacidade de transmitir o conteúdo) & 48 & & & \\
\hline Conhecimento que apresenta ter da matéria & 48 & & & \\
\hline
\end{tabular}

Considerações sobre os quesitos acima:

9. O quanto seu professor soube estimular seu senso crítico e seu interesse pelo conteúdo do curso?
47 Muito
Mais ou menos
$\square$ Pouco
Nada 


\section{INSTITUTO DE FÍSICA - USP \\ CAD-COMISSĀO DE AVALIAÇÃO DIDÁTICA AVALIAÇĀO CONTINUADA - $2^{\circ}$ Semestre de 2006 \\ QUESTIONÁRIO 1 - ESTUDANTES}

Este é o questionário da CAD, o qual deve ser preenchido por turma, que tem o objetivo de servir de apoio ao e CG. Caso haja algum problema referente à disciplina no decorrer do curso, registre seu comentário individual ou observação no site: http://www. if usp. br/cad/, que será verificado semanalmente.

Este questionário preenchido deverá ser entregue na CG ou seção de alunos do IFUSP. As linhas após cada questão servem para que os alunos façam observaçóes. Procure utilizar eșse espaço para
fazer criticas construtivas.

Disciplina: (nome) Fisian III

Professor(a):

(sigla) FGE-211

\section{Graduação:}

凶Diurno

Pós:

$\square$ Mestrado

$\square$ Doutorado

$\square$ Noturno

Turma /

Unidade de origem da turma:

:

DIME

$\square$ Licenciatura

$\square$ Laboratório

Bacharelado

$\square I B \quad \square I G C \quad \square I A G \quad \square I Q \quad \square I C B \quad \square$

1. O programa, as datas de provas e o critério de avaliação da disciplina foram apresentados no início do semestre letivo:
內sim
$\square$ Não

2.Qual é o númerọ médio de alunos presentes às aulas?

100

3. As aulas estão sendo ministradas pelo professor responsável pela disciplina?

Sim

$\square$ Não

ATENCÃO: Nos retânqulos correspondentes às perguntas a seguir, preencha com o NÚMERO DE ALUNOS que se manifestaram por cada op̧̧ão

\section{AVALIACÃO DA DISCIPLINA}

4. O conteúdo das aulas é coerente com os objetivos propostos no programa?

$73 \mathrm{Sim}$

O Não

0 Parcialmente

5. Você tem consultado a bibliografia indicada pelo professor? 73 Sim 0 Não 
6. A contribuição da bibliografia indicada na compreensão dos conteúdos expostos em aula é:
70
Muito boa
3 Boa
0 Média
O Ruim

7. Você tem procurado algum livro na biblioteca e năo tem encontrado? Em caso afirmativo, qual? Obs: Essa sugestão será encaminhada para a lista de compras da biblioteca do IFUSP.

\section{GRIfPItS RLETRODVNAMLS}

AVALIAÇÕES

8. Listas e Monitor:

\begin{tabular}{|c|c|c|c|c|c|c|}
\hline Quesitos referentes às listas e ao monitor & $\begin{array}{c}\text { Muito } \\
\text { boa }\end{array}$ & Boa & Média & Ruim & $\begin{array}{c}\text { Não } \\
\text { utilizamos }\end{array}$ & $\begin{array}{c}\text { Não } \\
\text { há }\end{array}$ \\
\hline $\begin{array}{c}\text { A contribuição das listas de exercícios para o } \\
\text { aprendizado é }\end{array}$ & & & & & & $\times$ \\
\hline $\begin{array}{c}\text { A contribuição do atendimento do monitor para o } \\
\text { aprendizado é }\end{array}$ & & & & & & \\
\hline
\end{tabular}

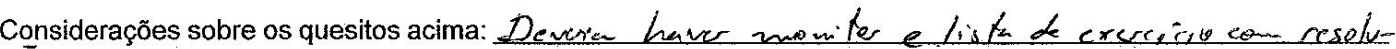
cás.

s

9. Caso essa disciplina não tenha monitor, seu professor está disponível fora da sala de aula para dúvidas ou esclarecimentos?

$5 \mathrm{Sim} \quad 5$ Não $\quad 20$ Não sei

10. Quantos alunos costumam utilizar a monitoria desta disciplina 0

\begin{tabular}{|c|c|c|c|c|c|}
\hline Quesitos referentes ao professor & $\begin{array}{c}\text { Muito } \\
\text { boa }\end{array}$ & Boa & Média & Ruim & Ruim \\
\hline Interação com a classe & 62 & 11 & 0 & 0 & 0 \\
\hline Preparação das aulas & 67 & 6 & 0 & 0 & 0 \\
\hline Didática (capacidade de transmitir o conteúdo) & 57 & 15 & 1 & 0 & 0 \\
\hline Assiduidade e pontualidade & 58 & 15 & 0 & 0 & 0 \\
\hline
\end{tabular}

Considerações sobre os quesitos acima: 


\section{INSTITUTO DE FÍSICA - USP \\ CAD - COMISSĀo dE AVALIAÇÃO DE DISCIPLINAS \\ AVALIAÇÃO CONTINUADA - $2^{\circ}$ Semestre de 2006 \\ QUESTIONÁRIO 2 - ESTUDANTES}

Este é o questionário da CAD, o qual deve ser preenchido por turma, e tem o objetivo de servir de apoio ao professor e fornecer subsidios para o aprimoramento das disciplinas.

Caso haja algum problema referente à disciplina no decorrer do curso, registre seu comentário individual ou observaçāo no site: http://wmw.if.usp.br/cadl, que será verificado semanalmente.

Este questionário preenchido deverá ser entregue na CG ou seção de alunos do IFUSP.

As linhas após cada questão servem para que os alunos façam observaçōes. Procure utilizar esse espaço para fazer críticas construtivas.

Disciplina: (nome) FIsi

Professor(a):

Graduação:

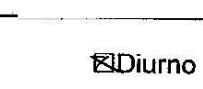

Pós:

पMestrado

$\square$ Doutorado

DNoturno पTeoria

(sigla) FGEO 211

Turma

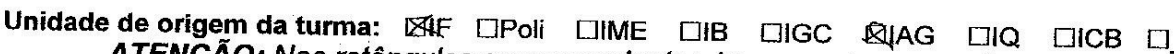

ATENCÃO: Nos retânqulos corrospondentes às perguntas a seguir, preencha com o NÚMERO DE ALUNOS que se manifestaram por cada opção

1. Você tem consultado a bibliografia indicada pelo professor?

56 Sim $\square$ Não

2. A contribuição da bibliografia indicada na compreensão dos conteúdos expostos em aula é:
40 Muito boa
43 Boa
3 Média
$\infty$ Ruim

3. Você tem procurado algum livro na biblioteca e näo tem encontrado? Em caso afirmativo, qual? Obs: Essa sugestäo será encaminhada para a lista de compras da biblioteca do IFUSP.

4. A carga horária desta disciplina, de acordo com o conteúdo atribuido à mesma, é adequada?

$$
56 \operatorname{sim} 10 \text { Não } 0 \text { Não sabemos }
$$

5. O tempo para fazer a prova é suficiente?
50 Sim
O Não
6 Mais ou menos

6. O grau de dificuldade da avaliação (nível de provas/relatório) é compativel com o conteúdo apresentado?

56 Sim 0 Não 0 Parcialmente


7. Você acha que esta disciplina está contribuindo para sua formação?

Muito
Mais ou menos
Nada

8. Listas e Monitor:

\section{AVALIACÕES}

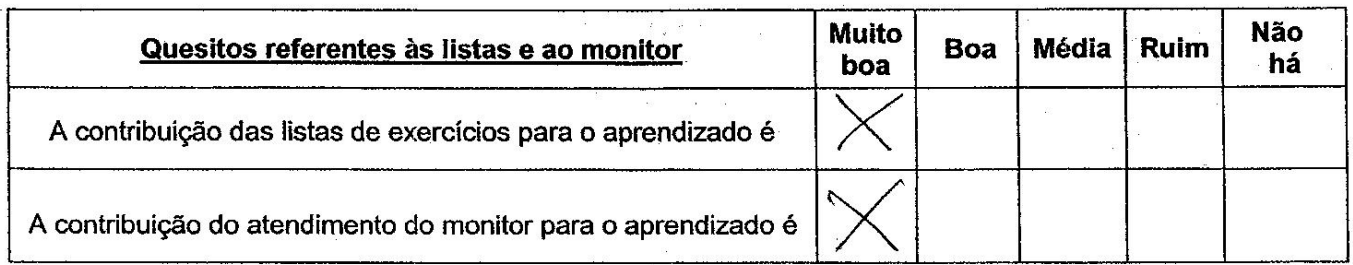

Consideraçōes sobre os quesitos acima:

9. Caso essa disciplina não tenha monitor, seu professor está disponível fora da sala de aula para dúvidas ou esclarecimentos?

$2 \sin$

Não

Não sei

10. Quantos alunos costumam utilizar a monitoria desta disciplina? 3

\begin{tabular}{|c|c|c|c|c|}
\hline Quesitos referentes ao professor & $\begin{array}{c}\text { Muito } \\
\text { boa }\end{array}$ & Boa & Média & Ruim \\
\hline Interação com a classe & & \\
\hline Preparação das aulas & & & \\
\hline Didática (capacidade de transmitir o conteúdo) & & & \\
\hline Assiduidade e pontualidade & & & \\
\hline
\end{tabular}

Considerações sobre os quesitos acima:

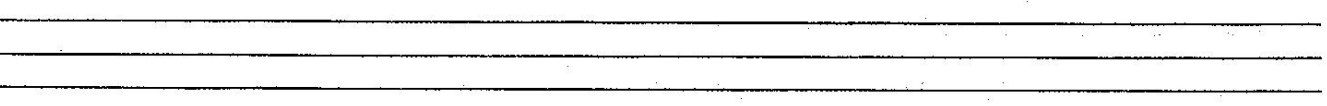

11. O quanto seu professor soube estimular seu interesse pelo conteúdo do curso?

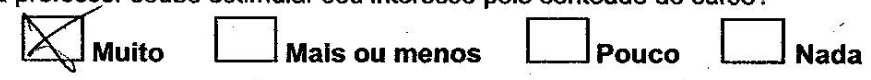




\section{AUTO-AVALIAÇ̃̃O DA CLASSE}

12. Durante a aula, há diálogo da classe com o professor acerca do conteúdo da matéria?
(5) Sim
I] Não

13. O interesse da classe pelo conteúdo da matéria pode ser considerado:
37
Muito bom 15
Bom 4
Médio $O$ Ruim

14. Quantas horas, por semana, são dedicadas ao estudo desta disciplina fora da sala de aula?

28 menos de 2 horas 28 horas $O 4$ horas $D 6$ horas

15. A freqüência média dos alunos, em relação ao primeiro questionário

0 aumentou 51 diminuiu 5 Permaneceu igual

Observações adicionais que julgarem pertinentes: (usem folha avulsa se necessário)

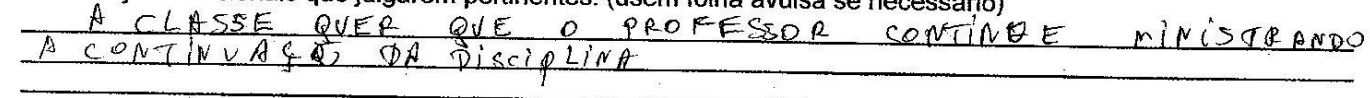
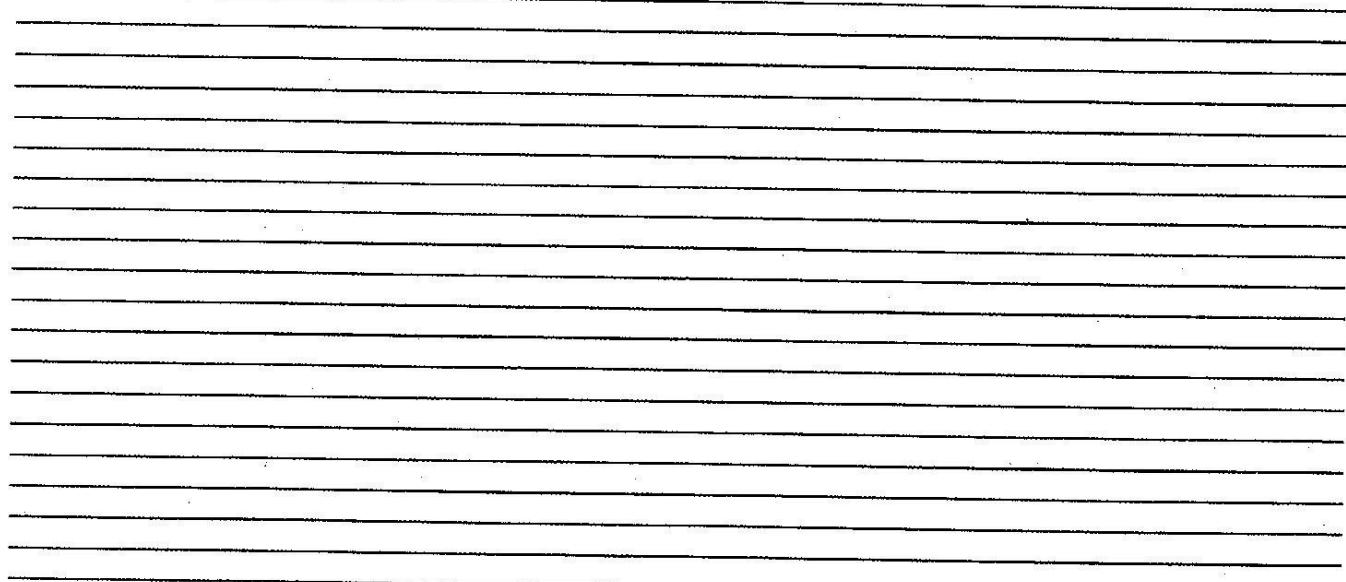

Data:24/1]/2006

$\mathrm{N}^{\circ}$ de alunos presentes na avaliação 56

Representante da Turma: e-mail: : 


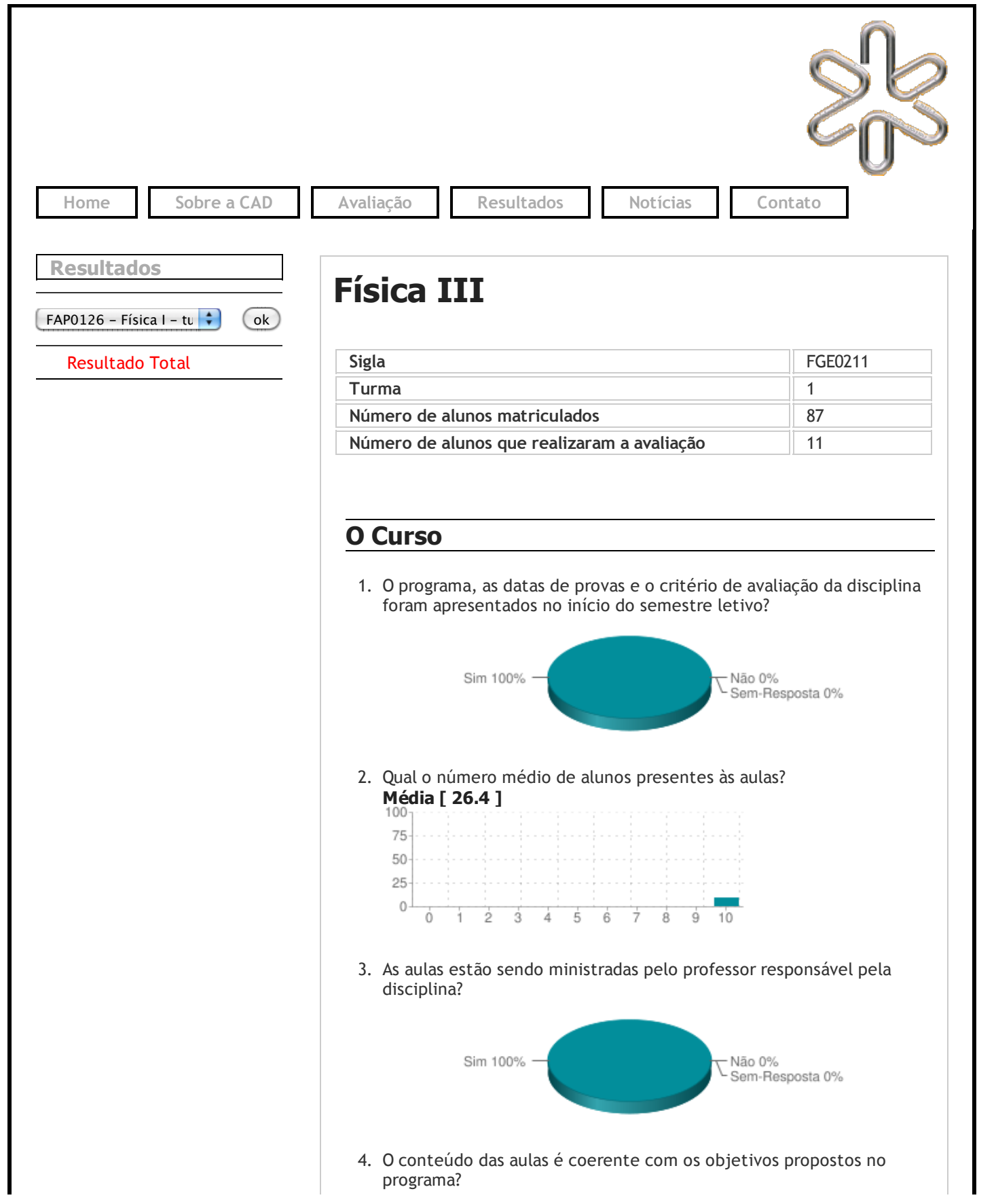




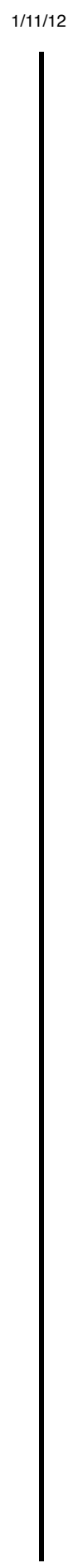

Física III - Resultados [CAD 2012] - Comissão de Avaliação das Disciplinas

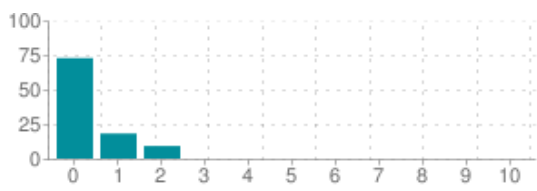

O Professor

1. A interacão do professor com a classe é: Média [ 9.1 ]

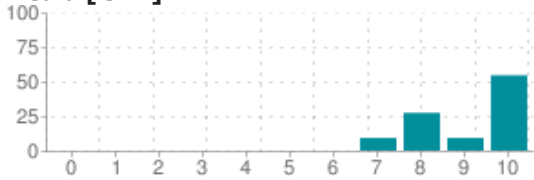

2. A preparação das aulas é: Média [ 9.3 ]

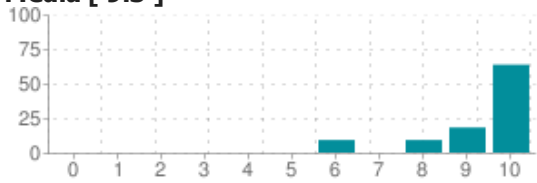

3. A capacidade do professor de transmitir o conteúdo (didática) é: Média [ 9.5 ]

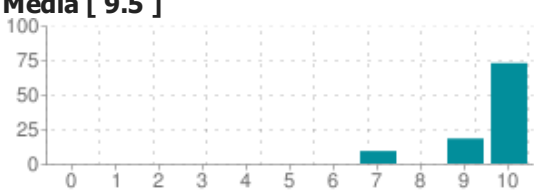

4. Quanto a assiduidade e pontualidade: Média [ 8.9 ]

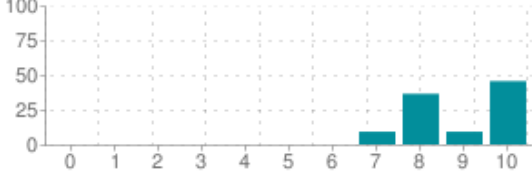

5. O quanto seu professor soube estimular seu interesse pelo conteúdo curso?

Média [ 9.5 ]

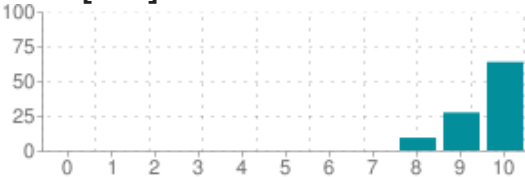


ANEXO 2

Provas aplicadas no curso de eletromagnetismo 2009/2

\section{Física 3}

\section{4 de setembro de 2009 - diurno e noturno}

$(1,0)$ 1. Explique o significado físico da lei de conservação da carga elétrica e dê um exemplo onde ela se aplica.

2. A figura representa duas esferas metálicas idênticas, sustentadas por bases isolantes. As várias situaçôes descritas abaixo ocorrem em seqüência. Faça desenhos claros, indicando a distribuição de cargas nos corpos metálicos, quando:

$(0,5)$ a) um bastão carregado positivamente é colocado entre as duas esferas, sem tocá-las;

$(0,5)$ b) a esfera da esquerda é aterrada, em presença do bastão;

$(0,5)$ c) a ligação com a Terra é desfeita e, em seguida, o bastão é retirado;

$(0,5)$ d) as duas esferas são ligadas por um fio metálico.

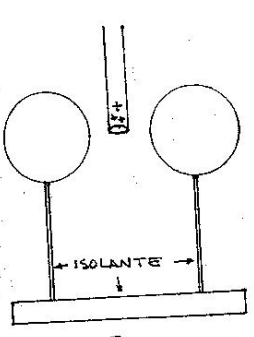

a.

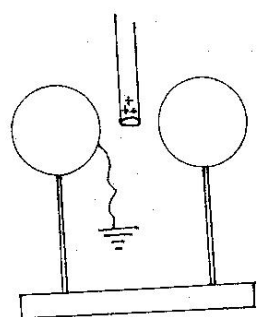

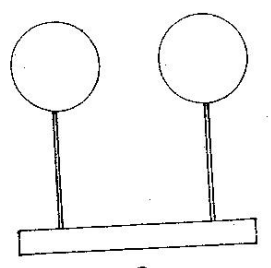

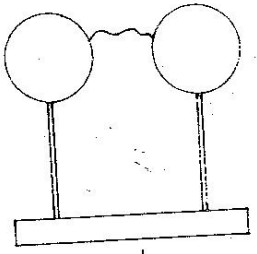

$d$

3. É dado um corpo isolante, na forma de cilindro de altura $a$ e raio $b$. Ele está carregado com

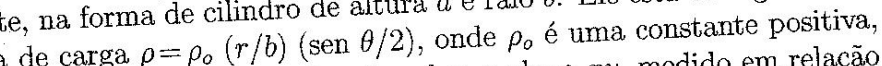
uma densidade volumétrica de carga $\rho=\rho_{o}(r / b)$ (sen $\theta$ êngulo sobre o plano $x y$, medido em relação ao eixo $x$.

$(0,5)$ a) faça um desenho representando a distribuição de cargas no interior do cilindro, num plano perpendicular ao seu eixo.

$(0,5)$ b) faça um desenho representando a distribuição de cargas no interior do corpo, ao longo do plano $x z$.

$(0,5)$ c) faça um desenho representando a distribuição de cargas no interior do corpo, ao longo

do plano $y z$.
$(0,5)$ d) escreva a expressão matemática genérica que representa um

corpo, explicando claramente o significado

$(1,5)$ e) calcule a carga total do cilindro.

4. Uma coroa circular, de raio interno a e raio externo $b$, localizada sobre o plano $x y$ e com centro coincidente com a origem do sistema de coordenadas, está carregada com uma densidade superficial de carga $\sigma=(c / r) \operatorname{sen} \theta$, onde $r$ e $\theta$ säo coordenadas cilíndricas e $c$ é uma constante positiva. Inicialmente, considere um pedacinho genérico do disco, localizado no ponto $(r \cos \theta, r \operatorname{sen} \theta, 0)$.

$(0,5)$ a) expresse matematicamente a carga contida nesse pedacinho;

a expressão do vetor campo elétrico criado por esse pedacinho do disco no ponto $P=(0,0, b)$

$(2,0)$ c) calcule o vetor campo elétrico criado pelo disco no ponto $P$. 


\section{Física 3}

19 de outubro de 2009 - diurno e noturno

- professor:

- nome:

1. Uma esfera isolante, de raio $a$, carregada com uma densidade volumétrica $\rho=\beta r$, onde $\beta$ é uma constante positiva e $r$ é a distância ao centro, é envolta por uma casca esférica metálica, concêntrica, de raio interno $2 \mathrm{a}$, raio externo $4 \mathrm{a}$, e eletricamente neutra.

$(0,5)$ a) Faça um desenho indicando as distribuições de carga no sistema.

$(0,5)$ b) Mostre que as densidades de carga da casca metálica são, em módulo, $\left(\beta a^{2} / 16\right)$ e $\left(\beta a^{2} / 64\right)$. Explicite os procedimentos usados na obtenção desses resultados.

$(1,0)$ c) Calcule o campo elétrico $E$ em todo o espaço.

$(1,0)$ d) Faça um gráfico, representando a parte escalar de E, em função da distância ao centro do sistema, indicando claramente sobre os eixos os valores significativos.

$(0,5)$ e) Em quais regiöes do sistema existe auto-energia acumulada? Justifique a sua resposta.

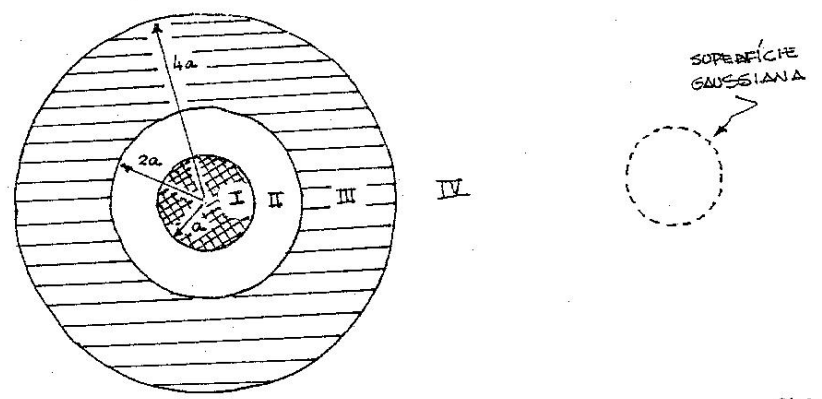

- 2. Considere, na situação descrita na questão anterior, uma superfície gaussiana esférica, ijo $10 a$ do centro do sistema. A lei de Gauss, aplicada a essa superfície gaussiana, permite calcular o fluxo do campo elétrico $\Phi$ e o campo elétrico $\boldsymbol{E}$ ? Justifique a sua resposta.

- 3. Numa região do espaço existe um potencial eletrostático dado por

$$
V(x, y, z)=a \frac{e^{-b(x+y)^{2}}}{\left(z^{2}+c\right)},
$$

onde $x, y, z$ são as coordenadas do ponto considerado e $a, b, c$ são constantes positivas

$(1,0)$ a) Calcule o campo elétrico associado a esse potencial.

$(1.0)$ b) Determine o trabalho realizado por esse campo elétrico quando uma carga puntiforme $q$ e levada do infinito até a origem do sistema de coordenadas.

- questões 4 a 8 , no verso 
0 enunciado que segue refere-se às questões 4 a 8 .

Sảo dados dois sistemas $A$ e $B$, cada um deles formado por duas placas circulares, paralelas, e carregadas com cargas iguais em módulo e de sinais opostos. As placas dos sistemas A e B têm, respectivamente, raios $R_{A}=R$ e $\underline{R}_{B}=2 R$. Nestas questões, os símbolos $d, \sigma, E, F$ e $U$ representam, para cada um dos sistemas, a distância entre as placas, o módulo da densidade de carga sobre as placas, o módulo do campo elétrico entre as placas, o módulo da força de atração entre as placas e a energia potencial acumulada, respectivar

$d<<R$. As figuras I, II e III mostram tres situaçoes diferentes: - na situação $I$, os dois sistemas estão desconectados e as cargas nelas são $Q_{A}=Q$ e $Q_{B}=2 Q$. as distâncias e entre as placas valem $d_{A}=d, d_{B}=d$ - na situação II, os dois sistemas continuam desconectados desprezada; as distâncias e entre as placas valos condutores, longos e $Q_{B}=2 Q$. - na situacaro e finos.

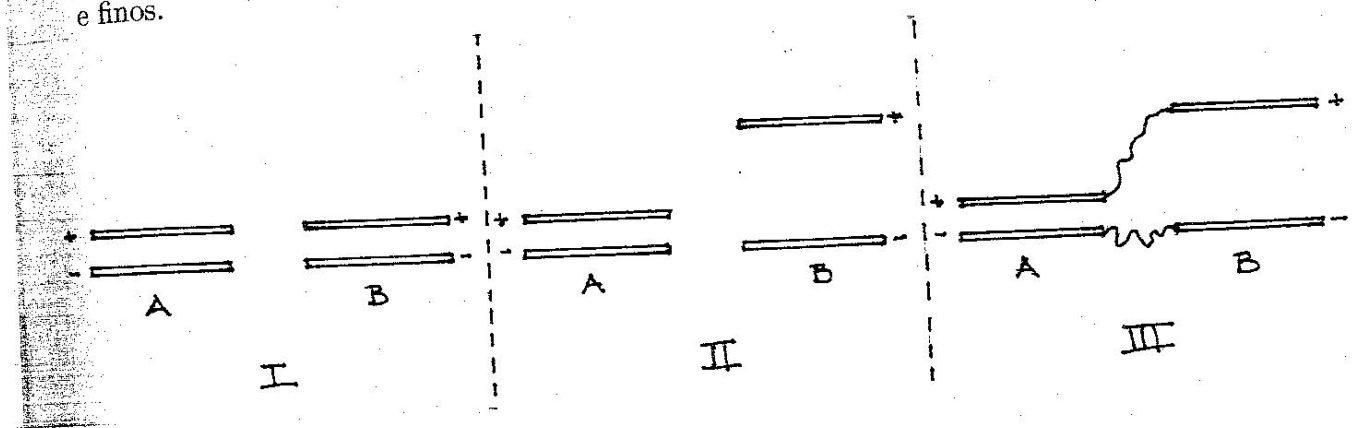

ATENÇÃO:

as respostas devem ser assinaladas diretamente sobre os enunciados; os cálculos relativos a estas questões devem ser deixados na folha 4 do caderno de respostas poderão ser verificados.
$(0,5)$-4. Na situação I, vale a relação:
(a) $E_{B}=4 E_{A}$;
(b) $E_{B}=2 E_{A}$;
(c) $E_{B}=E_{A}$;
(d) $E_{B}=E_{A} / 2$;
(e) $E_{B}=E_{A} / 4$.

$(0,5)$ - 5. Na situação I, vale a relação:

(a) $F_{A}=4 Q E_{A}$;

(b) $F_{A}=2 Q E_{A}$;

(c) $F_{A}=Q E_{A}$;

(d) $F_{A}=Q E_{A} / 2$;

(e) $F_{A}=Q E_{A} / 4$.

$(0,5) \bullet$ 6. Na situação I, vale a relação:

(a) $U_{B}=4 U_{A}$;

(b) $U_{B}=2 U_{A}$;

(c) $U_{B}=U_{A}$;

(d) $U_{B}=U_{A} / 2$;

(e) $U_{B}=U_{A} / 4$.

$(1,0) \bullet$ 7. Na situação II, vale a relação:
(a) $U_{B}=4 U_{A}$;
(b) $U_{B}=2 U_{A}$
(c) $U_{B}=U_{A}$;
(d) $U_{B}=U_{A} / 2$
$(1,0)$ - 8. Na situação III, após o equilíbrio, a carga no capacitor A vale:

(e) $U_{B}=U_{A} / 4$.

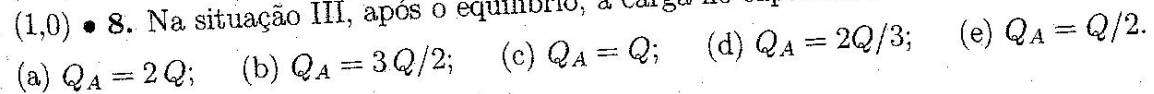

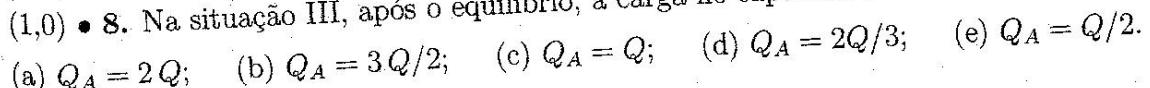

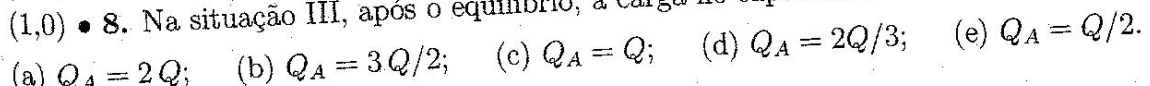

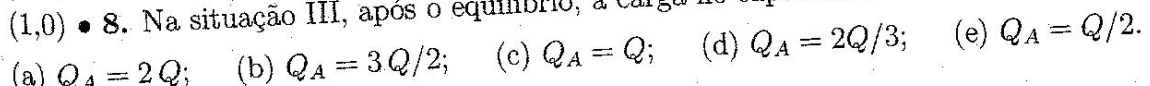

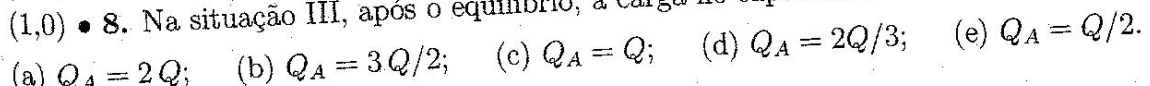




\title{
Física 3
}

\section{P3}

\author{
16 de novembro de 2009
}

(2,0) 1. Um disco circular, de raio a e espessura $d$, feito de material dielétrico, carregado com tensidade volumétrica de carga $\rho$, constante, gira com velocidade angular $\omega$ em torno de um nelo seu centro e perpendicular ao plano que o contem. Mastre que o módulo da densidade de corrente elétrica, $j(r)$, em função da distância $r$ do ponto considerado ao centro do disco, é dado pela expressão $j(r)=\rho \omega r$.

2. Um condutor é formado por dois cilindros metálicos $\mathrm{A}$ e $\mathrm{B}$, cada um deles com comprimento $L$ sec̃a transversal $S$, feitos de materiajs diferentes, com resistencias $R_{A}$ e $R_{B}$, respectivamente sendo $R_{A}<R_{B}$. Eles estão ligados como mostra a figura e sujeitos à diferença de potencial $V$.

$(0,5)$ a) Calcule as correntes $I_{A}$ e $I_{B}$, em cada cilindro.

$(0,5)$ b) Calcule as diferenças de potencial $V_{A}$ e $V_{B}$ entre as extremidades de cada um dos cilindros.

(0) Calcule os módulos dos campos elétricos $E_{A}$ e $E_{B}$, no interior de cada um dos cilindros.

Determine o sinal e módulo da densidade de carga existente na interface dos dois metais.
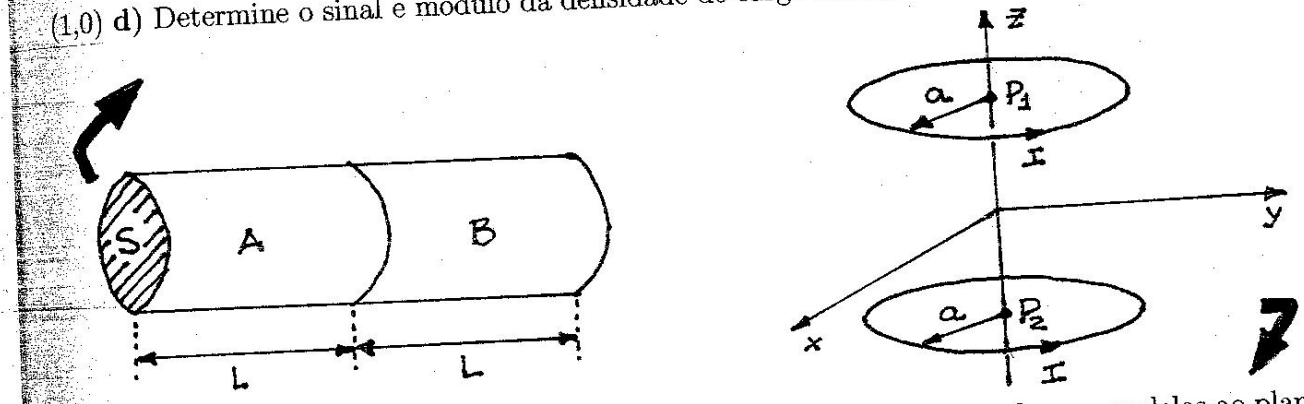

(2,5) 3. Considere duas espiras iguais, circulares, de raio $a$, situadas em planos paralelos ao plano W 7. correntes iguias, $I$, no mesmo sentido. Calcule o vetor campo magnético $B$ no (2) ponto $P_{2}$.

$(2,0)$ 4. Um solenóide cilíndrico, de altura $a$ e raio $b(b \ll a)$, formado por um número $e$ de espirs uniformemente distibuídas, é percorrido por uma corrente $I$. Usando a lei de Ampére, ampo magnético $B$ em uma região no interior do solenóide e longe de suas bordas.

$(1,0) 5$. Um sistema é composto por uma espira quadrada, de lado $L$, e por um fio retilíneo e mui o módulo do campo magnético criado pelo fio a uma distância $r$ do seu eixo vale $B=\mu_{0} I /(2 \pi r)$, determine 0 vetor força resultante que age sobre a espira.

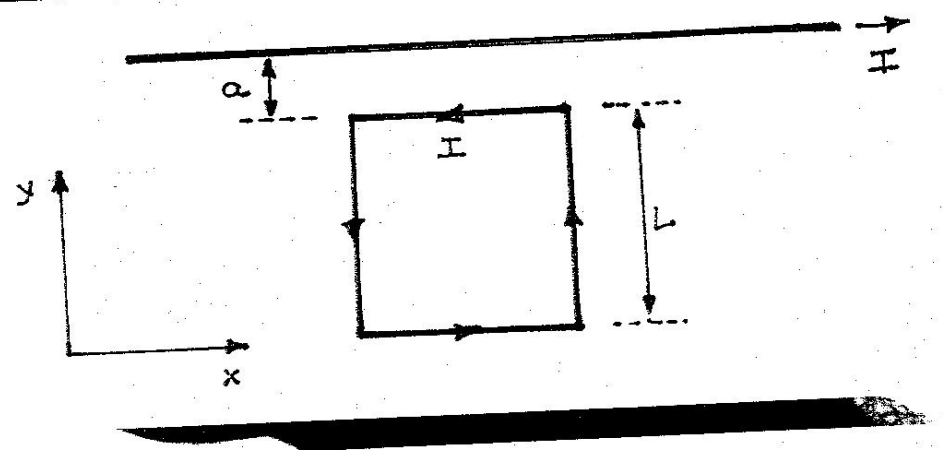




\section{Física 3}

14 de dezembro de 2009

NOME:

Professor:

- assinale com $[\mathrm{X}]$ a resposta correta

use o verso das folhas para rascunho

questões 1 a 6

0 solenóide cilíndrico, de raio $a$ e altura $b \gg a, \operatorname{com} N$

espiras distribuidas uniformemente, mostrado na figura, é

feito com um fio de resistividade $\rho$ e comprimento $c$.

Ele está ligado a uma bateria de tensão $V$, constante, e a

a um interruptor $K$, que é fechado no instante $t=0$.

W $\operatorname{lm}$ um instante $T>0$ :

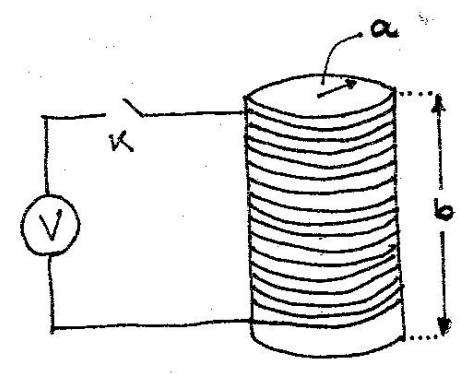

(0,5) - 1. O campo magnético no interior do solenóide é igual a

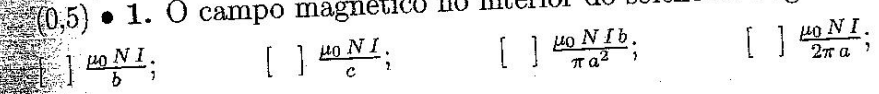

$=2$

- 2. O campo elétrico no interior do fio do solenóide devido ao fato de ele estar ligado a a bateria val
$\frac{N V}{2 \pi a}$
[] $\frac{V}{N b}$
[]$\frac{V}{2 \pi a}$;
[]$\frac{V}{b}$
[ ] $\frac{V}{c}$.

- 3. Sobre o campo elétrico induzido no interior do fio do solenóide, pode-se afirmar que

é gerado pela corrente induzida;

é gerado pela variação espacial do campo magnético no interior do solenóide.

] é gerado pela variação temporal do campo interior do solenóide é uniforme;

jé é nulo porque o campo magnético no inte gerado pela separação de cargas no fio provocada pela força de Lorentz;
fé

0) - 4. O campo elétrico induzido no interior do fio do solenóide é igual a

] $\frac{\mu_{0} N a}{2 b} \frac{d I}{d t} ; \quad[]^{\frac{\mu_{0} N b}{2 \pi a}} \frac{d I}{d t} ; \quad$ [ ] $\frac{\mu_{0} N \pi a^{2}}{b^{2}} \frac{d I}{d t} ; \quad$ [ ] $\frac{\mu_{0} N c}{2 b} \frac{d I}{d t} ;$

5. Sendo $E_{V}$ e $E_{\text {ind }}$, respectivamente, os modulos do cé igual a

$\left(E_{V}+E_{\text {ind }}\right) / \rho$

[ ] $\left(E_{V}-E_{\text {ind }}\right) / \rho$

[] $E_{V} / \rho$

[ $1 E_{\text {ind }} / p$

[]$\sqrt{E_{V}^{2}+E_{\text {ind }}^{2}} / \rho$.

$(1,0) \bullet$ 6. Sendo $\alpha$ e $\beta$ constantes positivas, a função que melhor representa a corrente $I(t)$ no interior do solenóide $e$
[ ] $\alpha$
[] $\alpha\left(1-e^{-\beta t}\right)$
[]$\alpha\left(1+e^{-\beta t}\right)$
[]$\alpha\left(1-e^{+\beta t}\right)$
[]$\alpha\left(1+e^{+\beta t}\right)$. 
campo magnético no interior de um solenóide toroidal com $N$ espiras, de seção tra $a$, raio interno $b$ e raio externo $c$, percorrido por uma corrente $I$, é dado por $2 \pi r$, onde $r$ é a distância ao eixo de simetria.

espira do solenóide pode ser escrita como $\frac{\mu_{0} N}{2 \pi} G \frac{d I(t)}{d t}$, fe.m. auto induzida numa
fator geométrico dado por

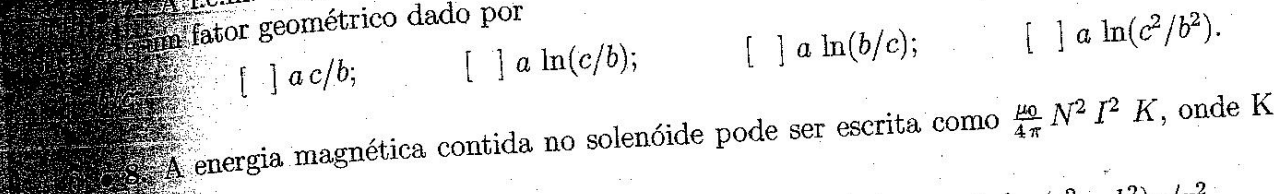

[.] $(c-b)$

[ ] $\pi\left(c^{2}-b^{2}\right) / a$

[ ] $\pi\left(c^{2}-b^{2}\right) a / r^{2}$.

9 a 11

mostra um fio condutor em forma de $U$, sobre o ita uma barra de fio, com velocidade constante $v$, ca de um campo magnético $B$, uniforme e consfos têm secões transversais e resistividades

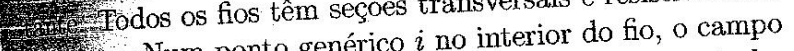
- Num ponto genérico $i$ no interón livre são representados T.

$\vec{B}$ SAI DA FOLHA

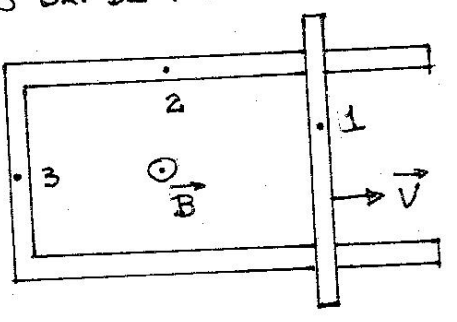

$x+9$.

$\left|v_{1}\right| \neq\left|v_{2}\right| \neq\left|v_{3}\right|$

[ ] $\left|\boldsymbol{v}_{1}\right|=\left|\boldsymbol{v}_{2}\right| \neq\left|\boldsymbol{v}_{3}\right|$

[ ] $\left|v_{2}\right|=\left|\boldsymbol{v}_{3}\right| \neq\left|\boldsymbol{v}_{1}\right|$

||l| $\left|\boldsymbol{v}_{3}\right|=\left|\boldsymbol{v}_{1}\right| \neq\left|\boldsymbol{v}_{2}\right|$

[ ] $\left|v_{1}\right|=\left|v_{2}\right|=\left|v_{3}\right|$.

$(0.5) \cdot 10$

$+\left|\boldsymbol{E}_{1}\right|=\left|\boldsymbol{E}_{2}\right|=\left|\boldsymbol{E}_{3}\right|$

[ $]\left|\boldsymbol{E}_{1}\right|<\left|\boldsymbol{E}_{2}\right|=\left|\boldsymbol{E}_{3}\right|$

[ $]\left|E_{1}\right|>\left|E_{2}\right|=\left|E_{3}\right| ;$

$[1]\left|\boldsymbol{E}_{1}\right|=\left|\boldsymbol{E}_{3}\right|>\left|\boldsymbol{E}_{2}\right|$

[ ] $\left|\boldsymbol{E}_{1}\right|=0,\left|\boldsymbol{E}_{2}\right|=\left|\boldsymbol{E}_{3}\right| \neq 0$.

$(1,0) \cdot 11$. Sendo $S_{i}=\boldsymbol{v}_{i} \cdot \boldsymbol{E}_{i}$ (produto escalar),

[] $S_{1}>0$ e $S_{2}>0 ; \quad$ [] $S_{1}<0$ e $S_{2}>0$

[ ] $S_{1}=0$ e $S_{2} \neq 0$

1) $S_{1}<0$ e $S_{2}<0$;

[ ] $S_{1}>0$ e $S_{2}<0$. 


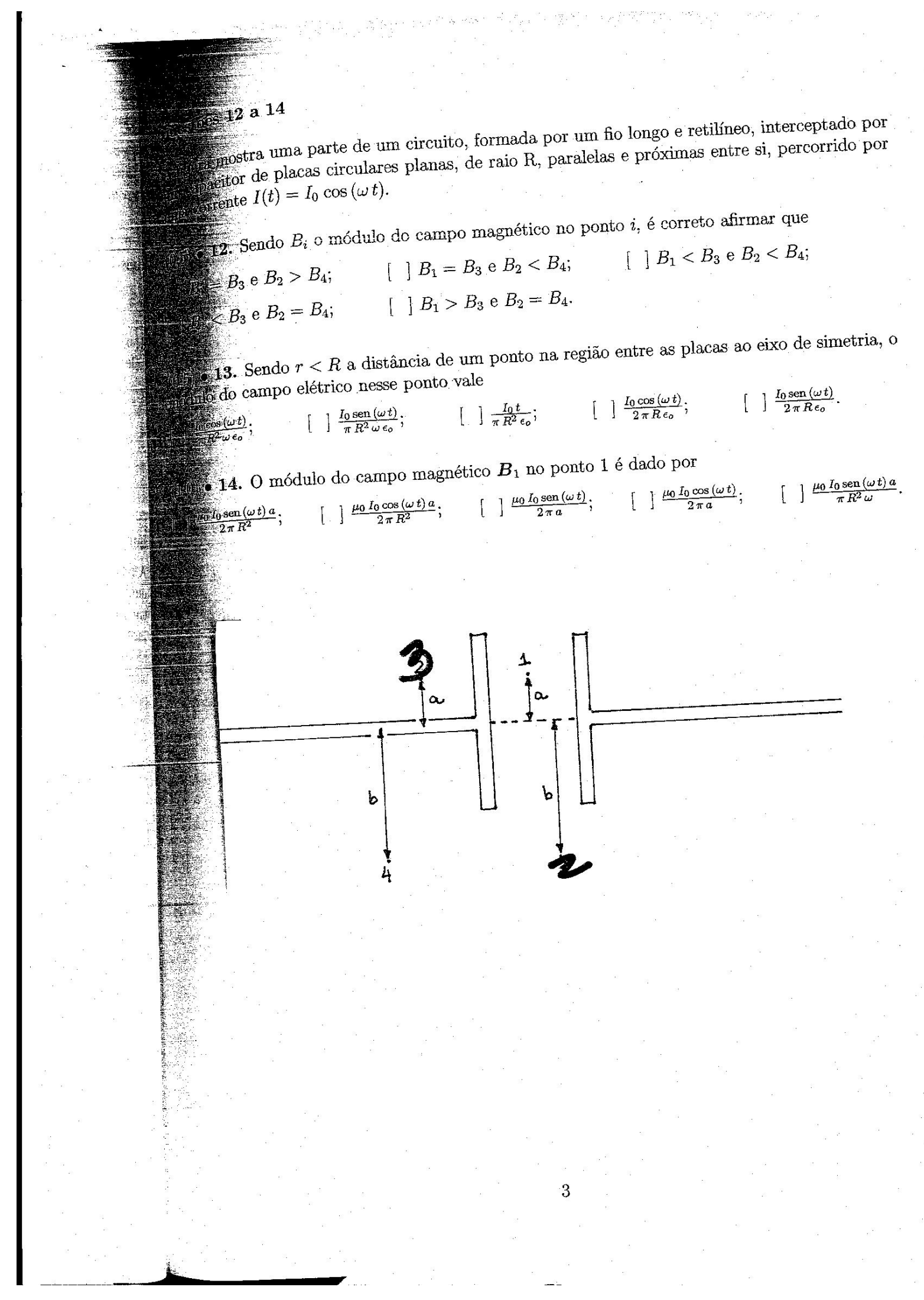




\section{ANEXO 3}

Resultado final dos 81 alunos do curso de eletromagnetismo 2009/2

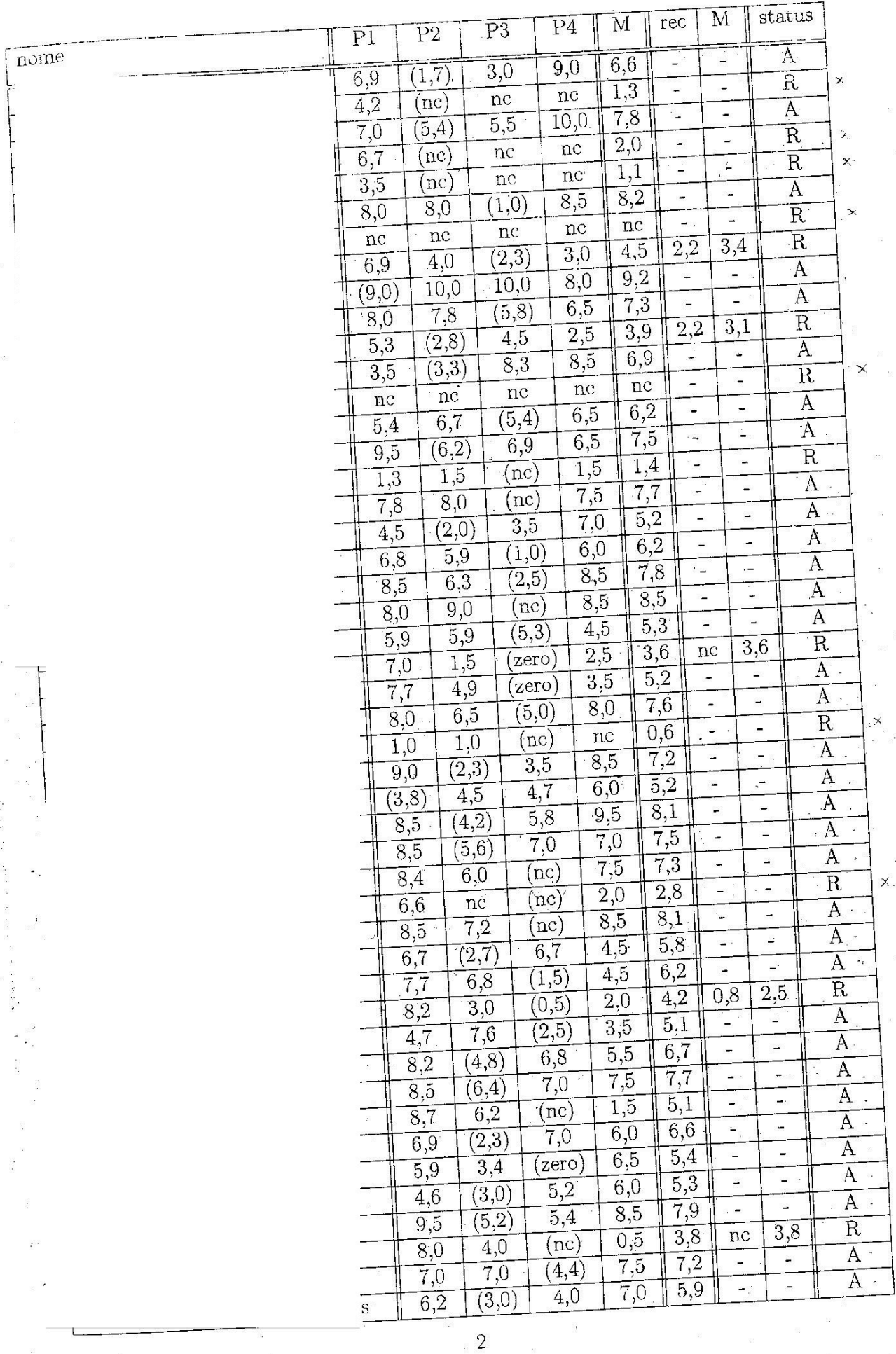




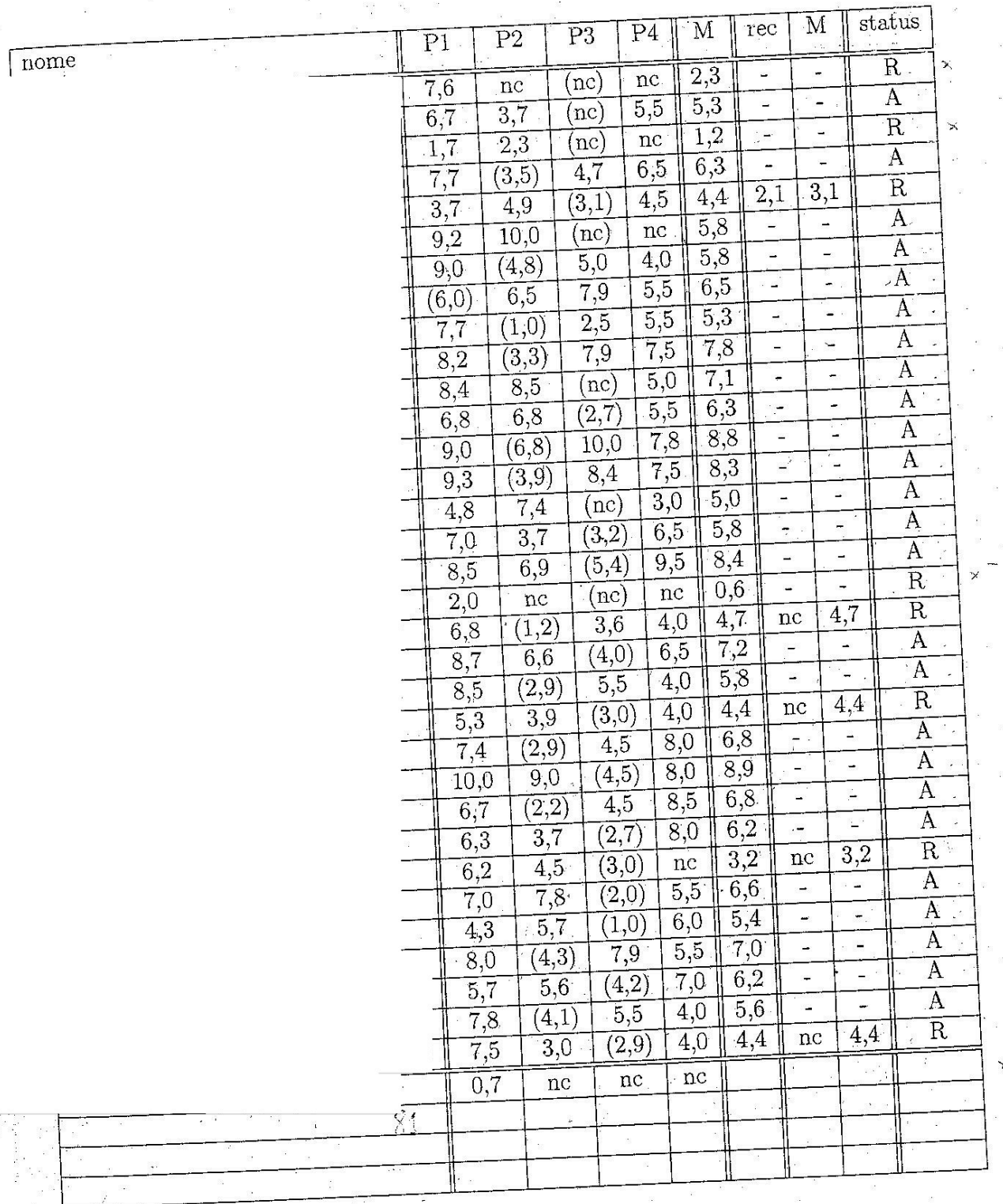




\section{ANEXO 4 \\ Transcrição Entrevistas com o Professor \\ Parte 1 - 30/08/2011 - Duração: 1:05:05}

[00:00:11.27] E - De uma maneira geral, eu assisti todo seu curso de eletromagnetismo e várias vezes tentando identificar, principalmente, a questão da matemática, da matematização e como é que você trata esse aspecto e aí eu identifiquei algumas estratégias suas em relação a esse processo que eu gostaria de saber um pouco mais, ou seja, eu gostaria de perguntar algumas coisas mais específicas. Nesse primeiro momento eu tenho como objetivo investigar melhor, pois ali eu tenho uma interpretação e eu gostaria de saber a sua intenção e por que você fez isso...

[00:01:00.04] P - O que você está trabalhando na sua tese diretamente agora, tem a ver com a transposição didática? Você está olhando sobre esse ângulo ou não?

[00:01:10.01] E - Não sobre esse ângulo em termos de um referencial teórico, mas ele perpassa. Se a gente pensar o que é o eletromagnetismo e qual a sua intenção didática, com certeza ele encaixa.

P - Tudo bem.

[00:01:39.23] E - Uma coisa que me chamou a atenção é um recurso que você usa de maneira recorrente que é trabalhar com algumas coisas muito concretas. Eu chamaria até de exemplos do cotidiano. Vou te dar alguns exemplos: para falar de gradiente você diz que um cachorro está em uma sala escura e vai achar um bife usando o faro; você está falando de densidade, distribuição de carga, você fala sobre a densidade populacional do Brasil; você fala de corrente elétrica e densidade de corrente, você fala de um metrô. Por que você faz uso dessas imagens concretas? Qual a importância disso pra você?

[00:02:33.19] P - Tem duas possibilidades nessa conversa. Uma é eu tentar responder e a outra é você tentar responder, o que é melhor, e ver se eu concordo. Porque se você acertar, você de certa forma apreendeu o meu pensamento. Se você não acertar, você fez uma leitura diferente do que eu mesmo faço.

[00:03:15.07] E - Pra mim, você acredita que o processo de matematização, o processo de aprendizagem disso se dá, na grande maioria das vezes de um concreto para um abstrato. Eu acredito que você usa esse arsenal de exemplos pra que haja um movimento na direção do que é mais concreto para uma abstração. Eu acredito que você, de alguma forma, acredita que assim o aluno entende e aprende melhor, partindo de exemplos concretos que estão mais próximos dele, que ele consiga fazer analogias e metáforas.

[00:04:25.16] P - Eu não vejo isso como um recurso pedagógico. Eu não faço isso como estratégia de ensino. Então é o quê?

[00:04:46.13] E - Se não é um recurso pedagógico, você acredita que a ciência em si de muitas formas funciona assim. 
[00:05:15.27] P - Exatamente. Isso não é uma transposição didática. Não é algo que eu fale assim: você é uma pessoa diferente de mim, então eu vou fazer uma estratégia para te passar alguma coisa ou ensinar algo. Não tem nada disso. Esse é o meu íntimo e como ser humano eu partilho essa sensação global com o estudante. A ideia é partilhar a minha vida com ele, me partilhar com ele.

[00:06:10.16] E - A sua experiência pessoal? Como você vê essas coisas e como você aprende?

[00:06:19.03] P - Não é nem o que eu vejo, nem o que eu aprendo, é o que eu sou. Tem menos razão nisso. O que você? Você é um ser biológico, mas é muito o que a cultura te fez. Todos nós somos assim. Então a aula é uma relação de ser com ser e ela não é mediada por estratégias intencionais. O que é uma analogia? É uma frase, ou falada, ou feita matematicamente, que carrega uma estrutura da qual você não pode falar. O exemplo do gradiente é muito legal pois ninguém fala de cachorro. Fala de outras coisas, mas não de cachorro, e o aluno entende. Ele entende que o cachorro tem que fazer assim, mas como o cachorro é matemático ele vira o nariz por toda sua volta, cheira todas as direções e dá um passo na direção onde o cheiro aumenta. Tudo que você quer saber está nesse exemplo. Você entende mais ou menos como o cachorro funciona? A gente tem uma experiência direta com cachorro. E o conhecimento com o qual a gente opera é um conhecimento que deixa de ser formal e deixa de ser verbal. Ele tem uma componente que a gente poderia chamar de gnóstica. A palavra "gnóstica" está muito associada ao misticismo, mas não é isso. Todos nós temos uma relação direta com o mundo não mediada por conceitos. E quando você fala do bife do cachorro, você está dizendo assim: aquela relação do cachorro com o cheiro, é uma relação que o cachorro sabe e ele não conhece gradiente. Então significa que a noção de gradiente foi tirada do mundo. $O$ gradiente não existe. O gradiente é uma construção humana. Se você pegar na natureza, não tem gradiente. Ele está fora do mundo. Então o mundo veio antes. E ai eu chego na ideia do Maurício, que é muito interessante, que a noção de realidade pode ser uma noção a priori. Todo animal sabe o que é o mundo antes de saber falar sobre ele, senão ele morreria. Uma mosca sabe o que é mundo. Tem relações econômicas, troca energia com o mundo pra viver. Ela sabe fazer isso e nela não fala. Então o gradiente é uma invenção humana. Por outro lado, é uma invenção que tem uma relação forte com essa coisa real, com o mundo. Aí, as pessoas que fizeram matemática e etc, eles tiraram dessa propriedade do mundo e colocaram no mundo da linguagem. E aí, se você não fizer de volta a ponte com o mundo, a linguagem é apenas uma linguagem e ela não serve pra uma quantidade de coisas. Ela até serve, mas é pobre. O que eu sinto é que o entendimento do gnóstico que dá barato. O aluno pensa no gradiente e no bife e "uau", aquilo entra de um jeito dentro dele... e isso não é uma estratégia de ensino. É uma estratégia de partilhar minha visão de ser humano. Claro que tem um pouco de entendimento... se eu refleti sobre isso um pouco e percebi pela prática que essa coisa funciona, tem esse poder é é bom.

(problema com o uso da palavra convicção - consulta ao dicionário)

[00:17:27.21] E - Uma possível pergunta, do ponto de vista educacional [...], seria se isso é realmente essencial para o que a gente acredita o que é aprender o eletromagnetismo, ou aprender o que é o gradiente. A gente poderia fazer um estudo de comparação, por exemplo. A gente poderia analisar que tipo de compreensão teve um aluno com um determinado discurso e a gente poderia ver que esse leque de analogias não apareceu na instrução, ele nunca parou para pensar sobre isso daquele jeito; e um aluno que parou pra pensar sobre 
isso. Eu acredito na justificativa epistemológica, eu me identifico... eu falo assim: olha foi assim que eles pensaram. Então você olha pra história do conhecimento e você vê algumas coisas. Me chama atenção quando você diz: ele aprende assim. Você dá essa disciplina há mais de 20 anos. O Exemplo do cachorro surgiu em algum momento, não tinha antes. Então isso também te dá subsídios para você acreditar que o exemplo do cachorro ou essas estratégias, de uma maneira geral, são importantes.

[00:19:41.06] P - Você falou muitas coisas e eu não entendi direito o que você quer saber.

[00:19:46.00] E - Minha pergunta é a seguinte: quando você fala "ele aprende assim", o que sustenta esse seu argumento?

[00:19:54.22] P - Nada. Ele é um argumento que ele não... porque sustentar quer dizer o quê? Eu vou de novo querer jogar esse problema para o mundo das palavras. E aí sim esse discurso eu posso querer persuadir alguém que isso é melhor... igual um anúncio de televisão. Ele persuade você. Então qualquer discurso em torno disso teria esse caráter. Esse exemplo do bife eu poderia mostrar pra uma pessoa que nunca pensou nisso e ele poderia achar legal e ensinar a partir disso. Isso é transmissivel nesse contexto, alguém que nunca pensou pode vir a pensar. O que eu acho que é desejável...isso não dá pra medir se acontece ou não, eu acho. Quando eu dou aula de gradiente pra um cara, o cara se apropria do gradiente e passa a ser um instrumento operacional dele e ai é igual chave de fenda. Você tem que entender que em algumas situações é bom usar chave de fenda e outras não. E a gente tem uma intuição em que casos a chave de fenda seria apropriada. Se eu tivesse feito um discurso formal a respeito da chave de fenda isso não passaria. Ele passa quando o cara tem esse entendimento imediato, sem mediação, gnóstico do que é uma chave de fenda. Que é o que um cara que é artesão tem. Ele praticou chave de fenda a vida inteira, ele sabe. Por outro lado, eu acho que não existe maneira de demonstrar isso, de você provar que isso é bom com alguma medida. Pode ser que não, mas...

[00:23:08.01] E - Essa é uma pergunta recorrente pra gente que está na educação: como é que você sabe que aprendeu, como é que você sabe que essa maneira é melhor. Mas eu também, muitas vezes, sou um pouco cético em relação a possibilidade de responder isso de uma maneira muito objetiva.

[00:23:37.02] P - Olha, tem uma outra medida, que é a medida que a gente faz do outro lado, dos alunos, e poderia perguntar pra ele se ele aprendeu. A nossa relação humana com o conhecimento ela é muito complexa e eu acho muito legal isso que você está fazendo porque eu acho que você está cutucando a interface dessa complexidade. O que eu sinto muitas vezes, também não conheço muito bem, mas a atitude da faculdade de educação é um pouco diferente, ela tende a ser mais superficial nesse problema. Então isso que você está fazendo eu acho muito legal, você está cutucando a interface e vendo como ela reage. Inclusive o fato de você estar aqui é raro porque os discursos na faculdade de educação, apesar de usar a gente como tema, a gente não discute, que é isso o que a gente está fazendo agora. [...] Nas duas turmas que se formaram esse ano eu fui escolhido paraninfo. É claro que isso me deixa muito contente, mas não é por isso que eu estou falando aqui. É porque isso indica algo. É um curso que ele teve dois anos antes de se formar e ele sente que tem alguma coisa que sobrou lá. E eu acho que essa coisa que sobrou tem muito a ver com essas coisas aí e ela não é, eu acho, um resultado da nossa relação pessoal. Porque a minha relação com os estudantes, quando eu era mais novo, era mais fácil e isso tinha uma componente pessoal razoável. Mas com esse pessoal não tem. Passei dois anos dando bronca 258 
nos caras porque eles não faziam perguntas. Quando eu saí do curso eu não senti prazer em dar aquele curso, mas de qualquer jeito sobra isso. E aí, se você for olhar o que sobra, o que talvez sobra é uma postura frente ao conhecimento. Isso que eu suspeito que tenha sido uma coisa que os caras apreciaram. Agora como é que você vai medir postura? Mas por outro lado, se você vai olhar a vida do cara é isso que ele, na vida dele, considera a coisa mais importante. Então isso é importante. E aí uma coisa que todo mundo pode fazer é olhar o seu curso e ver de quem você lembra como professor. Quem te deu álgebra 1? Já esqueceu... eu tenho um monte de cara que passou o semestre falando várias coisas na minha frente, várias horas por semana e eu nem lembro quem era. E aí tem três ou quatro que eu lembro. Por que você lembra?

[00:27:20.27] E - Sobre essa questão, eu apresentei um trabalho em Foz e um rapaz veio conversar comigo exatamente sobre essa questão: qual a relação, se o professor tem algum tipo de relação pessoal... eu falei pra ele exatamente isso. Eu me agarro muito nisso. $O$ fascinante não é a relação pessoal com os alunos é a relação com o conhecimento. É essa relação que toca. Também acredito que é assim que a gente fascina e é assim que os professores me fascinaram.

[00:28:33.26] E - Você diria que, não pensando do ponto de vista de intenção didática, mas você diria que isso é uma heurística, guia sua maneira de pensar e isso transcende até em áreas da fisica. Eu quero dizer assim, eu olhei um curso seu de eletromagnetismo, ele tem umas características lá que talvez te permitam fazer essas imagens assim mais coladas na realidade. Quando você ministra outras disciplinas, quando você pensa em outros campos da física, a sua maneira de operar de alguma forma continua a mesma? Essa é uma preocupação constante ou em alguns momentos você encontra dificuldade de fazer essa conexão mais próxima do concreto?

[00:29:35.18] P - A dificuldade ela depende muito do assunto. Os assuntos que se prestam mais... e também quando você se esfregou no curso você vai percebendo coisas que antes não tinha percebido. A história do bife surgiu no meio do curso, significa que se eu tivesse parado antes eu nunca teria pensado nisso. Isso tem a ver com a minha trajetória pessoal porque... de certa forma eu estou tentando consertar o mundo pra que as pessoas não sofram o que eu sofri. E o que eu sofri? Eu fazia engenharia e aí vim pra física... a física eu achava um ambiente muito mais legal que a engenharia, uma coisa de empatia pessoal. Ai eu fui fazer fisica de partículas, que envolve bastante matemática. O jeito que a coisa era discutida lá era extremamente formal. Eu tinha aula de mecânica quântica absolutamente formal. Quando eu terminei meu mestrado eu resolvi desistir de fazer física. Fui pra Inglaterra e tal. Outra coisa, se você for olhar a história de alguns problemas, os grandes físicos que fizeram as coisas formais, a primeira coisa que ele fez foi olhar pelo mundo... como é a régua, mexe assim... fez uma continha. Ai outro cara pegou aquela conta e levou a conta em diante, outro cara levou a conta em diante e ai virou uma matemática assim. Mas o primeiro cara ele olhou no mundo. Quando eu te dou formalismo a gente perde esse contato, essa relação que ela está lá dentro pois o cara que fez pôs e o cara que estudou muito enxerga também. Mas o cidadão comum não enxerga. Então isso vira um discurso autoritário. Isso é uma coisa que é marca registrada da minha geração é que a gente é muito contra autoridade. Então eu acho uma coisa meio anarquista legal. Eu acho legal, não ter autoridade não ter chefe. E não é que não tem autoridade, eu respeito a autoridade de pessoas, mas é o autoritarismo. E aí o que eu sentia era o seguinte: - isso talvez pode ter uma componente pedagógica, eu nunca tinha pensando nisso, estou pensando agora pela primeira vez - essa coisa de você dar as coisas formais, pra mim tem um cheiro de uma violência... de um ritual eclesiástico... que 
você é obrigado a acreditar, a entrar nesse rito. Ajoelha lá, por que? porque levanta na hora da missa... Ai você é obrigado a entrar nesse rito; na hora que pintar o 2 lá você deriva e tal. Ou seja, a porta por onde essas coisas entram para mim ela carrega uma dose de violência enorme. Por outro lado é um produto bonito, no fim. Então o problema é a introdução. Por exemplo, eu não tenho nada contra a religião, acho legal a religião. Acho que ela pega um lado nobre, melhor possivel do ser humano, mas eu sou contra o ritual e o ritual não é mais a religião. Eu acho que a minha insubordinação contra a fórmula pura, vem dai. E funciona. Isso valida meu discurso, de alguma forma. Valida minha intuição. Se eu der um tapa em você aí, que é uma coisa ousada, e de repente isso faça bem pra você. Isso valida o tapa, entende? Se fizer mal, tudo bem, foi uma estupidez.

[00:36:02.17] E - Quando a gente tem uma determinada estrutura formal, por exemplo você fala de fluxo de um campo vetorial. Ela é uma estrutura formal poderosa e que é aplicada em diversas áreas da física. Há um perigo e aí tem gente que pensa sobre isso e que muitas vezes a analogia de alguma forma poderia distorcer ou passar uma imagem, quer dizer, você tenta sempre por analogias chegar no que é mas na verdade nenhuma analogia te leva de verdade ao que é.

[00:37:13.25] P - Sim, analogia é analogia. Não é verdade.

(breve interrupção)

[00:38:35.18] P - Esse é um poema de um cara chamado José Paulo Paes. Esse é o discurso com qual eu mais concordo sobre o que é a educação formal. A minha intuição sobre o que é a educação formal está concretizada nesse poema.

"a sineta, a saliva, a comida

a sineta, a saliva, a saliva,

a saliva, a saliva, a saliva

o mistério, o rito, a igreja,

o rito, a igreja, a igreja,

a igreja, a igreja, a igreja

a revolta, a doutrina, o partido,

a doutrina, o partido, o partido,

o partido, o partido, o partido,

a emoção, a ideia, a palavra,

a ideia, a palavra, a palavra,

a palavra, a palavra, a palavra"

$P$ - É por isso que se você fizer essa coisa da analogia, ela mexe com a coisa daqui pra cá.

[00:40:50.12] E - Ela vai buscar alguma coisa. Faz o caminho inverso.

[00:41:14.07] P - A emoção, a ideia, a palavra, na gênese essas coisas estão juntas e tem um nível hierárquico. A santíssima trindade é essa coisa aí. E aí a trindade você vai jogando fora, jogando fora e sobra só palavra. [...] O que a gente deveria fazer para falar sobre isso, a gente deveria ler isso e ficar quieto. 
[00:42:57.29] E - A sua aula é muito visual, no sentido gestual e pictórico. A sua apostila tem várias funções na aula. Ela não é só o seu material de apoio. Ela é por onde as linhas de fluxo passam. A porta tem mais do que funções. Desenhos. Também está associado a essa maneira de que representar o conhecimento por palavras é um aspecto pequeno de uma coisa maior?

[00:43:44.24] P - Sem dúvida. Isso daí tem uma componente sessenta e oito nisso daí. Quando eu puder fazer uma demonstração com um aparelho moderno e uma gambiarra, eu vou preferir uma gambiarra. Eu acho que um Volks é um carro muito mais democrático do que o meu Honda que eu tenho aí. Por que? Porque se o Volks quebrasse, eu, sem saber grande coisa, poderia fazer alguma coisa ali.

\section{Você conhece o conceito de reificação?}

[00:44:29.13] E - Algo como tornar real. Tratar algo que é muito abstrato de maneira mais concreta. Você, por exemplo, já falou assim: você vai lá, pega a carga com a mão e coloca aqui. Me veio um pouco a imagem de reificação. Ninguém pega a carga com a mão. Mas é uma ideia de reificar algo que está longe.

[00:45:01.02] P - Esse aspecto de reificação está presente na minha prática profissional. (interrupção)

[00:46:47.01] P - Tem dois conceitos que foram muito discutidos - e isso tem uma componente política aí - que é alienação e reificação. O que é alienação? Você aliena um imóvel. Você vende. Esses caras detectaram um mecanismo na sociedade onde existem instrumentos que roubam de você coisas sem que você perceba. E aí quando eu tenho um carro tipo Honda, que a regulagem dele é eletrônica o cara roubou de mim a capacidade de fazer isso. E aí foi junto um pedaço da minha cidadania, por que se tiver uma coisa mais simples, eu tenho o direito de optar sobre o que fazer. Do jeito que é o outro carro, eu só tenho a opção de ficar com ele ou não. Que ainda é uma opção, mas eu não sou obrigado. Uma vez que eu fiquei com ele, eu aceitei a regra do jogo. Então eu chego pra você e digo: você quer entrar em uma pós-graduação? Você pode ou não entrar, mas se você quiser, você ter que fazer o que eu quero. Isso significa que eu estou chupando a sua alma e você passa a ser um servo meu, do sistema. Então esse negócio de fazer uma demonstração com gambiarra... eu prefiro jogar laser em um clip torto lá, que eu faço assim, faço de propósito, isso é ideológico... então você pega esse negócio, tira da gaveta, tira da orelha, sei lá... isso pra mim é melhor do que o aparelho sofisticado. Claro que se você for fazer fisica vai ter que usar o aparelho sofisticado. Mas essa coisa de você colocar a coisa ao alcance do cidadão comum, ai tem esse caráter de dizer "você também é proprietário dessa coisa". Física não é o que os caras fazem no laboratório, é o que você pode fazer. Então é meio isso de transferir a propriedade do conhecimento para o cara. Isso é uma componente que ela é intencional e ideológica. Dito isso, quando falo em ideologia eu falo assim "eu quero que você siga os ideais da minha causa", não é nada abstrato, é uma coisa mais direta que quer dizer o seguinte: você pode ser o que eu sou. Só isso. É ideológico nesse sentido. Não deixa o cara te roubar. Eu estou lutando aqui para não roubarem do meu e você também luta para não roubarem do seu. Só isso. E aí cada um segue a sua vida, você não precisa seguir as minhas ideias, segue as suas. Mas você é proprietário de um pedaço da relação. 
[00:50:38.06] E - As representações visuais então são uma espécie de gambiarra nesse sentido do formalismo?

[00:50:47.26] P - Não. Com a gambiarra eu estou lutando contra a alienação, acho. $O$ visual, ele tem a ver com a ideia de que o conhecimento da física é silencioso. É o movimento contrário dessa coisa aqui (poema). Porque a imagem que você tem da natureza é importante. E não é uma imagem visual, é uma imagem em um outro espaço platônico que a gente tem na cabeça, que tem a ver com a visão mas não é igual. É relacionado com a visão. Se eu falo "cubo" pra você, você tem um cubo guardado dentro da sua cabeça. Ele foi visual um dia, mas ele já um conceito que transcendeu essa coisa visual.

[00:51:59.07] E - Com frequência você fala explicitamente que você está trabalhando... vamos pensar nesse movimento de matematização de uma ideia, quer dizer, ou de abstração, num sentido de descolar da realidade e ficar indo em um determinado sentido. Você com frequência faz questão de mencionar... você usa termos do tipo "olha, esse sistema de referência ele não está na natureza, ele é um instrumento de pensamento", isso aparece de maneira... ou as idealizações e aproximações. Você também faz questão de mencionar "isso aqui não é bem um quadrado, não é bem unidimensional". Quer dizer, qual é a importância de deixar isso de uma maneira clara nesse processo de abstração? E eu percebo que isso leva um tempo bastante grande da aula, de você tentar...quer dizer, pensando na construção de... tem analogias, faço as correlações, mas aí vou construindo uma abstração. Queria que você falasse um pouco sobre os motivos de fazer isso de maneira explícita, de deixar claro... você está fazendo um modelo, que isso é um instrumento de pensamento.

[00:53:31.28] P - Eu acho que é o mesmo movimento de você explicitar para o cara que o nosso discurso é uma construção. Quando eu faço isso na aula, eu faço porque eu acho legal. Eu fico feliz em fazer isso. Agora, se você me perguntar por que eu fico feliz com isso, eu acho que é porque na aula e no conhecimento ele tem um elemento religioso. Ele tem uma ligação com o mundo, com o cosmos, mas não com o mundo material, com a nossa coisa aqui nesse mundo. Essa relação é mais construída do que a gente costuma acreditar. Então, isso é apenas para partilhar a minha sensação que, sei lá, você pega um sistema de referência (gesticula três eixos) aquilo lá é uma coisa falsa. Entre aspas. Mas aqui não é o mundo, é uma representação do mundo. A fisica e o discurso do conhecimento são representações do mundo. E essa representação ela é falha, necessariamente, porque ele pega apenas um pedaço da nossa relação com ele. Pega dez por cento da parte do mundo que dá pra gente cobrir com verbos, palavras, símbolos e etc. E aí outra vez eu volto pra ideia do Maurício: o cachorro sabe melhor que a gente. Solto você, você morre de fome. Se não tiver o cara que produz comida você morre de fome. Você pode comer grama, mas vai morrer em duas semanas. Assaltar lanchonete, mas depois que acabou, não tem mais. Mas o cachorro sabe. Significa que ele tem um conhecimento do mundo que é maior que o nosso em muitos aspectos.. E a gente substitui isso pelo conhecimento de alguma coisa relacionada a linguagem, que é uma característica humana. Houve uma fase do conhecimento da filosofia ocidental, da ciência e tal, que as pessoas falavam "nós somos completamente distintos", e talvez restaurar nossa ligação com o cachorro fosse... noventa por cento cachorro, dez por cento cara que fala.

[00:57:19.24] E- Eu pensei em identificar nesse processo e aí reflete uma frase que você falou uma vez, em um determinado momento você falou assim: a física sai da natureza, mas tem que voltar pra natureza. Então pensar a matematização como um processo. Você matematizou, você chegou em uma estrutura. Mas, e isso é muito fácil de identificar quando 
você resolve.. vamos pegar um problema. Você vai fazer um problema. Chama atenção também que problemas tem uma duração, tem uma importância muito grande. Levam cinquenta, sessenta minutos. Quer dizer, você usa o problema para também fazer um discurso conceitual. Mas me chama atenção que depois que terminou a conta, aí começa um processo de volta. Começa um discurso de dizer o que é que essa conta está me dizendo no mundo física, qual o significado disso. Então, eu queria te perguntar se pra você, soa razoável que a gente possa falar... eu sei que talvez dentro da cabeça essas coisas acontecem simultaneamente, mas analisando a aula, analisando o discurso, eu percebi dois movimentos: um, por exemplo, eu vou caminhando no sentido de matematização, aí eu chego, eventualmente ai eu opero com isso, eu uso a ferramenta, a estrutura e chego no final e retorno. Ai eu começo a me perguntar o que isso significa, e se isso for zero e tal. Eu queria te perguntar se isso é razoável, se você se identifica, se você acha plausivel falar nesse processos de matematizar alguma coisa e interpretar. Trazer o formalismo de volta para o mundo real.

[00:59:20.00] P - Eu acho isso fundamental, mas por que isso é importante? Isso dai é uma coisa que talvez a gente deva falar outro dia porque tem muito "sulco" por trás. Uma coisa que acontece é o escolismo. O que escolismo? O conhecimento deixa de ser alguma coisa que vai ser propriedade sua e passa a ser a moeda de você poder ter sucesso na escola. Ai quando você termina o problema na prova, você põe um retângulo em volta da fórmula e acabou. Aquilo lá é onde você queria chegar. Na apostila eu acho que eu cito a coisa do dedo da lua. É um provérbio chinês que fala que o dedo serve para apontar para a lua, o bobo olha para o dedo e uma pessoa inteligente olha para a lua. Então esse construto ai que é o resultado formal da coisa, ele é um dedo. E ai é a hora de você começar a ter o barato. Ai se você parar lá: (olhando para o dedo) resolvi: e é igual a não sei quanto, quatro terços pi etc... Se você parar lá...você deixou de fazer tudo... pegou a parte mais legal que você tinha da atividade e falou "eu agora parei antes". É a mesma coisa de você falar assim: vamos almoçar em um restaurante legal. Aí você vai, pega o trânsito, para na porta e não entra no restaurante. É meio isso. Toda essa discussão se dá no contexto do mercado de livros. Porque esse grandes livros, tipo Halliday, eles não fazer isso de propósito. Porque na hora que você olhar a linha pontilhada, se torna meio que um caminho pessoal. E você vai olhar uma coisa, você entra em um restaurante, você pede uma comida, eu peço outra e isso se torna uma coisa assim. E aí isso não vende. Porque se ele optar por um ele deixou o outro de lado. É igual o jornal Folha. A Folha é um jornal calhorda, porque quer agradar todo mundo. Ela é um grande nada que tenta agradar você. A rede Globo mais ainda. Todo mundo tem que estra lá dentro. Você aguenta um pouco o programa chato porque você vê outro programa e vira essa grande pasta. E o Halliday é a TV Globo. Ele é construído ideologicamente dessa maneira. Não é por acaso que a Globo faz isso. Se ele colocou um palhaço a mais lá ele perdeu audiência com os intelectuais e aí ele tira o palhaço, coloca uma notícia que agrada e ai ele maximiza o público, que é o que interessa. Então os livros didáticos também fazem isso. Então eles não colocam questão de interpretação, de nada pessoal ...é o dedo. [...] Isso não é só gostoso, é útil também. Se você olhasse esses resultados de uma conta que você calcula campo elétrico de sei lá o que, se você olha aquela expressão final ... que diálogo bizarro entre os vários elementos. O elemento da geometria com elemento da carga, um foi parar em baixo, ou tem a raiz de três no outro... Aquela expressão é uma espécie de bolo que você colocou vários ingredientes e ele se amalgamou lá e virou aquela expressão compacta, mas de certa forma você vê de que maneira que as ideias de vários setores diferentes são misturadas naquela expressão. Isso também é um negócio legal. 
[00:00:24.10] E - A gente começou discutindo sobre o papel dessas analogias, desses exemplos do cotidiano que você usa, como o cachorro e uma série de coisas. A gente começou discutindo qual é a função que isso tem, os motivos de isso ser tão forte e presente nas suas aulas. [...] Durante uns quarenta minutos nós ficamos tocando nesse tema, que me parece ser bastante importante e central. Ai a gente passou um pouquinho para o caráter visual das suas aulas, e ai eu separo em gestos, gestos concretos do tipo abrir a porta, pegar uma caixa, pegar uma apostila, fazer assim... você tem uma aula muito visual e pictórico também, você desenha muito e são recursos muito fortes para a sua explicação. Ela faz uso de diversas representações semióticas. Você vai falar a equação, gestos, desenhos...

Depois nós fomos para a questão da... eu perguntei pra você se você achava razoável um movimento em dois sentidos: um no sentido da matematização. Então a gente analisou um pouquinho como você, de maneira explícita, fala para os alunos que você está construindo uma abstração... isso não está na natureza... isso é a sua cabeça. Então, como você vai gradativamente fazendo esse processo de construção de representações matemáticas de coisas do mundo físico. Por fim, a gente falou... você até comentou que talvez a gente precisasse de mais tempo para discutir sobre isso, mas o que você falou em dez minutos também foi muito forte, que seria o movimento no sentido oposto. Você ao resolver um problema, durante cinquenta, sessenta minutos, você vai construindo a representação matemática, faz as operações e o momento da volta é muito importante. Você falou "você enfrenta um engarrafamento, chega no restaurante e não come". Quer dizer, você não faz a parte super importante que é interpretar e ver o que aquilo te diz no mundo físico. Foi isso que nós discutimos e como eu te falei, em termos de coisas que eu queria te perguntar isso já é sessenta por cento ou mais. [...] Então eu vou te perguntar alguns outros temas que estão associados a minha análise das suas aulas.

E - Eu queria conversar um pouco com você sobre o papel que a parte operacional, técnica, que você chama de "girar a manivela"... qual você acha que é o papel que essas coisas tem nas suas aulas? Eu vou te dizer a minha impressão e aí a gente conversa um pouco sobre isso. Eu percebo que você faz isso. Isso faz parte das suas aulas. O girar a manivela. Resolvendo uma integral, chama isso de U e deriva. Mas você passa uma imagem claramente de... não sei se eu uso a palavra displicência, ou algo de ser mecânico. [...] A imagem que você passa, a sua mensagem é diferente quando você está fazendo essas coisas. Qual é o papel, pra você, desse processo de girar a manivela nas aulas?

[00:04:50.11] P - Talvez tenha o papel e a maneira que eu me relaciono com ele. São duas coisas. O papel é o seguinte: isso em fisica é absolutamente importante. Se você olhar meu trabalho de pesquisa, se você pegar o número de horas que eu trabalho, a maior parte do tempo eu estou fazendo isso. Por outro lado, eu considero que isso é uma coisa que pertence a um outro domínio do conhecimento, que é importante, mas ele na aula... a aula é uma outra coisa. [...] Na aula você não pode fazer tudo. A aula é uma janela que você oferece para o estudante. Você não pode aprender lá. Você vai lá, eu dou a aula e você diz que aprendeu tudo aquilo. Isso é impossível. A parte técnica, por exemplo, fazendo uma analogia: um cara que toca violino, a mão dele tem que saber muito para ele ser um bom violinista. Eu não posso ensinar a sua mão a saber as coisas. Você tem que praticar. Aí você erra, pratica, erra, pratica. Então, eu sinto que na aula não dá para ensinar isso. Então qual a função da aula? É situar o conhecimento. Tá tudo meio confuso. Por que eu faço isso? Grande parte do ensino que eu tive, eu nunca fui na sala do professor dos meus colegas e ver o jeito que ele ensina... então eu não sei isso. Os alunos sabem mais que eu. Mas a sensação 
das aulas que eu tive, e eu tenho a intuição que de certa forma ela se perpetua, a pessoa sente que se ela fizer a conta inteirinha na lousa e fizer todas as passagens, aquilo é uma aula boa. Porque aquilo é um material que você viu uma vez na vida, seguiu a sequência da conta, toma nota, se apropria, codifica pra você mesmo aquele conhecimento, você depois reproduz... Você sabe o que quer dizer a palavra explicar? Essa palavra "plica" é a mesma origem da palavra "prega"... uma roupa você faz uma prega. E isso que dizer dobra. Vestido pliçado é a mesma coisa e é dobrado. Então explicar é você eliminar as dobras. Então você explica, você alisa algo que está engruvinhado. E aí se você pegar o conhecimento de um certo tema, tem muitas coisas engruvinhadas. O que eu sinto que normalmente é a opção que é feita é desengruvinhar bem a matemática. O formal. Mencionando pouco as outras coisas. Eu sinto, por exemplo, da minha experiência pessoal de trabalhador na área, que a ligação entre a matemática e a natureza é bastante complicada e ela ocorre de muitas maneiras. [...] É como se houvesse muitas dobras escondidas que você tivesse que abrir e essa imagem eu não acho ruim, não. Essa coisa engruvinhada é uma coisa que você só olha o lado de fora dela. E quando você começa a abrir que você percebe que tem uma outra dimensão, no sentido matemático mesmo, do conhecimento que é interno lá dentro e tem várias dimensões internas. [...] Então eu gosto de aproveitar a aula para tentar abrir essas outras coisas, sendo que para os alunos que a gente tem aqui, eles têm o treino matemático. Eles fazem isso bastante bem em outro lugar. Então, na aula, não vale a pena gastar muito tempo. Tem coisas mais importantes pra gastar o tempo da aula. [...] Você tem no espaço múltiplas dimensões, vários eixos de valores, de dimensões do problema e aí a gente não pode ficar em um só. E aí a gente fez toda a matemática e você se vira com os outros. Isso é muito duro. Eu diria que a maioria das pessoas se ela não for incitada a fazer isso ela não fará. E aí se ele for pra pós, ele vai fazer com grande dificuldade. Então, o que eu gosto de fazer na aula é pegar a multidimensionalidade desse espaço de eixos de dimensões do conhecimento e exercitar um pouco cada uma delas. E na verdade, com isso eu espero estar mostrando que existe o espaço. Que se eu exercitar um eixo só, as outras dimensões nem existem e o cara acha que mundo é unidimensional. Essa é a motivação de fazer isso. Agora, por outro lado, o exercício do eixo da técnica é super importante, mas por outro lado ele é técnico. [...] Eu acho que a coisa da técnica, você não aprende uma vez só. Você tem que repetir isso porque você não entende direito. Mesma coisa o violinista, se você colocar um arco assim o cara não faz lá na primeira. Ele vai errar umas centenas de vezes até ele entender o que ele tem que fazer. O que ele tem que fazer é invisivel. Eu não posso ensinar isso, mas posso mostrar que ela existe. Você que tem que aprender. Pra terminar esse tema, e por que eu tenho uma atitude meio displicente? É meio para... ai é meio uma atitude política. Mostrando que tem isso aí, mas isso é só um pedaço. Eu não acho que isso é o máximo. Isso é uma coisa modesta. Importante, porém parte. Modesta é uma palavra errada. É uma parte. Não venha com a atitude de que isso aí é tudo porque não é.

[00:14:09.20] E - Eu vejo que em alguns casos você até fala "essa conta está feita na apostila", por exemplo. É comum e às vezes proposital que às vezes foi um 2 lá e o aluno fala "foi um 2 lá" e você fala "ah! um 2. Pronto." É essa imagem que você está mostrando mesmo: errei uma coisa, desculpa e pronto. É importante mas não é o que... e aí eu queria te perguntar... porque pra mim essa é uma coisa... assim, talvez também de experiência de aulas que eu tive, mas de ouvir falar... pra mim essa é uma das grandes diferenças que existem, que faz com que a sua aula tenha um diferencial. [...] Talvez seja uma questão da tradição, o cara foi ensinado desse jeito e ele ensina desse jeito. A minha pergunta seria essa: qual será a razão, teria que talvez conversar com outros professores. [...] na verdade eu não sei se vem ao caso especular sobre isso, me parece que é um fato que a tradição ou a maioria dos professores de física dão um peso muito grande para essa parte técnica e se 
esvazia as outras coisas. Então o que me interessa começar a olhar mais pra frente é olhar o contraste... é o tempo, é a ênfase dada a essa parte operacional e técnica. [...] Quais seriam as possíveis razões para isso ser assim? A pessoa não reflete sobre a importância disso? Para os valores?

[00:16:29.26] P - Olha, tem uma razão cínica que eu não sei qual é o peso dela no processo, mas isso dai é fácil. Esse fato pesa em alguma coisa em algum lugar. Eu não acho que é um fato preponderante, mas ele tem essa coisa. Porque se você fizer isso, você meio que. é fácil em dois sentidos porque... eu digo, é fácil e é ingênuo, talvez. É ingênuo porque se você teve aula desse jeito você vai lá e reproduz e fácil porque você não precisa criticar o que você está fazendo, você vai lá e faz. Tem uma coisa que sempre me surpreende na educação que é o seguinte: muitas vezes as pessoas apresentam uma coisa que pra elas foi muito difícil de aprender, como se fosse fácil. Elas falam "tá vendo aqui" e isso dai custou um tempão para ela chegar nisso. Quando era ela um aluno ela não entendia isso. Então eu não sei se isso também envolve uma imagem de como é que a gente funciona com o ser humano inteligente... se eu achei o caminho das pedras, se eu contar pra você, você vai entender direto. Ou seja, isso dai talvez vá a ideia antiga de que a gente é uma página em branco para ser ecrita do que uma estrutura na qual os conhecimentos dialogam com as coisas pré existentes, que você tem que mudar coisas, rearrumar coisas, o que é muito mais difícil. Então, não sei, estou chutando...essa componente está lá presente. E também tem uma coisa que você sair dessa coisa, você se compromete mais, porque essa forma é uma coisa sobre a qual ninguém diverge. Então, de certa forma, esse é o núcleo de comunicação da física e aí a gente só fala acerca de unanimidades. E talvez esse seja o motivo. Eu ensino as unanimidades da fisica que é a conta... como eu passo de uma linha pra outra e aí não tem dúvida, todo mundo vai fazer meio igual. Tem um cara que conhece três métodos ele faz lá 1 , 2, 3, mas de certa forma eu vou ter que concordar com ele que esse é um uso que existe. Isso pode ter a ver com o mercado editorial. Os livros texto não autorais de grande massa... se o Einstein escrever um livro, ele pode escrever como ele quiser que todos vão ler, mas os livros escritos para as massas eles precisam vender. E essa é a razão pela qual, sei lá, a rede Globo não se posiciona política/regionalmente (???), porque em não se posicionando ela atinge um público maior. Então o texto foge de questões de interpretação do mundo porque isso poderia reduzir o âmbito de possiveis compradores do livros. Então isso eu acho que também influencia. E aí como a gente é baseado na coisa do livro texto, continuamente, a gente vai lá e pega o livro texto e acha que aquilo lá é o que é... adota o livro texto pra você e para os alunos e vai fazendo isso. Mas a gente não leva em conta de que maneira o livro foi escrito e por quais razões ele foi escrito desse jeito. E eu acho que a limpeza e essa limpeza é usada no sentido de limpeza étnica...dos nazistas, tem uma limpeza epistemológica lá. O cara matou todas as possibilidades de contrvérsia, ao máximo disponível. Aí quando tem uma coisinha joga lá na nota de rodapé e acabou. [...] Eu estava lendo um livro do Heisenberg... eu não gosto muito dele porque eu acho ele um cara meio esquisito, mas...como físico, um grande físico, mas como pensador eu acho ele esquisito. Mas ele se questionou se o espaço existe, teoria do átomo...você não fala isso... pode ser que não exista espaço. O que isso quer dizer eu não sei, mas o cara se preocupou com isso. E esse tipo de questão some. Então quando você dá a matemática você está dando o oficial.

[00:22:32.05] E - Uma das coisas que mais me motiva quando eu falei que eu tenho muita vontade de ir pra frente é sistematizar essa discussão, na formação do professor também e mostrar que essa maneira... o quanto se perde... mostrar o contraste. De novo, em vários lugares em que eu fui e apresentava algumas partes das suas aulas... a tradição é muito mais forte e está muito mais espalhada do que a gente imagina. E aí você ouve "Nossa! Que legal! 
Que tipo de discussão diferente." As aulas que eu assisti na Alemanha não são muito diferentes desse modelo que a gente conhece. Esse é um ponto que me parece muito forte, muito central: qual o valor que essas coisas possuem nas aulas e você vê no discurso se você olhar uma aula inteira em que é um formalismo do início ao fim.

[00:23:44.15] P - Uma coisa que eu tenho reparado, porque a gente tem o seminário de física toda terça, quando o seminarista é mais novo, em geral ele mostra as contas. Quando o cara é mais velho ele dá o quadro. Ou seja, ele se liberta do formal e passa a falar em um nível que só depois de ter uma certa experiência que você pode falar. Mais uma evidência disso.

[00:24:31.08] E - Você falou uma hora agora, que às vezes na educação as pessoas não se dão conta do quão difícil foi pra elas mesmas aprenderem e essa consciência se reflete nas suas aulas... é uma espécie de metacognição. Você explicita isso, você incentiva isso. Você incentiva que o aluno pare, pense e não ache que aquilo é fácil. [...] Eu acho que você já me sinalizou a resposta, e de novo também é uma grande diferença porque você não constrói aquele discurso que você acabou de falar "veja como isso é fácil e trivial". Mas acredito que nessa resposta anterior você já me sinalizou a importância de você fazer esse processo.

[00:25:43.04] P - Só para completar, tem uma outra coisa: se você fala "veja como isso é fácil", inibe a sua pergunta... que também pode ser um instrumento pedagógico. Porque você mantém sua aula no trilho, você segue o horário que você planejou.

[00:26:05.06] E - Você bloqueia essa via.

[00:26:12.02] P - Ela é incipiente. Ela se manifesta com dificuldade. Ela foi muito reprimida e vão continuar sendo reprimidos... aí ela não se manifesta e acabou. Fica lá quieta. De novo a rede Globo. Se tivesse um espaço na televisão legal para o público usar os equipamentos da rede globo, já que é concessão do governo, para as pessoas falarem coisas contrárias ao que ela fala... isso devia existir, mas não existe. E ela continuamente inibe... até falando da liberdade de imprensa na hora que você fala alguma coisa. Ou seja, esses meios continuamente inibem a crítica e o questionamento. Então a aula ela pode ter um pouco disso.

[00:27:25.16] E - Associado a isso, mas aí um pouquinho mais... não relacionado com a dificuldade que o aluno tem ou que a gente tem de aprender isso, eu também percebo isso nas suas aulas... não em todas, mas eu vejo uma preocupação, vamos dizer assim... epistemológica... falar sobre essa relação e eu vou falar especificamente de matemática e física. Eventualmente isso te diferencia...não é tão comum achar uma pessoa que pare e pense: qual é o papel da matemática na física. Você tem comentários... momentos em que você para pra pensar sobre a construção da ciência. Acredito que isso se deva à sua inquietação pessoal e à sua formação em epistemologia, em pensar sobre essas coisas. A pergunta estaria associada a que importância você dá a esses comentários epistemológicos na aula?

[00:29:03.19] P - A separação entre algo que a gente chama de física e epistemologia ela é artificial. Ela não está no mundo. A gente que fez, sociologicamente, em algum momento. E eu acho que se você praticar um pouco, você vai ver que a epistemologia está em todo lugar. $E$ é até um jogo divertido... você vai olhando e achando esses componentes muito fortes. Até esse negócio da etimologia também, se você vê esse negócio da palavra "explicar"... quando 
me contaram isso eu fiquei muito feliz. Isso é legal porque é auto contido... quando você explicou, você explicou a palavra explicar. [...] Então a possibilidade de fazer isso ela está na linguagem verbal e está na linguagem simbólica também e está na nossa relação com o mundo. Então eu acho que o mundo é assim, a nossa relação com o mundo é assim. Só que a gente procura ficar de um lado só... em uma posição unilateral. [...] Eu acho que essa é uma imagem boa. Tem um preconceito aí, de algum jeito. E é só tirar o preconceito que isso acontece sozinho. Claro que pra você tirar o preconceito dá trabalho. Mas então essa coisa na aula, talvez é uma defesa contra o preconceito. Eu sei que você não pega todo mundo, mas tem uns caras que são mais sensiveis a esse tipo de coisa e pra eles isso é bom.

[00:31:20.15] E - Tem outro item que eu queria perguntar. A gente já conversou uma vez sobre isso depois de eu ter assistido uma aula sua de relatividade e eu fiz uma pergunta bem especifica em um determinado momento lá. Mas assistindo o curso de eletromagnetismo, eu vi que ocorreram menos... eu estou falando sobre as demonstrações, ou deduções, em que você vai partir de alguns princípios e você vai demonstrar alguma proposição. Posso dar um exemplo concreto. Talvez seja melhor pra gente discutir. O teorema de Gauss, o teorema do divergente e o teorema de Stokes. Nas suas aulas você fala assim: olha, isso é um teorema matemático. E você não apresenta a demonstração formal do teorema matemático mas você mostra que ele é válido em uma situação. Você faz isso para os dois. Você constrói um problema, faz o cálculo de um lado da equação, do outro, e mostra que é verdadeiro. Então a pergunta, de maneira geral, é essa: demonstrações, partir de princípios, articular a maneira dedutiva, qual é o papel desses processos nas suas aulas? Ou podemos falar de maneira especifica... alguma demonstração do teorema de Gauss, do teorema do divergente... qual a opção consciente que você faz por não apresentar esse tipo de demonstração de dedução.

[00:33:17.03] P - Tem a ver como é que você aproveita o tempo da aula e o que é possível você aprender. A minha sensação quando demonstraram coisas na minha frente é que ela é muito mais sociológica do que lógica. No seguinte sentido, eu falo assim: tudo bem. Esse cara estudou bastante, ele é uma pessoa honesta. Ele não está me enganando. Então o que ele está fazendo é correto. Mas eu não consigo, dada uma situação complexa de demonstração, se for uma coisinha pequena tudo bem, mas se for uma coisa complexa, eu não consigo seguir aquelas coisas e ser crítico... pensar "nossa, será que essa hipótese realmente se sustenta? Será que isso realmente é assim". Isso não dá. Você vai engolindo aquele negócio lá. E aí, no fim tudo fica respaldado pelo fato de um cara honesto ter feito isso na sua frente. Então, ainda que você não tenha entendido, o cara era honesto, então deve ser assim. A atitude intelectual frente a essa coisa, é essa. Por outro lado, é óbvio que se alguém demonstrou o teorema e os matemáticos criticaram isso... isso é muito importante porque tem o respaldo deles no resultado. Então é legal que aquele resultado tenha sido criticado e etc. Mas eu acho que a demonstração não permite a crítica. E para a física é muito mais importante você ter uma intuição... a intuição do teorema é melhor do que a demonstração, porque a demonstração... no limite você poderia falar que ela é uma truculência... porque eu falo assim "olha, é assim, você entendeu?" (aponta para o papel) E aí o que você faz lá? Não faz nada, vai engolindo. E aí terminou e está ali demonstrado. E aí o que você faz com isso? Você entendeu? Não entendeu. Porque você não é capaz de entender daquele jeito. Tem um monte de passagens lá. Mas por outro lado, aí você tem um negócio que está registrado em algum lugar que é do jeito que deve ser feito. Feito isso, você tem que ir pra casa e seguir aquele negócio. Mas se é pra ser assim, você vai, segue em casa direto dai você ganha intuição. A intuição seria assim: quando você usa, quando ele é útil, quando não é, etc. Ou seja, situar o teorema no contexto naquele instante, que também é o primeiro contato... isso é diferente, não estou falando que em todos lugares vai ser assim. Se 
você tiver uma formação mais madura, aí você pode fazer outras coisas. Mas naquela primeira vez que você vê, é muito melhor falar pra que ele serve.

[00:36:38.22] E - Você acha que um dos fatores pode ser também a questão da maturidade? Porque quando você diz: eu vejo a demonstração, eu não entendo. Eu tenho que aceitar com uma espécie de autoridade. $E$ possível, talvez, falar assim: tem demonstrações $e$ demonstrações. Porque, por exemplo, eu estou lembrando da nossa conversa lá do curso de relatividade que as transformações de Lorentz, passo a passo, você não chegou a demonstrar. Tinha o processo de rodar a manivela. Você estruturou. Os princípios... as asserções são essas e fazendo essas asserções eu chego nisso daqui. Mas em uma aula que você faz a demonstração... as transformações de Lorentz para os campos. Você vai passo a passo fazendo as demonstrações. Você faz todo o destrinchar. E naquela época a gente conversou e você falou "aqui tem valores que me mostram alguma coisa do processo criativo, ou das angústias que eu acho importante mostrar e aqui não teria". Então você acha que existem demonstrações e demonstrações?

[00:38:20.18] P - Por exemplo, esse negócio do curso de relatividade, eu também faço no curso de física quatro... desse jeito aí. Isso eu acho importante porque isso talvez ensine naquela situação lá, como é que a gente pensa na transformação dos campos... que é uma coisa dura da gente entender o que significa a transformação dos campos... mudança de referencial dos campos. Então aquele caso lá, é um caso onde eu acredito que o conteúdo central do curso está sendo importante. Porque no teorema de Gauss não, porque é um teorema da mecânica dos fluidos lá. Como o teorema de Pitágoras... eu não iria demonstrar isso nunca em uma aula. Mesmo que o cara nunca tivesse visto, eu ia pegar alguns exemplos e fazer lá. A série de Taylor eu faço assim, por exemplo. Uso a calculadora, expande ali, primeira ordem não sei o que. Porque ai é mais uma coisa que... eu diria que é uma demonstração de uma técnica e não de uma coisa que traga um conteúdo epistemológico sobre o tema central do curso. Essa é a diferença. Quer dizer, não é uma política e ponto. Tem hora que sim e hora que não.

[00:40:29.28] E - É impossível não notar que o quadro que você monta... provavelmente já da primeira ou segunda aula até a última aula, tem papel fundamental no curso inteiro, no seu discurso. Você vai ficar quinze, vinte minutos do inicio de cada aula montando aquele quadro. Então ele tem papel central. E uma coisa que me parece muito interessante... as leis com palavras, com figuras, com equações. Vai montando toda aquela estrutura. A impressão que eu tive é que isso... Eu queria te perguntar quando que ele nasce, quando ele foi sendo aprimorado... qual a importância? Olhando me parece clara a importância... podemos até conversar do ponto de vista pedagógico... por que você acha que esse quadro é tão importante no curso como um todo?

[00:41:52.17] P - Eu não sei se isso seria universal em qualquer curso, mas nesse curso é porque o icone são as equações de Maxwell mais a força de Lorentz. Então é uma coisa que você depois do curso deveria aprender o significado. Quando eu comecei a dar esse curso, eu não tinha essa visão e eu tive que gastar bastante tempo pensando nisso para recuperar essa ideia que ela dita em algum lugar assim... mas que ela nunca é enfatizada que o objeto de desejo são as equações de Maxwell. E a mágica que a gente poderia usar... assim... as equações de Maxwell é uma espécie de catedral que é o produto final, tridimensional, superdimensional... de organização daquele conhecimento. E aí, o livro corresponde a uma planta e a passagem por ele é lenta e você é inexperiente. Se você der a planta para um arquiteto ele olha e vê um prédio, mas o cara comum não vê. Então você chega lá e fala 
(mostra uma folha): olha o primeiro andar, aí você passa para o segundo e nem lembra que o primeiro existia e tal. Então, claro que isso está sendo feito espalhadamente. Ai você faz exercício... você puxa um negócio que precisava estar no meio, falar de metais, que não nada a ver com as equações de Maxwell. Então você vai fazendo uma coisa meio fractal, meio desorganizada. Uma espécie de hipertexto. Do mesmo jeito que o hipertexto destrói a sua racionalidade moderna, no sentido de pós-renascentista, essa apresentação destrói a unidade moderna, também no sentido de pós-renascentista do eletromagnetismo. Como se fosse fácil pra gente perceber essas unidades. Isso pra mim foi dificil. Eu tive que militar em cima. Fiquei contente de ter visto isso... achei que isso é um instrumento unificador, é um foco... é um centro. Então se você imaginar que o curso é um círculo... todos aqueles negócios se referem àquele centro lá. Então não adianta falar o centro de cara, mas eu falo que tem um. E ai a ideia é ir construindo o diálogo do centro com as bordas lentamente mas sempre me referindo ao centro. Ai também tem várias coisas legais... a teoria de Maxwell é uma teoria muito importante na física mesmo, particularmente todo mundo acha bonita e eu também acho, mas isso é uma outra relação afetiva que a gente tem, mas ela é importante. E a unidade dela simplifica sua relação com o mundo, porque eu acho que é muito legal se eu te der uma situação inesperada que... uma vez vieram umas meninas da arquitetura aqui e elas vieram com um projeto complicadíssimo. Elas pegavam um papel verde e dobrava, iluminava por trás... quando o papel fazia isso parecia vermelho. E elas tiveram coragem de vir até a fisica discutir sobre aquilo. Esse é um problema completamente inesperado, nunca tinha visto. [...] E ai em uma situação dessa é confortante falar: equações de Maxwell. Corre lá. Você vai ter que sair daí. Então isso eu diria que tem um lance de economia e de força da teoria, de saber que aquilo lá tem que dar conta.

[00:47:03.21] E - Como você vê o papel da história da fisica no ensino, especificamente para esses alunos aí? Eu percebo que você é cauteloso. Vou pegar um exemplo bem especifico: você vai falar da corrente de deslocamento de Maxwell, você tem uma cautela em falar "Maxwell fez isso"... eu já estou na verdade dando a resposta... a história, como os caras pensaram na época é algo que você tem muita cautela em dizer e que a gente não vê. Tem livro que vai dizer textualmente: o Maxwell fez assim. Então a história está ali completamente deturpada, simplificada. Você, de maneira geral, qual você acha que é o papel da história da física nas suas aulas?

[00:48:31.07] P - Tem duas coisas, tem a história e fotografias da história. Uma coisa fala assim a história da sua vó. Isso é uma coisa. Outra coisa é você mostrar uma foto dela e falar essa era a minha vó, esse era meu avô, sua fazendo seu cavalo e tal. Que é um flash, um corte sincrônico no passado lá. Mostrar foto eu acho útil, porque ele mostra pra você que o mundo não foi sempre do jeito que ele é hoje, teve um processo e teve personagens que foram importantes nessa coisa. Agora, por outro lado, eu não gosto chamar mostrar fotos de história, porque história é uma coisa que você teria que... que nem a história da sua vó que é tão próxima dá pra reconstruir direito. Dá para você pegar algumas coisas, fazer umas linhas mestras e tal...por mais esforço que você faça. Então história é dificil. A história da fisica... as três leis de Kepler.. eu aprendi com o Zanetic que as três leis de Kepler eram seis ou sete, porque eles aproveitaram as que eram boas e jogaram fora as outras. Então história são sete leis de Kepler, isso é história. Mas falar a história das três leis de Kepler é desonesto. Então eu prefiro não fazer. Falta assim um "flashback"... o passado e acabou. Isso eu acho que tem uma função. Mas chamar isso de história é criminoso.

(Conversa sobre o livro Bruxa de Kepler) 
[00:52:03.08] E - Essa relação na própria formação do professor, é muito debatida. Você está fazendo seu curso de física lá e apresenta algumas fotos, mas a necessidade ou não de se ter um curso da história da física onde pelo menos pega um caso e analisa direito e fala assim "fazer isso aqui é complexo"... vai mostrar muitas outras coisas e aí você fica em uma balança.

[00:52:35.06] P - Só que que diria que você não faz isso sem saber física. Você primeiro tem que saber fisica, depois... o fato de saber física é que vai dar sentido àquelas ações daquelas pessoas.

[00:52:51.20] E-Ou seja, o curso de história da física, para você, teria que estar localizado no final e não no primeiro semestre.

[00:52:58.15] P - Pode até dar uma pincelada, tem uma utilidade, mas se você usar a história no sentido de uma área de pesquisa, certamente eu não acho que isso deveria ser dado para a escola básica. Isso é um escape falso para um problema difícil. Vou fazer o que é mais fácil, mais gostoso. Passar slides.

[00:53:28.28] E - É muito dificil quando a gente tenta olhar os originais. É um esforço muito grande quase que de tradução para a linguagem que você tem hoje.

[00:53:44.02] P - "O que é que aquele cara está pensando?" Você sabendo física, se não souber não tem jeito.

[00:54:49.06] E - Eu vou te mostrar duas coisas. O que nós conversamos nesses dois encontros na verdade estavam bem direcionados às categorias que eu encontrei. Um processo bastante dificil, olhar suas aulas e tentar ver como é que eu vou identificar momentos, classificar momentos. Então os assuntos que nós fomos discutindo nessas duas entrevistas são categorias de análise... foram categorias de análise pra mim. A história da pesquisa foi tentar identificar isso. Óbvio que não é um olhar neutro, é um olhar que tem reflexão epistemológica, histórica. Então as categorias de análise são essas daqui. As duas principais são esses dois movimentos: o movimento da matematização e o da interpretação. Quando aparece um aspecto mais técnico, ou eventualmente de autoridade... autoridade eu digo assim "pelo teorema de"... eu não vou a fundo. As representações visuais e aí as categorias não são mutuamente exclusivas elas podem e normalmente me interessa também ver se você está nesse processo, usando esse recurso. Então as representações visuais. As analogias. $O$ exemplo do cachorro... os inúmeros exemplos é o azul escuro. A parte mais associada à dedução ou demonstração... às vezes até comentários, não é nem fazer a demonstração, mas quando você comenta "eu posso provar isso". Comentários mais epistemológicos, filosóficos e um incentivo à metacognição... você vai falar "presta atenção, isso não é fácil". E nesse software te permite criar essas categorias e te permite videografar a aula. Eu tenho aqui de trinta minutos até uma hora e meia, então normalmente eu não pego uma aula inteira. Eu tenho dividido em momentos... vai explicar o conceito de densidade de carga, começou aqui, vai terminar aqui. Mas isso me ajudou bastante. Esse não é o resultado central porque o que eu vou fazer na escrita da tese, eu vou detalhar cada categoria, vou rechear de exemplos para que a pessoa tenha uma ideia melhor. Mas essa foto aqui me pareceu bastante interessante e me ajuda a explicar também... ou seja, essa aula que é a aula cinco, você vai falar de densidade de carga, de distribuição linear, superficial, volumétrica... então o que a gente percebe? A gente percebe que você está em um processo de matematização. Então você está pegando coisas, pegando ideias e dando forma matemática. 
Você vê recursos visuais o tempo todo... gestos e desenhos. Você vê as analogias... densidade de população do Brasil, alunos na fila de carteira... então essa foto... isso eu já acho que é um passo depois da tese, porque a tese é um estudo de caso, vou defender mas ela está me parecendo uma possibilidade até de você pegar uma aula do mesmo tema e ter uma outra foto. Então, por exemplo, aspecto técnico... tudo bem, essa aula não tinha um problema sendo resolvido aqui, então em um momento só você fala lá, ou você faz alguma continha meio displicente, técnica.

[00:59:56.22] P - Muito interessante... o que é curioso nessa aula é essa continuidade final aqui que pareceria sugerir que tudo o que veio antes é um funil para leva aí.

[01:00:21.13] E - Eu lembro que esses momentos aqui... aqui é densidade volumétrica, essa segunda linha é a hora que você...essas subcategorias são mais finas. A primeira parte seria a idealização, a abstração, a construção do modelo e a segunda parte é quando você de verdade usa uma estrutura matemática... e aqui são coordenadas polares, coordenadas cilíndricas. Então aqui realmente você está mostrando como é que se trabalha com coordenadas polares, cilíndricas e cartesianas, para descrever o elemento de volume lá na densidade volumétrica. Mas realmente, aqui tem um tempo...aqui deve ser a superficial, aqui a volumétrica.

[01:01:24.21] P - Eu achei interessante isso.

[01:01:34.23] E - Vou te mostrar umas outras, na verdade, aí, na maneira como eu apresentei...

[01:01:36.18] P - Mas isso deve ser muito dependente do tema da aula, né?

[01:01:41.12] E - É. Eu encontro padrões... e o que eu complementava era com algumas frases suas como, por exemplo: "imaginem que vocês são cargas pontuais e eu quero calcular..."Então eu trazia isso porque é aqui que dava a imagem boa... aqui, é gesto mas é uma analogia porque os alunos são cargas pontuais e eu quero calcular... enfim". [...]

(Conversas sobre problemas sobre colocar a imagem do professor)

[01:04:31.26] Existem aulas que tem padrões semelhantes. Essa é a aula doze, em que você começa a explicar o conceito de fluxo. Fluxo de um campo vetorial. E aí tem um padrão semelhante. O tema te ajuda a fazer uma série de analogias, então isso tem um papel bastante importante. Você está criando representações matemáticas, você vai chegar em uma expressão para o fluxo... então, também muito visual. Então ela depende do tema, mas... é porque nessa apresentação eu baseei só nesse tipo de modelo, e aí eu comecei a mostrar que parece que no momento que você faz a explicação, você começa a introduzir um conceito novo ou o padrão, mais ou menos, é semelhante, não se repete, mas é um padrão semelhante. Quando eu vou analisar, por exemplo, quando você resolve um problema, ai eu já vejo um outro tipo de padrão. É mais ou menos esses dois tipos de olhares que eu vou fazendo... momentos em que um determinado conceito é explicado, de maneira mais ampla... ou que um problema é resolvido, lógico que o problema também é usado para explicar um conceito, mas um problema tem uma formulação, um desenvolvimento, tem uma resposta, tem uma análise. A aula do fluxo também é bem gestual e aqui a questão da metacognição... fica bem evidente: "A pergunta dele é muito boa. Indica uma confusão, mas a confusão ocorre sempre com todo mundo que estuda isso. Se ela ainda não ocorreu com você, ela está ocorrendo e 
você não sabe". A confusão de que o fluxo teria que ter... de que o campo vetorial teria que ter uma velocidade... você fala "o campo elétrico está lá, o campo gravitacional está lá". Enfim, essa aula tem muito disso. E aqui tem a corrente elétrica e densidade de corrente... é um tempinho um pouco mais curto, mas de certa forma a gente encontra também padrões de matematização e representação visual.

[01:06:57.02] E aí, uma coisa que não vai dar tempo mas eu não me aguentei... não vai dar tempo assim... na tese eu fiz um estudo de caso, mas que muitas pessoas para as quais eu apresentava isso, me sugeriam era fazer uma espécie de... me mostra um outro professor, um outro padrão. O Maurício sempre ficava um pouco reticente porque parecia que estava mostrando o bom exemplo e o mau exemplo... é muito complicado isso. A gente foi fugindo disso ao longo desses quatro anos de tese, mas nesse evento que eu fui na Alemanha, eu fiz um teste. Tem muitas aulas disponíveis na rede... a pessoa disponibiliza lá e eu fui achar uma aula que seria uma aula tradicional padrão de um tema que era o fluxo de campo elétrico. E aí, nessa apresentação na Alemanha eu resolvi fazer esse teste. E aí, isso que está parecendo que é mais pra frente que viria. Seria um passo seguinte. Algo como identificar padrões... um raio-x de aulas. Tentar buscar critérios objetivos. Mas essa mesma aula de fluxo que você ministrou, eu achei uma aula... ela tem um tempo menor, mas fica muito clara a diferença no perfil. E ai eu vou atacar pontos específicos aqui. Por exemplo: a introdução do conceito. Essa aula que eu olhei, é muito claro o seguinte: fluxo do campo elétrico é definido como integral de E escalar d A e tal. A primeira coisa é isso aqui. E é claro que na sua aula a gente vê que é bem diferente. Você quer construir imagens, você quer construir motivos para que o cara chegue... "acho que seria interessante fazer um produto escalar... acho que tem a ver com direção". Então aqui tem uma maneira bem diferente de começar. Qual a ideia de um fluxo de um campo vetorial. Como é que a gente pensa sobre o problema... se vai na porta, está entrando ar, não está. Então eu estou achando que esse tipo de coisa vai ser interessante. Eu procuro tomar cuidado... muitas vezes eu não consigo, lógico, em fazer um julgamento de valor... e dizer que isso é melhor que isso. Eu procuro me policiar. Mas eu estou mostrando uma diferença do ponto de vista objetivo aqui. Existe uma maneira de apresentar e existe uma outra maneira de apresentar e a gente abre uma série de perguntas aí.. o que é melhor, o que o aluno aprende mais.

[01:10:21.21] P - Eu estou com medo disso pelo seguinte: se um tecnocrata pega isso daqui, o cara vai começar a ir no concurso e levar uma maquininha dessa, em vez de ficar na aula que o cara dá ele vai ficar fazendo isso e se ele tiver um padrão do que ele considera o ideal, ele vai dar nota pela máquina.

[01:10:49.11] E - Aí ele deturpou totalmente. Eu tenho esse cuidado na minha cabeça. Essa imagem é legal, ela me mostra uma diferença...

[01:11:11.02] P - Ela quantifica, é legal mesmo...

(Interrupção telefone)

[01:12:37.02] E - Quando você falou no tecnocrata, eu não entendi se você estava brincando... você estava pensando que poderia ser algo realmente útil?

[01:12:48.11] P - Útil eu não acho. Como instrumento de pensamento eu acho muito interessante porque isso mostra de uma maneira visualmente e você não entra no mérito... se eu faço uma analogia, você não diz se ela é boa ou não...isso não aparece aí e eu acho legal. 
Então eu não tenho julgamento de mérito. Mas é um dado quantitativo que... o que é sempre legal, porque senão você fala assim "gostei porque a analogia dele foi fantástica", mas não é isso. É usar ou não analogias. Isso aí aparece claramente no quadro de cima. Então eu acho um instrumento muito legal. Porque uma coisa é perceber que a aula é diferente, outra coisa é ver como é que a pessoa está usando o tempo disponível no espaço de categorias que você tem lá e isso eu acho muito legal.

[01:13:54.24] E - A minha intenção quando eu estava buscando um software desse tipo, era justamente olhar... era mais específico. Era ver a questão técnica e ver essa coisa mesmo... de qual o peso que ela faz e o que vem antes e vem depois. Quando tem um problema é legal. Aqui, porque está aparecendo o que eu chamo de técnico/autoridade? Tem muita informação que é simplesmente dada, não é justificada... o tempo todo. Exatamente... a questão da justificativa. O que ele faz é pegar fatos ou regras e simplesmente enunciar: "vocês já conhecem isso do cálculo três. Quando você tem uma superfície, o vetor é normal a essa superficie". Sendo que aqui você está em um outro movimento, você está tentando ver como é que eu relaciono a área, a direção da área ainda com um campo. Como é que eu penso nisso. Então é diferente. Não é vocês já sabem, vocês já conhecem. Você falou do uso de analogia. Olha que legal aqui. Ele faz uma analogia. Mas primeiro, é uma analogia e ele vai dizer que o fluxo do campo elétrico... ele faz uma analogia de uma esponja e água. Ele vai dizer que ela é uma medida do quão úmida a esponja fica quando a água passa através dela. $E$ ai se a gente for discutir, a gente pode discutir a qualidade dessa analogia e dos problemas que ela tem. Não entrei tanto nesse mérito, mas eu vejo uma diferença aqui. Você faz várias. Ou seja, há um cuidado que você vai falar de abelhas, de ar, de fluxo de campo gravitacional... porque parece que você está querendo pegar uma ideia e você não está querendo... eu penso que seja uma estratégia interessante essa de você mostrar várias porque você justamente mostra... é mais amplo do que você se limitar a uma analogia, aí parece que o cara fica preso a essa. A questão que você discute quando você faz analogia com o campo gravitacional, que você mostra que o campo gravitacional não tem velocidade e um aluno ainda fala na aula "mas g é uma aceleração, então você não tem que usar velocidade"... aí você para a aula e fala... apesar de você já ter chamado a atenção para esse problema no início da aula, você para de novo e fala "é uma boa pergunta"... ele ainda está achando que tem que furar. Aqui essa discussão ela não aparece porque é a água que está fluindo através de uma esponja, então vai. Então isso aqui não me mostra a qualidade... eu não estou iludido de que agora é só pegar, olhar uma aula, fazer um gráfico desse e dizer se a aula é boa ou é ruim. Não. Não é isso. E tem muita gente dizendo que eu poderia fazer uns cálculos... mas o que eu quero é essa imagem. Essa imagem me diz o que eu quero. Eu não estou interessado se foi trinta e cinco por cento.

[01:17:30.17] P - Isso aí mostra o uso do espectro de possibilidades e a escolha que você vai fazendo. E evidentemente isso reflete por trás o que é saber alguma coisa, porque eu diria que isso é um mapa de cada cabeça. Partindo do princípio que as duas pessoas são honestas, ou seja, que eu estou fazendo o melhor possível. Isso daí reflete um mapa da cabeça de como é que esse conhecimento está amarrado no cérebro das pessoas que estão ministrando... porque na verdade o desejo latente é que ele fique meio parecido com o seu depois do processo.

[01:18:31.02] E-Aquilo que você falou dos eixos... não sei se eu achei todos os eixos, mas exatamente isso que você falou de... eu mostro isso, eu mostro isso, mostro que tem isso e mostro que tem isso. Então de certa forma essas categorias são um pouco nessa ideia dos 
eixos que você vai mostrando e aí se você pega uma coisa muito uniforme ou menos. O cara não falou isso, não interpretou depois, o problema acabou ali mesmo.

[01:19:00.16] P - Uma coisa que eu acho marcante da minha aula é que ela tenta ser o menos autoritária possível. Que isso eu acho que é bom para o conhecimento. Isso é uma postura frente ao conhecimento. Agora uma coisa que poderia ser olhada, que eu nunca olhei assim é o seguinte: essa variação das categorias, o colorido, são movimentos de trazer a pessoa para dentro da aula, ou seja, de ampliar um diálogo. Isso é uma preocupação que eu tenho e que essa seja uma manifestação que reflita isso. De dizer "você tá entendendo?", pega o cara com a mão assim... puxar o cara de volta para dentro, individualmente.

[01:20:07.12] E - Esse aspecto da interação eu também analisei diferente. Bem diferente. Essa é uma aula tradicional em que o canal inverso está bloqueado, por que é apresentado como fácil... "eu vou mostrar pra vocês como funciona". Ele fala isso. E eventualmente ele fala "ok?"... mas não é uma pergunta sincera, ele fala "ok" e já continua. Ele não dá esse espaço. E aqui, esses momentos em alaranjado, não é uma categoria, mas eu queria localizar e você mesmo falou "essa turma eu fiquei frustrado porque ela pergunta pouco". Nessa aula tem momentos que eles até perguntam e é interessante fazer essa análise do que motivou aquela pergunta. De alguma forma você falou alguma coisa que deixou a vontade de perguntar. Então realmente "como é que a gente usa essa noção intuitiva de fluxo, pense nisso. Você poderia ficar aqui esperando a resposta, mas seria melhor se você pensasse melhor sobre isso". Então é esse seu movimento... de tirar ele da inércia. De trazer para participar. E a gente sabe que é dificil porque a tradição de escolaridade dela é uma coisa diferente, ele não se sente confortável. Não está acostumado. 